\title{
TOXIC SUBSTANCES FROM COAL COMBUSTION-A Comprehensive Assessment
}

\author{
Quarterly Report \\ Start Date: 04/01/2000 \\ End Date: 06/30/2000
}

DOE Award No.: DE-AC22-95PC95101-18

\section{Authors: FEHuggins, GPHuffman, Nshah, Nyap/2 JOLWendt, and Wseames/3 MRAmes}

\author{
Physical Science Inc. \\ 20 New England Business Center \\ Andover, MA 01810-1077
}




\section{TABLE OF CONTENTS}

$\underline{\text { Section }}$

$\underline{\text { Page }}$

ABSTRACT

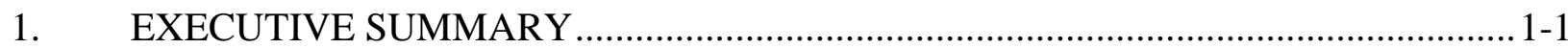

2. INTRODUCTION AND PROGRAM OVERVIEW ............................................2-1

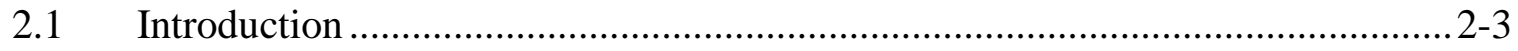

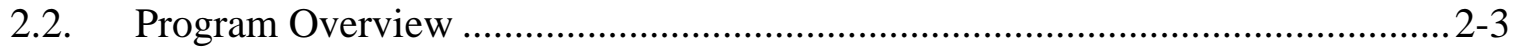

3. $\quad$ RESULTS AND DISCUSSION ................................................................. $3-1$

3.1 Program Management (PSI) ..................................................................... $3-3$

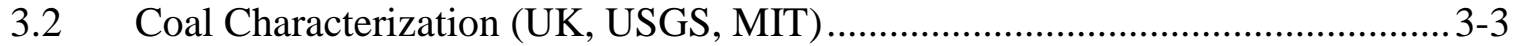

3.2.1 Coal Mineralogy.......................................................................................... $3-3$

3.2.2 Trace Element Content of Coals by Selective Leaching and Microprobe

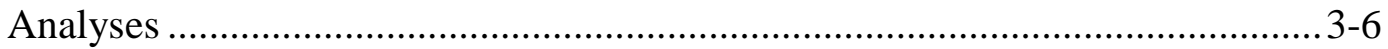

3.2.3 Element Speciation by XAFS Spectroscopy ….......................................... 3-9

3.3 Combustion Zone Transformations (UU, MIT) ......................................... 3-12

3.3.1 Single Particle Combustion Studies .............................................................. 3-12

3.3.2 Low Temperature Volatilization ................................................................. 3-17

3.4 Post-Combustion Transformations (UA, UK, UC, EERC)............................. 3-17

3.4.1 Large Scale Integrated Combustion Studies ................................................ 3-17

3.4.2 Mercury-Ash Interactions in Fixed Bed Tests .............................................. 3-63

3.4.3 Morphology of Ash Samples Used in Bench Scale Testing ............................ 3-77

4. SUMMARY AND FUTURE PLANS ....................................................... $4-1$

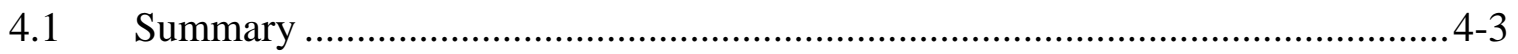

Future Plans..................................................................................... $4-6$

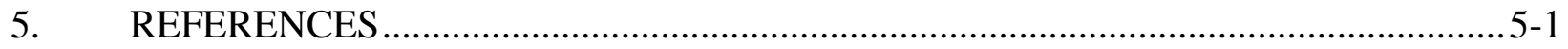

APPENDIX A. Summary of USGS Leaching Results .............................................. A -1

APPENDIX B. Composite Results from Baseline Large-Scale Combustion Studies at the University of Arizona.

APPENDIX C. Composite Results from Special Large-Scale Combustion Studies at the University of Arizona C-1 


\section{LIST OF FIGURES}

Figure No.

$\underline{\text { Page }}$

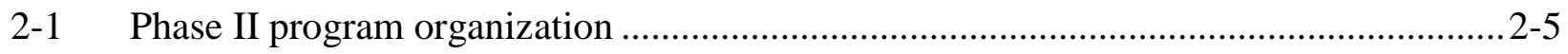

3-1 Mössbauer spectra of top and bottom layers of Illinois \#6 coal.................................... 3-5

3-2 Silicate minerals from project coals by CCSEM ............................................... 3-7

3-3 Selective leaching results for chalcophilic elements Fe, As, Se. ............................... 3-8

3-4 Revised correlation between the XAFS step-height and the concentration of arsenic in the identical leached residues.

3-5 Least-squares fitted As XANES spectrum of the Ohio bituminous coal after the

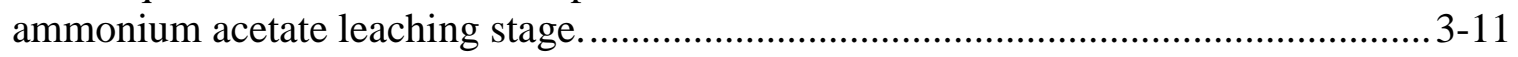

3-6 Mass distribution of the ash on impactor stages and final filter.............................. 3-13

3-7 Fraction of selected elements in the submicron ash as a function of oxygen

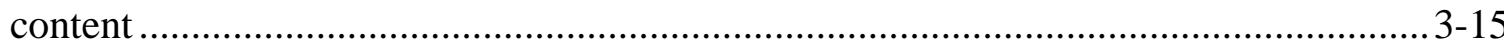

3-8 Fraction of selected elements in submicron ash for pyrolysis $\left(100 \% \mathrm{~N}_{2}\right)$ conditions and for combustion in varying amounts of $\mathrm{O}_{2}$

3-9 Comparison of fraction of selected elements in submicron ash as a function of oxygen content with either $\mathrm{N}_{2}$ or $\mathrm{CO}_{2}$ as the balance of combustion gas.

3-10 The effect of combustion temperature on the volatility of calcium, iron, and aluminum during the combustion of Wyodak Coal

3-11 Particle size dependence of arsenic in supermicron fly ash particles for all six study coals sampled at Port 14 .

3-12 Particle size dependence of arsenic in submicron fly ash particles for all six study coals sampled at Port 14 .

3-13 Differential mass distributions of arsenic, calcium, iron, and total ash for the six study coals sampled at Port 14 .

3-14 Cross correlation of Illinois arsenic to calcium and iron differential distribution curves at baseline screening experimental conditions sampled at Port 4 for the supermicron region 


\section{LIST OF FIGURES (Continued)}

Figure No.

$\underline{\text { Page }}$

3-15 Cross correlation of Illinois arsenic to calcium and iron differential distribution curves at baseline screening experimental conditions sampled at Port 14 for the supermicron region

3-16 Cross correlation of Pittsburgh arsenic to calcium and iron differential distribution curves at baseline screening experimental conditions sampled at Port 4 for the supermicron region

3-17 Cross correlation of Pittsburgh arsenic to calcium and iron differential distribution curves at baseline screening experimental conditions sampled at Port 14 for the supermicron region

3-18 Cross correlation of Ohio arsenic to calcium and iron differential distribution curves at baseline screening experimental conditions sampled at Port 4 for the supermicron region

3-19 Cross correlation of Ohio arsenic to calcium and iron differential distribution curves at baseline screening experimental conditions sampled at Port 14 for the supermicron region

3-20 Cross correlation of Kentucky arsenic to calcium and iron differential distribution curves at baseline screening experimental conditions sampled at Port 4 for the supermicron region

3-21 Cross correlation of Kentucky arsenic to calcium and iron differential distribution curves at baseline screening experimental conditions sampled at Port 14 for the supermicron region.

3-22 Cross correlation of Wyodak arsenic to calcium and iron differential distribution curves at baseline screening experimental conditions sampled at Port 4 for the supermicron region

3-23 Cross correlation of Wyodak arsenic to calcium and iron differential distribution curves at baseline screening experimental conditions sampled at Port 14 for the supermicron region.

3-24 Cross correlation of North Dakota arsenic to calcium and iron differential distribution curves at baseline screening experimental conditions sampled at Port 4 for the supermicron region 


\section{LIST OF FIGURES (Continued)}

Figure No.

$\underline{\text { Page }}$

3-25 Cross correlation of North Dakota arsenic to calcium and iron differential distribution curves at baseline screening experimental conditions sampled at Port 14 for the supermicron region

3-26 Comparison of arsenic differential distribrutions when adjusting the arsenic-tocalcium ratio at constant maximum combustion temperature in theWyodak coal

3-27 Comparison of arsenic differential distributions when adjusting the arsenic-tocalcium ratio of the Wyodak coal with combustion near the Ohio maximum combustion temperature.

3-28 Comparison of arsenic differential distributions when adjusting the arsenic-tocalcium ratio of the Wyodak coal to the Ohio and Kentucky distributions with combustion near the Ohio maximum combustion temperature

3-29 Comparison of arsenic differential distributions when adjusting the arsenic-tocalcium ratio of the Ohio with combustion at the Ohio maximum combustion temperature.

3-30 Comparison of arsenic differential distributions when adjusting the arsenic-tocalcium ratio of the Ohio with combustion at the Wyodak maximum combustion temperature.

3-31 Particle size dependence of arsenic in supermicron fly ash particles for all six study coals sampled at Port 4

3-32 Particle size dependence of arsenic in submicron fly ash particles for all six study coals sampled at Port 4

3-33 Differential mass distributions of arsenic, calcium, iron, and total ash for the six study coals sampled at Port 4

3-34 Summary of arsenic partitioning mechanisms

3-35 Simulated temperature-dependent equilibrium profiles of arsenic during combustion of the six study coals under baseline conditions.

3-36 Simulated temperature-dependent equilibrium profiles of arsenic omitting AsO as a valid product

3-37 Breakthrough as a function of time for the four runs with the Ohio blend ash and $\mathrm{Hg}^{0}$ injection. 


\section{LIST OF FIGURES (Continued)}

Figure No.

$\underline{\text { Page }}$

3-38 Breakthrough as a function of time for the four runs with the Wyodak ash and $\mathrm{Hg}^{0}$ injection.

3-39 Breakthrough as a function of time for the North Dakota lignite and the ash from the Coal Creek station.

3-40 Breakthrough as a function of time for the Blacksville ash at $350^{\circ} \mathrm{F}$ with $\mathrm{Hg}^{0}$ injection. 3-66

3-41 Breakthrough as a function of time for the Comanche station ash at $250^{\circ} \mathrm{F}$ with $\mathrm{Hg}^{0}$ injection.

3-42 Breakthrough as a function of time for the Station A ash at $250^{\circ} \mathrm{F}$ with $\mathrm{Hg}^{0}$ injection.

3-43 Breakthrough as a function of time for the Station $\mathrm{B}$ ash at $350^{\circ} \mathrm{F}$ with $\mathrm{Hg}^{0}$ injection.

3-44 Breakthrough as a function of time for the GA ash with either $\mathrm{Hg}^{0}$ or $\mathrm{HgCl}_{2}$ injection.

3-45 Breakthrough as a function of time for the AA ash with either $\mathrm{Hg}^{0}$ or $\mathrm{HgCl}_{2}$ injection.

3-46 Breakthrough as a function of time for the DMA ash with either $\mathrm{Hg}^{0}$ or $\mathrm{HgCl}_{2}$ injection

3-47 Breakthrough as a function of time for the DA ash with either $\mathrm{Hg}^{0}$ or $\mathrm{HgCl}_{2}$ injection.

3-48 Breakthrough as a function of time for the $\mathrm{MA}$ ash with $\mathrm{HgCl}_{2}$ injection

3-49 Breakthrough as a function of time for three runs with the Ohio blend ash with $\mathrm{HgCl}_{2}$ injection.

3-50 Breakthrough as a function of time for three runs with the Wyodak ash with $\mathrm{HgCl}_{2}$ injection.

3-51 Breakthrough as a function of time for three runs with the Station A ash with $\mathrm{HgCl}_{2}$ injection. 


\section{LIST OF FIGURES (Continued)}

Figure No.

$\underline{\text { Page }}$

3-52 Breakthrough as a function of time for three runs with the Blacksville ash with $\mathrm{HgCl}_{2}$ injection

3-53 SEM photograph of Ohio ash sample (590 times magnification) .............................. 3-78

3-54 SEM photograph of Ohio ash sample (4,890 times magnification) ........................... 3-79

3-55 SEM photograph of Ohio ash sample (7,230 times magnification) ........................... 3-79

3-56 SEM photograph of Ohio ash sample (28,600 times magnification) ......................... 3-80

3-57 SEM photograph of North Dakota lignite ash sample (343 times magnification).........3-81

3-58 SEM photograph of North Dakota lignite ash sample (1,070 times magnification)...... 3-81

3-59 SEM photograph of North Dakota lignite ash sample (4,370 times magnification)...... 3-82

3-60 SEM photograph of North Dakota lignite ash sample (17,500 times magnification).... 3-82

3-61 SEM photograph of North Dakota lignite ash sample (4,370 times magnification)......3-83

3-62 SEM photograph of North Dakota lignite ash sample (7,160 times magnification)......3-83

3-63 SEM photograph of Wyodak ash sample (378 times magnification) ..........................3-84

3-64 SEM photograph of Wyodak ash sample (3,020 times magnification) ...................... 3-85

3-65 SEM photograph of Wyodak ash sample (6,290 times magnification) ....................... 3-85

3-66 SEM photograph of Wyodak ash sample (1,440 times magnification) ....................... 3-86

3-67 SEM photograph of Wyodak ash sample (11,400 times magnification) ..................... 3-86

3-68 SEM photograph of Wyodak ash sample (14,800 times magnification) ..................... 3-87

3-69 SEM photograph of Wyodak ash sample (24,900 times magnification) ..................... 3-87 


\section{LIST OF TABLES}

Table No.

$\underline{\text { Page }}$

2-1 Task Breakdown.......................................................................................... 2-4

3-1 Mössbauer Data for Top and Bottom Layers of Coal Samples from University of Utah ......................................................................................... $3-4$

3-2 As Contents of Residues Remaining after Leaching Experiments ........................... 3-10

3-3 Estimates of Arsenic Forms Remaining after Each Leaching Step in the Ohio Coal ....

3-4 Fraction of Each Element Recovered in the Submicron Ash for Ohio Coal.................3-14

3-5 Forms of Occurrence of Arsenic in the Six Study Coals ....................................... 3-21

3-6 Mass Fraction of Arsenic in Vapor, Submicron, and Supermicron Regimes at Three Combustor Sample Locations

3-7 Arsenic Enrichment Factors for Submicron-Sized Fly Ash Samples ..........................3-23

3-8 Correlation Coefficients for Arsenic versus Calcium and Iron in Fly Ash Particles from the Six Study Coals Sampled at Port 14

3-9 Arsenic Partitioning Mechanism Hypotheses and Validation Text Matrix ..................3-40

3-10 Comparison of Arsenic Mass Concentration Values from Ohio Coal Calcium Doping Experiments

3-11 Comparison of Arsenic Mass Concentration Values from Kentucky Coal $\mathrm{SO}_{2}$ Doping Experiments

3-12 A Comparison of Absolute Arsenic Concentration Values from Pittsburgh Seam Coal Cation Doping Experiments.

3-13 Summary of Arsenic Solubility in Fly Ash from Baseline Screening Experiments

3-14 Correlation Coefficients for Arsenic Versus Calcium and Iron in Fly Ash Particles from the Six Study Coals Sampled at Port 14

3-15 Primary Partitioning Mechanisms for Arsenic During the Combustion of the Six Study Coals 


\section{LIST OF TABLES (Continued)}

Table No. $\quad \underline{\text { Page }}$

3-16 Possible Arsenic Products from Thermodynamic Simulation .................................. 3-62

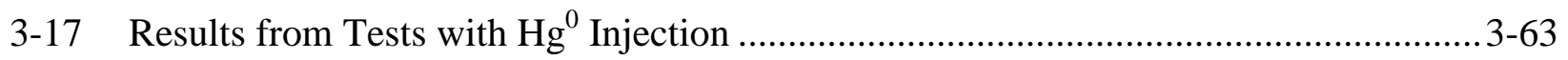

3-18 Surface Area of Ash Samples Before and After Ashing ........................................ 3-64

3-19 Characteristics of Eastern Bituminous Coal Ash Samples.........................................3-69

3-20 Results from Tests with $\mathrm{HgCl}_{2}$ Injection (at $350^{\circ} \mathrm{F}$ ) ........................................ 3-72

3-21 Amount of Elemental Mercury Oxidized in Bench Scale Tests as a Function

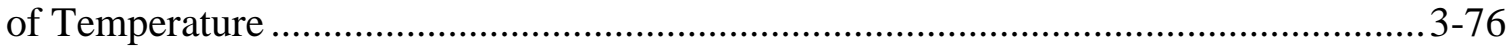

3-22 Surface Area and LOI of Ash Samples for Morphological Analysis........................... 3-77 


\begin{abstract}
The Clean Air Act Amendments of 1990 identify a number of hazardous air pollutants (HAPs) as candidates for regulation. Should regulations be imposed on HAP emissions from coal-fired power plants, a sound understanding of the fundamental principles controlling the formation and partitioning of toxic species during coal combustion will be needed. With support from the Federal Energy Technology Center (FETC), the Electric Power Research Institute, and VTT (Finland), Physical Sciences Inc. (PSI) has teamed with researchers from USGS, MIT, the University of Arizona (UA), the University of Kentucky (UK), the University of Connecticut (UC), the University of Utah (UU) and the University of North Dakota Energy and Environmental Research Center (EERC) to develop a broadly applicable emissions model useful to regulators and utility planners. The new Toxics Partitioning Engineering Model (ToPEM) will be applicable to all combustion conditions including new fuels and coal blends, low- $\mathrm{NO}_{\mathrm{x}}$ combustion systems, and new power generation plants. Development of ToPEM will be based on PSI's existing Engineering Model for Ash Formation (EMAF).
\end{abstract}

The work discussed in this report covers the reporting period from 1 April 2000 to 30 June 2000. The final program review meeting of Phase II was held on June 22 in Salt Lake City. The goals of the meeting were to present work in progress and to identify the remaining critical experiments or analyses, particularly those involving collaboration among various groups. Mössbauer analyses of coal samples from the University of Utah were completed; samples from the top and bottom layers of containers of five different coals showed little oxidation of pyrite in the top relative to the bottom except for Wyodak. Recently, new (INAA) data were obtained for arsenic and other elements in the actual leached coal fractions on which the XAFS data were recorded. XAFS spectroscopy shows clearly that the major fraction of arsenic leached from both coals by $\mathrm{HCl}$ is arsenate and that $\mathrm{HNO}_{3}$ removes much of the remaining arsenic in both coals. Leaching with HF has little effect on the arsenic content of both coals examined and appears restricted to removing any arsenate species that remains after the $\mathrm{HCl}$ leach. During the reporting period, staff at the Stanford/USGS SHRIMP-RG ion microprobe tested a new cesium primary beam. Tests included using the cesium ions to investigate the ionization behavior of mercury in a cinnabar $(\mathrm{HgS})$ standard. The University of Utah has completed the experiments in the drop tube furnace and begun analysis of the single particle combustion experiments. The initial analysis shows a pronounced bimodal size distribution. Analysis of the Ohio data shows an enrichment of several elements in the submicron ash as oxygen concentrations are increased. In the presence of carbon dioxide, the fraction of several metals in the submicron ash is reduced. A comprehensive study has been performed at the University of Arizona to investigate the partitioning of arsenic during pulverized coal combustion. The partitioning of arsenic to fly ash surfaces is dependent on the availability of active cation sites. For coals with relatively low As/Ca ratios, arsenic is expected to react with calcium surface sites to form calcium arsenate complexes. If the As/Ca ratio is relatively high and the sulfur content is moderate to high, cationic surface sites will not be available for arsenic partitioning. In these cases, most of the arsenic is expected to exit the furnace in the vapor phase or as fly ash surface-based $\mathrm{As}_{2} \mathrm{O}_{3}$. Complimentary leaching experiments were done to assess the potential impact of these compounds on leaching of arsenic into groundwater. Active cationic surface sites are primarily due to major elements (i.e., calcium and iron) volatilizing in the vicinity of the carbon oxidizing in the coal particles and then 
homogeneously and heterogeneously condensing. Increasing the combustion temperature can increase cationic surface site availability and subsequently reduce the emission of vapor phase or physically condensed $\mathrm{As}_{2} \mathrm{O}_{3}$ from the furnace. A thermodynamic modeling study of arsenic behavior in the post-combustion flue gas was undertaken. Most of the bench-scale testing at EERC on the current suite of ash samples has been completed, although not all of the characterization tests have been completed. Few of the ash samples adsorbed elemental mercury; most adsorbed mercuric chloride. Adsorption appears to decrease with increasing temperature. Oxidation appears to increase with increasing temperature. The samples from the University of Arizona combustor which were tested at bench scale at EERC were also examined at the University of Utah be scanning electron microscopy. All the carbon in the North Dakota and the Ohio samples is in the form of char. The Wyodak sample had a high surface area and carbon content and ultrafine aggregates were observed in the ash, suggesting the presence of soot. 


\section{SECTION 1}

EXECUTIVE SUMMARY 


\section{EXECUTIVE SUMMARY}

The technical objectives of this project are:

a) To identify the effect of the mode-of-occurrence of toxic elements in coal on the partitioning of these elements among vapor, submicron fume, and fly ash during the combustion of pulverized coal,

b) To identify the mechanisms governing the post-vaporization interaction of toxic elements and major minerals or unburned carbon (char),

c) To determine the effect of combustion environment (i.e., fuel rich or fuel lean) on the partitioning of trace elements among vapor, submicron fume, and fly ash during the combustion of pulverized coal,

d) To model the partitioning of toxic elements among various chemical species in the vapor phase and between the vapor phase and complex aluminosilicate melts,

e) To develop the new Toxics Partitioning Engineering Model (ToPEM), applicable to all combustion conditions including new fuels and coal blends, low- $\mathrm{NO}_{\mathrm{x}}$ combustion systems, and new power generation plants.

A description of the work plan for accomplishing these objectives is presented in Section 2.1 of this report.

The work discussed in this report covers the reporting period from 1 April 2000 to 30 June 2000. The final program review meeting of Phase II was held on June 22 in Salt Lake City. The goals of the meeting were to present work in progress and to identify the remaining critical experiments or analyses, particularly those involving collaboration among various groups. The information presented at the meeting is summarized in this report. Remaining fixed bed, bench-scale experiments at EERC were discussed. There are more ash samples which can be run. Of particular interest are high carbon ash samples to be generated by the University of Arizona this summer and some ash-derived sorbents that EERC has evaluated on a different program. The use of separation techniques (electrostatic or magnetic) was also discussed as a way to understand the active components in the ash with respect to mercury.

XAFS analysis of leached and unleached ash samples from the University of Arizona was given a high priority. In order to better understand the fixed bed test results, CCSEM and Mössbauer analyses of those ash samples need to be completed. Utah plans to analyze the ash from the single particle combustion experiments for those major elements not measured by INAA. USGS must still complete mercury analyses on the whole coals and leaching residues. Priorities for further work at the SHRIMP-RG facility include arsenic on ash surfaces and mercury in sulfide minerals. 
Mössbauer analyses of coal samples from the University of Utah were completed; samples from the top and bottom layers of containers of five different coals showed little oxidation of pyrite in the top relative to the bottom except for Wyodak.

Recently, new (INAA) data were obtained for arsenic and other elements in the actual leached coal fractions on which the XAFS data were recorded. These analyses therefore represent the first direct comparison of the XAFS spectroscopic method and the leaching method of determining speciation. In light of now having both XAFS and INAA data on the identical residue fractions, the conclusions reported in previous reports have to be significantly revised. INAA data were correlated with the XAFS data on the arsenic edge-step reported previously for the same fractions and similar trends to that obtained previously for the relationship between arsenic content and arsenic edge-step height were seen.

A number of important conclusions can be reached from this detailed, direct comparison of the XAFS spectroscopy and leaching protocol methods for speciation of arsenic in coal. XAFS spectroscopy shows clearly that the major fraction of arsenic leached from both coals by $\mathrm{HCl}$ is arsenate and that $\mathrm{HNO}_{3}$ removes much of the remaining arsenic in both coals. Leaching with HF has little effect on the arsenic content of both coals examined and appears restricted to removing any arsenate species that remains after the $\mathrm{HCl}$ leach. Such a result indicates that there is no need to postulate the presence of minor arsenic associated with silicates. The arsenic associated with pyrite in the bituminous coal is removed effectively by nitric acid, but a quite different form is removed from the lignite by nitric acid. Finally, a small fraction of the arsenic ( 5 to $15 \%$ ) remains in the coal after the nitric acid leach. We suspect that this might be an organo-arsenate formed by a side reaction between the arsenic leached from the coal and new oxygen functionality on the coal introduced by reaction of the coal macerals with the oxidizing nitric acid.

Processing of leaching analytical results obtained from the USGS Denver laboratories has been completed and these results are reported. The results show excellent recoveries. Results for Fe and As show a strong sulfide association for the Ohio sample and mixed associations, dominantly $\mathrm{HCl}$-leachable associations for the two lower rank coals. Leaching results are now available for all elements except mercury. A new direct-method instrument devoted to mercury analysis, was tested during the reporting period, and is now available for use on unknowns. Mercury analysis splits saved from leaching solid residues are now being submitted for analysis using this instrument. USGS microprobe and SEM facilities are currently unavailable for use, but planned studies include more complete integration of leaching results and SEM mineralogy.

During the reporting period, staff at the Stanford/USGS SHRIMP-RG ion microprobe tested a new cesium primary beam. Tests included using the cesium ions to investigate the ionization behavior of mercury in a cinnabar $(\mathrm{HgS})$ standard. This test did not yield satisfactory results, and our efforts to determine $\mathrm{Hg}$ and other metals in sulfides, must await the changeover to the oxygen source, later in the summer, to determine if there is sufficient ionization of mercury to make the planned determinations on sulfides. 
The University of Utah has completed the experiments in the drop tube furnace and begun analysis of the single particle combustion experiments. The initial analysis shows a pronounced bimodal size distribution. Analysis of the Ohio data shows an enrichment of several elements in the submicron ash as oxygen concentrations are increased. In the presence of carbon dioxide, the fraction of several metals in the submicron ash is reduced.

A comprehensive study has been performed to investigate the partitioning of arsenic during pulverized coal combustion. The partitioning of arsenic is governed primarily by the extent of arsenic volatilization during combustion. The majority of the arsenic for all six coals is attributed to pyrite/sulfide or mono-sulfide fractions. Organically-associated arsenic was only detected in the Wyodak coal. The large fraction of arsenic not contained in silicates is expected to volatilize during combustion. Volatilized arsenic will heterogeneously transform to both submicron and supermicron particles primarily by reaction with active cation sites. Only a small fraction will remain in the vapor phase and exit the boiler.

The partitioning of arsenic to fly ash surfaces is dependent on the availability of active cation sites. For coals with relatively low As/Ca ratios, arsenic is expected to react with calcium surface sites to form calcium arsenate complexes. These arsenate complexes are partially soluble and some of the arsenic in this form is expected to leach into groundwater. If the As/Ca ratio is relatively high and the sulfur content is low, arsenic will most likely react with both calcium and iron surface sites to form iron arsenates and calcium arsenates. These complexes are partially soluble and are likely to contribute arsenic to groundwater due to leaching. If the As/Ca ratio is relatively high and the sulfur content is moderate to high, cationic surface sites will not be available for arsenic partitioning. In these cases, most of the arsenic is expected to exit the furnace in the vapor phase or as fly ash surface-based $\mathrm{As}_{2} \mathrm{O}_{3}$ (e.g., the Ohio study coal). $\mathrm{As}_{2} \mathrm{O}_{3}$ is partially soluble and is likely to contribute arsenic to groundwater due to leaching. Further, a portion of the $\mathrm{As}_{2} \mathrm{O}_{3}$ may oxidize to $\mathrm{As}_{2} \mathrm{O}_{5}$. $\mathrm{As}_{2} \mathrm{O}_{5}$ is very soluble and any arsenic in this form will most likely leach out of fly ash particles when contacted by water.

Active cationic surface sites are primarily due to major elements (i.e., calcium and iron) volatilizing in the vicinity of the carbon oxidizing in the coal particles and then homogeneously and heterogeneously condensing. Increasing the combustion temperature can increase cationic surface site availability and subsequently reduce the emission of vapor phase or physically condensed $\mathrm{As}_{2} \mathrm{O}_{3}$ from the furnace.

A thermodynamic modeling study of arsenic behavior in the post-combustion flue gas was undertaken. The constrained simulation results appear to be more reflective of the actual partitioning of arsenic during pulverized coal combustion. The analysis of arsenic partitioning based on experimental data showed that vapor-phase arsenic is reactive with cation surface sites available on fly ash particles. This reaction mechanism is more likely with vapor-phase arsenic in an oxy-anion form, such as $\mathrm{As}_{2} \mathrm{O}_{4}$ rather than a simple oxide form (i.e., AsO). It should be noted that thermodynamic data for Fe-As reaction products were not available for use in these simulations. Therefore, it was not possible to assess whether the formation of Fe-As oxy-anion complexes is thermodynamically favorable. 
Most of the bench-scale testing at EERC on the current suite of ash samples has been completed, although not all of the characterization tests have been completed. Few of the ash samples adsorbed elemental mercury; most adsorbed mercuric chloride. Adsorption appears to decrease with increasing temperature.

The amount of oxidation was measured one to three hours into the tests when the concentration of mercury in the gas exiting the ash had become constant (as indicated in the figures in this section). Oxidation appears to increase with increasing temperature. There does not seem to be any clear correlation between either surface area or carbon content when comparing ash from different coals. Although carbon has been shown to oxidize mercury, there are other factors at play, perhaps related to the composition of the non-carbonaceous part of the ash.

The samples from the University of Arizona combustor which were tested at bench scale at EERC were also examined at the University of Utah be scanning electron microscopy. The carbon content of these samples was high, particularly that of the two low rank coals. In addition, the surface area of the Wyodak ash was abnormally high, and suggested that perhaps this ash sample contained soot. Therefore, a small study was undertaken of the morphology of these ash samples. From the origin of particles (based on the surface area data and what is known about the formation of particle during coal combustion) and the images that were taken, the conclusion was reached that all the carbon in the North Dakota and the Ohio is in the form of char. The Wyodak sample hardly had any char in it. The high surface area and carbon content of this ash, along with the observation of ultrafine aggregates, suggests that soot was present in the ash. 


\section{SECTION 2}

INTRODUCTION AND PROGRAM OVERVIEW 


\section{INTRODUCTION AND PROGRAM OVERVIEW}

\section{$2.1 \quad \underline{\text { Introduction }}$}

Before electric utilities can plan or implement emissions minimization strategies for hazardous pollutants, they must have an accurate and site-specific means of predicting emissions in all effluent streams for the broad range of fuels and operating conditions commonly utilized. Development of a broadly applicable emissions model useful to utility planners first requires a sound understanding of the fundamental principles controlling the formation and partitioning of toxic species during coal combustion. Physical Sciences Inc. (PSI) and its team members will achieve this objective through the development of an "Engineering Model" that accurately predicts the formation and partitioning of toxic species as a result of coal combustion. The "Toxics Partitioning Engineering Model" (ToPEM) will be applicable to all conditions including new fuels or blends, low- $\mathrm{NO}_{\mathrm{x}}$ combustion systems, and new power systems being advanced by DOE in the Combustion 2000 program.

Based on a goal of developing and delivering this ToPEM model, a 5-year research program was proposed. This program is divided into a 2-year Phase I program and a 3-year Phase II program. The objective of the ongoing Phase II program is to develop an experimental and conceptual framework for the behavior of selected trace elements (arsenic, selenium, chromium, and mercury) in combustion systems and incorporate these concepts into a new engineering model. This Phase II objective will be achieved by a team of researchers from USGS, the Massachusetts Institute of Technology (MIT), the University of Arizona (UA), the University of Kentucky (UK), the University of Connecticut (UC), the University of Utah (UU), the University of North Dakota Energy \& Environmental Research Center (EERC) and PSI. Model development and commercialization will be carried out by PSI.

\subsection{Program Overview}

Our general approach to the development of the ToPEM model is to break the process for toxic formation into sub-processes, each of which will be addressed by team members who are experts in the area. Ultimately, this will result in new sub-models which will be added to the existing Engineering Model for Ash Formation (EMAF) to create ToPEM. Table 2-1 describes the work breakdown structure for the Phase II program. Figure 2-1 illustrates the relationship between the elements of the Phase I work breakdown structure and the subprocesses. Each of the areas identified in the figure will be addressed in the Phase II program as described below.

\section{Forms of Occurrence of Trace Elements in Coal}

One of the most important questions to be answered in the program as a whole is whether the form of a particular element in the coal affects its form of emission at the end of the process. The answer to this question will determine the shape of the sub-models that must be developed in this program. Thus, a detailed understanding of the forms of individual trace elements in coal provides a foundation for much of the rest of the program. Key issues that will be addressed in 
Table 2-1. Task Breakdown

\begin{tabular}{|l|c|c|}
\hline \multicolumn{1}{|c|}{ Technical Task } & Team Member & $\begin{array}{c}\text { Task (WBS) } \\
\text { Number }\end{array}$ \\
\hline \hline Program management & PSI & 1 \\
\hline Coal acquisition, characterization & PSI & 2 \\
\hline Coal, ash trace element characterization & PSI & 2 \\
\hline Coal (and ash) characterization -- forms of occurrence & UK, USGS & 3,4 \\
\hline $\begin{array}{l}\text { Coal, ash trace element characterization and mercury } \\
\text { capture and analysis }\end{array}$ & MIT & 5.2 \\
\hline $\begin{array}{l}\text { Mechanistic study: dilute bench scale combustion tests } \\
\text { plus equilibrium, kinetic modeling }\end{array}$ & UU & 5.1 \\
\hline Large scale tests at 100,000 Btu/h facility & UA & 6 \\
\hline $\begin{array}{l}\text { Mechanistic study of kinetic rates for gas-phase } \\
\text { reactions }\end{array}$ & UC & 10 \\
\hline Mercury-fly ash interactions at bench scale & EERC & 11 \\
\hline Fundamental Engineering Model development & PSI & 9.1 \\
\hline $\begin{array}{l}\text { Inorganic emissions: literature survey and model } \\
\text { validation }\end{array}$ & UC & 9.2 \\
\hline
\end{tabular}

Phase II are the specific mineral associations of individual elements and the relationship between trace metal form and "standard" coal analyses.

Because of the importance of elemental form (e.g., sulfate versus silicate mineral) on partitioning, it is critical that coals representing a broad range of elemental forms be examined in this program. In Task 2 we will select and acquire a total of three coals for study in this program. The coals chosen will represent a broad range of elemental forms of occurrence taken from the major coal ranks and commercial coal seams used for pulverized coal power generation in the U.S. Once selected, fresh coal samples will be acquired and distributed to team members. These samples will be subjected to ultimate, proximate, and ASTM ash analysis. Coal samples will be analyzed for trace element concentrations by Neutron Activation Analysis (NAA) at the MIT Nuclear Reactor Laboratory (Task 5.2).

Advanced analytical techniques such as Mössbauer spectroscopy and ComputerControlled Scanning Electron Microscopy (CCSEM) will be used by UK (Task 3) to determine the major mineral species present in the program coals and the combustion generated ash. Whole coal samples and density segregated coal samples will be studied. This analysis will provide important insight on the minerals present in the coal, how they interact during the combustion process, and how this interaction may affect the partitioning of toxic elements.

Another important issue is the form-of-occurrence of the trace elements in the coal. In this task the mode of occurrence of As, Cr, and Se will be determined by combining XAFS and the Mössbauer/CCSEM derived data discussed above. $\mathrm{Hg}$ will also be evaluated where possible. 


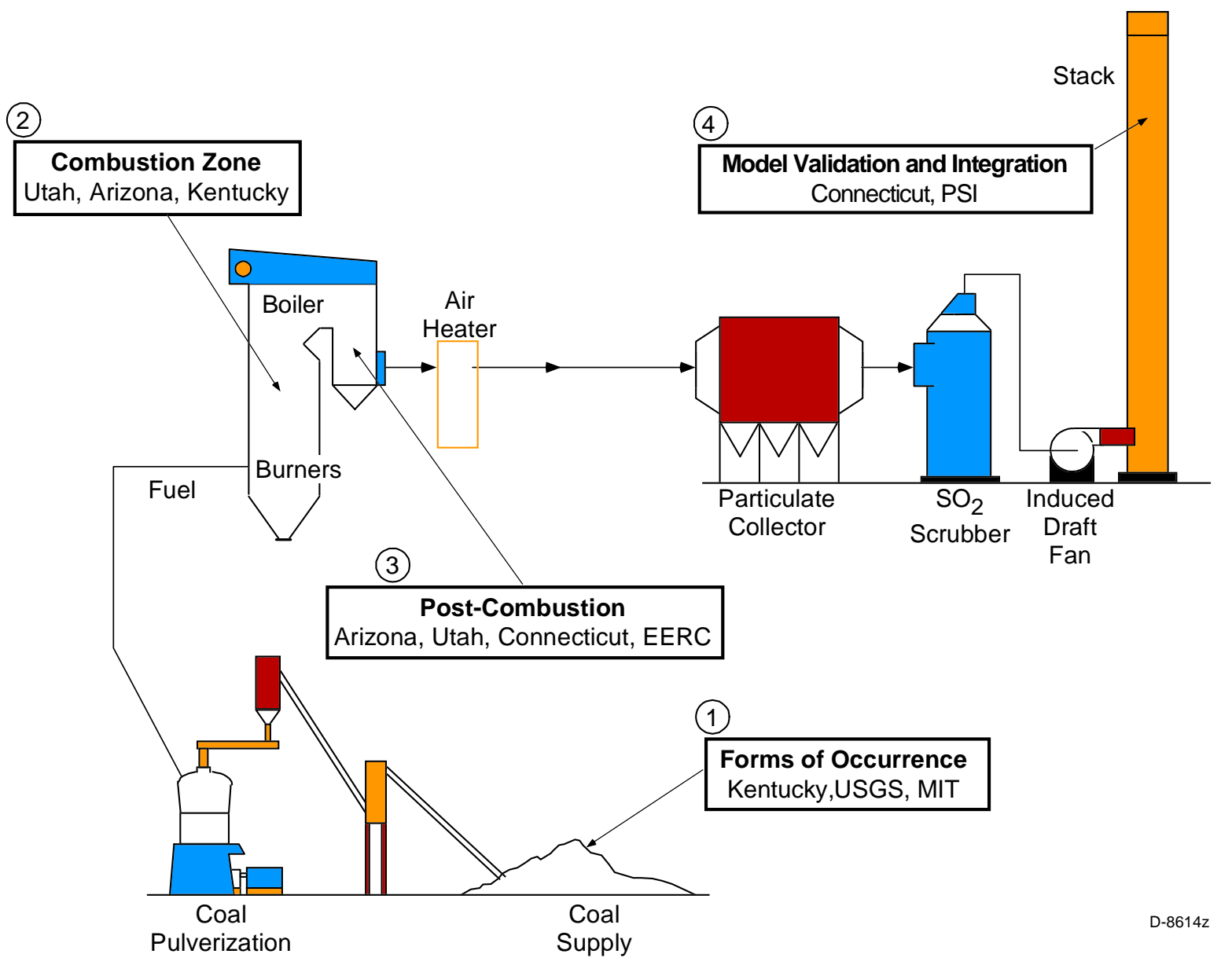

Figure 2-1. Phase II program organization.

Other less critical trace elements ( $\mathrm{Mn}, \mathrm{Ni}, \mathrm{Zn}, \mathrm{Pb}, \mathrm{U}$, etc.) may also be evaluated, especially if their abundance is unusually high in any of the program coals. In addition, the form-ofoccurrence of $\mathrm{Cl}$ and $\mathrm{S}$ in coals and chars will be investigated.

As a complement to the XAFS analysis mentioned above, a unique protocol developed by USGS will be used in Task 4 to analyze selected raw coal, and size and density segregated coal, samples for trace element forms of occurrence. This protocol combines low temperature $(<200 E C)$ ashing, chemical analysis, $x$-ray diffraction, coal segregation via flotation, ammonium acetate and selected acid leaching, electron microbeam measurements, and low and moderate temperature heating tests to determine the forms of elements in coal. Because of the unique combination of existing testing and analytical facilities available at USGS, the work will be conducted at USGS laboratories.

\section{Combustion Zone Transformations}

The effect of coal type and combustion conditions on the emission of the toxic trace elements will be investigated using the UU laminar-flow drop tube reactor (Task 5.1). The fundamental mechanisms of toxic species formation and partitioning will be determined from 
careful examination of the ash formed under a variety of combustion conditions. Measurements will be made of the partitioning of the trace elements in the three coals as a function of temperature and equivalence ratio. These measurements will provide the baseline data on the fraction vaporized. Individual size-segregated ash samples (collected with a cascade impactor) will then be analyzed by NAA for total composition and other analyses as needed, for example, Auger and STEM for surface composition, TEM and SEM for particle morphology, and possibly water washing and/or chemical leaching to determine the solubility of selected trace elements in the ash samples. Samples will also be submitted to UK for chemical species analysis by XAFS and other techniques.

\section{Post-Combustion Transformations}

The goal of this task is an increased understanding of the transformations of selected metals as the flue gases cool following the high temperature combustion zone. Bench scale experimentation will be carried out by several organizations as well as large scale combustion measurements. Advanced analytical methods will be used extensively to understand speciation of trace elements in the post-combustion flue gas.

At UC (Task 10) experiments will focus on determination of trace vapor-ash particle reactions rates in post-combustion gases, including

- Identification of the rate controlling phenomena in the oxidation of arsenic under combustion conditions

- Relative rates of gas-phase reaction of elemental mercury with $\mathrm{HCl}$ and $\mathrm{Cl}_{2}$ under combustion conditions

- Measurement of rates of heterogeneous conversion of $\mathrm{HCl}$ to $\mathrm{Cl}_{2}$ in the presence of coal combustion products such as iron oxide, iron sulfate, and fly ash samples.

Interactions of mercury with ash and ash components at lower temperatures will be the focus of the effort at EERC in Task 11. A bench-scale sorbent evaluation system will be used to increase our understanding of the interactions between gas-phase mercury and coal ash. Experiments will explore the effects of temperature and the interactions between elemental mercury or mercuric chloride and fly ash samples generated under oxidizing conditions, the effect of mercury concentration on the interactions between elemental mercury and fly ash, and the effect of coal combustion conditions on the ash and ultimately on the interaction between mercury and ash.

On a larger scale in Task 6, UA will determine how both coal composition, detailed mineralogy and combustion conditions (including low $\mathrm{NO}_{\mathrm{x}}$ conditions) govern the fate of toxic metals under practical time/temperature, self sustained, yet still aerodynamically well defined, pulverized coal combustion conditions. Program coals will be burned in the UA self-sustained combustor under premixed conditions. The baseline tests will employ the naturally occurring temperature profile for each coal at a stoichiometric ratio of 1.2. Samples will be withdrawn at several ports, representing a range of temperatures and residence times. Complete impactor 
samples will be collected and analyzed for each toxic metal (11 as listed in the CAAA plus U and Th) plus major elements. This will yield the particle size segregated toxic metal composition, which can be compared to data obtained from other tasks of this program. These data will then be examined to determine particle size dependence in order to infer possible mechanisms governing the fate of each metal.

\section{Model Validation}

UC will conduct a more in-depth review of the relevant field data on inorganic emissions (Task 9.2). In Phase II we will emphasize use of the field data to validate the models we will develop. The Phase II effort focuses on data from the following sources:
- $\quad$ EPRI PISCES
- DOE Program
- $\quad$ VTT (Finland)
- $\quad$ KEMA (Netherlands).

Important issues to be addressed when reviewing these data include mass balance closure, methods of analysis and sample collection, effect of APCD, effect of bulk coal ash chemistry, particle size distribution, and speciation of $\mathrm{Hg}$.

\section{Model Development}

In Task 9.1, data obtained from subcontractor and PSI tasks will be combined to create a comprehensive model of the transformations of important inorganic species during combustion. This model, denoted the ToPEM, will be based on an existing model (the PSI Engineering Model for Ash Formation which predicts ash particle size and composition distributions - EMAF). Because the development of this model is strongly dependent on the mechanistic, equilibrium, and kinetic information being developed under the experimental tasks, ToPEM will incorporate information on the mechanisms controlling species behavior, equilibrium modeling where appropriate and kinetic modeling to mimic kinetic constraints on species behavior. During the later stages of the Phase II work, sufficient detailed information will be available to support specific modifications to EMAF in order to describe the combustion transformations of important inorganic trace elements. Based on the experimental studies, equilibrium modeling, and kinetic modeling, it will be clear which modifications are required. Once complete, the model will be validated using a combination of laboratory and field data. As part of the validation effort, coal and size fractionated ash samples collected from operating utility boilers will be provided by Dr. Esko Kauppinen of VTT, Finland. Once validated, the ToPEM will be used to simulate the behavior of these and other coals under utility boiler conditions. The results from these simulations will then be compared to field data from PISCES obtained through EPRI participation in this program, DOE field sampling campaigns, and other relevant data in the literature. This validation procedure will ensure that the model developed as the result of the proposed research efforts accurately predicts the behavior of toxic metals species from a wide range of coals during the combustion process in any combustion system. 


\section{SECTION 3}

RESULTS AND DISCUSSION 


\section{RESULTS AND DISCUSSION}

\subsection{Program Management (PSI)}

The final program review meeting of Phase II was held on June 22 in Salt Lake City. The goals of the meeting were to present work in progress and to identify the remaining critical experiments or analyses, particularly those involving collaboration among various groups. The information presented at the meeting is summarized in this report. Remaining fixed bed, benchscale experiments at EERC were discussed. There are more ash samples which can be run. Of particular interest are high carbon ash samples to be generated by the University of Arizona this summer and some ash-derived sorbents that EERC has evaluated on a different program. The use of separation techniques (electrostatic or magnetic) was also discussed as a way to understand the active components in the ash with respect to mercury.

XAFS analysis of leached and unleached ash samples from the University of Arizona was given a high priority. In order to better understand the fixed bed test results, CCSEM and Mössbauer analyses of those ash samples need to be completed. Utah plans to analyze the ash from the single particle combustion experiments for those major elements not measured by INAA. USGS must still complete mercury analyses on the whole coals and leaching residues. Priorities for further work at the SHRIMP-RG facility include arsenic on ash surfaces and mercury in sulfide minerals.

\subsection{Coal Characterization (UK, USGS, MIT)}

\subsubsection{Coal Mineralogy}

\section{$\underline{\text { Mössbauer Analysis }}$}

A number of Mössbauer analyses have been completed in the current quarter. These are from two sources: (a) a set of ten samples from Swenson and Sarofim (University of Utah) representing five sets of top and bottom layers of coal samples in jars that have been stored for a significant period of time; and (b) fly-ash and other samples from G. Dunham (UNDEERC) and C. Senior (PSI) that are intended for mercury sorption experiments.

It was postulated that storage of coal samples in jars for long periods of time might lead to a gradation of coal oxidation between the coal at the top of the jar and the coal at the bottom of the jar and hence therefore a significant difference in the combustion behavior of the coal. To test this hypothesis, various coals that had been stored in jars for long periods of time were divided into top and bottom fractions and subjected to iron Mössbauer spectroscopy. The results are summarized in Table 3-1 and representative spectra are shown in Figure 3-1. Four out of five coals show no oxidation of pyrite in the top layer relative to the bottom layer. The Wyodak coal shows some oxidation although the pyrite content of this coal is low. Therefore, the oxidation may not be significant. 
Table 3-1: Mössbauer Data for Top and Bottom Layers of Coal Samples from University of Utah

\begin{tabular}{|c|c|c|c|c|c|c|c|c|}
\hline Run ID & Sample ID & Abs'n & Phase & $\begin{array}{l}\text { I.S. } \\
\mathrm{mm} / \\
\mathrm{sec}\end{array}$ & $\begin{array}{c}\text { Q.S. } \\
\mathrm{mm} / \\
\mathrm{sec}\end{array}$ & $\begin{array}{c}\text { Width } \\
\mathrm{mm} / \\
\mathrm{sec}\end{array}$ & $\begin{array}{l}\% \\
\mathrm{Fe}\end{array}$ & $\begin{array}{c}\% \mathrm{Pyr} \\
\mathrm{S}\end{array}$ \\
\hline \multirow[t]{2}{*}{ MK2593 } & 10. Wyodak Bottom Layer & $1 \mathrm{QS}$ & Pyrite & 0.31 & 0.63 & 0.4 & 75 & 0.035 \\
\hline & & $2 \mathrm{QS}$ & Jarosite & 0.36 & 1.27 & 0.4 & 25 & \\
\hline \multirow[t]{3}{*}{ MK2592 } & 9. Wyodak Top Layer & $1 \mathrm{QS}$ & Pyrite/Marcasite & 0.32 & 0.56 & 0.37 & 48 & 0.05 \\
\hline & & $2 \mathrm{QS}$ & Jarosite & 0.37 & 1.17 & 0.37 & 43 & \\
\hline & & $3 \mathrm{QS}$ & Siderite? & 1.23 & 1.86 & 0.37 & 9 & \\
\hline \multirow[t]{2}{*}{ MK2590 } & 8. Pittsburgh Bottom Layer & $1 \mathrm{QS}$ & Pyrite & 0.3 & 0.61 & 0.28 & 85 & 0.75 \\
\hline & $0.4511 \mathrm{~g}$ & $2 \mathrm{QS}$ & Szomolnokite & 1.24 & 2.74 & 0.27 & 15 & \\
\hline \multirow[t]{2}{*}{ MK2589 } & 7. Pittsburgh Top Layer & $1 \mathrm{QS}$ & Pyrite & 0.3 & 0.64 & 0.29 & 85 & 0.69 \\
\hline & $0.4463 \mathrm{~g}$ & $2 \mathrm{QS}$ & Szomolnokite & 1.24 & 2.74 & 0.3 & 15 & \\
\hline \multirow[t]{3}{*}{ MK2588 } & 6. ND Lignite Bottom Layer & r1 QS & Pyrite & 0.31 & 0.61 & 0.34 & 66 & 0.27 \\
\hline & $0.615 \mathrm{~g}$ & $1 \mathrm{P}+2 \mathrm{P}$ & Jarosite & 0.37 & 1.13 & 0.49 & 22 & \\
\hline & & $1 \mathrm{P}+3 \mathrm{P}$ & Fe2+/Clay & 1.13 & 2.63 & 0.37 & 12 & \\
\hline \multirow[t]{3}{*}{ MK2587 } & 5. ND Lignite Top Layer & $1 \mathrm{QS}$ & Pyrite & 0.3 & 0.63 & 0.38 & 71 & 0.23 \\
\hline & $0.6038 \mathrm{~g}$ & $1 \mathrm{P}+2 \mathrm{P}$ & Jarosite & 0.37 & 1.23 & 0.41 & 16 & \\
\hline & & $1 \mathrm{P}+3 \mathrm{P}$ & $\mathrm{Fe} 2+/$ Clay & 1.08 & 2.64 & 0.42 & 13 & \\
\hline \multirow[t]{3}{*}{ MK2586 } & 4. Illinois \#6 Bottom Layer & $1 \mathrm{QS}$ & Pyrite & 0.29 & 0.58 & 0.27 & 78.4 & 1.07 \\
\hline & $0.4566 \mathrm{~g}$ & $2 \mathrm{QS}$ & Jarosite & 0.31 & 1.16 & 0.32 & 3.5 & \\
\hline & & $3 \mathrm{QS}$ & Szomolnokite & 1.24 & 2.7 & 0.24 & 18 & \\
\hline \multirow[t]{3}{*}{ MK2585 } & 3 Illinois \#6 Top Layer & $1 \mathrm{QS}$ & Pyrite & 0.3 & 0.61 & 0.29 & 79.6 & 1.15 \\
\hline & $0.4579 \mathrm{~g}$ & $2 \mathrm{QS}$ & Jarosite & 0.36 & 1.19 & 0.29 & 1.9 & \\
\hline & & $3 \mathrm{QS}$ & Szomolnokite & 1.24 & 2.74 & 0.29 & 19.5 & \\
\hline \multirow[t]{3}{*}{ MK2584 } & 2. Elkhorn Bottom Layer & $1 \mathrm{QS}$ & Pyrite & 0.3 & 0.58 & 0.33 & 55 & 0.15 \\
\hline & $0.4463 \mathrm{~g}$ & $2 \mathrm{QS}$ & Jarosite & 0.33 & 1.14 & 0.31 & 12 & \\
\hline & & 3 QS & $\mathrm{Fe} 2+/$ Clay & 1.13 & 2.52 & 0.46 & 33 & \\
\hline \multirow[t]{3}{*}{ MK2583 } & 1. Elkhorn, Top Layer & $1 \mathrm{QS}$ & Pyrite & 0.32 & 0.61 & 0.36 & 59 & 0.17 \\
\hline & $0.4782 \mathrm{~g}$ & $2 \mathrm{QS}$ & Jarosite & 0.34 & 1.25 & 0.23 & 8 & \\
\hline & & $3 \mathrm{QS}$ & $\mathrm{Fe} 2+/$ Clay & 1.13 & 2.56 & 0.45 & 33 & \\
\hline
\end{tabular}



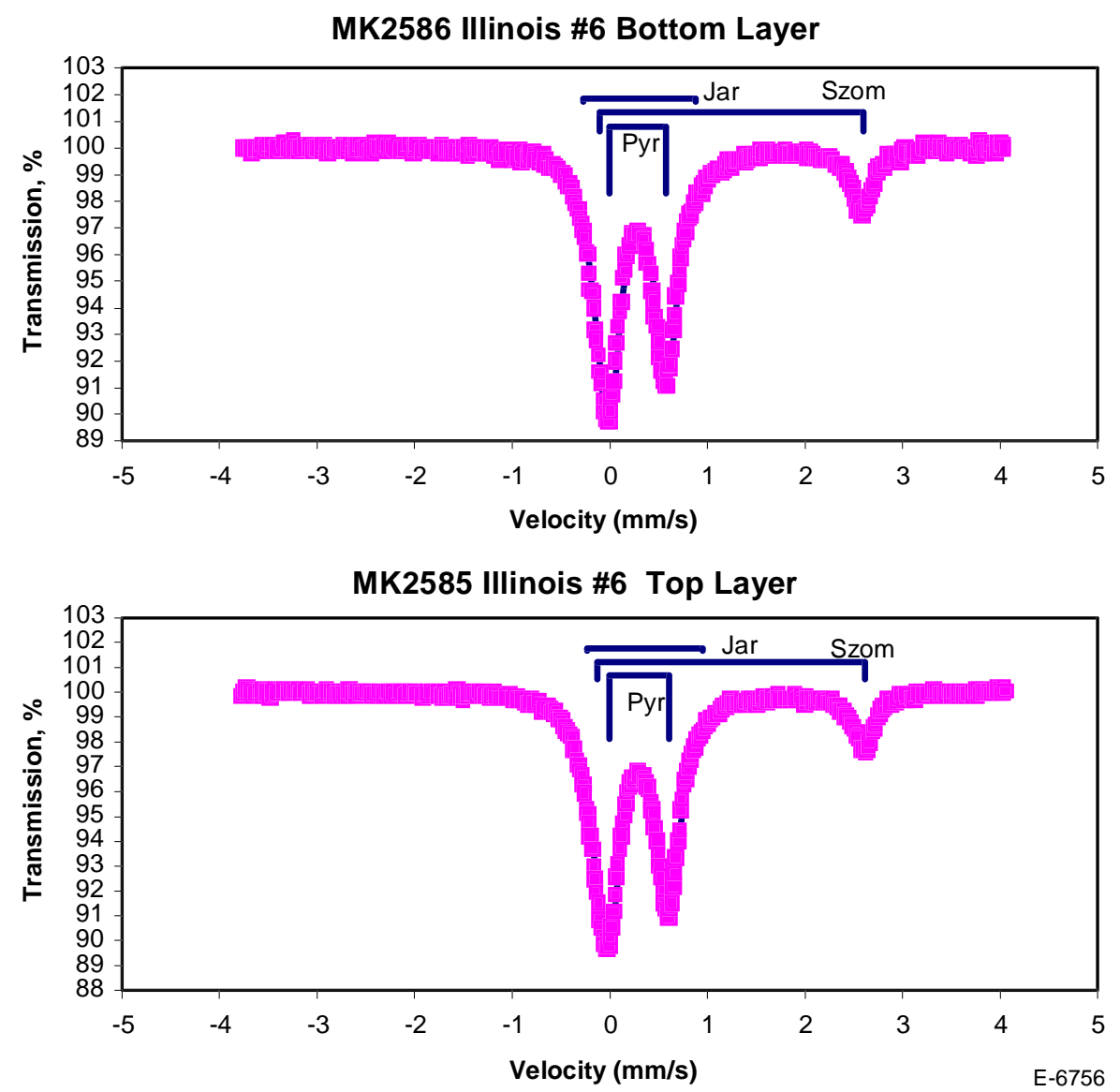

Figure 3-1. Mössbauer Spectra of Top and Bottom Layers of Illinois \#6 Coal. For all samples except the Wyodak samples, the differences between the Mössbauer spectra of the top and bottom layers were not significant. For the Wyodak samples, some significant differences were noted in the ratio of the pyrite:sulfate minerals that may indicate more pronounced oxidation of the top layer.

Similar Mössbauer characterization of fly-ash and other ash samples received from UNDEERC (Grant Dunham) are underway and will be reported when the analysis has been completed of all samples. Sulfur and Cl XANES spectra have also been obtained of the same ash samples.

\section{CCSEM Investigation of Discrete Mineralogy in Project Coals}

As reported in the previous Quarterly Report for January through March 2000, the data formatting problems for the CMA and APA analyses between the new and old CCSEM systems have been resolved. However, some further instrument-related incompatibilities were then seen when comparing the CMA data for pyrite and other iron-bearing minerals compared to the Mössbauer data. These differences appear to be related to the change in detector systems between the two CCSEMs used for the analysis. Our previous instrument employed an X-ray detector with a thick beryllium window, whereas the detector on the current instrument is ultrathin. Consequently, for low-Z elements, the number of X-rays reaching the new detector relative to the high- $Z$ elements is significantly higher than in the old system. As a result, the 
classification criteria that we use to define mineral classes, which are largely based on ratios of elemental X-rays, need to be checked and revised. This is most readily seen for phases of binary composition involving a high-Z element and a low-Z element, such as Fe and $\mathrm{S}$ in pyrite, or iron sulfates. We hope to do this in the next Quarter.

Meanwhile, some analysis of the data continues. For example, with the data formatting problems resolved, we now have available the pseudo-ternary representations for displaying elemental associations for the project coals and derived ash samples. An example of this is shown in Figure 3-2, which depicts the silicate mineralogy of the three project coals. Such plots constitute a means to readily visualize the differences in the discrete mineral matter of the three coals.

\subsubsection{Trace Element Content of Coals by Selective Leaching and Microprobe Analyses}

$\underline{\text { Leaching Studies }}$

Laboratory leaching procedures are conducted in replicate in the coal chemistry lab at the USGS National Center in Reston. Leachates and solid residues are then sent to the Energy Program analytical labs in Denver for analysis. Analytical results have been returned for all stages of the leaching procedure, including re-leaching necessitated by changes in the procedure reported in the quarterly report for the period ending June 30, 1999. Processing these data has also been completed and leaching results for all elements except mercury were reported at the review meeting in Salt Lake City (Appendix A). The results show excellent recoveries, totaling $100 \%$ or less. Results for chalcophile elements Fe, As, and Se are shown in Figure 3-3. A strong sulfide association is shown for Fe, As, and to a lesser extent, Se, in the bituminous Ohio sample. The lower rank coals show an HCl-leachable association for As (probably arsenate) and $\mathrm{Fe}$ (carbonate?). These results supercede the preliminary data reported in the quarterly report for the January to March 2000. Full interpretation of the leaching results will be given in a subsequent report.

\section{$\underline{\text { Probe/SEM }}$}

The USGS Reston microprobe and SEM labs are currently being moved to new renovated quarters. Previous results include SEM mineralogy of the project coals and of leached residues, and electron microprobe analyses of sulfides, clays and carbonate minerals in the Phase II coals. When these labs return to service at the beginning of August 2000, we will concentrate on the final SEM mineralogy to check for phases indicated by the leaching results, but not seen in preliminary SEM.

\section{$\underline{\text { Ion Probe }}$}

Ion probe analysis of illite/smectite clay minerals in project coals was conducted during two trips to the Stanford/USGS SHRIMP RG ion microprobe facility, in August 1999, and February 2000, as reported in the last quarterly. These analyses were conducted using an oxygen ion source and calibrated using natural and synthetic aluminosilicate glass standards. During the last quarter, a second ion source, producing a cesium ion primary beam, was brought on line and tested. We anticipated using the cesium ion source to investigate $\mathrm{Hg}$ in sulfides in the project 
(a)

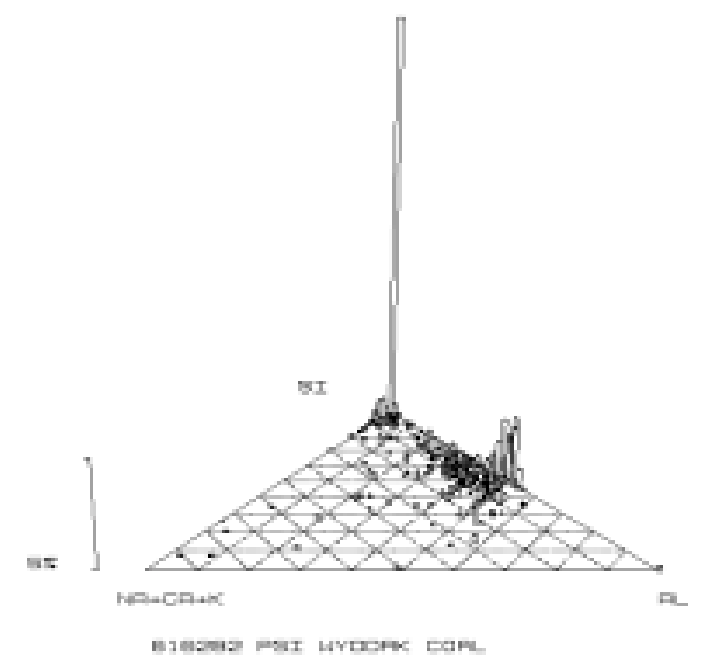

(b)
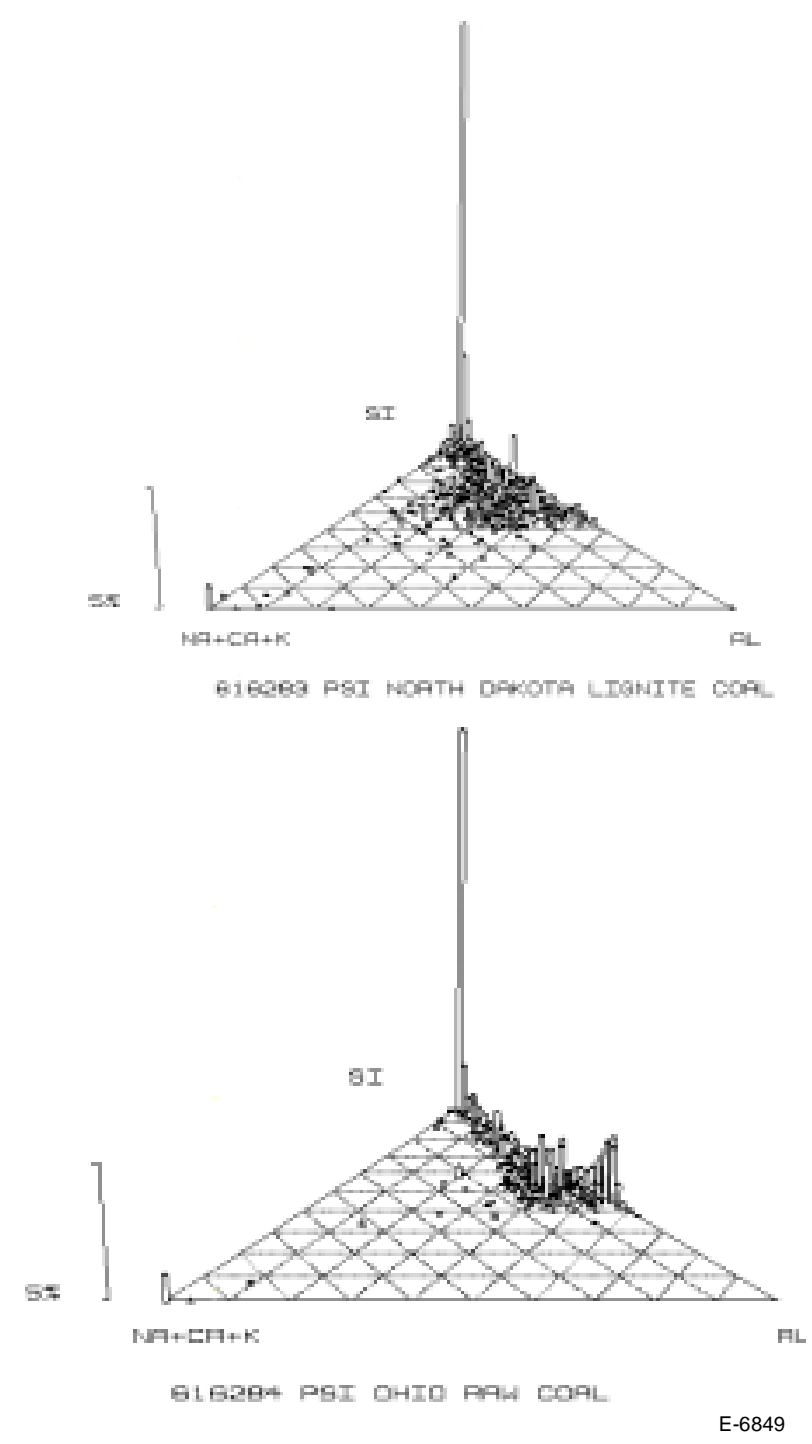

Figure 3-2. Silicate minerals from project coals by CCSEM: (a) Wyodak coal; (b) North Dakota lignite; (c) Ohio Blend coal. 
As

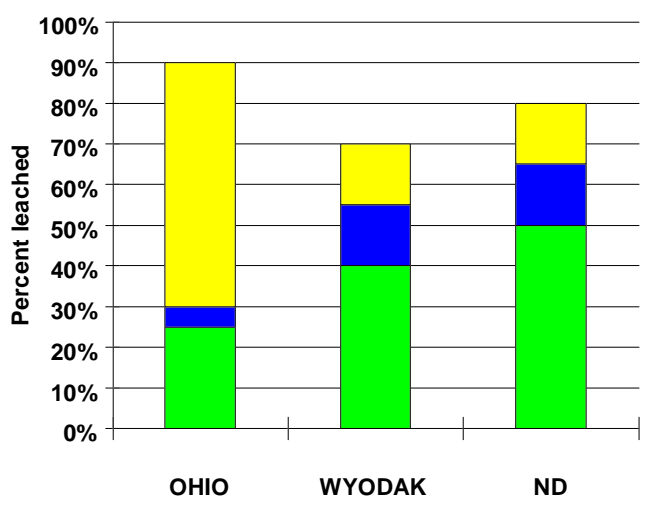

(a)

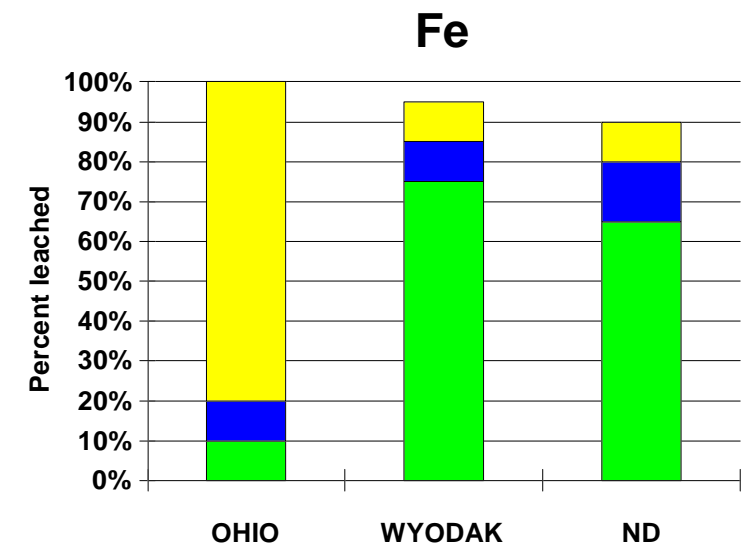

(b)

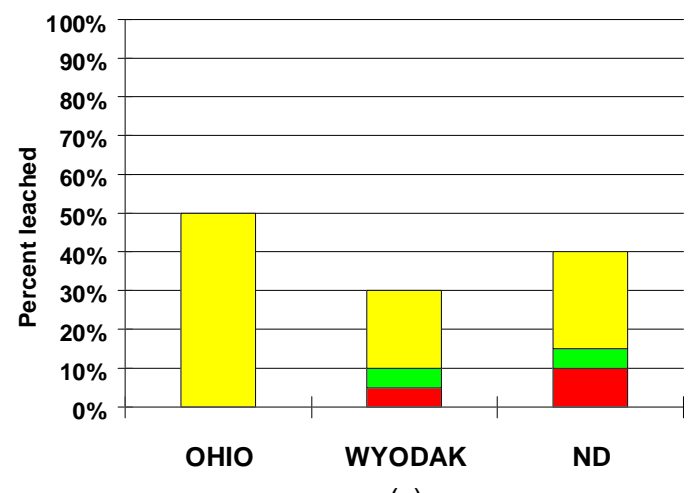

(c)

E-6757

Figure 3-3. (a-c) Selective leaching results for chalcophilic elements Fe, As, Se.

coals, and arsenic that may be present on the surfaces of ash particles. Tests of the cesium source by USGS laboratory staff Joe Wooden and Harold Persing showed that ionization of mercury in a cinnabar $(\mathrm{HgS})$ standard was insufficient for determination with the SHRIMP. Because mercury contents are expected to be orders of magnitude lower in pyrite, it was concluded that the Cs source cannot be used for the planned analysis of mercury in sulfides. The SHRIMP-RG will be returned to the oxygen configuration in several weeks, once unexpected contamination by $\mathrm{Cs}$ has been removed, and baffles are installed to prevent this from happening in future use of the Cs source. Ionization of mercury with the oxygen source will be tested once the SHRIMP-RG is returned to this configuration.

\section{$\underline{\text { Hg Analyses }}$}

A new direct analyzer that is compliant with EPA method 7473 has been acquired by our Denver laboratories, tested, and is now available for use on unknowns. Splits of leaching solid residues saved for mercury determination are now being submitted. The direct analysis method eliminates reagent blank-level problems encountered in our earlier attempt to develop an atomic fluorescence method for $\mathrm{Hg}$ analysis, as reported previously. 


\section{$\underline{\text { Integration with XAFS }}$}

To help integrate the leaching and XAFS portions of this project, XAFS splits were taken from each of the leaching steps conducted. Arsenic XAFS spectra were obtained by Frank Huggins for leached residues of the Ohio and North Dakota samples. These results show that $\mathrm{HCl}$ removes arsenate, $\mathrm{HF}$ has little effect on As, and that $\mathrm{HNO}_{3}$ removes pyritic arsenic (Ohio only). The XAFS results show that a small amount of residual arsenic remains after leaching. Arsenate forms extracted by $\mathrm{HCl}$ and ammonium acetate are believed to be oxidation products from the other major arsenic forms, resulting from exposure of the powdered coal samples to air. These results are consistent with Phase I XAFS results for bituminous coals [1], showing that significant fractions of arsenate can result from in-situ oxidation.

\subsubsection{Element Speciation by XAFS Spectroscopy}

In October 1999, for each project coal, we received a complete suite of the residues after each step of the USGS leaching protocol [1] for trace-element speciation from our colleagues at the USGS. Arsenic and chromium XAFS data and some preliminary conclusions have been reported for these fractions in the previous Quarterly reports [2,3]; however, the conclusions were subject to revision because the instrumental neutron activation analysis (INAA) data used in part to make those conclusions were obtained from an earlier suite of leached samples of the same coals. In April, new (INAA) data were obtained for arsenic and other elements in the actual coal fractions on which the XAFS data were recorded. Hence, these analyses therefore represent the first direct comparison of the XAFS spectroscopic method and the leaching method of determining speciation. In light of now having both XAFS and INAA data on the identical residue fractions, the conclusions reported in previous reports [2,3] have to be significantly revised.

The arsenic contents of the residue fractions, determined by instrumental neutron activation analysis (INAA) after each extraction, are summarized in Table 3-2. The new INAA data summarized in Table 3-2 show some significant differences, especially for the Ohio bituminous coal, from those reported previously [2,3] for similar fractions and must reflect differences due to the sampling variability of the coal with respect to arsenic. Since arsenic is usually associated with pyrite in bituminous coals, this is not too surprising since pyrite is notoriously difficult to distribute homogeneously among different fractions, even in fine grinds. The INAA data shown in Table 3-2 can be correlated with the XAFS data on the arsenic edgestep reported previously [2,3] for the same fractions and similar trends to that obtained previously for the relationship between arsenic content and arsenic edge-step height can be seen. This correlation is shown in Figure 3-4. The correlations between the analytical data and the XAFS edge-step heights for the two coals show a reasonable approximation to a linear relationship. For the Ohio bituminous coal, the correlation coefficient $\left(\mathrm{r}^{2}\right)$ exceeds $98 \%$, whereas it is about $90 \%$ for the North Dakota lignite. This result indicates that both analyses are consistent with each other. 
Table 3-2. As Contents Of Residues Remaining After Leaching Experiments

\begin{tabular}{lccc}
\hline & $\begin{array}{c}\text { Ohio Bituminous } \\
\text { As in ppm }\end{array}$ & $\begin{array}{c}\text { Wyodak Subbit. } \\
\text { As in ppm }\end{array}$ & $\begin{array}{c}\text { N. D. Lignite } \\
\text { As in ppm }\end{array}$ \\
\hline After Amm. Acet. leach & 19.1 & 1.7 & 11.0 \\
After $\mathrm{HCl}$ leach & 15.1 & 1.0 & 5.2 \\
After $\mathrm{HF}$ leach & 15.2 & 0.7 & 3.6 \\
After $\mathrm{HNO}_{3}$ leach & 0.9 & 0.4 & 1.6 \\
\hline
\end{tabular}

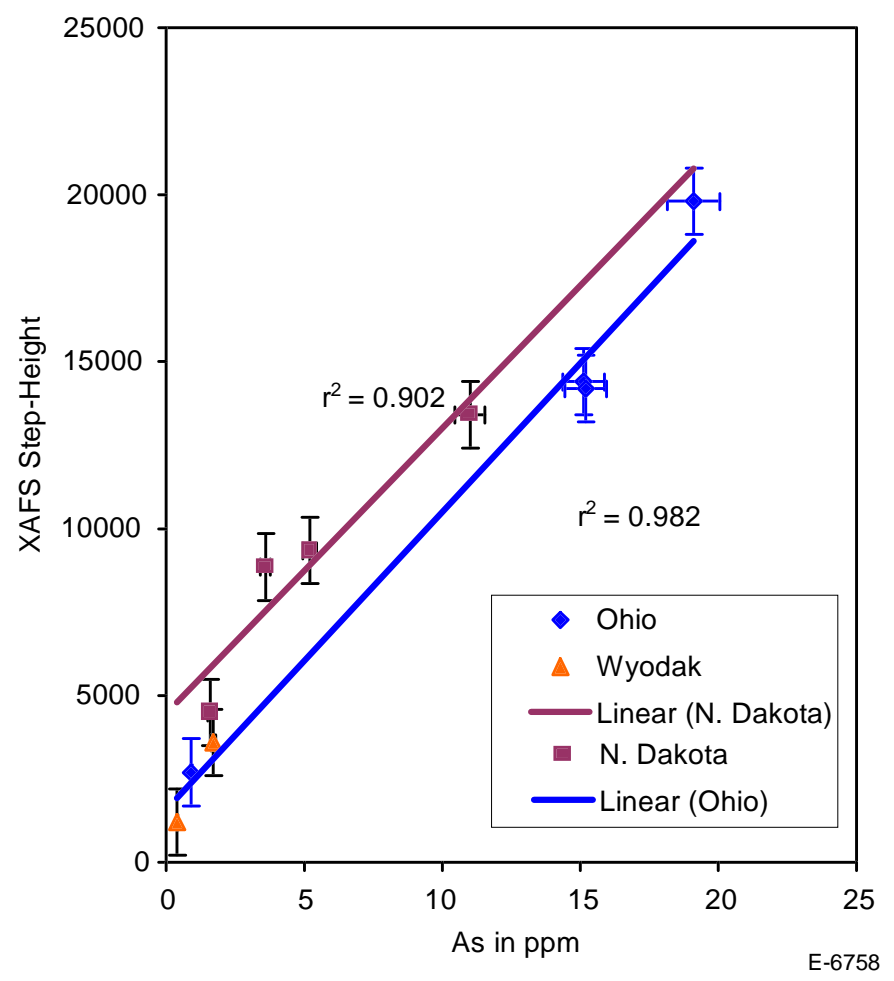

Figure 3-4. Revised correlation between the XAFS step-height and the concentration of arsenic in the identical leached residues.

As reported previously [3], for the bituminous coal, a more quantitative analysis was carried out of the XAFS spectra. This analysis is based on the method we have previously developed for quantification of arsenical pyrite and its oxidation products in oxidized coals [4]; it involves a least-squares analysis of the XAFS spectral data that provides estimates of the percentages of the total arsenic in the coal in different forms. The arsenic XANES spectral data for the Ohio bituminous coal were subject to such an analysis, and an example of it is shown in Figure 3-5.

Using this method of analysis for the XAFS data, the results on the different arsenic forms in the leached fractions of the Ohio bituminous coal have been determined. These results are summarized in Table 3-3. Also in Table 3-3, the INAA data of Table 3-2 are combined with the XAFS data to estimate the arsenic concentrations in ppm of the different forms in the coal. 


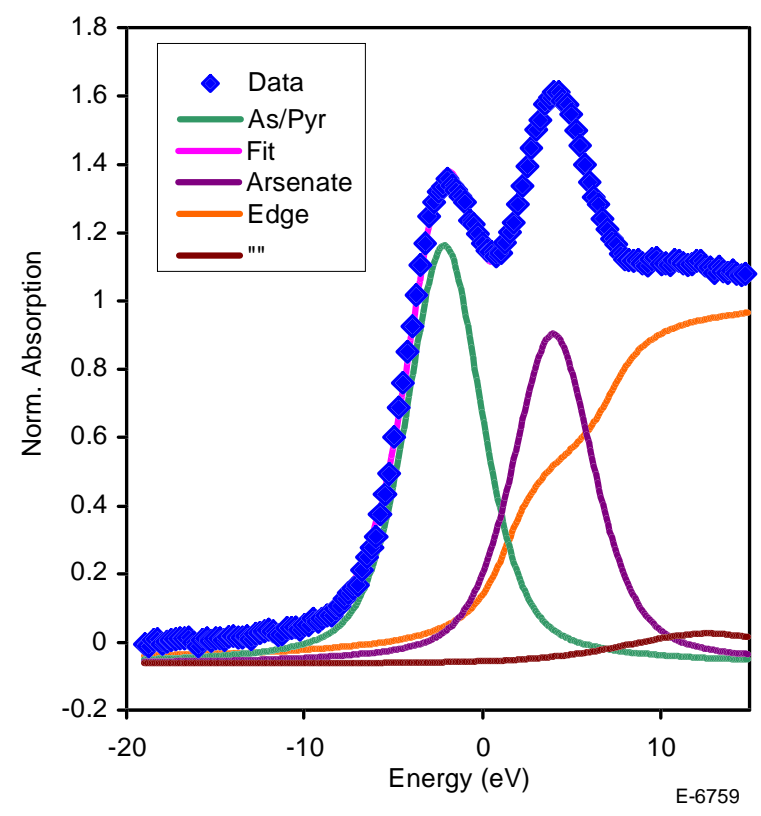

Figure 3-5. Least-squares fitted As XANES spectrum of the Ohio bituminous coal after the ammonium acetate leaching stage.

Table 3-3. Estimates of Arsenic Forms Remaining after Each Leaching Step in the Ohio Coal

\begin{tabular}{lcccc}
\hline \multicolumn{1}{c}{ Leachant } & $\begin{array}{c}\text { \%As as } \\
\text { As/pyrite }\end{array}$ & $\begin{array}{c}\text { \%As as } \\
\text { Arsenate }\end{array}$ & $\begin{array}{c}\text { ppm As as } \\
\text { As/pyrite }\end{array}$ & $\begin{array}{c}\text { ppm As as } \\
\text { Arsenate }\end{array}$ \\
\hline $\begin{array}{l}\text { Amm. Acetate } \\
19.1 \text { ppm As remains }\end{array}$ & 75 & 25 & 14.3 & 4.8 \\
$\mathrm{HCl}$ & 93 & 7 & 14.0 & 1.1 \\
$\begin{array}{l}15.1 \text { ppm As remains } \\
\mathrm{HF}\end{array}$ & $>95$ & $<5$ & $>14.4$ & $<0.8$ \\
$\begin{array}{l}15.2 \text { ppm As remains } \\
\mathrm{HNO}_{3}\end{array}$ & & & & \\
$0.9 \mathrm{ppm} \mathrm{As} \mathrm{remains}$ & $<10$ & $>90$ & $<0.1$ & $>0.8$ \\
\hline
\end{tabular}

Based on this analysis, the concentration of arsenic as As/pyrite after the first three leaching steps is approximately the same, $14 \pm 1 \mathrm{ppm}$. This indicates that none of the three reagents, ammonium acetate, $\mathrm{HCl}$, or $\mathrm{HF}$ removes significant arsenic as As/pyrite. As has been postulated previously [4], the presence of arsenic in pyrite appears to make pyrite more reactive to oxidation. However, for this particular coal, it does not appear that any arsenic associated with pyrite is leached prior to the $\mathrm{HNO}_{3}$ treatment. The $\mathrm{HF}$ leach appears to remove only the minor arsenate remaining after the $\mathrm{HCl}$ leach. The $\mathrm{HNO}_{3}$ leach removes all of the arsenic as arsenical pyrite and appears to leave a small residue of arsenate on the carbonaceous materials. It should be noted that the arsenate in the $\mathrm{HNO}_{3}$ residue is higher than that remaining after the $\mathrm{HF}$ leach, suggesting that it has been formed during the nitric acid leach. 
Unfortunately, this quantitative method of analyzing the arsenic XANES data is not yet applicable to the North Dakota lignite because the major arsenic form present in this coal is not arsenical pyrite. Rather, the XANES data suggest that the major form in the North Dakota lignite is an $\mathrm{As}^{3+}$ species. However, qualitatively, the leaching and XAFS trends for the North Dakota lignite are similar to those for the Ohio bituminous coal.

A number of important conclusions can be reached from this detailed, direct comparison of the XAFS spectroscopy and leaching protocol methods for speciation of arsenic in coal. XAFS spectroscopy shows clearly that the major fraction of arsenic leached from both coals by $\mathrm{HCl}$ is arsenate and that $\mathrm{HNO}_{3}$ removes much of the remaining arsenic in both coals. Leaching with HF has little effect on the arsenic content of both coals examined and appears restricted to removing any arsenate species that remains after the $\mathrm{HCl}$ leach. Such a result indicates that there is no need to postulate the presence of minor arsenic associated with silicates. The arsenic associated with pyrite in the bituminous coal is removed effectively by nitric acid, but a quite different form is removed from the lignite by nitric acid. Finally, a small fraction of the arsenic (5 to 15\%) remains in the coal after the nitric acid leach. We suspect that this might be an organoarsenate formed by a side reaction between the arsenic leached from the coal and new oxygen functionality on the coal introduced by reaction of the coal macerals with the oxidizing nitric acid.

This study has demonstrated very clearly the powerful advantages of combining the indirect leaching and direct spectroscopic methods for investigating the speciation of elements in coal. Not only do the XAFS data confirm or refute the underlying assumptions inherent in the indirect leaching method, but the leaching method provides better fractions for the XAFS spectroscopic investigation than the physically separated fractions examined previously. However, it should be emphasized that such combined investigations must be conducted on identical fractions.

\subsection{Combustion Zone Transformations (UU, MIT)}

\subsubsection{Single Particle Combustion Studies}

This quarter, we have completed the experiments in the drop tube furnace and begun analysis of the single particle combustion experiments. The initial analysis shows a pronounced bimodal size distribution (Figure 3-6). For all coals, stages 0 and the final filter were sent for INAA. Stage 3 is also being analyzed for ND Lignite and Wyodak at 20\% and 50\% oxygen because the supermicron particles have a greater size range for these coals. At 100\% oxygen there is no clear distinction between residual and submicron ash, therefore all stages will be analyzed for all coals.

The INAA results have been returned for Ohio (Table 3-4). Because of an error interpreting the results, there are some changes from what we have previously reported. Concentrations of several elements were not detected by INAA. 


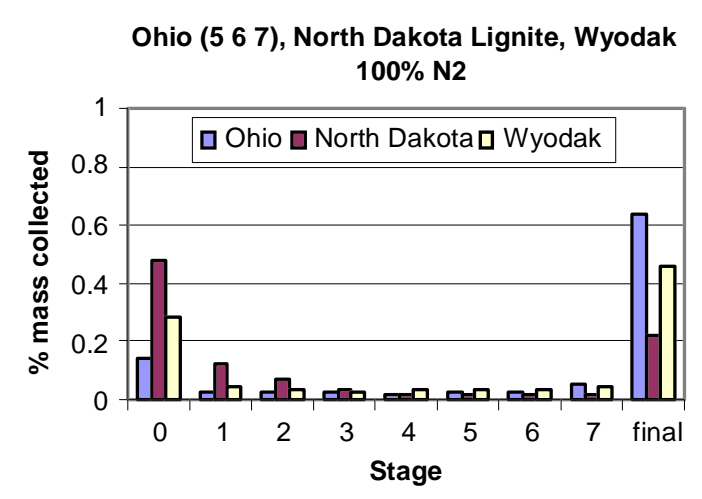

(a)

Ohio (5 6 7), North Dakota Lignite, Wyodak $20 \%$ O2 in N2

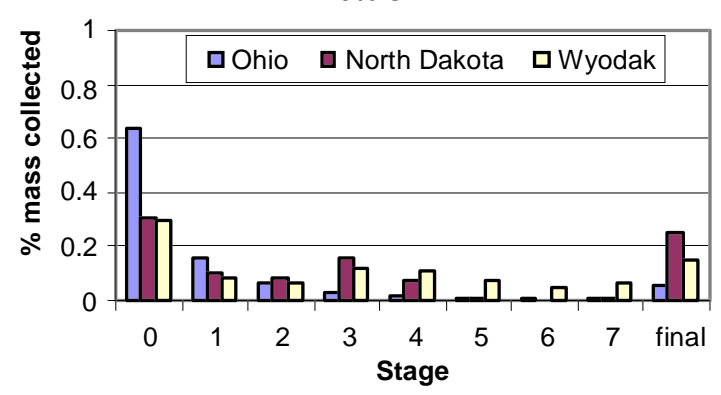

(c)

Ohio (5 6 7), North Dakota Lignite, Wyodak $50 \% 02$ in N2

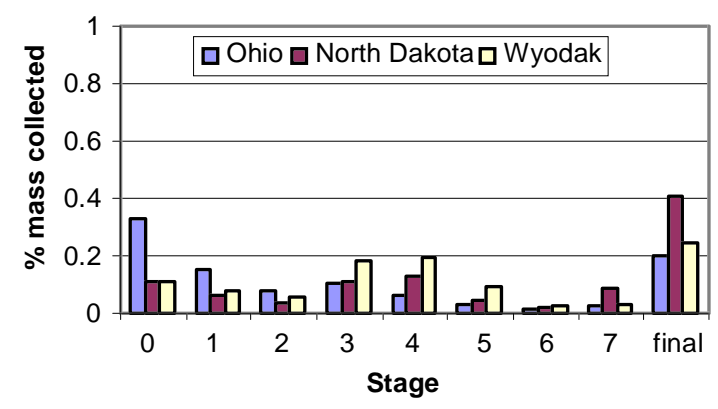

(e)

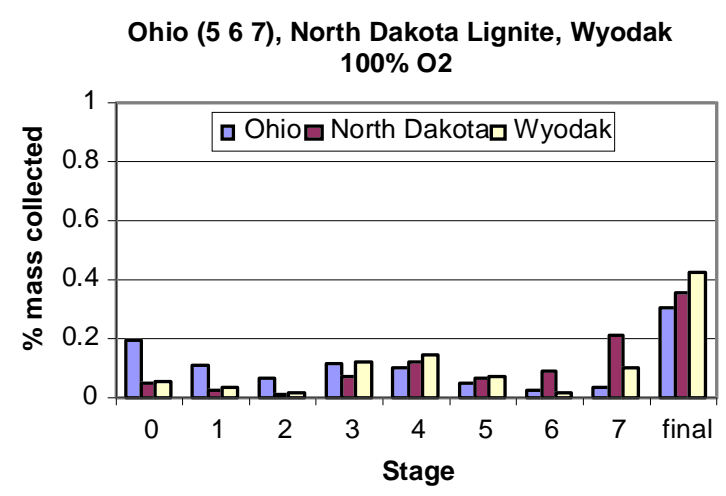

(b)

Ohio (5 6 7), North Dakota Lignite, Wyodak $20 \% \mathrm{O} 2$ in $\mathrm{CO} 2$

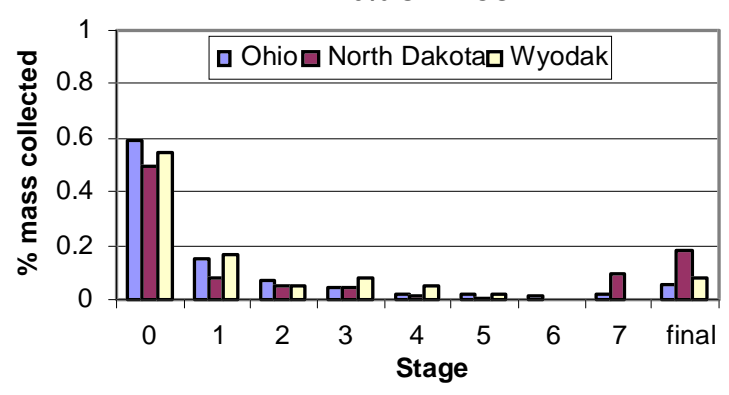

(d)

Ohio (5 6 7), North Dakota Lignite, Wyodak $50 \% \mathrm{O} 2$ in $\mathrm{CO} 2$

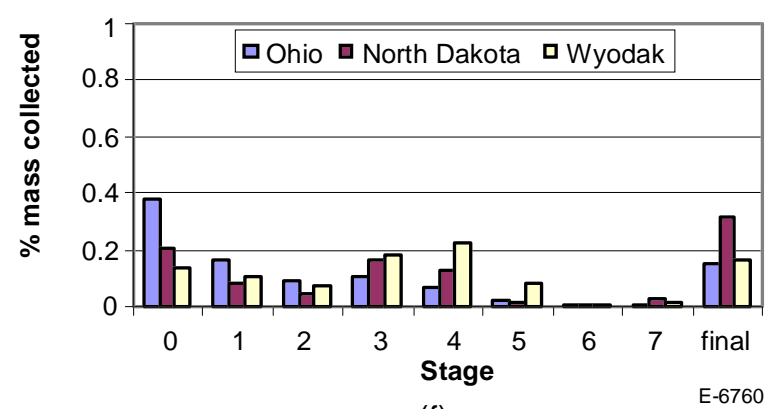

(f)

Figure 3-6. Mass distribution of the ash on impactor stages and final filter: (a) $100 \% \mathrm{~N}_{2}$, (b) $100 \% \mathrm{O}_{2}$, (c) $20 \% \mathrm{O}_{2}$ in $\mathrm{N}_{2}$, (d) $20 \% \mathrm{O}_{2}$ in $\mathrm{CO}_{2}$, (e) $50 \% \mathrm{O}_{2}$ in $\mathrm{N}_{2}$, (f) $50 \% \mathrm{O}_{2}$ in $\mathrm{CO}_{2}$. 
Table 3-4. Fraction of Each Element Recovered in the Submicron Ash for Ohio Coal

\begin{tabular}{|l|c|c|c|c|c|}
\hline & $100 \% \mathrm{~N}_{2}$ & $20 \% \mathrm{O}_{2} \mathrm{~W} \mathrm{~N}_{2}$ & $50 \% \mathrm{O}_{2} \mathrm{~W} \mathrm{~N}_{2}$ & $20 \% \mathrm{O}_{2} \mathrm{WCO}_{2}$ & $50 \% \mathrm{O}_{2} \mathrm{~W} \mathrm{CO}_{2}$ \\
\hline \hline $\mathrm{Na}$ & 1.10728103 & 0.575912952 & 0.278862312 & 0.248552583 & 0.3713 \\
\hline $\mathrm{Mg}$ & 0.00873147 & 0.014527743 & 0.049617357 & 0.007393849 & 0.0379 \\
\hline $\mathrm{Al}$ & 0.00803982 & 0.008685639 & 0.007193362 & 0.001799059 & 0.0498 \\
\hline $\mathrm{Cl}$ & 1.25965768 & 0.328809271 & 0.096312704 & 0.127676933 & 0.1995 \\
\hline $\mathrm{K}$ & $\mathrm{ND}$ & 0.031666564 & 0.099339031 & 0.037367568 & 0.0744 \\
\hline $\mathrm{Ca}$ & 0.1548948 & $\mathrm{ND}$ & 0.032014753 & $\mathrm{ND}$ & $\mathrm{ND}$ \\
\hline $\mathrm{Sc}$ & $\mathrm{ND}$ & 0.002185198 & 0.018071965 & 0.000813071 & 0.0123 \\
\hline $\mathrm{Ti}$ & $\mathrm{ND}$ & $\mathrm{ND}$ & 0.045072945 & $\mathrm{ND}$ & 0.0266 \\
\hline $\mathrm{V}$ & $\mathrm{ND}$ & 0.094716343 & 0.413741313 & 0.055902982 & 0.7043 \\
\hline $\mathrm{Cr}$ & 0.2222896 & 0.138071732 & 0.274836389 & 0.053978597 & 0.2459 \\
\hline $\mathrm{Mn}$ & 0.01195243 & 0.041210818 & 0.142722734 & 0.019885432 & 0.06768 \\
\hline $\mathrm{Fe}$ & 0.00299567 & 0.006577669 & 0.057479253 & 0.003358882 & 0.0534 \\
\hline $\mathrm{Co}$ & 0.06756126 & 0.057462855 & 0.177291263 & 0.042329165 & 0.2019 \\
\hline $\mathrm{Zn}$ & 0.15019439 & 0.345732496 & 0.239718932 & 0.165547144 & 0.2396 \\
\hline $\mathrm{As}$ & 0.18797336 & 0.277189801 & 0.320489052 & 0.227734589 & 0.4141 \\
\hline $\mathrm{Se}$ & $\mathrm{ND}$ & $\mathrm{ND}$ & $\mathrm{ND}$ & $\mathrm{ND}$ & 0.01695 \\
\hline $\mathrm{Br}$ & 0.24692219 & $\mathrm{ND}$ & 0.019941434 & 0.032479728 & 0.0142 \\
\hline $\mathrm{Sr}$ & $\mathrm{ND}$ & $\mathrm{ND}$ & $\mathrm{ND}$ & $\mathrm{ND}$ & $\mathrm{ND}$ \\
\hline $\mathrm{Mo}$ & 0.00898222 & 0.03558312 & 0.043599443 & 0.014223281 & 0.0632 \\
\hline $\mathrm{Cd}$ & $\mathrm{ND}$ & $\mathrm{ND}$ & $\mathrm{ND}$ & $\mathrm{ND}$ & $\mathrm{ND}$ \\
\hline $\mathrm{Sb}$ & 0.05839049 & 0.262721512 & 0.313872379 & 0.268356313 & 0.221 \\
\hline $\mathrm{Ba}$ & $\mathrm{ND}$ & 0.021235685 & 0.013244523 & $\mathrm{ND}$ & $\mathrm{ND}$ \\
\hline $\mathrm{La}$ & 0.00232182 & 0.002251415 & 0.005803941 & 0.001050041 & 0.00517 \\
\hline $\mathrm{Ce}$ & 0.01174622 & $\mathrm{ND}$ & 0.035155896 & 0.003805061 & 0.0271 \\
\hline $\mathrm{Nd}$ & $\mathrm{ND}$ & $\mathrm{ND}$ & 0.000590376 & $\mathrm{ND}$ & 0.004656 \\
\hline $\mathrm{Sm}$ & 0.00296445 & 0.003123561 & 0.016159267 & 0.002515442 & 0.013 \\
\hline $\mathrm{Au}$ & 0.00051644 & 0.000313455 & $9.83022 \mathrm{E}-05$ & $\mathrm{ND}$ & 0.7849 \\
\hline $\mathrm{Hg}$ & 0.62490108 & 0.278655218 & 0.125155478 & 0.099642709 & 0.00036 \\
\hline $\mathrm{Th}$ & $\mathrm{ND}$ & $\mathrm{ND}$ & 0.004767399 & $\mathrm{ND}$ & 0.017344 \\
\hline $\mathrm{ND}$ & & 2 & & \\
\hline
\end{tabular}

ND indicates that a concentration was not detected through INAA.

The analysis shows an enrichment of several elements in the submicron ash as oxygen concentrations are increased (Figure 3-7). A number of elements: chromium, cobalt, mercury, lanthanum, and gold show an increased fraction in the submicron ash under pyrolyzing conditions (Figure 3-8). It has been shown that titanium is released with the volatiles during pyrolysis, and it appears likely that, with the exception of mercury, these elements are also associated with volatile compounds in coal [4]. Mercury is probably just being absorbed by the high carbon submicron particles formed under pyrolyzing conditions.

In the presence of carbon dioxide, the fraction of several metals in the submicron ash is reduced (Figure 3-9). This supports the hypothesis that metal vaporization is governed by the reaction:

$$
\mathrm{MO}(\mathrm{s})+\mathrm{CO}(\mathrm{g})=\mathrm{M}(\mathrm{g})+\mathrm{CO} 2(\mathrm{~g}) \text {. }
$$

as expected for refractory oxides. It is interesting that mercury, which is not a refractory oxide, is affected by the addition of carbon dioxide (Figure 3-9b).

The analysis for the ND Lignite and Wyodak coals should be completed soon. 


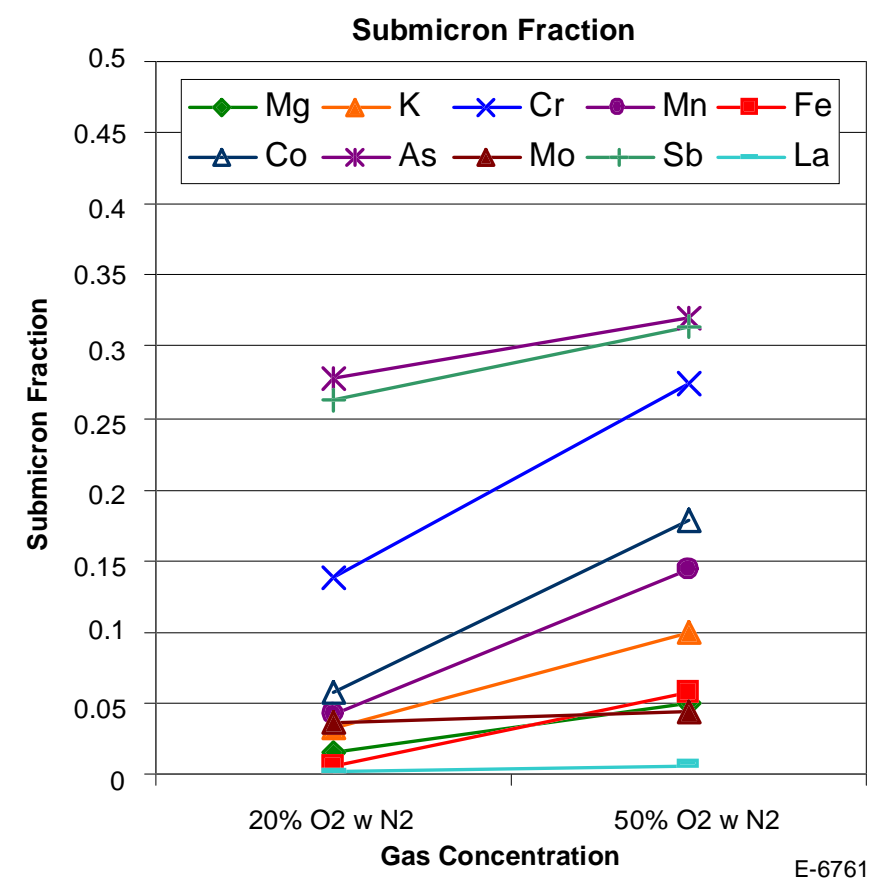

Figure 3-7. Fraction of selected elements in the submicron ash as a function of oxygen content (for $\mathrm{O}_{2}$ in $\mathrm{N}_{2}$ ).

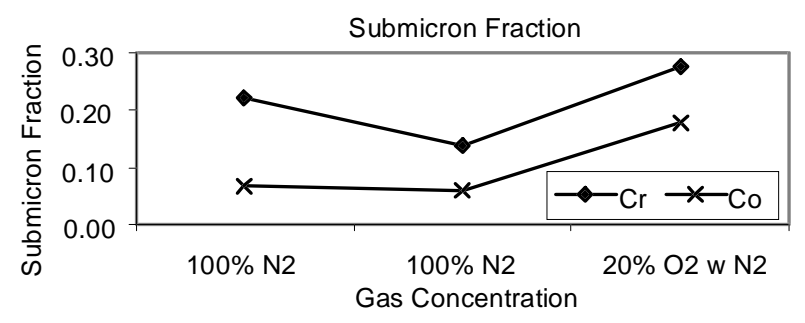

(a)

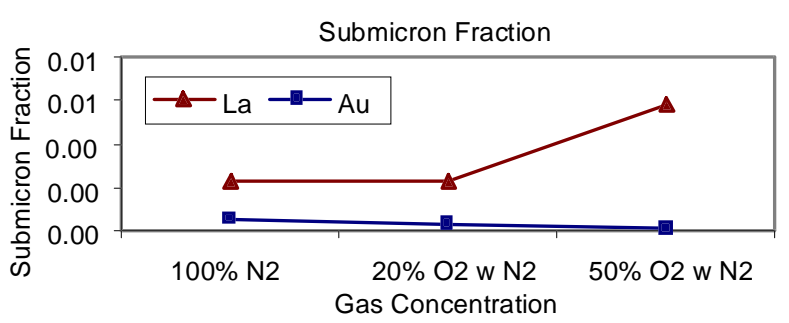

(b)

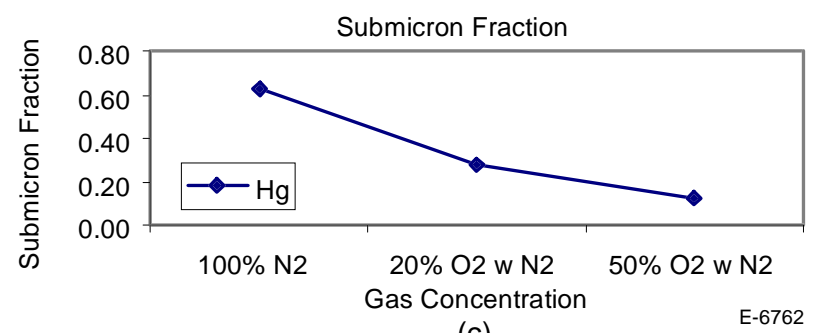

(c)

Figure 3-8. Fraction of selected elements in submicron ash for pyrolysis $\left(100 \% \mathrm{~N}_{2}\right)$ conditions and for combustion in varying amounts of $\mathrm{O}_{2}$. 


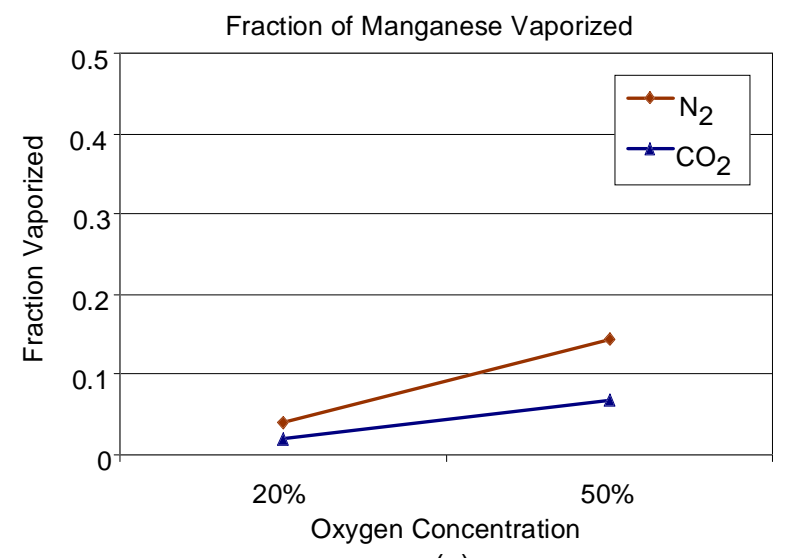

(a)

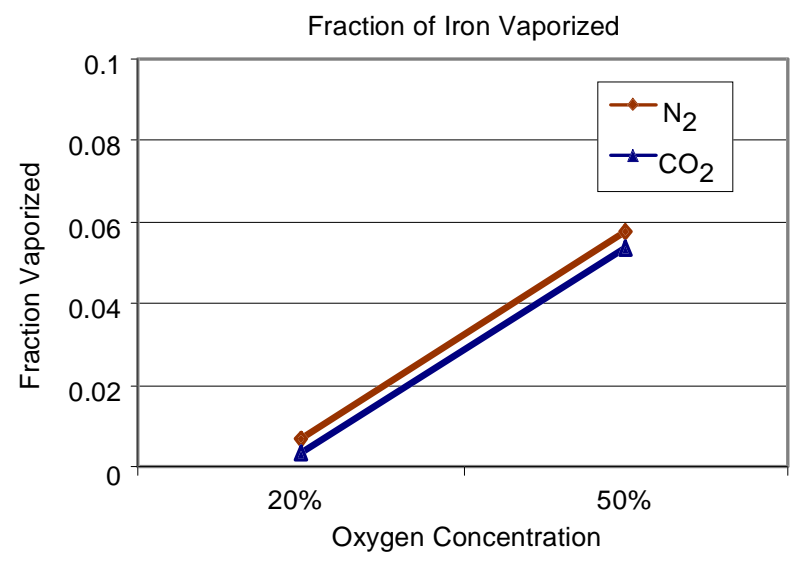

(c)

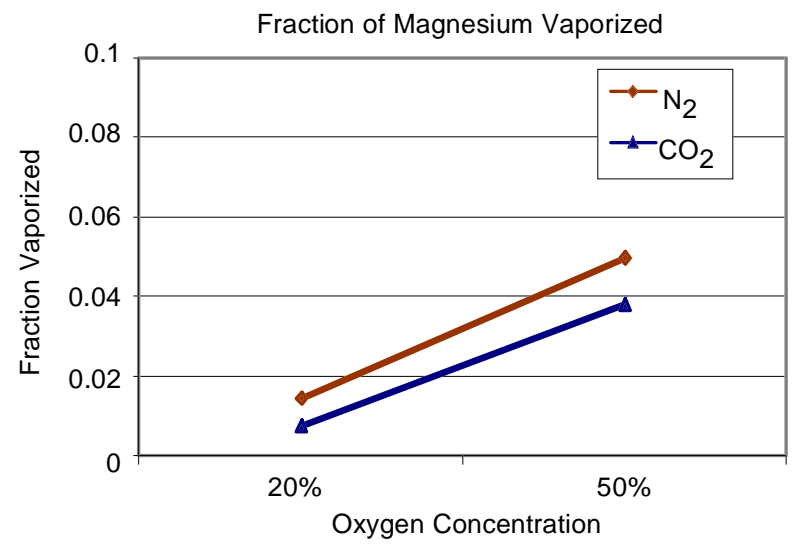

(e)

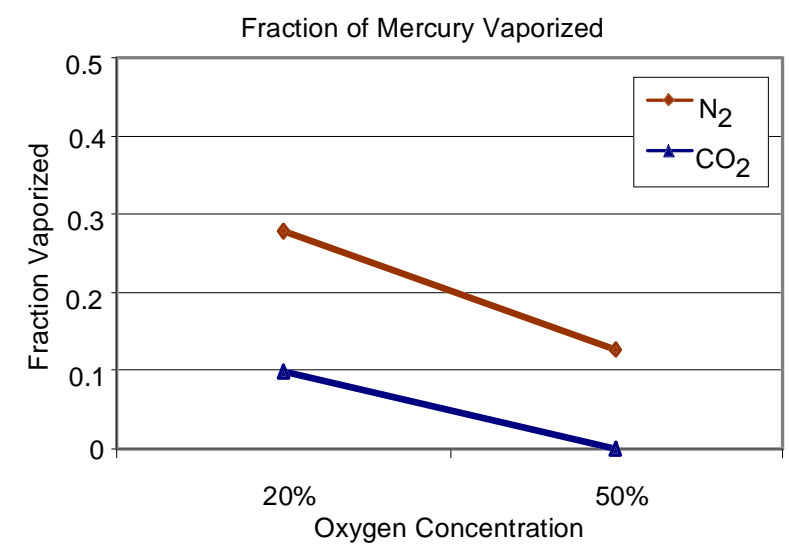

(b)

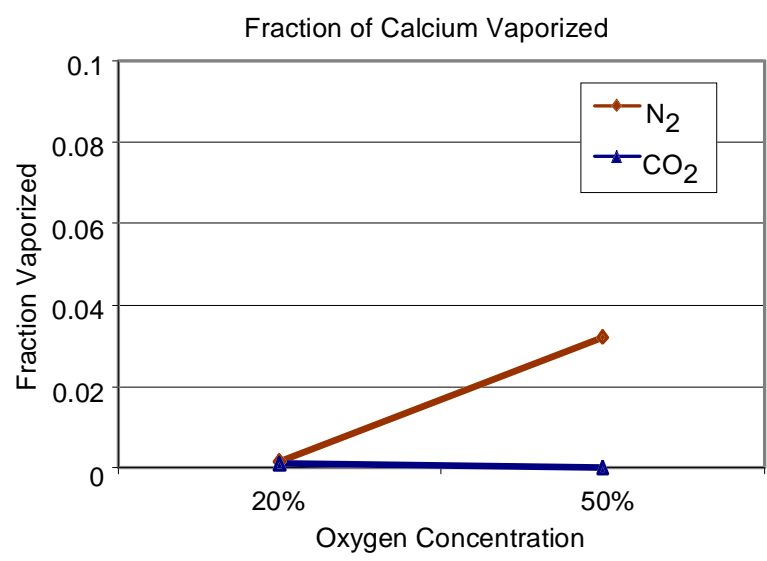

(d)

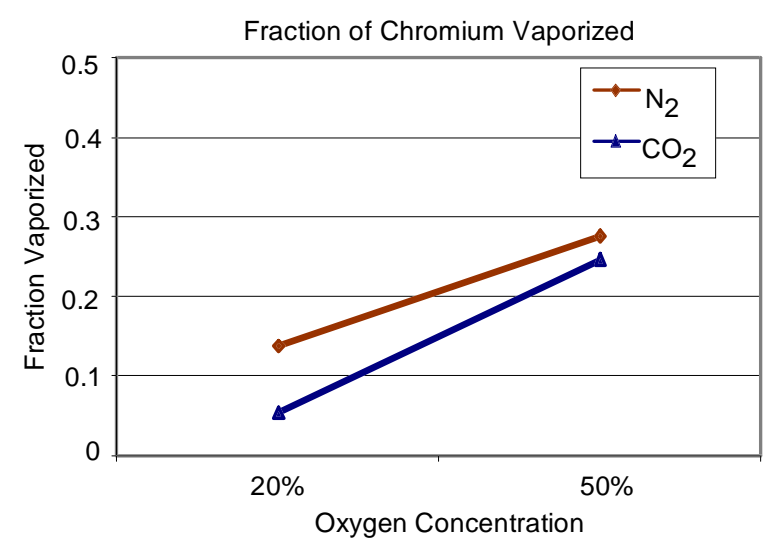

(f)

Figure 3-9. Comparison of fraction of selected elements in submicron ash as a function of oxygen content with either $\mathrm{N}_{2}$ or $\mathrm{CO}_{2}$ as the balance of combustion gas for (a) Manganese, (b) Mercury, (c), Iron, (d) Calcium, (e) Magnesium, (f) Chromium. 


\subsubsection{Low Temperature Volatilization}

The INAA results for these experiments appear to be inconsistent. We suspect contamination and are working to resolve the data using known non-volatiles. We have requested the return of the samples so that complementary analysis can be performed to confirm the results. If this is not successful, the experiments will be repeated.

\subsection{Post-Combustion Transformations (UA, UK, UC, EERC)}

\subsubsection{Large Scale Integrated Combustion Studies}

\subsubsection{Experimental Results - Final Composite Size-Segregated Analytical Data}

This section describes the analytical results generated during this research project which are contained in two appendices. Appendix B (Tables B-1 through B-18) contains the composite results from the baseline combustion experiments conducted in Phases I and IIa. The composite results from the special experiments conducted in Phase IIb are presented in Appendix C (Tables C-1 through C-15).

\subsubsection{The Partitioning of Arsenic During Pulverized Coal Combustion}

This work has focused on defining vapor-phase to solid-phase transformations of trace elements during pulverized coal combustion. How these elements partition during combustion depends upon:

- The form of occurrence of the trace element and potential reactants in the coal,

- The volatility of the trace element and potential reactants during combustion, and

- The vapor-to-solid phase transformation mechanisms available to the metal in the combustor.

A detailed evaluation was performed of the partitioning of arsenic. The issues addressed by this evaluation included:

- Assessment of volatility,

- Quantification of vapor-phase emission under the experimental conditions,

- $\quad$ Confirmation of heterogeneous partitioning as the primary mechanism for vaporto-solid phase transformation,

- Identification of the most likely rate-controlling transport mechanism for vaporto-solid phase partitioning, 
- Identification of the most likely reactants when surface reaction is the ratecontrolling transport mechanism,

- Assessment of the environmental impact of trace element leachability from submicron and supermicron fly ash particles, and

- Assessment of the timing of the various partitioning processes.

From this evaluation, hypotheses were developed for the mechanisms and parameters governing the partitioning of the specific trace element examined. These hypotheses are:

1. Arsenic partitioning is controlled by surface reaction with calcium and/or iron active surface sites if a particle size dependence analysis indicates that surface reaction is the dominant mechanism for the heterogeneous vapor-to-solid phase partitioning to fly ash surfaces.

2. Increasing the combustion temperature increases the availability of active cation surface sites and thus increases the recovery of As out of the fly ash by surface reaction.

3. Increased sulfur inhibits the recovery of As by occupying active cation surface sites.

4. Sulfur preferentially occupies iron surface sites compared to calcium surface sites.

5. Arsenic is more reactive with calcium surface sites than with iron surface sites.

Samples were collected and analyzed from two different locations in the experimental furnace. Most of the analysis provided below is based on samples taken at Port 14 and represent typical conditions near the end of a commercial combustor (post-combustion zone conditions). To gain insight into the timing of trace element partitioning, samples were also collected and analyzed from Port 4 . This sampling location is located about $0.6 \mathrm{~m}$ below the location in the furnace where the maximum combustion temperature occurs. Based on visual observation of the combusting coal particles, the vast majority of carbon burnout has occurred prior to this location during combustion of a bituminous coal. This location has been chosen to represent conditions that approximate the conditions in the commercial combustion just after primary carbon oxidation is completed (combustion zone conditions).

\section{Fly Ash Particle Surface Sites}

Due to the low concentration of trace elements compared to the major species in the coal, there is a very high probability that a volatilized trace element molecule will contact submicron or supermicron particles prior to reaching the supersaturation condition necessary to initiate homogeneous nucleation. Therefore, the availability of potential reactants on the surface of submicron and supermicron particles may be significant in the partitioning of the trace element. 
Fly ash particle surfaces primarily consist of a solid matrix composed of various solidphase oxidized silica, aluminum, iron, and calcium structures. The oxidized forms of silica, iron, and calcium are cationic and the oxidized form of aluminum is anionic. When bound in the inorganic structure of the bulk fly ash particle, these species are believed to have limited reactivity for other elements. However, when these species volatilize and recondense to the solid phase, active surface sites are expected to be present. Active sites are also expected when larger particles fragment into smaller-sized particles.

The major refractory elements (iron, silica, aluminum, and calcium) are believed to vaporize as suboxides formed by reduction with carbon monoxide $(\mathrm{CO})$ in the immediate vicinity of the burning char [6-8]. As the molecules diffuse out of the reducing atmosphere of the char, they are oxidized. These oxides are not very volatile and will nucleate while still in the flame zone to form a submicron fume [6, 8-13].

The oxide forms of silica, aluminum, iron, and calcium have boiling points substantially above the bulk gas temperature in the combustion zone. As a result, volatilization is dependent on the forms of occurrence in the coal and the proximity to burning carbon molecules where the temperature is substantially higher than the bulk gas temperature [7]. The relative volatility of these oxides is: $\mathrm{CaO}>\mathrm{Fe}_{2} \mathrm{O}_{3}>\mathrm{Al}_{2} \mathrm{O}_{3}>\mathrm{SiO}_{2}$.

If this theory of submicron fume formation (volatilization of refractory elements with subsequent nucleation and coagulation to form submicron particles) is correct, then changing the combustion temperature should change the composition of the submicron particles. A set of special experiments was performed to investigate the effect of combustion temperature on the partitioning (and thus by inference the volatility) of calcium, iron, aluminum, and silicon during coal combustion. In these experiments, the maximum temperature of Wyodak coal combustion was increased $60 \mathrm{~K}$ (as measured at Port $1^{1}$ ) by adding oxygen to the main combustion air. Evaluation of this hypothesis can be performed using a differential mass fraction distribution analysis.

A comparison of the differential mass fraction distributions for calcium, iron, aluminum and silicon are shown in Figure 3-10. The results show the greatest increase in the mass fraction in the submicron stages of calcium for the $1580 \mathrm{~K}$ case compared to the $1520 \mathrm{~K}$ case. Iron also shows an increase in the mass fraction in the submicron stages for the $1580 \mathrm{~K}$ results compared to the $1520 \mathrm{~K}$ results but not as significantly as calcium. Increasing the combustion temperature had no appreciable effect on the aluminum or silicon distributions. These results are consistent with the hypothesis stated above.

The results shown in Figure 3-10 also help to evaluate another important parameter during coal combustion - namely carbon burnout. Incomplete carbon burnout can affect the liberation of organically-associated trace elements and the degree of volatilization of major species (and thus the formation of active cation and anion surface sites). One way of minimizing incomplete carbon burnout is to enrich the combustion air with oxygen. If incomplete carbon burnout is significant, there will be an increase in the volatilization (and thus the submicron particle formation) of all major inorganic elements in the results from experiments with

\footnotetext{
${ }^{1}$ Based on the actual temperature profile, the maximum is located slightly above this port.
} 


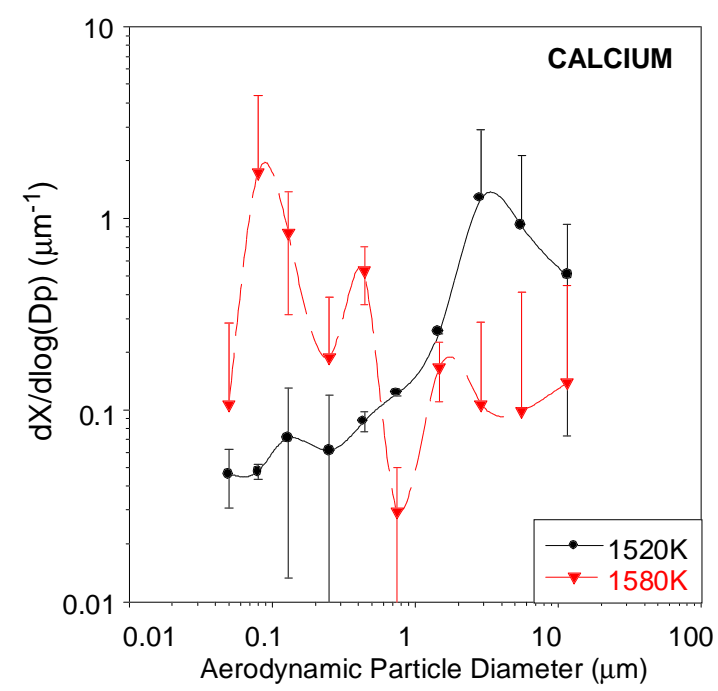

(a)

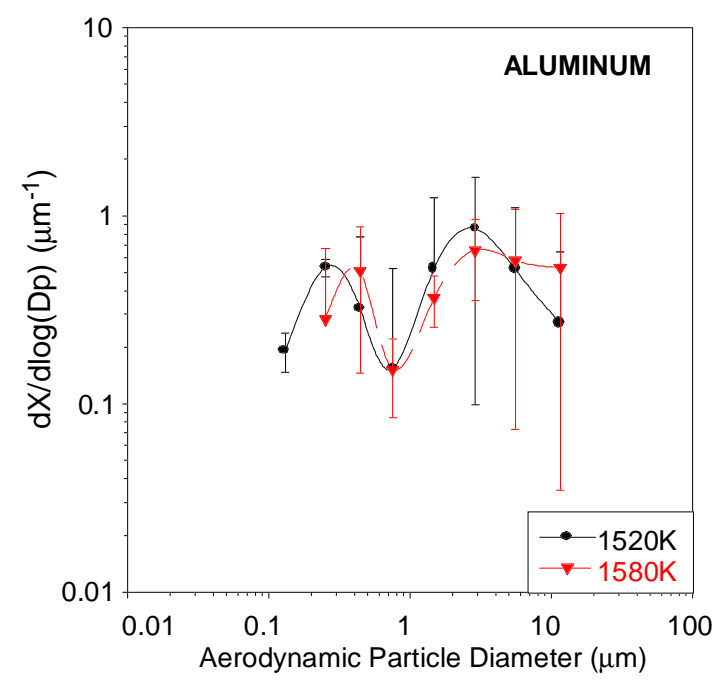

(c)

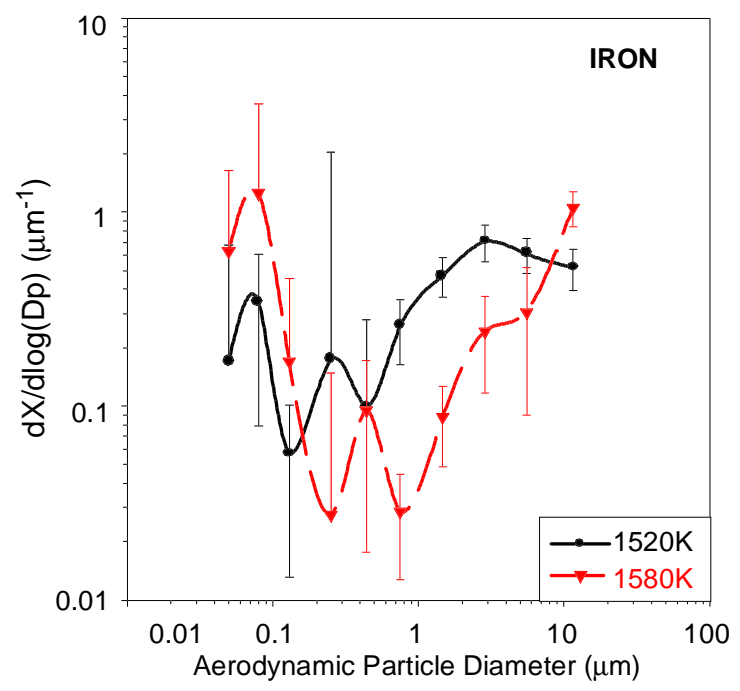

(b)

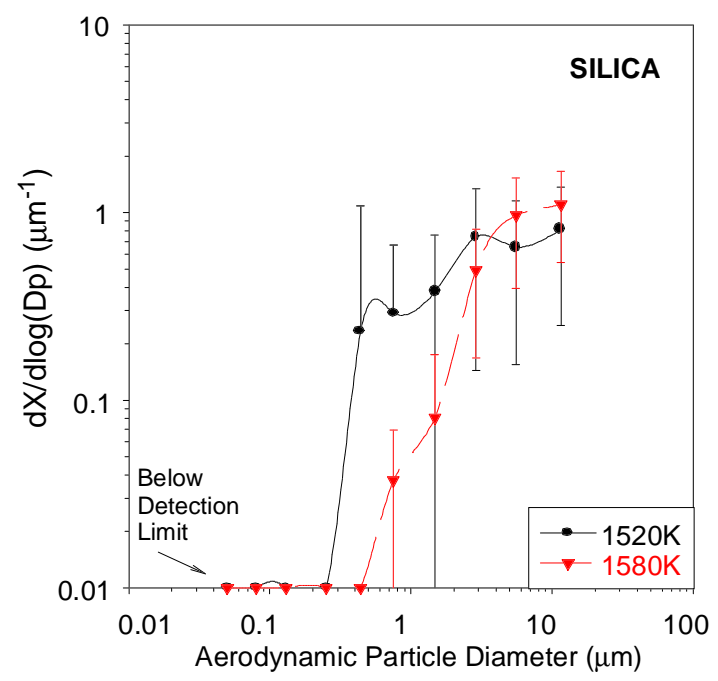

(d)

Figure 3-10. The effect of combustion temperature on the volatility of calcium, iron, and aluminum during the combustion of Wyodak Coal: (a) calcium; (b) iron; (c) aluminum; (d) silica.

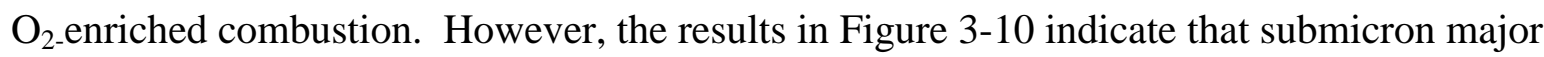
element enrichment at higher oxygen combustion conditions is selective (i.e., only calcium and iron show increases in the submicron region). Therefore, carbon burnout was not considered to be an important parameter in these experiments.

Based on the particle size distributions presented in earlier reports, we hypothesize that a micron-sized fragmentation-based particle region is formed under baseline combustion conditions for many of the coals studied. The presence of this region affects the shape of the elemental differential distributions of both major and trace element inorganic species. 


\section{$\underline{\text { Arsenic }}$}

Arsenic Volatility. Finkleman and coworkers [1,14,15] determined the forms of occurrence of arsenic for the six coals utilized in this study. The results are summarized in Table 3-5. The majority of the arsenic for all six coals is attributed to pyrite/sulfide or mono-sulfide fractions although four of the coals have silicate fractions of 5 to 15\%. Organically-associated arsenic was only detected in the Wyodak coal. Consistent with Bool and Helble [16], the large fraction of arsenic not contained in silicates is expected to volatilize during combustion.

Table 3-5. Forms of Occurrence of Arsenic in the Six Study Coals [1, 14]

\begin{tabular}{|c|c|c|c|c|}
\hline Coal & $\begin{array}{c}\text { Ammonium } \\
\text { Acetate Leachable } \\
\text { (organic) }\end{array}$ & $\begin{array}{c}\mathrm{HCl} \text { Leachable } \\
\text { (mono-sulfide) }\end{array}$ & $\begin{array}{c}\text { HF Leachable } \\
\text { (silicate) }\end{array}$ & $\begin{array}{c}\mathrm{HNO}_{3} \text { Leachable } \\
\text { (pyrite/sulfide) }\end{array}$ \\
\hline \hline Pittsburgh & $0 \%$ & $10 \%$ & $0 \%$ & $80 \%$ \\
\hline Illinois & $0 \%$ & $20 \%$ & $0 \%$ & $60 \%$ \\
\hline Kentucky & $0 \%$ & $30 \%$ & $5 \%$ & $35 \%$ \\
\hline Ohio & $0 \%$ & $30 \%$ & $5 \%$ & $35 \%$ \\
\hline Wyodak & $5 \%$ & $25 \%$ & $15 \%$ & $25 \%$ \\
\hline North Dakota & $0 \%$ & $60 \%$ & $10 \%$ & $15 \%$ \\
\hline
\end{tabular}

Results from thermodynamic equilibrium simulations predict that $\mathrm{AsO}$ is the favorable form of occurrence at the combustion temperatures of all six coals studied in this research (see Section 3.4.1.3, below). Arsenic is predicted to remain as AsO throughout the post-combustion zone (see Figure 3-35 in Section 3.4.1.3). If $\mathrm{AsO}$ is not an allowable formation product, the simulations predict $\mathrm{As}, \mathrm{As}_{2}$, and $\mathrm{AsCl}_{3}$ as the most favorable forms of occurrence (see Figure 3-36 in Section 3.4.1.3). In this case, arsenic is predicted to transform into oxy-anions (e.g. $\left.\mathrm{Ca}_{3}\left(\mathrm{AsO}_{4}\right)_{2}, \mathrm{As}_{2} \mathrm{O}_{3}, \mathrm{As}_{2} \mathrm{O}_{5}\right)$.

Vapor-to-Particle Surface Arsenic Transport Mechanisms. Due to its low volatility, only a very small portion of the volatilized arsenic will exit the combustor in the vapor phase. In this study the average mass fraction of arsenic still in the vapor phase at the post-combustion zone sampling location (Port 14) for the baseline screening experiments was $4.5 \mathrm{wt} \%$ (compared to $13 \%$ for selenium). However, there was significant variation between coal types (see Table 3-6). For all of the study coals, most of the arsenic partitions back to the solid phase prior to exiting the combustor. For four of the coals - Pittsburgh, Illinois \#6, Ohio, and Kentucky - very little $(<3 \mathrm{wt} \%)$ of the arsenic is still in the vapor phase at Port 14.

The average mass fraction of arsenic still in the vapor phase at the baghouse inlet sampling port for the baseline screening experiments was $14 \mathrm{wt} \%$ (compared to $20 \%$ for selenium). It should be noted that a portion of the bulk fly ash particles has been removed from the flue gas prior to this sample.

Due to the low concentration of arsenic compared to the major species in the coal, there is a very high probability that a volatilized arsenic molecule will contact submicron or supermicron particles prior to reaching the supersaturated conditions necessary for nucleation. Therefore, a majority of the volatilized arsenic is expected to heterogeneously partition onto the 
Table 3-6. Mass Fraction of Arsenic in Vapor, Submicron, and Supermicron Regimes at Three Combustor Sample Locations

\begin{tabular}{|c|c|c|c|c|}
\hline Coal/Location & $\begin{array}{c}\text { Average } \\
\text { Sampling } \\
\text { Temperature }(\mathrm{K})\end{array}$ & $\begin{array}{c}\text { Vapor } \\
\text { Regime } \\
(\mathrm{Wt} \%)\end{array}$ & $\begin{array}{c}\text { Submicron } \\
\text { Regime }(\mathrm{Wt} \%)\end{array}$ & $\begin{array}{c}\text { Supermicron } \\
\text { Regime (Wt } \%)\end{array}$ \\
\hline \multicolumn{5}{|l|}{ Pittsburgh } \\
\hline Port 4 & 1440 & 0.4 & 57 & 43 \\
\hline Port 14 & 1140 & 1.3 & 15 & 84 \\
\hline Baghouse Inlet & 470 & 9.7 & 16 & 74 \\
\hline \multicolumn{5}{|l|}{ Illinois } \\
\hline Port 4 & 1410 & 3.3 & 19 & 78 \\
\hline Port 14 & 1130 & 0.6 & 20 & 79 \\
\hline Baghouse Inlet & 220 & 11 & 11 & 78 \\
\hline \multicolumn{5}{|l|}{ Ohio } \\
\hline Port 4 & 1330 & 8.2 & 5.1 & 87 \\
\hline Port 14 & 1040 & 2.8 & 1.2 & 96 \\
\hline Baghouse Inlet & 610 & 36 & 19 & 46 \\
\hline \multicolumn{5}{|l|}{ Kentucky } \\
\hline Port 4 & 1490 & 9.3 & 5.3 & 85 \\
\hline Port 14 & 1150 & 1.0 & 2.3 & 97 \\
\hline Baghouse Inlet & 490 & 20 & 16 & 64 \\
\hline \multicolumn{5}{|l|}{ Wyodak } \\
\hline Port 4 & 1080 & 0.7 & 1.8 & 98 \\
\hline Port 14 & 760 & 14 & 21 & 65 \\
\hline Baghouse Inlet & 210 & 5.7 & 9.3 & 85 \\
\hline \multicolumn{5}{|l|}{ North Dakota } \\
\hline Port 4 & 1250 & 16 & 11 & 72 \\
\hline Port 14 & 870 & 7.5 & 13 & 79 \\
\hline Baghouse Inlet & 400 & 4.2 & 9.3 & 87 \\
\hline \multicolumn{5}{|l|}{ Average All Coals } \\
\hline Port 4 & & 6.4 & 17 & 77 \\
\hline Port 14 & & 4.5 & 12 & 83 \\
\hline Baghouse Inlet & & 14 & 13 & 72 \\
\hline
\end{tabular}

surfaces of both submicron and supermicron particles [17]. If this theory is valid, there will be an enrichment of arsenic onto submicron particles. Arsenic enrichment factors for fly ash particles from the baseline screening experiments sampled at the Port 14 (post-combustion zone) sampling location are given in Table 3-7. The enrichment factor, $\mathrm{E}_{\mathrm{i}, \mathrm{x}}$ is defined as: $\mathrm{E}_{\mathrm{i}, \mathrm{x}}=\mathrm{M}_{\mathrm{i}, \mathrm{x}}$ / $\left(\Sigma_{\mathrm{N}} \mathrm{M}_{\mathrm{i}, \mathrm{x}} / \mathrm{N}\right)$. All of the submicron fly ash samples taken at the post-combustion zone sampling location (Port 14) show enrichment of arsenic (values greater than 1.0). These results are consistent with observations by previous researchers [7,11,12, 18-33].

To be consistent with the heterogeneous vapor-to-solid phase partitioning theory, supermicron particles should contain a higher absolute mass fraction of arsenic than the submicron particles. In the current work, the average arsenic mass fraction in the supermicron particles was $83 \mathrm{wt} \%$ (see Table 3-6 for individual values). Vapor phase arsenic is believed to 
Table 3-7. Arsenic Enrichment Factors for Submicron-Sized Fly Ash Samples

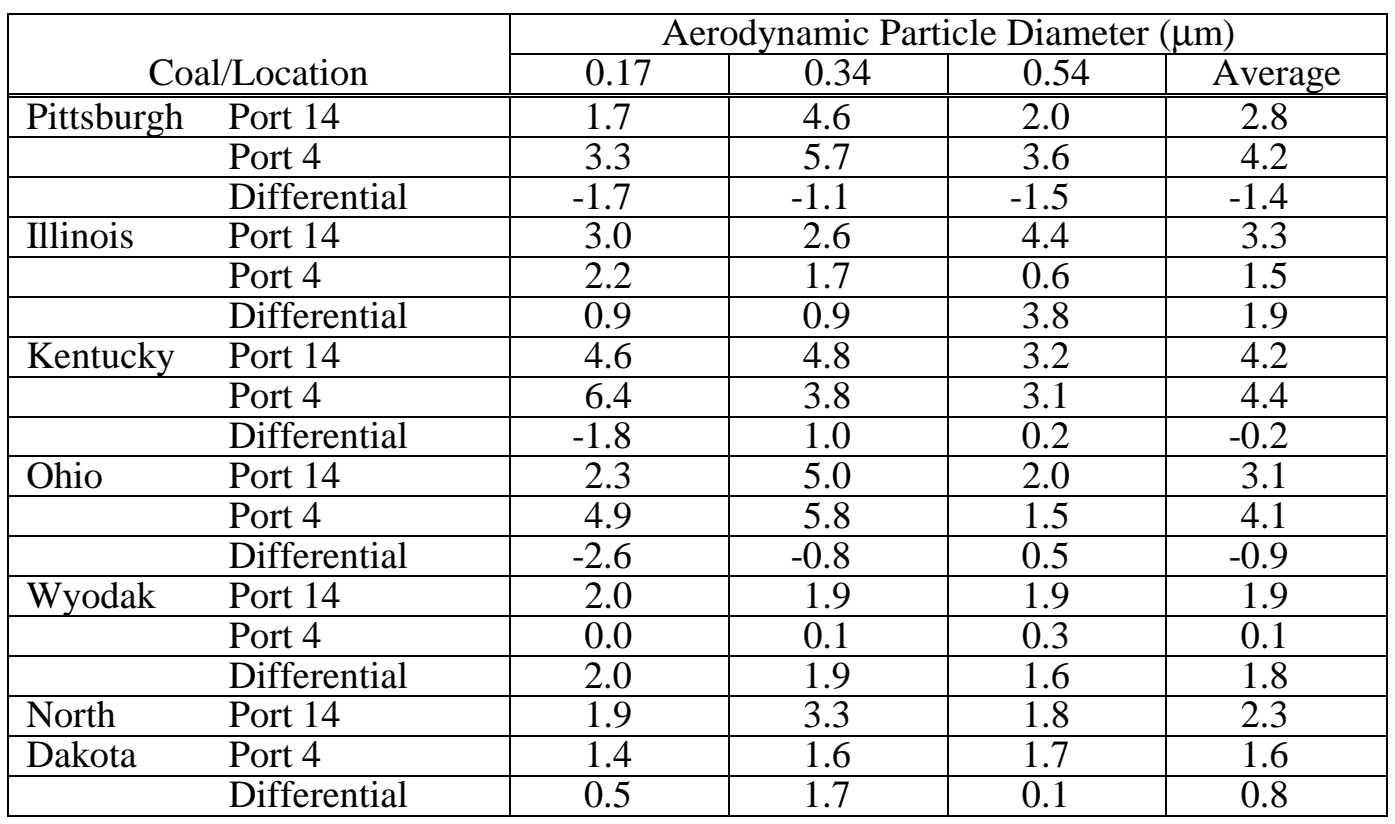

form an oxy-anion of the form $\mathrm{As}_{2} \mathrm{O}_{3}[24,38]$ although many thermodynamic studies, including the work presented in Section 3.4.1.3, predict $\mathrm{AsO}$ as the primary form at coal combustion conditions. However, when formation of AsO is constrained, oxy-anions (including $\mathrm{As}_{2} \mathrm{O}_{3}$ ) are the predicted forms of occurrence (see Section 3.4.1.3 and Reference 16). The probability of $\mathrm{As}_{2} \mathrm{O}_{3}$ adherence to a particle's surface is primarily due to the number of active cation sites on the particle surface. $\mathrm{As}_{2} \mathrm{O}_{3}$ will become incorporated into the particle if subsequent reaction between the anion and cation (chemical bonding). The probability that chemical reaction will occur depends upon the rate at which the anion can migrate across the particle surface to the cation site and the kinetic reaction rate between the anion and cation.

Because of the low volatility of arsenic, gas-phase concentrations of $\mathrm{As}_{2} \mathrm{O}_{3}$ are insufficient in most combustion systems to initiate physical condensation prior to the stack. Therefore, $\mathrm{As}_{2} \mathrm{O}_{3}$ presence on/within fly ash particle surfaces is not expected to occur by this mechanism.

The particle size dependence of arsenic associated with supermicron fly ash particles for the six study coals at the Port 14 sampling location is shown in Figure 3-11. Only the Ohio arsenic distribution does not follow a near $1 / \mathrm{D}_{\mathrm{p}}$ dependence (excluding the $1 \mu \mathrm{m}$ data point). This indicates that volatile arsenic partitioning to supermicron particles in the post-combustion zone is controlled by exterior surface reaction for Illinois, Pittsburgh, Kentucky, Wyodak, and North Dakota. For Ohio, the results indicate that this mechanism is not important after the combustion zone, most likely due to saturation of active cation sites by more abundant anions (the low arsenic-to-calcium ratio of this coal implies that less active cation sites are generated during combustion). These results are consistent with those reported by others $[11,16,25,26$, $35,36]$ who report a $1 / \mathrm{D}_{\mathrm{p}}$ arsenic concentration dependence for supermicron fly ash particles sampled at the end of the post-combustion zone. 


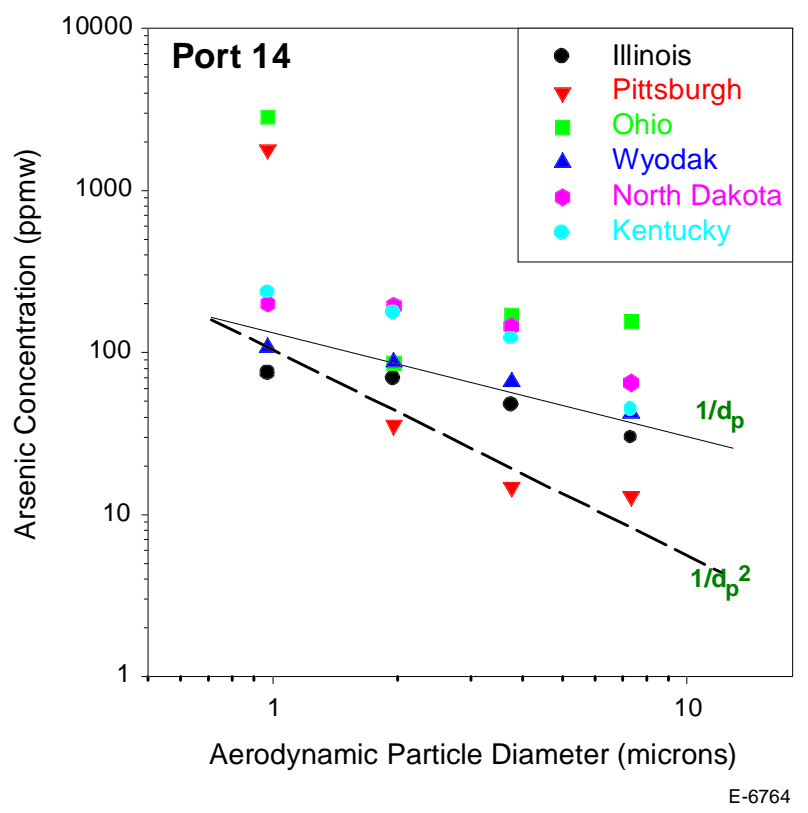

Figure 3-11. Particle size dependence of arsenic in supermicron fly ash particles for all six study coals sampled at Port 14.

The size-segregated concentration of arsenic in submicron particles from the current study is shown in Figure 3-12 for the six study coals at the Port 14 sampling location. No particle size dependence is apparent for any of the coals studied. In the study by Smith and coworkers [35] the arsenic concentration was also found to be independent of particle size in the submicron region.

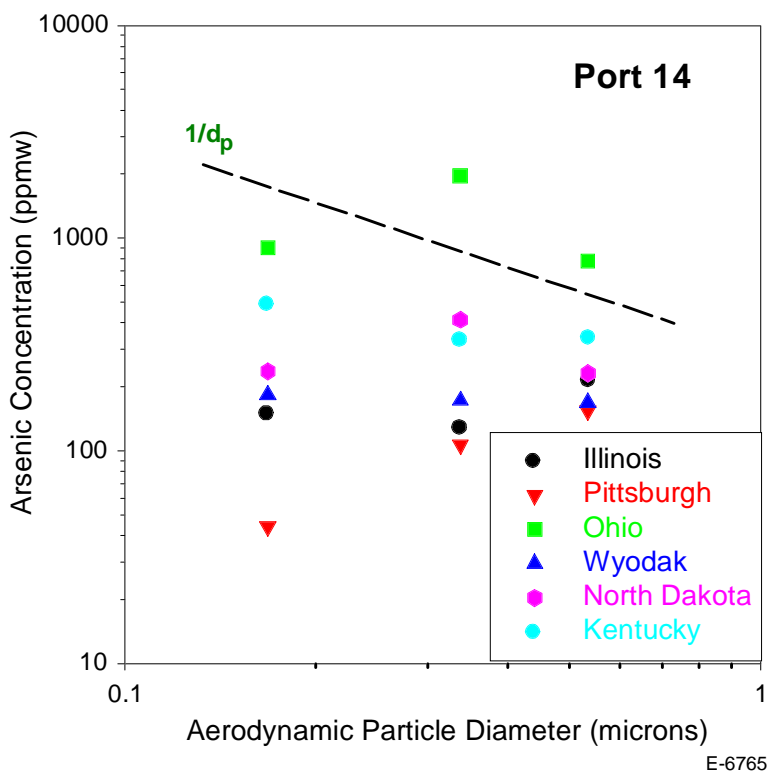

Figure 3-12. Particle size dependence of arsenic in submicron fly ash particles for all six study coals sampled at Port 14. 
Fly Ash Surface Arsenic Reaction Mechanisms. Many researchers have proposed a reaction of $\mathrm{As}_{2} \mathrm{O}_{3}$ with calcium cations as the most likely partitioning mechanism. If $\mathrm{AsO}$ is constrained as a reaction product, calcium arsenate is a favored form of occurrence (as predicted by thermodynamic simulation) for five of the six coals studied (except for Kentucky, see Section 3.4.1.3) in the post-combustion zone. In Irgolic and coworker's [40] examination of 11,000 fly ash particles they found arsenic only in the arsenate form and most likely in the form of calcium arsenate. Bool and Helble [16] performed equilibrium calculations that predicted the formation of calcium arsenate during the combustion of a Black Thunder coal. Gullett and Ragnunathan [40] demonstrated that Ca-based sorbents can increase solid-phase arsenic recoveries by $>160 \%$ whereas kaolinite (Al-Si cation sites) and bauxite (Al cation sites) have only a small effect on arsenic recoveries. Mahuli and coworkers [41] also report substantially higher solid-phase arsenic recoveries from Ca-based sorbents compared to kaolinite-, alumina-, or silica-based sorbents.

Due to the similarities in the oxy-anions of arsenic and selenium, it is postulated that arsenic may also react with active iron surface sites. Previous research pointing to the formation of As-Fe surface complexes has not been identified.

The potential for As-Fe or As-Ca reactions as a dominant partitioning mechanism can be evaluated by comparing the total ash size distribution and the size distributions of iron, calcium, and arsenic. The differential mass concentration distributions of arsenic, calcium, iron, and the total ash from full impactor sets for all six coals under baseline combustion conditions at the Port 14 sampling location are shown in Figure 3-13.

To examine the results more carefully, the distributions were decomposed into their submicron and supermicron components and cross correlation coefficients were calculated (see the quarterly report for January through March 2000 for a description of these coefficients). The correlation of arsenic to calcium and iron using both evaluation methods for both submicron and supermicron fly ash sampled at Port 14 is shown in Table 3-8 for all six study coals. Key differential distribution cross correlation graphs for arsenic versus calcium and iron can be found in Figures 3-14 through 3-25.

Calcium in the Illinois \#6 fly ash appears to correlate with both calcium and iron in the submicron and bulk fly ash regions. No correlation is discerned in the fragmentation region. By contrast, selenium showed correlation with calcium in all three particle regions. Like selenium, arsenic appears to correlate with both calcium and iron in all three particle regions for the Pittsburgh coal. This is due to the similarity between the iron and calcium distributions. It cannot be determined from this data whether arsenic correlates with one cation or with both. The Ohio arsenic distribution does not correlate with calcium or iron in the submicron or fragmentation regions but shows an apparent correlation with both calcium and iron in the bulk fly ash region. For the Kentucky coal, arsenic correlates with iron in the submicron and fragmentation regions but shows no apparent correlation in the bulk fly ash region. Arsenic in the Wyodak coal correlates with calcium and iron in both supermicron regions but shows no apparent correlation in the submicron region. For the North Dakota fly ash, arsenic correlates with calcium in all three particle regions but only strongly correlates with iron in the fragmentation region. 


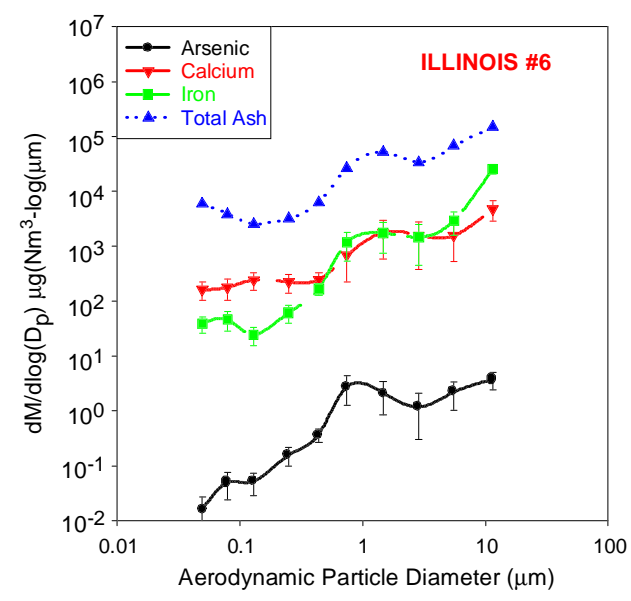

(a)

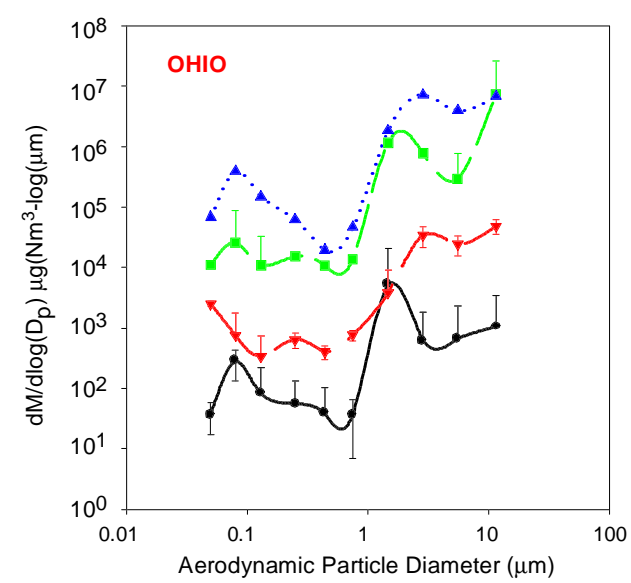

(c)

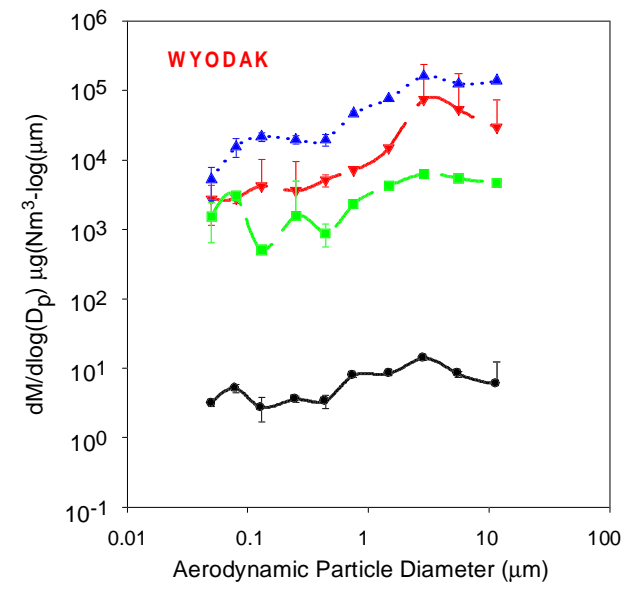

(e)

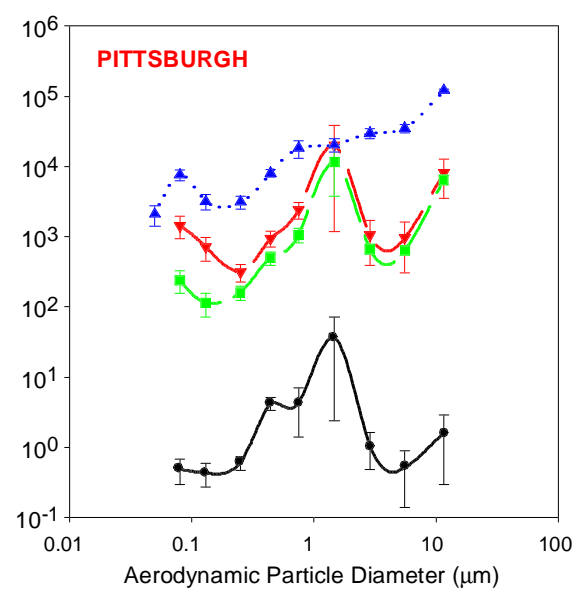

(b)

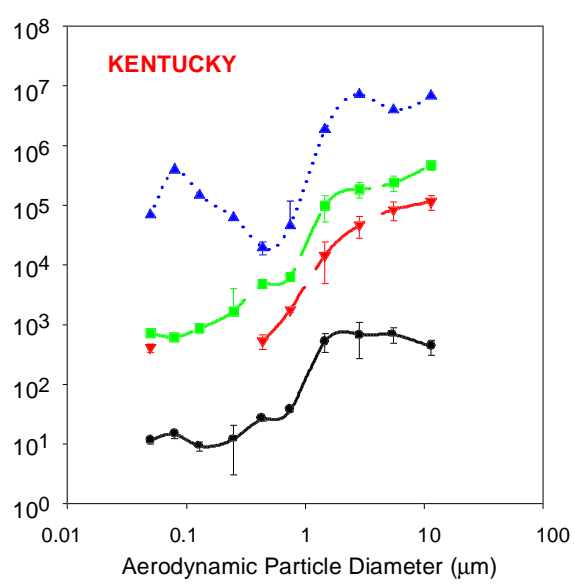

(d)

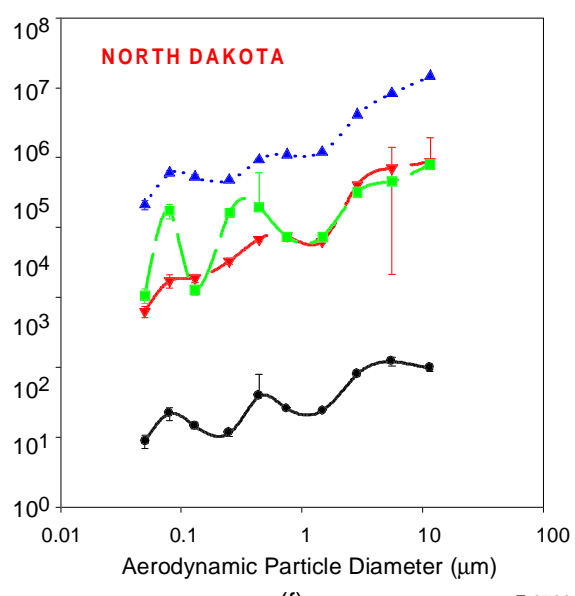

(f)

Figure 3-13. Differential mass distributions of arsenic, calcium, iron, and total ash for the six study coals sampled at Port 14. 
Table 3-8. Correlation Coefficients for Arsenic versus Calcium and Iron in Fly Ash Particles from the Six Study Coals Sampled at Port 14

\begin{tabular}{|c|c|c|c|c|c|c|}
\hline \multirow[b]{2}{*}{ Coal } & \multicolumn{2}{|c|}{ Submicron Correlations } & \multirow[b]{2}{*}{$\begin{array}{c}\text { Overall } \\
\text { Absolute } \\
\text { Concentra- } \\
\text { tions }\end{array}$} & \multicolumn{2}{|c|}{ Supermicron Correlations } & \multirow[b]{2}{*}{$\begin{array}{c}\text { Bulk Fly } \\
\text { Ash Region } \\
\text { Differential } \\
\text { Distributions }\end{array}$} \\
\hline & $\begin{array}{l}\text { Absolute } \\
\text { Concentra- } \\
\text { tions }\end{array}$ & $\begin{array}{c}\text { Differential } \\
\text { Distributions }\end{array}$ & & $\begin{array}{c}\text { Overall } \\
\text { Differential } \\
\text { Distributions }\end{array}$ & $\begin{array}{c}\text { Fragmentation } \\
\text { Region } \\
\text { Differential } \\
\text { Distributions } \\
\end{array}$ & \\
\hline Illinois: $\mathrm{As} v \mathrm{Ca}$ & $\sim 0$ & 0.92 & 0.31 & $\sim 0$ & $\sim 0$ & 0.80 \\
\hline As vs $\mathrm{Fe}$ & 0.97 & 0.99 & $\sim 0$ & $\sim 0$ & $\sim 0$ & 0.87 \\
\hline Pittsburgh: As vs Ca & $\sim 0$ & 0.99 & 1.0 & 0.84 & 1.0 & $\sim 0$ \\
\hline As vs Fe & 0.51 & 0.99 & 0.99 & 1.0 & 1.0 & 0.16 \\
\hline Ohio: As vs Ca & 0.92 & $\sim 0$ & $\sim 0$ & $\sim 0$ & 0.10 & 0.87 \\
\hline As vs Fe & 0.89 & $\sim 0$ & $\sim 0$ & $\sim 0$ & $\sim 0$ & 1.0 \\
\hline Kentucky: As vs Ca & na & na & $\sim 0$ & 0.45 & 0.76 & $\sim 0$ \\
\hline As vs Fe & $\sim 0$ & 1.0 & 0.24 & 0.77 & 0.94 & $\sim 0$ \\
\hline Wyodak: As vs Ca & $\sim 0$ & $\sim 0$ & $\sim 0$ & 0.50 & 1.0 & 0.98 \\
\hline As vs $\mathrm{Fe}$ & $\sim 0$ & $\sim 0$ & 0.65 & 0.53 & 0.75 & 0.99 \\
\hline N. Dakota: As vs Ca & $\sim 0$ & 0.82 & $\sim 0$ & 1.0 & 1.0 & 0.83 \\
\hline As vs Fe & $\sim 0$ & $\begin{array}{c}\sim 0 \\
\sim 0\end{array}$ & 0.34 & 1.0 & 1.0 & 0.53 \\
\hline
\end{tabular}

This assessment of the distribution curves in Figure 3-13 and the cross correlations listed in Table 3-8 suggests that the mechanisms controlling arsenic partitioning:

- $\quad$ Are different depending on the fly ash particle region,

- $\quad$ Are often surface reaction controlled,

- When surface reaction controlled, the reaction is with calcium and/or iron active surface sites.

The Illinois and Pittsburgh coals have moderate calcium contents and relatively high sulfur contents. The Ohio coal (where no size dependence is observed) has a low calcium content and high sulfur content. The Kentucky coal has a low calcium content and low sulfur content. The Wyodak and North Dakota coals have high calcium content, low sulfur content, and a lower maximum combustion temperature (than the four bituminous coals). Thus, the three parameters that appear to be important in determining the nature of arsenic-cation surface reactions are: arsenic-to-calcium ratio, coal sulfur content, and combustion temperature.

From these results a set of hypotheses related to arsenic partitioning were developed. To test these hypotheses, a set of special experiments was developed. Table 3-9 summarizes the hypotheses and the special test matrix developed for validation. 


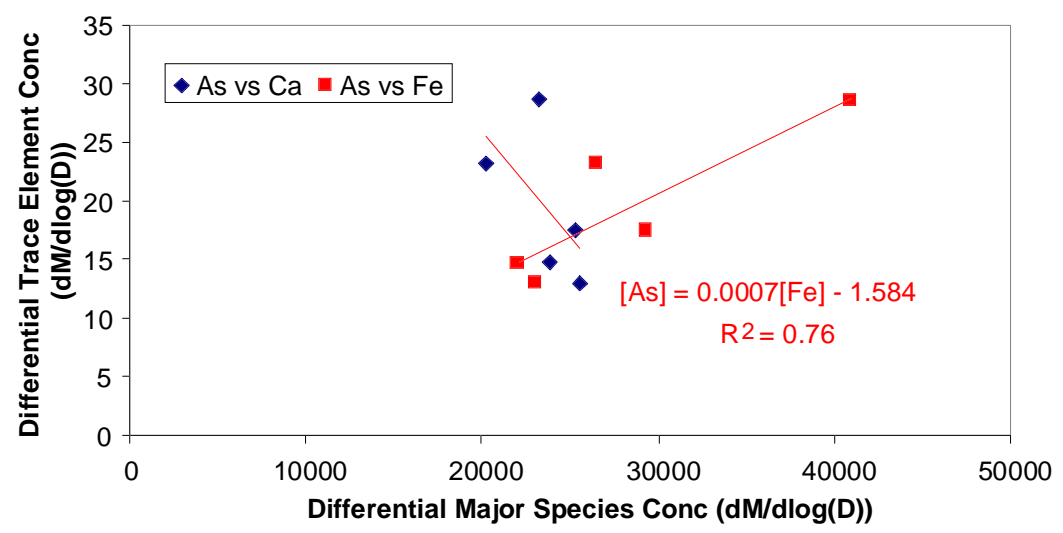

(a)

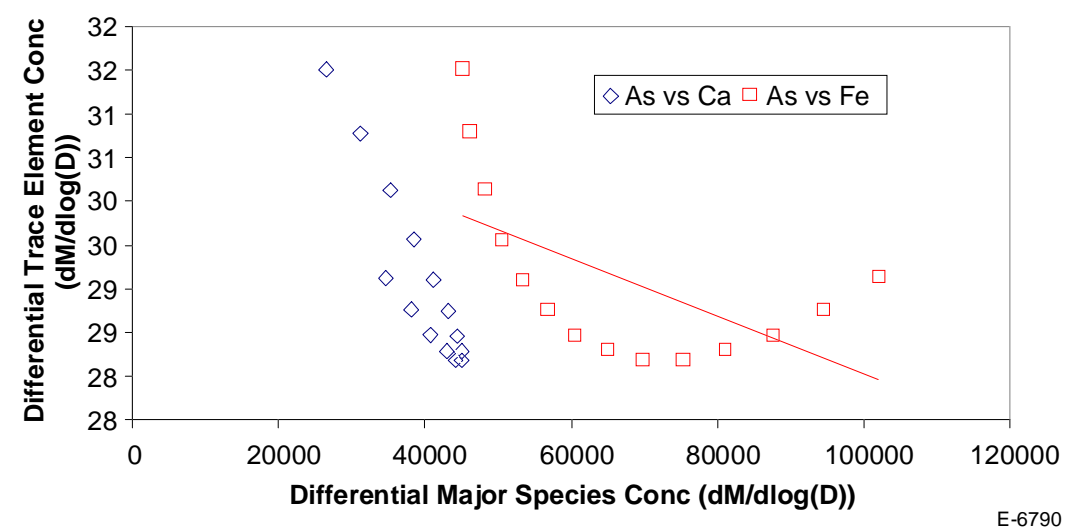

(b)

Figure 3-14. Cross correlation of Illinois arsenic to calcium and iron differential distribution curves at baseline screening experimental conditions sampled at Port 4 for the supermicron region. (a) Cross correlation of data from 0.75 to $3.0 \mu \mathrm{m}$ particle diameter (fragmentation region) derived from the curves shown in a.; (b) Cross correlation of data from 3.0 to $10 \mu \mathrm{m}$ particle diameter derived from the curves shown in a. 


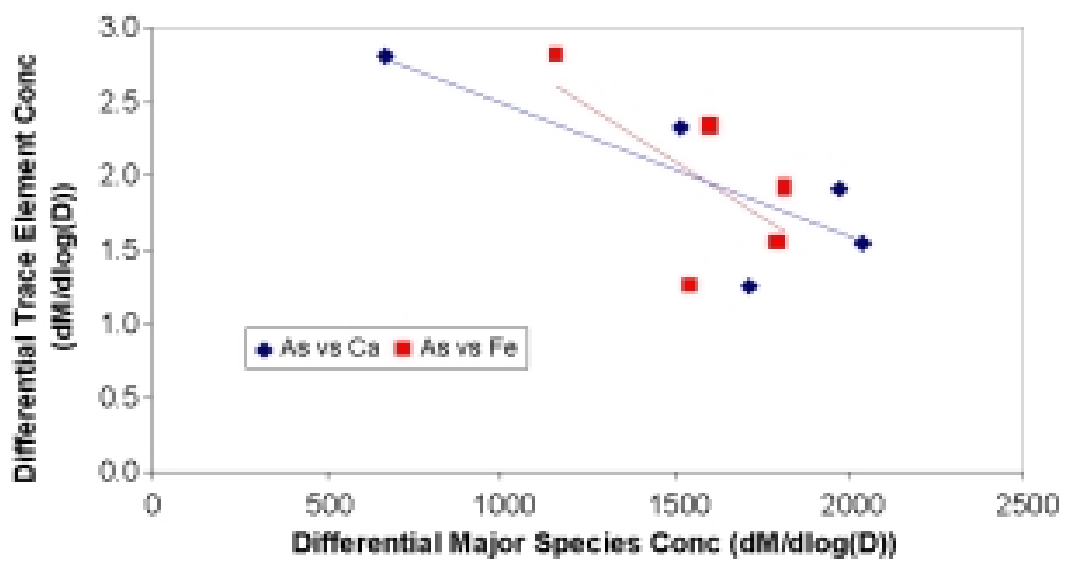

(a)

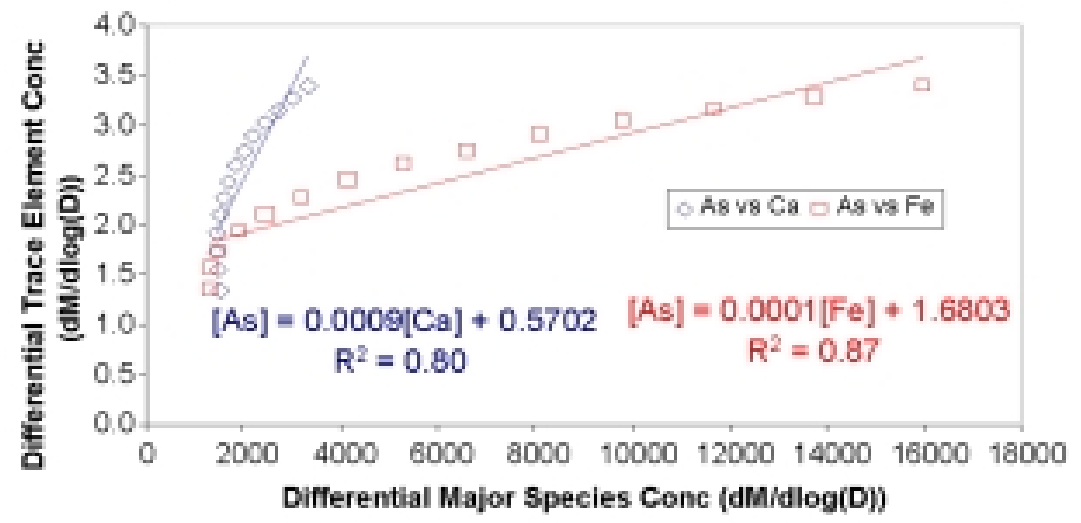

(b)

E-4791

Figure 3-15. Cross correlation of Illinois arsenic to calcium and iron differential distribution curves at baseline screening experimental conditions sampled at Port 14 for the supermicron region. (a) Cross correlation of data from 0.75 to $3.0 \mu \mathrm{m}$ particle diameter (fragmentation region) derived from the curves shown in a.; (b) Cross correlation of data from 3.0 to $10 \mu \mathrm{m}$ particle diameter derived from the curves shown in a. 


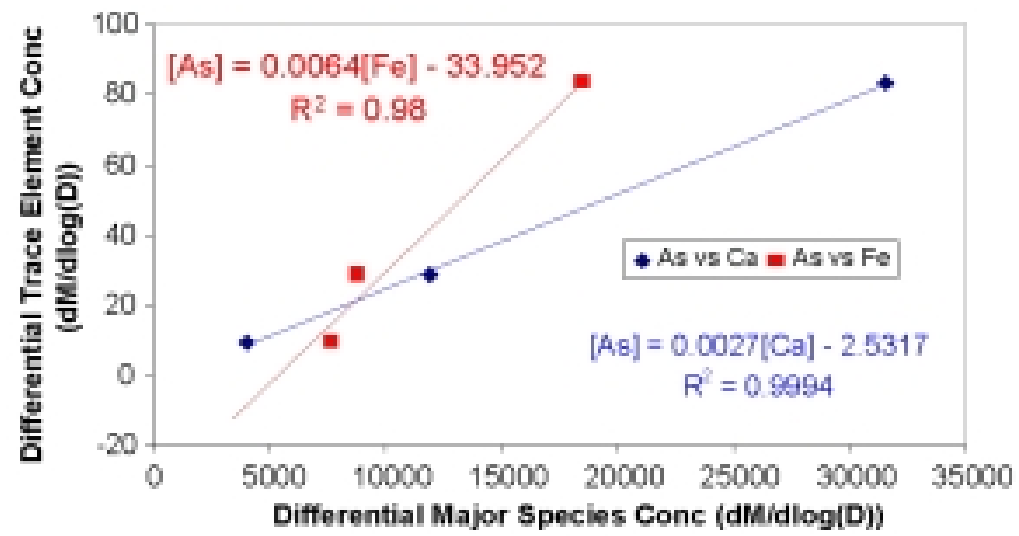

(a)

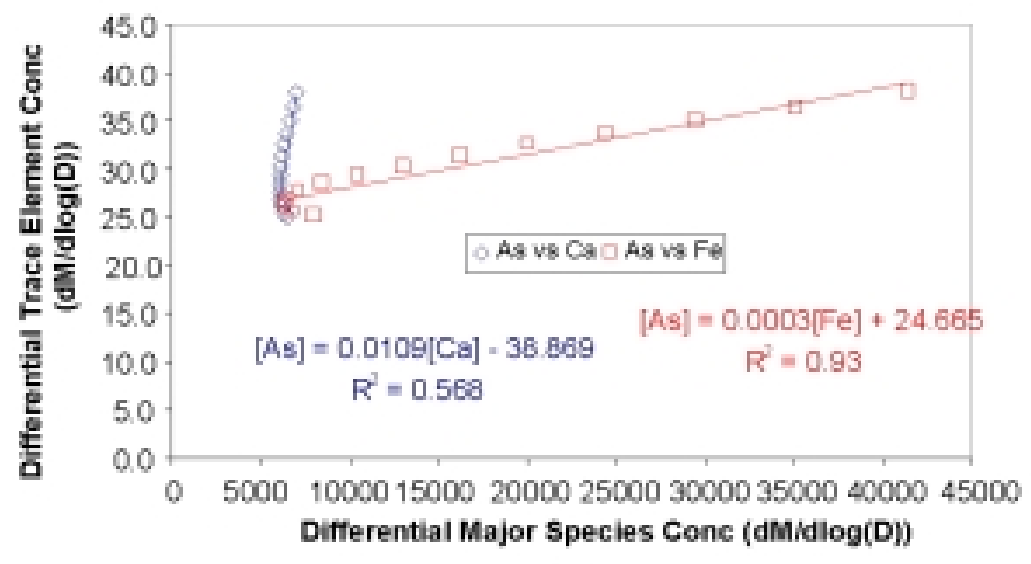

(b)

E-4792

Figure 3-16. Cross correlation of Pittsburgh arsenic to calcium and iron differential distribution curves at baseline screening experimental conditions sampled at Port 4 for the supermicron region. (a) Cross correlation of data from 0.75 to $3.0 \mu \mathrm{m}$ particle diameter (fragmentation region) derived from the curves shown in a.; (b) Cross correlation of data from 3.0 to $10 \mu \mathrm{m}$ particle diameter derived from the curves shown in a. 


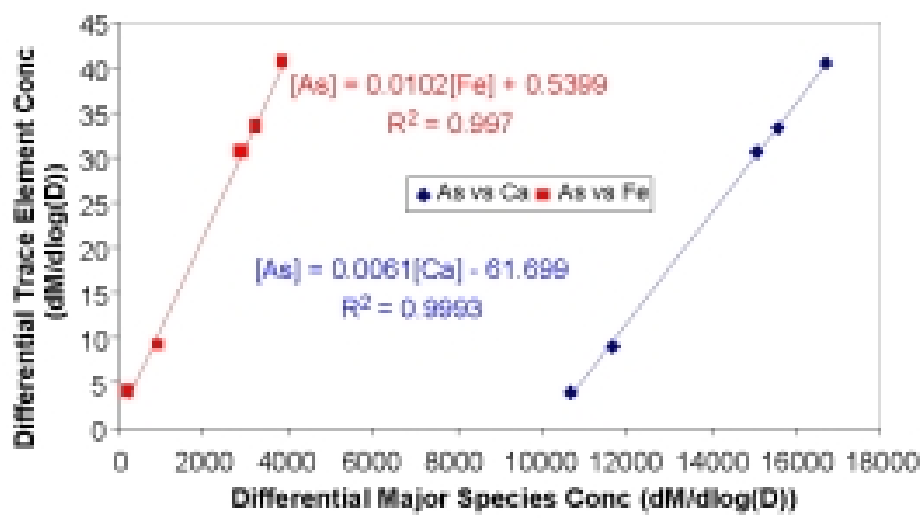

(a)

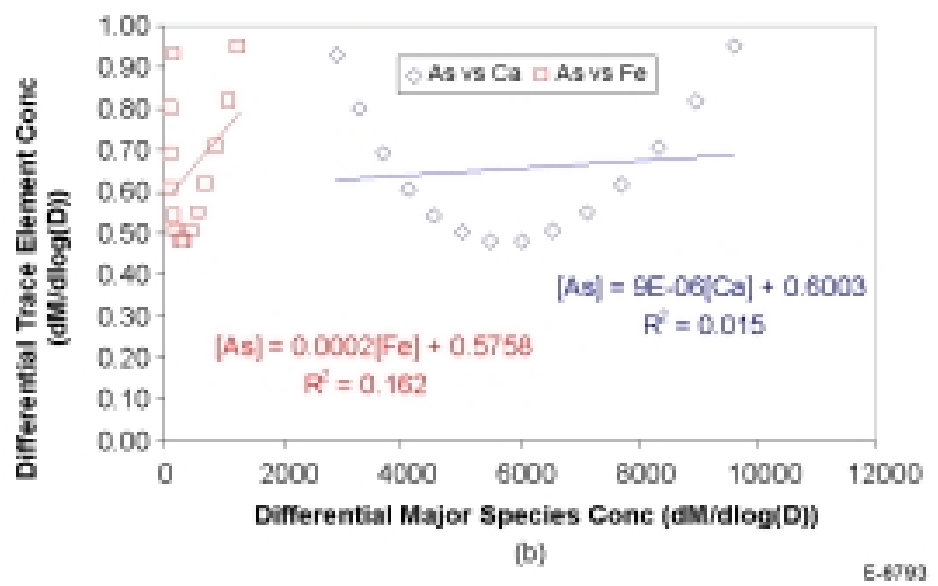

Figure 3-17. Cross correlation of Pittsburgh arsenic to calcium and iron differential distribution curves at baseline screening experimental conditions sampled at Port 14 for the supermicron region. (a) Cross correlation of data from 0.75 to $3.0 \mu \mathrm{m}$ particle diameter (fragmentation region) derived from the curves shown in a.; (b) Cross correlation of data from 3.0 to $10 \mu \mathrm{m}$ particle diameter derived from the curves shown in a. 


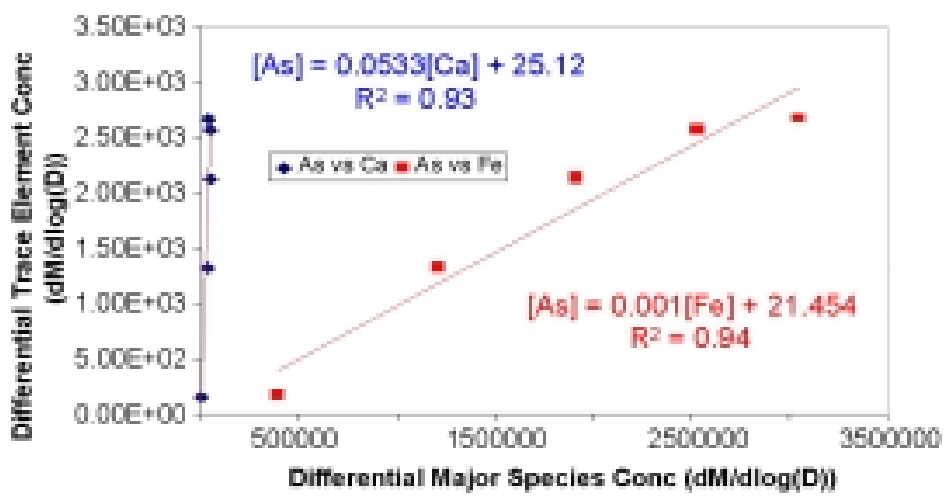

(a)

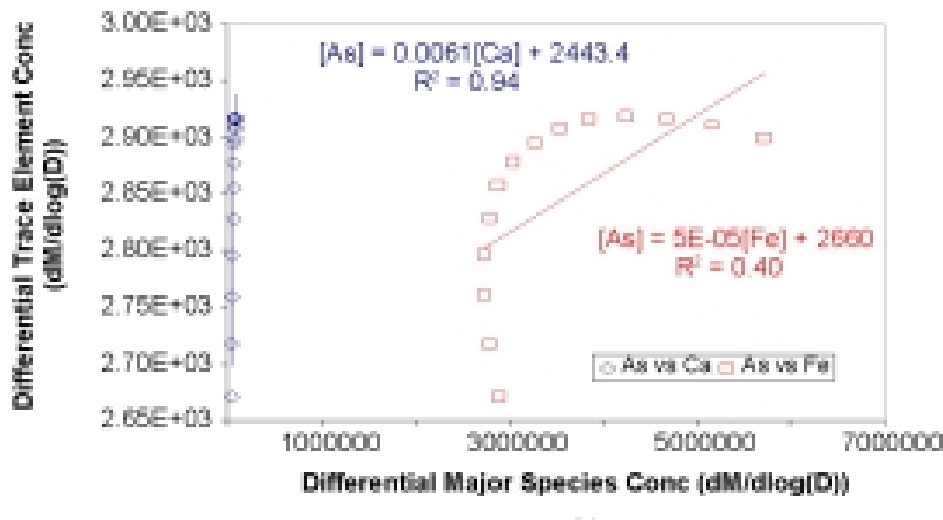

(b)

E-4754

Figure 3-18. Cross correlation of Ohio arsenic to calcium and iron differential distribution curves at baseline screening experimental conditions sampled at Port 4 for the supermicron region. (a) Cross correlation of data from 0.75 to $3.0 \mu \mathrm{m}$ particle diameter (fragmentation region) derived from the curves shown in a.; (b) Cross correlation of data from 3.0 to $10 \mu \mathrm{m}$ particle diameter derived from the curves shown in a. 


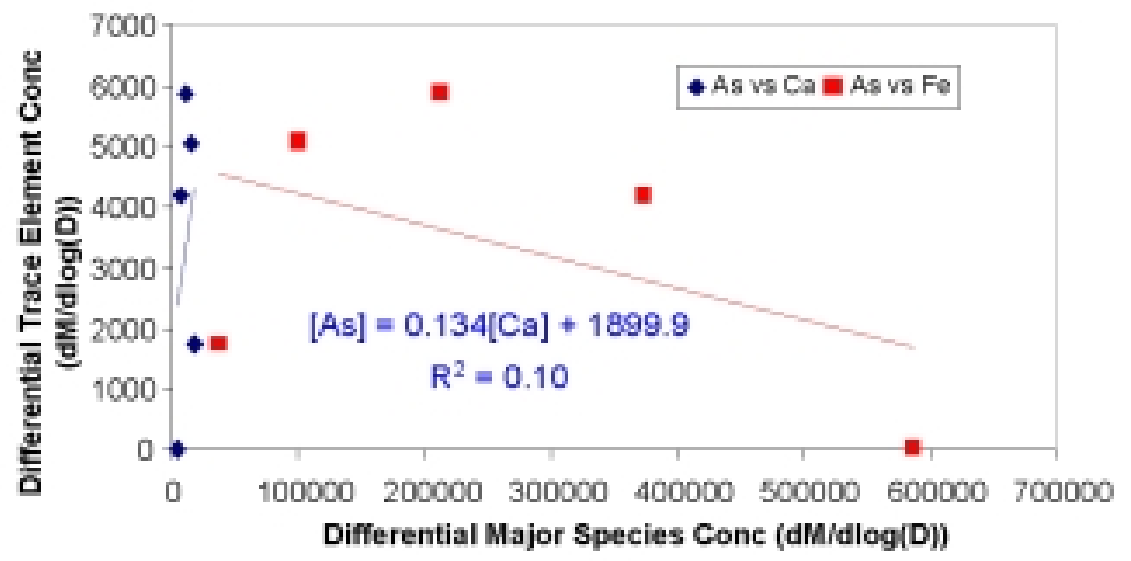

(a)

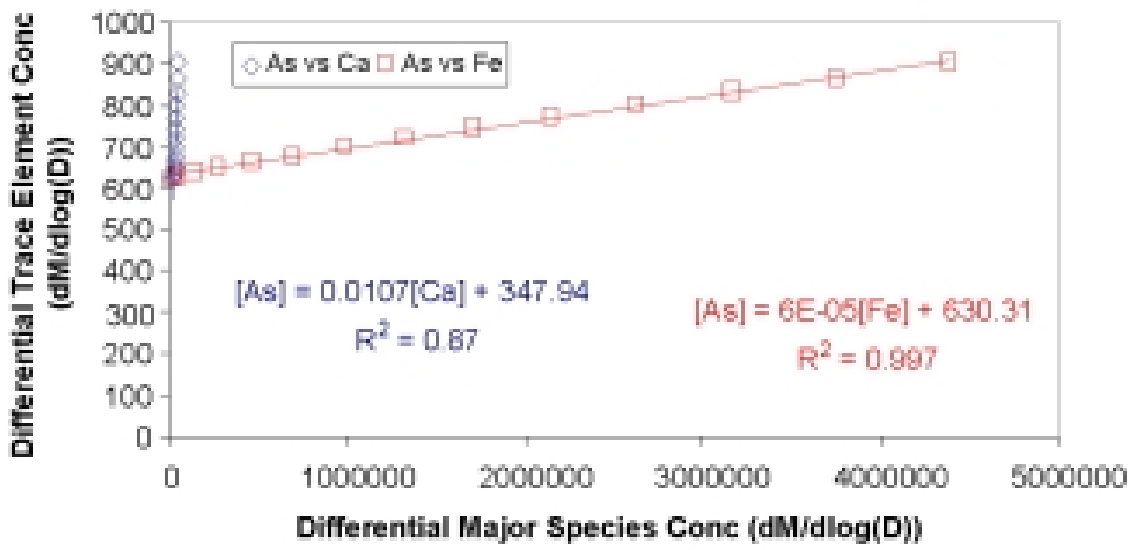

(b)

E4780

Figure 3-19. Cross correlation of Ohio arsenic to calcium and iron differential distribution curves at baseline screening experimental conditions sampled at Port 14 for the supermicron region. (a) Cross correlation of data from 0.75 to $3.0 \mu \mathrm{m}$ particle diameter (fragmentation region) derived from the curves shown in a.; (b) Cross correlation of data from 3.0 to $10 \mu \mathrm{m}$ particle diameter derived from the curves shown in a. 


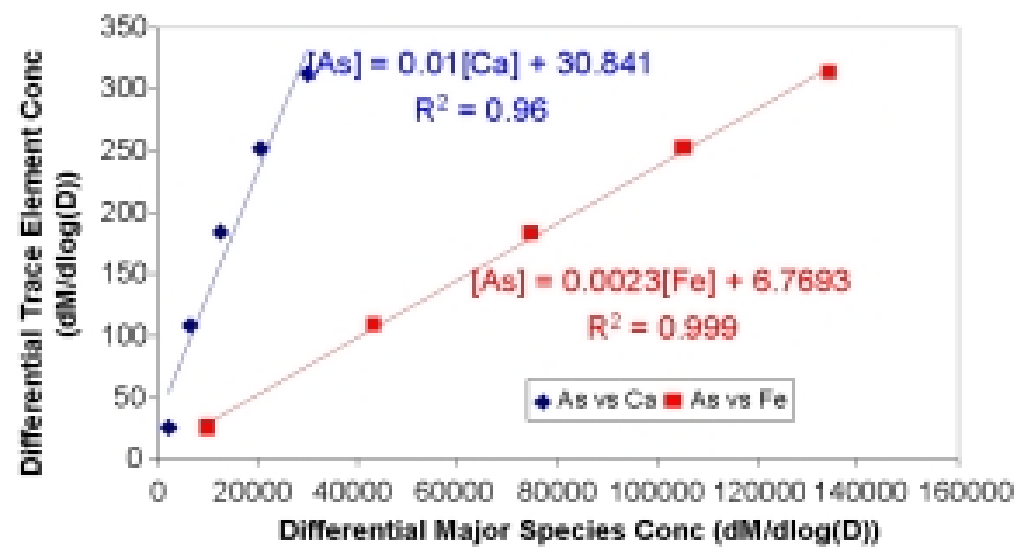

(a)

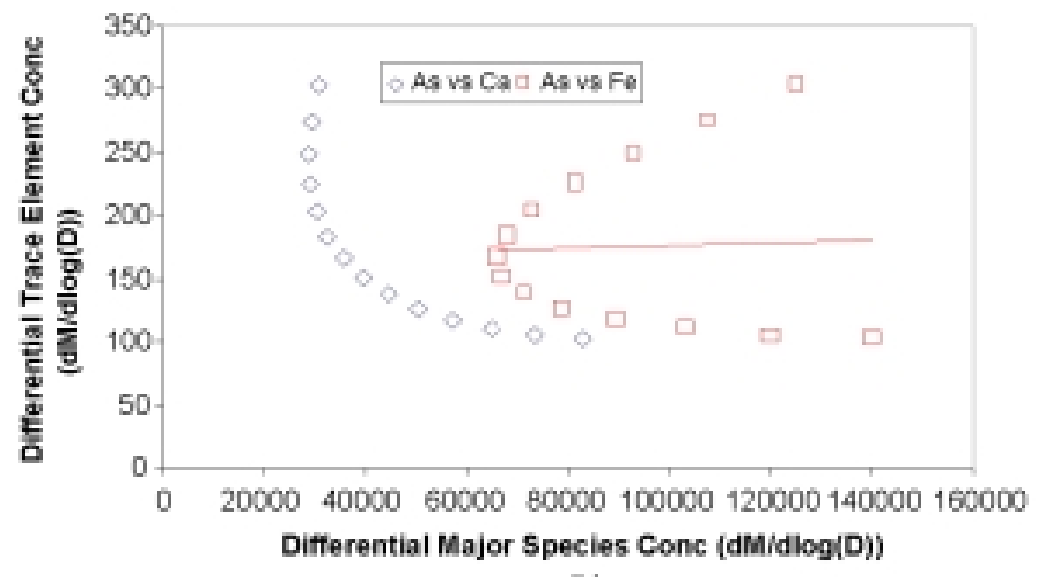

(b)

E-67es

Figure 3-20. Cross correlation of Kentucky arsenic to calcium and iron differential distribution curves at baseline screening experimental conditions sampled at Port 4 for the supermicron region. (a) Cross correlation of data from 0.75 to $3.0 \mu \mathrm{m}$ particle diameter (fragmentation region) derived from the curves shown in a.; (b) Cross correlation of data from 3.0 to $10 \mu \mathrm{m}$ particle diameter derived from the curves shown in a. 


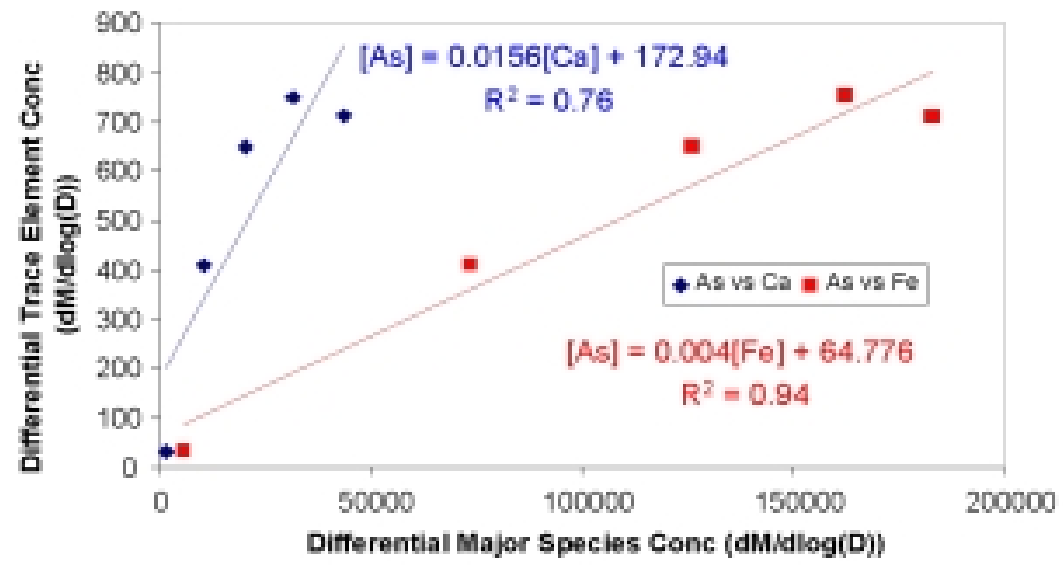

(a)

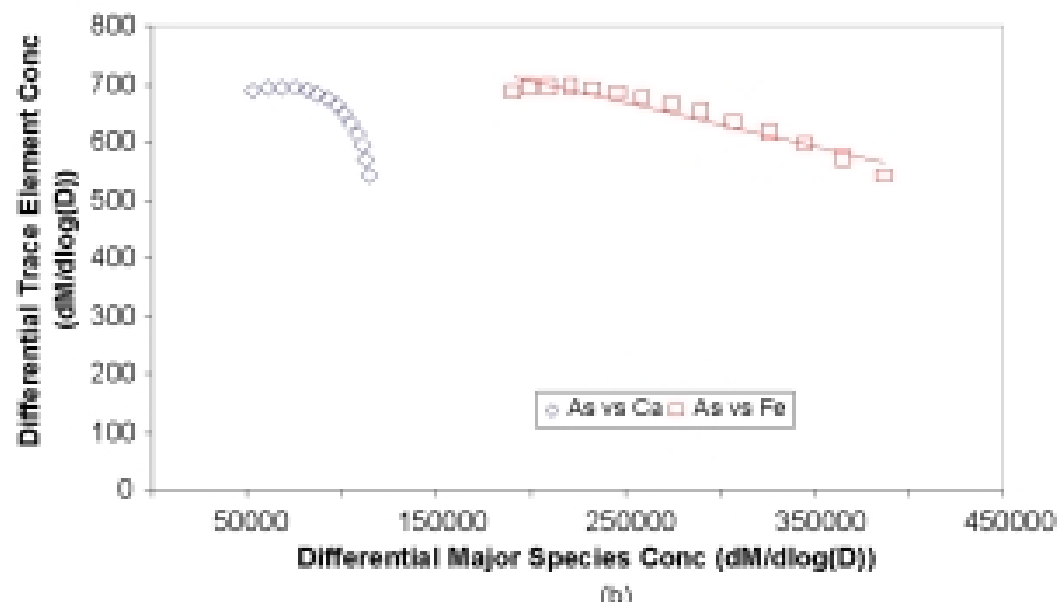

Figure 3-21. Cross correlation of Kentucky arsenic to calcium and iron differential distribution curves at baseline screening experimental conditions sampled at Port 14 for the supermicron region. (a) Cross correlation of data from 0.75 to $3.0 \mu \mathrm{m}$ particle diameter (fragmentation region) derived from the curves shown in a.; (b) Cross correlation of data from 3.0 to $10 \mu \mathrm{m}$ particle diameter derived from the curves shown in a. 


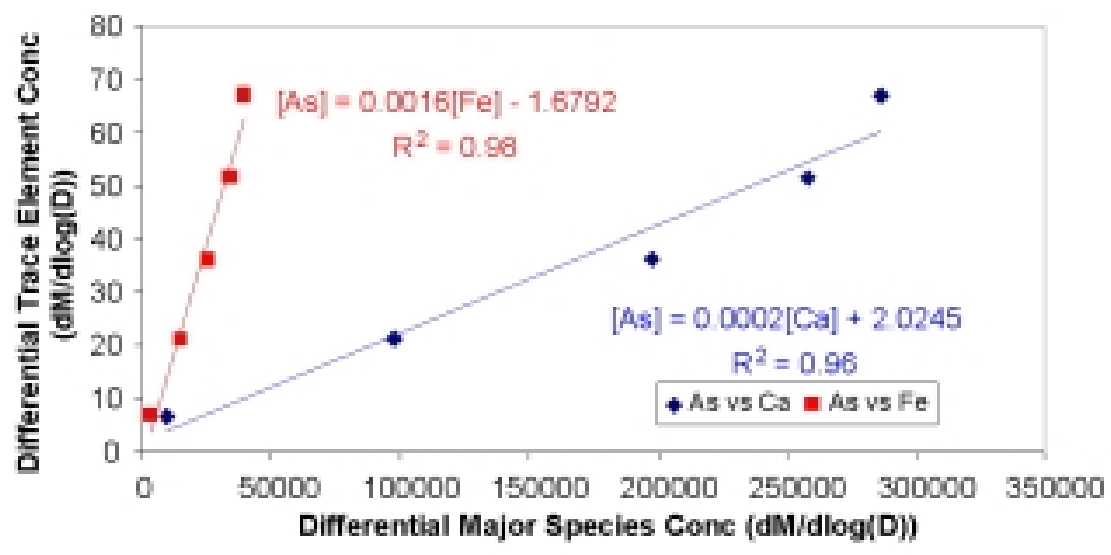

(a)

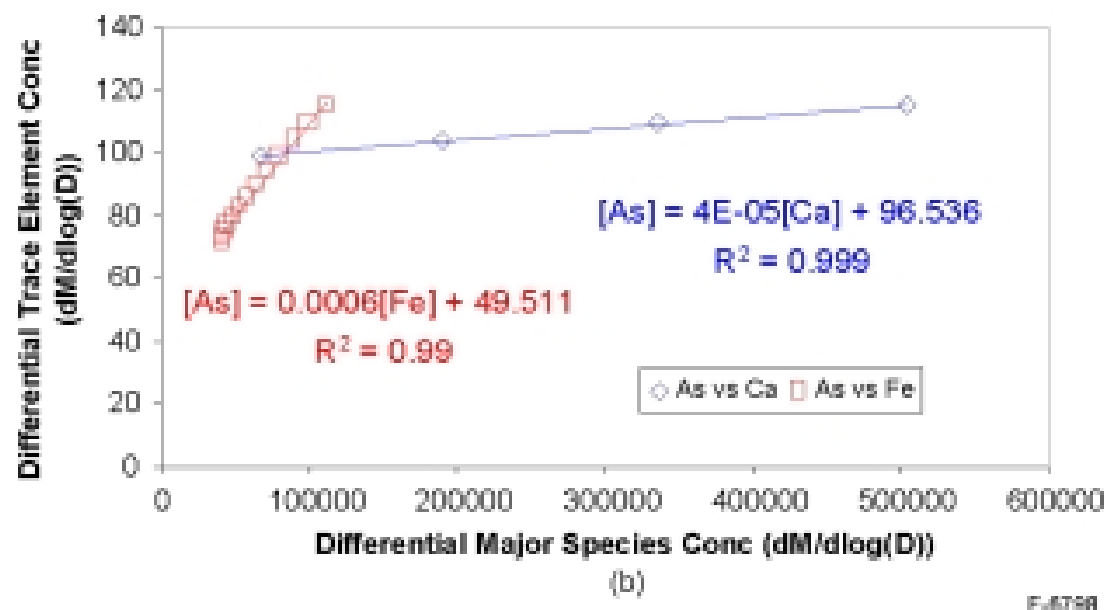

Figure 3-22. Cross correlation of Wyodak arsenic to calcium and iron differential distribution curves at baseline screening experimental conditions sampled at Port 4 for the supermicron region. (a) Cross correlation of data from 0.75 to $3.0 \mu \mathrm{m}$ particle diameter (fragmentation region) derived from the curves shown in a.; (b) Cross correlation of data from 3.0 to $10 \mu \mathrm{m}$ particle diameter derived from the curves shown in a. 


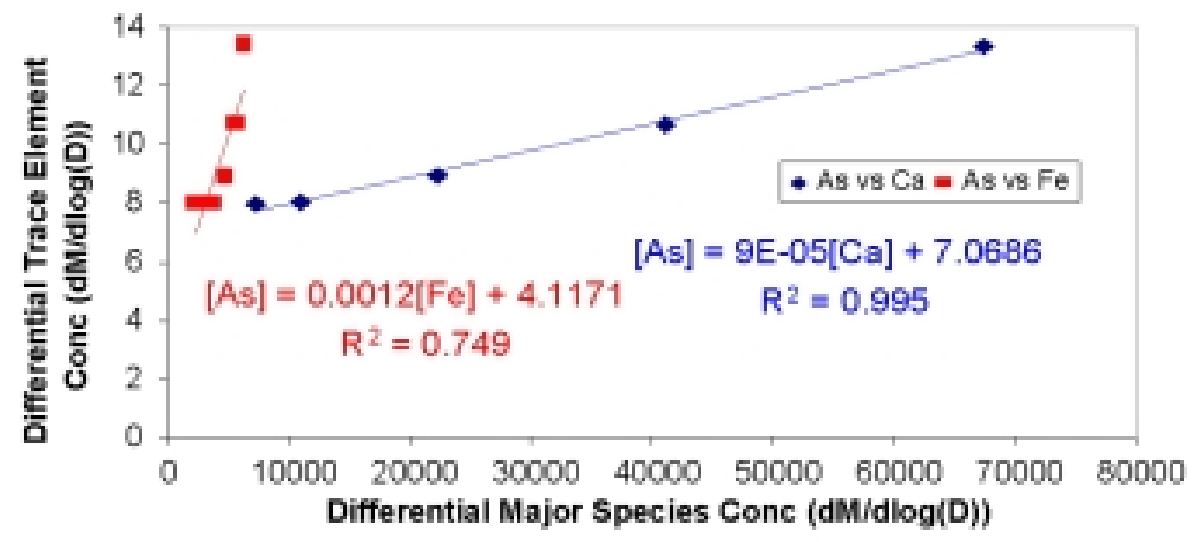

(a)

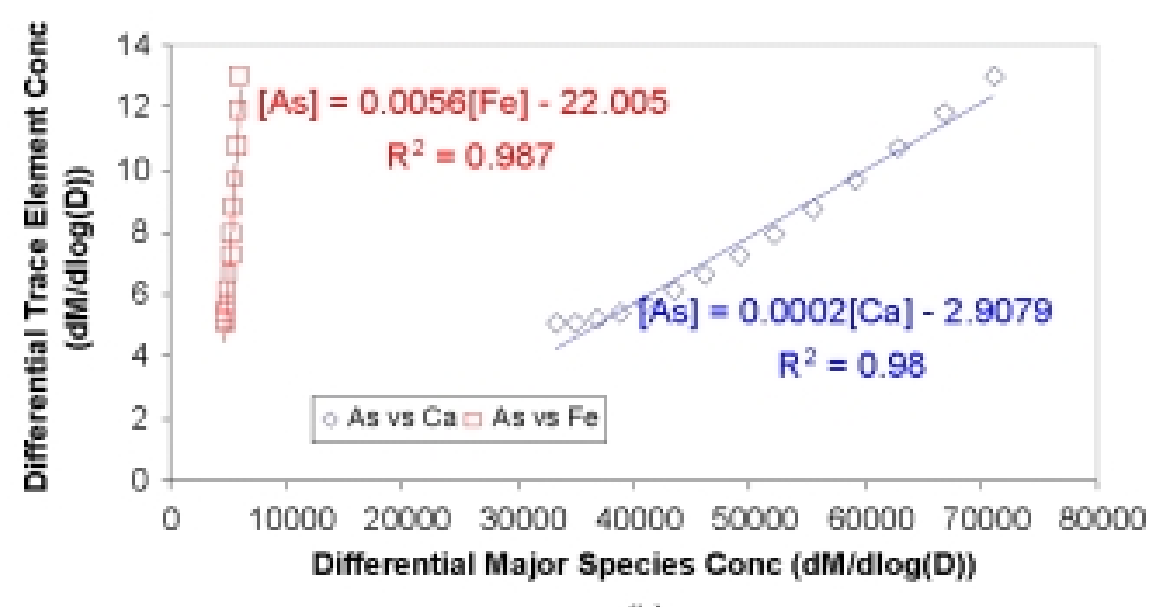

(b)

E-6799

Figure 3-23. Cross correlation of Wyodak arsenic to calcium and iron differential distribution curves at baseline screening experimental conditions sampled at Port 14 for the supermicron region. (a) Cross correlation of data from 0.75 to $3.0 \mu \mathrm{m}$ particle diameter (fragmentation region) derived from the curves shown in a.; (b) Cross correlation of data from 3.0 to $10 \mu \mathrm{m}$ particle diameter derived from the curves shown in a. 


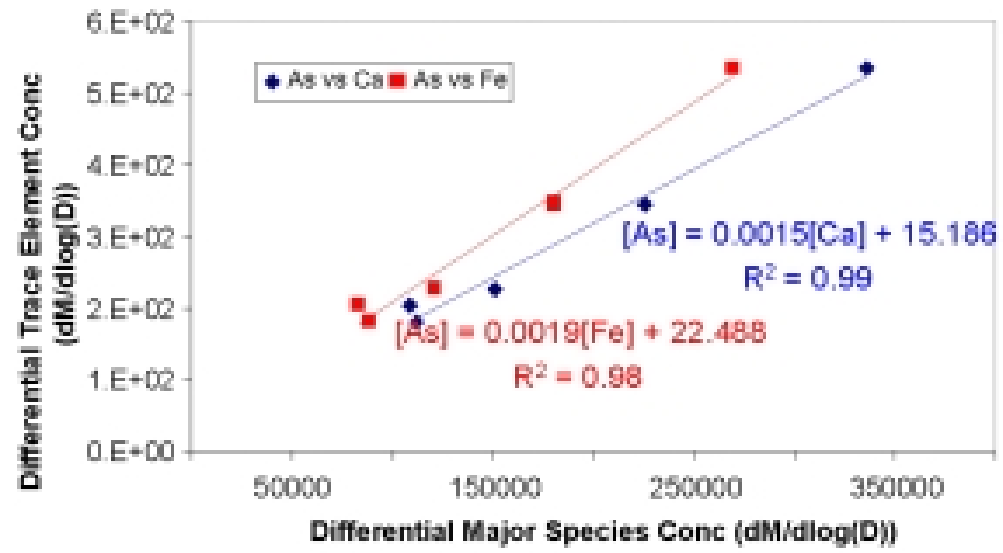

(a)

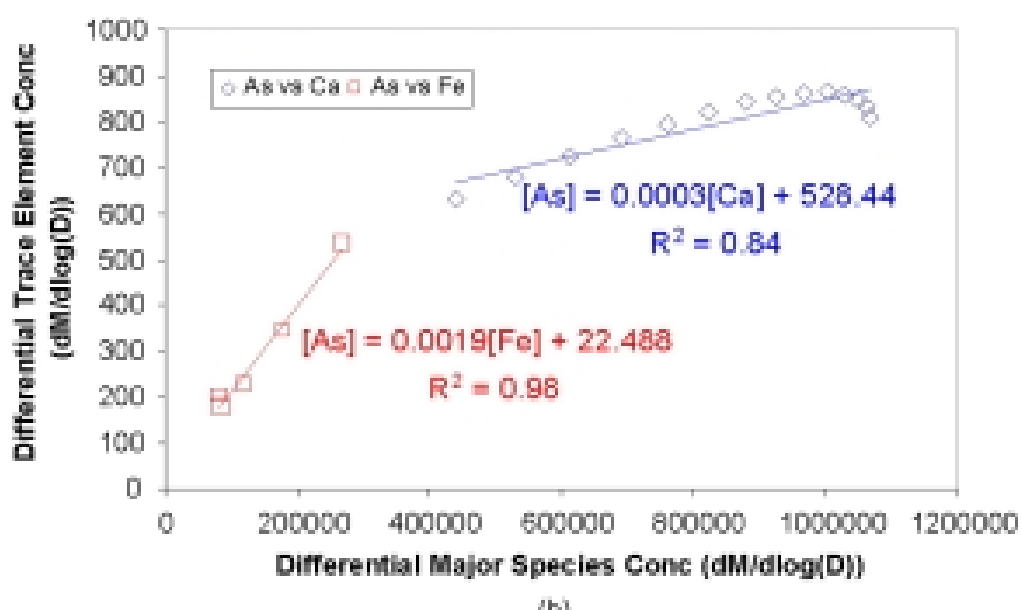

(b)

E-asoo

Figure 3-24. Cross correlation of North Dakota arsenic to calcium and iron differential distribution curves at baseline screening experimental conditions sampled at Port 4 for the supermicron region. (a) Cross correlation of data from 0.75 to $3.0 \mu \mathrm{m}$ particle diameter (fragmentation region) derived from the curves shown in a.; (b) Cross correlation of data from 3.0 to $10 \mu \mathrm{m}$ particle diameter derived from the curves shown in a. 


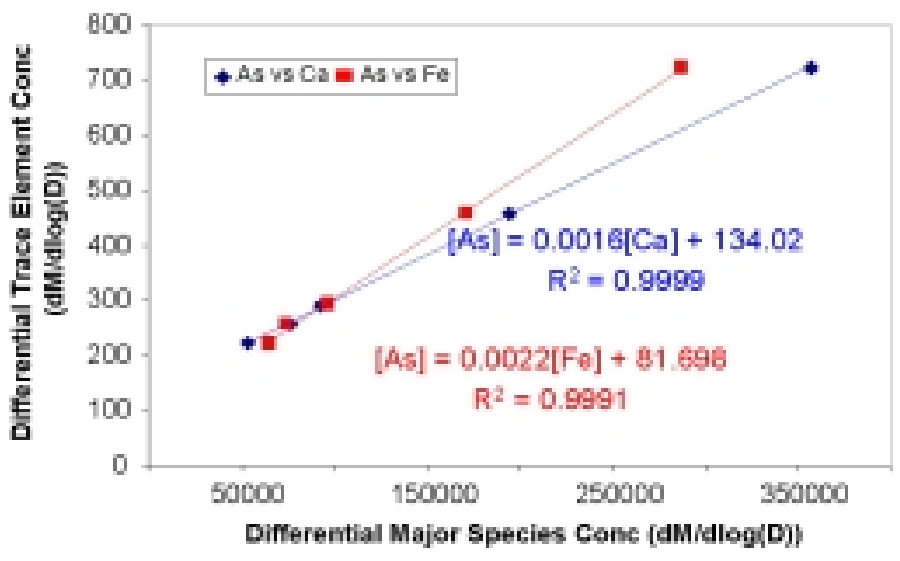

(a)

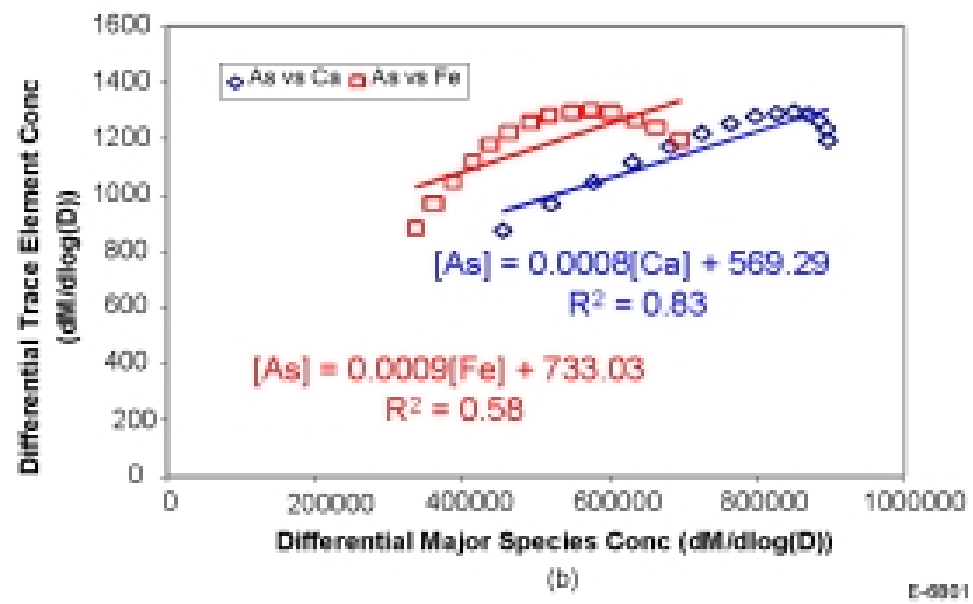

Figure 3-25. Cross correlation of North Dakota arsenic to calcium and iron differential distribution curves at baseline screening experimental conditions sampled at Port 14 for the supermicron region. (a) Cross correlation of data from 0.75 to $3.0 \mu \mathrm{m}$ particle diameter (fragmentation region) derived from the curves shown in a.; (b) Cross correlation of data from 3.0 to $10 \mu \mathrm{m}$ particle diameter derived from the curves shown in a. 
Table 3-9. Arsenic Partitioning Mechanism Hypotheses and Validation Test Matrix

\begin{tabular}{|c|c|c|c|}
\hline Hypothesis & $\begin{array}{l}\text { Baseline Test and Fly Ash } \\
\text { Region Where Observed }\end{array}$ & Test Number & Test Description \\
\hline \multirow{2}{*}{$\begin{array}{l}\text { Vapor-to-solid phase arsenic partitioning } \\
\text { is controlled by surface reaction when } \\
\text { sufficient surface sites are available for } \\
\text { reaction }\end{array}$} & $\begin{array}{l}\text { Ohio baseline coal vs. other } 5 \\
\text { coals; Ohio does not follow a } \\
\text { dependence }\end{array}$ & (99W-8, 00W-4 & $\begin{array}{l}\text { Arsenic doped into Wyodak coal combustion } \\
\text { until As-to-Ca ratio matched Ohio ratio }\end{array}$ \\
\hline & & $00 \mathrm{O}-1,00 \mathrm{O}-2$ & $\begin{array}{l}\text { Calcium blended into Ohio coal for combustion } \\
\text { until As-to-Ca ratio matched Wyodak ratio. } \\
\text { Temperature decreased to match Wyodak } \\
\text { combustion temperature }\end{array}$ \\
\hline $\begin{array}{l}\text { Arsenic reacts with active calcium } \\
\text { surface sites }\end{array}$ & $\begin{array}{l}\text { Wyodak fragmentation and } \\
\text { bulk fly ash; North Dakota } \\
\text { submicron and bulk fly ash }\end{array}$ & $\begin{array}{l}99 \mathrm{~W}-8, \mathrm{OOW}- \\
4\end{array}$ & $\begin{array}{l}\text { Arsenic doped into Wyodak coal combustion } \\
\text { until As-to-Ca ratio matched Ohio ratio }\end{array}$ \\
\hline $\begin{array}{l}\text { Arsenic reacts with active iron surface } \\
\text { sites when sulfur is not available to } \\
\text { consume all of the iron surface sites }\end{array}$ & $\begin{array}{l}\text { Kentucky submicron and } \\
\text { fragmentation; }\end{array}$ & $00 \mathrm{~K}-1$ & $\begin{array}{l}\text { Sulfur was doped into the Kentucky coal } \\
\text { combustion until the sulfur content matched the } \\
\text { Ohio sulfur content }\end{array}$ \\
\hline $\begin{array}{l}\text { Arsenic reacts with iron and/or calcium } \\
\text { active surface sites }\end{array}$ & $\begin{array}{l}\text { Illinois submicron and bulk fly } \\
\text { ash; Pittsburgh submicron and } \\
\text { fragmentation; North Dakota } \\
\text { fragmentation }\end{array}$ & $\begin{array}{l}00 \mathrm{P} 8-1 \\
00 \mathrm{P} 8-2\end{array}$ & $\begin{array}{l}\text { Calcium was doped into Pittsburgh coal to } \\
\text { assess recovery of arsenic; then Iron was doped } \\
\text { into Pittsburgh coal to assess recovery of arsenic }\end{array}$ \\
\hline $\begin{array}{l}\text { Arsenic partitioning is not controlled by } \\
\text { reaction with iron or calcium when } \\
\text { sufficient surface sites are not available } \\
\text { for reaction }\end{array}$ & $\begin{array}{l}\text { Ohio submicron; Ohio } \\
\text { fragmentation; Ohio bulk fly } \\
\text { ash }\end{array}$ & $00 \mathrm{~K}-1,00 \mathrm{O}-1$ & $\begin{array}{l}\text { Sulfur was doped into the Kentucky coal } \\
\text { combustion until the sulfur content matched the } \\
\text { Ohio sulfur content; Calcium blended into Ohio } \\
\text { coal for combustion until As-to-Ca ratio } \\
\text { matched Wyodak ratio. }\end{array}$ \\
\hline $\begin{array}{l}\text { Increasing the maximum combustion } \\
\text { temperature will increase the availability } \\
\text { of active calcium and iron surface sites } \\
\text { for reaction }\end{array}$ & & $00 \mathrm{~W}-3,00 \mathrm{O}-2$ & $\begin{array}{l}\text { Oxygen blended into Wyodak combustion air; } \\
\mathrm{CO}_{2} \text { blended into Ohio combustion air. }\end{array}$ \\
\hline $\begin{array}{l}\text { Arsenic has similar reactivity with iron } \\
\text { as with calcium }\end{array}$ & & 00P8-1, 00P8-2 & $\begin{array}{l}\text { Calcium was doped into Pittsburgh coal to } \\
\text { assess recovery of arsenic; then Iron was doped } \\
\text { into Pittsburgh coal to assess recovery of arsenic }\end{array}$ \\
\hline
\end{tabular}


The control of arsenic vapor-to-solid phase partitioning by surface reaction is proposed when sufficient active cation sites are available to accommodate the arsenic present in the flue gas. To test this hypothesis, a set of special experiments was developed to explore these parameters in more detail. In one set of experiments using the Wyodak coal, arsenic was dissolved in dilute acid and then doped into the furnace at the burner outlet to increase the As-to$\mathrm{Ca}$ ratio in the combustion environment to match the Ohio coal As-to-Ca ratio. This was done at both the Wyodak maximum combustion temperature and an increased combustion temperature.

Figure 3-26 shows a comparison of the differential arsenic distribution at the Wyodak baseline combustion conditions with As-doped Wyodak coal and undoped Ohio coal at the same combustion temperature. The As-doped Wyodak distribution is somewhat more similar to the Ohio As distribution $\left(\mathrm{CO}_{2}\right.$ addition to decrease max. combustion temperature) than to the Wyodak baseline As distribution (except for the $11.5 \mu \mathrm{m}$ data point). Correlation coefficients from the cross correlation between the absolute concentration values on each relevant impactor stage are $\mathrm{R}^{2}=0.94$ for the As-doped Wyodak As distribution versus the Ohio As distribution and $\mathrm{R}^{2}=0.82$ for the As-doped Wyodak As distribution versus the undoped Wyodak As distribution. The cross correlation from differential distribution curves are $\mathrm{R}^{2}=0.72$ for the As-doped Wyodak versus the Ohio As distribution and $\mathrm{R}^{2}=0.64$ for the As-doped Wyodak versus the Wyodak As distribution. This suggests that arsenic partitioning for the doped case is controlled by the same mechanism as during Ohio combustion rather than the Wyodak arsenic partitioning mechanism.

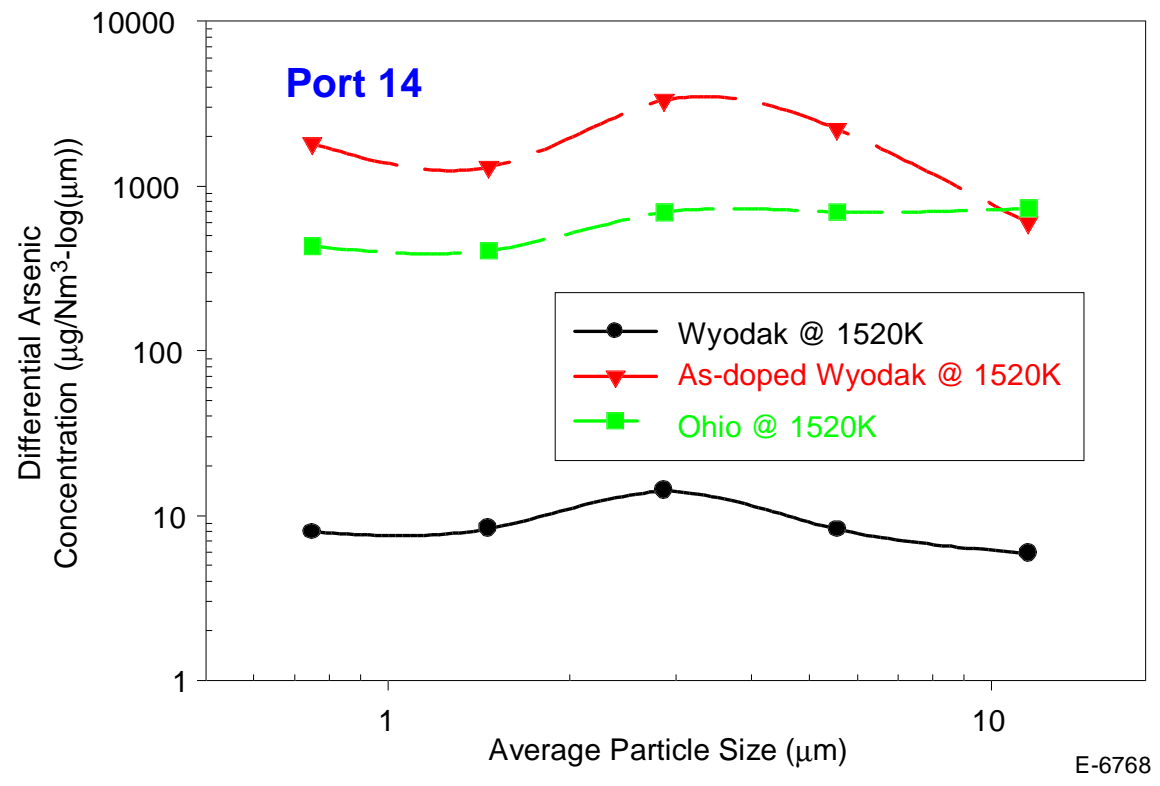

Figure 3-26. Comparison of arsenic differential distribrutions when adjusting the arsenic-tocalcium ratio at constant maximum combustion temperature in theWyodak coal.

A similar comparison is shown in Figure 3-27. This figure shows a comparison of the differential arsenic distribution at the Ohio baseline combustion conditions with As-doped Wyodak coal at an elevated combustion temperature approaching the Ohio temperature and with an undoped Wyodak coal at the same elevated temperature. The As-doped Wyodak distribution 


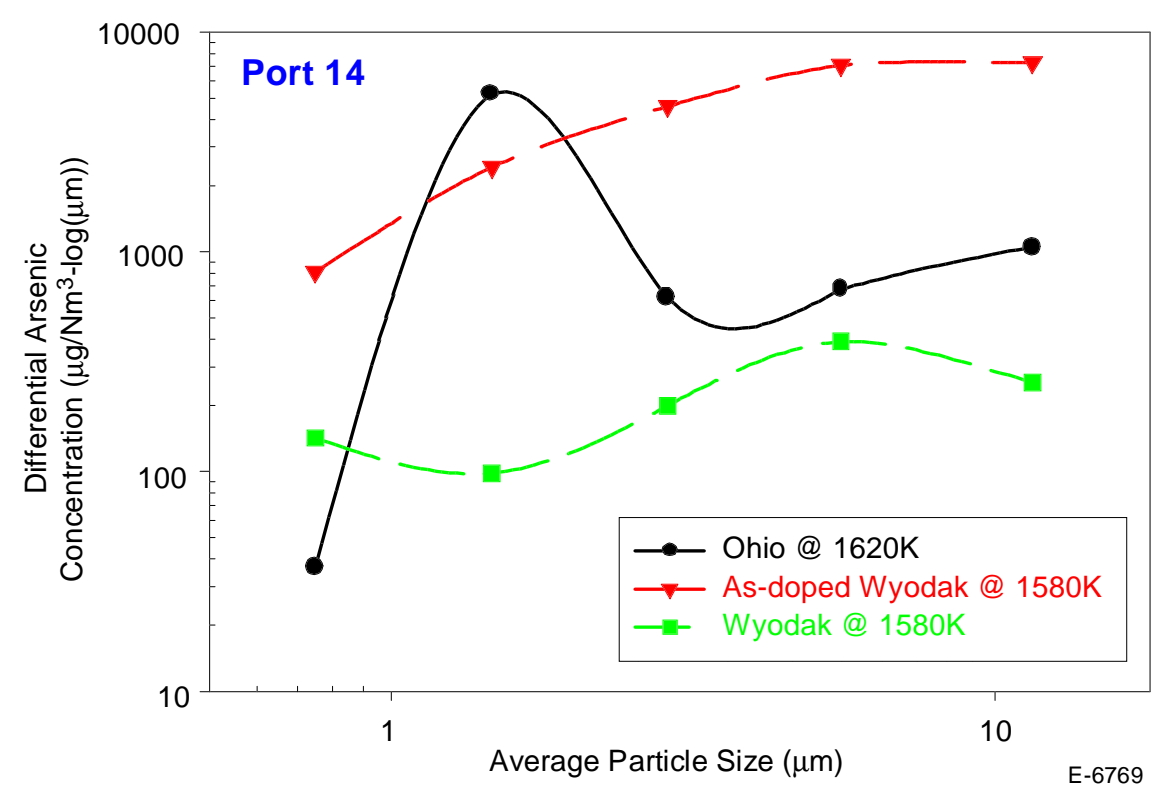

Figure 3-27. Comparison of arsenic differential distributions when adjusting the arsenic-tocalcium ratio of the Wyodak coal with combustion near the Ohio maximum combustion temperature.

does not resemble either of the other two distributions. Most likely, the increased combustion temperature is increasing the availability of active iron surface sites (see Figure 3-10). Unlike the Ohio coal, the Wyodak coal has a low sulfur content. As will be postulated below, the sulfur content affects the availability of iron cation surface sites for reaction with trace elements. The reaction of arsenic with Fe will change the shape of both the undoped and doped Wyodak arsenic distribution curves at the elevated combustion temperature conditions. To gain some perspective on this hypothesis, Figure 3-28 shows the same information as Figure 3-27 but with the addition of the Kentucky baseline arsenic differential distribution curve. Even though the As-to-Ca ratio of the doped Wyodak coal exceeds the Kentucky As-to-Ca ratio, the doped Wyodak distribution has a shape that is more like the Kentucky coal than the other coals.

In another set of experiments, pulverized lime was blended into the Ohio coal in the entrance to the burner. The amount of lime added decreased the As-to-Ca ratio to match the Asto-Ca ratio of the Wyodak coal. Samples were collected at the Ohio maximum combustion temperature and at a depressed temperature similar to the Wyodak maximum combustion temperature (by adding $\mathrm{CO}_{2}$ to the inlet air).

Figure 3-29 shows a comparison of the differential arsenic distribution at the Ohio baseline combustion conditions with Ca-doped Ohio coal at the Ohio combustion temperature and with an undoped Wyodak coal at a similar elevated temperature. The Ca-doped Ohio coal arsenic distribution is more similar to the Wyodak distribution (elevated by $\mathrm{O}_{2}$ enrichment of the combustion air) compared to the undoped Ohio distribution. The cross correlation between the absolute concentration values on each relevant impactor stage are $\mathrm{R}^{2}=0.24$ for the Ca-doped Ohio As distribution versus the Wyodak As distribution and $\mathrm{R}^{2}<0$ for the Ca-doped Ohio As 


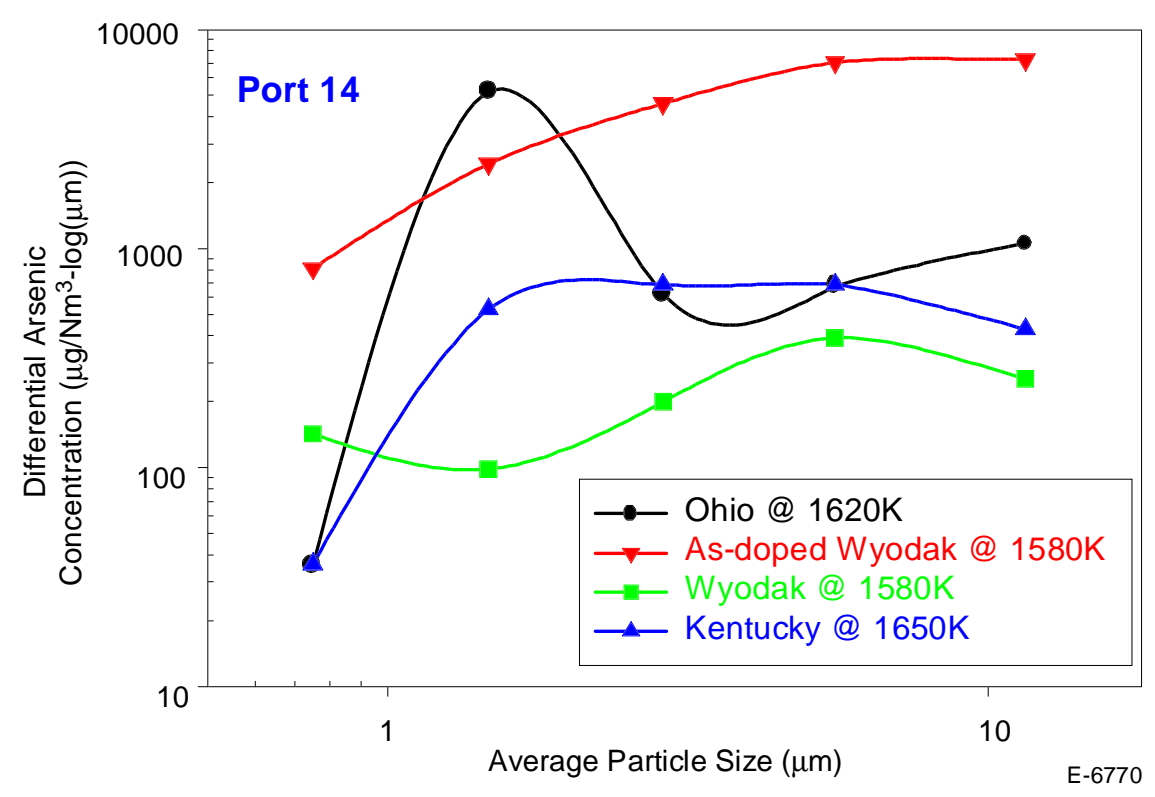

Figure 3-28. Comparison of arsenic differential distributions when adjusting the arsenic-tocalcium ratio of the Wyodak coal to the Ohio and Kentucky distributions with combustion near the Ohio maximum combustion temperature.

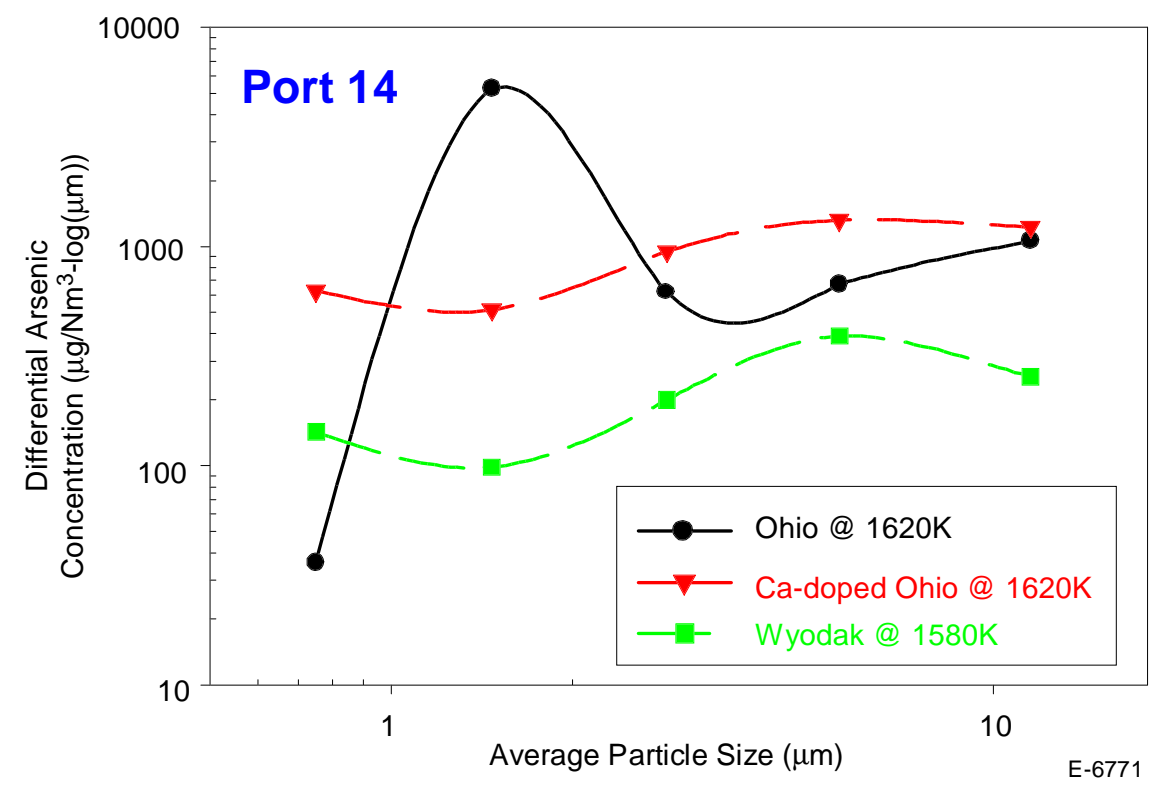

Figure 3-29. Comparison of arsenic differential distributions when adjusting the arsenic-tocalcium ratio of the Ohio with combustion at the Ohio maximum combustion temperature. 
distribution versus the undoped Ohio As distribution. The cross correlation between the differential distributions are $\mathrm{R}^{2}=0.84$ for the $\mathrm{Ca}$-doped Ohio As distribution versus the Wyodak As distribution and $\mathrm{R}^{2}<0$ for the Ca-doped Ohio As distribution versus the undoped Ohio As distribution. Figure 3-30 shows a comparison of the differential arsenic distribution at the Ohio baseline combustion conditions with Ca-doped Ohio coal at the Wyodak combustion temperature and with an undoped Wyodak coal at its natural combustion temperature. All three distribution curves are similar in shape so no useful information is gained.

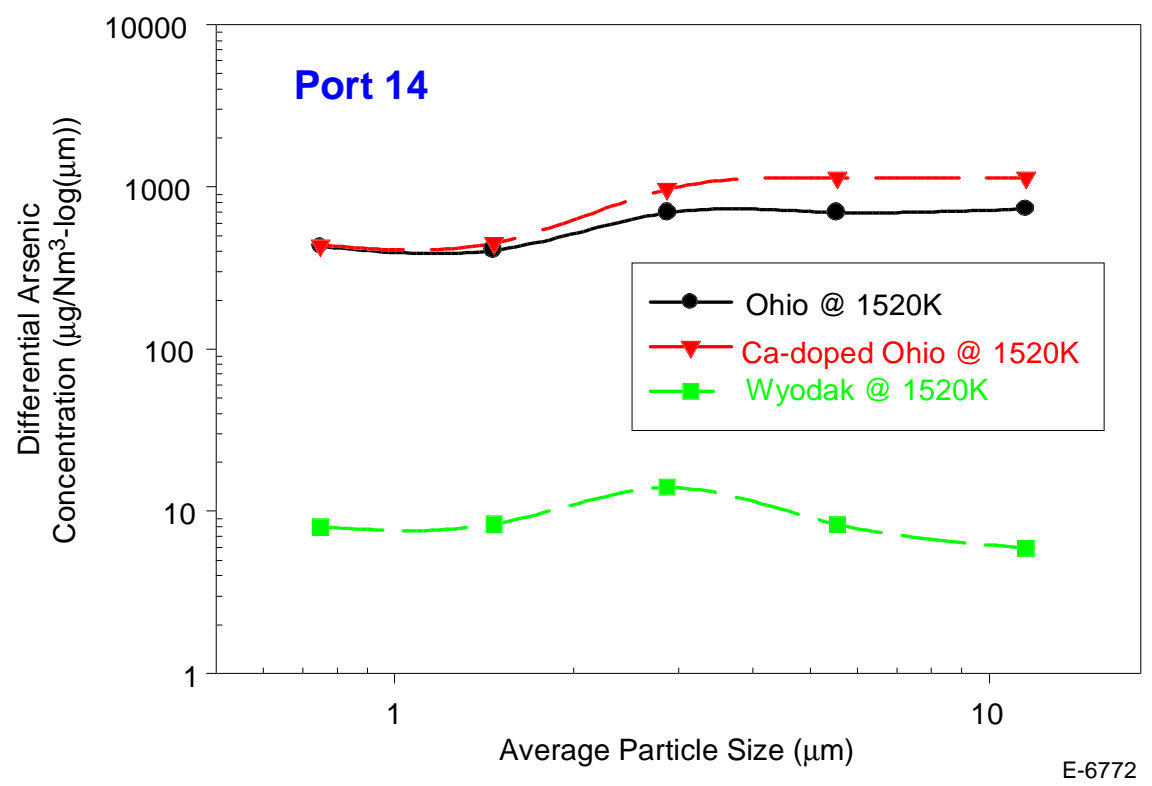

Figure 3-30. Comparison of arsenic differential distributions when adjusting the arsenic-tocalcium ratio of the Ohio with combustion at the Wyodak maximum combustion temperature.

Useful information can be obtained by comparing the arsenic supermicron mass concentrations in the doped and undoped Ohio fly ash samples. This information is shown in Table 3-10 at two maximum combustion temperatures (with and without $\mathrm{CO}_{2}$ doping of the combustion air). At both temperatures, there is an increase in arsenic recovery in the supermicron particles (where $83+\mathrm{wt} \%$ of the arsenic collected resides). Table 3-10 also provides information on the impact of combustion temperature upon arsenic recovery. The arsenic recovery is greater at the higher combustion temperature at the same As-to-Ca ratio. This result supports the hypothesis that the net impact of combustion temperature is the affect on the volatility of the cations (e.g., calcium and iron) not on the volatility of the trace element.

To summarize the results of this set of experiments, by manipulating the As-to-Ca ratio and the maximum combustion temperature, the partitioning behavior of arsenic can be manipulated in directionally predictable ways. Namely, the partitioning behavior of arsenic during Wyodak combustion, which appears to be controlled by reaction with active calcium surface sites was changed to match the partitioning behavior of arsenic during Ohio combustion (where partitioning does not appear to be controlled by reaction due to a lack of available cation surface sites) by adding arsenic to the combustion environment so that the As-to-Ca ratio 
Table 3-10. Comparison of Arsenic Mass Concentration Values from Ohio Coal Calcium Doping Experiments

\begin{tabular}{|c|c|c|c|c|}
\hline $\begin{array}{c}\text { Particle } \\
\text { Diameter } \\
(\mu \mathrm{m})\end{array}$ & $\begin{array}{c}\text { Undoped Ohio } \\
\text { Arsenic at 1620 K } \\
\left(\mu \mathrm{g} / \mathrm{Nm}^{3}\right)\end{array}$ & $\begin{array}{c}\text { Calcium-Doped } \\
\text { Ohio Arsenic at } \\
1620 \mathrm{~K}\left(\mu \mathrm{g} / \mathrm{Nm}^{3}\right)\end{array}$ & $\begin{array}{c}\text { Undoped Ohio } \\
\text { Arsenic at 1520 K } \\
\left(\mu \mathrm{g} / \mathrm{Nm}^{3}\right)\end{array}$ & $\begin{array}{c}\text { Calcium-Doped } \\
\text { Ohio Arsenic at } \\
1520 \mathrm{~K}\left(\mu \mathrm{g} / \mathrm{Nm}^{3}\right)\end{array}$ \\
\hline \hline 1.96 & 176 & 269 & 197 & 275 \\
\hline 3.77 & 194 & 381 & 201 & 329 \\
\hline 7.33 & 348 & 405 & 241 & 377 \\
\hline Sum & 718 & 1055 & 639 & 981 \\
\hline
\end{tabular}

matched the Ohio As-to-Ca ratio. Then the partitioning behavior of arsenic during Ohio combustion was changed to match the partitioning behavior of arsenic during Wyodak combustion by adding calcium to the Ohio combustion environment and reducing the combustion temperature through $\mathrm{CO}_{2}$ addition. Further, the partitioning behavior of arsenic during Wyodak combustion was changed to match the partitioning behavior of arsenic during Kentucky combustion (where partitioning appears to be controlled by reaction with both iron and calcium surface sites) by making the As-to-Ca ratio similar to the Kentucky As-to-Ca ratio (which is similar to the Ohio As-to-Ca ratio) and making the maximum combustion temperature similar to the Kentucky combustion temperature through $\mathrm{O}_{2}$ addition.

In the Port 14 Kentucky baseline screening experimental results, the As distribution appears to follow the iron distribution more closely than the calcium distribution (see Figure 3-13) but not as definitively as the selenium distributions reviewed in the Quarterly report for January through March 2000. The one main difference between the Kentucky and Ohio coals is the sulfur content. Could sulfur be preferentially competing for available active cation sites in the Ohio experiments yet be insufficient to exhaust these sites in the Kentucky experiments? To examine the effect of sulfation on arsenic partitioning, the main combustion air was doped with $\mathrm{SO}_{2}$ during the combustion of the Kentucky coal so that the sulfur in the combustion environment matched the sulfur content of the Ohio coal. Table 3-11 shows a comparison of the As supermicron size mass concentration distribution for the $\mathrm{SO}_{2}$-doped Kentucky experiment versus the baseline Kentucky experiment. The As concentration recovered is significantly lower for the $\mathrm{SO}_{2}$-doped experiment indicating that less arsenic is partitioning to supermicron fly ash particles when additional $\mathrm{SO}_{2}$ is present.

It was postulated that arsenic reactivity with calcium and iron were of similar magnitude. Two sets of experiments were performed with the Pittsburgh seam coal to investigate whether arsenic partitioning has a preference for reaction with calcium or with iron. The differential distributions of calcium and iron in Figure 3-13 are too similar to determine whether arsenic is preferentially reacting with one or the other of these cations. In the first set of experiments the calcium content of the feedstock was increased by $50 \mathrm{~mol} \%$ by pulverized lime addition. In the second set of experiments the iron content of the feedstock was increased by the same molar amount as in the calcium tests (this is a much small \% increase since there is more iron in the Pittsburgh coal than calcium). The results are summarized in Table 3-12. Doping with either calcium or iron increased the arsenic recovery in the supermicron fly ash particles. There is no definitive difference between the arsenic recoveries for the two dopants. This is in sharp contrast 
Table 3-11. Comparison of Arsenic Mass Concentration Values from Kentucky Coal $\mathrm{SO}_{2}$ Doping Experiments

\begin{tabular}{|c|c|c|}
\hline $\begin{array}{c}\text { Particle Diameter } \\
(\mu \mathrm{m})\end{array}$ & $\begin{array}{c}\text { Baseline Experiment } \\
\text { Arsenic }\left(\mu \mathrm{g} / \mathrm{Nm}^{3}\right)\end{array}$ & $\begin{array}{c}\mathrm{SO}_{2} \text {-Doped } \\
\text { Experiment } \\
\text { Arsenic }\left(\mu \mathrm{g} / \mathrm{Nm}^{3}\right)\end{array}$ \\
\hline \hline 0.973 & 161 & 74 \\
\hline 1.96 & 194 & 90 \\
\hline 3.77 & 198 & 81 \\
\hline 7.33 & 142 & 78 \\
\hline
\end{tabular}

Table 3-12. A Comparison of Absolute Arsenic Concentration Values from Pittsburgh Seam Coal Cation Doping Experiments

\begin{tabular}{|c|c|c|c|c|c|c|}
\hline Size & $\begin{array}{c}\text { Port } 4 \\
\text { Baseline }\end{array}$ & Ca Doped & $\begin{array}{l}\text { As (ppmw) } \\
\text { Fe Doped }\end{array}$ & $\begin{array}{c}\text { Port } 14 \\
\text { Baseline }\end{array}$ & Ca Doped & $\begin{array}{l}\text { As (ppmw) } \\
\text { Fe Doped }\end{array}$ \\
\hline 0.535 & 304 & 1144 & 935 & 233 & 795 & 1138 \\
\hline 0.973 & 113 & 478 & 350 & 1787* & 306 & 794 \\
\hline 1.96 & 103 & 231 & 199 & 36 & 233 & 273 \\
\hline 3.77 & 96 & 192 & 119 & 15 & 185 & 127 \\
\hline 7.33 & 16 & 61 & 47 & 13 & 46 & 91 \\
\hline
\end{tabular}

* This data point is considered to be an outlier.

to the selenium results reported in the quarterly report for January through March 2000, where the iron dopant showed a significant increase in selenium recovery compared to the calcium dopant. From these results we conclude that arsenic has similar reactivity with active iron surface sites compared to active calcium surface sites.

Environmental Impact of Arsenic from Fly Ash Surfaces. Based on the current study results, calcium arsenate compounds are likely to make up the majority of arsenic compounds that form due to arsenic partitioning in coals with low As/Ca ratios and high sulfur contents. Both calcium and iron arsenate compounds are likely to make up the majority of arsenic compounds for coals with high As/Ca ratios and low sulfur contents. For coals with high As/Ca ratios and high sulfur contents, only a small portion of the As will complex with surface cation sites while the majority of the As will be present on/within the particle in other forms.

In the current study, selected impactor plates were subjected to a sequential leaching protocol adapted from EPA method 1310 (TCLP) for five of the study coals. Arsenic leaching results for the supermicron region post-combustion zone samples are summarized in Table 3-13. Calcium arsenate is slightly soluble in neutral aqueous solutions and is soluble in acidic solutions.[42,43] Iron arsenate has similar solubility characteristics to calcium arsenate - slightly soluble in neutral aqueous solutions and greater solubility in acidic solutions [44]. To further complicate the situation, arsenic trioxide $\left(\mathrm{AsO}_{3}\right)$ also has a low solubility in neutral aqueous solutions and is soluble in acidic solutions [42]. Of the species that are postulated as possibly present, only arsenic pentoxide $\left(\mathrm{AsO}_{5}\right)$ has different solubility characteristics. $\mathrm{AsO}_{5}$ is very soluble in neutral aqueous solutions $[42,43]$. 
Table 3-13. Summary of Arsenic Solubility in Fly Ash from Baseline Screening Experiments

\begin{tabular}{|l|c|c|c|c|}
\hline \multicolumn{1}{|c|}{ Coal/Sample Location } & $\begin{array}{c}\text { Submicron Size } \\
\% \text { Soluble } \\
\text { at pH 4.9 }\end{array}$ & $\begin{array}{c}\text { Submicron Size } \\
\% \text { Soluble } \\
\text { at pH 2.9 }\end{array}$ & $\begin{array}{c}\text { Supermicron Size } \\
\% \text { Soluble } \\
\text { at pH 4.9 }\end{array}$ & $\begin{array}{c}\text { Supermicron } \\
\text { Size \% Soluble } \\
\text { at pH 2.9 }\end{array}$ \\
\hline \hline Pittsburgh / Port 4 & $45 \%$ & $66 \%$ & $42 \%$ & $67 \%$ \\
\hline Pittsburgh / Port 14 & $20 \%$ & $41 \%$ & $28 \%$ & $37 \%$ \\
\hline Ohio / Port 4 & $52 \%$ & $92 \%$ & $21 \%$ & $52 \%$ \\
\hline Ohio / Port 14 & $39 \%$ & $64 \%$ & $49 \%$ & $84 \%$ \\
\hline Kentucky / Port 4 & $16 \%$ & $57 \%$ & $18 \%$ & $60 \%$ \\
\hline Kentucky / Port 14 & $38 \%$ & $63 \%$ & $17 \%$ & $41 \%$ \\
\hline Wyodak / Port 4 & $30 \%$ & $59 \%$ & $13 \%$ & $51 \%$ \\
\hline Wyodak / Port 14 & $33 \%$ & $49 \%$ & $18 \%$ & $42 \%$ \\
\hline North Dakota / Port 4 & $31 \%$ & $49 \%$ & $17 \%$ & $59 \%$ \\
\hline North Dakota / Port 14 & $47 \%$ & $71 \%$ & $10 \%$ & $61 \%$ \\
\hline
\end{tabular}

For all of the coals except Ohio, the results are consistent with the solubility of calcium arsenate, iron arsenate, or $\mathrm{As}_{2} \mathrm{O}_{3}$. Arsenic in the Ohio supermicron fly ash is more soluble than arsenic in the fly ash from the other coals. This is most likely due to the oxidation of some of the $\mathrm{As}_{2} \mathrm{O}_{3}$ predicted to be present on Ohio fly ash surfaces to $\mathrm{As}_{2} \mathrm{O}_{5}$. There are no appreciable differences between the arsenic solubility results for submicron particles compared to supermicron particles. This is not surprising since all of the arsenic forms of occurrence expected to be present have similar solubility characteristics.

The $\mathrm{pH} 4.9$ leachability data helps assess the potential for arsenic contained in submicron and supermicron particles to migrate into the water supply after ground deposition downwind of the combustor. In every case examined, arsenic is partially soluble and some arsenic is expected to leach out of ash particles exposed to aqueous environments (e.g., rainfall). If the dominant arsenic partitioning mechanism is physical absorption of $\mathrm{As}_{2} \mathrm{O}_{3}$ (e.g., Ohio coal), oxidation of $\mathrm{As}_{2} \mathrm{O}_{3}$ to $\mathrm{As}_{2} \mathrm{O}_{5}$ may result in increased arsenic leachability.

The $\mathrm{pH} 2.8$ leachability data helps assess how arsenic might leach from an ash disposal pile/landfill. As water migrates through the ash pile it can become much more acidic than the original water source. All of the arsenic forms of occurrence are partially soluble and are likely to leach from the fly ash. If the dominant arsenic partitioning mechanism is physical absorption of $\mathrm{As}_{2} \mathrm{O}_{3}$ (e.g., Ohio coal), oxidation of $\mathrm{As}_{2} \mathrm{O}_{3}$ to $\mathrm{As}_{2} \mathrm{O}_{5}$ may result in increased arsenic leachability.

Querol and coworkers [45] reported arsenic leachability results for four subbituminous coals and associated fly ash from the Teruel mining district. They found arsenic in both the original coal and combusted fly ash to be only slightly leachable in water, a pH7 fluid, and a pH5 fluid but highly soluble in a concentrated nitric acid solution. They interpreted these results as implying that the arsenic was present as sulfide-bound material in both the coal and the fly ash since this explanation was consistent with previously reported forms of occurrence of arsenic in coal $[38,43,46]$. However, no attempts were made to ascertain the exact chemical composition of the leached arsenic material. The interpretation by Querol and coworkers of their leaching 
results for the fly ash samples may need to be reexamined in light of the current understanding of arsenic partitioning onto fly ash surfaces. Their leaching results are consistent with a calcium and/or iron arsenate-controlled partitioning theory as well as with an $\mathrm{As}_{2} \mathrm{O}_{3}$ condensationcontrolled partitioning theory.

Silberman and Harris [47] used a pH 5 citric acid solution. They selected this leaching acid because citric acid has been shown to dissolve large amount of iron and aluminum compounds from fly ash surfaces. Using this method, they report that most surface deposited arsenic on fly ash surfaces is in the As $(+\mathrm{V})$ form rather than the As(+III) form. This result is consistent with the findings of Sato [48], Warren and Dudas [48], and Wadge and Hutton [49] but contradictory to leaching studies performed by others $[50,51]$ which conclude that the majority of arsenic present on fly ash surfaces may be in the As(+III) form and is inconsistent with the partitioning theory presented above. Jones [48] suggests that oxidation of As(+III) to $\mathrm{As}(+\mathrm{V})$ during the leaching test itself may be responsible for the inconsistency in results. This suggestion is supported by batch extraction experiments performed by Turner [50].

Temporal Resolution of Arsenic Partitioning Processes. The analysis above has shown that arsenic partitioning to fly ash surfaces may be dominated by surface reaction with calcium and/or iron active cation sites. Further insight can be gained into arsenic partitioning mechanisms by examining size-segregated samples from Port 4 and comparing these results to those obtained from Port 14.

Insight into the timing of arsenic volatilization can be gained by comparing the mass fraction of arsenic still in the vapor phase at the combustion zone sampling location (Port 4) for the baseline screening experiments to the mass fraction of arsenic still in the vapor phase at the post-combustion zone sampling location (Port 14). The mass fraction of arsenic still in the vapor phase at both sampling locations for the six study coals was summarized in Table 3-6. The mass fraction of vapor-phase arsenic is lower in the combustion zone sample for all of the study coals except the Wyodak and Pittsburgh coals. This indicates that significant arsenic volatilization appears to continue after Port 4 for four of the study coals.

The timing of partitioning from the vapor phase back to particle surfaces can be evaluated by comparing the enrichment factors of the submicron particles. Calculating a differential enrichment factor by subtracting the combustion zone enrichment factor from the postcombustion zone enrichment factor provides insight into when partitioning is occurring. Arsenic enrichment factors at Ports 4 and 14 along with differential enrichment factors were shown in Table 3-7 for all six study coals.

A positive arsenic differential enrichment factor is found for Illinois, Wyodak, and North Dakota submicron particles. This suggests that volatilized arsenic continue to partition to submicron particle surfaces after Port 4. By contrast the negative differential enrichment factors shown for the Pittsburgh, Ohio, and Kentucky submicron particles suggest that the majority of the arsenic associated with submicron particle for these coals is present prior to Port 4 . Note that these results are consistent with the mass fraction data in Table 3-6. For coals with a positive differential enrichment factor, there is an increase in the arsenic mass fraction in the submicron 
regime while coals with a negative differential enrichment factor show a decrease in arsenic mass fraction in the submicron regime.

Further insight into the timing of vapor-to-solid phase partitioning can be obtained using particle size dependence models based on transport theory. The particle size dependence of arsenic associated with supermicron fly ash particles for the six study coals at the Port 4 sampling location is shown in Figure 3-31. The results show that the Pittsburgh, Ohio, and North Dakota arsenic distributions follow a near $1 / \mathrm{D}_{\mathrm{p}}$ dependence. This indicates that the rate of partitioning of volatile arsenic to supermicron particles is dominated by exterior surface reaction and that a significant portion of this process occurs prior to Port 4 for these coals. The Kentucky arsenic distributions follow a near $1 / \mathrm{D}_{\mathrm{p}}{ }^{2}$ dependence that indicates that the reactivity of arsenic with fly ash surface species is sufficiently rapid that the partitioning is limited by gas film transfer prior to Port 4. The Illinois and Wyodak arsenic distributions do not follow any dependence implying that partitioning may be occurring later for these coals (since at Port 14 a $1 / \mathrm{D}_{\mathrm{p}}$ dependence is observed for both coals).

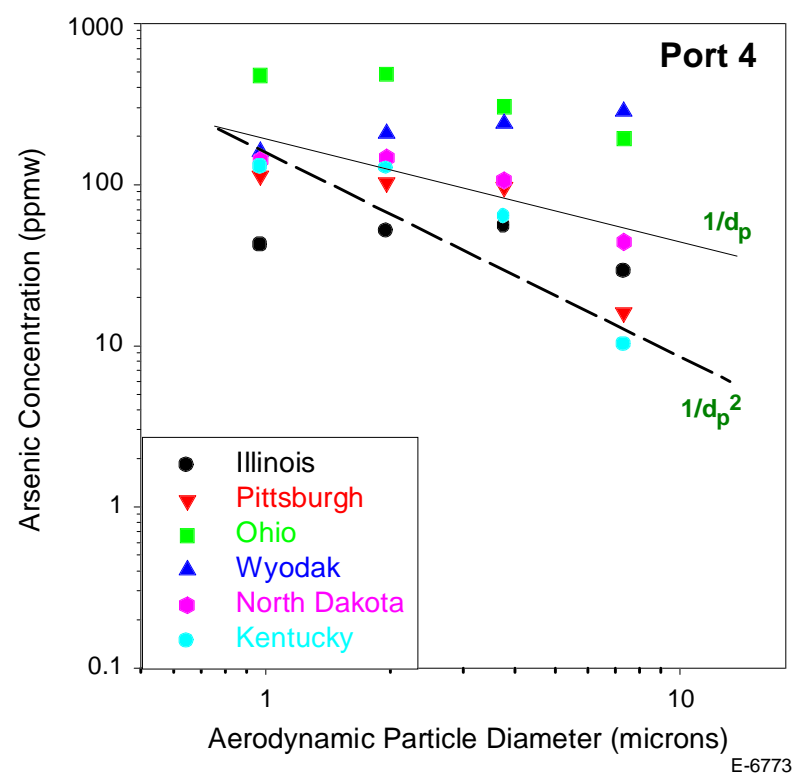

Figure 3-31. Particle size dependence of arsenic in supermicron fly ash particles for all six study coals sampled at Port 4.

Note that the Ohio arsenic distribution follows a $1 / \mathrm{D}_{\mathrm{p}}$ dependence at Port 4 but not at Port 14 . The results imply that active cation sites are available during or immediately after combustion but that additional sites are no longer available as the particles and flue gas travel through the combustor. This same scenario was observed for the Ohio selenium distribution.

The size-segregated concentration of arsenic in submicron particles are shown in Figure 3-32 for the six study coals at the Port 4 sampling location. There appears to be a decrease in concentration with particle size for the Illinois and Kentucky coals. These results imply that the rate of partitioning of arsenic to the particle surface is controlled by a transport 


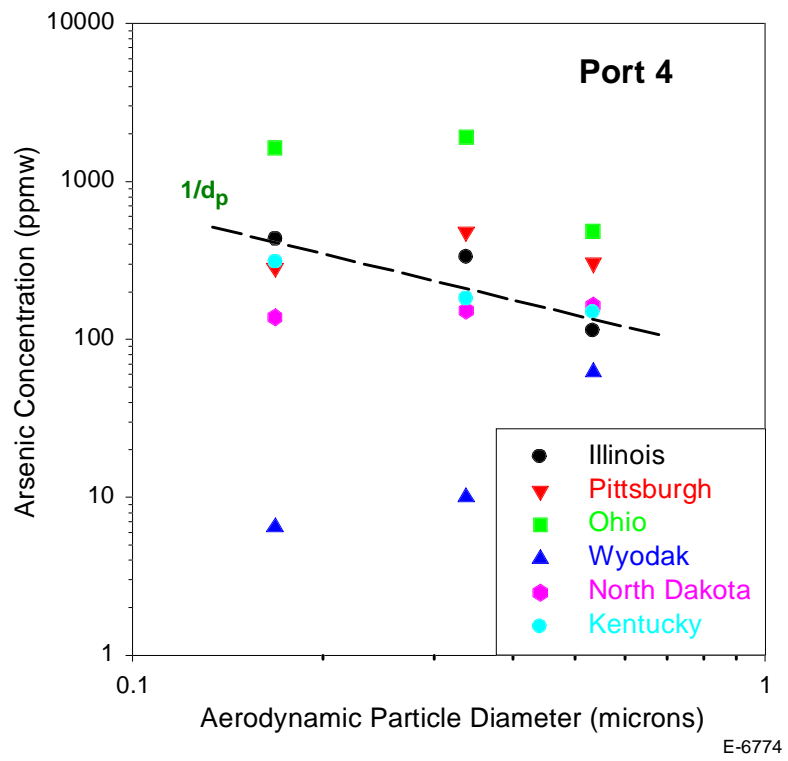

Figure 3-32. Particle size dependence of arsenic in submicron fly ash particles for all six study coals sampled at Port 4.

process for the Illinois and Kentucky coals. No particle size dependence is apparent for the Pittsburgh, Ohio, Wyodak, or North Dakota coals.

Timing issues and any differences in As-Fe or As-Ca reactions as a dominant partitioning mechanism between Ports 4 and 14 can be evaluated by comparing the total ash size distribution and the size distributions of iron, calcium, and arsenic. The differential mass concentration distributions of arsenic, calcium, iron, and the total ash from full impactor sets for all six coals under baseline combustion conditions at the Port 4 sampling location are shown in Figure 3-33. The corresponding correlations of arsenic to calcium and iron using both evaluation methods for both submicron and supermicron fly ash sampled at Port 4 is shown in Table 3-14 for all six study coals.

The differential distribution curves in Figure 3-33 and the cross correlations listed in Table 3-14 can be compared to the arsenic distributions and correlations at Port 14 (Figure 3-13, Table 3-8). The correlation of arsenic in the Illinois fly ash distributions in both submicron and supermicron regions are different at Ports 4 and 14. The submicron As distribution at Port 4 does not appear to follow either $\mathrm{Ca}$ or Fe while at Port 14, the As distribution follows the iron and calcium submicron distributions (which are too similar to separate). The fragmentation region supermicron arsenic distribution at Port 14 appears to follow the Fe distribution while at Port 4 no correlation is apparent. These results imply that active cation surface sites appear to develop after Port 4 and that arsenic then partitions to these sites in the post-combustion zone.

Similar to selenium, the Ohio arsenic distribution appears to correlate with calcium and/or iron at Port 4 in all three particle regions. By contrast, the Port 14 arsenic distributions do not appear to correlate with either cation distribution (except possibly in the bulk fly ash). This 


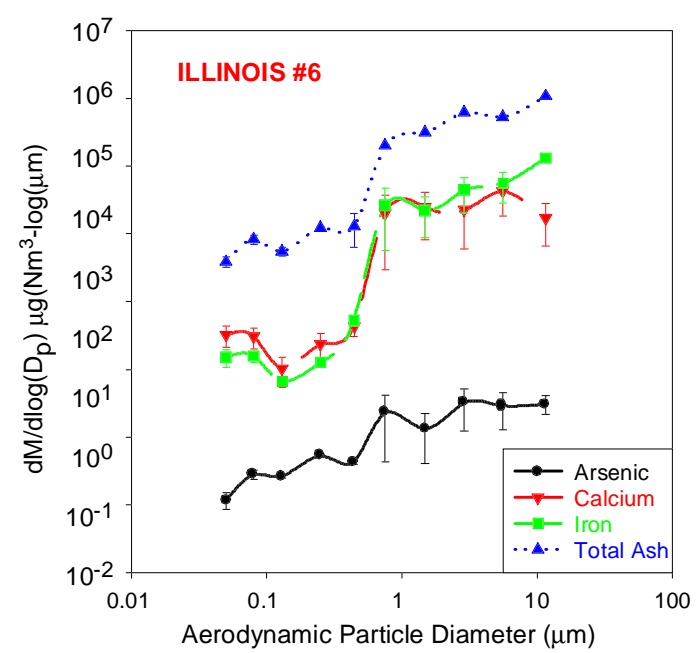

(a)

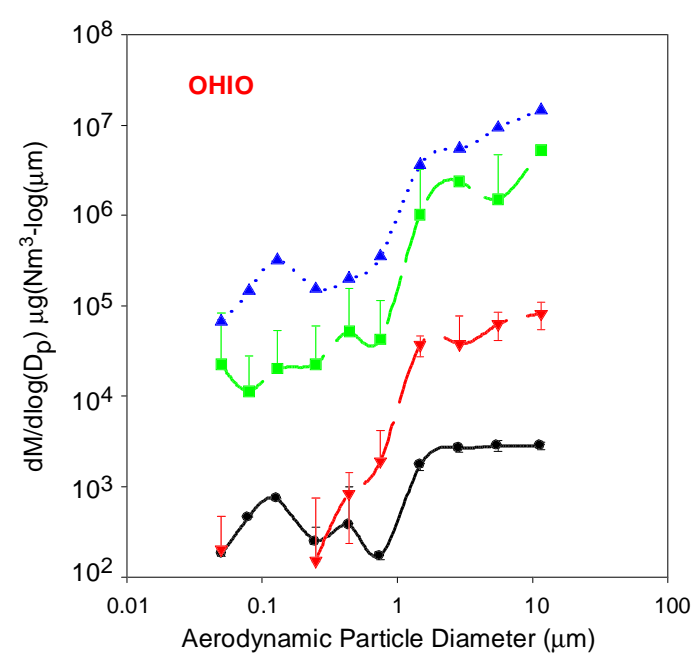

(c)

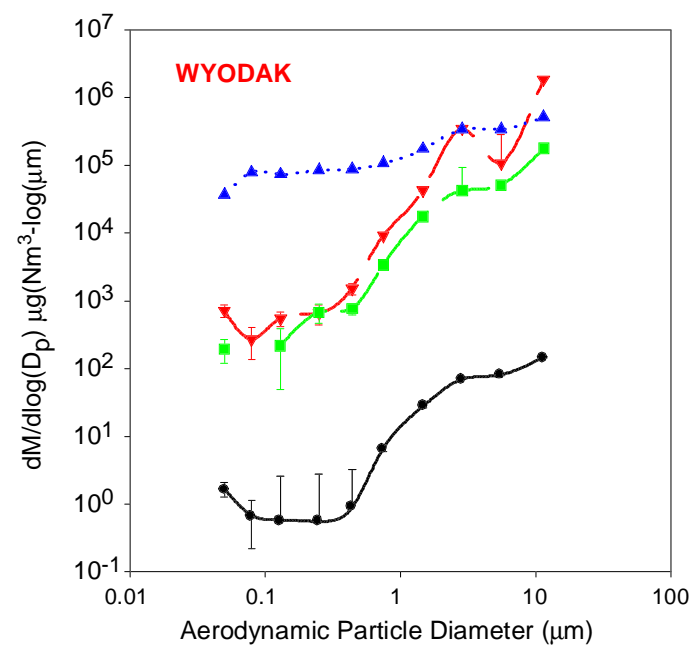

(e)

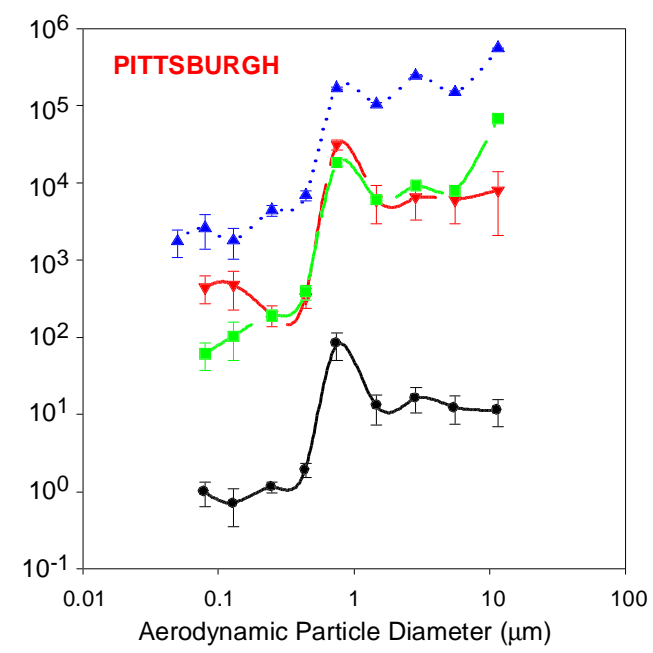

(b)

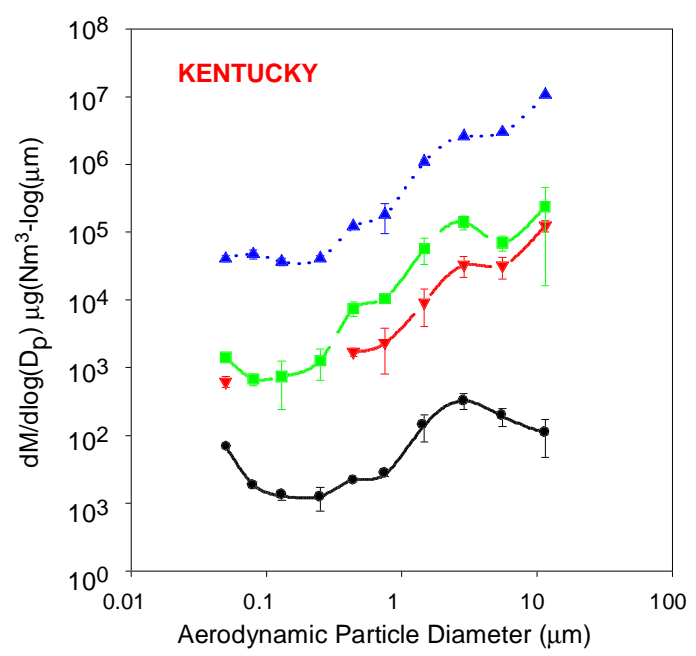

(d)

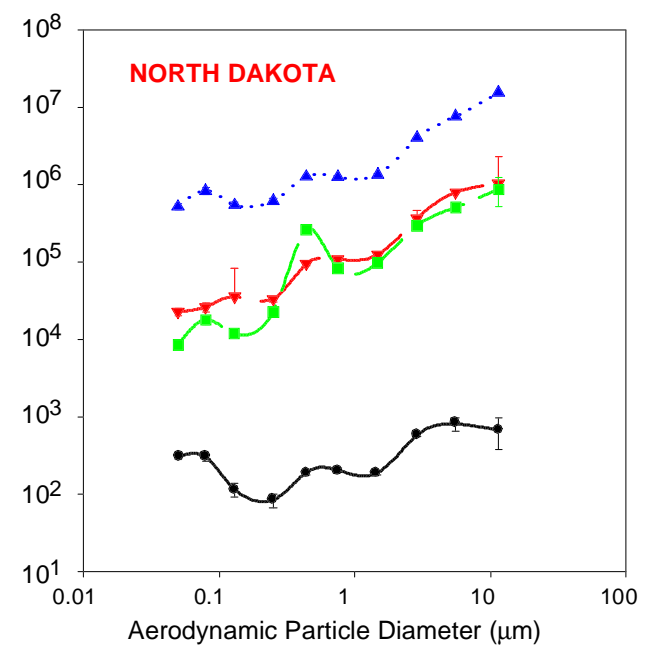

(f)

Figure 3-33. Differential mass distributions of arsenic, calcium, iron, and total ash for the six study coals sampled at Port 4. 
Table 3-14. Correlation Coefficients for Arsenic Versus Calcium and Iron in Fly Ash Particles from the Six Study Coals Sampled at Port 14

\begin{tabular}{|c|c|c|c|c|c|c|}
\hline Coal & $\begin{array}{c}\text { Absolute } \\
\text { Concentrations }\end{array}$ & $\begin{array}{c}\text { Differential } \\
\text { Distributions }\end{array}$ & $\begin{array}{l}\text { Overall Absolute } \\
\text { Concentrations }\end{array}$ & $\begin{array}{c}\text { Overall } \\
\text { Differential } \\
\text { Distributions } \\
\end{array}$ & $\begin{array}{c}\text { Fragmentation } \\
\text { Region Differential } \\
\text { Distributions } \\
\end{array}$ & $\begin{array}{c}\text { Bulk Fly Ash } \\
\text { Region Differential } \\
\text { Distributions }\end{array}$ \\
\hline Illinois: $\quad$ As vs $\mathrm{Ca}$ & 告 & $\sim 0$ & 0.45 & 0.28 & $\sim 0$ & $\sim 0$ \\
\hline As vs Fe & $\sim 0$ & $\sim 0$ & 0.21 & 0.78 & 0.76 & $\sim 0$ \\
\hline Pittsburgh: As vs Ca & 0.28 & 0.88 & 1.0 & 0.93 & 1.0 & 0.57 \\
\hline As vs Fe & 0.89 & 1.0 & 0.99 & 0.84 & 0.99 & 0.93 \\
\hline As vs $\mathrm{Ca}$ & $\sim 0$ & 0.99 & $\sim 0$ & 0.85 & 0.93 & 0.94 \\
\hline As vs Fe & $\sim 0$ & 0.97 & $\begin{array}{ll}\sim 0 \\
\sim\end{array}$ & 0.96 & 0.94 & 0.40 \\
\hline Kentucky: As vs Ca & na & na & $\sim 0$ & 0.67 & 0.96 & $\sim 0$ \\
\hline As vs Fe & $\sim 0$ & 1.0 & 0.24 & 0.98 & 1.0 & $\sim 0$ \\
\hline Wyodak: $\quad$ As vs $\mathrm{Ca}$ & $\sim 0$ & 1.0 & 0.97 & 0.96 & 0.96 & 1.0 \\
\hline As vs Fe & $\sim 0$ & $\sim 0$ & 0.99 & 0.98 & 0.98 & 1.0 \\
\hline N. Dakota: As vs Ca & $\sim 0$ & 1.0 & 0.36 & 0.95 & 0.99 & 0.84 \\
\hline As vs Fe & $\sim 0$ & 0.99 & 0.30 & 0.98 & 0.98 & 0.98 \\
\hline
\end{tabular}


suggests that arsenic may initially be reacting with available active surface sites immediately after combustion and then is displaced by more thermodynamically favorable anions (most probably sulfur).

Summary of Arsenic Partitioning. A comprehensive study has been performed to investigate the partitioning of arsenic during pulverized coal combustion. The primary partitioning mechanisms for arsenic during the combustion of the six coals investigated as predicted by this study are summarized in Figure 3-34 and Table 3-15.

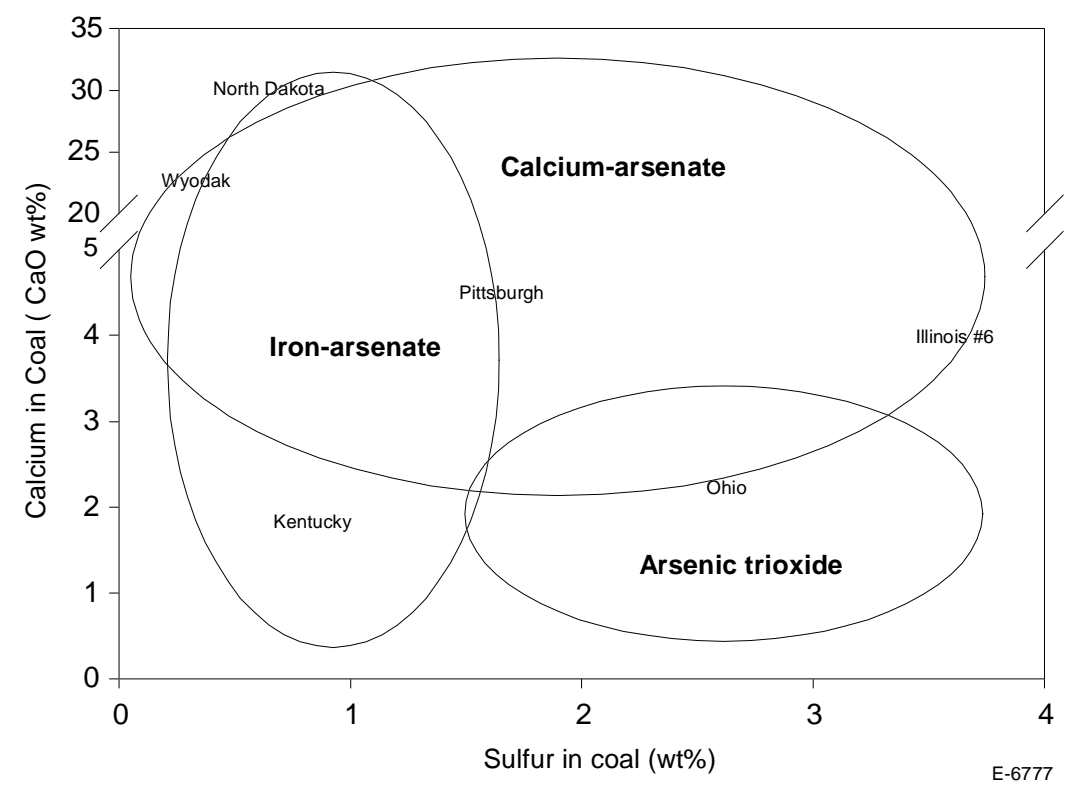

Figure 3-34. Summary of arsenic partitioning mechanisms.

The partitioning of arsenic is governed primarily by the extent of arsenic volatilization during combustion. The majority of the arsenic for all six coals is attributed to pyrite/sulfide or mono-sulfide fractions although four of the coals have silicate fractions of 5 to $15 \%$.

Organically-associated arsenic was only detected in the Wyodak coal. The large fraction of arsenic not contained in silicates is expected to volatilize during combustion. Volatilized arsenic will heterogeneously transform to both submicron and supermicron particles primarily by reaction with active cation sites. Only a small fraction (less than $5 \mathrm{wt} \%$ of the total arsenic at Port 14) will remain in the vapor phase and exit the boiler.

The partitioning of arsenic to fly ash surfaces is dependent on the availability of active cation sites. For coals with relatively low As/Ca ratios, arsenic is expected to react with calcium surface sites to form calcium arsenate complexes. These arsenate complexes are partially soluble and some of the arsenic in this form is expected to leach into groundwater. If the As/Ca ratio is relatively high and the sulfur content is low, arsenic will most likely react with both calcium and iron surface sites to form iron arsenates and calcium arsenates. These complexes are partially 
Table 3-15. Primary Partitioning Mechanisms for Arsenic During the Combustion of the Six Study Coals

\begin{tabular}{|c|c|c|}
\hline Coal & Submicron Region & Supermicron Region \\
\hline Pittsburgh & $\begin{array}{l}\text { Partitioning occurs and is essentially completed in the } \\
\text { combustion zone }(<2.2 \text { seconds residence time from the burner). } \\
\text { Reaction with active calcium surface sites form calcium } \\
\text { arsenate-type compounds. Sulfur partially inhibits reaction of } \\
\text { arsenic with active iron surface sites. }\end{array}$ & $\begin{array}{l}\text { Partitioning to fly ash surfaces occurs in the combustion zone. } \\
\text { Reaction with active calcium surface sites form calcium } \\
\text { arsenate-type compounds. Sulfur partially inhibits reaction of } \\
\text { arsenic with active iron surface sites. }\end{array}$ \\
\hline Illinois & $\begin{array}{l}\text { Partitioning begins in the combustion zone and continues in the } \\
\text { post-combustion zone ( }>2.2 \text { seconds residence time). Reaction } \\
\text { with active calcium surface sites form calcium arsenate-type } \\
\text { compounds. }\end{array}$ & $\begin{array}{l}\text { Partitioning to fly ash surfaces begins in the combustion zone. } \\
\text { Initial reaction with active iron surface sites. In the post- } \\
\text { combustion zone, sulfur displaces arsenic from iron surface sites } \\
\text { and the arsenic reacts with active calcium surface sites form } \\
\text { calcium arsenate-type compounds. }\end{array}$ \\
\hline Ohio & $\begin{array}{l}\text { Partitioning occurs and is essentially completed in the } \\
\text { combustion zone }(<3.2 \text { seconds residence time). High } \\
\text { sulfur/low calcium content results in a lack of available active } \\
\text { surface cation sites, } \mathrm{As}_{2} \mathrm{O}_{3} \text { partitions to particle surfaces. }\end{array}$ & $\begin{array}{l}\text { Partitioning begins in the combustion zone. High sulfur/low } \\
\text { calcium content results in a lack of available active surface } \\
\text { cation sites, } \mathrm{As}_{2} \mathrm{O}_{3} \text { partitions to particle surfaces. }\end{array}$ \\
\hline Kentucky & $\begin{array}{l}\text { Partitioning occurs and is essentially completed in the } \\
\text { combustion zone }(<2.9 \text { seconds residence time }) \text {. Active iron } \\
\text { surface sites are available due to the low sulfur content of the } \\
\text { coal. Reaction with active iron and calcium surface sites forms } \\
\text { iron and calcium arsenate-type compounds. }\end{array}$ & $\begin{array}{l}\text { Partitioning to fly ash surfaces occurs in the combustion zone. } \\
\text { Active iron surface sites are available due to the low sulfur } \\
\text { content of the coal. Reaction with active iron and calcium } \\
\text { surface sites iron and calcium arsenate-type compounds. }\end{array}$ \\
\hline Wyodak & $\begin{array}{l}\text { Partitioning begins in the combustion zone and continues in the } \\
\text { post-combustion zone ( }>6.6 \text { seconds residence time). Active } \\
\text { iron and calcium surface sites are available due to the low } \\
\text { sulfur/high calcium content of the coal. Reaction with active } \\
\text { iron and calcium surface sites forms iron and calcium arsenate- } \\
\text { type compounds. }\end{array}$ & $\begin{array}{l}\text { Partitioning to fly ash surfaces begins in the combustion zone. } \\
\text { Active iron and calcium surface sites are available due to the } \\
\text { low sulfur/high calcium content of the coal. Reaction with active } \\
\text { iron and calcium surface sites forms iron and calcium arsenate- } \\
\text { type compounds. }\end{array}$ \\
\hline $\begin{array}{l}\text { North } \\
\text { Dakota }\end{array}$ & $\begin{array}{l}\text { Partitioning begins in the combustion zone and continues in the } \\
\text { post-combustion zone }(>9.3 \text { seconds residence time). Active } \\
\text { iron and calcium surface sites are available due to the low } \\
\text { sulfur/high calcium content of the coal. Reaction with active } \\
\text { iron and calcium surface sites forms iron and calcium arsenate- } \\
\text { type compounds. }\end{array}$ & $\begin{array}{l}\text { Partitioning begins in the combustion zone. Active iron and } \\
\text { calcium surface sites are available due to the low sulfur/high } \\
\text { calcium content of the coal. Reaction with active iron and } \\
\text { calcium surface sites forms iron and calcium arsenate-type } \\
\text { compounds. }\end{array}$ \\
\hline
\end{tabular}


soluble and are likely to contribute arsenic to groundwater due to leaching. If the As/Ca ratio is relatively high and the sulfur content is moderate to high, cationic surface sites will not be available for arsenic partitioning. In these cases, most of the arsenic is expected to exit the furnace in the vapor phase or as fly ash surface-based $\mathrm{As}_{2} \mathrm{O}_{3}$ (e.g., the Ohio study coal). $\mathrm{As}_{2} \mathrm{O}_{3}$ is partially soluble and is likely to contribute arsenic to groundwater due to leaching. Further, a portion of the $\mathrm{As}_{2} \mathrm{O}_{3}$ may oxidize to $\mathrm{As}_{2} \mathrm{O}_{5}$. $\mathrm{As}_{2} \mathrm{O}_{5}$ is very soluble and any arsenic in this form will most likely leach out of fly ash particles when contacted by water.

Active cationic surface sites are primarily due to major elements (i.e., calcium and iron) volatilizing in the vicinity of the carbon oxidizing in the coal particles and then homogeneously and heterogeneously condensing. Increasing the combustion temperature can increase cationic surface site availability and subsequently reduce the emission of vapor phase or physically condensed $\mathrm{As}_{2} \mathrm{O}_{3}$ from the furnace.

\subsubsection{Simulating Arsenic Partitioning During Coal Combustion}

Thermodynamic equilibrium simulation is a useful tool to assist in understanding the chemistry of complex combustion environments. In the present study, equilibrium simulations were executed for arsenic for the six coals studied under this research program.

Simulations were performed using the NASA CEA equilibrium code [52]. CEA determines the equilibrium environment by minimizing the Gibbs free energy of the reaction environment. Gaseous species are treated as ideal gases and gaseous mixtures are also considered to be ideal. All condensed species are treated as pure. The most influential reaction parameters are composition, temperature, and stoichiometry [53]. Similar simulations have been performed by others $[16,34,54,55]$.

The first set of calculations simulates the combustion conditions in the baseline screening experiments for arsenic with no constraints on the compounds available for formation. Actual coal compositions and combustion conditions were utilized in all simulations. Isothermal simulations were performed at intervals of $100 \mathrm{~K}$ to generate a series of temperature profiles ranging from well above the maximum combustion temperature to below the furnace outlet temperature (2200 to $300 \mathrm{~K})$.

In the second set of simulations, constraints were placed on the formation of simple oxides for arsenic (e.g., AsO). Previous research [16,38] has shown that these trace elements form oxy-anions during combustion (e.g. $\mathrm{As}_{2} \mathrm{O}_{3}$ ). Simple oxides were inhibited to more accurately simulate the combustion products expected to be generated during combustion [16].

The predicted forms of occurrence of arsenic resulting from the combustion of the six study coals under baseline screening conditions (i.e., 20\% excess air) are shown in Figure 3-35. For all six coals, arsenic-sulfur compounds are predicted above $2000 \mathrm{~K}$. However, AsO is predicted in the region bounding the maximum combustion temperatures (1430 to $1665 \mathrm{~K}$ ), the Port 4 (Port 4b in Phase I) particle sampling temperatures (1230 to $1520 \mathrm{~K}$ ), and the Port 14 (Port 12 in Phase I) particle sampling temperatures (840 to $1190 \mathrm{~K}$ ) for the experiments performed in this research program. A portion of the arsenic is predicted to be present as 


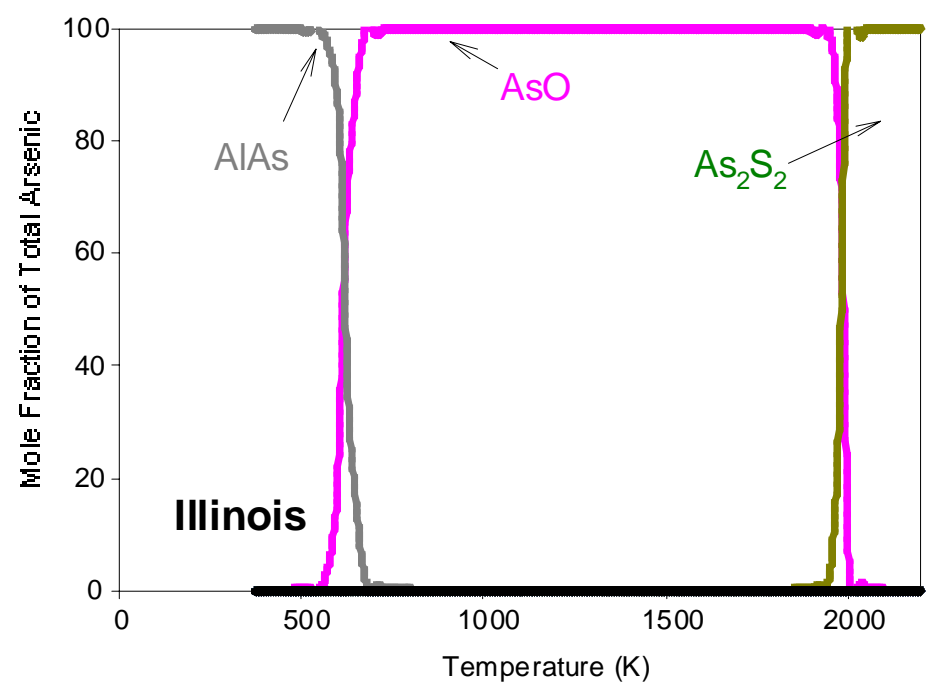

(a)

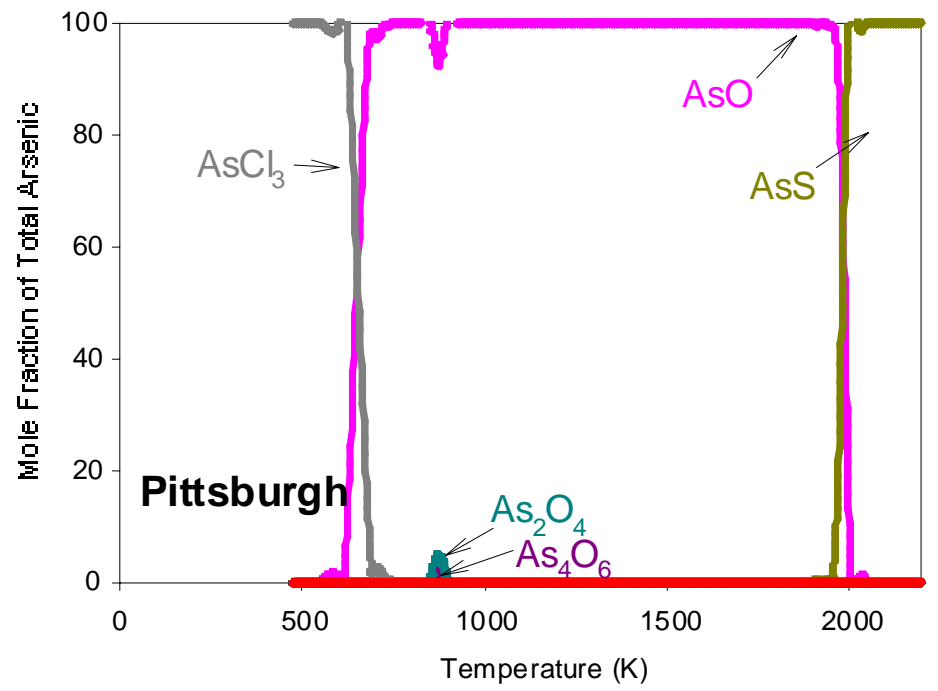

(b)

E-6778

Figure 3-35. Simulated temperature-dependent equilibrium profiles of arsenic during combustion of the six study coals under baseline conditions. 


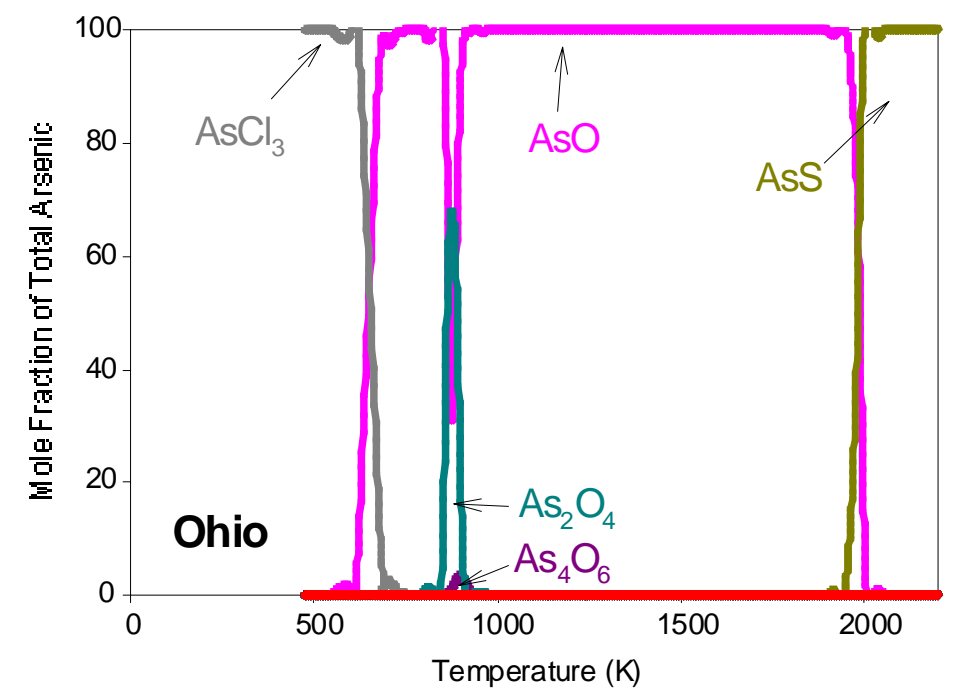

(c)

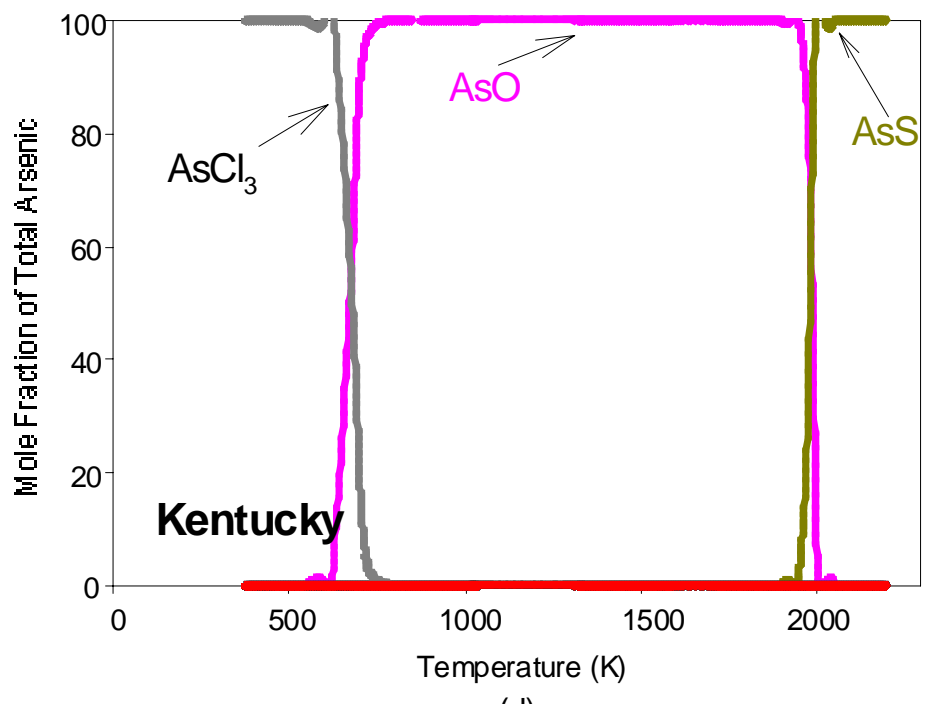

(d)

E-6778a

Figure 3-35. (Continued) Simulated temperature-dependent equilibrium profiles of arsenic during combustion of the six study coals under baseline conditions. 


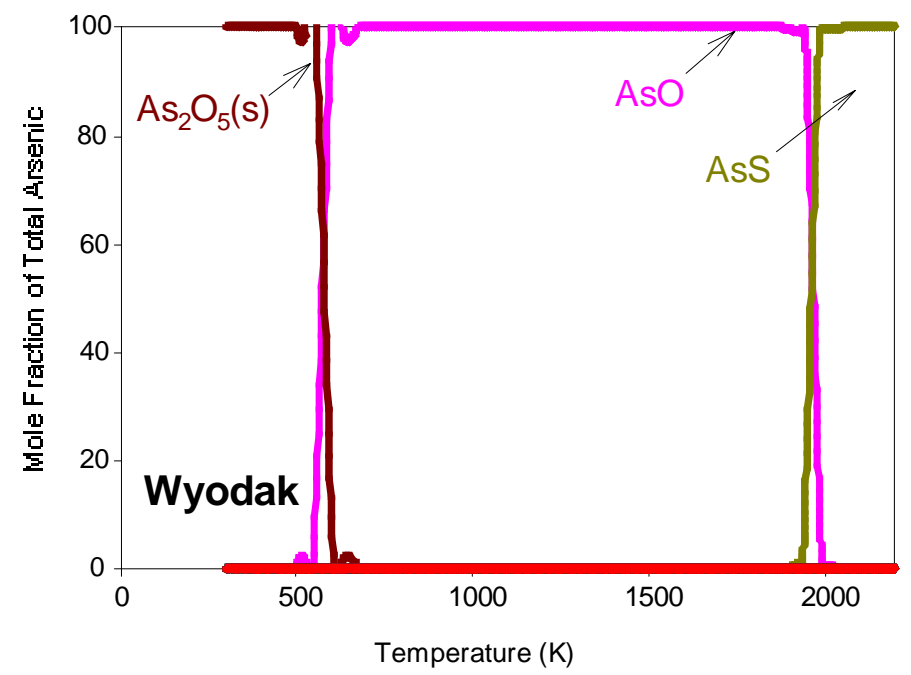

(e)

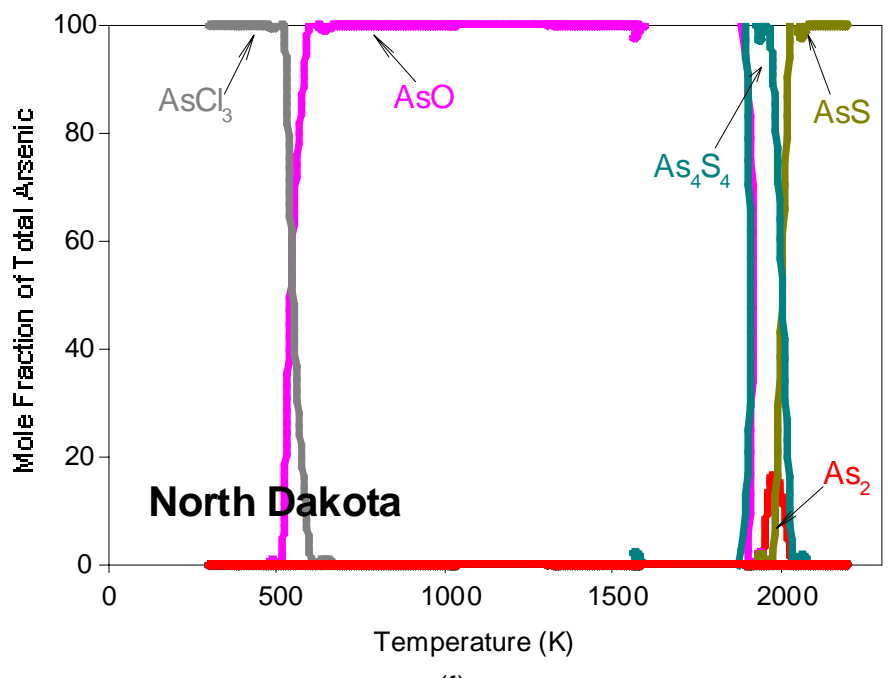

(f)

$E-6778 b$

Figure 3-35. (Continued) Simulated temperature-dependent equilibrium profiles of arsenic during combustion of the six study coals under baseline conditions.

oxy-anions $\left(\mathrm{As}_{2} \mathrm{O}_{4}, \mathrm{As}_{4} \mathrm{O}_{6}\right)$ for the Pittsburgh and Ohio coals. For the Pittsburgh coal less than $10 \%$ is predicted to be present in this form. Up to $65 \%$ of the Ohio coal arsenic is expected to be present in an oxy-anion form in the narrow temperature range of 850 to $900 \mathrm{~K}$. Arsenic is not predicted in an oxy-anion form for the other four coals.

All of the baghouse inlet port samples were collected below $600 \mathrm{~K}$. AsO is not predicted below $600 \mathrm{~K}$. For the Illinois coal, the predicted form is AlAs(s). The predicted form for the Pittsburgh, Ohio, Kentucky, and North Dakota coals is $\mathrm{AsCl}_{3}(\mathrm{~g})$. The formation of $\mathrm{AsCl}_{3}(\mathrm{~g})$ at low temperatures is not supported by the experimental partitioning results. During Wyodak coal combustion, $\mathrm{As}_{2} \mathrm{O}_{5}(\mathrm{~s})$ is predicted. 
The simulation results when arsenic oxide $(\mathrm{AsO})$ is omitted as a valid combustion product are shown in Figure 3-36 for all six coals. For all six coals, a mixture of oxy-anions are predicted in the post-combustion zone temperature range. The Illinois results predict the formation of oxy-anions - $\mathrm{As}_{4} \mathrm{O}_{6}(\mathrm{~g}), \mathrm{As}_{2} \mathrm{O}_{4}(\mathrm{~s})$, and $\mathrm{Ca}_{3}\left(\mathrm{AsO}_{4}\right)_{2}(\mathrm{~s})$ - plus elemental arsenic in the form of As and $\mathrm{As}_{2}$. The Pittsburgh results are similar, the oxy-anions $\mathrm{As}_{4} \mathrm{O}_{6}(\mathrm{~g}), \mathrm{As}_{2} \mathrm{O}_{4}(\mathrm{~s})$, and $\mathrm{Ca}_{3}\left(\mathrm{AsO}_{4}\right)_{2}$ (s) are predicted along with $\mathrm{As}$ and $\mathrm{As}_{2}$. In addition, a portion of the arsenic is predicted to form $\mathrm{AsCl}_{3}(\mathrm{~g})$.

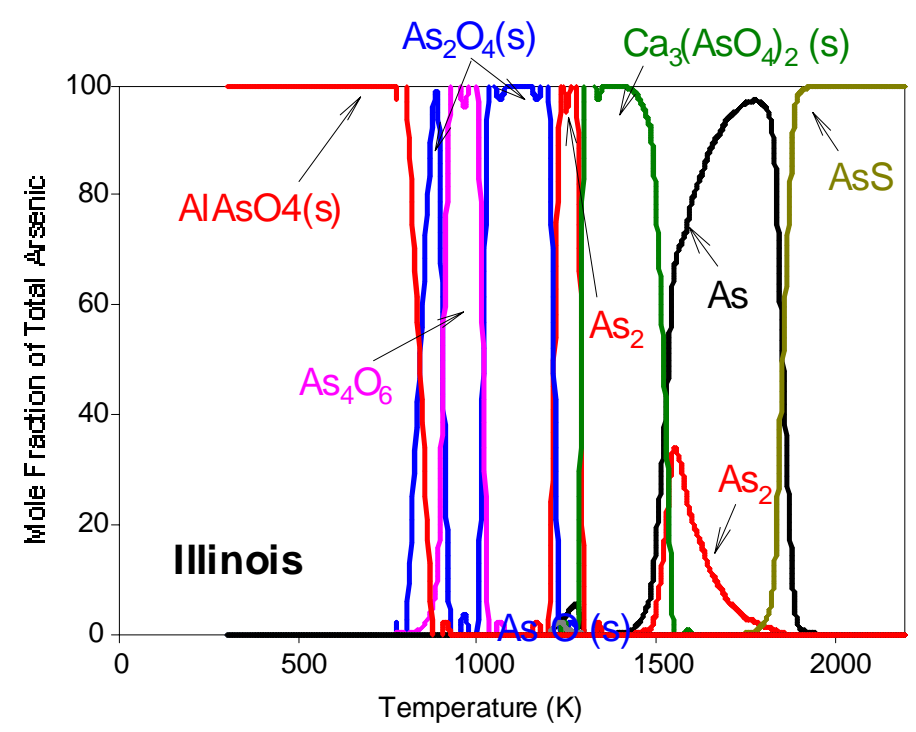

(a)

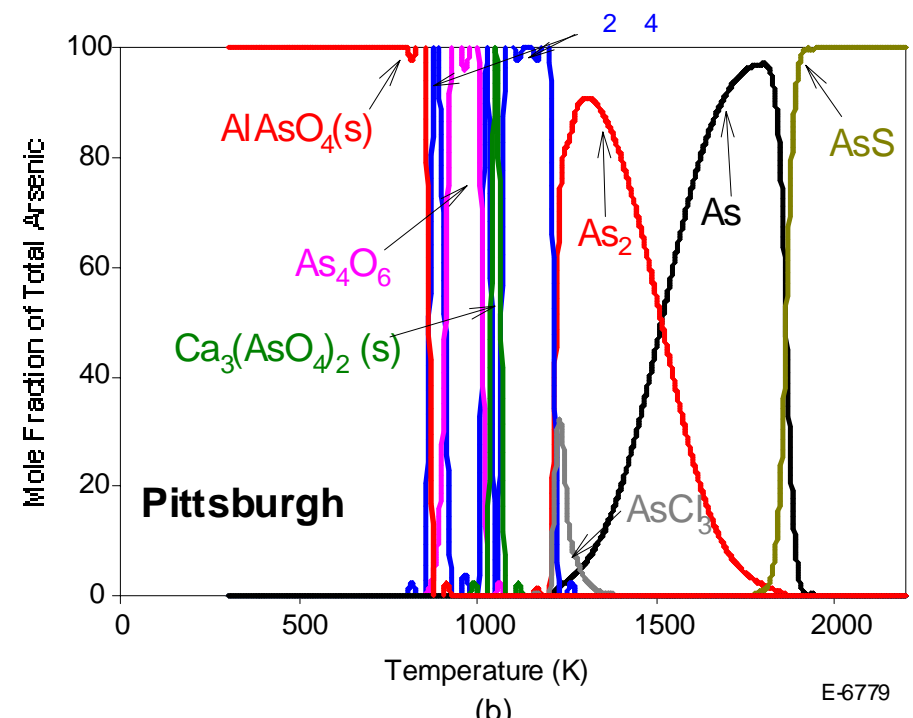

Figure 3-36. Simulated temperature-dependent equilibrium profiles of arsenic omitting AsO as a valid product. 


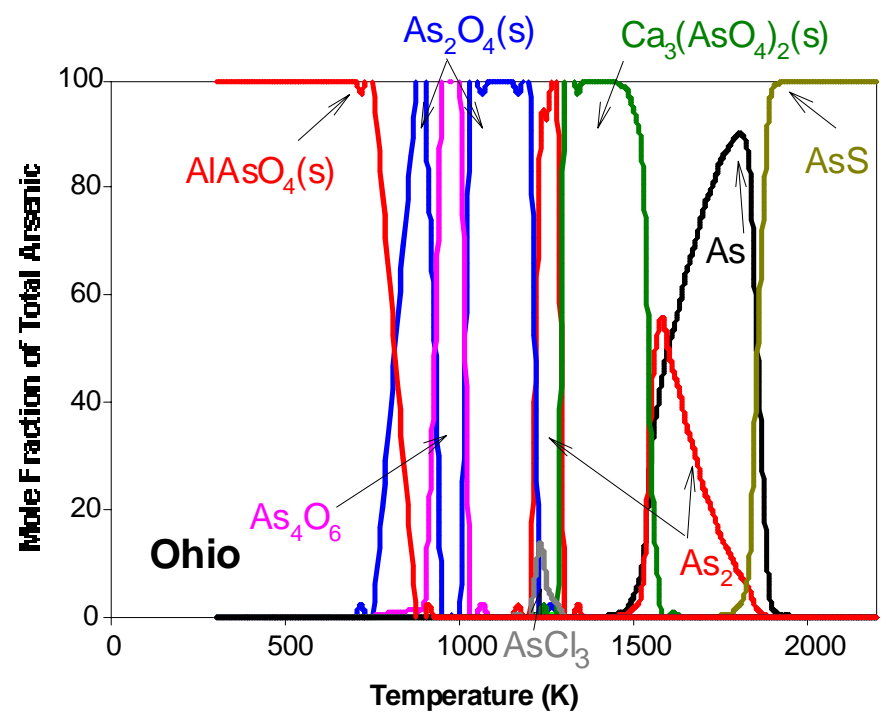

(c)

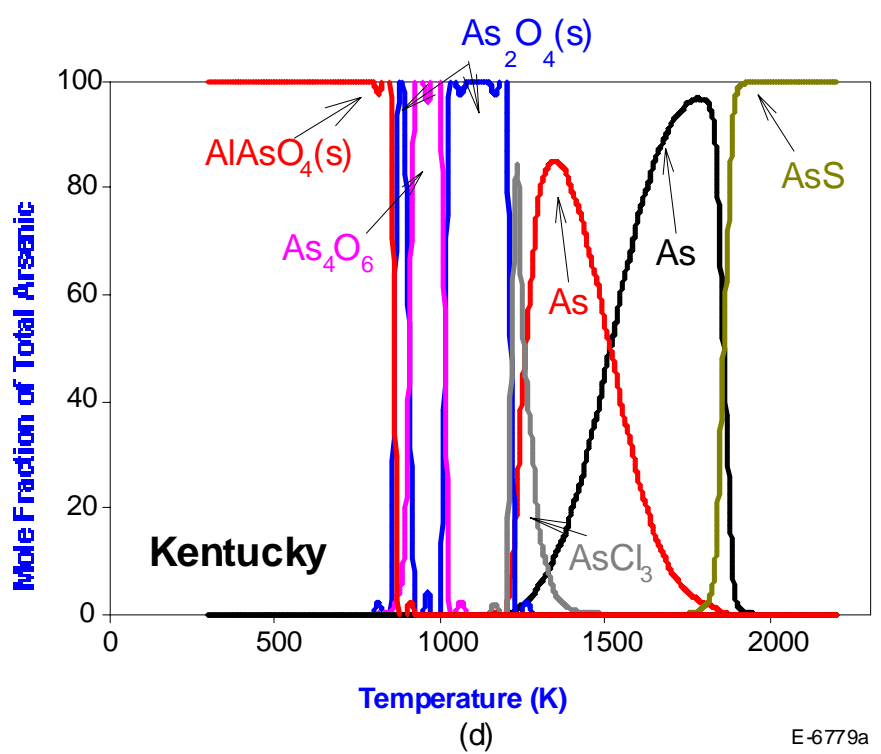

Figure 3-36. (Continued) Simulated temperature-dependent equilibrium profiles of arsenic omitting $\mathrm{AsO}$ as a valid product. 


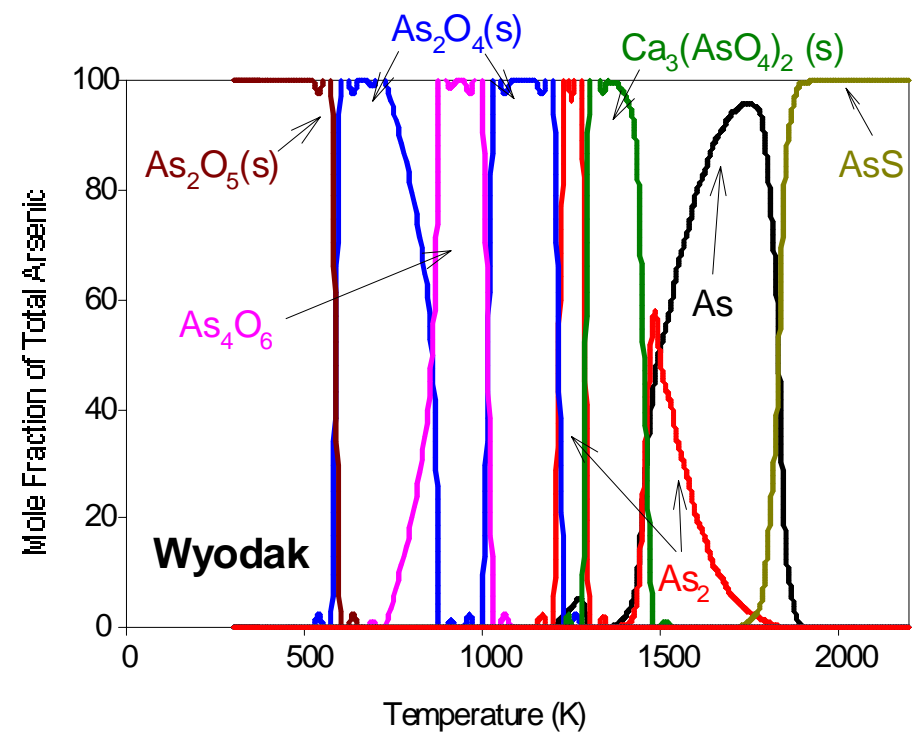

(e)

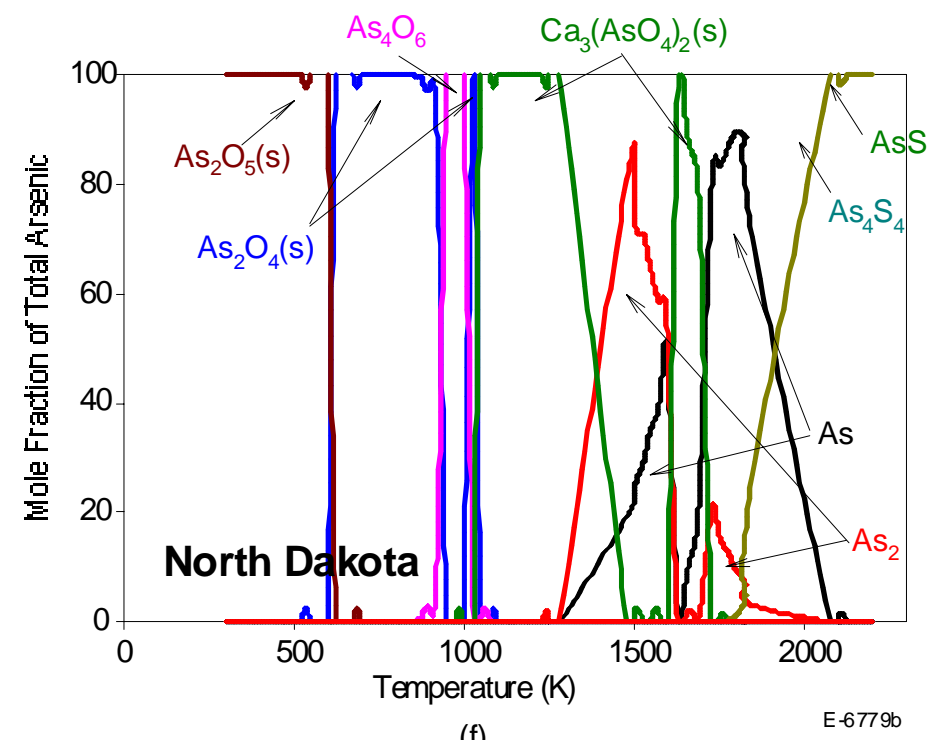

(f)

Figure 3-36. (Continued) Simulated temperature-dependent equilibrium profiles of arsenic omitting $\mathrm{AsO}$ as a valid product.

Although the Ohio coal has a much lower calcium content than the Illinois or Pittsburgh coals, $\mathrm{Ca}_{3}\left(\mathrm{AsO}_{4}\right)_{2}(\mathrm{~s})$ is still predicted as one of the oxy-anions forms along with $\mathrm{As}_{4} \mathrm{O}_{6}(\mathrm{~g})$ and $\mathrm{As}_{2} \mathrm{O}_{4}(\mathrm{~s})$. The elemental forms As and $\mathrm{As}_{2}$ are also predicted. By contrast, $\mathrm{Ca}_{3}\left(\mathrm{AsO}_{4}\right)_{2}(\mathrm{~s})$ is not predicted as one of the oxy-anions formed during the combustion of the Kentucky coal. The Kentucky coal calcium content is similar to the Ohio coal. However, a much higher fraction is predicted in the form $\mathrm{AsCl}_{3}(\mathrm{~g})$.

The results for both the Wyodak subbituminous coal and North Dakota lignite are similar to the Illinois coal results. 
Below 700K, $\mathrm{AlAsO}_{4}(\mathrm{~s})$ is the predicted form of occurrence for the four bituminous coals (Illinois, Pittsburgh, Ohio, and Kentucky) while $\mathrm{As}_{2} \mathrm{O}_{5}(\mathrm{~s})$ is predicted for the two low rank coals (Wyodak and North Dakota).

The constrained simulation results appear to be more reflective of the actual partitioning of arsenic during pulverized coal combustion. The analysis of arsenic partitioning described in the previous section showed that vapor-phase arsenic is reactive with cation surface sites available on fly ash particles. This reaction mechanism is more likely with vapor-phase arsenic in an oxy-anion form, such as $\mathrm{As}_{2} \mathrm{O}_{4}$ rather than a simple oxide form (i.e., AsO). It should be noted that thermodynamic data for $\mathrm{Fe}$-As reaction products were not available for use in these simulations. Therefore, it was not possible to assess whether the formation of Fe-As oxy-anion complexes is thermodynamically favorable. A listing of all possible arsenic products available in the thermodynamic database are shown in Table 3-16.

Table 3-16. Possible Arsenic Products from Thermodynamic Simulation

\begin{tabular}{|c|c|c|}
\hline Gas Phase & Liquid Phase & Solid Phase \\
\hline $\begin{array}{l}\mathrm{AsI}_{3} \\
\mathrm{As} \\
\mathrm{As}_{2} \\
\mathrm{As}_{3} \\
\mathrm{As}_{4} \\
\mathrm{As} 4 \mathrm{O} 6_{\mathrm{AsBr}_{3}} \\
\mathrm{AsCl}_{3} \\
\mathrm{AsH}_{3} \\
\mathrm{AsO} \\
\mathrm{AsSe} \\
\mathrm{AsF}_{3} \\
\mathrm{AsF}_{5} \\
\mathrm{AsTe} \\
\mathrm{Hg}_{3}\left(\mathrm{AsO}_{4}\right)_{2} \\
\mathrm{As}_{3}\left(\mathrm{H}_{3}\right)_{3} \\
\mathrm{AsH}_{3}\left(\mathrm{H}_{3}\right)_{2} \\
\mathrm{AsH}_{2}\left(\mathrm{H}_{3}\right) \\
\mathrm{As}_{2} \mathrm{~S}_{3} \\
\mathrm{Na}_{3} \mathrm{As}\end{array}$ & $\begin{array}{l}\mathrm{As}_{4} \mathrm{~S}_{4} \\
\mathrm{As}_{2} \mathrm{O}_{3} \\
\mathrm{As}_{2} \mathrm{~S}_{2} \\
\mathrm{As}_{2} \mathrm{~S}_{3} \\
\mathrm{AsCl}_{3} \\
\mathrm{AsI}_{3} \\
\mathrm{AsF}_{3} \\
\mathrm{As}_{2} \mathrm{Te}_{3}\end{array}$ & $\begin{array}{l}\mathrm{Cd}_{3}\left(\mathrm{AsO}_{4}\right)_{2} \\
\mathrm{Be}_{3}\left(\mathrm{AsO}_{4}\right)_{2} \\
\mathrm{Ni}_{11} \mathrm{As}_{8} \\
\mathrm{As} \\
\mathrm{TlAsO}_{4} \\
\mathrm{Sr}_{3}\left(\mathrm{AsO}_{4}\right)_{2} \\
\mathrm{Ni}_{3}\left(\mathrm{AsO}_{4}\right)_{2} \\
\mathrm{NiAs} \mathrm{As}_{5} \\
\mathrm{Ni}_{5} \mathrm{As}_{2} \\
\mathrm{Cr}_{3}\left(\mathrm{AsO}_{4}\right)_{2} \\
\mathrm{CrAsO}_{4} \\
\mathrm{Ca}_{3}\left(\mathrm{AsO}_{4}\right)_{2} \\
\mathrm{Ba}_{3}\left(\mathrm{AsO}_{4}\right)_{2} \\
\mathrm{As}_{4} \mathrm{~S}_{4} \\
\mathrm{As}_{2} \mathrm{O}_{5} \\
\mathrm{As}_{2} \mathrm{~S}_{2} \\
\mathrm{As}_{2} \mathrm{~S}_{3} \\
\mathrm{As}_{2} \mathrm{Se}_{3} \\
\mathrm{As}_{4} \mathrm{~S}_{4} \\
\mathrm{AsI}_{3} \\
\mathrm{AlAs} \mathrm{As} \\
\mathrm{AlAsO}_{4} \\
\mathrm{Ag}_{3} \mathrm{AsO}_{4} \\
\mathrm{Cd}_{3} \mathrm{As}_{2} \\
\mathrm{As}_{2} \mathrm{Te}_{3} \\
\mathrm{Hg}_{3}\left(\mathrm{AsO}_{4}\right)_{2} \\
\mathrm{MnAs}_{2} \\
\mathrm{Mn}_{3}\left(\mathrm{AsO}_{4}\right)_{2} \\
\mathrm{~Pb}_{3}\left(\mathrm{AsO}_{4}\right)_{2} \\
\mathrm{BAsO}_{4} \\
\mathrm{As}_{2} \mathrm{O}_{4} \\
\mathrm{Na}_{3} \mathrm{AsO}_{4} \\
3 \mathrm{Na}_{2} \mathrm{O}^{*} \mathrm{As}_{2} \mathrm{O}_{5} \\
\end{array}$ \\
\hline
\end{tabular}




\subsubsection{Mercury-Ash Interactions in Fixed Bed Tests}

The initial bench-scale tests with elemental mercury injection have been completed and are summarized in Table 3-17. Figure 3-37 plots breakthrough as a function of time for the four runs with the Ohio blend ash. In addition to evaluation of the baseline ash at two temperatures, the carbon was removed from the baseline ash by ashing it at $400^{\circ}$ and $750^{\circ} \mathrm{C}$ then these "ashed" samples were exposed to elemental mercury in simulated flue gas at $300^{\circ} \mathrm{F}\left(149^{\circ} \mathrm{C}\right)$. Table $3-18$ gives the surface area of the samples before and after ashing.

To help with the interpretation of the results, the test protocol for each run is essentially the same and the mercury concentration data have been normalized to a percentage of the inlet elemental mercury concentration. At the start of each test, the concentration of total mercury at the outlet of the fixed bed is measured until it has lined out at $100 \%$ of the inlet concentration. At this point, the conditioning/conversion system is switched to measure the elemental mercury concentration at the outlet of the fixed bed (noted on the plots as $\mathrm{Hg}^{0}$ ). If no oxidation is taking

Table 3-17. Results from Tests with $\mathrm{Hg}^{0}$ Injection

\begin{tabular}{|c|c|c|c|c|c|c|c|}
\hline $\begin{array}{l}\text { Run } \\
\text { No. }\end{array}$ & Fly Ash & $\begin{array}{l}\text { Temp., } \\
{ }^{\circ} \mathrm{F}\end{array}$ & $\begin{array}{l}\mathrm{Hg}^{0} \text { on } \\
\text { Ash, } \\
\mu \mathrm{g} / \mathrm{g}\end{array}$ & LOI & $\begin{array}{c}\mathrm{Hg}^{0} \text { on } \\
\text { Spent Ash, } \\
\mu \mathrm{g} / \mathrm{g}\end{array}$ & $\begin{array}{c}\mathrm{Hg}^{0} \\
\text { Generated, } \\
\mu \mathrm{g}\end{array}$ & $\begin{array}{c}\text { Mass Balance, } \\
\%\end{array}$ \\
\hline 957 & Ohio & 250 & 0.276 & 6.79 & ND & ND & ND \\
\hline 960 & Ohio & 350 & 0.276 & 6.79 & ND & ND & ND \\
\hline 988 & $\begin{array}{l}\text { Ohio } \\
\text { @ } 400^{\circ} \mathrm{C}\end{array}$ & 300 & ND & ND & ND & ND & ND \\
\hline 989 & $\begin{array}{c}\text { Ohio ashed } \\
@ 750^{\circ} \mathrm{C}\end{array}$ & 300 & ND & ND & ND & ND & ND \\
\hline 958 & Wyodak & 250 & 1.29 & 4.45 & 2.51 & 43.8 & 97 \\
\hline 962 & Wyodak & 350 & 1.29 & 4.45 & ND & ND & ND \\
\hline 990 & $\begin{array}{c}\text { Wyodak } \\
\text { ashed @ } \\
400^{\circ} \mathrm{C}\end{array}$ & 350 & ND & ND & ND & ND & ND \\
\hline 991 & $\begin{array}{c}\text { Wyodak } \\
\text { ashed } \\
@ 750^{\circ} \mathrm{C}\end{array}$ & 350 & ND & ND & ND & ND & ND \\
\hline 959 & ND lignite & 250 & 0.536 & 2.86 & ND & ND & ND \\
\hline 961 & ND lignite & 350 & 0.536 & 2.86 & ND & ND & ND \\
\hline 963 & Coal Creek & 350 & 0.0067 & 0.01 & ND & ND & ND \\
\hline 964 & Blacksville & 350 & 0.140 & 4.06 & ND & ND & ND \\
\hline 974 & Station A & 250 & 0.557 & 4.50 & ND & ND & ND \\
\hline 975 & Comanche & 250 & 1.05 & 0.90 & ND & ND & ND \\
\hline 992 & Station B & 350 & ND & 0.88 & ND & ND & ND \\
\hline 993 & Station B & 350 & ND & 0.88 & ND & ND & ND \\
\hline 1044 & GA & 250 & 0.002 & 0.67 & ND & ND & ND \\
\hline 1047 & AA & 250 & 0.282 & 37.12 & ND & ND & ND \\
\hline 1048 & DA & 250 & 0.114 & 6.22 & ND & ND & ND \\
\hline 1049 & DMA & 250 & 0.051 & 1.5 & ND & ND & ND \\
\hline
\end{tabular}

$\mathrm{ND}=$ not determined. 


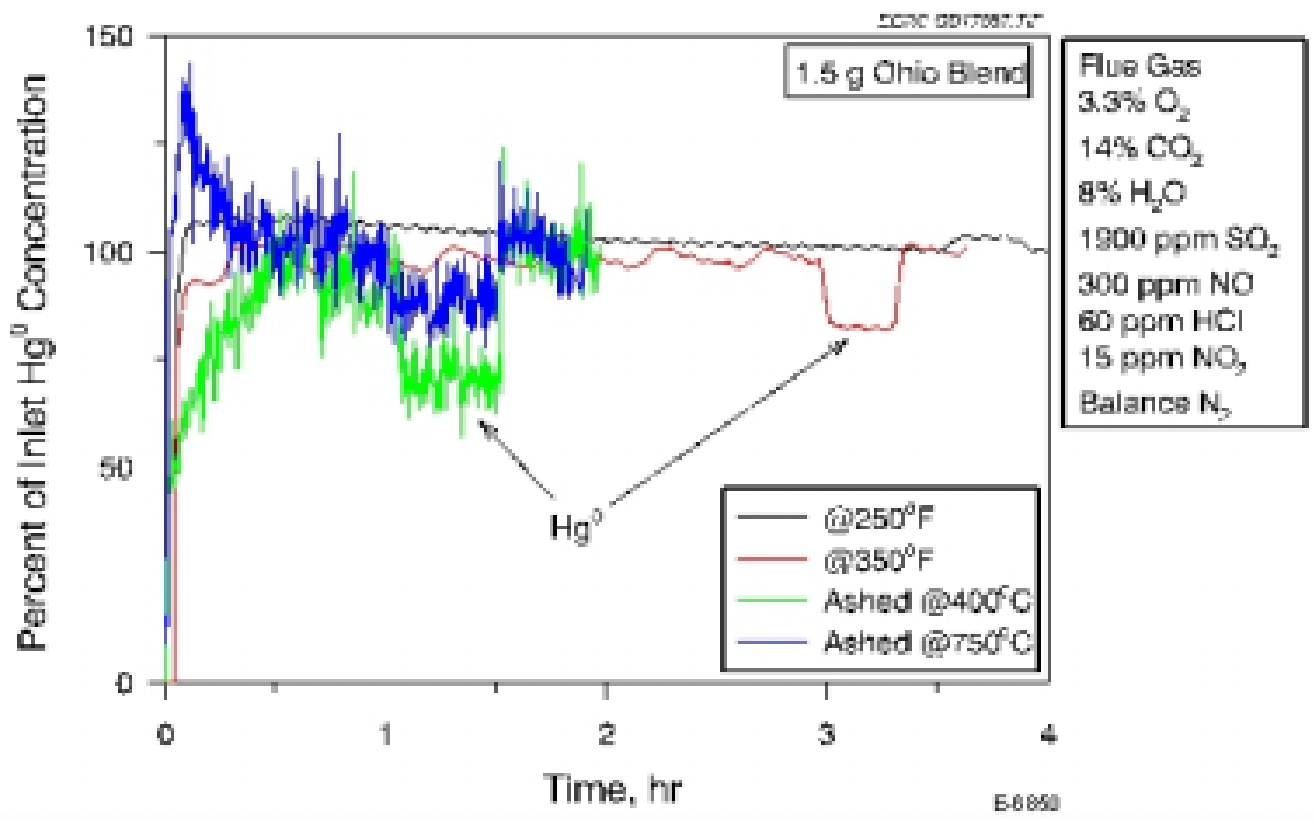

Figure 3-37. Breakthrough as a function of time for the four runs with the Ohio blend ash and $\mathrm{Hg}^{0}$ injection.

Table 3-18. Surface Area of Ash Samples Before and After Ashing

\begin{tabular}{|l|c|c|}
\hline Ash Sample & Ashing T, ${ }^{\circ} \mathrm{C}$ & Surface Area, $\mathrm{m}^{2} / \mathrm{g}$ \\
\hline \hline Ohio Blend & ---- & 1.52 \\
\hline Ohio Blend & 400 & 4.15 \\
\hline Ohio Blend & 750 & 10.00 \\
\hline Wyodak & ---- & 13.42 \\
\hline Wyodak & 400 & 2.65 \\
\hline Wyodak & 750 & 2.83 \\
\hline Blacksville & ---- & ND \\
\hline Blacksville & 400 & 2.50 \\
\hline Blacksville & 750 & 4.16 \\
\hline Station A & ---- & ND \\
\hline Station A & 400 & 8.13 \\
\hline Station A & 750 & 12.66 \\
\hline
\end{tabular}

place, the concentration will remain at $100 \%$ of the inlet elemental mercury concentration. However, if any of the elemental mercury is being oxidized across the filter, it will show as a drop in the outlet concentration of elemental mercury. After the outlet elemental mercury concentration is measured, the system is switched to measure the total inlet mercury concentration. The objective of these tests is to find fly ashes that are reactive in terms of mercury capture and/or oxidation of elemental mercury. Once the reactive ashes are identified, they can be evaluated further. On the basis of these criteria, the Ohio ash is not very reactive, with elemental mercury showing only slight oxidation of elemental mercury at $350^{\circ} \mathrm{F}\left(177^{\circ} \mathrm{C}\right)$. 
Figure 3-38 plots the results from the four tests with the Wyodak ash and elemental mercury. The Wyodak did show some capture of elemental mercury at both $250^{\circ}$ and $350^{\circ} \mathrm{F}$ $\left(121\right.$ and $\left.177^{\circ} \mathrm{C}\right)$. As with the Ohio ash, it also showed increased oxidation at the elevated temperature. The spent ash from the test at $250^{\circ} \mathrm{F}\left(121^{\circ} \mathrm{C}\right)$ was submitted for mercury analysis, and a mass balance was performed. The mass balance for the test was $97 \%(\mathrm{Hg}$ measured/ $\mathrm{Hg}$ generated) and is based on the mercury measured on the base and spent ash samples, the average mercury permeation rate, and the mercury measured by the continuous emission monitors (CEMs) (integrated area under the curve). The analysis showed the mercury on the ash roughly doubled. But is this significant, considering the amount of mercury the ash was exposed to? We will have to consider the amount of mercury captured and the time to reach $100 \%$ breakthrough. The removal of the carbon by ashing at $400^{\circ}$ and $750^{\circ} \mathrm{C}$ essentially killed the reactivity of the fly ash.

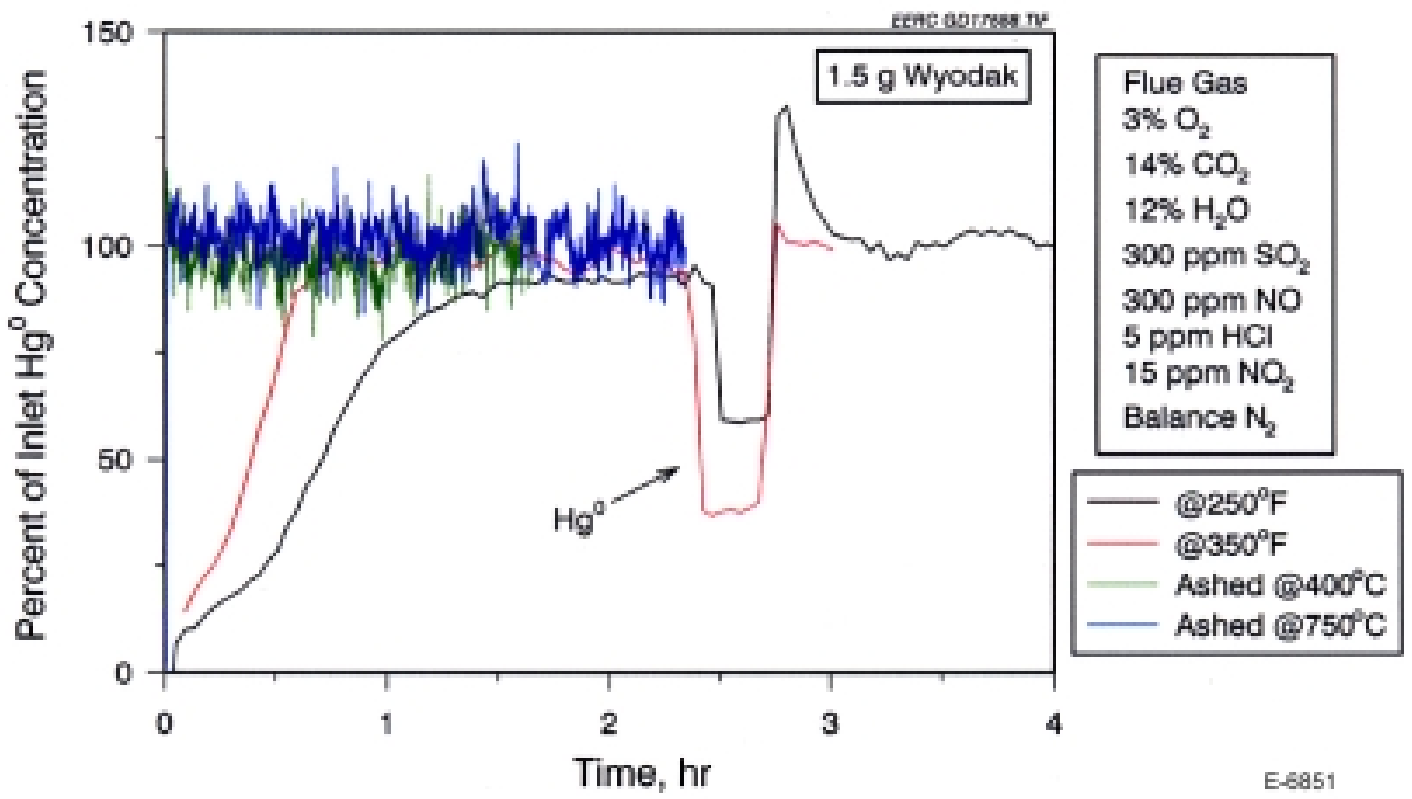

Figure 3-38. Breakthrough as a function of time for the four runs with the Wyodak ash and $\mathrm{Hg}^{0}$ injection.

Figure 3-39 plots the results for the North Dakota lignite and the ash from the Coal Creek station (North Dakota lignite ash from utility boiler) with elemental mercury; the North Dakota lignite showed no reactivity with the elemental mercury. The results are consistent with sampling results performed at the Coal Creek station, which showed no capture or oxidation of mercury by the fly ash.

Figure 3-40 plots the results from the test with the Blacksville ash at $350^{\circ} \mathrm{F}$ with elemental mercury injection. Three different mercury CEMs were used for this test (the Semtech 2000, PSA Sir Galahad, and Tekran 2537A), and the figure shows the good agreement between the instruments. The results are consistent with the results from other labs [57,58], showing roughly $30 \%$ oxidation of the elemental mercury. The Blacksville sample was ashed at $400^{\circ}$ and $750^{\circ} \mathrm{C}$, but the samples were not evaluated with elemental mercury because the base ash was not as reactive as previously thought. 


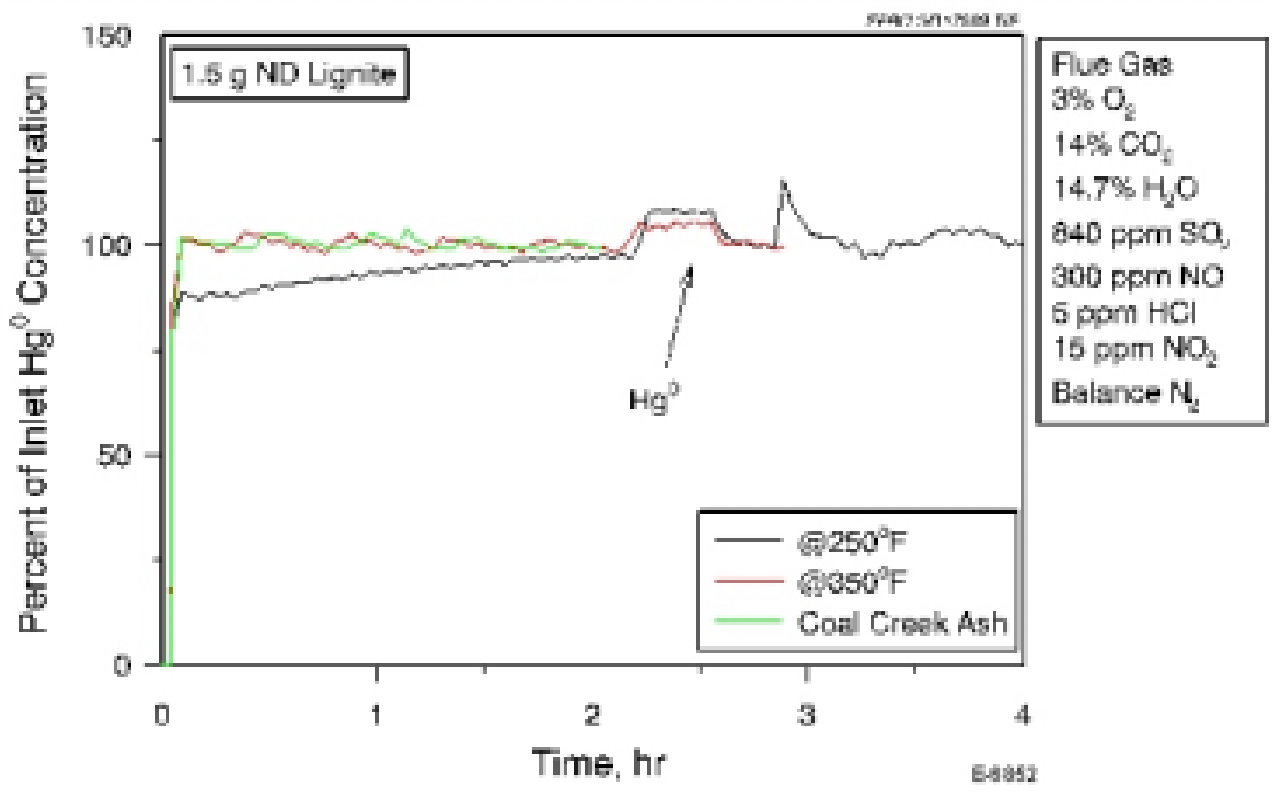

Figure 3-39. Breakthrough as a function of time for the North Dakota lignite and the ash from the Coal Creek station.

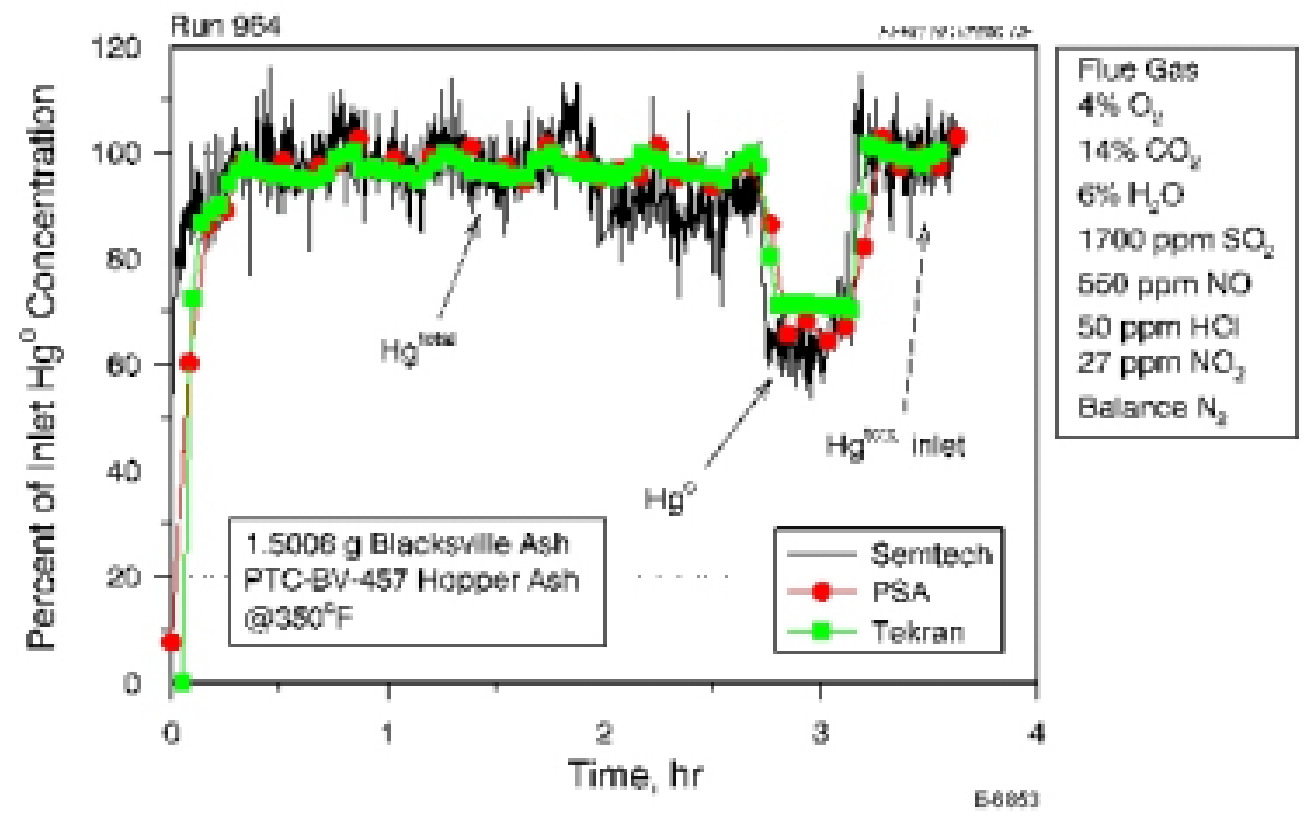

Figure 3-40. Breakthrough as a function of time for the Blacksville ash at $350^{\circ} \mathrm{F}$ with $\mathrm{Hg}^{0}$ injection. 
A sample of ash from the Comanche station (public Service of Colorado) was sent by PSI to be evaluated in the bench-scale simulator. The sample was collected by ADA Technologies on 1/23/98 when the plant was burning a Powder River Basin coal from the Belle Ayr mine. Figure 3-41 plots the results from a run with this ash and elemental mercury injection. This sample showed some capture of elemental mercury and roughly $25 \%$ oxidation.

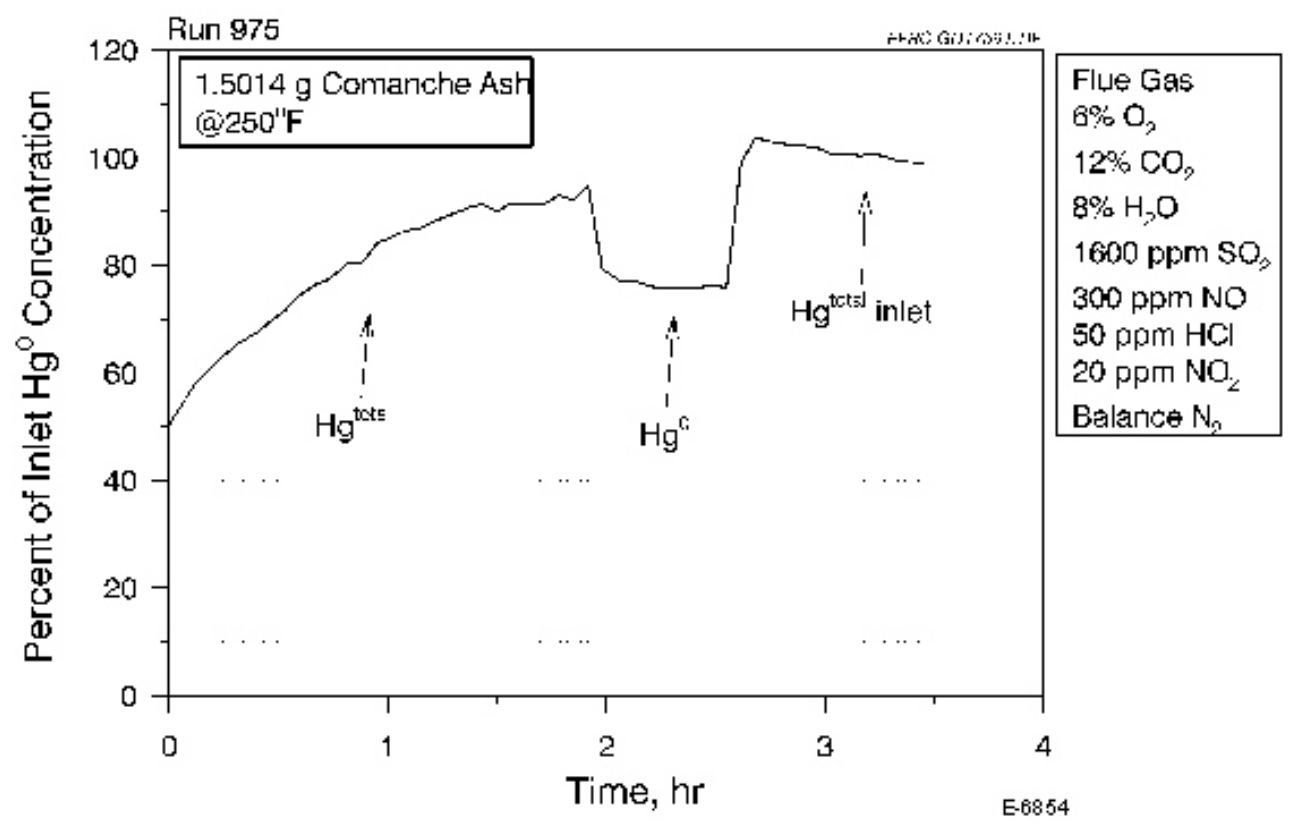

Figure 3-41. Breakthrough as a function of time for the Comanche station ash at $250^{\circ} \mathrm{F}$ with $\mathrm{Hg}^{0}$ injection.

An ash from a western bituminous coal obtained from the Station A was evaluated at the bench scale (see Figure 3-42) and showed good mercury capture and roughly $40 \%$ oxidation of the elemental mercury. The Station A ash was ashed at $400^{\circ}$ and $750^{\circ} \mathrm{C}$, but those samples have not been evaluated. It appears this ash should be evaluated further by looking at different fractions (i.e., carbon-rich and or iron-rich fractions).

A second western bituminous ash, from the Station B, was evaluated in a fixed bed with the bench-scale unit, and the results are plotted in Figure 3-43. The first test was aborted after roughly 1.5 hours because of leaking $\mathrm{SnCl}_{2}$ solution, and no elemental concentration or inlet total concentration data were collected. The results from a repeat run have an unexplained gap in the data near the beginning, but generally follow the results from the previous test. There appear to have been some problems with the sampling system during both of these runs, and the ash will likely be reevaluated at a later time. However, it appears the ash is fairly reactive, with roughly $80 \%$ oxidation of the elemental mercury.

Five ash samples taken from ESP hoppers of full-scale power plants burning eastern bituminous coal were supplied by PSI for testing in the bench-scale fixed-bed system. The ashes are designated as GA, AA, DMA, DA, and MA, and the information provided for each ash is presented in Table 3-19. Figures 3-44 through 3-48 plot the results from the $\mathrm{Hg}^{0}$ and $\mathrm{HgCl}_{2}$ injection tests for the five ash samples. 


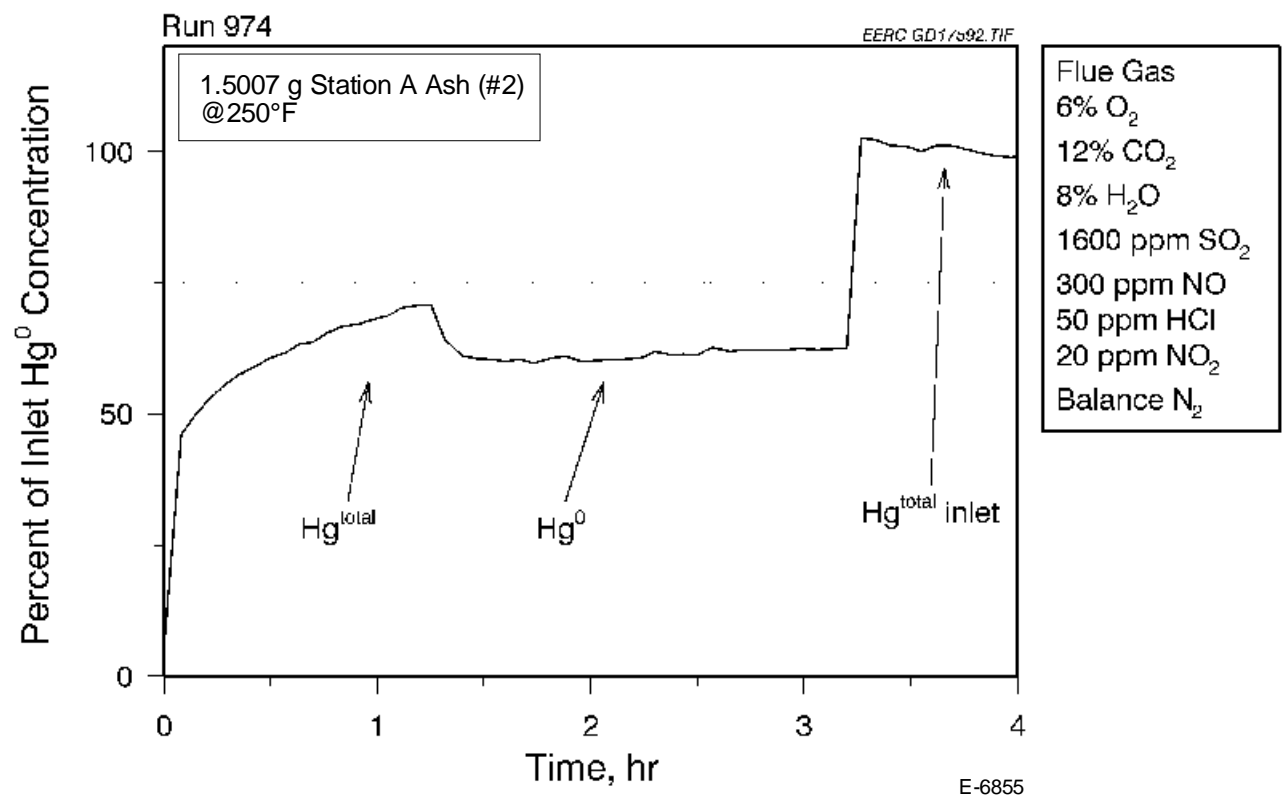

Figure 3-42. Breakthrough as a function of time for the Station A ash at $250^{\circ} \mathrm{F}$ with $\mathrm{Hg}^{0}$ injection.

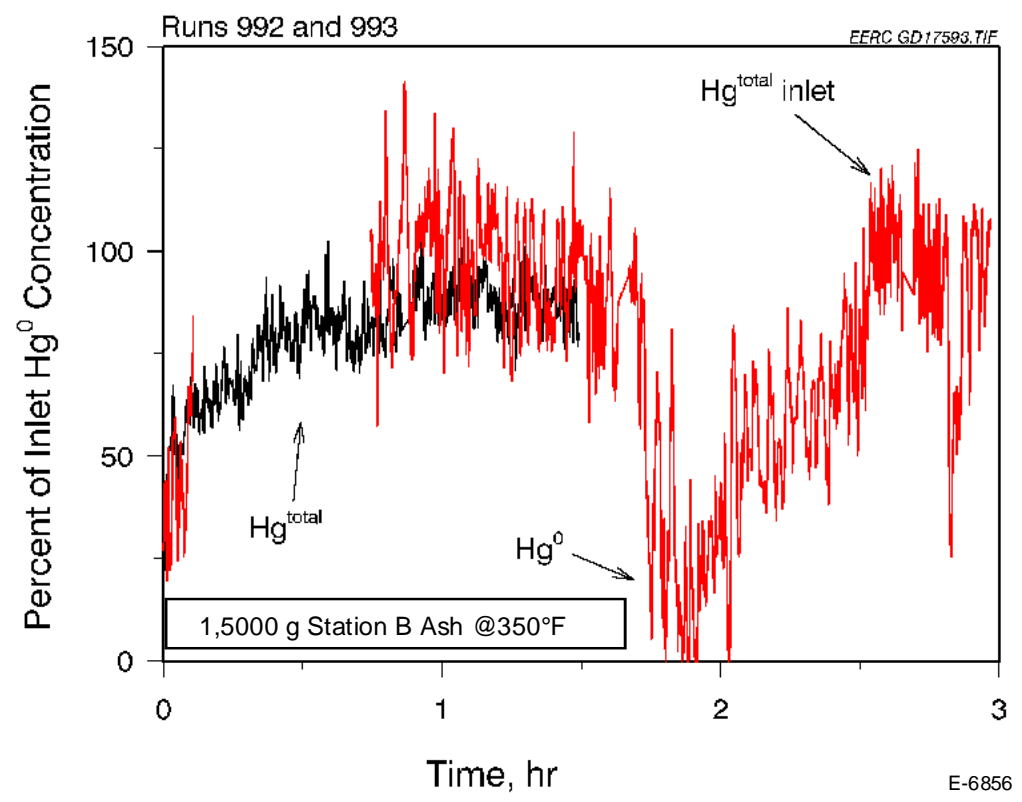

Figure 3-43. Breakthrough as a function of time for the Station B ash at $350^{\circ} \mathrm{F}$ with $\mathrm{Hg}^{0}$ injection. 
Table 3-19. Characteristics of Eastern Bituminous Coal Ash Samples

\begin{tabular}{|l|c|c|r|r|c|}
\hline Parameter & GA ash & $\begin{array}{c}\text { DMA } \\
\text { ash }\end{array}$ & DA ash & AA ash & MA ash \\
\hline \hline Sample Properties: & & & & & \\
\hline Surface area, m $^{2} \mathrm{~g}$ & 0.17 & 0.96 & 6.17 & 4.36 & 3.92 \\
\hline LOI (sample), & 0.67 & 1.5 & 6.22 & 37.12 & 44.4 \\
\hline Parent Coal Composition: & & & & & \\
\hline Hg in Coal, ppm & 0.18 & 0.09 & 0.12 & 0.09 & 0.09 \\
\hline Cl in Coal, ppm & 1300 & 1600 & 1100 & 1100 & 2300 \\
\hline Coal Ash Content, \% & 13.6 & 10.9 & 13.9 & 18.5 & 10.1 \\
\hline $\begin{array}{l}\text { Observations from Full } \\
\text { Scale Operation: }\end{array}$ & & & & & \\
\hline LOI (ESP ash), \% & 0.1 & 1 & 4 & 35 & 42 \\
\hline ESP-in: \%Hg + Hg & & & & & 76 \\
\hline Hg Removal by Ash, \% & 73 & 81 & 80 & 89 & 76.4 \\
\hline Boiler Type & 6.8 & 7.8 & 24.0 & 10.1 & 42.4 \\
\hline
\end{tabular}

LOI = loss on ignition; $\mathrm{pc}=$ pulverized coal.

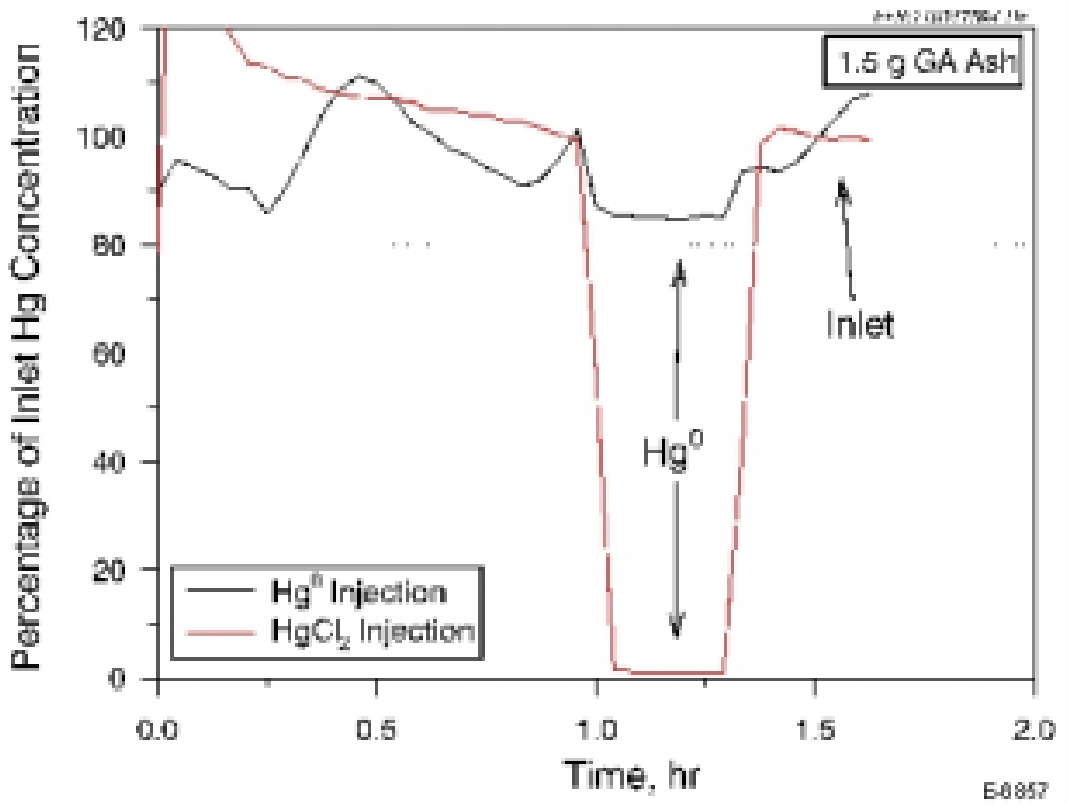

Figure 3-44. Breakthrough as a function of time for the GA ash with either $\mathrm{Hg}^{0}$ or $\mathrm{HgCl}_{2}$ injection. 


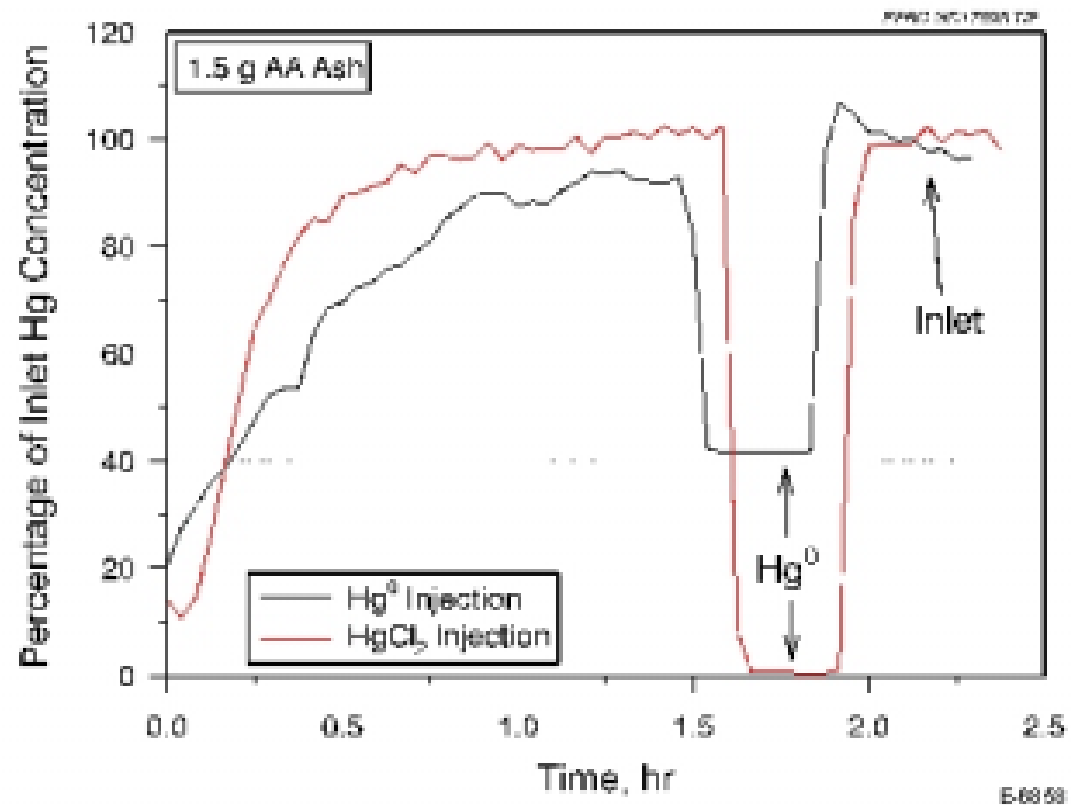

Figure 3-45. Breakthrough as a function of time for the AA ash with either $\mathrm{Hg}^{0}$ or $\mathrm{HgCl}_{2}$ injection.

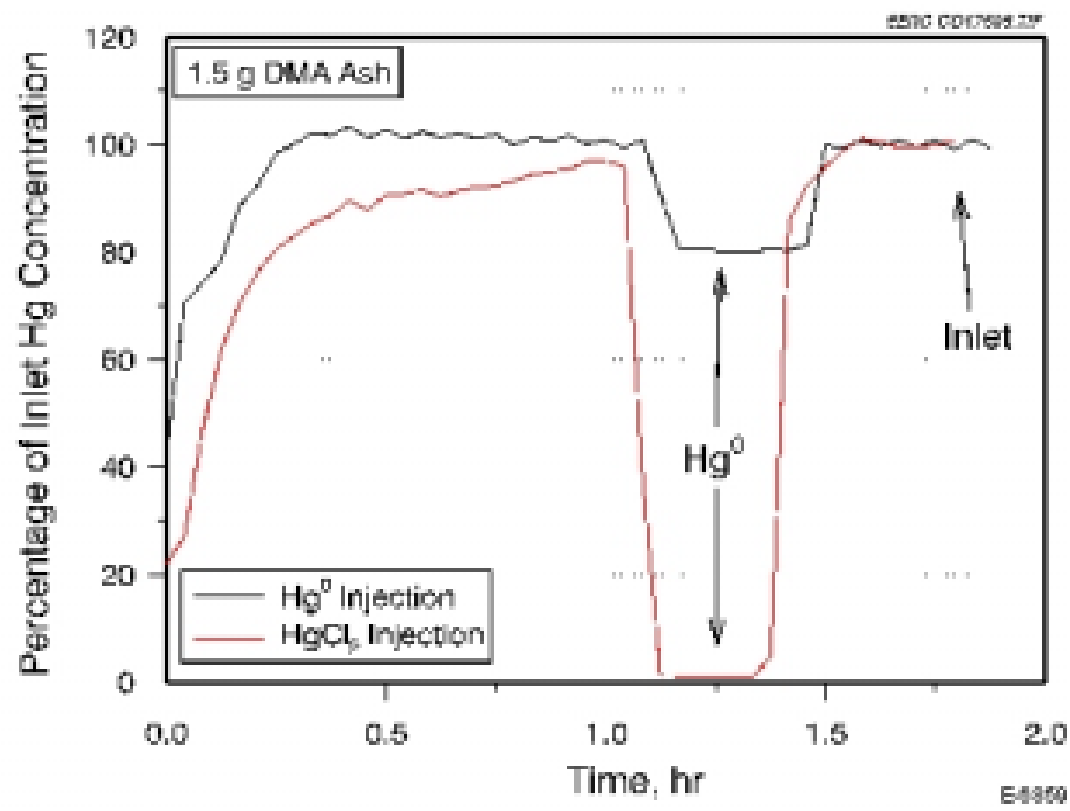

Figure 3-46. Breakthrough as a function of time for the DMA ash with either $\mathrm{Hg}^{0}$ or $\mathrm{HgCl}_{2}$ injection. 


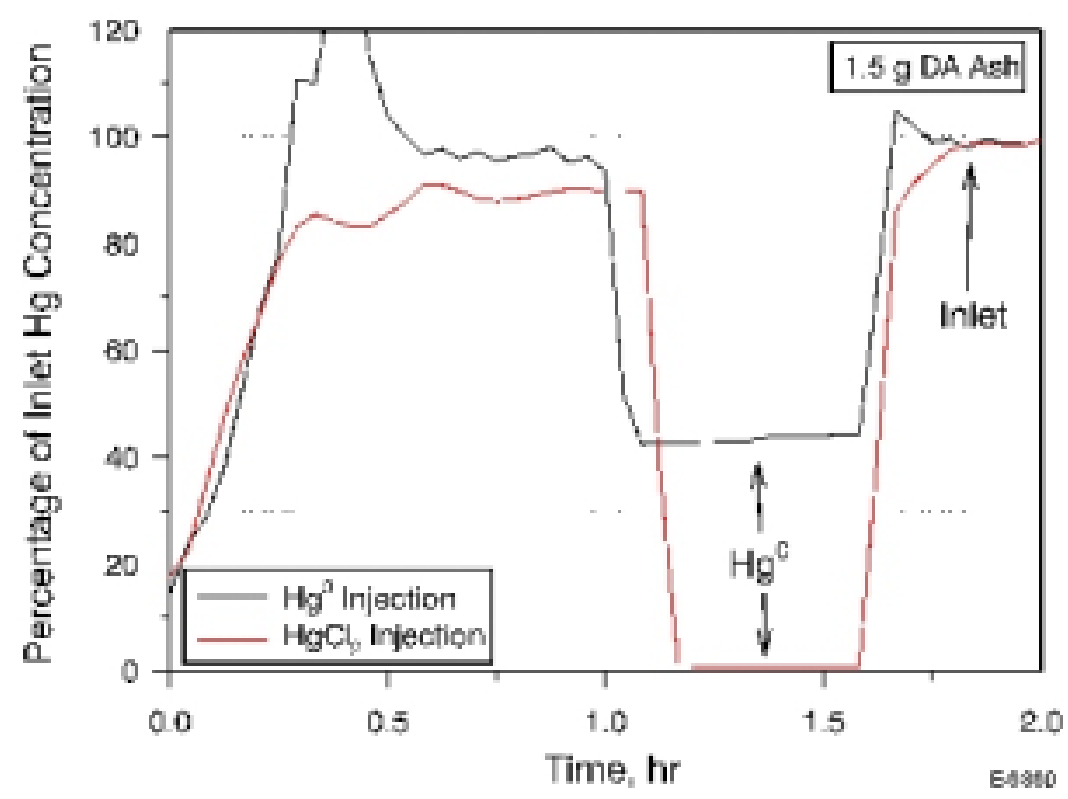

Figure 3-47. Breakthrough as a function of time for the DA ash with either $\mathrm{Hg}^{0}$ or $\mathrm{HgCl}_{2}$ injection.

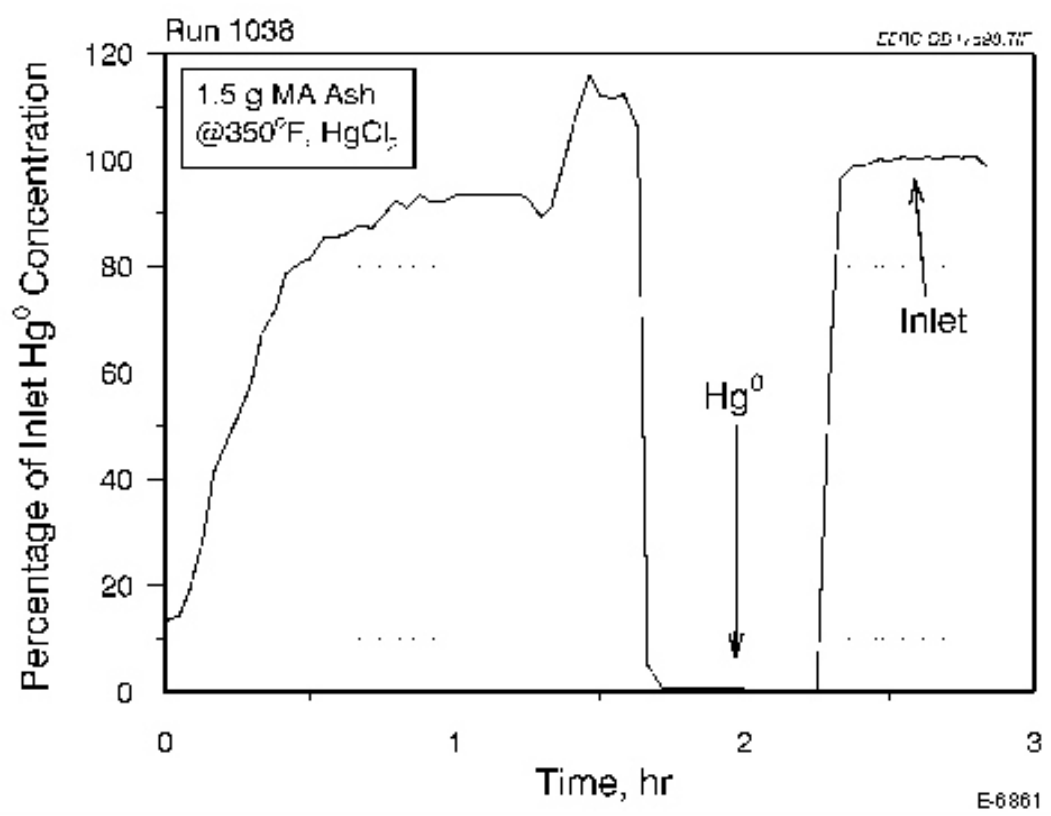

Figure 3-48. Breakthrough as a function of time for the $\mathrm{MA}$ ash with $\mathrm{HgCl}_{2}$ injection. 
Figure 3-44 plots the results from the $\mathrm{Hg}^{0}$ and $\mathrm{HgCl}_{2}$ injection tests with the GA ash. This ash did not show any reactivity to elemental mercury. The results from the tests with $\mathrm{HgCl}_{2}$ injection are summarized in Table 3-20. All of the $\mathrm{HgCl}_{2}$ injection tests were performed at a fixed-bed temperature of $350^{\circ} \mathrm{F}\left(177^{\circ} \mathrm{C}\right)$. The same basic protocol of sampling the outlet total mercury concentration until it lined out at $100 \%$ of the inlet concentration, followed by sampling of the outlet elemental mercury concentration and, lastly, sampling the inlet total mercury concentration was followed for the $\mathrm{HgCl}_{2}$ injection tests. Also to note: a low reading when elemental mercury is sampled indicates that the $\mathrm{HgCl}_{2}$ is not being reduced and the ash is not reactive in this manner. Figure 3-44 shows the GA ash was also unreactive with $\mathrm{HgCl}_{2}$ and is not a good candidate for further testing. The spent ash samples were not submitted for mercury analysis, but were sent to the University of Kentucky for x-ray absorption fine structure (XAFS) (sulfur and $\mathrm{Cl}$ ) and Mössbauer analysis.

Table 3-20. Results from Tests with $\mathrm{HgCl}_{2}$ Injection (at $350^{\circ} \mathrm{F}$ )

\begin{tabular}{|c|c|c|c|c|c|c|c|}
\hline $\begin{array}{l}\text { Run } \\
\text { No. }\end{array}$ & Fly Ash & $\begin{array}{l}\text { Hg on } \\
\text { Ash, } \\
\mu g / g\end{array}$ & LOI, \% & $\begin{array}{c}\mathrm{Hg} \text { on } \\
\text { Spent Ash, } \\
\mu \mathrm{g} / \mathrm{g}\end{array}$ & $\begin{array}{c}\mathrm{HgCl}_{2} \\
\text { Generated, } \\
\mu \mathrm{g}\end{array}$ & $\begin{array}{c}\text { Mass } \\
\text { Balance, } \\
\%\end{array}$ & $\begin{array}{c}\mathrm{HgCl}_{2} \\
\text { Collection } \\
\text { Efficiency, } \\
\%\end{array}$ \\
\hline 1000 & Ohio & 0.276 & 6.79 & 0.88 & 42 & 76 & 2.5 \\
\hline 1037 & $\begin{array}{c}\text { Ohio } \\
\text { ashed } @ 400^{\circ} \mathrm{C}\end{array}$ & ND & ND & 0.04 & 33 & ND & 0.2 \\
\hline 1029 & $\begin{array}{c}\text { Ohio } \\
\text { ashed } @ 750^{\circ} \mathrm{C}\end{array}$ & ND & ND & 0.01 & 23 & 66 & 0.6 \\
\hline 999 & Wyodak & 1.29 & 4.45 & 2.12 & 45 & ND & 4.2 \\
\hline 1005 & $\begin{array}{c}\text { Wyodak } \\
\text { ashed } @ 400^{\circ} \mathrm{C}\end{array}$ & ND & ND & 0.13 & 61 & 73 & 0.3 \\
\hline 1003 & $\begin{array}{c}\text { Wyodak } \\
\text { ashed @ } 950^{\circ} \mathrm{C}\end{array}$ & ND & ND & 0.03 & 46 & 55 & 0.1 \\
\hline 1022 & Station A & 0.557 & 4.50 & 0.60 & 24 & 58 & 1.4 \\
\hline 1026 & $\begin{array}{c}\text { Station A } \\
\text { ashed } @ 400^{\circ} \mathrm{C}\end{array}$ & ND & ND & 0.16 & 20 & ND & 1.2 \\
\hline 1027 & $\begin{array}{c}\text { Station A } \\
\text { ashed @ } 950^{\circ} \mathrm{C}\end{array}$ & ND & ND & 0.38 & 20 & 84 & $2 . .9$ \\
\hline 1023 & Blacksville & 0.140 & 4.06 & 0.26 & 27 & 56 & 0.9 \\
\hline 1033 & $\begin{array}{c}\text { Blacksville } \\
\text { ashed } @ 400^{\circ} \mathrm{C}\end{array}$ & ND & ND & 0.08 & 25 & 64 & 0.5 \\
\hline 1034 & $\begin{array}{c}\text { Blacksville } \\
\text { ashed } @ 750^{\circ} \mathrm{C}\end{array}$ & ND & ND & 0.66 & 37 & ND & 2.7 \\
\hline 1028 & GA & 0.002 & 0.67 & ND & 21 & ND & ND \\
\hline 1030 & DA & 0.114 & 6.22 & ND & 32 & ND & ND \\
\hline 1032 & DMA & 0.051 & 1.5 & ND & 24 & ND & ND \\
\hline 1035 & $\mathrm{AA}$ & 0.282 & 37.12 & ND & 31 & ND & ND \\
\hline 1038 & MA & 0.060 & 44.4 & ND & ND & ND & $\mathrm{ND}$ \\
\hline
\end{tabular}


Figure 3-45 plots the results from the tests with the AA ash. This ash showed a small amount of capture of elemental mercury and possibly some capture of $\mathrm{HgCl}_{2}$. The ash also oxidized roughly $60 \%$ of the elemental mercury. The LOI and the mercury on this ash were both high. This may be a good ash for fractionation and further analysis.

Figure 3-46 is a plot of the results with the DMA ash. This ash did not capture significant amounts of either elemental mercury or $\mathrm{HgCl}_{2}$. It showed only $20 \%$ oxidation of elemental mercury. This was a low-LOI ash that did not capture a significant amount of mercury in the full-scale system.

Figure 3-47 plots the results for the DA ash. This ash showed some capture of elemental mercury. However, there was a spike in the mercury concentration once it reached $100 \%$ of the inlet concentration. This may be the initial mercury that was captured offgassing. This ash was not reactive with the $\mathrm{HgCl}_{2}$. The LOI for this ash was not very high, but the ash did contain a significant amount of mercury.

Figure 3-48 plots the results from the test with $\mathrm{HgCl}_{2}$ injection for the $\mathrm{MA}$ ash. The ash may have captured some $\mathrm{HgCl}_{2}$, but did not reduce it to elemental mercury. The LOI for this ash is high, but it captured only one-fourth of the mercury, much as the AA ash, which had a similar LOI.

Tests with the original fly ash samples and $\mathrm{HgCl}_{2}$ injection were also completed, and are summarized in Table 3-20. Figure 3-49 plots the results from three tests with the Ohio blend ash. Prior to these tests, under a different program, tests were conducted with a catalyst that oxidized elemental mercury and appears to have contaminated the system and slightly affected the results for some runs (i.e., the Ohio ash at $350^{\circ} \mathrm{F}$ ). The contamination does not appear to have affected the concentrations, but caused a cyclic signal, which was not an instrument problem because it showed up on both the Tekran and the Semtech (Semtech data not shown in the figures). The system was cleaned a number of times, but the contamination continued to affect the results, until it eventually cleared from the system. The results from the tests with the Ohio ash indicate the ash did not capture any $\mathrm{HgCl}_{2}$ and did not reduce any of the $\mathrm{HgCl}_{2}$. The mass balances presented in Table 3-19 indicate that $\mathrm{HgCl}_{2}$ was being captured, but the analysis of the spent ash samples indicate it was not being captured by the ash. It is possible the $\mathrm{HgCl}_{2}$ was captured somewhere in the system or converted to a form that is not reduced by the $\mathrm{SnCl}_{2}$ solution. Tests under another program to develop different oxidized mercury permeation sources showed that one form of oxidized mercury was actually being captured in the $\mathrm{SnCl}_{2}$ solution.

Figure 3-50 plots the results from three separate runs with the Wyodak ash. All of the tests show the effects of the contamination in the system. The elevated elemental mercury concentrations are also a byproduct of the contamination, because the inlet elemental concentrations were checked and found to be the same as the outlet (should be zero elemental mercury). The $\mathrm{HgCl}_{2}$ permeation tube has been checked repeatedly with Ontario Hydro sampling trains, and results indicate no elemental mercury coming from the $\mathrm{HgCl}_{2}$ permeation tube. The results from these tests indicate the Wyodak ash is not reactive in terms of capturing $\mathrm{HgCl}_{2}$ or reducing it to elemental mercury. 


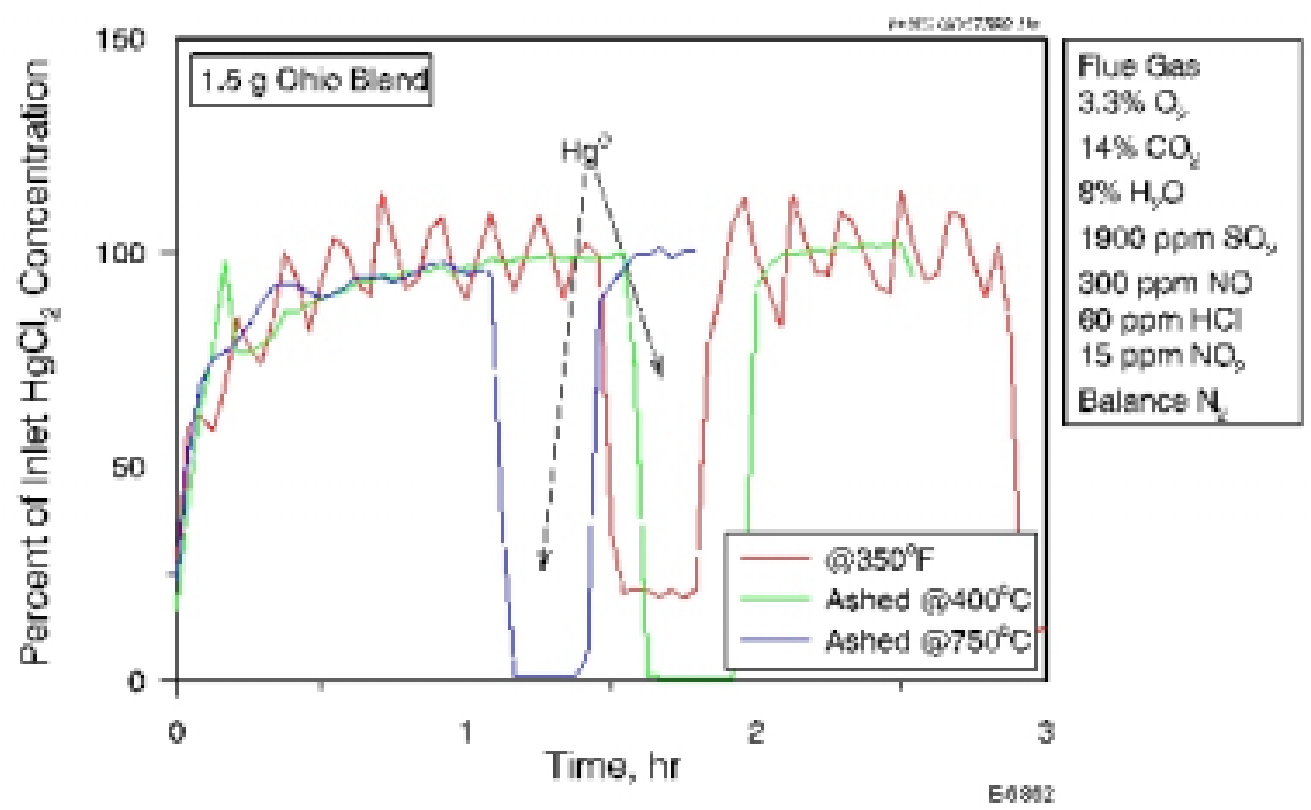

Figure 3-49. Breakthrough as a function of time for three runs with the Ohio blend ash with $\mathrm{HgCl}_{2}$ injection.

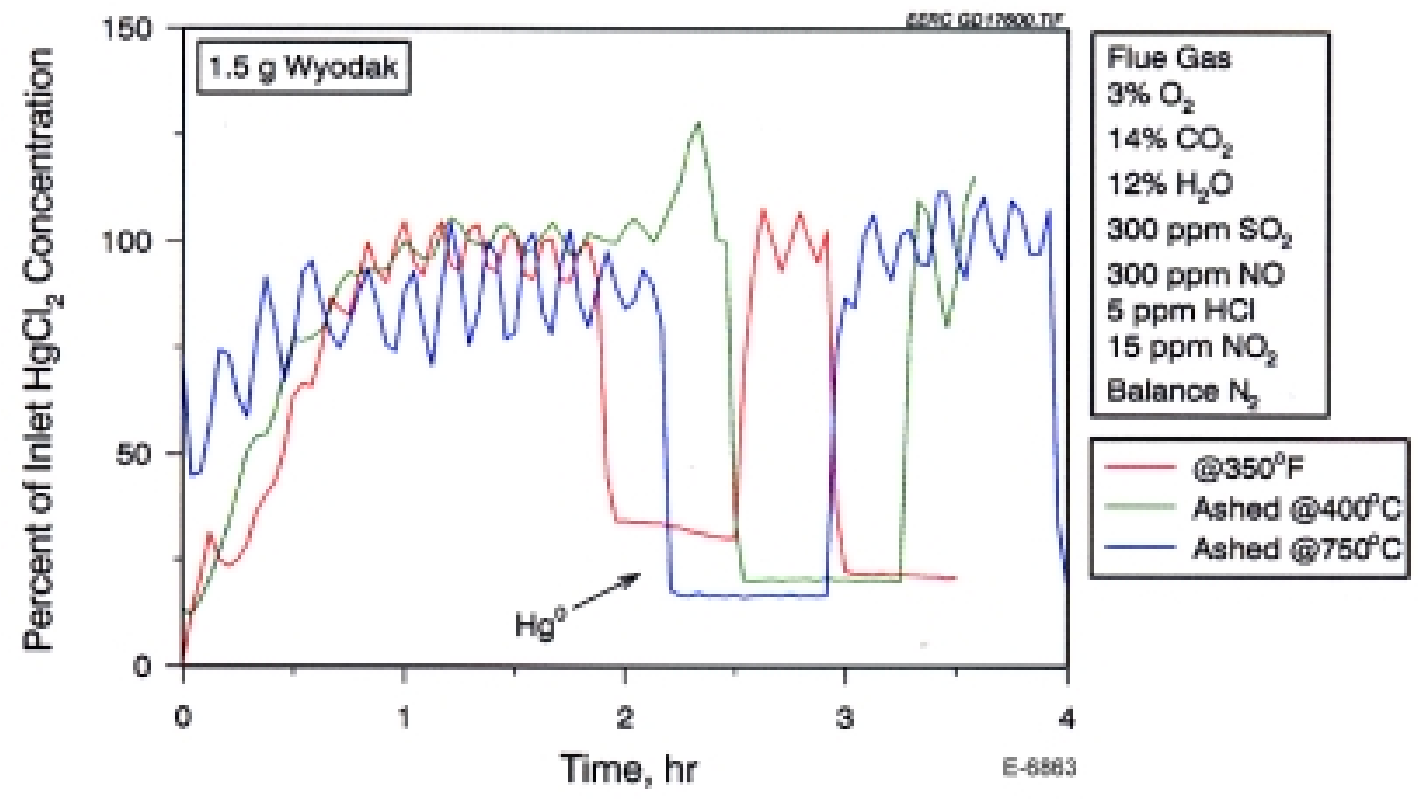

Figure 3-50. Breakthrough as a function of time for three runs with the Wyodak ash with $\mathrm{HgCl}_{2}$ injection.

Figures 3-51 and 3-52 plot the results from tests with the Station A and Blacksville ashes respectively. Results from these tests indicate both ashes have no reactivity to $\mathrm{HgCl}_{2}$ in terms of capture or reduction to elemental mercury under these test conditions. The dip in total mercury concentration $1.5 \mathrm{hr}$ into the run with the sample ashed at $750^{\circ} \mathrm{C}$ was caused when the conversion unit inadvertently went off-line. When this was found, it was brought back on-line, and the total mercury concentration again lined out at $100 \%$ of the inlet concentration. 


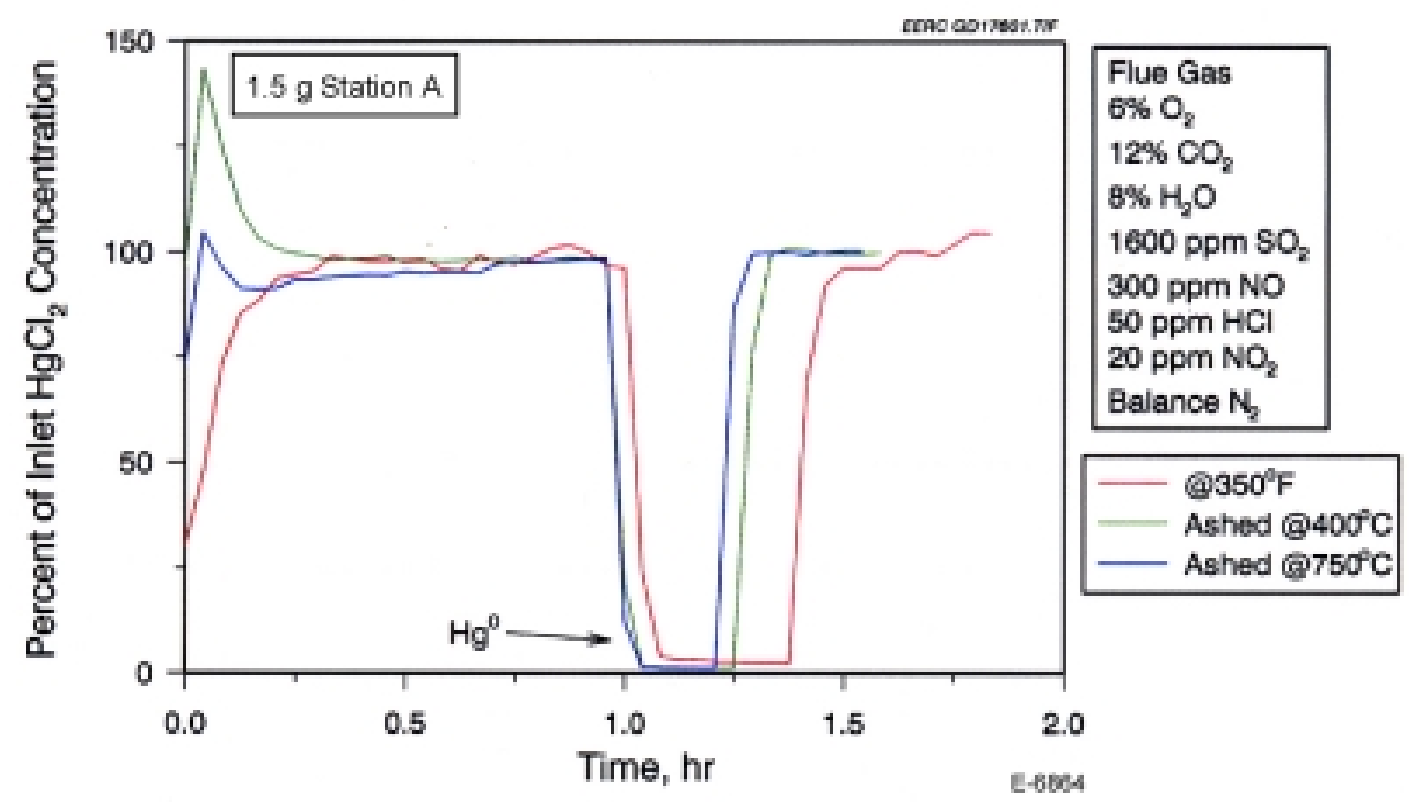

Figure 3-51. Breakthrough as a function of time for three runs with the Station A ash with $\mathrm{HgCl}_{2}$ injection.

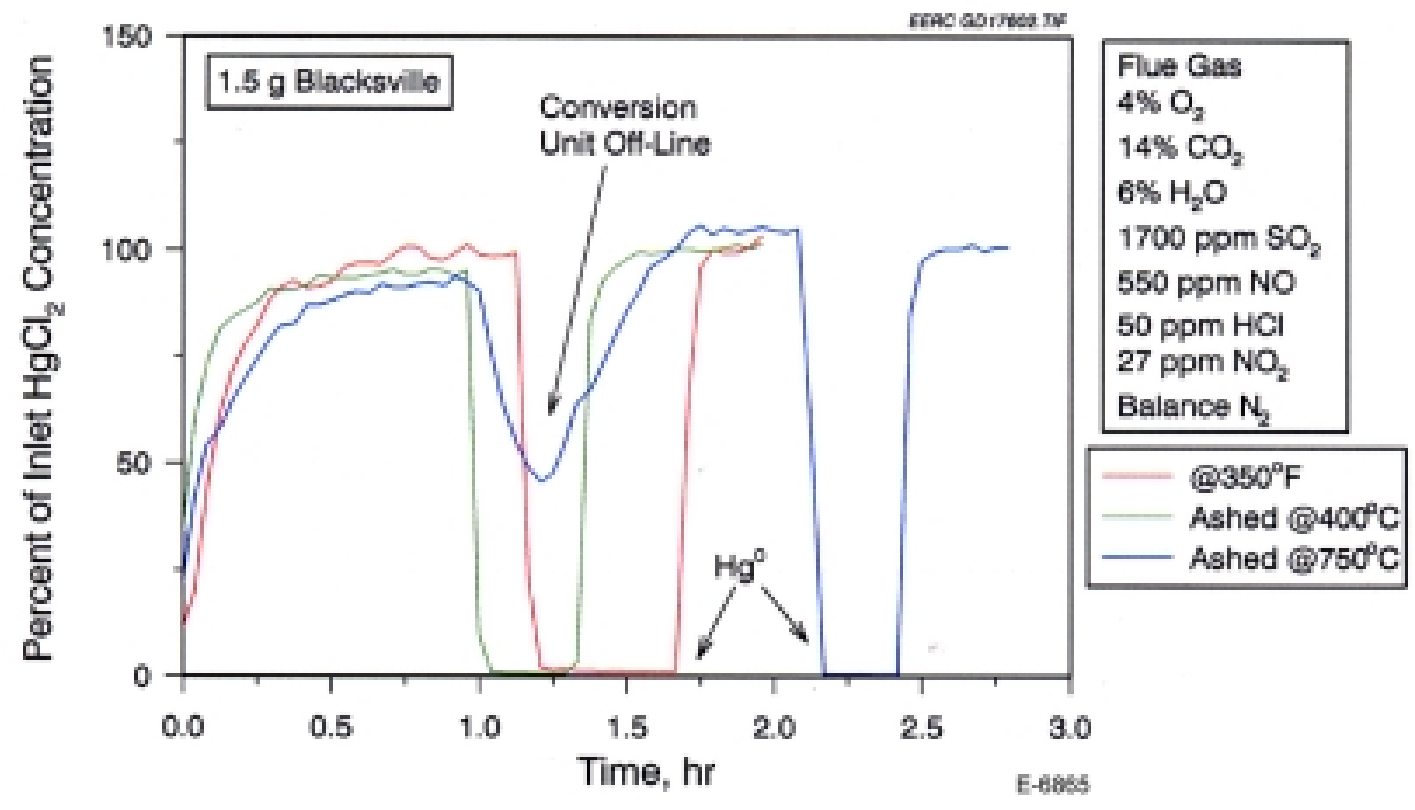

Figure 3-52. Breakthrough as a function of time for three runs with the Blacksville ash with $\mathrm{HgCl}_{2}$ injection. 
Table 3-21 summarizes the amount of oxidation observed in the bench scale tests with elemental mercury added to the simulated flue gas. The amount of oxidation was measured 1 to 3 hours into the tests when the concentration of mercury in the gas exiting the ash had become constant (as indicated in the figures in this section). Oxidation appears to increase with increasing temperature, based on the results of the Wyodak and Ohio ash samples.

Table 3-21. Amount of Elemental Mercury Oxidized in Bench Scale Tests as a Function of Temperature

\begin{tabular}{|l|c|c|c|c|c|}
\cline { 4 - 6 } \multicolumn{2}{c|}{} & \multicolumn{3}{c|}{ Mercury Oxidation } \\
\hline Ash Sample & LOI, wt $\%$ & $\mathrm{SA}, \mathrm{m}^{2} / \mathrm{g}$ & $250^{\circ} \mathrm{F}$ & $300^{\circ} \mathrm{F}$ & $3500^{\circ} \mathrm{F}$ \\
\hline Ohio & $6.79 \%$ & 1.52 & $0.0 \%$ & & $17.0 \%$ \\
\hline Ohio - ashed $400^{\circ} \mathrm{C}$ & $0.0 \%$ & 4.15 & & $30.0 \%$ & \\
\hline Ohio - ashed $750^{\circ} \mathrm{C}$ & $0.0 \%$ & 10.0 & & $17.0 \%$ & \\
\hline Wyodak & $4.45 \%$ & 13.42 & $40.4 \%$ & & $62.0 \%$ \\
\hline Wyodak - ashed $400^{\circ} \mathrm{C}$ & $0.0 \%$ & 2.65 & & & $0.0 \%$ \\
\hline Wyodak - ashed $750^{\circ} \mathrm{C}$ & $0.0 \%$ & 2.83 & & & $0.0 \%$ \\
\hline ND Lignite & $2.86 \%$ & 0.55 & $0.0 \%$ & & $0.0 \%$ \\
\hline Blacksville (pilot) & $4.06 \%$ & $\mathrm{ND}$ & & & $40.0 \%$ \\
\hline Comanche (full scale) & $0.9 \%$ & $\mathrm{ND}$ & $25.4 \%$ & & \\
\hline Station A (full scale) & $4.50 \%$ & $\mathrm{ND}$ & $38.1 \%$ & & \\
\hline Station B (full scale) & $0.88 \%$ & $\mathrm{ND}$ & & & $78.0 \%$ \\
\hline Ash GA & $0.67 \%$ & 0.71 & & & $15.2 \%$ \\
\hline Ash AA & $37.12 \%$ & 4.36 & & & $50.9 \%$ \\
\hline Ash DMA & $1.5 \%$ & 0.96 & & & $20.3 \%$ \\
\hline Ash DA & $6.22 \%$ & 6.17 & & & $56.9 \%$ \\
\hline
\end{tabular}

There does not seem to be any clear correlation between either surface area or carbon content when comparing ash from different coals. Although carbon has been shown to oxidize mercury, there are other factors at play, perhaps related to the composition of the noncarbonaceous part of the ash. The Wyodak sample has been shown to have soot in the ash (which may account for its high surface area). When the Wyodak sample is ashed to remove the carbon, the ability to oxidize mercury also disappears, suggesting that carbon is responsible for mercury oxidation. For the Ohio ash, on the other hand, the ability to oxidize mercury is retained in the ash samples, suggesting that something other than carbon is responsible for mercury oxidation in this ash.

The tests with elemental mercury injection identified the Station A ash and the AA ash as candidates for further evaluation. The ash from the Station B station is a third possibility. A sample of fly ash from the Dale station was evaluated under a different program as a possible sorbent for mercury. Results indicated it was not effective for mercury capture, but did oxidize over $80 \%$ of the elemental mercury. The baseline Dale station ash was treated with sulfur to increase its ability to capture mercury (it didn't), but the more sulfur that was added, the less elemental mercury was oxidized. We have received permission to perform further tests with these samples. Results from the tests with $\mathrm{HgCl}_{2}$ injection indicate none of the ash samples were reactive with the $\mathrm{HgCl}_{2}$. It may be necessary to repeat some of the tests at a lower temperature to improve capture. 
Future tests include evaluation of the Station B ash and possibly tests with the Dale station ash samples. Also, high-carbon ash samples from the University of Arizona will be evaluated.

\subsubsection{Morphology of Ash Samples Used in Bench Scale Testing}

The samples from the University of Arizona combustor which were tested at bench scale at EERC (Section 3.4.2) were also examined at the University of Utah be scanning electron microscopy. The carbon content of these samples was high, particularly that of the two low rank coals. In addition, the surface area of the Wyodak ash was abnormally high, and suggested that perhaps this ash sample contained soot. Therefore, a small study was undertaken of the morphology of these ash samples. The LOI and surface area data, of each sample are listed in Table 3-22.

Table 3-22. Surface Area and LOI of Ash Samples for Morphological Analysis

\begin{tabular}{|c|c|c|c|c|}
\hline Sample No. & Identity Number & Type & LOI in \% & Surface Area $\mathrm{m}^{2} / \mathrm{g}$ \\
\hline \hline 1 & INO24-1 & Ohio & 6.79 & 1.52 \\
\hline 2 & INO24-2 & N.Dakota & 2.86 & 0.55 \\
\hline 3 & INO24-3 & Wyodak & 4.45 & 13.42 \\
\hline
\end{tabular}

\subsubsection{Method}

The samples were prepared for electron microscopy by suspending the materials in ethyl alcohol using an ultrasonic agitator. The ultrasonic agitator was run for two minutes to ensure a thorough suspension. The suspension was subsequently diluted to one-tenth and one-hundredth of the original strength. The material was then deposited on a $0.4 \mu \mathrm{m}$ pore size polycarbonate membrane filter by vacuum filtration, dried in room temperature overnight and then mounted, for investigation with SEM (Cambridge S 240, tungsten filament, kavex energy dispersive X-ray, Dapple energy dispersive X-ray analyzer). Each microscopy sample had a strip of filter for both the strengths $(1 / 10 \& 1 / 100)$.

The imaging was done with the scanning electron microscope in the Material Sciences department, University of Utah, Salt Lake City.

To identify the carbon, the samples were examined for the presence of large irregular shaped particles or aggregates of ultrafine particles. The hypothesis of this investigation is that the large chunks of irregular shaped particles are unburnt coal and that the fine aggregates are soot. This hypothesis is based on previous investigations of carbon in coal combustion products.[58,59] The EDS study on the samples was not conducted for problems mentioned in the discussion. 


\subsubsection{Observations with Electron Microscopy}

Sample 1: (Ohio). Large irregular shaped particles, suggesting char, were found in the sample along with large spherical particles that looked like mineral ash due to their glassy or crystalline appearance. At higher magnification, the pores of the polycarbonate membrane filter were clearly seen. No aggregates of ultrafine particles were seen.

The four pictures (Figures 3-53 through 3-56), though not a zoom-sequence, are representative of the sample. The first picture, Figure 3-53, shows the general collection of particles of different sizes and shapes. The most common particles are the spherically shaped ones. From this picture it can be safely stated that they are 2 to $10 \mu \mathrm{m}$ in size. At higher magnification, it was found that they had a glassy or crystalline surface suggesting the presence of mineral ash particles [60-62]. A large number of irregularly shaped particles can also be seen in this picture, suggesting unburnt char [58]. Figures 3-54 and 3-55 show such particles. Figure 3-56 shows that at higher magnification, no aggregates or ultrafine particles are seen.

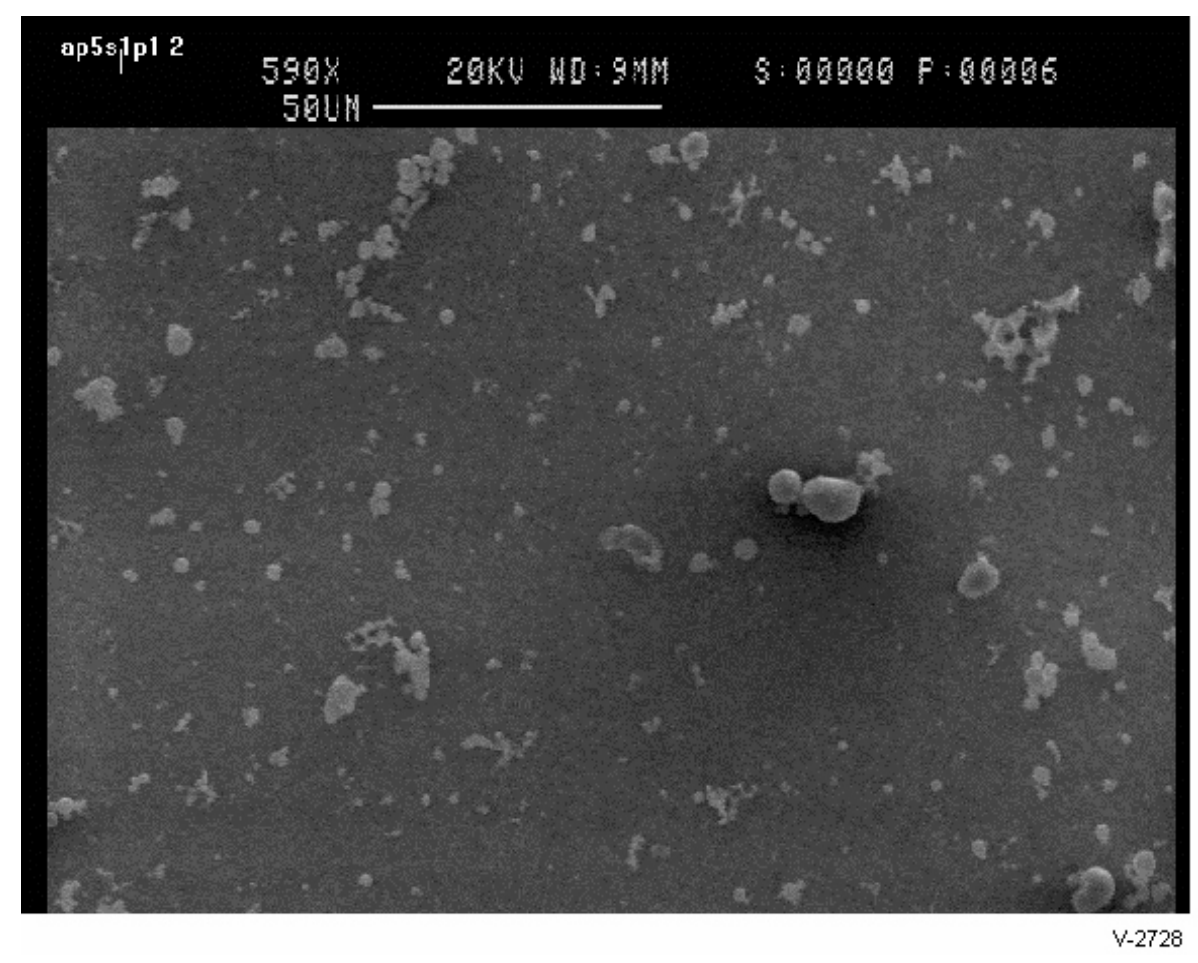

Figure 3-53. SEM photograph of Ohio ash sample (590 times magnification). 


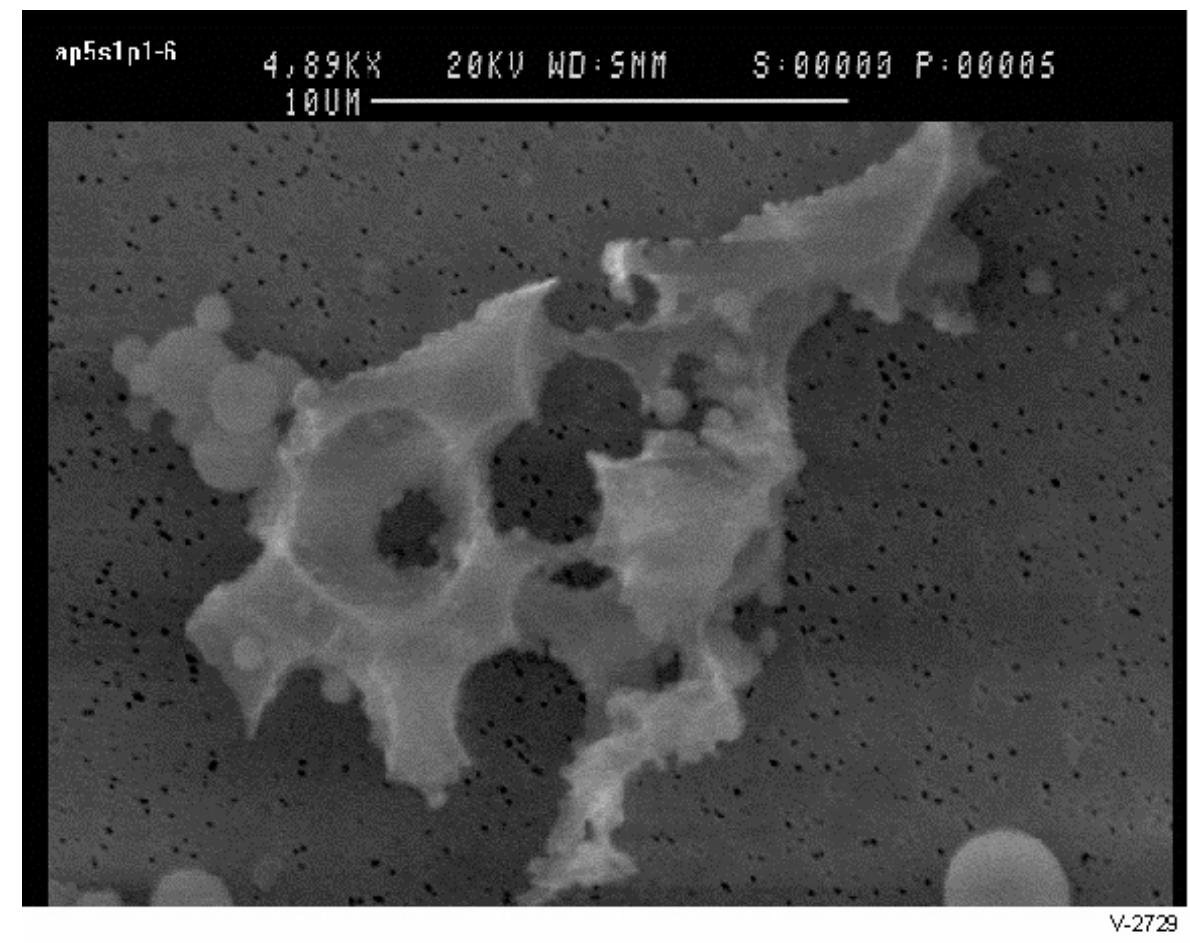

Figure 3-54. SEM photograph of Ohio ash sample (4,890 times magnification).

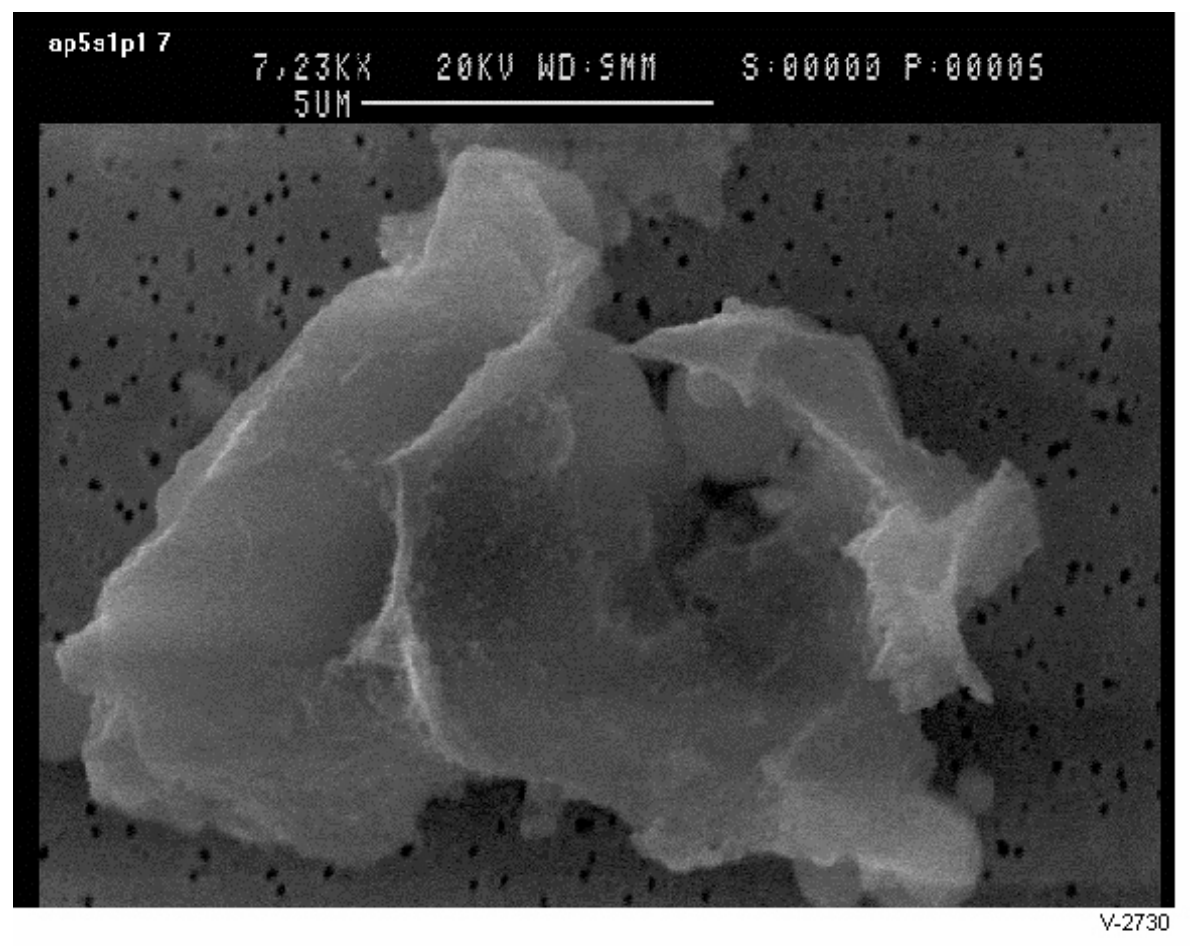

Figure 3-55. SEM photograph of Ohio ash sample (7,230 times magnification). 


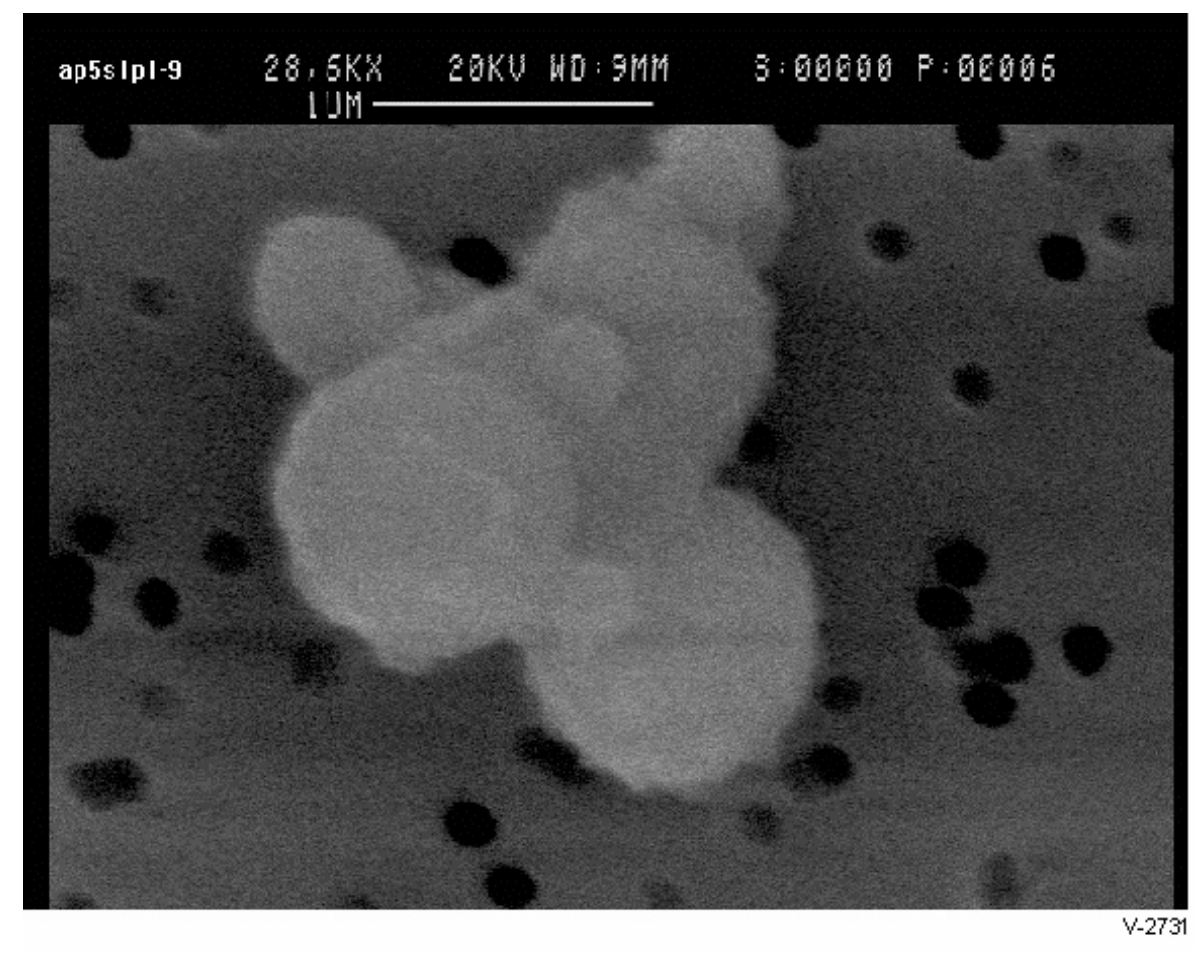

Figure 3-56. SEM photograph of Ohio ash sample (28,600 times magnification).

Sample 2: (North Dakota). Sample 2 has a large number of spherical particles that are glassy or crystalline suggesting mineral ash particles formed by coalescing of minerals during combustion [60-62]. The zoom-sequence of Figures 3-57 through 3-60 shows the mineral ash particles.

After a thorough study of the sample it was found that it contained a lot of irregularly shaped particles. No aggregates of ultrafine particles were found in the sample. The following pictures (Figures 3-61 and 3-62) show the spherically shaped particles and the irregularly shaped particles in the sample.

The first four pictures show a zoom in sequence of a particular area in the North Dakota sample filter strip. Lots of spherical shaped particles are seen in these pictures suggesting mineral ash content. Figure 3-60 shows a particle covered with micro-crystals that look similar to crystals of calcium sulfate as reported in earlier works [64]. The remaining pictures show some irregularly shaped particles that could possibly be unburnt char as suggested by the hypothesis framed. The aggregates of ultrafines discussed earlier were not found in this sample also. This leads to the conclusion that the carbon in the North Dakota sample is found in the large irregular shaped particles and not the ultrafine aggregates. This was surprising since previous samples of fly ash from North Dakota lignite have contained clusters of ultrafine particles [63]. 


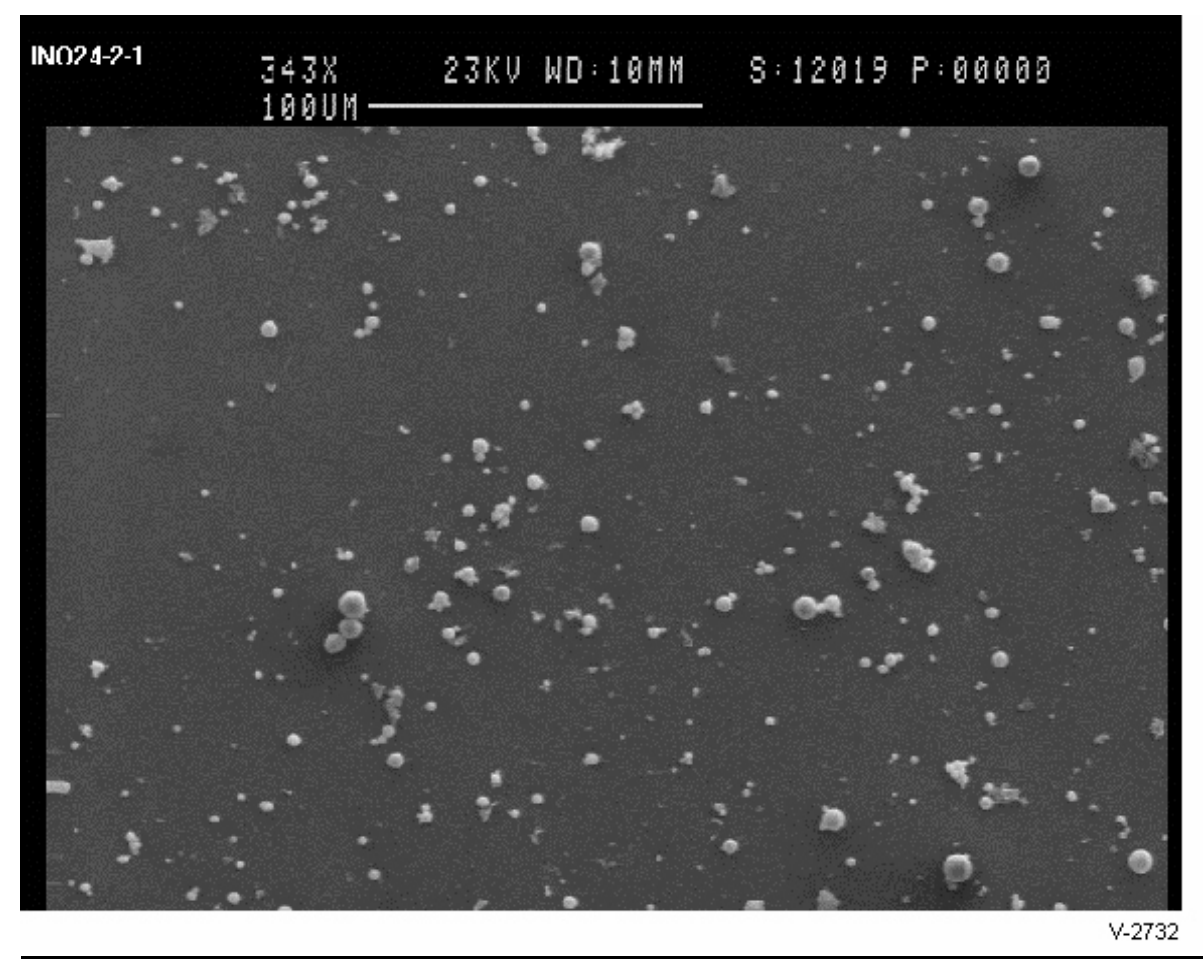

Figure 3-57. SEM photograph of North Dakota lignite ash sample (343 times magnification).

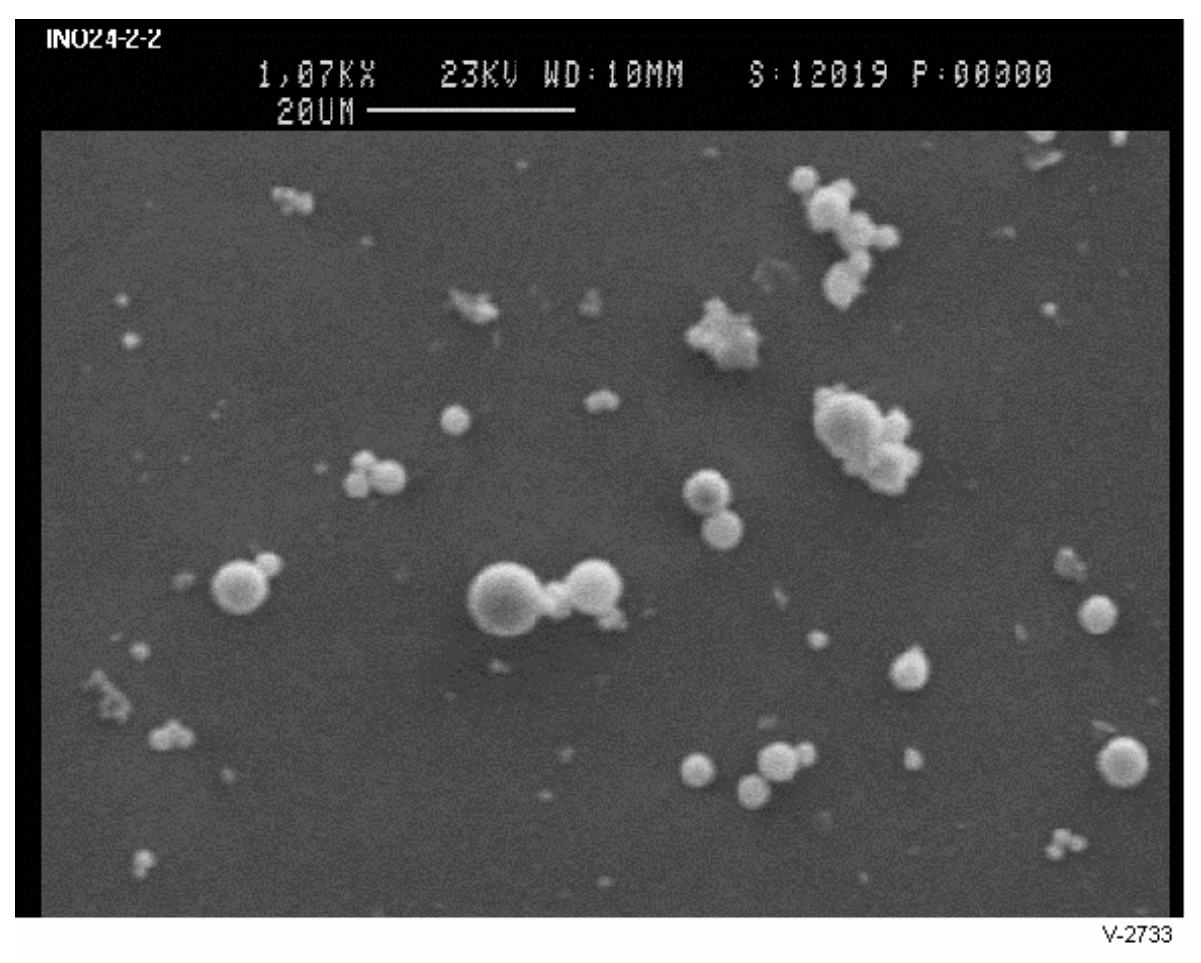

Figure 3-58. SEM photograph of North Dakota lignite ash sample (1,070 times magnification). 


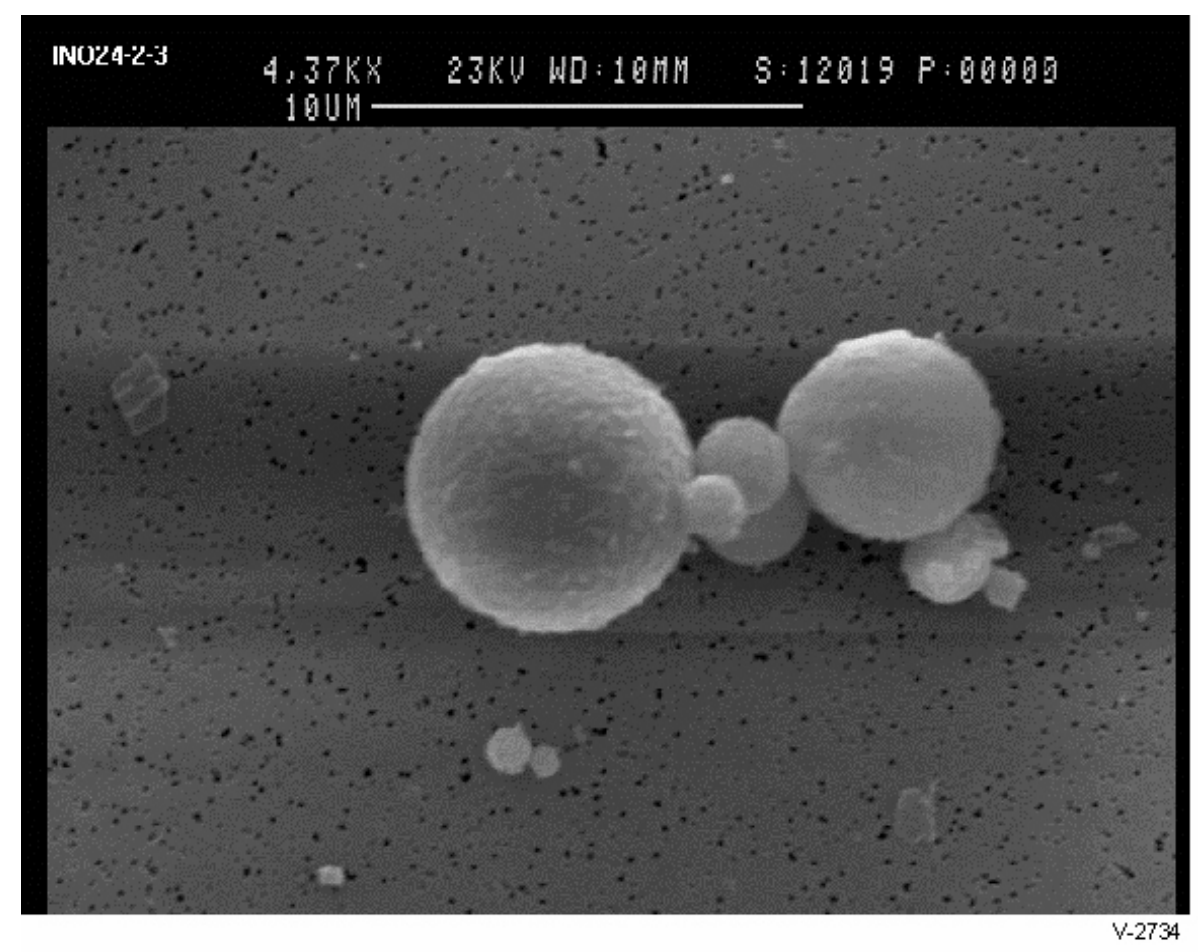

Figure 3-59. SEM photograph of North Dakota lignite ash sample (4,370 times magnification).

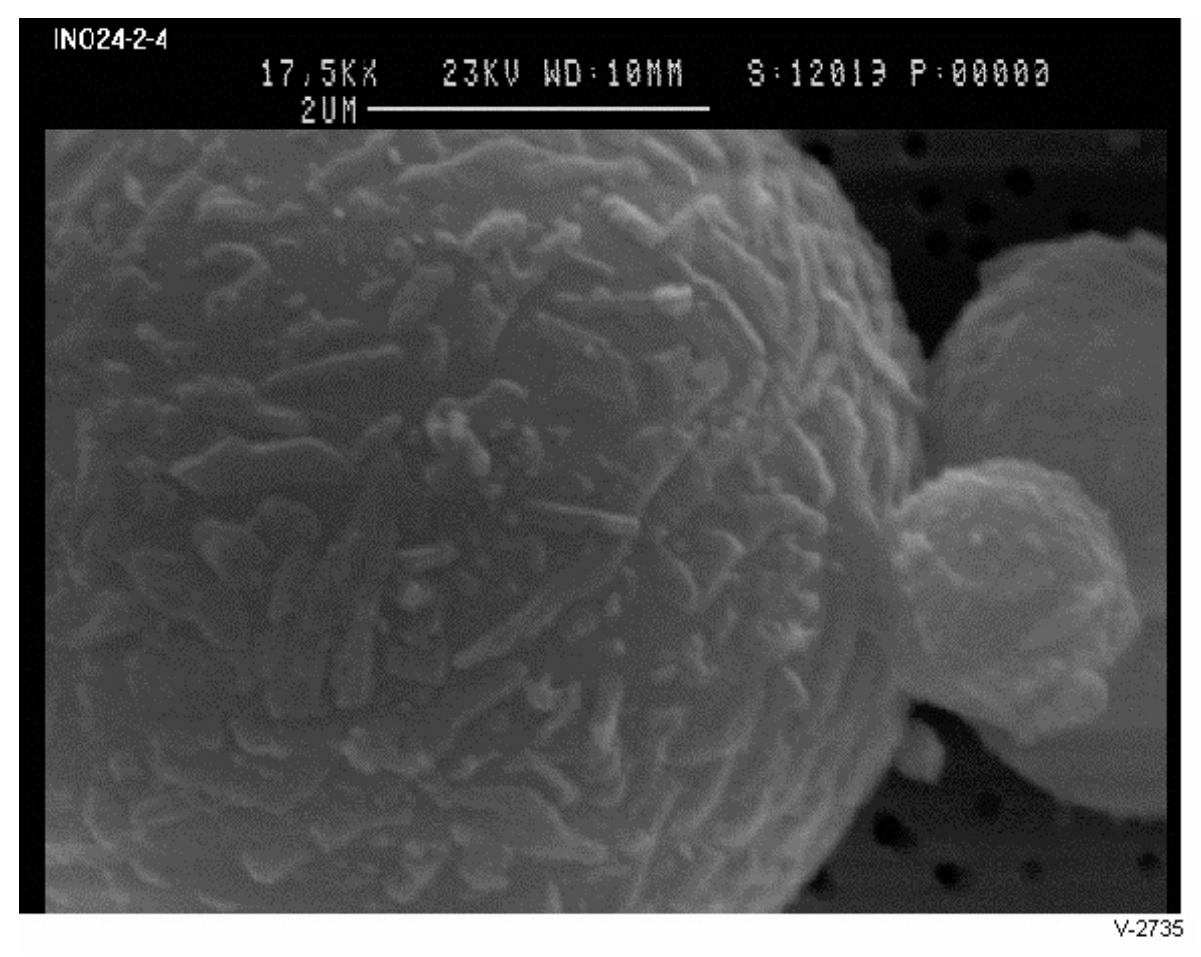

Figure 3-60. SEM photograph of North Dakota lignite ash sample (17,500 times magnification). 


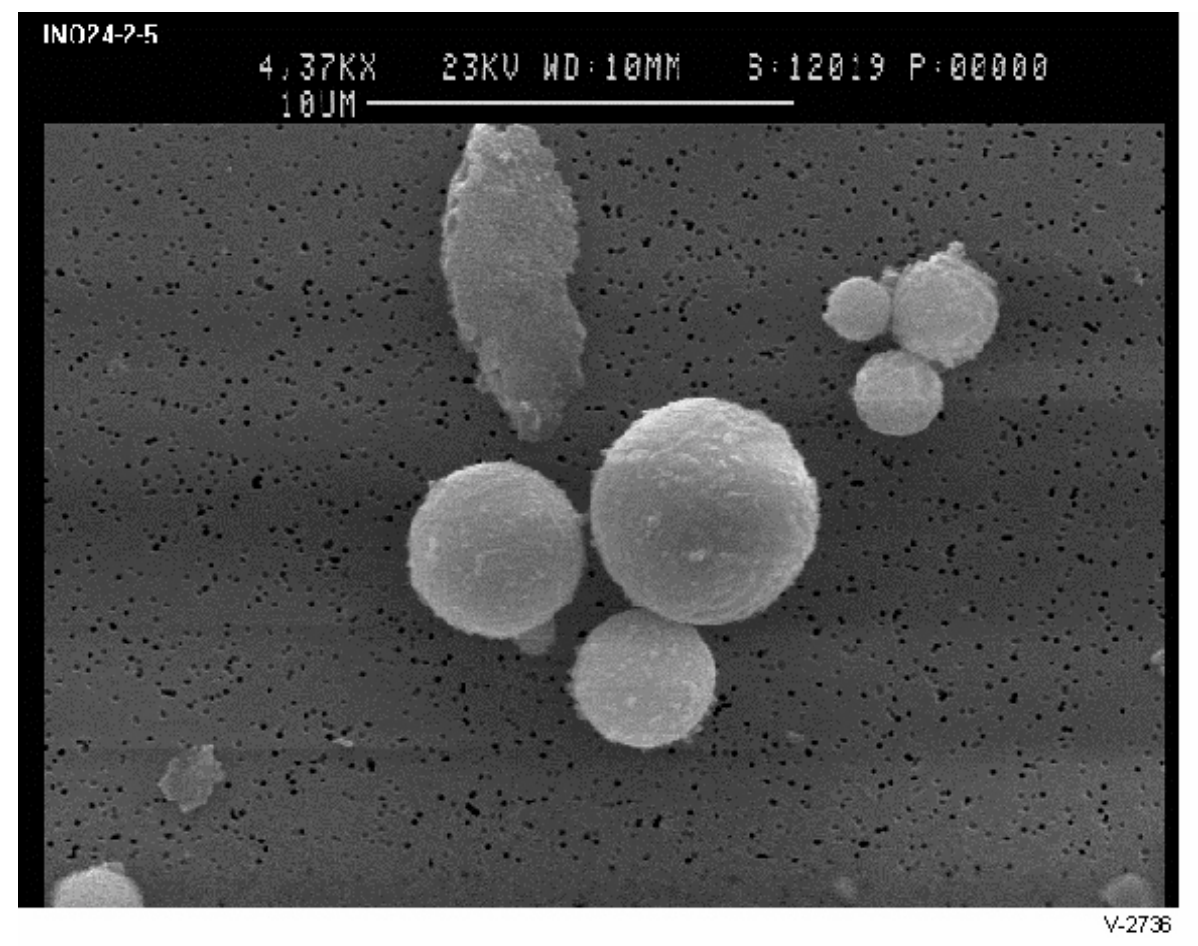

Figure 3-61. SEM photograph of North Dakota lignite ash sample (4,370 times magnification).

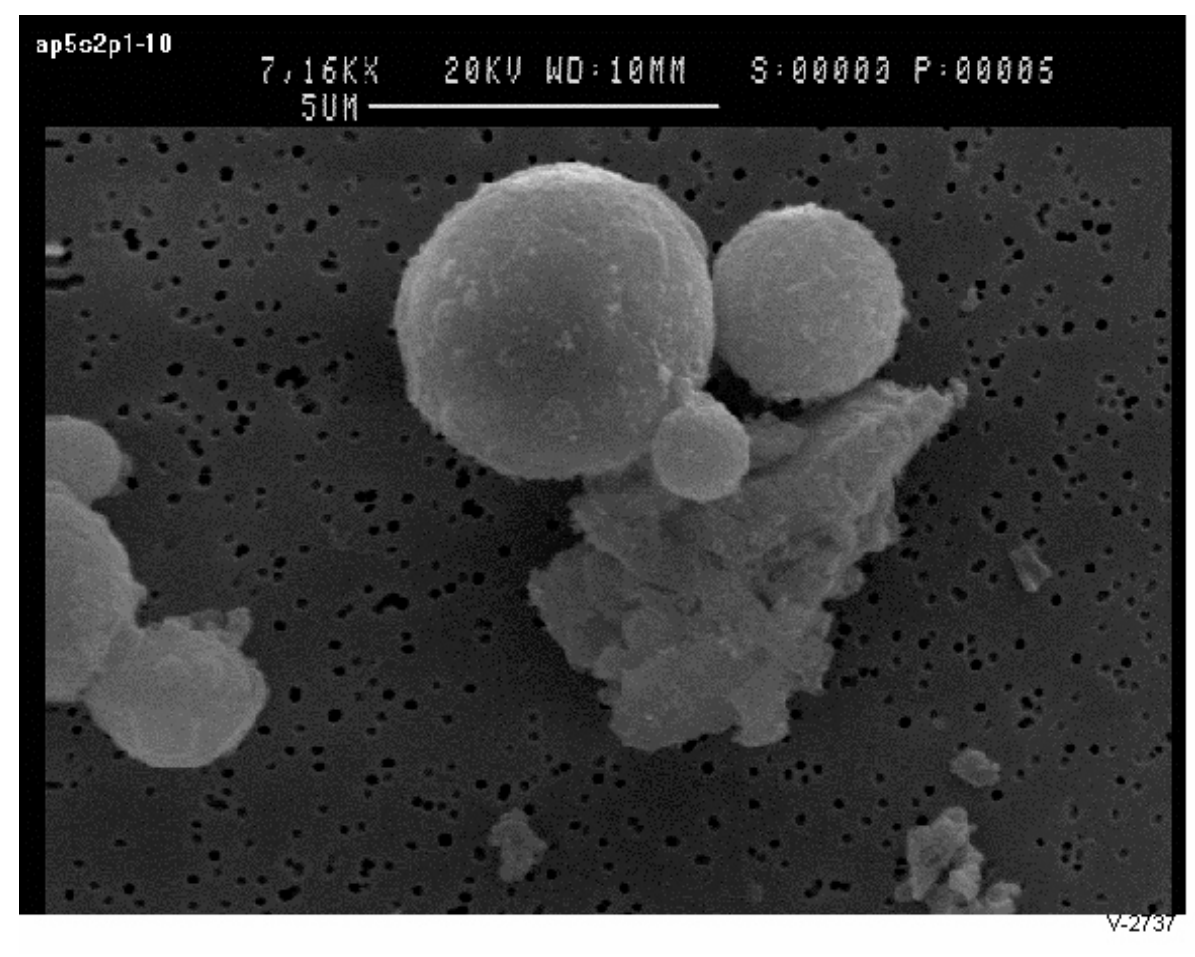

Figure 3-62. SEM photograph of North Dakota lignite ash sample (7,160 times magnification). 
Sample 3: (Wyodak). The third sample showed a large number of spherical particles along with some ultrafine aggregates. The irregular shaped particles mentioned earlier were not found in this sample.

The first three pictures, Figures 3-63 through 3-65, in the third sample are a zoomsequence showing the general types of particles present in the sample. The third picture in the sequence shows some aggregates present in it. This is the general trend, as observed in from the investigation. The number of irregulars is very small in comparison with the other two samples.

The next sequence (Figures 3-66 through 3-69) is also from the third sample (Wyodak) and shows large $(2$ to $5 \mu \mathrm{m})$ irregular particles which might be char and ultrafine aggregates 200 to $500 \mathrm{~nm}$ in size with primary particles on the order of tens of nanometers.

\subsubsection{Discussion}

From the literature, it can said that the spherical particles found in the samples are mineral ash particles formed by the coalescence of minerals during combustion. The large irregularly shaped particles could be unburnt char and the small aggregates, found in abundance only in the Wyodak sample, could possibly be soot. However, these ultrafine particles could also be mineral ash formed by vaporization and condensation. The inference that the Wyodak sample contained soot was made by the fact that a large amount ultrafine aggregates was found by microscopy (that also explains that large surface area of the sample). The sample did not contain the large irregularly shaped particles, suggestive of char, that were found in the other two samples, even though the LOI measurement showed that unburnt carbon was present. Hence the carbon in the sample could be in the form of soot.

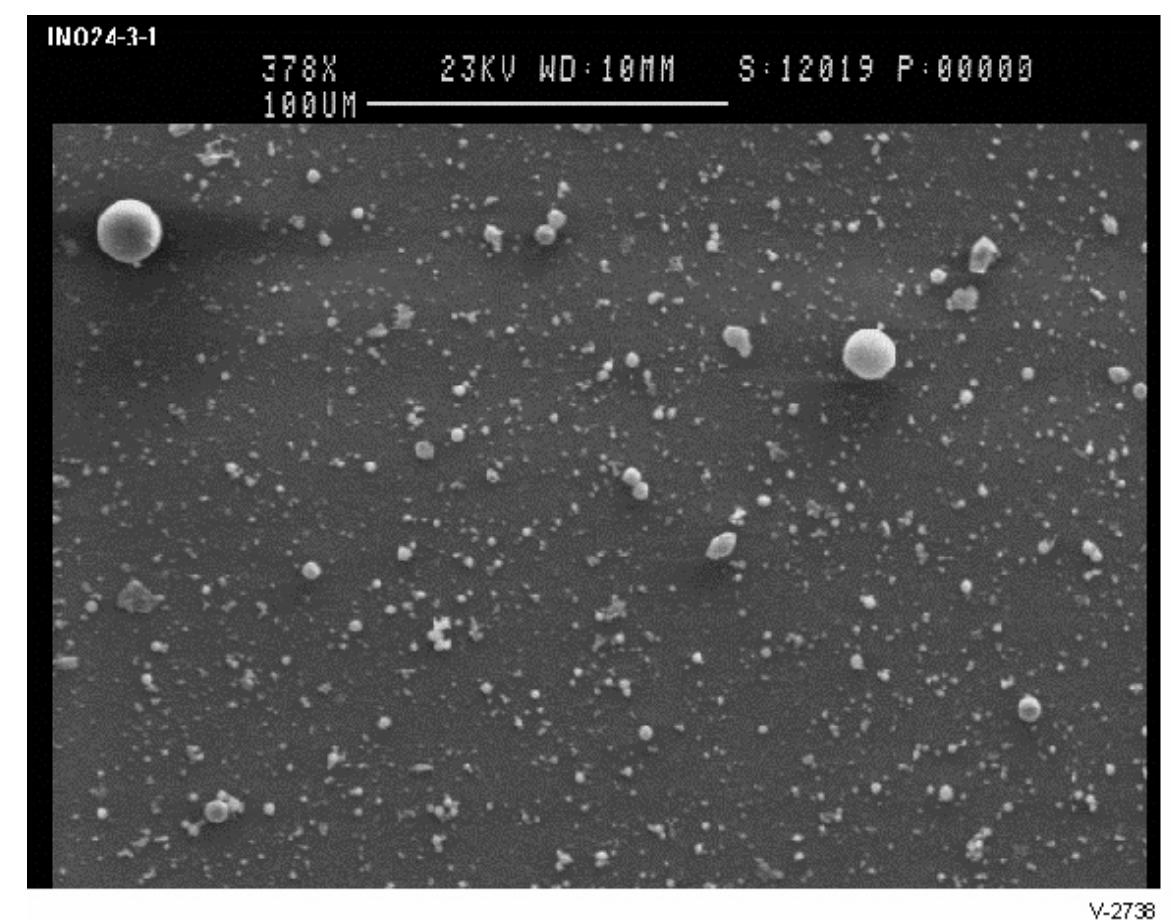

Figure 3-63. SEM photograph of Wyodak ash sample (378 times magnification). 


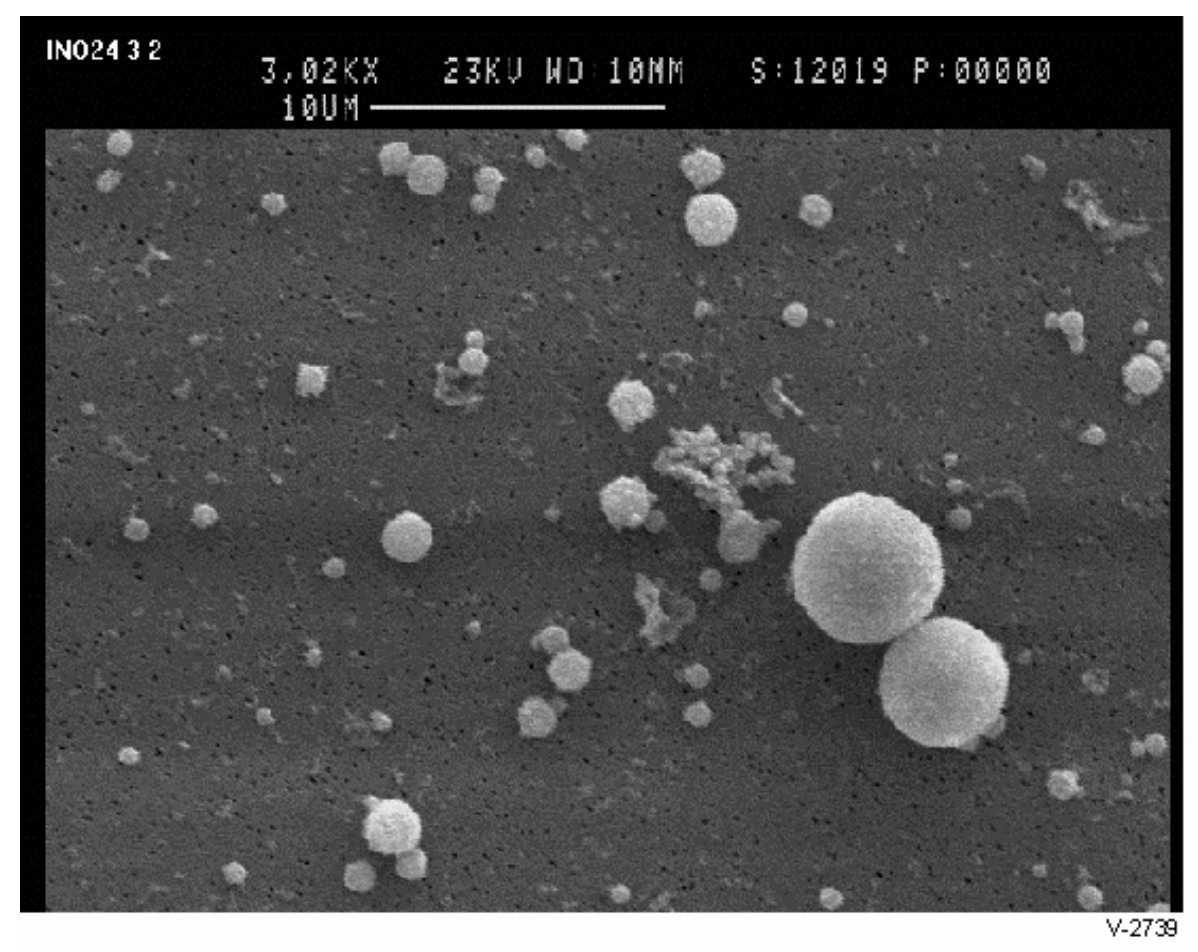

Figure 3-64. SEM photograph of Wyodak ash sample (3,020 times magnification).

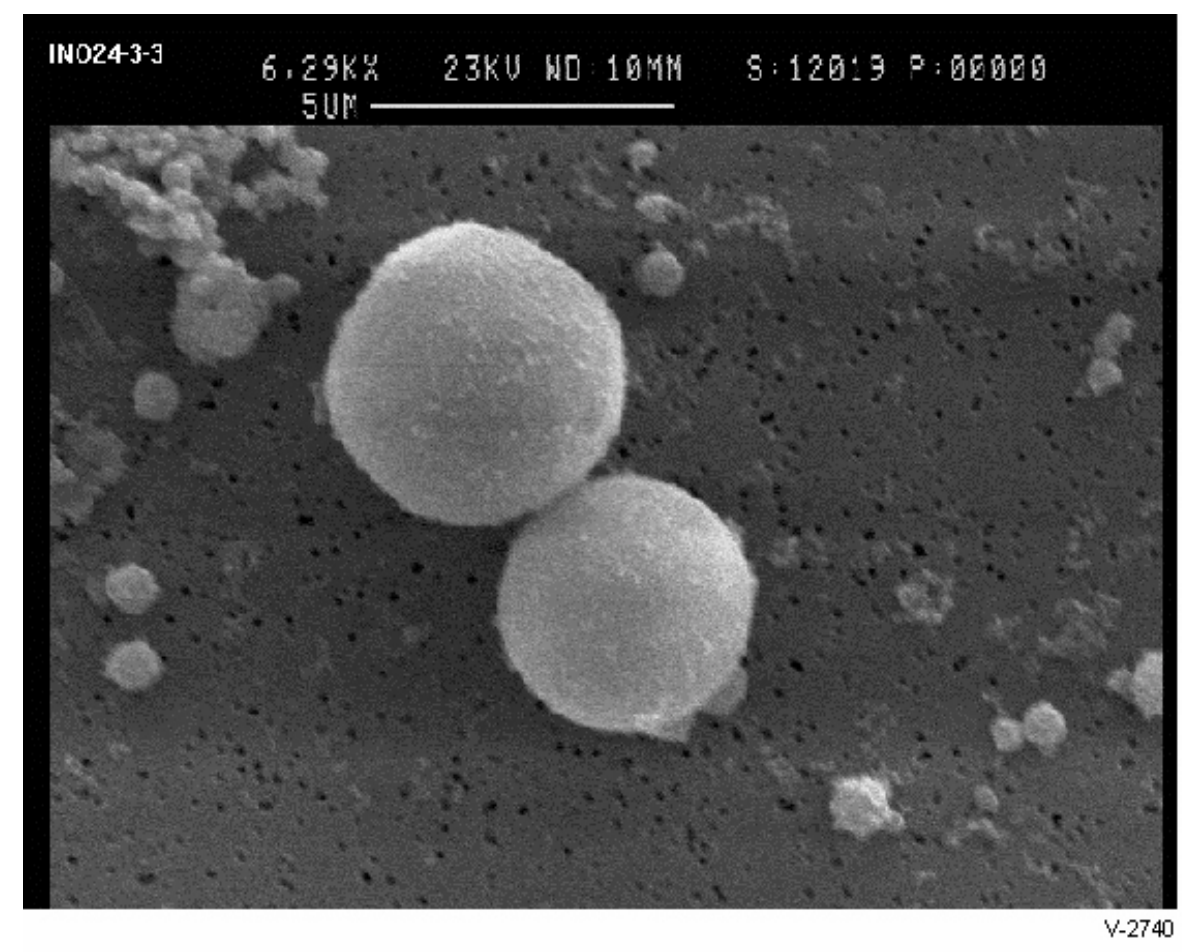

Figure 3-65. SEM photograph of Wyodak ash sample (6,290 times magnification). 


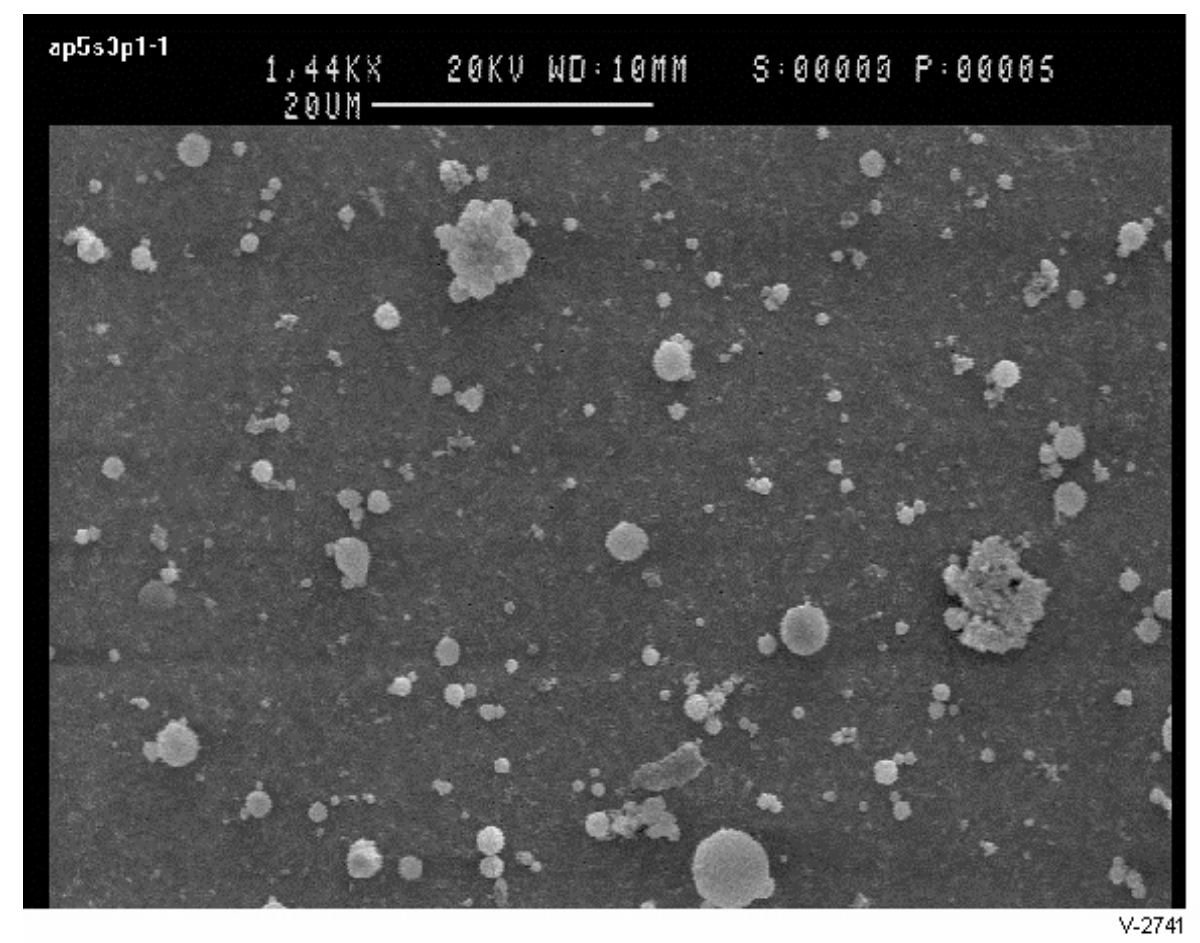

Figure 3-66. SEM photograph of Wyodak ash sample (1,440 times magnification).

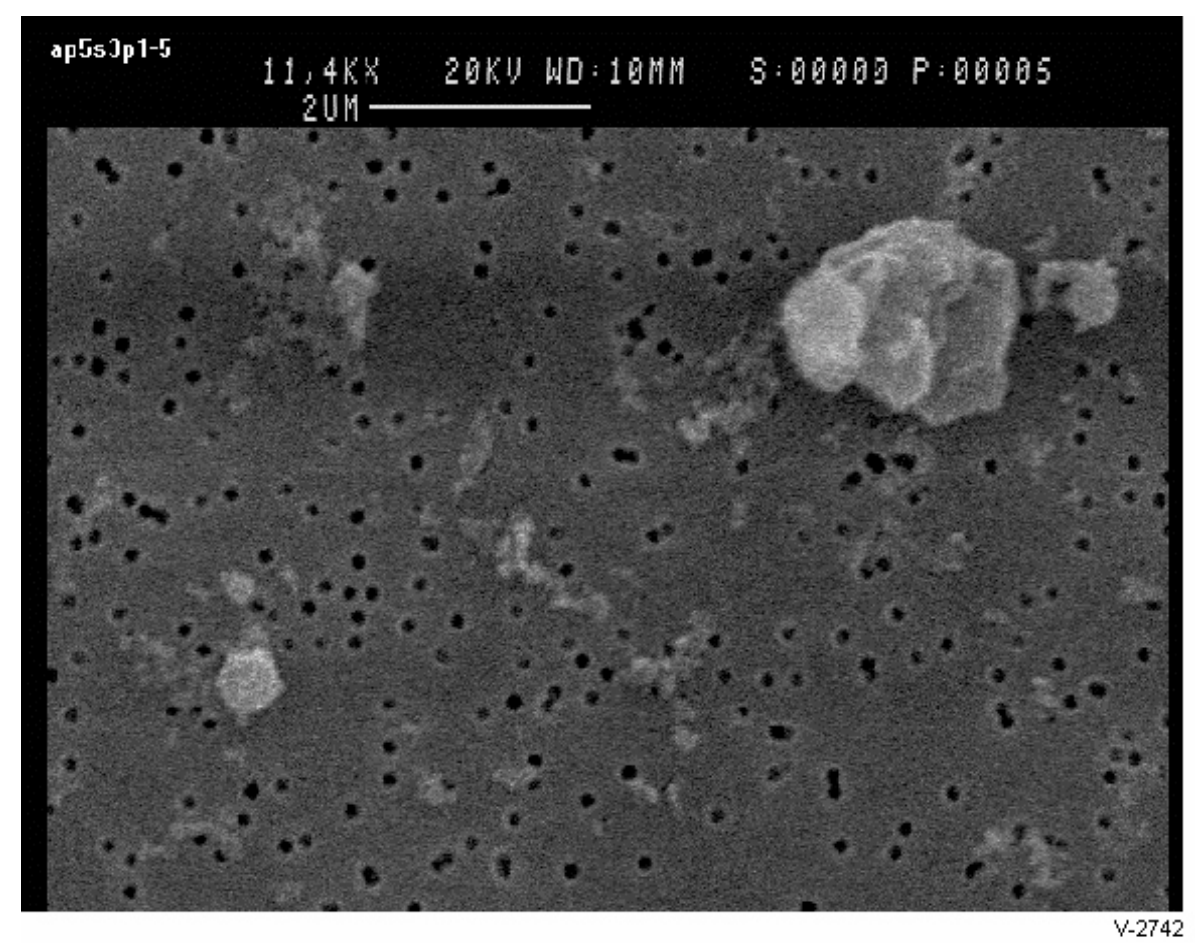

Figure 3-67. SEM photograph of Wyodak ash sample (11,400 times magnification). 


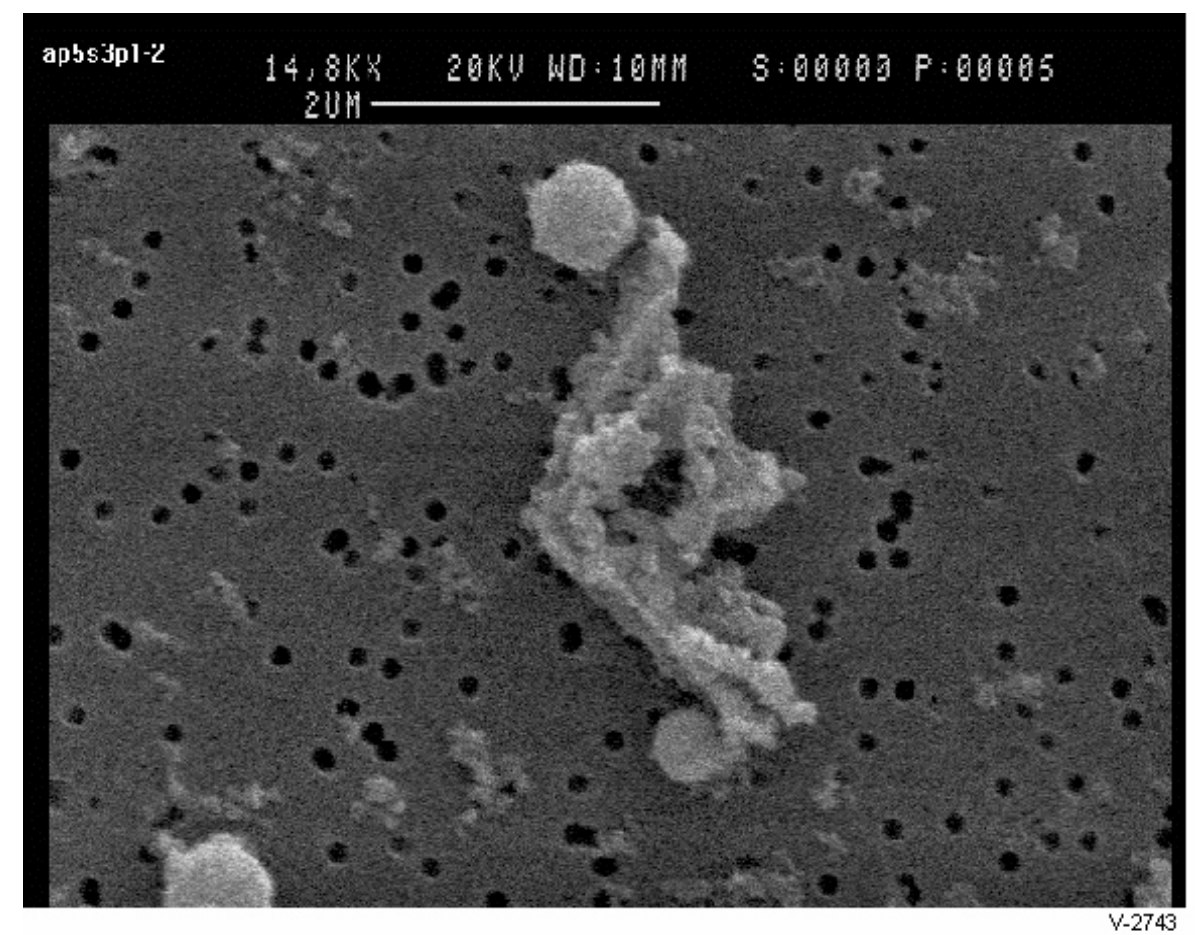

Figure 3-68. SEM photograph of Wyodak ash sample (14,800 times magnification).

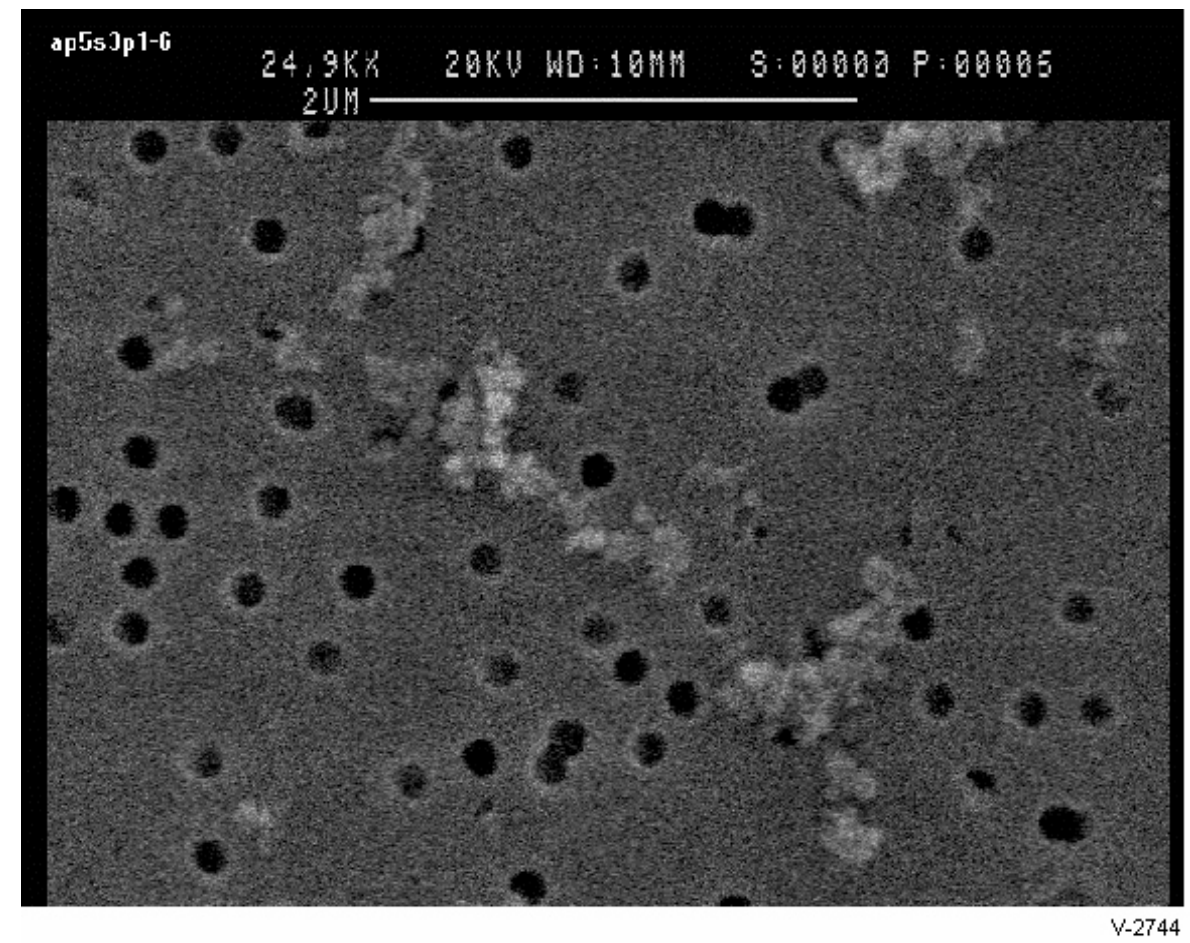

Figure 3-69. SEM photograph of Wyodak ash sample (24,900 times magnification). 
The EDS or a qualitative analysis is very useful in determining whether the ultrafine particles are carbon or metal oxides. EDS analysis was not performed on these particles due to limitations of the instrument in the Material Sciences department. The instrument tended to lose focus, when the working distance was changed for the purpose the EDS analyses. Direct viewing at large working distances was also not possible due to limitations of the instrument. The instrument will soon be replaced. Further studies in-depth are hence possible. From the origin of particles (based on the surface area data and what is known about the formation of particle during coal combustion) and the images that were taken, the conclusion made was that the North Dakota and the Ohio samples contained char and the aggregates suggesting soot was not seen. Hence all the carbon in these samples is in the form of char. The Wyodak sample hardly had any char in it. The aggregates suggesting soot were present. Hence the carbon in the sample is in the form of soot also. 


\section{SECTION 4}

SUMMARY AND FUTURE PLANS

4-1/4-2 


\section{SUMMARY AND FUTURE PLANS}

\subsection{Summary}

The final program review meeting of Phase II was held on June 22 in Salt Lake City. The goals of the meeting were to present work in progress and to identify the remaining critical experiments or analyses, particularly those involving collaboration among various groups. The information presented at the meeting is summarized in this report. Remaining fixed bed, benchscale experiments at EERC were discussed. There are more ash samples which can be run. Of particular interest are high carbon ash samples to be generated by the University of Arizona this summer and some ash-derived sorbents that EERC has evaluated on a different program. The use of separation techniques (electrostatic or magnetic) was also discussed as a way to understand the active components in the ash with respect to mercury.

XAFS analysis of leached and unleached ash samples from the University of Arizona was given a high priority. In order to better understand the fixed bed test results, CCSEM and Mössbauer analyses of those ash samples need to be completed. Utah plans to analyze the ash from the single particle combustion experiments for those major elements not measured by INAA. USGS must still complete mercury analyses on the whole coals and leaching residues. Priorities for further work at the SHRIMP-RG facility include arsenic on ash surfaces and mercury in sulfide minerals.

Mössbauer analyses of coal samples from the University of Utah were completed; samples from the top and bottom layers of containers of five different coals showed little oxidation of pyrite in the top relative to the bottom except for Wyodak.

Recently, new (INAA) data were obtained for arsenic and other elements in the actual leached coal fractions on which the XAFS data were recorded. These analyses therefore represent the first direct comparison of the XAFS spectroscopic method and the leaching method of determining speciation. In light of now having both XAFS and INAA data on the identical residue fractions, the conclusions reported in previous reports have to be significantly revised. INAA data were correlated with the XAFS data on the arsenic edge-step reported previously for the same fractions and similar trends to that obtained previously for the relationship between arsenic content and arsenic edge-step height were seen.

A number of important conclusions can be reached from this detailed, direct comparison of the XAFS spectroscopy and leaching protocol methods for speciation of arsenic in coal. XAFS spectroscopy shows clearly that the major fraction of arsenic leached from both coals by $\mathrm{HCl}$ is arsenate and that $\mathrm{HNO}_{3}$ removes much of the remaining arsenic in both coals. Leaching with HF has little effect on the arsenic content of both coals examined and appears restricted to removing any arsenate species that remains after the $\mathrm{HCl}$ leach. Such a result indicates that there is no need to postulate the presence of minor arsenic associated with silicates. The arsenic associated with pyrite in the bituminous coal is removed effectively by nitric acid, but a quite different form is removed from the lignite by nitric acid. Finally, a small fraction of the arsenic ( 5 to $15 \%$ ) remains in the coal after the nitric acid leach. We suspect that this might be an organo-arsenate formed by a side reaction between the arsenic leached from the coal and new 
oxygen functionality on the coal introduced by reaction of the coal macerals with the oxidizing nitric acid.

Processing of leaching analytical results obtained from the USGS Denver laboratories has been completed and these results are reported in the Quarterly Report for April through June, 2000. The results show excellent recoveries. Results for Fe and As show a strong sulfide association for the Ohio sample and mixed associations, dominantly HCl-leachable associations for the two lower rank coals. Leaching results are now available for all elements except mercury. A new direct-method instrument devoted to mercury analysis, was tested during the reporting period, and is now available for use on unknowns. Mercury analysis splits saved from leaching solid residues are now being submitted for analysis using this instrument. USGS microprobe and SEM facilities are currently unavailable for use, but planned studies include more complete integration of leaching results and SEM mineralogy.

During the reporting period, staff at the Stanford/USGS SHRIMP-RG ion microprobe tested a new cesium primary beam. Tests included using the cesium ions to investigate the ionization behavior of mercury in a cinnabar $(\mathrm{HgS})$ standard. This test did not yield satisfactory results, and our efforts to determine $\mathrm{Hg}$ and other metals in sulfides, must await the changeover to the oxygen source, later in the summer, to determine if there is sufficient ionization of mercury to make the planned determinations on sulfides.

The University of Utah has completed the experiments in the drop tube furnace and begun analysis of the single particle combustion experiments. The initial analysis shows a pronounced bimodal size distribution. Analysis of the Ohio data shows an enrichment of several elements in the submicron ash as oxygen concentrations are increased. In the presence of carbon dioxide, the fraction of several metals in the submicron ash is reduced.

A comprehensive study has been performed to investigate the partitioning of arsenic during pulverized coal combustion. The partitioning of arsenic is governed primarily by the extent of arsenic volatilization during combustion. The majority of the arsenic for all six coals is attributed to pyrite/sulfide or mono-sulfide fractions. Organically-associated arsenic was only detected in the Wyodak coal. The large fraction of arsenic not contained in silicates is expected to volatilize during combustion. Volatilized arsenic will heterogeneously transform to both submicron and supermicron particles primarily by reaction with active cation sites. Only a small fraction will remain in the vapor phase and exit the boiler.

The partitioning of arsenic to fly ash surfaces is dependent on the availability of active cation sites. For coals with relatively low As/Ca ratios, arsenic is expected to react with calcium surface sites to form calcium arsenate complexes. These arsenate complexes are partially soluble and some of the arsenic in this form is expected to leach into groundwater. If the As/Ca ratio is relatively high and the sulfur content is low, arsenic will most likely react with both calcium and iron surface sites to form iron arsenates and calcium arsenates. These complexes are partially soluble and are likely to contribute arsenic to groundwater due to leaching. If the As/Ca ratio is relatively high and the sulfur content is moderate to high, cationic surface sites will not be available for arsenic partitioning. In these cases, most of the arsenic is expected to exit the furnace in the vapor phase or as fly ash surface-based $\mathrm{As}_{2} \mathrm{O}_{3}$ (e.g. the Ohio study coal). $\mathrm{As}_{2} \mathrm{O}_{3}$ is 
partially soluble and is likely to contribute arsenic to groundwater due to leaching. Further, a portion of the $\mathrm{As}_{2} \mathrm{O}_{3}$ may oxidize to $\mathrm{As}_{2} \mathrm{O}_{5}$. $\mathrm{As}_{2} \mathrm{O}_{5}$ is very soluble and any arsenic in this form will most likely leach out of fly ash particles when contacted by water.

Active cationic surface sites are primarily due to major elements (i.e., calcium and iron) volatilizing in the vicinity of the carbon oxidizing in the coal particles and then homogeneously and heterogeneously condensing. Increasing the combustion temperature can increase cationic surface site availability and subsequently reduce the emission of vapor phase or physically condensed $\mathrm{As}_{2} \mathrm{O}_{3}$ from the furnace.

A thermodynamic modeling study of arsenic behavior in the post-combustion flue gas was undertaken. The constrained simulation results appear to be more reflective of the actual partitioning of arsenic during pulverized coal combustion. The analysis of arsenic partitioning based on experimental data showed that vapor-phase arsenic is reactive with cation surface sites available on fly ash particles. This reaction mechanism is more likely with vapor-phase arsenic in an oxy-anion form, such as $\mathrm{As}_{2} \mathrm{O}_{4}$ rather than a simple oxide form (i.e., AsO). It should be noted that thermodynamic data for Fe-As reaction products were not available for use in these simulations. Therefore, it was not possible to assess whether the formation of Fe-As oxy-anion complexes is thermodynamically favorable.

Most of the bench-scale testing at EERC on the current suite of ash samples has been completed, although not all of the characterization tests have been completed. Few of the ash samples adsorbed elemental mercury; most adsorbed mercuric chloride. Adsorption appears to decrease with increasing temperature.

The amount of oxidation was measured one to three hours into the tests when the concentration of mercury in the gas exiting the ash had become constant (as indicated in the figures in this section). Oxidation appears to increase with increasing temperature. There does not seem to be any clear correlation between either surface area or carbon content when comparing ash from different coals. Although carbon has been shown to oxidize mercury, there are other factors at play, perhaps related to the composition of the non-carbonaceous part of the ash.

The samples from the University of Arizona combustor which were tested at bench scale at EERC were also examined at the University of Utah be scanning electron microscopy. The carbon content of these samples was high, particularly that of the two low rank coals. In addition, the surface area of the Wyodak ash was abnormally high, and suggested that perhaps this ash sample contained soot. Therefore, a small study was undertaken of the morphology of these ash samples. From the origin of particles (based on the surface area data and what is known about the formation of particle during coal combustion) and the images that were taken, the conclusion was reached that all the carbon in the North Dakota and the Ohio is in the form of char. The Wyodak sample hardly had any char in it. The high surface area and carbon content of this ash, along with the observation of ultrafine aggregates, suggests that soot was present in the ash. 


\section{2 $\quad \underline{\text { Future Plans }}$}

A new XAFS experimental session has been scheduled for July $13^{\text {th }}$ through $16^{\text {th }}$ at NSLS, Brookhaven National Laboratory. During the time at NSLS, both a high Z (Fe - ??) beam-line and a low Z (S- Fe) beam-line will be available to us. One exploratory topic that we wish to do on the low $\mathrm{Z}$ beam-line at NSLS is to look at the $\mathrm{M}$ absorption edges of mercury for possible additional information regarding the structure of $\mathrm{Hg}$ sorbents, in addition to work on $\mathrm{S}$ and $\mathrm{Cl}$ characterization of various fly-ash materials. The $\mathrm{M}$ edges should be somewhat more sensitive to differences in the bonding of mercury than the L edges.

Analysis of the single particle combustion data for Wyodak and North Dakota experiments will continue at the University of Utah. The University of Arizona will prepare for another series of special combustion studies, focusing on staged or low NOx combustion conditions. The University of Connecticut will continue gas-phase mercury studies (theoretical and experimental) as well as arsenic-ash experiments. Bench-scale work at EERC will focus on evaluation of new ash samples for adsorption and oxidation of mercury. 


\section{SECTION 5}

\section{REFERENCES}

$5-1 / 5-2$ 


\section{REFERENCES}

1. Kolker, Allan, Huggins, F. E., Palmer, C. A., Shah, Naresh, Crowley, S. S., Huffman, G. P., and Finkelman, R. B., 2000, Mode of occurrence of arsenic in four U.S. coals: Fuel Processing Technology, v. 63, p. 167-178.

2. $\quad$ C. L. Senior, et al., Toxic Substances from Coal Combustion - A Comprehensive Assessment. Quarterly Report, DOE Contract No. DE-AC22-95PC95101, U.S. Department of Energy, January 2000.

3. C. L. Senior, et al., Toxic Substances from Coal Combustion - A Comprehensive Assessment. Quarterly Report, DOE Contract No. DE-AC22-95PC95101, U.S. Department of Energy, April 2000.

4. F. E. Huggins, J. Zhao, N. Shah, F. Lu, G. P. Huffman, L. E. Bool, III, and C. L. Senior, Investigation of the oxidation of arsenical pyrite in coal and its effect on the behavior of arsenic during combustion, Proceedings, ICCS '97, 9th International Conference on Coal Science, (Essen, Germany), (eds. A. Ziegler, K. H. van Heek, J. Klein, and W. Wanzl), 1, 381-384, P \& W Druck und Verlag GMBH, Essen (1997).

5. Baxter, L.L., R.E. Mitchell, and T.H. Fletcher. "Release of Inorganic Material During Coal Devolatilization." Combustion and Flame. 108:494-502 (1997).

6. Linak, W.P. and T. W. Peterson (1984), "Effect of Coal Type and Residence Time on the Submicron Aerosol Distribution from Pulverized Coal Combustion", Aerosol Science and Technology, 3:77-96.

7. Senior, C.L. and Flagan, R.C. (1982), “Ash vaporization and condensation during combustion of a suspended coal particle", Aeros Sci Tech, 1:371-383.

8. McNallan, M.J., Yurek, G.J., and J.F. Elliott (1981), "The formation of inorganic particulates by homogeneous nucleation in gases produced by the combustion of coal", Combustion and Flame, 42:45-60.

9. Mulholland, J.A. and Sarofim, A.F. (1990), "Mechanisms of Inorganic particle formation during suspension heating of simulated aqueous wastes", Environ Sci \& Tech, 25:268274.

10. Sarofim, A.F., Howard, J.B., and Padia, A.S. (1977), "The physical transformation of mineral matter in pulverized coal under simulated combustion conditions", Combustion Science and Technology, 16:187-204.

11. Natusch, D.F.S., Wallace, J.F., and Evans, C.A.(1974), “Toxic trace elements: preferential conc. in respirable particles", Science, 183:202-204. 
12. Taylor, D.D. and Flagan, R.C. (1983), "The influence of combustor operation on fine particles from coal combustion', Aeros Sci Tech, 1:103-117.

13. Helble, J.J. and Sarofim, A.F. (1989), "Influence of char fragmentation on ash particle size distributions", Combustion and Flame, 76:183-196.

14. Senior, C.L., Bool III, L.E., Huggins, F., Huffman, G.P., Shah, N., Wendt, J.O.L., Seames, W., Peterson, T., Shadman, F., Helble, J., Wornat, M., Sarofim, A., Olmez, I., Crowley, S., and R. Finkelman (1997), Toxic Substances from Coal Combustion -- A Comprehensive Assessment, Phase I Final Report, DOE Contract DE-AC22-95PC95101, September, 1997.

15. Finkelman, R. (1999), unpublished correspondence.

16. Bool, L.E. and Helble, J.L. (1995), “A Laboratory Study of the Partitioning of Trace Elements during Pulverized Coal Combustion”, Energy \& Fuels, 9:880-887.

17. Ratafia-Brown, J.A. (1994), "Overview of trace element partitioning in flames and furnaces of utility coal-fired boilers”, Fuel Proc Tech, 39:139-157.

18. Biermann, A.H. and Ondov, J.M. (1980), "Selenium in Coal-fired steam plant emissions", Atmos Environ, 14:289-295.

19. Davison, R.L., Natusch, D.F.S., Wallace, J.R., and Evans, C.A. (1974), "Trace elements in fly ash dependence of concentration on particle size", Env Sci Tech, 8:1107-1113.

20. Klein, D.H., Andren, A.W., Carter, J.A., Emery, J.F., Feldman, C., Fulkerson, W., Lyon, W.S., Ogle, J.C., Talmi, Y., Van Hook, R.I., and Bolton, N. (1975), "Pathways of 37 Trace Elements Through Coal-Fired Power Plant”, Env. Sci. \& Tech., 9:973-979.

21. Kaakinen, J.W., Jorden, R.M., Lawasani, M.H., and R.E. West(1975), “Trace Element Behavior in Coal-Fired Power Plant”, Environmental Science and Technology, 9:862869.

22. Gladney. E.S., Small, J.A., Gordon, G.E., and W.H. Zoller (1976), "Composition and size distribution of in-stack particulate material at a coal-fired power plant", Atmos. Environ., 10:1071-1077.

23. Block, C. and Dams, R. (1976), "Study of Fly Ash Emission During Combustion of Coal", Env Sci Tech, 10:1011-1017.

24. Campbell, J.A., Laul, J.C., Nielson, K.K., and Smith, R.D. (1978), "Separation and Chemical Characterization of Finely-Sized Fly-Ash Particles", Analy Chem, 50:163-173. 
25. Haynes, B.S., Neville, M., Quann, R.J., and Sarofim, A.F. (1982), "Factors Governing the Surface Enrichment of Fly Ash in Volatile Trace Species", J. Colloid \& Interface Sci, 87:266-279.

26. Smith, R.D., Campbell, J.A., and Nielson, K K. (1979), "Concentration Dependence upon Particle Size of Volatilized elements in Fly Ash”, Env Sci Tech, 13:553-558.

27. Damle, A.S., Ensor, D.S., and Ranade, M.B. (1982), "Coal combustion aerosol formation mechanisms: a review", Aeros Sci Tech, 1:119-133.

28. Flagan, R.C. and Friedlander, K. (1976), "Particle Formation in Pulverized Coal Combustion - A Review", in Recent Developments in Aerosol Science (ed: D.T. Shaw) Chpt. 2, Wiley-Interscience, pp. 25-59.

29. Shendrikar, A.D., Ensor, D.S., Cowen, S.J., and Woffinden, G.J. (1983), "Size-dependent penetration of trace elements through a utility baghouse", Atmos Environ, 17:1411-1421.

30. Coles, D.G., Ragaini R.C., and Ondov, J.M. (1978), "Behavior of Natural Radionuclides in Western Coal-fired Power Plants," Environmental Science and Technology, 12:442466.

31. Markowski, G.R. and R. Filby (1985), "Trace Element Concentration as a function of particle size in fly ash from a pulverized coal utility boiler”, Environ Sci \& Tech, 19:796804.

32. Martinez-Tarazona, M., and Spears, D.A. (1996), "The fate of trace elements and bulk minerals in pulverized coal combustion in a power station", Fuel Proc Tech, 47:79-92.

33. Swaine, D.J. (1994), "Trace elements in coal and their dispersal during combustion", Fuel Proc Tech, 39:121-137.

34. Linak, W.P. and Wendt, J.O.L. (1994), “Trace Metal Transformation Mechanisms During Coal Combustion", Fuel Processing Technology, 39:173-198.

35. Smith, R.D., Campbell, J.A., and Nielson, K K. (1979), "Characterization and formation of submicron particles in coal-fired plants”, Atmos Environ, 13:607-617.

36. Neville, M., McCarthy, J.F., and Sarofim, A.F. (1983), "Size fractionation of submicrometer coal combustion aerosol for chemical analysis", Atmos Environ, 17:25992604.

37. Clarke, L.B. (1993), "The Fate of Trace Elements During Coal Combustion and Gasification: An Overview”, Fuel, 72:731-736. 
38. Huggins, F.E., Shah, N., Zhao, J., Lu, F., and Huffman, G.P. (1993), "Nondestructive determination of trace element speciation in coal and coal ash by XAFS spectroscopy", Energy \& Fuels, 7:482-489 .

39. Irgolic, K.J., Hass, G., and Goesseler, W. (1997), “Arsenic Compounds in Fly Ash from Coal-Fired Power Plants", Managing Hazardous Air Pollutants, 4th Intl. Conf.; Washington, D.C., Nov. 12-14.

40. Gullett, B.K. and Ragnunathan, K. (1994), "Reduction of Coal-Based Metal Emissions by Furnace Sorbent Injection”, Energy \& Fuels, 8:1068-1076.

41. Mahuli, S., Agnihotri, R., Chauk, A., Ghosh-Dastidar, A., and Fan, L.S. (1997), "Mechanism of Arsenic Sorption By Hydrated Lime", Environmental Science \& Technology, 31:3226-3231.

42. Weast, R.C., Handbook of Chemistry and Physics ( $68^{\text {th }}$ ed.), CRC Press, Cleveland, (1987)

43. Finkelman, R.B. (1994), "Modes of occurrence of potentially hazardous elements in coal: levels of confidence", Fuel Processing Technology, 39:21-34.

44. Dean, J.A. (1992), Langes Handbook of Chemistry, $14^{\text {th }}$ Edition, McGraw-Hill.

45. Querol, X., Juan, R., Lopez-Soler, A., Fernandez-Turiel, J., and Ruiz, C. (1996), "Mobility of trace elements from coal and combustion wastes", Fuel, 75:821-838.

46. Finkelman, R.B., Stanton, R.W., Cecil, C.B., and Minkin, J.B. (1979), "Modes of Occurrence of Selected trace elements in several appalachian coals", J. Am. Chem. Soc., Prepr Fuel Chem Div, 39:236-241

47. Silberman, D. and Harris, W.R. (1984), "Determination of arsenic (III) and arsenic (V) in coal and oil fly ashes", Intern J Environ Anal Chem, 17:73-83.

48. Jones, D.R. in Swaine, D.J. and Goodarzi, F (1995), Environmental Aspects of Trace Elements in Coal, Kluwer Academic, Boston, Chapter 12.

49. Wadge, A. and M. Hutton (1987), "The leachability and chemical speciation of selected trace elements in fly ash from coal combustion and refuse incineration", Environ. Pollut., 48:85-99.

50. Turner, J.R. (1981), “Oxidation State of Arsenic in Coal Ash Leachate”, Env. Sci. \& Tech., 15:1062-1066. 
51. Hansen, L.D., Silberman, D., Fisher, G.L., and D.J. Eatough (1984), "Chemical Speciation of Elements in stack-collected, respirable-size coal fly ash", Env. Sci. \& Tech., 18:181-186.

52. Gordon, S. and B.J. McBride (1994), “Computer Program for Calculation of Complex Chemical Equilibrium Compositions and Applications", NASA Reference Publication 1311.

53. Dugwell, D. (2000), "Trace element emissions from combustion and gasification processes", Intl. Conf. on Ind. Furnaces and Boilers, Portugal, April, 2000.

54. Owens, T.M., Chang-Yu, W., and P. Biswas (1995), "An equilibrium analysis for reaction of metal compounds with sorbents in high temperature systems", Chem. Eng. Comm., 133:31-52.

55. Yan, R., Gauthier, D., Flamant, G., and J. M. Badie (1999), "Thermodynamic study of the behaviour of minor coal elements and their affinities to sulphur during coal combustion, Fuel Proc Tech, 78:1817-1829.

56. C.W. Lee, J. D. Kilgroe, and S.B. Ghorishi, "Speciation of Mercury in the Presence of Coal and Waste Combustion Fly Ashes," presented at the 93rd annual Air \& Waste Management Association Meeting, Salt Lake City, UT (June 2000).

57. G.A. Norton, H. Yang, R. C. Brown, D. L. Laudal, G. E. Dunham, and J. M. Okoh, "Effects of Fly Ash on Mercury Oxidation in Simulated Flue Gas Environments," presented at the 93rd annual Air \& Waste Management Association Meeting, Salt Lake City, UT (June 2000).

58. John M.Veranth, Thomas H. Fletcher, David Pershing, Adel Sarofim, Measurement of soot and char in pulverised coal fly ash, Fuel.

59. John M. Veranth, David W. Pershing, Adel F. Sarofim and Jefferey E. Shield, Sources of unburned carbon in the fly ash produced from low $\mathrm{NO}_{\mathrm{x}}$ pulverised coal combustion, $27^{\text {th }}$ symposium (international) on combustion / the combustion institute, 1998/pp 1737-1744.

60. Tiiu Alliksaar, Jan Mati Punning, Water, Air \& Soil Pollution, v. 106, 219-239, 1998, Kluwer Academic Publishers.

61. Tiiu Alliksaar, Per Horstedt, Ingenar Renberg, Water, Air \& Soil Pollution, v. 104, 149160, 1998, Kluwer Academic Publishers.

62. J. Watt, Water, Air \& Soil Pollution, v. 106 n 3-4, September 1998, Kluwer Academic Publishers, p 309-327 0049-6979.

63. Personal communication with John M. Veranth, Research Assistant Professor, Chemical and Fuels Engineering Department, University of Utah, Salt Lake City, Utah.

64. Fisher G. L, M. Brunner, Fly ash collected by electrostatic precipitators: microcrystalline structure and the mystery of spheres, Science 192:553 - 557 (1996). 


\section{APPENDIX A}

$\underline{\text { Summary of USGS Leaching Results }}$

A-1/A-2 
USGS Leaching Results for OHIO 5/6/7

$\begin{array}{cccccc}\text { Element } & \text { NH4Ac } & \text { HCl } & \text { HF } & \text { HNO } & \text { Total } \\ \text { Li } & 0 \% & 0 \% & 65 \% & 0 \% & 65 \% \\ \mathbf{B e} & 0 \% & 5 \% & 50 \% & 0 \% & 55 \% \\ \mathbf{N a} & 25 \% & 10 \% & 40 \% & 10 \% & 85 \% \\ \mathbf{M g} & 10 \% & 5 \% & 70 \% & 0 \% & 85 \% \\ \mathbf{A l} & 0 \% & 0 \% & 100 \% & 0 \% & 100 \% \\ \mathbf{P} & 0 \% & 50 \% & 50 \% & 0 \% & 100 \% \\ \mathbf{K} & 0 \% & 5 \% & 90 \% & 0 \% & 95 \% \\ \mathbf{C a} & 30 \% & 30 \% & 5 \% & 5 \% & 70 \% \\ \mathbf{S c} & 0 \% & 5 \% & 40 \% & 0 \% & 45 \% \\ \mathbf{T i} & 0 \% & 0 \% & 65 \% & 0 \% & 65 \% \\ \mathbf{V} & 0 \% & 0 \% & 35 \% & 0 \% & 35 \% \\ \mathbf{C r} & 0 \% & 0 \% & 30 \% & 0 \% & 30 \% \\ \mathbf{M n} & 15 \% & 30 \% & 20 \% & 30 \% & 95 \% \\ \mathbf{F e} & 0 \% & 10 \% & 10 \% & 80 \% & 100 \% \\ \mathbf{C o} & 15 \% & 30 \% & 10 \% & 20 \% & 75 \% \\ \mathbf{N i} & 5 \% & 15 \% & 10 \% & 25 \% & 55 \% \\ \mathbf{C u} & 0 \% & 10 \% & 5 \% & 65 \% & 80 \% \\ \mathbf{Z n} & 5 \% & 30 \% & 10 \% & 30 \% & 75 \% \\ \mathbf{A s} & 0 \% & 25 \% & 5 \% & 60 \% & 90 \% \\ \mathbf{S e} & 0 \% & 0 \% & 0 \% & 50 \% & 50 \% \\ \mathbf{R b} & 0 \% & 5 \% & 70 \% & 10 \% & 85 \% \\ \mathbf{S r} & 5 \% & 5 \% & 60 \% & 5 \% & 75 \% \\ \mathbf{Y} & 0 \% & 20 \% & 10 \% & 25 \% & 55 \% \\ \mathbf{Z r} & 0 \% & 5 \% & 70 \% & 25 \% & 100 \% \\ \mathbf{M o} & 5 \% & 10 \% & 20 \% & 25 \% & 60 \% \\ \mathbf{C d} & 5 \% & 20 \% & 5 \% & 35 \% & 65 \% \\ \mathbf{S n} & 0 \% & 5 \% & 35 \% & 0 \% & 40 \% \\ \mathbf{S b} & 0 \% & 5 \% & 20 \% & 15 \% & 40 \% \\ \mathbf{C s} & 5 \% & 5 \% & 75 \% & 5 \% & 90 \% \\ \mathbf{B a} & 5 \% & 0 \% & 90 \% & 5 \% & 100 \% \\ \mathbf{L a} & 0 \% & 5 \% & 5 \% & 55 \% & 65 \% \\ \mathbf{C e} & 0 \% & 5 \% & 5 \% & 60 \% & 70 \% \\ \mathbf{S m} & 0 \% & 25 \% & 5 \% & 35 \% & 65 \% \\ \mathbf{E u} & 5 \% & 25 \% & 5 \% & 30 \% & 65 \% \\ \mathbf{T b} & 5 \% & 20 \% & 5 \% & 25 \% & 55 \% \\ \mathbf{Y b} & 0 \% & 5 \% & 10 \% & 25 \% & 40 \% \\ \mathbf{L u} & 0 \% & 5 \% & 10 \% & 30 \% & 45 \% \\ \mathbf{H f} & 0 \% & 0 \% & 50 \% & 0 \% & 50 \% \\ \mathbf{T a} & 0 \% & 0 \% & 35 \% & 5 \% & 40 \% \\ \mathbf{W} & 5 \% & 10 \% & 25 \% & 0 \% & 40 \% \\ \mathbf{T l} & 10 \% & 15 \% & 15 \% & 50 \% & 90 \% \\ \mathbf{P b} & 0 \% & 35 \% & 10 \% & 40 \% & 85 \% \\ \mathbf{T h} & 0 \% & 10 \% & 10 \% & 35 \% & 55 \% \\ \mathbf{U} & 0 \% & 5 \% & 20 \% & 5 \% & 30 \% \\ & & & & & \end{array}$


USGS Leaching Results for ND

$\begin{array}{cccccc}\text { Element } & \text { NH4Ac } & \text { HCl } & \text { HF } & \text { HNO } & \text { Total } \\ \text { Li } & 10 \% & 0 \% & 35 \% & 0 \% & 45 \% \\ \mathbf{B e} & 0 \% & 70 \% & 20 \% & 0 \% & 90 \% \\ \mathbf{N a} & 85 \% & 5 \% & 5 \% & 0 \% & 95 \% \\ \mathbf{M g} & 50 \% & 35 \% & 10 \% & 0 \% & 95 \% \\ \mathbf{A l} & 0 \% & 25 \% & 65 \% & 0 \% & 90 \% \\ \mathbf{P} & 0 \% & 85 \% & 10 \% & 0 \% & 95 \% \\ \mathbf{K} & 10 \% & 5 \% & 80 \% & 0 \% & 95 \% \\ \mathbf{C a} & 40 \% & 60 \% & 0 \% & 0 \% & 100 \% \\ \mathbf{S c} & 0 \% & 15 \% & 80 \% & 5 \% & 100 \% \\ \mathbf{T i} & 0 \% & 20 \% & 60 \% & 0 \% & 80 \% \\ \mathbf{V} & 0 \% & 35 \% & 45 \% & 0 \% & 80 \% \\ \mathbf{C r} & 0 \% & 10 \% & 35 \% & 5 \% & 50 \% \\ \mathbf{M n} & 15 \% & 75 \% & 10 \% & 0 \% & 100 \% \\ \mathbf{F e} & 0 \% & 65 \% & 15 \% & 10 \% & 90 \% \\ \mathbf{C o} & 0 \% & 55 \% & 40 \% & 0 \% & 95 \% \\ \mathbf{N i} & 0 \% & 45 \% & 25 \% & 15 \% & 85 \% \\ \mathbf{C u} & 0 \% & 30 \% & 10 \% & 20 \% & 60 \% \\ \mathbf{Z n} & 0 \% & 65 \% & 10 \% & 5 \% & 80 \% \\ \mathbf{A s} & 0 \% & 50 \% & 15 \% & 15 \% & 80 \% \\ \mathbf{S e} & 10 \% & 5 \% & 0 \% & 25 \% & 40 \% \\ \mathbf{R b} & 0 \% & 5 \% & 70 \% & 0 \% & 75 \% \\ \mathbf{S r} & 40 \% & 60 \% & 0 \% & 0 \% & 100 \% \\ \mathbf{Y} & 0 \% & 80 \% & 10 \% & 5 \% & 95 \% \\ \mathbf{Z r} & 0 \% & 5 \% & 65 \% & 0 \% & 70 \% \\ \mathbf{M o} & 0 \% & 0 \% & 60 \% & 0 \% & 60 \% \\ \mathbf{C d} & \mathrm{ND} & \mathrm{ND} & \mathrm{ND} & \mathrm{ND} & \mathrm{ND} \\ \mathbf{S n} & \mathrm{ND} & \mathrm{ND} & \mathrm{ND} & \mathrm{ND} & \mathrm{ND} \\ \mathbf{S b} & 0 \% & 0 \% & 40 \% & 10 \% & 50 \% \\ \mathbf{C s} & 0 \% & 5 \% & 75 \% & 5 \% & 85 \% \\ \mathbf{B a} & 0 \% & 80 \% & 15 \% & 5 \% & 100 \% \\ \mathbf{L a} & 0 \% & 55 \% & 10 \% & 20 \% & 85 \% \\ \mathbf{C e} & 0 \% & 60 \% & 10 \% & 20 \% & 90 \% \\ \mathbf{S m} & 5 \% & 70 \% & 10 \% & 15 \% & 100 \% \\ \mathbf{E u} & 0 \% & 60 \% & 15 \% & 10 \% & 85 \% \\ \mathbf{T b} & 0 \% & 60 \% & 15 \% & 10 \% & 85 \% \\ \mathbf{Y b} & 0 \% & 60 \% & 20 \% & 10 \% & 90 \% \\ \mathbf{L u} & 0 \% & 60 \% & 15 \% & 0 \% & 75 \% \\ \mathbf{H f} & 0 \% & 0 \% & 60 \% & 5 \% & 65 \% \\ \mathbf{T a} & 5 \% & 0 \% & 45 \% & 0 \% & 50 \% \\ \mathbf{W} & 10 \% & 10 \% & 50 \% & 5 \% & 75 \% \\ \mathbf{T l} & \mathrm{ND} & \mathrm{ND} & \mathrm{ND} & \mathrm{ND} & \mathrm{ND} \\ \mathbf{P b} & 0 \% & 85 \% & 10 \% & 5 \% & 100 \% \\ \mathbf{T h} & 0 \% & 20 \% & 45 \% & 15 \% & 80 \% \\ \mathbf{U} & 0 \% & 45 \% & 45 \% & 5 \% & 95 \%\end{array}$




\section{USGS Leaching Results for WYODAK}

$\begin{array}{cccccc}\text { Element } & \text { NH4Ac } & \text { HCl } & \text { HF } & \text { HNO } & \text { Total } \\ \text { Li } & 0 \% & 0 \% & 35 \% & 0 \% & 35 \% \\ \text { Be } & 0 \% & 55 \% & 35 \% & 0 \% & 90 \% \\ \mathbf{N a} & 90 \% & 5 \% & 0 \% & 0 \% & 95 \% \\ \mathbf{M g} & 55 \% & 30 \% & 0 \% & 0 \% & 85 \% \\ \mathbf{A l} & 0 \% & 25 \% & 55 \% & 0 \% & 80 \% \\ \mathbf{P} & 0 \% & 80 \% & 10 \% & 0 \% & 90 \% \\ \mathbf{K} & 30 \% & 5 \% & 50 \% & 0 \% & 85 \% \\ \mathbf{C a} & 45 \% & 55 \% & 0 \% & 0 \% & 100 \% \\ \mathbf{S c} & 0 \% & 60 \% & 35 \% & 0 \% & 95 \% \\ \mathbf{T i} & 0 \% & 20 \% & 60 \% & 0 \% & 80 \% \\ \mathbf{V} & 0 \% & 65 \% & 25 \% & 0 \% & 90 \% \\ \mathbf{C r} & 0 \% & 10 \% & 45 \% & 0 \% & 55 \% \\ \mathbf{M n} & 5 \% & 80 \% & 5 \% & 5 \% & 95 \% \\ \mathbf{F e} & 0 \% & 75 \% & 10 \% & 10 \% & 95 \% \\ \mathbf{C o} & 0 \% & 30 \% & 60 \% & 5 \% & 95 \% \\ \mathbf{N i} & 0 \% & 25 \% & 15 \% & 20 \% & 60 \% \\ \mathbf{C u} & 0 \% & 20 \% & 5 \% & 20 \% & 45 \% \\ \mathbf{Z n} & 0 \% & 50 \% & 10 \% & 25 \% & 85 \% \\ \mathbf{A s} & 0 \% & 40 \% & 15 \% & 15 \% & 70 \% \\ \mathbf{S e} & 5 \% & 5 \% & 0 \% & 20 \% & 30 \% \\ \mathbf{R b} & 10 \% & 0 \% & 65 \% & 0 \% & 75 \% \\ \mathbf{S r} & 30 \% & 65 \% & 5 \% & 0 \% & 100 \% \\ \mathbf{Y} & 0 \% & 65 \% & 10 \% & 10 \% & 85 \% \\ \mathbf{Z r} & 0 \% & 5 \% & 60 \% & 0 \% & 65 \% \\ \mathbf{M o} & 0 \% & 0 \% & 45 \% & 0 \% & 45 \% \\ \mathbf{C d} & 0 \% & 70 \% & 5 \% & 10 \% & 85 \% \\ \mathbf{S n} & \mathrm{ND} & \mathrm{ND} & \mathrm{ND} & \mathrm{ND} & \mathrm{ND} \\ \mathbf{S b} & 0 \% & 5 \% & 35 \% & 15 \% & 55 \% \\ \mathbf{C s} & 5 \% & 5 \% & 60 \% & 5 \% & 75 \% \\ \mathbf{B a} & 5 \% & 80 \% & 5 \% & 0 \% & 90 \% \\ \mathbf{L a} & 0 \% & 60 \% & 5 \% & 15 \% & 80 \% \\ \mathbf{C e} & 0 \% & 65 \% & 5 \% & 15 \% & 85 \% \\ \mathbf{S m} & 0 \% & 70 \% & 5 \% & 10 \% & 85 \% \\ \mathbf{E u} & 0 \% & 60 \% & 10 \% & 10 \% & 80 \% \\ \mathbf{T b} & 0 \% & 70 \% & 5 \% & 10 \% & 85 \% \\ \mathbf{Y b} & 5 \% & 40 \% & 15 \% & 15 \% & 75 \% \\ \mathbf{L u} & 5 \% & 45 \% & 15 \% & 10 \% & 75 \% \\ \mathbf{H f} & 0 \% & 0 \% & 45 \% & 5 \% & 50 \% \\ \mathbf{T a} & 0 \% & 0 \% & 40 \% & 5 \% & 45 \% \\ \mathbf{W} & 10 \% & 5 \% & 45 \% & 5 \% & 65 \% \\ \mathbf{T l} & \mathrm{ND} & \mathrm{ND} & \mathrm{ND} & \mathrm{ND} & \mathrm{ND} \\ \mathbf{P b} & 0 \% & 70 \% & 20 \% & 10 \% & 100 \% \\ \mathbf{T h} & 0 \% & 30 \% & 25 \% & 15 \% & 70 \% \\ \mathbf{U} & 10 \% & 50 \% & 30 \% & 5 \% & 95 \%\end{array}$




\section{APPENDIX B}

Composite Results from Baseline Large-Scale Combustion Studies at the University of Arizona

B-1/B-2 
Table B-1

Size-Segregated Elemental Concentrations of the Pittsburgh Fly Ash Sampled at Port 4b (0.5 residence second)

a) Major Species Results

\begin{tabular}{|c|c|c|c|c|c|c|c|c|c|c|c|c|}
\hline Impactor & Stage & I & 2 & 3 & 4 & 5 & 6 & 7 & 8 & 9 & 10 & II \\
\hline Cut-off & $\begin{array}{l}\text { Diameter } \\
\text { (microns) }\end{array}$ & 0.0324 & 0.0636 & 0.0926 & 0.168 & 0.337 & 0.535 & 0.973 & 1.96 & 3.77 & 7.33 & 15.7 \\
\hline Element & $\begin{array}{c}\text { Analytical } \\
\text { Method }\end{array}$ & & & & & & & & & & & \\
\hline $\begin{array}{l}\text { Total Mass Conc } \\
(\mathrm{g} / \mathrm{Nm} \wedge 3)\end{array}$ & Gravimetric & 0.00 & $4.17 \mathrm{E}-04$ & $1.96 \mathrm{E}-04$ & $1.23 \mathrm{E}-03$ & $8.09 \mathrm{E}-04$ & 7.07E-02 & 3.4 IE-02 & $4.56 \mathrm{E}-02$ & $3.74 \mathrm{E}-02$ & $2.29 \mathrm{E}-0 \mathrm{I}$ & $5.30 \mathrm{E}-02$ \\
\hline $\mathrm{Fe}_{2} \mathrm{O}_{3}(\mathrm{Wt} \%)$ & NAA & & $3 . E+00$ & $1.9 \mathrm{E}+0 \mathrm{I}$ & $7 . \mathrm{E}+00$ & $1.4 \mathrm{E}+0 \mathrm{I}$ & $9 . \mathrm{E}+00$ & $8 . \mathrm{E}+00$ & $8 . \mathrm{E}+00$ & $9 . \mathrm{E}+00$ & $|.4 \mathrm{E}+0|$ & $2.4 \mathrm{E}+0 \mathrm{I}$ \\
\hline$+/-$ & & & I.E +00 & $4 . E+00$ & $2 . E+00$ & $3 . E+00$ & $4 . E+00$ & $3 . \mathrm{E}+00$ & $3 . E+00$ & $3 . \mathrm{E}+00$ & I.E +00 & $7 . \mathrm{E}+00$ \\
\hline $\mathrm{CaO}(\mathrm{Wt} \%)$ & NAA & & $2.4 \mathrm{E}+0 \mathrm{I}$ & $9 . \mathrm{E}+0 \mathrm{I}$ & $7 . \mathrm{E}+00$ & $1.2 \mathrm{E}+0 \mathrm{I}$ & $1.6 \mathrm{E}+0 \mathrm{I}$ & $8 . E+00$ & $6 . \mathrm{E}+00$ & $7 . \mathrm{E}+00$ & $2 . \mathrm{E}+00$ & $3 . E+00$ \\
\hline$+/-$ & & & $9 . \mathrm{E}+00$ & $5 . E+0 I$ & $2 . E+00$ & $3 . E+00$ & $2 . E+00$ & $4 . E+00$ & $3 . E+00$ & $3 . \mathrm{E}+00$ & I.E +00 & $2 . \mathrm{E}+00$ \\
\hline $\begin{array}{l}\text { Trace Elements } \\
(\mathrm{Wt} \%)\end{array}$ & NAA & & $5.0 \mathrm{E}-0 \mathrm{I}$ & $1.2 \mathrm{E}+00$ & $3.2 \mathrm{E}-0 \mathrm{I}$ & $9.2 \mathrm{E}-0 \mathrm{I}$ & $3.2 \mathrm{E}-0 \mathrm{I}$ & I.IE-0I & I.3E-0I & 2.IE-0I & $2.4 \mathrm{E}-02$ & $4.5 \mathrm{E}-02$ \\
\hline
\end{tabular}

Note: Elemental concentrations have been converted to oxide forms on a $\mathrm{SO}_{3}$-free basis. 
Table B-1 (continued)

Size-Segregated Elemental Concentrations of the Pittsburgh Fly Ash Sampled at Port 4b (0.5 residence second)

b) Trace Element Concentrations

\begin{tabular}{|c|c|c|c|c|c|c|c|c|c|c|c|c|}
\hline Impactor & Stage & I & 2 & 3 & 4 & 5 & 6 & 7 & 8 & 9 & 10 & II \\
\hline Cut-off & $\begin{array}{l}\text { Diameter } \\
\text { (microns) }\end{array}$ & 0.0324 & 0.0636 & 0.0926 & 0.168 & 0.337 & 0.535 & 0.973 & 1.96 & 3.77 & 7.33 & 15.7 \\
\hline Element & $\begin{array}{c}\text { Analytical } \\
\text { Method }\end{array}$ & & & & & & & & & & & \\
\hline As & NAA & $3.1 \mathrm{IE}+02$ & $3.4 \mathrm{E}+02$ & $2 . E+00$ & $4.3 \mathrm{E}+02$ & $3.3 \mathrm{E}+02$ & I.IE +02 & $4 . E+0 I$ & $5 . E+0 I$ & $5 . E+0 I$ & $2.9 \mathrm{E}+0 \mathrm{I}$ & $1.8 \mathrm{E}+0 \mathrm{I}$ \\
\hline Se & NAA & $2 . \mathrm{E}+02$ & $2 . \mathrm{E}+02$ & $\mathrm{I} . \mathrm{E}+00$ & $3.7 \mathrm{E}+02$ & $2.7 \mathrm{E}+02$ & $9 . \mathrm{E}+0 \mathrm{I}$ & $2 . \mathrm{E}+0 \mathrm{I}$ & $5 . E+01$ & $5 . \mathrm{E}+0 \mathrm{I}$ & I.E+0I & $7 . E+00$ \\
\hline Sb & NAA & $5 . E+0 I$ & $5.6 \mathrm{E}+0 \mathrm{I}$ & 2.E-0I & $6.6 \mathrm{E}+0 \mathrm{I}$ & $4.3 \mathrm{E}+0 \mathrm{I}$ & $2 . \mathrm{E}+0 \mathrm{I}$ & $7 . \mathrm{E}+00$ & $9 . \mathrm{E}+00$ & $7 . \mathrm{E}+00$ & $3 . E+00$ & $2 . \mathrm{E}+00$ \\
\hline$C_{0}$ & NAA & $5 . E+01$ & 34.4 & nd & $1.2 \mathrm{E}+0 \mid$ & $3.3 \mathrm{E}+0 \mathrm{I}$ & I.E+02 & $5 . E+0 I$ & $7 . \mathrm{E}+\mathrm{OI}$ & $7 . \mathrm{E}+04$ & $2.3 \mathrm{E}+01$ & $1.8 \mathrm{E}+0 \mathrm{I}$ \\
\hline Cs & NAA & $4 . \mathrm{E}+0 \mathrm{I}$ & $4.4 \mathrm{E}+0 \mathrm{I}$ & 2.E-OI & $5.6 \mathrm{E}+0 \mathrm{I}$ & $3.8 \mathrm{E}+0 \mathrm{I}$ & $3 . \mathrm{E}+0 \mathrm{I}$ & $2 . E+0 I$ & $8 . E+00$ & $2 . E+0 I$ & $6 . \mathrm{E}+00$ & $7 . E+00$ \\
\hline Sc & NAA & $1.8 \mathrm{E}+00$ & $1.2 \mathrm{E}+00$ & nd & $1.7 \mathrm{E}+00$ & I.IE+0I & $2 . \mathrm{E}+0 \mathrm{I}$ & I.IE +01 & $1.6 \mathrm{E}+01$ & $1.9 \mathrm{E}+01$ & $1.2 \mathrm{E}+01$ & $7 . E+00$ \\
\hline $\ln$ & NAA & $3.2 \mathrm{E}+03$ & $3.2 \mathrm{E}+03$ & I.E $+0 \mathrm{I}$ & $5.0 \mathrm{E}+03$ & $3.8 \mathrm{E}+03$ & $2 . \mathrm{E}+03$ & $1.0 \mathrm{E}+03$ & $7 . \mathrm{E}+02$ & $8 . E+02$ & $4 . \mathrm{E}+02$ & $2 . E+02$ \\
\hline $\mathrm{Rb}$ & NAA & $3 . E+02$ & $2.1 \mathrm{IE}+02$ & 9.E-OI & $4.2 \mathrm{E}+02$ & $2.2 \mathrm{E}+02$ & $5 . \mathrm{E}+02$ & $\mathrm{I} . \mathrm{E}+02$ & $8 . \mathrm{E}+0 \mathrm{I}$ & I.E +02 & $8 . \mathrm{E}+0 \mathrm{I}$ & $4 . E+01$ \\
\hline Mo & NAA & $5 . E+02$ & $5.2 \mathrm{E}+02$ & $2 . E+00$ & $6 . \mathrm{IE}+02$ & $4.5 \mathrm{E}+02$ & $2 . E+02$ & $5 . E+01$ & $7 . \mathrm{E}+0 \mathrm{I}$ & $7 . \mathrm{E}+0 \mathrm{I}$ & $5 . E+01$ & $3 . \mathrm{E}+0 \mathrm{I}$ \\
\hline$C d$ & NAA & $2 . \mathrm{E}+0 \mathrm{I}$ & $3 . E+0 I$ & I.E-OI & $4 . E+0 I$ & $3 . \mathrm{E}+0 \mathrm{I}$ & $4 . \mathrm{E}+0 \mathrm{I}$ & $9 . \mathrm{E}+00$ & $\mathrm{I} . \mathrm{E}+0 \mathrm{I}$ & $3 . E+01$ & $I . E+0 \mid$ & $4 . E+00$ \\
\hline La & NAA & $3.7 \mathrm{E}+0 \mathrm{I}$ & $4 . I E+00$ & $4.2 \mathrm{E}-03$ & $5.2 \mathrm{E}+00$ & $3.3 \mathrm{E}+0 \mathrm{I}$ & $7 . \mathrm{E}+\mathrm{Ol}$ & $2 . \mathrm{E}+0 \mathrm{I}$ & $3 . \mathrm{E}+\mathrm{Ol}$ & $3 . E+0 I$ & $2.2 \mathrm{E}+0 \mathrm{I}$ & $1.3 \mathrm{E}+01$ \\
\hline $\mathrm{Ce}$ & NAA & $7 . \mathrm{E}+0 \mathrm{I}$ & $9 . \mathrm{E}+00$ & 5.E-02 & $2.3 \mathrm{E}+0 \mathrm{I}$ & $7.7 \mathrm{E}+0 \mathrm{I}$ & I.E +02 & $3 . \mathrm{E}+0 \mathrm{I}$ & $5 . \mathrm{E}+\mathrm{Ol}$ & $7 . \mathrm{E}+0 \mathrm{I}$ & $4.5 \mathrm{E}+0 \mathrm{I}$ & $2.6 \mathrm{E}+0 \mathrm{I}$ \\
\hline $\mathrm{Sm}$ & NAA & $1.7 \mathrm{E}+00$ & $1.8 \mathrm{E}+00$ & 8.E-03 & $2.7 \mathrm{E}+00$ & $7.2 \mathrm{E}+00$ & I.IE $+0 \mid$ & $4 . \mathrm{E}+00$ & $6 . \mathrm{E}+00$ & 7.E +00 & $4.3 \mathrm{E}+00$ & $2.6 \mathrm{E}+00$ \\
\hline Eu & NAA & $6 . \mathrm{E}+00$ & $3.7 \mathrm{E}+00$ & nd & $1.9 \mathrm{E}+00$ & $3.3 \mathrm{E}+00$ & $\mathrm{I} . \mathrm{E}+00$ & $3 . \mathrm{E}+00$ & $3 . \mathrm{E}+00$ & $6 . \mathrm{E}+00$ & I.IE +00 & $1.6 \mathrm{E}+00$ \\
\hline $\mathrm{Yb}$ & NAA & 3.E-0I & 6.E-0I & nd & $3.7 \mathrm{E}-0 \mathrm{I}$ & $2.5 \mathrm{E}+00$ & $5 . \mathrm{E}+00$ & $2 . \mathrm{E}+00$ & $3 . \mathrm{E}+00$ & $3 . \mathrm{E}+00$ & $2.7 \mathrm{E}+00$ & $1.3 \mathrm{E}+00$ \\
\hline Lu & NAA & 4.E-OI & 5.E-Ol & I.E-03 & $6.3 \mathrm{E}-01$ & $8.0 \mathrm{E}-01$ & 8.E-0I & 3.E-0I & 7.E-0I & 6.E-0I & 5.E-0I & 2.E-OI \\
\hline $\mathrm{Au}$ & NAA & 6.E-02 & $6 . \mathrm{E}-02$ & nd & 2.E-02 & 2.E-02 & 8.E-02 & 8.E-02 & 8.E-02 & $6 . \mathrm{E}-02$ & I.E-02 & 8.E-03 \\
\hline $\mathrm{Hg}$ & NAA & $1.6 \mathrm{E}+01$ & $8 . E+00$ & nd & $3.0 \mathrm{E}+00$ & $9.3 \mathrm{E}+00$ & I.E+0I & $6 . \mathrm{E}+00$ & $3 . \mathrm{E}+00$ & $5 . \mathrm{E}+00$ & $1.3 \mathrm{E}+00$ & 9.E-0I \\
\hline Th & NAA & $1.2 \mathrm{E}+0 \mid$ & $2.4 \mathrm{E}+0 \mathrm{I}$ & nd & $1.2 \mathrm{E}+00$ & $1.0 \mathrm{E}+0 \mathrm{I}$ & $2 . \mathrm{E}+0 \mathrm{I}$ & $1.3 \mathrm{E}+0 \mathrm{I}$ & $8 . E+00$ & $1.3 \mathrm{E}+0 \mathrm{I}$ & $8 . E+00$ & $5 . \mathrm{E}+00$ \\
\hline $\begin{array}{c}\text { Total } \\
\text { (wt\%) }\end{array}$ & & $4.8 \mathrm{E}-0 \mathrm{I}$ & $4.7 E-01$ & $2.0 \mathrm{E}-03$ & 7.0E-0I & $5.4 \mathrm{E}-0 \mathrm{I}$ & $3.5 \mathrm{E}-01$ & $1.5 \mathrm{E}-0 \mathrm{I}$ & I.IE-0I & $7.5 \mathrm{E}+00$ & $6.7 \mathrm{E}-02$ & $3.4 \mathrm{E}-02$ \\
\hline
\end{tabular}


Table B-1 (continued)

Size-Segregated Elemental Concentrations of the Pittsburgh Fly Ash Sampled at Port 4b (0.5 residence second)

c) Trace Element Uncertainties

\begin{tabular}{|c|c|c|c|c|c|c|c|c|c|c|c|c|}
\hline Impactor & Stage & I & 2 & 3 & 4 & 5 & 6 & 7 & 8 & 9 & 10 & II \\
\hline Cut-off & $\begin{array}{l}\text { Diameter } \\
\text { (microns) }\end{array}$ & 0.0324 & 0.0636 & 0.0926 & 0.168 & 0.337 & 0.535 & 0.973 & 1.96 & 3.77 & 7.33 & 15.7 \\
\hline Element & $\begin{array}{c}\text { Analytical } \\
\text { Method }\end{array}$ & & & & & & & & & & & \\
\hline As & NAA & $8 . E+01$ & $5 . E+0 I$ & $5 . E+00$ & $2 . \mathrm{E}+0 \mathrm{I}$ & $3 . E+0 I$ & $9 . E+0 I$ & $3 . E+0 I$ & $3 . E+0 I$ & $3 . E+0 I$ & $8 . E+00$ & $9 . \mathrm{E}+00$ \\
\hline $\mathrm{Se}$ & NAA & $7 . E+0 I$ & $4 . E+0 I$ & $|. E+0|$ & $2 . E+0 I$ & $3 . \mathrm{E}+0 \mathrm{I}$ & $9 . E+0 I$ & $3 . E+0 I$ & $4 . \mathrm{E}+0 \mathrm{I}$ & $3 . \mathrm{E}+0 \mathrm{I}$ & I.E $+0 \mid$ & I.E+OI \\
\hline Sb & NAA & I.E $+0 \mid$ & $8 . E+00$ & 6.E-OI & $3 . E+00$ & $3 . \mathrm{E}+00$ & $2 . E+0 I$ & $5 . E+00$ & $5 . E+00$ & $4 . E+00$ & I.E +00 & $\mathrm{I} . \mathrm{E}+00$ \\
\hline$C_{0}$ & NAA & I.E $+0 \mid$ & $6 . \mathrm{E}+00$ & I.E +00 & $2 . E+00$ & $3 . E+00$ & I.E +02 & $3 . E+01$ & $4 . E+0 I$ & $3 . E+04$ & $4 . E+00$ & $6 . \mathrm{E}+00$ \\
\hline Cs & NAA & $\mid \mathrm{I} . \mathrm{E}+0 \mathrm{I}$ & $8 . E+00$ & $2 . E+00$ & $4 . \mathrm{E}+00$ & $4 . E+00$ & $2 . \mathrm{E}+0 \mathrm{I}$ & $\mid \mathrm{I} . \mathrm{E}+0 \mathrm{I}$ & $6 . \mathrm{E}+00$ & I.E+0I & $3 . \mathrm{E}+00$ & $4 . \mathrm{E}+00$ \\
\hline Sc & NAA & 5.E-OI & 2.E-0I & $5 . E-02$ & I.E-0I & 8.E-0I & $2 . \mathrm{E}+0 \mathrm{I}$ & $6 . E+00$ & $8 . E+00$ & $9 . \mathrm{E}+00$ & $2 . \mathrm{E}+00$ & $2 . E+00$ \\
\hline $\ln$ & NAA & $9 . \mathrm{E}+02$ & $5 . E+02$ & $9 . \mathrm{E}+0 \mathrm{I}$ & $3 . \mathrm{E}+02$ & $3 . E+02$ & $2 . \mathrm{E}+03$ & $7 . E+02$ & $4 . \mathrm{E}+02$ & $5 . E+02$ & I.E +02 & I.E +02 \\
\hline $\mathrm{Rb}$ & NAA & I.E +02 & $5 . E+0 I$ & $2 . \mathrm{E}+0 \mathrm{I}$ & $4 . E+0 I$ & $4 . \mathrm{E}+0 \mathrm{I}$ & $4 . E+02$ & I.E +02 & $6 . \mathrm{E}+0 \mathrm{I}$ & $7 . \mathrm{E}+0 \mathrm{I}$ & $3 . \mathrm{E}+0 \mathrm{I}$ & $3 . \mathrm{E}+0 \mathrm{O}$ \\
\hline Mo & NAA & I.E +02 & $8 . \mathrm{E}+0 \mathrm{I}$ & $2 . \mathrm{E}+0 \mathrm{I}$ & $4 . E+0 I$ & $5 . \mathrm{E}+0 \mathrm{I}$ & $2 . E+02$ & $5 . E+01$ & $5 . \mathrm{E}+0 \mathrm{I}$ & $5 . E+0 I$ & $2 . \mathrm{E}+0 \mathrm{I}$ & $2 . E+01$ \\
\hline$C d$ & NAA & $4 . E+03$ & $4 . E+03$ & $4 . E+03$ & $4 . E+03$ & $4 . E+03$ & $4 . E+03$ & $4 . E+03$ & $4 . E+03$ & $4 . E+03$ & $4 . E+03$ & $4 . E+03$ \\
\hline $\mathrm{La}$ & NAA & $9 . \mathrm{E}+00$ & 6.E-0I & I.E-OI & 3.E-0I & $2 . \mathrm{E}+00$ & $5 . E+01$ & $\mid \mathrm{I} . \mathrm{E}+0 \mathrm{I}$ & I.E+0I & $2 . \mathrm{E}+0 \mathrm{I}$ & $3 . \mathrm{E}+00$ & $3 . \mathrm{E}+00$ \\
\hline $\mathrm{Ce}$ & NAA & $2 . \mathrm{E}+0 \mathrm{I}$ & $3 . \mathrm{E}+00$ & $2 . E+00$ & $2 . E+00$ & $7 . \mathrm{E}+00$ & I.E+02 & $2 . E+0 I$ & $3 . \mathrm{E}+0 \mathrm{I}$ & $3 . E+0 I$ & $7 . \mathrm{E}+00$ & $8 . E+00$ \\
\hline $\mathrm{Sm}$ & NAA & 5.E-OI & 3.E-OI & 3.E-02 & I.E-0| & 5.E-0I & $8 . E+00$ & $3 . E+00$ & $3 . E+00$ & $3 . E+00$ & 6.E-0l & 7.E-OI \\
\hline $\mathrm{Eu}$ & NAA & 2.E +00 & 8.E-0I & $3 . \mathrm{E}-0 \mathrm{I}$ & 3.E-0I & 5.E-Ol & I.E +00 & $2 . E+00$ & $2 . E+00$ & $3 . E+00$ & 4.E-OI & 7.E-0I \\
\hline $\mathrm{Yb}$ & NAA & 2.E-OI & 2.E-0I & 8.E-02 & 9.E-02 & 2.E-OI & $4 . E+00$ & I.E +00 & 2.E +00 & $2 . E+00$ & 4.E-OI & 4.E-OI \\
\hline Lu & NAA & I.E-OI & I.E-0I & 4.E-02 & 6.E-02 & 9.E-02 & 7.E-OI & 2.E-OI & 4.E-OI & 3.E-OI & I.E-0I & I.E-0| \\
\hline $\mathrm{Au}$ & NAA & 4.E +00 & $4 . E+00$ & $4 . E+00$ & $4 . \mathrm{E}+00$ & $4 . E+00$ & $4 . E+00$ & $4 . E+00$ & $4 . E+00$ & $4 . E+00$ & $4 . E+00$ & $4 . E+00$ \\
\hline $\mathrm{Hg}$ & NAA & $4 . E+00$ & I.E +00 & 2.E-OI & 3.E-OI & 8.E-Ol & $8 . E+00$ & $4 . E+00$ & $2 . \mathrm{E}+00$ & $3 . E+00$ & 4.E-OI & 4.E-0I \\
\hline Th & NAA & $4 . \mathrm{E}+00$ & $4 . E+00$ & 7.E-0I & 7.E-0I & I.E +00 & $2 . E+0 I$ & $8 . E+00$ & $5 . E+00$ & $7 . E+00$ & $2 . E+00$ & $2 . \mathrm{E}+00$ \\
\hline
\end{tabular}


Table B-2

Size-Segregated Elemental Concentrations of the Pittsburgh Fly Ash Sampled at Port 12 (2.2 residence second)

a) Major Species Results

\begin{tabular}{|c|c|c|c|c|c|c|c|c|c|c|c|c|}
\hline Impactor & Stage & I & 2 & 3 & 4 & 5 & 6 & 7 & 8 & 9 & 10 & II \\
\hline Cut-off & $\begin{array}{l}\text { Diameter } \\
\text { (microns) }\end{array}$ & 0.0324 & 0.0636 & 0.0926 & 0.168 & 0.337 & 0.535 & 0.973 & 1.96 & 3.77 & 7.33 & 15.7 \\
\hline Element & $\begin{array}{c}\text { Analytical } \\
\text { Method }\end{array}$ & & & & & & & & & & & \\
\hline $\begin{array}{l}\text { Total Mass Conc } \\
(\mathrm{g} / \mathrm{Nm} \wedge 3)\end{array}$ & Gravimetric & $6.13 \mathrm{E}-04$ & $1.24 \mathrm{E}-03$ & $8.21 \mathrm{E}-04$ & $9.44 \mathrm{E}-04$ & $1.62 \mathrm{E}-03$ & $4.75 E-03$ & $6.30 \mathrm{E}-03$ & $8.32 \mathrm{E}-03$ & 1.01E-02 & $4.04 E-02$ & $5.32 \mathrm{E}-03$ \\
\hline $\mathrm{Fe}_{2} \mathrm{O}_{3}(\mathrm{Wt} \%)$ & NAA & & $4 . E+00$ & $5 . E+00$ & $7 . E+00$ & $9 . \mathrm{E}+00$ & $8 . E+00$ & $8 . E+01$ & $3 . E+00$ & $3 . E+00$ & $7 . \mathrm{E}+00$ & $2 . E+00$ \\
\hline$+/-$ & & & $2 . E+00$ & $3 . E+00$ & $2 . E+00$ & $2 . E+00$ & $5 . E+00$ & $7 . \mathrm{E}+0 \mathrm{I}$ & I.E +00 & I.E +00 & $4 . E+00$ & I.E +00 \\
\hline $\mathrm{Ca} 0(\mathrm{Wt} \%)$ & NAA & & $2.6 \mathrm{E}+0 \mathrm{I}$ & $3 . \mathrm{E}+0 \mathrm{I}$ & $1.4 \mathrm{E}+0 \mid$ & $1.6 \mathrm{E}+01$ & $1.9 \mathrm{E}+0 \mathrm{I}$ & $1 . E+02$ & $5 . E+00$ & $4 . \mathrm{E}+00$ & $9 . \mathrm{E}+00$ & $8 . E+00$ \\
\hline$+/-$ & & & $9 . \mathrm{E}+00$ & I.E $+0 \mid$ & $4 . E+00$ & $4 . E+00$ & $5 . E+00$ & I.E +02 & $3 . \mathrm{E}+00$ & $3 . E+00$ & $5 . E+00$ & $6 . \mathrm{E}+00$ \\
\hline $\begin{array}{l}\text { Trace Elements } \\
(\mathrm{Wt} \%)\end{array}$ & NAA & & 2.IE-0I & 2.IE-0I & $3.4 \mathrm{E}-0 \mathrm{I}$ & $3.8 \mathrm{E}-0 \mathrm{I}$ & I.7E-0I & $2.3 \mathrm{E}+00$ & $5.4 \mathrm{E}-02$ & $4.6 \mathrm{E}-02$ & I.IE-OI & I.OE-OI \\
\hline
\end{tabular}

Note: Elemental concentrations have been converted to oxide forms on $\mathrm{SO}_{3}$-free basis. 
TABLE B-2 (continued)

Size-Segregated Elemental Concentrations of the Pittsburgh Fly Ash Sampled at Port 12 (2.2 residence second)

b) Trace Element Concentrations

\begin{tabular}{|c|c|c|c|c|c|c|c|c|c|c|c|c|}
\hline Impactor & Stage & I & 2 & 3 & 4 & 5 & 6 & 7 & 8 & 9 & 10 & II \\
\hline Cut-off & $\begin{array}{l}\text { Diameter } \\
\text { (microns) }\end{array}$ & 0.0324 & 0.0636 & 0.0926 & 0.168 & 0.337 & 0.535 & 0.973 & 1.96 & 3.77 & 7.33 & 15.7 \\
\hline Element & $\begin{array}{c}\text { Analytical } \\
\text { Method }\end{array}$ & & & & & & & & & & & \\
\hline As & NAA & & $6 . \mathrm{E}+0 \mathrm{I}$ & $1.4 \mathrm{E}+02$ & $1.9 \mathrm{E}+02$ & $5 . E+02$ & $2 . E+02$ & $2 . E+03$ & $4 . E+0 I$ & $|. E+0|$ & I.E $+0 \mid$ & $|. E+0|$ \\
\hline $\mathrm{Se}$ & NAA & & $8 . E+0 I$ & $4 . E+0 I$ & $4 . E+0 I$ & $5 . E+0 I$ & $5 . E+0 I$ & $4 . E+02$ & $3 . \mathrm{E}+0 \mathrm{I}$ & I.E+0I & $2 . E+0 I$ & $4 . E+0 I$ \\
\hline $\mathrm{Sb}$ & NAA & & $5 . E+00$ & $2.5 \mathrm{E}+0 \mathrm{I}$ & $9.6 \mathrm{E}+00$ & $2 . I E+0 I$ & $\begin{array}{c}9.6 \mathrm{E}+0 \\
0\end{array}$ & 7.E $+0 \mathrm{I}$ & $2 . E+00$ & I.E +00 & I.E +00 & I.E +00 \\
\hline$C_{0}$ & NAA & & $2.5 \mathrm{E}+0 \mathrm{I}$ & $1.2 \mathrm{E}+02$ & $8.3 \mathrm{E}+01$ & $\mathrm{I} . \mathrm{IE}+02$ & $7 . \mathrm{E}+0 \mathrm{I}$ & $5 . E+02$ & $1.5 \mathrm{E}+0 \mathrm{I}$ & $6 . \mathrm{E}+00$ & $1.2 \mathrm{E}+0 \mathrm{I}$ & $3.0 \mathrm{E}+0 \mathrm{I}$ \\
\hline Sc & NAA & & $5 . E+00$ & $2 . I E+0 \mid$ & $\mathrm{I} .3 \mathrm{E}+0 \mathrm{I}$ & $4.0 \mathrm{E}+01$ & $4 . E+0 I$ & $2 . \mathrm{E}+02$ & $2.4 \mathrm{E}+0 \mathrm{I}$ & $1.9 \mathrm{E}+0 \mathrm{I}$ & $6 . \mathrm{E}+00$ & $6.2 \mathrm{E}+00$ \\
\hline $\mathrm{Zn}$ & NAA & & $5 . E+02$ & nd & $1.6 \mathrm{E}+03$ & nd & nd & $8.9 \mathrm{E}+03$ & I.E +02 & I.E +02 & $3 . E+02$ & $4 . E+02$ \\
\hline $\mathrm{Rb}$ & NAA & & $7 . \mathrm{E}+02$ & $6 . \mathrm{E}+02$ & $6 . \mathrm{E}+00$ & $1.9 \mathrm{E}+02$ & $4 . E+02$ & $5 . E+03$ & $1.3 \mathrm{E}+02$ & $2 . E+02$ & $3 . E+02$ & $3 . E+02$ \\
\hline Mo & NAA & & $8 . E+0 I$ & $8 . \mathrm{E}+0 \mathrm{I}$ & $1.2 \mathrm{E}+02$ & $1.5 \mathrm{E}+02$ & $5 . E+0 I$ & $5 . E+02$ & $2 . \mathrm{E}+0 \mathrm{I}$ & $|. E+0|$ & I.E+0| & $|. E+0|$ \\
\hline$C d$ & NAA & & $5 . E+02$ & $\mathrm{I} . \mathrm{E}+03$ & I.E +03 & $2 . E+03$ & $7 . \mathrm{E}+02$ & $5 . E+03$ & I.E +02 & $6 . \mathrm{E}+01$ & $5 . \mathrm{E}+0 \mathrm{I}$ & $3 . \mathrm{E}+0 \mathrm{I}$ \\
\hline Cs & NAA & & 6.E-0I & nd & $2.0 \mathrm{E}+0 \mathrm{I}$ & $1.8 \mathrm{E}+01$ & $3 . E+0 I$ & I.E $+0 \mid$ & nd & $9 . \mathrm{E}+00$ & $1.6 \mathrm{E}+0 \mathrm{I}$ & $5 . E+00$ \\
\hline $\mathrm{La}$ & NAA & & $|. E+0|$ & $1.8 \mathrm{E}+0 \mid$ & $2.5 \mathrm{E}+0 \mathrm{I}$ & $6 . \mathrm{E}+0 \mathrm{I}$ & $5 . E+0 I$ & $4 . E+02$ & $1.2 \mathrm{E}+0 \mid$ & $|. E+0|$ & $\mathrm{I} . \mathrm{IE}+02$ & $7 . \mathrm{E}+0 \mathrm{I}$ \\
\hline Ce & NAA & & $9 . \mathrm{E}+0 \mathrm{I}$ & $2 . I E+0 \mid$ & $5 . E+01$ & $1.3 \mathrm{E}+02$ & $8 . \mathrm{E}+0 \mathrm{I}$ & $7 . E+02$ & $4 . E+0 I$ & $2 . \mathrm{E}+0 \mathrm{I}$ & $1.8 \mathrm{E}+02$ & I.IE +02 \\
\hline Sm & NAA & & 8.E-OI & $5 . E+00$ & $4.2 \mathrm{E}+00$ & I.IE $+0 \mathrm{I}$ & $8 . E+00$ & $6 . \mathrm{E}+0 \mathrm{I}$ & $1.8 \mathrm{E}+00$ & 9.E-0I & 9.E-0I & 4.E-0I \\
\hline $\mathrm{Eu}$ & NAA & & nd & 4.E-0I & $7 . \mathrm{E}+00$ & $9 . \mathrm{E}+00$ & $3 . E+00$ & nd & nd & $1.0 \mathrm{E}+00$ & $3 . E+00$ & nd \\
\hline $\mathrm{Yb}$ & NAA & & $5 . E+00$ & nd & 8.E-02 & $3.7 \mathrm{E}+00$ & $2 . E+00$ & $2 . E+0 I$ & 3.E-OI & $1.0 \mathrm{E}+00$ & $1.4 \mathrm{E}+00$ & $9.6 \mathrm{E}-0 \mathrm{I}$ \\
\hline Lu & NAA & & $\mathrm{I} .6 \mathrm{E}-0 \mathrm{I}$ & $8 . E-01$ & 4.E-0I & 9.E-0I & $2 . \mathrm{E}-0 \mathrm{I}$ & $2 . E+00$ & $3 . E-02$ & $2 . \mathrm{E}-01$ & 9.E-02 & 3.E-0I \\
\hline $\mathrm{Au}$ & NAA & & nd & 9.E-02 & 3.E-0I & 6.E-02 & 7.E-03 & 3.E-0I & nd & 4.E-02 & nd & $5 . \mathrm{E}-03$ \\
\hline $\mathrm{Hg}$ & NAA & & nd & nd & nd & $1.4 \mathrm{E}+00$ & nd & nd & nd & nd & nd & nd \\
\hline Th & NAA & & $6 . E+00$ & I.E +00 & $7 . E+00$ & $1.5 \mathrm{E}+0 \mid$ & $5 . E+00$ & 7.E+OI & I.E-0| & $2 . E+00$ & 7.E-0I & $4 . E+00$ \\
\hline $\begin{array}{c}\text { Total } \\
\text { (wt\%) }\end{array}$ & & & 2.IE-0I & 2.IE-0I & $3.4 \mathrm{E}-0 \mathrm{I}$ & $3.8 \mathrm{E}-0 \mathrm{I}$ & I.7E-0I & $2.3 \mathrm{E}+00$ & $5.4 \mathrm{E}-02$ & $4.6 \mathrm{E}-02$ & I.IE-0I & I.OE-0I \\
\hline
\end{tabular}


TABLE B-2 (continued)

Size-Segregated Elemental Concentrations of the Pittsburgh Fly Ash Sampled at Port 12 (2.2 residence second)

c) Trace Element Uncertainties

\begin{tabular}{|c|c|c|c|c|c|c|c|c|c|c|c|c|}
\hline Impactor & Stage & I & 2 & 3 & 4 & 5 & 6 & 7 & 8 & 9 & 10 & II \\
\hline Cut-off & $\begin{array}{l}\text { Diameter } \\
\text { (microns) }\end{array}$ & 0.0324 & 0.0636 & 0.0926 & 0.168 & 0.337 & 0.535 & 0.973 & 1.96 & 3.77 & 7.33 & 15.7 \\
\hline Element & $\begin{array}{c}\text { Analytical } \\
\text { Method }\end{array}$ & & & & & & & & & & & \\
\hline As & NAA & & $2 . E+0 I$ & $5 . E+01$ & $4 . E+0 I$ & $1 . E+02$ & $2 . E+02$ & $2 . E+03$ & $2 . E+0 I$ & $|. E+0|$ & $I . E+0 \mid$ & $I . E+0 \mid$ \\
\hline $\mathrm{Se}$ & NAA & & $4 . E+0 I$ & $2 . \mathrm{E}+0 \mathrm{I}$ & $2 . E+0 I$ & $2 . E+0 I$ & $5 . E+01$ & $4 . E+02$ & $3 . \mathrm{E}+0 \mathrm{I}$ & $2 . E+0 I$ & $2 . E+0 I$ & $3 . E+01$ \\
\hline $\mathrm{Sb}$ & NAA & & $2 . E+00$ & $9 . E+00$ & $3 . E+00$ & $5 . E+00$ & $3 . E+00$ & $6 . \mathrm{E}+0 \mathrm{I}$ & $2 . E+00$ & I.E +00 & I.E +00 & I.E +00 \\
\hline$C_{0}$ & NAA & & $9 . \mathrm{E}+00$ & $4 . \mathrm{E}+0 \mathrm{I}$ & $2 . \mathrm{E}+0 \mathrm{I}$ & $2 . \mathrm{E}+0 \mathrm{I}$ & $2 . E+0 I$ & $3 . E+02$ & $3 . \mathrm{E}+00$ & $2 . E+00$ & $2 . \mathrm{E}+00$ & $6 . \mathrm{E}+00$ \\
\hline Cs & NAA & & $2 . \mathrm{E}+00$ & $2 . \mathrm{E}+00$ & $6 . \mathrm{E}+00$ & $6 . \mathrm{E}+00$ & $2 . E+0 I$ & I.E+0| & $2 . \mathrm{E}+00$ & $6 . \mathrm{E}+00$ & $9 . \mathrm{E}+00$ & $5 . E+00$ \\
\hline Sc & NAA & & I.E +02 & $2 . E+00$ & $2 . E+00$ & $5 . E+00$ & $I . E+0 \mid$ & I.E +02 & $2 . E+00$ & $\mathrm{I} . \mathrm{E}+00$ & I.E +00 & 8.E-OI \\
\hline $\ln$ & NAA & & $3 . E+02$ & $9 . \mathrm{E}+0 \mathrm{I}$ & $4 . \mathrm{E}+02$ & $9 . \mathrm{E}+0 \mathrm{I}$ & $6 . \mathrm{E}+03$ & $2 . E+02$ & I.E +02 & $2 . \mathrm{E}+02$ & $3 . E+02$ & $3 . E+02$ \\
\hline $\mathrm{Rb}$ & NAA & & $2 . E+02$ & $2 . E+02$ & $3 . E+01$ & $6 . \mathrm{E}+01$ & $3 . E+02$ & $4 . \mathrm{E}+03$ & $8 . \mathrm{E}+0 \mathrm{I}$ & I.E+02 & $2 . E+02$ & $2 . E+02$ \\
\hline Mo & NAA & & $4 . \mathrm{E}+0 \mathrm{I}$ & $4 . \mathrm{E}+0 \mathrm{I}$ & $4 . E+0 I$ & $4 . \mathrm{E}+0 \mathrm{I}$ & $5 . E+0 I$ & $5 . E+02$ & $2 . \mathrm{E}+0 \mathrm{I}$ & $2 . \mathrm{E}+0 \mathrm{I}$ & $2 . E+0 I$ & $2 . \mathrm{E}+0 \mathrm{I}$ \\
\hline$C d$ & NAA & & $4 . E+03$ & $4 . E+03$ & $4 . E+03$ & $4 . E+03$ & $4 . E+03$ & $8 . E+03$ & $4 . E+03$ & $4 . E+03$ & $4 . E+03$ & $4 . E+03$ \\
\hline $\mathrm{La}$ & NAA & & $3 . E+00$ & $6 . \mathrm{E}+00$ & $5 . E+00$ & $|. E+0|$ & $3 . \mathrm{E}+0 \mathrm{I}$ & $4 . \mathrm{E}+02$ & $5 . E+00$ & $4 . E+00$ & $5 . E+0 I$ & $4 . \mathrm{E}+0 \mathrm{I}$ \\
\hline Ce & NAA & & $3 . \mathrm{E}+0 \mathrm{I}$ & $9 . E+00$ & I.E+0I & $3 . \mathrm{E}+0 \mathrm{I}$ & $6 . \mathrm{E}+0 \mathrm{I}$ & $7 . E+02$ & $2 . E+0 I$ & $I . E+0 \mid$ & $9 . \mathrm{E}+0 \mathrm{I}$ & $7 . \mathrm{E}+0 \mathrm{I}$ \\
\hline Sm & NAA & & 3.E-OI & $2 . E+00$ & 9.E-OI & $2 . E+00$ & $5 . E+00$ & $6 . \mathrm{E}+0 \mathrm{I}$ & 8.E-OI & 4.E-OI & 4.E-OI & 3.E-OI \\
\hline Eu & NAA & & 3.E-0I & 4.E-0I & $2 . E+00$ & $2 . \mathrm{E}+00$ & $2 . E+00$ & 3.E-OI & 3.E-0I & 7.E-0I & $2 . E+00$ & 3.E-0I \\
\hline $\mathrm{Yb}$ & NAA & & $2 . E+00$ & 8.E-02 & I.E-OI & 8.E-0I & $\mathrm{I} . \mathrm{E}+00$ & $2 . E+0 I$ & 2.E-0I & 5.E-0I & 7.E-0I & 6.E-0I \\
\hline Lu & NAA & & 9.E-02 & 3.E-OI & I.E-OI & 2.E-0I & I.E-OI & $2 . E+00$ & 5.E-02 & I.E-0I & 8.E-02 & 2.E-OI \\
\hline $\mathrm{Au}$ & NAA & & $4 . E+00$ & $4 . E+00$ & $4 . E+00$ & $4 . E+00$ & $4 . E+00$ & $4 . E+00$ & $4 . E+00$ & $4 . E+00$ & $4 . E+00$ & $4 . E+00$ \\
\hline $\mathrm{Hg}$ & NAA & & 2.E-0I & 2.E-OI & 2.E-0I & 5.E-0I & 2.E-0I & 2.E-OI & 2.E-0I & 2.E-0I & 2.E-0I & 2.E-OI \\
\hline Th & NAA & & $3 . E+00$ & I.E +00 & $2 . E+00$ & $4 . E+00$ & $4 . E+00$ & $7 . E+0 I$ & 7.E-0I & $2 . E+00$ & I.E +00 & $3 . E+00$ \\
\hline
\end{tabular}


Table B-3

Size-Segregated Elemental Concentrations of the Pittsburgh Fly Ash Sampled at the Baghouse Inlet Port

a) Major Species Results

\begin{tabular}{|c|c|c|c|c|c|c|c|c|c|c|c|c|}
\hline Impactor & Stage & I & 2 & 3 & 4 & 5 & 6 & 7 & 8 & 9 & 10 & II \\
\hline Cut-off & $\begin{array}{l}\text { fDiameter } \\
\text { (microns) }\end{array}$ & 0.0324 & 0.0636 & 0.0926 & 0.168 & 0.337 & 0.535 & 0.973 & 1.96 & 3.77 & 7.33 & 15.7 \\
\hline Element & $\begin{array}{l}\text { Analytical } \\
\text { Method }\end{array}$ & & & & & & & & & & & \\
\hline $\begin{array}{l}\text { Total Mass Conc } \\
(\mathrm{g} / \mathrm{Nm} \wedge 3)\end{array}$ & Gravimetric & $1.63 \mathrm{E}-02$ & $1.56 \mathrm{E}-02$ & $2.48 \mathrm{E}-02$ & $2.35 \mathrm{E}-02$ & $2.30 \mathrm{E}-02$ & $4.63 \mathrm{E}-02$ & $1.23 \mathrm{E}-0 \mid$ & $2.47 \mathrm{E}-01$ & $3.36 \mathrm{E}-01$ & $6.79 \mathrm{E}-01$ & $1.30 \mathrm{E}-0 \mid$ \\
\hline $\mathrm{SiO}_{2}(\mathrm{Wt} \%)$ & AAS & $1.29 \mathrm{E}+0 \mathrm{I}$ & $3.6 \mathrm{E}+01$ & $2.9 \mathrm{E}+0 \mathrm{I}$ & $3 . I E+0 I$ & $4 . I E+0 I$ & $3.0 \mathrm{E}+0 \mathrm{I}$ & $3.9 \mathrm{E}+0 \mathrm{I}$ & $4.3 \mathrm{E}+0 \mathrm{I}$ & $4.4 \mathrm{E}+0 \mathrm{I}$ & $2.86 \mathrm{E}+0 \mathrm{I}$ & $6.0 \mathrm{E}+0 \mathrm{I}$ \\
\hline $\mathrm{Al}_{2} \mathrm{O}_{3}(\mathrm{Wt} \%)$ & AAS & nd & nd & nd & $4.4 \mathrm{E}+0 \mathrm{I}$ & $5.3 \mathrm{E}+0 \mathrm{I}$ & $6.9 \mathrm{E}+0 \mathrm{I}$ & $7.0 \mathrm{E}+0 \mathrm{I}$ & $7.3 \mathrm{E}+0 \mathrm{I}$ & $5.48 \mathrm{E}+0 \mathrm{I}$ & $3.32 \mathrm{E}+01$ & $5.94 \mathrm{E}+0 \mathrm{I}$ \\
\hline$+/-$ & & & & & $3 . E+00$ & $5 . E+00$ & $4 . E+00$ & $2 . E+00$ & I.E +00 & 6.E-0I & 4.E-0I & 6.E-0I \\
\hline $\mathrm{Fe}_{2} \mathrm{O}_{3}(\mathrm{Wt} \%)$ & AAS & $3.22 \mathrm{E}+00$ & $5.5 \mathrm{E}+00$ & $5.7 \mathrm{E}+00$ & $1.0 \mathrm{E}+0 \mathrm{I}$ & $9.9 \mathrm{E}+00$ & $1.6 \mathrm{E}+0 \mathrm{I}$ & $1.8 \mathrm{E}+0 \mid$ & $1.8 \mathrm{E}+0 \mid$ & $2.2 \mathrm{E}+0 \mathrm{I}$ & $|.30 \mathrm{E}+0|$ & $2.8 \mathrm{E}+0 \mathrm{I}$ \\
\hline$+/-$ & & 4.E-OI & 4.E-OI & 5.E-0I & 9.E-OI & I.E +00 & I.E +00 & 8.E-0I & 5.E-OI & 4.E-OI & 4.E-OI & 5.E-0I \\
\hline $\mathrm{Ca} 0(\mathrm{Wt} \%)$ & AAS & nd & nd & $2.0 \mathrm{E}+00$ & $\mathrm{I} .4 \mathrm{E}+00$ & $3.4 \mathrm{E}+00$ & $4.3 \mathrm{E}+00$ & $4.8 \mathrm{E}+00$ & $4.9 \mathrm{E}+00$ & $4.9 \mathrm{E}+00$ & $2.28 \mathrm{E}+00$ & $6 . \mathrm{IE}+00$ \\
\hline$+/-$ & & & & 3.E-0I & 3.E-0I & 6.E-0I & 5.E-0I & 4.E-OI & 3.E-0I & 3.E-0I & 2.E-OI & 3.E-0I \\
\hline $\begin{array}{l}\text { Trace Elements } \\
(\mathrm{Wt} \%)\end{array}$ & NAA & I.OE-OI & $6.6 \mathrm{E}-02$ & $6.7 \mathrm{E}-02$ & $5.7 \mathrm{E}-02$ & $4.0 \mathrm{E}-02$ & $4.3 \mathrm{E}-02$ & $3.2 \mathrm{E}-02$ & $2.2 \mathrm{E}-02$ & $1.2 \mathrm{E}-02$ & $6.6 \mathrm{E}-03$ & $1.2 \mathrm{E}-02$ \\
\hline Total (Wt\%) & & 33 & 61 & 67 & 113 & 133 & 149 & 156 & 155 & 138 & 83 & 165 \\
\hline
\end{tabular}

Note: Elemental concentrations have been converted to oxide forms on a $\mathrm{SO}_{3}$-free basis.

nd $=$ below detection limit 
Table B-3 (continued)

Size-Segregated Elemental Concentrations of the Illinois \#6 Fly Ash Sampled at the Baghouse Inlet Port

b) Trace Element Concentrations

\begin{tabular}{|c|c|c|c|c|c|c|c|c|c|c|c|c|}
\hline Impactor & Stage & I & 2 & 3 & 4 & 5 & 6 & 7 & 8 & 9 & 10 & II \\
\hline Cut-off & Diameter (microns) & 0.0324 & 0.0636 & 0.0926 & 0.168 & 0.337 & 0.535 & 0.973 & 1.96 & 3.77 & 7.33 & 15.7 \\
\hline Element & $\begin{array}{l}\text { Analytical } \\
\text { Method }\end{array}$ & & & & & & & & & & & \\
\hline As & GFAA & $1.82 \mathrm{E}+02$ & $1.82 \mathrm{E}+02$ & $\mathrm{I} .6 \mathrm{IE}+02$ & $8.8 \mathrm{E}+01$ & $1.54 \mathrm{E}+02$ & $8 . \mathrm{E}+0 \mathrm{I}$ & $9 . \mathrm{E}+\mathrm{OI}$ & $6 . \mathrm{E}+0 \mathrm{I}$ & $4 . \mathrm{E}+0 \mathrm{I}$ & $3 . E+01$ & $4 . E+01$ \\
\hline Se & GFAA & $1.74 \mathrm{E}+02$ & $1.74 \mathrm{E}+02$ & I. $18 \mathrm{E}+02$ & $4.9 \mathrm{E}+0 \mathrm{I}$ & $6.8 \mathrm{E}+0 \mathrm{I}$ & $3.0 \mathrm{E}+0 \mathrm{I}$ & $2 . \mathrm{E}+0 \mathrm{I}$ & $8 . E+00$ & 7.E +00 & 7.E+00 & $|. E+0|$ \\
\hline $\mathrm{Sb}$ & GFAA & $8.9 \mathrm{E}+0 \mathrm{I}$ & $8.9 \mathrm{E}+01$ & $4.5 \mathrm{E}+0 \mathrm{I}$ & $3.6 \mathrm{E}+0 \mathrm{I}$ & $7.5 \mathrm{E}+01$ & $2.4 \mathrm{E}+01$ & $\mathrm{I} . \mathrm{E}+0 \mathrm{I}$ & $\mathrm{I} . \mathrm{E}+0 \mathrm{I}$ & $3 . \mathrm{E}+0 \mathrm{I}$ & $9 . \mathrm{E}+00$ & $2 . E+01$ \\
\hline$C_{0}$ & GFAA & $5.8 \mathrm{E}+0 \mathrm{I}$ & $5.8 \mathrm{E}+01$ & $4.3 \mathrm{E}+0 \mathrm{I}$ & $2.6 \mathrm{E}+01$ & $8.4 \mathrm{E}+0 \mathrm{l}$ & $4.0 \mathrm{E}+0 \mathrm{I}$ & $3 . \mathrm{E}+0 \mathrm{I}$ & $2.4 \mathrm{E}+0 \mathrm{I}$ & $2 . \mathrm{E}+0 \mathrm{I}$ & $3 . \mathrm{E}+0 \mathrm{I}$ & $3 . E+01$ \\
\hline Total (wt\%) & & $5.0 \mathrm{E}-02$ & $5.0 \mathrm{E}-02$ & $3.7 \mathrm{E}-02$ & $2.0 \mathrm{E}-02$ & $3.8 \mathrm{E}-02$ & $1.8 \mathrm{E}-02$ & $1.5 \mathrm{E}-02$ & I.IE-02 & I.IE-02 & $7.7 \mathrm{E}-03$ & $1.0 \mathrm{E}-02$ \\
\hline
\end{tabular}

c) Trace Element Uncertainties

\begin{tabular}{|c|c|c|c|c|c|c|c|c|c|c|c|c|}
\hline Impactor & Stage & I & 2 & 3 & 4 & 5 & 6 & 7 & 8 & 9 & 10 & II \\
\hline Cut-off & Diameter (microns) & 0.0324 & 0.0636 & 0.0926 & 0.168 & 0.337 & 0.535 & 0.973 & 1.96 & 3.77 & 7.33 & 15.7 \\
\hline Element & $\begin{array}{c}\text { Analytical } \\
\text { Method }\end{array}$ & & & & & & & & & & & \\
\hline As & & $6 . \mathrm{E}+00$ & $5 . E+00$ & $6 . E+00$ & $6 . \mathrm{E}+00$ & $8 . E+00$ & $I . E+0 \mid$ & $4 . \mathrm{E}+0 \mathrm{I}$ & $2 . \mathrm{E}+0 \mathrm{I}$ & $3 . \mathrm{E}+0 \mathrm{I}$ & $3 . E+0 I$ & $5 . \mathrm{E}+\mathrm{OI}$ \\
\hline Se & & $5 . E+00$ & $4 . E+00$ & $4 . E+00$ & $4 . E+00$ & $5 . E+00$ & $6 . \mathrm{E}+00$ & $2 . \mathrm{E}+0 \mathrm{I}$ & I.E $+0 \mid$ & $2 . E+0 I$ & $2 . E+0 I$ & $6 . \mathrm{E}+0 \mathrm{I}$ \\
\hline $\mathrm{Sb}$ & & $6 . \mathrm{E}+00$ & $6 . E+00$ & $6 . \mathrm{E}+00$ & $6 . \mathrm{E}+00$ & $6 . \mathrm{E}+00$ & $7 . E+00$ & $3 . \mathrm{E}+0 \mathrm{I}$ & $|. E+0|$ & I.E +0 I & $|. E+0|$ & $3 . \mathrm{E}+0 \mathrm{I}$ \\
\hline$C_{0}$ & & $4 . \mathrm{E}+00$ & $4 . E+00$ & $4 . E+00$ & $4 . E+00$ & $5 . E+00$ & $6 . E+00$ & $3 . \mathrm{E}+0 \mathrm{I}$ & $7 . \mathrm{E}+00$ & I.E +0 I & $2 . \mathrm{E}+0 \mathrm{I}$ & $2 . \mathrm{E}+\mathrm{OI}$ \\
\hline
\end{tabular}


Table B-4

Size-Segregated Elemental Concentrations of the Illinois \#6 Fly Ash Sampled at Port 4b (0.5 residence second)

a) Major Species Results

\begin{tabular}{|c|c|c|c|c|c|c|c|c|c|c|c|c|}
\hline Impactor & Stage & 1 & 2 & 3 & 4 & 5 & 6 & 7 & 8 & 9 & 10 & 11 \\
\hline Cut-off & $\begin{array}{l}\text { Diameter } \\
\text { (microns) }\end{array}$ & 0.0324 & 0.0636 & 0.0926 & 0.168 & 0.337 & 0.535 & 0.973 & $1: 96$ & 3.77 & 7.33 & 15.7 \\
\hline Element & $\begin{array}{c}\text { Analytical } \\
\text { Method }\end{array}$ & & & & & & & & & & & \\
\hline $\begin{array}{l}\text { Total Mass Conc } \\
\left(\mathrm{g} / \mathrm{Nm}^{\wedge} 3\right)\end{array}$ & Gravimetric & $1.13 \mathrm{E}-03$ & $1.35 E-03$ & $1.41 \mathrm{E}-03$ & $3.69 \mathrm{E}-03$ & $2.60 \mathrm{E}-03$ & $5.27 \mathrm{E}-02$ & $9.43 \mathrm{E}-02$ & $1.76 \mathrm{E}-01$ & $1.52 \mathrm{E}-01$ & $3.58 \mathrm{E}-01$ & $1.75 \mathrm{E}-01$ \\
\hline $\mathrm{Fe}_{2} \mathrm{O}_{3}(\mathrm{Wt} \%)$ & NAA & $5 . \mathrm{E}+00$ & $2.6 E+00$ & nd & $1.5 E+00$ & $5.7 \mathrm{E}+00$ & $2 . E+01$ & $9.9 \mathrm{E}+00$ & $1.0 \mathrm{E}+01$ & $1.5 \mathrm{E}+01$ & $1.7 \mathrm{E}+01$ & $9 . \mathrm{E}+00$ \\
\hline$+1-$ & & 2.E+00 & 5.E-01 & 2.E-01 & 2.E-01 & 5.E-01 & $1 . E+01$ & $6 . E+00$ & $5 . \mathrm{E}+00$ & 7.E +00 & $2 . E+00$ & $2 . E+00$ \\
\hline $\mathrm{CaO}(\mathrm{Wt} \%)$ & NAA & $1.2 \mathrm{E}+01$ & $5 . E+00$ & $.9 . \mathrm{E}-03$ & $3 . E+00$ & $5 . E+00$ & $1 . E+01$ & $1.1 \mathrm{E}+01$ & $5 . E+00$ & $1.1 \mathrm{E}+01$ & 2.E+00 & $2 . E+00$ \\
\hline+1 & & $4 . E+00$ & $2 . E+00$ & $1 . E+00$ & $1 . E+00$ & 1.E+00 & $1 . E+01$ & $8 . E+00$ & 4.E+00 & $6 . E+00$ & $1 . E+00$ & $1 . E+00$ \\
\hline $\begin{array}{l}\text { Trace Elements } \\
\left(w_{t} \%\right)\end{array}$ & NAA & $4.8 \mathrm{E}-01$ & 4.7E-01 & $2.0 \mathrm{E}-03$ & $7.0 \mathrm{E}-01$ & $5.4 \mathrm{E}-01$ & $3.5 \mathrm{E}-01$ & $1.5 \mathrm{E}-01$ & $1.1 E-01$ & $7.5 \mathrm{E}+00$ & $6.7 \mathrm{E}-02$ & $3.4 \mathrm{E}-02$ \\
\hline
\end{tabular}

Note: Elemental concentrations have been converted to oxide forms on a $\mathrm{SO}_{3}$-free basis. 
Table B-4 (Continued)

Size-Segregated Elemental Concentrations of the Illinois \#6 Fly Ash Sampled at Port 4b (0.5 residence second)

b) Trace Element Concentrations

\begin{tabular}{|c|c|c|c|c|c|c|c|c|c|c|c|c|}
\hline Impactor & Stage & 1 & 2 & 3 & 4 & 5 & 6 & 7 & 8 & 9 & 10 & 11 \\
\hline Cut-off & $\begin{array}{l}\text { Diameter } \\
\text { (microns) }\end{array}$ & 0.0324 & 0.0636 & 0.0926 & 0.168 & 0.337 & 0.535 & 0.973 & 1.96 & 3.77 & 7.33 & 15.7 \\
\hline Element & $\begin{array}{c}\text { Analytical } \\
\text { Method }\end{array}$ & & & & & & & & & & & \\
\hline As & NAA & $3.1 E+02$ & $3.4 \mathrm{E}+02$ & $2 . E+00$ & $4.3 E+02$ & $3.3 \mathrm{E}+02$ & $1.1 \mathrm{E}+02$ & 4.E+01 & $5 . \mathrm{E}+01$ & $5 . E+01$ & $2.9 \mathrm{E}+01$ & $1.8 \mathrm{E}+01$ \\
\hline $\mathrm{Se}$ & NAA & 2.E+02 & $2 . E+02$ & 1.E+00 & $3.7 \mathrm{E}+02$ & $2.7 \mathrm{E}+02$ & $9 . \mathrm{E}+01$ & $2 . E+01$ & $5 . E+01$ & $5 . \mathrm{E}+01$ & $1 . E+01$ & $7 . E+00$ \\
\hline $\mathrm{Sb}$ & NAA & $5 . E+01$ & $5.6 \mathrm{E}+01$ & 2.E-01 & $6.6 \mathrm{E}+01$ & $4.3 \mathrm{E}+01$ & $2 . E+01$ & 7.E+00 & $9 . E+00$ & $7 . E+00$ & $3 . E+00$ & $2 . E+00$ \\
\hline Co & NAA & $5 . E+01$ & 34.4 & 0 & $1.2 \mathrm{E}+01$ & $3.3 E+01$ & $1 . E+02$ & $5 . E+01$ & 7.E+01 & 7.E+04 & $2.3 \mathrm{E}+01$ & $1.8 \mathrm{E}+01$ \\
\hline Cs & NAA & $4 . E+01$ & $4.4 \mathrm{E}+01$ & 2.E-01 & $5.6 \mathrm{E}+01$ & $3.8 \mathrm{E}+01$ & $3 . E+01$ & $2 . E+01$ & $8 . E+00$ & 2.E+01 & $6 . E+00$ & 7.E+00 \\
\hline $\mathrm{Sc}$ & NAA & $1.8 \mathrm{E}+00$ & $1.2 \mathrm{E}+00$ & 0 & $1.7 \mathrm{E}+00$ & $1.1 \mathrm{E}+01$ & 2.E+01 & $1.1 \mathrm{E}+01$ & $1.6 \mathrm{E}+01$ & $1.9 \mathrm{E}+01$ & $1.2 \mathrm{E}+01$ & 7.E+00 \\
\hline $\mathrm{Zn}$ & NAA & $3.2 E+03$ & $3.2 \mathrm{E}+03$ & $1 . \mathrm{E}+01$ & $5.0 \mathrm{E}+03$ & $3.8 \mathrm{E}+03$ & $2 . E+03$ & $1.0 \mathrm{E}+03$ & $7 . E+02$ & $8 . E+02$ & 4.E+02 & $2 . \mathrm{E}+02$ \\
\hline $\mathrm{Rb}$ & NAA & $3 . E+02$ & $2.1 E+02$ & 9.E-01 & $4.2 \mathrm{E}+02$ & $2.2 \mathrm{E}+02$ & $5 . E+02$ & $1 . E+02$ & $8 . E+01$ & $1 . E+02$ & $8 . E+01$ & 4.E+01 \\
\hline Mo & NAA & $5 . E+02$ & $5.2 \mathrm{E}+02$ & $2 . E+00$ & $6.1 E+02$ & $4.5 \mathrm{E}+02$ & $2 . E+02$ & $5 . E+01$ & 7.E+01 & 7.E+01 & $5 . E+01$ & $3 . E+01$ \\
\hline $\mathrm{Cd}$ & NAA & $2 . E+01$ & $3 . E+01$ & 1.E-01 & 4.E+01 & $3 . E+01$ & 4.E+01 & $9 . E+00$ & 1.E+01 & $3 . E+01$ & $1 . E+01$ & $4 . E+00$ \\
\hline ta & NAA & $3.7 E+01$ & $4.1 E+00$ & $4.2 \mathrm{E}-03$ & $5.2 \mathrm{E}+00$ & $3.3 \mathrm{E}+01$ & 7.E+01 & $2 . E+01$ & $3 . E+01$ & $3 . E+01$ & $2.2 \mathrm{E}+01$ & $1.3 \mathrm{E}+01$ \\
\hline $\mathrm{Ce}$ & NAA & $7 . E+01$ & $9 . \mathrm{E}+00$ & 5.E-02 & $2.3 \mathrm{E}+01$ & 7.7E+01 & $1 . E+02$ & $3 . E+01$ & $5 . \mathrm{E}+01$ & 7.E+01 & $4.5 \mathrm{E}+01$ & $2.6 \mathrm{E}+01$ \\
\hline $\mathrm{Sm}$ & NAA & $1.7 E+00$ & $1.8 \mathrm{E}+00$ & 8.E-03 & $2.7 \mathrm{E}+00$ & $7.2 \mathrm{E}+00$ & $1.1 E+01$ & $4 . E+00$ & $6 . \mathrm{E}+00$ & 7.E+00 & $4.3 \mathrm{E}+00$ & $2.6 \mathrm{E}+00$ \\
\hline Eu & NAA & $6 . \mathrm{E}+00$ & $3.7 \mathrm{E}+00$ & 0 & $1.9 \mathrm{E}+00$ & $3.3 \mathrm{E}+00$ & 1.E+00 & $3 . E+00$ & $3 . E+00$ & $6 . E+00$ & $1.1 \mathrm{E}+00$ & $1.6 \mathrm{E}+00$ \\
\hline$Y b$ & NAA & 3.E-01 & 6.E-01 & 0 & 3.7E-01 & $2.5 \mathrm{E}+00$ & $5 . \mathrm{E}+00$ & $2 . E+00$ & $3 . \mathrm{E}+00$ & $3 . E+00$ & $2.7 \mathrm{E}+00$ & $1.3 \mathrm{E}+00$ \\
\hline Lu & NAA & 4.E-01 & 5.E-01 & 1.E-03 & $6.3 \mathrm{E}-01$ & $8.0 \mathrm{E}-01$ & 8.E-01 & 3.E-01 & 7.E-01 & $6 . E-01$ & 5.E-01 & 2.E-01 \\
\hline $\mathrm{Au}$ & NAA & $6 . \mathrm{E}-02$ & 6.E-02 & 0 & 2.E-02 & 2.E-02 & 8.E-02 & 8.E-02 & 8.E-02 & $6 . \mathrm{E}-02$ & 1.E-02 & 8.E-03 \\
\hline $\mathrm{Hg}$ & NAA & $1.6 \mathrm{E}+01$ & 8.E+00 & 0 & $3.0 \mathrm{E}+00$ & $9.3 \mathrm{E}+00$ & 1.E+01 & $6 . E+00$ & $3 . E+00$ & $5 . E+00$ & $1.3 \mathrm{E}+00$ & $9 . E-01$ \\
\hline Th & NAA & $1.2 E+01$ & $2.4 \mathrm{E}+01$ & 0 & $1.2 \mathrm{E}+00$ & $1.0 \mathrm{E}+01$ & $2 . \mathrm{E}+01$ & $1.3 \mathrm{E}+01$ & $8 . E+00$ & $1.3 \mathrm{E}+01$ & $8 . \mathrm{E}+00$ & $5 . E+00$ \\
\hline Total (wt\%) & & $4.8 \mathrm{E}-01$ & 4.7E-01 & $2.0 \mathrm{E}-03$ & 7.0E-01 & $5.4 \mathrm{E}-01$ & $3.5 \mathrm{E}-01$ & $1.5 \mathrm{E}-01$ & 1.1E-01 & $7.5 \mathrm{E}+00$ & $6.7 \mathrm{E}-02$ & $3.4 \mathrm{E}-02$ \\
\hline
\end{tabular}


Table B-4 (Continued)

Size-Segregated Elemental Concentrations of the Illinois \#6 Fly Ash Sampled at Port 4b (0.5 residence second)

c) Trace Element Uncertainties

\begin{tabular}{|c|c|c|c|c|c|c|c|c|c|c|c|c|}
\hline Impactor & Stage & 1 & 2 & 3 & 4 & 5 & 6 & 7 & 8 & 9 & 10 & 11 \\
\hline Cut-off & $\begin{array}{l}\text { Diameter } \\
\text { (microns) }\end{array}$ & 0.0324 & 0.0636 & 0.0926 & 0.168 & 0.337 & 0.535 & 0.973 & 1.96 & 3.77 & 7.33 & 15.7 \\
\hline Element & $\begin{array}{c}\text { Analytical } \\
\text { Method }\end{array}$ & & & & & & & & & & & \\
\hline As & NAA & $8 . E+01$ & $5 . E+01$ & $5 . E+00$ & $2 . E+01$ & $3 . E+01$ & $9 . E+01$ & $3 . E+01$ & $3 . E+01$ & $3 . E+01$ & $8 . E+00$ & $9 . E+00$ \\
\hline $\mathrm{Se}$ & NAA & $7 . E+01$ & $4 . E+01$ & 1.E+01 & 2.E+01 & $3 . E+01$ & $9 . E+01$ & $3 . E+01$ & $4 . E+01$ & $3 . E+01$ & 1.E+01 & $1 . E+01$ \\
\hline $\mathrm{Sb}$ & NAA & $1 . E+01$ & $8 . E+00$ & $6 . E-01$ & $3 . E+00$ & $3 . E+00$ & $2 . E+01$ & $5 . E+00$ & $5 . E+00$ & 4.E+00 & $1 . E+00$ & $1 . E+00$ \\
\hline $\mathrm{Co}$ & NAA & $1 . E+01$ & $6 . \mathrm{E}+00$ & $1 . E+00$ & $2 . E+00$ & $3 . \mathrm{E}+00$ & $1 . E+02$ & $3 . E+01$ & 4.E+01 & $3 . E+04$ & $4 . E+00$ & $6 . E+00$ \\
\hline Cs & NAA & $1 . E+01$ & $8 . E+00$ & $-2 . E+00$ & 4.E+00 & $4 . E+00$ & $2 . E+01$ & 1.E+01 & $6 . E+00$ & $1 . E+G I$ & $3 . E+00$ & $4 . E+00$ \\
\hline $\mathrm{Sc}$ & NAA & $5 . E-01$ & 2.E-01 & 5.E-02 & 1.E-01 & 8.E-01 & 2.E+01 & $6 . E+00$ & $8 . E+00$ & $9 . E+00$ & $2 . E+00$ & $2 . E+00$ \\
\hline $\mathrm{Zn}$ & NAA & $9 . E+02$ & $5 . \mathrm{E}+02$ & $9 . E+01$ & $3 . E+02$ & $3 . E+02$ & $2 . E+03$ & $7 . E+02$ & $4 . E+02$ & $5 . \mathrm{E}+02$ & $1 . E+02$ & $1 . E+02$ \\
\hline $\mathrm{Rb}$ & NAA & $1 . E+02$ & $5 . E+01$ & $2 . E+01$ & 4.E+01 & 4.E+01 & 4.E+02 & $1 . E+02$ & $6 . E+01$ & 7.E+01 & $3 . E+01$ & $3 . E+01$ \\
\hline Mo & NAA & $1 . E+02$ & $8 . E+01$ & 2.E+01 & $4 . E+01$ & $5 . \mathrm{E}+01$ & $2 . \mathrm{E}+02$ & $5 . E+01$ & $5 . E+01$ & $5 . E+01$ & $2 . E+01$ & $2 . E+01$ \\
\hline $\mathrm{Cd}$ & NAA & $4 . E+03$ & $4 . \mathrm{E}+03$ & $4 . E+03$ & $4 . E+03$ & $4 . E+03$ & $4 . E+03$ & 4.E+03 & $4 . E+03$ & $4 . \mathrm{E}+03$ & $4 . E+03$ & $4 . E+03$ \\
\hline $\mathrm{La}$ & NAA & $9 . E+00$ & 6.E-01 & 1.E-01 & 3.E-01 & $2 . E+00$ & $5 . E+01$ & 1.E+01 & 1.E+01 & $2 . E+01$ & $3 . E+00$ & $3 . E+00$ \\
\hline $\mathrm{Ce}$ & NAA & $2 . E+01$ & $3 . E+00$ & 2.E+00 & $2 . E+00$ & 7.E+00 & 1.E+02 & $2 . E+01$ & $3 . E+01$ & $3 . E+01$ & 7.E+00 & $8 . E+00$ \\
\hline $\mathrm{Sm}$ & NAA & 5.E-01 & 3.E-01 & 3.E-02 & 1.E-01 & 5.E-01 & $8 . E+00$ & $3 . E+00$ & $3 . E+00$ & $3 . E+00$ & 6.E-01 & 7.E-01 \\
\hline Eu & NAA & 2.E+00 & 8.E-01 & 3.E-01 & 3.E-01 & 5.E-01 & 1.E +00 & $2 . E+00$ & $2 . E+00$ & $3 . E+00$ & 4.E-01 & 7.E-01 \\
\hline $\mathrm{Yb}$ & NAA & 2.E-01 & 2.E-01 & $8 . E-02$ & 9.E-02 & 2.E-01 & $4 . E+00$ & $1 . E+00$ & $2 . E+00$ & $2 . E+00$ & 4.E-01 & 4.E-01 \\
\hline Lu & NAA & 1.E-01 & 1.E-01 & 4.E-02 & $6 . \mathrm{E}-02$ & 9.E-02 & 7.E-01 & 2.E-01 & 4.E-01 & 3.E-01 & 1.E-01 & 1.E-01 \\
\hline $\mathrm{Au}$ & NAA & $4 . E+00$ & 4.E+00 & $4 . E+00$ & $4 . E+00$ & 4.E+00 & 4.E+00 & 4.E+00 & 4.E+00 & 4.E+00 & 4.E+00 & 4.E+00 \\
\hline $\mathrm{Hg}$ & NAA & 4.E+00 & 1.E+00 & 2.E-01 & 3.E-01 & 8.E-01 & $8 . E+00$ & $4 . E+00$ & $2 . E+00$ & $3 . E+00$ & 4.E-01 & 4.E-01 \\
\hline Th & NAA & $4 . E+00$ & 4.E+00 & 7.E-01 & 7.E-01 & $1 . E+00$ & $2 . E+01$ & $8 . E+00$ & $5 . E+00$ & 7.E +00 & 2.E+00 & $2 . E+00$ \\
\hline
\end{tabular}


Table B-5

Size-Segregated Elemental Concentrations of the Illinois \#6 Fly Ash Sampled at Port 12 (2.2 residence second)

a) Major Species Results

\begin{tabular}{|c|c|c|c|c|c|c|c|c|c|c|c|c|}
\hline Impactor & Stage & 1 & 2 & 3 & 4 & 5 & 6 & 7 & 8 & 9 & 10 & 11 \\
\hline Cut-off & $\begin{array}{l}\text { Diameter } \\
\text { (microns) }\end{array}$ & 0.0324 & 0.0636 & 0.0926 & 0.168 & 0.337 & 0.535 & 0.973 & 1.96 & 3.77 & 7.33 & 15.7 \\
\hline Element & $\begin{array}{c}\text { Analytical } \\
\text { Method }\end{array}$ & & & & & & & & & & & \\
\hline $\begin{array}{l}\text { Total Mass Conc } \\
\left(\mathrm{g} / \mathrm{Nm}^{\wedge} 3\right)\end{array}$ & Gravimetric & $4.0 \mathrm{E}-04$ & $3.0 \mathrm{E}-04$ & $4.2 E-04$ & $3.2 E-04$ & $5.8 \mathrm{E}-04$ & $3.4 \mathrm{E}-03$ & $8.8 \mathrm{E}-03$ & $4.9 \mathrm{E}-03$ & $1.3 \mathrm{E}-02$ & 4.1E-02 & $3.6 \mathrm{E}-02$ \\
\hline $\mathrm{Fe}_{2} \mathrm{O}_{3}(\mathrm{Wt} \%)$ & NAA & $4 . E+00$ & $3.6 E+00$ & 2 & $8.2 \mathrm{E}+00$ & $8.2 E+00$ & $1 . E+01$ & $8.3 \mathrm{E}+00$ & $1.2 \mathrm{E}+01$ & $8.7 \mathrm{E}+00$ & $2.9 E+01$ & $2 . E+01$ \\
\hline+1 & & $1 . E+00$ & $1 . E+00$ & $8 . E-01$ & $3 . E+00$ & $2 . E+00$ & $7 . E+00$ & $5 . E+00$ & $8 . E+00$ & $4 . E+00$ & $6 . E+00$ & $4 . E+00$ \\
\hline $\mathrm{CaO}(\mathrm{Wt} \%)$ & NAA & $1.7 \mathrm{E}+01$ & $1 . E+01$ & $2 . E+01$ & $3 . E+01$ & $1 . E+01$ & $7 . E+00$ & $8.5 E+00$ & 1.E+01 & $4.7 \mathrm{E}+00$ & $5 . E+00$ & $2 . E+00$ \\
\hline+1 & & $6 . E+00$ & $6 . \mathrm{E}+00$ & $7 . E+00$ & $1 . E+01$ & 4.E+00 & $5 . E+00$ & $6 . E+00$ & 1.E+01 & $3 . E+00$ & $2 . E+00$ & $2 . E+00$ \\
\hline $\begin{array}{l}\text { Trace Elements } \\
(\mathrm{Wt} \%)\end{array}$ & NAA & $2.4 \mathrm{E}-01$ & $1.4 \mathrm{E}+01$ & $2.0 \mathrm{E}-01$ & 6.7E-01 & $3.0 \mathrm{E}-01$ & $4.2 \mathrm{E}-01$ & $1.9 \mathrm{E}-01$ & $1.7 \mathrm{E}-01$ & $8.9 \mathrm{E}-02$ & $8.2 \mathrm{E}-02$ & $3.6 \mathrm{E}-02$ \\
\hline
\end{tabular}

Note: Elemental concentrations have been converted to oxide forms on a $\mathrm{SO}_{3}$-free basis. 
Table B-5 (Continued)

Size-Segregated Elemental Concentrations of the Illinois \#6 Fly Ash Sampled at Port 12 (2.2 residence second)

b) Trace Element Concentrations

\begin{tabular}{|c|c|c|c|c|c|c|c|c|c|c|c|c|}
\hline Impactor & Stage & 1 & 2 & 3 & 4 & 5 & 6 & 7 & 8 & 9 & 10 & 11 \\
\hline Cut-off & $\begin{array}{l}\text { Diameter } \\
\text { (microns) }\end{array}$ & 0.0324 & 0.0636 & 0.0926 & 0.168 & 0.337 & 0.535 & 0.973 & 1.96 & 3.77 & 7.33 & 15.7 \\
\hline Element & $\begin{array}{c}\text { Analytical } \\
\text { Method }\end{array}$ & & & & & & & & & & & \\
\hline As & NAA & $1.2 \mathrm{E}+01$ & $3 . E+01$ & $3 . E+01$ & $1.5 E+02$ & $1.3 \mathrm{E}+02$ & $2 . E+02$ & $7 . E+01$ & $7 . E+01$ & $5 . \mathrm{E}+01$ & $3.0 \mathrm{E}+01$ & $1.2 \mathrm{E}+01$ \\
\hline $\mathrm{Se}$ & NAA & $9 . E+01$ & $1.2 \mathrm{E}+02$ & $7 . E+01$ & $1.6 \mathrm{E}+02$ & $5 . E+01$ & $5 . E+01$ & $5 . E+01$ & $4 . E+01$ & $2 . E+01$ & $1 . E+01$ & $3 . E+00$ \\
\hline $\mathrm{Sb}$ & NAA & $5 . E+00$ & $5 . E+00$ & $6 . \mathrm{E}+00$ & $1.7 \mathrm{E}+01$ & $9 . E+00$ & $2 . E+01$ & $9 . E+00$ & $6 . E+00$ & $5 . E+00$ & $3 . E+\infty 0$ & $2 . E+00$ \\
\hline $\mathrm{Co}$ & NAA & $8 . E+01$ & $6.9 \mathrm{E}+01$ & $1.1 \mathrm{E}+02$ & $8 . E+01$ & $9 . E+01$ & $5 . E+01$ & $5 . E+01$ & $1.1 \mathrm{E}+02$ & $4 . E+01$ & $3.4 \mathrm{E}+01$ & $2.4 \mathrm{E}+01$ \\
\hline Cs & NAA & $6 . E+01$ & $4 . E+01$ & $2 . E+01$ & 4.E+01 & $2 . E+01$ & $6 . E+00$ & $2 . E+01$ & 3.E+01 & $1.3 \mathrm{E}+01$ & $9 . E+00$ & $9 . E+00$ \\
\hline $\mathrm{Sc}$ & NAA & $1.7 \mathrm{E}+00$ & $1.6 \mathrm{E}+00$ & $2.0 \mathrm{E}+00$ & $8 . E+00$ & $1.2 \mathrm{E}+01$ & $1.8 \mathrm{E}+01$ & $1 . E+01$ & $1 . E+01$ & $1.4 \mathrm{E}+01$ & $1.6 \mathrm{E}+01$ & $1.1 \mathrm{E}+01$ \\
\hline $\mathrm{Zn}$ & NAA & $1.3 E+03$ & $1.4 \mathrm{E}+03$ & $1 . E+03$ & $5 . E+03$ & $2.1 \mathrm{E}+03$ & $3 . E+03$ & $1.3 \mathrm{E}+03$ & $8 . E+02$ & $4 . E+02$ & $4 . E+02$ & $1 . E+02$ \\
\hline $\mathrm{Rb}$ & NAA & $6 . E+02$ & $4 . E+02$ & $4 . E+02$ & $6 . \mathrm{E}+02$ & $2.7 E+02$ & $3 . E+02$ & $2 . E+02$ & $3 . E+02$ & $1.5 E+02$ & $7 . E+01$ & $4 . E+01$ \\
\hline Mo & NAA & 1.1. +02 & 7.E+01 & $1.1 \mathrm{E}+02$ & $2.2 \mathrm{E}+02$ & $9 . E+01$ & $2 . E+02$ & $6 . E+01$ & $5 . E+01$ & $5 . E+01$ & $5 . E+01$ & $2 . E+01$ \\
\hline $\mathrm{Cd}$ & NAA & 4.E+01 & $1.4 \mathrm{E}+05$ & $3 . E+01$ & $3 . E+01$ & $3 . E+01$ & $4 . E+01$ & $3 . E+01$ & 4.E+01 & $3 . E+01$ & $3 . E+01$ & $2 . E+01$ \\
\hline La & NAA & $1.1 E+01$ & $1.7 \mathrm{E}+01$ & $1.3 \mathrm{E}+01$ & $4 . E+01$ & $3.8 \mathrm{E}+01$ & $6 . E+01$ & $3 . E+01$ & $5 . E+01$ & $3 . E+01$ & $3.1 \mathrm{E}+01$ & $2.2 \mathrm{E}+01$ \\
\hline $\mathrm{Ce}$ & NAA & $3 . E+01$ & $1.5 E+01$ & $1.9 \mathrm{E}+01$ & $5 . E+01$ & 7.E +01 & $1.2 \mathrm{E}+02$ & $5 . E+01$ & $8 . E+01$ & $5 . E+01$ & $6 . E+01$ & $4 . E+01$ \\
\hline $\mathrm{Sm}$ & NAA & 4.E-01 & 5.E-01 & 8.E-01 & $4 . E+00$ & $6 . E+00$ & $1.0 \mathrm{E}+01$ & 4.E+00 & $6 . \mathrm{E}+00$ & $5 . E+00$ & $6 . E+00$ & $4 . E+00$ \\
\hline Eu & NAA & 4.E+00 & $1.7 \mathrm{E}+00$ & $8 . E+00$ & $3 . E+00$ & $4 . E+\infty 0$ & $4 . E+00$ & 4.E+00 & $6 . E+00$ & $3 . E+00$ & 9.E-01 & 7.E-01 \\
\hline$Y b$ & NAA & $1.3 \mathrm{E}+00$ & $1.2 \mathrm{E}+00$ & $5 . \mathrm{E}+00$ & $1.5 \mathrm{E}+00$ & $2.9 \mathrm{E}+00$ & 4.E+00 & $2 . E+00$ & 8.E-01 & $3 . E+00$ & $3.4 \mathrm{E}+00$ & $2.6 \mathrm{E}+00$ \\
\hline Lu & NAA & 4.E-01 & $9.9 \mathrm{E}-01$ & $1.6 \mathrm{E}-01$ & $1.0 \mathrm{E}+00$ & 5.E-01 & 5.E-01 & 4.E-01 & $6 . E-01$ & 4.E-01 & 7.E-01 & 5.E-01 \\
\hline $\mathrm{Au}$ & NAA & 4.E-02 & 9.E-02 & $2 . E+00$ & 1.E-01 & 2.E-01 & 4.E-02 & 4.E-02 & 7.E-02 & 2.E-02 & 1.E-02 & 3.E-03 \\
\hline $\mathrm{Hg}$ & NAA & $1.3 \mathrm{E}+01$ & $1.2 \mathrm{E}+01$ & $9.6 \mathrm{E}+00$ & $1.7 \mathrm{E}+01$ & $8 . E+00$ & $1.0 \mathrm{E}+01$ & $6 . E+00$ & $9 . E+00$ & $5 . E+00$ & $1.5 \mathrm{E}+00$ & 6.E-01 \\
\hline Th & NAA & $1.5 E+01$ & $1.2 \mathrm{E}+01$ & $2 . E+00$ & $1.5 \mathrm{E}+01$ & $1.8 \mathrm{E}+01$ & $2 . E+01$ & $7 . E+00$ & $8 . E+00$ & $1.1 E+01$ & $1.2 \mathrm{E}+01$ & $9 . E+00$ \\
\hline Total $(w t \%)$ & & $2.4 \mathrm{E}-01$ & $1.4 \mathrm{E}+01$ & $2.0 E-01$ & $6.7 \mathrm{E}-01$ & $3.0 \mathrm{E}-01$ & $4.2 \mathrm{E}-01$ & $1.9 \mathrm{E}-01$ & 1.7E-01 & $8.9 \mathrm{E}-02$ & $8.2 \mathrm{E}-02$ & $3.6 \mathrm{E}-02$ \\
\hline
\end{tabular}


Table B-5 (Continued)

Size-Segregated Elemental Concentrations of the Illinois \#6 Fly Ash Sampled at Port 12 (2.2 residence second)

c) Trace Element Uncertainties

\begin{tabular}{|c|c|c|c|c|c|c|c|c|c|c|c|c|}
\hline Impactor & Stage & 1 & 2 & 3 & 4 & 5 & 6 & 7 & 8 & 9 & 10 & 11 \\
\hline Cut-off & $\begin{array}{l}\text { Diameter } \\
\text { (microns) }\end{array}$ & 0.0324 & 0.0636 & 0.0926 & 0.168 & 0.337 & 0.535 & 0.973 & 1.96 & 3.77 & 7.33 & 15.7 \\
\hline Element & $\begin{array}{c}\text { Analytical } \\
\text { Method }\end{array}$ & & & & & & & & & & & \\
\hline As & NAA & $8 . E+00$ & $1 . E+01$ & $1 . E+01$ & $6 . E+01$ & $3 . E+01$ & 1.E+02 & 4.E+01 & $5 . E+01$ & $3 . E+01$ & 1.E+01 & $8 . E+00$ \\
\hline $\mathrm{Se}$ & NAA & 4.E+01 & $5 . E+01$ & $3 . E+01$ & 7.E+01 & 2.E+01 & 4.E+01 & $4 . \mathrm{E}+01$ & 4.E+01 & $2 . E+01$ & $1 . E+01$ & $1 . E+01$ \\
\hline $\mathrm{Sb}$ & NAA & 2.E+00 & $2 . E+00$ & $2 . E+00$ & $7 . \mathrm{E}+00$ & $3 . E+00$ & $1 . E+01$ & $5 . E+00$ & $5 . E+00$ & $3 . E+00$ & $1 . E+00$ & $1 . E+00$ \\
\hline $\mathrm{Co}_{0}$ & NAA & $3 . \mathrm{E}+01$ & $2 . E+01$ & $3 . E+01$ & $3 . E+01$ & 2.E+01 & $3 . \mathrm{E}+01$ & $3 . E+01$ & 7.E+01 & 2.E+01 & $8 . E+00$ & $7 . E+00$ \\
\hline Cs & NAA & $2 . E+01$ & 1.E+01 & $\because 9 . E+00$ & $2 . E+01$ & 7.E+00 & $5 . E+00$ & 1.E+01 & $2 . \mathrm{E}+01$ & $8 . E+00$ & $4 . E+00$ & 4.E+00 \\
\hline Sc & NAA & 5.E-01 & 6.E-01 & 6.E-01 & $3 . E+00$ & $3 . E+00$ & $9 . E+00$ & $5 . E+00$ & $1 . E+01$ & $6 . E+00$ & $3 . E+00$ & $3 . E+00$ \\
\hline $\mathrm{Zn}$ & NAA & $5 . E+02$ & $6 . \mathrm{E}+02$ & 4.E+02 & $2 . E+03$ & $6 . E+02$ & $2 . E+03$ & $8 . E+02$ & $7 . \mathrm{E}+02$ & $3 . E+02$ & $2 . \mathrm{E}+02$ & 1.E+02 \\
\hline $\mathrm{Rb}$ & NAA & $2 . \mathrm{E}+02$ & $2 . E+02$ & $1 . E+02$ & $2 . \mathrm{E}+02$ & $9 . E+01$ & $2 . E+02$ & $2 . E+02$ & $3 . E+02$ & $9 . E+01$ & 4.E+01 & $3 . E+01$ \\
\hline Mo & NAA & $5 . E+01$ & 4.E+01 & $5 . E+01$ & $9 . E+01$ & $4 . E+01$ & $1 . E+02$ & $5 . E+01$ & $5 . E+01$ & $4 . E+01$ & $3 . E+01$ & $2 . E+01$ \\
\hline $\mathrm{Cd}$ & NAA & 4.E+03 & 5.E+04 & $4 . E+03$ & 4.E+03 & 4.E+03 & $4 . E+03$ & 4.E+03 & 4.E+03 & 4.E+03 & 4.E+03 & 4.E+03 \\
\hline $\mathrm{La}$ & NAA & $3 . E+00$ & $6 . \mathrm{E}+00$ & 4.E+00 & $1 . \mathrm{E}+01$ & $9 . E+00$ & $3 . E+01$ & $1 . E+01$ & $3 . E+01$ & $1 . E+01$ & $6 . E+00$ & $5 . E+00$ \\
\hline $\mathrm{Ce}$ & NAA & $1 . E+01$ & $7 . E+00$ & 7.E+00 & $2 . E+01$ & $2 . \mathrm{E}+01$ & $6 . E+01$ & $3 . E+01$ & $6 . \mathrm{E}+01$ & 2.E+01 & $1 . E+01$ & 1.E+01 \\
\hline $\mathrm{Sm}$ & NAA & 1.E-01 & 2.E-01 & 3.E-01 & 1.E+00 & $1 . \mathrm{E}+00$ & $5 . E+00$ & $2 . E+00$ & 4.E+00 & 2.E+00 & 1.E+00 & 1. $E+00$ \\
\hline Eu & NAA & $1 . E+00$ & 9.E-01 & $3 . E+00$ & 1.E+00 & 1.E+00 & $2 . E+00$ & $3 . E+00$ & 4.E+00 & $1 . E+00$ & $5 . \mathrm{E}-01$ & 4.E-01 \\
\hline $\mathrm{Yb}$ & NAA & 5.E-01 & 5.E-01 & $1 . E+00$ & 6.E-01 & 7.E-01 & $2 . E+00$ & $1 . E+00$ & 7.E-01 & $2 . E+00$ & 8.E-01 & 7.E-01 \\
\hline $\mathrm{Lu}$ & NAA & 2.E-01 & 4.E-01 & 9.E-02 & 4.E-01 & 2.E-01 & 3.E-01 & 2.E-01 & 4.E-01 & 2.E-01 & 2.E-01 & 2.E-01 \\
\hline $\mathrm{Au}$ & NAA & 4.E+00 & 4.E+00 & $5 . E+00$ & $4 . E+00$ & $4 . E+00$ & $4 . E+00$ & $4 . E+00$ & 4.E+00 & 4.E+00 & 4.E+00 & $4 . E+00$ \\
\hline $\mathrm{Hg}$ & NAA & $4 . E+00$ & $4 . E+00$ & $3 . E+00$ & $6 . E+00$ & $2 . E+00$ & $5 . E+00$ & $3 . E+00$ & $6 . E+00$ & $2 . E+00$ & 5.E-01 & 3.E-01 \\
\hline Th & NAA & $5 . E+00$ & $5 . E+00$ & 1.E+00 & $6 . E+00$ & $5 . E+00$ & $9 . \mathrm{E}+00$ & $5 . E+00$ & $6 . \mathrm{E}+00$ & $5 . E+00$ & $3 . E+00$ & $3 . E+00$ \\
\hline
\end{tabular}


Table B-6

Size-Segregated Elemental Concentrations of the Illinois \#6 Fly Ash Sampled at the Baghouse Inlet Port

a) Major Species Results

\begin{tabular}{|c|c|c|c|c|c|c|c|c|c|c|c|c|}
\hline Impactor & Stage & 1 & 2 & 3 & 4 & 5 & 6 & 7 & 8 & 9 & 10 & 11 \\
\hline Cut-off & $\begin{array}{l}\text { Diameter } \\
\text { (microns) }\end{array}$ & 0.0324 & 0.0636 & 0.0926 & 0.168 & 0.337 & 0.535 & 0.973 & 1.96 & 3.77 & 7.33 & 15.7 \\
\hline Element & $\begin{array}{c}\text { Analytical } \\
\text { Method }\end{array}$ & & & & & & & & & & & \\
\hline $\begin{array}{l}\text { Total Mass Conc } \\
\left(\mathrm{g} / \mathrm{Nm}^{\wedge} 3\right)\end{array}$ & Gravimetric & $1.63 \mathrm{E}-02$ & $1.56 \mathrm{E}-02$ & $2.38 \mathrm{E}-02$ & $2.35 \mathrm{E}-02$ & $2.30 \mathrm{E}-02$ & $4.63 \mathrm{E}-02$ & $1.23 \mathrm{E}-01$ & $2.47 \mathrm{E}-01$ & $3.36 \mathrm{E}-01$ & $6.79 \mathrm{E}-01$ & $1.30 \mathrm{E}-01$ \\
\hline $\mathrm{SiO}_{2}(\mathrm{Wt} \%)$ & AAS & nd & $1.1 \mathrm{E}+00$ & 4.E+00 & $1.56 \mathrm{E}+01$ & $3.9 \mathrm{E}+01$ & $1.5 E+01$ & $5 . E+00$ & $1.4 \mathrm{E}+01$ & $2.2 \mathrm{E}+01$ & $3.14 \mathrm{E}+01$ & $2.04 \mathrm{E}+01$ \\
\hline$+1-$ & & & 9.E-01 & 1.E+00 & 9.E-01 & $1 . E+00$ & $2 . E+00$ & $9 . E+00$ & $2 . \mathrm{E}+00$ & $1 . E+00$ & 9.E-01 & 8.E-01 \\
\hline $\mathrm{Al}_{2} \mathrm{O}_{3}(\mathrm{Wt} \%)$ & AAS & 2.E-01 & 7.E-01 & $8.9 \mathrm{E}+00$ & $3.8 \mathrm{E}+00$ & $1.28 \mathrm{E}+01$ & $1.42 \mathrm{E}+01$ & $1.68 \mathrm{E}+01$ & $2.43 \mathrm{E}+01$ & $2.54 \mathrm{E}+01$ & $2.35 \mathrm{E}+01$ & $2.72 \mathrm{E}+01$ \\
\hline$+1-$ & & $2 . E-01$ & 2.E-01 & 2.E-01 & 2.E-01 & 2.E-01 & 2.E-01 & 2.E-01 & 2.E-01 & 2.E-01 & 2.E-01 & 2.E-01 \\
\hline $\mathrm{Fe}_{2} \mathrm{O}_{3}(\mathrm{Wt} \%)$ & AAS & $5.8 \mathrm{E}+00$ & $8.4 \mathrm{E}+00$ & $9.5 \mathrm{E}+00$ & $9.8 \mathrm{E}+00$ & $3.00 E+01$ & $2.2 \mathrm{E}+01$ & $2.5 E+01$ & $1.5 E+01$ & $1.1 \mathrm{E}+01$ & $9 . E+00$ & $1.6 E+01$ \\
\hline+1 & & 5.E-01 & 3.E-01 & 4.E-01 & 4.E-01 & 9.E-01 & $2 . E+00$ & $7 . E+00$ & $2 . \mathrm{E}+00$ & $2 . \mathrm{E}+00$ & $1 . E+00$ & $2 . E+00$ \\
\hline $\mathrm{CaO}(\mathrm{Wt} \%)$ & AAS & $2.08 \mathrm{E}+01$ & $1.50 \mathrm{E}+01$ & $1.09 \mathrm{E}+01$ & $1.28 \mathrm{E}+01$ & $3.32 E+01$ & $1.15 E+01$ & 4.E+00 & $6 . \mathrm{E}+00$ & $5 . \mathrm{E}+00$ & $6 . E+00$ & $5 . \mathrm{E}+00$ \\
\hline+1 & & 4.E-01 & 3.E-01 & 3.E-01 & 4.E-01 & 4.E-01 & 9.E-01 & $6 . \mathrm{E}+00$ & $2 . \mathrm{E}+00$ & $2 . E+00$ & $2 . E+00$ & $4 . E+00$ \\
\hline $\mathrm{MgO}(\mathrm{Wt} \%)$ & AAS & $1.11 \mathrm{E}+00$ & $7.3 \mathrm{E}-01$ & $1.94 \mathrm{E}+00$ & 7.7E-01 & $1.34 \mathrm{E}+00$ & $6.3 \mathrm{E}-01$ & 5.E-01 & 5.E-01 & 7.E-01 & 8.E-01 & $6 . E-01$ \\
\hline$+1-$ & & $2 . E-02$ & 1.E-02 & 2.E-02 & $2 . E-02$ & $3 . E-02$ & $6 . E-02$ & 3.E-01 & 1.E-01 & 3.E-01 & 1.E-01 & 3.E-01 \\
\hline $\mathrm{Na}_{2} \mathrm{O}(\mathrm{Wt} \%)$ & AES & $6.62 \mathrm{E}+00$ & $4.30 E+00$ & $4.46 \mathrm{E}+00$ & $2.62 \mathrm{E}+00$ & $3.54 \mathrm{E}+00$ & $1.1 \mathrm{E}+00$ & 8.E-01 & 5.E-01 & 7.E-01 & 5.E-01 & $8 . E-01$ \\
\hline+1 & & 7.E-02 & $6 . E-02$ & 7.E-02 & 7.E-02 & 8.E-02 & 2.E-01 & 9.E-01 & 4.E-01 & 8.E-01 & 7.E-01 & $2 . \mathrm{E}+00$ \\
\hline $\begin{array}{l}\text { Trace Elements } \\
(\mathrm{Wt} \%)\end{array}$ & NAA & $5.0 \mathrm{E}-02$ & $5.0 \mathrm{E}-02$ & $3.7 \mathrm{E}-02$ & $2.0 \mathrm{E}-02$ & $3.8 \mathrm{E}-02$ & $1.8 \mathrm{E}-02$ & $1.5 \mathrm{E}-02$ & $1.1 \mathrm{E}-02$ & $1.1 \mathrm{E}-02$ & 7.7E-03 & $1.0 \mathrm{E}-02$ \\
\hline & & 34 & 30 & 31 & 42 & 108 & 50 & 36 & 36 & 39 & 48 & 43 \\
\hline
\end{tabular}

Note: Elemental concentrations have been converted to oxide forms on a $\mathrm{SO}_{3}$-free basis.

nd $=$ below detection limit 
Table B-6 (Continued)

Size-Segregated Elemental Concentrations of the Illinois \#6 Fly Ash Sampled at the Baghouse Inlet Port

b) Trace Element Concentrations

\begin{tabular}{|c|c|c|c|c|c|c|c|c|c|c|c|c|}
\hline Impactor Stage & 1 & 2 & 3 & 4 & 5 & 6 & 7 & 8 & 9 & 10 & 11 \\
\hline Cut-off & $\begin{array}{c}\text { Diameter } \\
\text { (microns) }\end{array}$ & 0.0324 & 0.0636 & 0.0926 & 0.168 & 0.337 & 0.535 & 0.973 & 1.96 & 3.77 & 7.33 & 15.7 \\
\hline Element & $\begin{array}{c}\text { Analytical } \\
\text { Method }\end{array}$ & & & & & & & & & & & \\
\hline As & GFAA & $.82 \mathrm{E}+02$ & $.82 \mathrm{E}+02$ & $1.61 \mathrm{E}+02$ & $8.8 \mathrm{E}+01$ & $1.54 \mathrm{E}+02$ & $8 . \mathrm{E}+01$ & $9 . \mathrm{E}+01$ & $6 . \mathrm{E}+01$ & $4 . \mathrm{E}+01$ & $3 . \mathrm{E}+01$ & $4 . \mathrm{E}+01$ \\
\hline Se & GFAA & $.74 \mathrm{E}+02$ & $.74 \mathrm{E}+02$ & $1.18 \mathrm{E}+02$ & $4.9 \mathrm{E}+01$ & $6.8 \mathrm{E}+01$ & $3.0 \mathrm{E}+01$ & $2 . \mathrm{E}+01$ & $8 . \mathrm{E}+00$ & $7 . \mathrm{E}+00$ & $7 . \mathrm{E}+00$ & $1 . \mathrm{E}+01$ \\
\hline Sb & GFAA & $8.9 \mathrm{E}+01$ & $8.9 \mathrm{E}+01$ & $4.5 \mathrm{E}+01$ & $3.6 \mathrm{E}+01$ & $7.5 \mathrm{E}+01$ & $2.4 \mathrm{E}+01$ & $1 . \mathrm{E}+01$ & $1 . \mathrm{E}+01$ & $3 . \mathrm{E}+01$ & $9 . \mathrm{E}+00$ & $2 . \mathrm{E}+01$ \\
\hline Co & GFAA & $5.8 \mathrm{E}+01$ & $5.8 \mathrm{E}+01$ & $4.3 \mathrm{E}+01$ & $2.6 \mathrm{E}+01$ & $8.4 \mathrm{E}+01$ & $4.0 \mathrm{E}+01$ & $3 . \mathrm{E}+01$ & $2.4 \mathrm{E}+01$ & $2 . \mathrm{E}+01$ & $3 . \mathrm{E}+01$ & $3 . \mathrm{E}+01$ \\
\hline Total (wt\%) & & $5.0 \mathrm{E}-02$ & $5.0 \mathrm{E}-02$ & $-3.7 \mathrm{E}-02$ & $2.0 \mathrm{E}-02$ & $3.8 \mathrm{E}-02$ & $1.8 \mathrm{E}-02$ & $1.5 \mathrm{E}-02$ & $1.1 \mathrm{E}-02$ & $1.1 \mathrm{E}-02$ & $7.7 \mathrm{E}-03$ & $1.0 \mathrm{E}-02$ \\
\hline
\end{tabular}

c) Trace Element Uncertainties

\begin{tabular}{|c|c|c|c|c|c|c|c|c|c|c|c|c|}
\hline Impactor & Stage & 1 & 2 & 3 & 4 & 5 & 6 & 7 & 8 & 9 & 10 & 11 \\
\hline Cut-off & $\begin{array}{l}\text { Diameter } \\
\text { (microns) }\end{array}$ & 0.0324 & 0.0636 & 0.0926 & 0.168 & 0.337 & 0.535 & 0.973 & 1.96 & 3.77 & 7.33 & 15.7 \\
\hline Element & $\begin{array}{c}\text { Analytical } \\
\text { Method }\end{array}$ & & & & & & & & & & & \\
\hline As & & $6 . \mathrm{E}+00$ & $5 . E+00$ & $6 . \mathrm{E}+00$ & $6 . E+00$ & $8 . E+00$ & $1 . E+01$ & 4.E+01 & 2.E+01 & $3 . E+01$ & $3 . E+01$ & $5 . E+01$ \\
\hline $\mathrm{Se}$ & & $5 . E+00$ & $4 . E+00$ & $4 . E+00$ & 4.E+00 & $5 . E+00$ & $6 . E+00$ & 2.E+01 & 1.E+01 & $2 . E+C_{i}$ & 2.E+01 & $6 . E+01$ \\
\hline $\mathrm{Sb}$ & & $6 . E+00$ & $6 . E+00$ & $6 . E+00$ & $6 . E+00$ & $6 . E+00$ & $7 . E+00$ & $3 . E+01$ & 1.E+01 & $1 . E+01$ & 1.E+01 & $3 . E+01$ \\
\hline Co & & $4 . E+00$ & $4 . E+00$ & $4 . E+00$ & 4.E+00 & $5 . E+00$ & $6 . E+00$ & $3 . E+01$ & 7.E+00 & 1.E+01 & 2.E+01 & $2 . E+01$ \\
\hline
\end{tabular}


Table B-7

Size-Segregated Elemental Concentrations of the Kentucky Fly Ash Sampled at Port 4 (0.7 residence second)

a) Major Species Results

\begin{tabular}{|c|c|c|c|c|c|c|c|c|c|c|c|c|}
\hline Impactor & Stage & 1 & 2 & 3 & 4 & 5 & 6 & 7 & 8 & 9 & 10 & 11 \\
\hline Cut-off & $\begin{array}{l}\text { Diameter } \\
\text { (microns) }\end{array}$ & 0.0324 & 0.0636 & 0.0926 & 0.168 & 0.337 & 0.535 & 0.973 & 1.96 & 3.77 & 7.33 & 15.7 \\
\hline Element & $\begin{array}{l}\text { Analytical } \\
\text { Method }\end{array}$ & & & & & & & & & & & \\
\hline $\begin{array}{c}\text { Total Mass Conc } \\
\left(\mathrm{g} / \mathrm{Nm}^{\wedge} 3\right)\end{array}$ & Gravametric & $1.18 \mathrm{E}-02$ & $7.70 E-03$ & $9.47 E-03$ & $1.24 \mathrm{E}-02$ & $2.46 \mathrm{E}-02$ & $4.71 \mathrm{E}-02$ & $3.31 \mathrm{E}-01$ & $7.34 \mathrm{E}-01$ & $8.65 \mathrm{E}-01$ & $\begin{array}{c}3.52 E+0 \\
0\end{array}$ & $4.83 \mathrm{E}-01$ \\
\hline $\mathrm{SiO}_{2}(\mathrm{Wt} \%)$ & AAS & nd & nd & $1.4 \mathrm{E}+01$ & $2.1 E+01$ & $3.7 \mathrm{E}+01$ & $4.3 E+01$ & $4 . E+01$ & $4 . E+01$ & $3.2 \mathrm{E}+01$ & $2.4 \mathrm{E}+01$ & $3.2 \mathrm{E}+01$ \\
\hline+1 & & & & $2 . E+00$ & $2 . E+00$ & $2 . E+00$ & $2 . E+00$ & $2 . E+01$ & $1 . E+01$ & 7.E+00 & $2 . E+00$ & 1.E+01 \\
\hline $\mathrm{Al}_{2} \mathrm{O}_{3}(\mathrm{Wt} \%)$ & AAS & $1.1 E+01$ & $1: 1 E+01$ & $1.6 \mathrm{E}+01$ & $2 . E+01$ & $4 . E+01$ & $5.2 E+01$ & $4 . E+01$ & $4 . E+01$ & $3.7 E+01$ & $2.4 \mathrm{E}+01$ & $4 . E+01$ \\
\hline$+1-$ & & $1 . E+00$ & $1 . E+00$ & $2 . E+00$ & $1 . E+01$ & $2 . E+01$ & $8 . E+00$ & 2.E+01 & $1 . E+01$ & $8 . E+00$ & $2 . E+00$ & $1 . E+01$ \\
\hline $\mathrm{Fe}_{2} \mathrm{O}_{3}(\mathrm{~W}+\%)$ & AAS & $1.0 \mathrm{E}+01$ & $4.1 E+00$ & $6 . E+00$ & $9 . \mathrm{E}+00$ & $1.7 \mathrm{E}+01$ & $1.66 \mathrm{E}+01$ & $1.5 \mathrm{E}+01$ & $1.6 \mathrm{E}+01$ & 7.E +00 & $6 . E+00$ & $8 . E+00$ \\
\hline$+1-$ & & $1 . E+00$ & 8.E-01 & $4 . E+00$ & $4 . E+00$ & $4 . E+00$ & 7.E-01 & $6 . E+00$ & $4 . E+00$ & $2 . E+00$ & $6 . E+00$ & $8 . E+00$ \\
\hline $\mathrm{CaO}(\mathrm{Wt} \%)$ & AAS & $2.2 \mathrm{E}+00$ & nd & nd & nd & $2.0 E+00$ & $2 . \mathrm{E}+00$ & $1.2 \mathrm{E}+00$ & $1.8 \mathrm{E}+00$ & $1.5 E+00$ & $1.6 \mathrm{E}+00$ & 2.E+00 \\
\hline$+1-$ & & 4.E-01 & & & & 3.E-01 & 1.E+00 & 7.E-01 & 6.E-01 & 5.E-01 & 3.E-01 & $3 . E+00$ \\
\hline $\mathrm{MgO}(\mathrm{Wt} \%)$ & AAS & $3.3 \mathrm{E}+00$ & $3.9 \mathrm{E}+00$ & $3.7 \mathrm{E}+00$ & $7.0 \mathrm{E}+00$ & $6.7 \mathrm{E}+00$ & $6.5 E+00$ & $5 . E+00$ & $4 . E+00$ & $2.9 \mathrm{E}+00$ & $1.1 \mathrm{E}+00$ & $2.1 E+00$ \\
\hline+1 & & 3.E-01 & $6 . E-01$ & $5 . E-01$ & 5.E-01 & 2.E-01 & 1.E-01 & 2.E+00 & $1 . E+00$ & 6.E-01 & 9.E-01 & 5.E-01 \\
\hline $\mathrm{Na}_{2} \mathrm{O}(\mathrm{W} t \%)$ & AES & $1.4 \mathrm{E}+01$ & $4.8 \mathrm{E}+00$ & 7.E+00 & $5.0 E+00$ & $4.8 E+00$ & $5 . E+00$ & $3 . E+00$ & $3.6 \mathrm{E}+00$ & $2.6 \mathrm{E}+00$ & 8.E-01 & $1.9 \mathrm{E}+00$ \\
\hline$+1-$ & & $1 . E+00$ & 6.E-01 & $6 . E+00$ & 4.E-01 & 3.E-01 & $2 . E+00$ & $1 . E+00$ & $9 . E-01$ & $6 . E-01$ & 5.E-01 & 6.E-01 \\
\hline $\begin{array}{c}\text { Trace Elements } \\
(W t \%)\end{array}$ & GFAA & $3.0 \mathrm{E}-01$ & $1.1 E-01$ & $6.2 \mathrm{E}-02$ & $7.8 \mathrm{E}-02$ & $5.4 \mathrm{E}-02$ & $5.4 \mathrm{E}-02$ & $4.5 E-02$ & $3.7 \mathrm{E}-02$ & $1.9 \mathrm{E}-02$ & $6.2 \mathrm{E}-03$ & $1.3 \mathrm{E}-02$ \\
\hline Total (W'\%) & & 41 & 24 & 46 & 63 & 107 & 125 & 109 & 110 & 83 & 59 & 86 \\
\hline
\end{tabular}

Note: Elemental concentrations have been converted to oxide forms on a $\mathrm{SO}_{3}$-free basis.

nd $=$ below detection limit 
Table B-7 (Continued)

Size-Segregated Elemental Concentrations of the Kentucky Fly Ash Sampled at Port 4 (0.7 residence second)

b) Normalized Major Species Results

\begin{tabular}{|c|c|c|c|c|c|c|c|c|c|c|c|c|}
\hline Impactor & Stage & 1 & 2 & 3 & 4 & 5 & 6 & 7 & 8 & 9 & 10 & 11 \\
\hline Cut-off & $\begin{array}{l}\text { Diameter } \\
\text { (microns) }\end{array}$ & 0.0324 & 0.0636 & 0.0926 & 0.168 & 0.337 & 0.535 & 0.973 & 1.96 & 3.77 & 7.33 & 15.7 \\
\hline Element & $\begin{array}{c}\text { Analytical } \\
\text { Method }\end{array}$ & & & & & & & & & & & \\
\hline $\begin{array}{l}\text { Total Mass Conc } \\
\left(\mathrm{g} / \mathrm{Nm}^{\wedge} 3\right)\end{array}$ & Gravametric & $1.2 \mathrm{E}-02$ & 7.7E-03 & $9.5 \mathrm{E}-03$ & $1.2 \mathrm{E}-02$ & $2.5 E-02$ & $4.7 \mathrm{E}-02$ & $3.3 \mathrm{E}-01$ & 7.3E-01 & 8.7E-01 & $3.5 E+00$ & $4.8 \mathrm{E}-01$ \\
\hline $\mathrm{SiO}_{2}(\mathrm{Wt} \%)$ & AAS & nd & nd & 29 & 32 & 35 & 35 & 38 & 36 & 39 & 41 & 37 \\
\hline $\mathrm{Al}_{2} \mathrm{O}_{3}(\mathrm{Wt} \%)$ & AAS & 27 & 46 & 35 & 35 & 36 & 42 & 40 & 41 & 45 & 42 & 47 \\
\hline $\mathrm{Fe}_{2} \mathrm{O}_{3}(\mathrm{Wt} \%)$ & AAS & 25 & $\because 17$ & 13 & 14 & 16 & 13 & 14 & 14 & 8.0 & 11 & 9.4 \\
\hline $\mathrm{CaO}\left(\mathrm{Wt}_{\mathrm{t}}\right)$ & AAS & 5.3 & nd & nd & nd & 1.8 & 1.4 & 1.1 & 1.6 & 1.8 & 2.8 & 2.0 \\
\hline $\mathrm{MgO}(\mathrm{Wt} \%)$ & AAS & 8.1 & 16 & 8.1 & 11 & 6.2 & 5.2 & 4.9 & 3.9 & 3.5 & 2.0 & 2.4 \\
\hline $\mathrm{Na}_{2} \mathrm{O}(\mathrm{Wt} \%)$ & AES & 34 & 20 & 14 & 7.9 & 4.5 & 3.6 & 2.7 & 3.3 & 3.1 & 1.4 & 2.2 \\
\hline $\begin{array}{c}\text { Trace Elements } \\
(W \mathrm{t} \%)\end{array}$ & GFAA & 0.74 & 0.47 & 0.13 & 0.12 & 0.050 & 0.043 & 0.041 & 0.033 & 0.023 & 0.011 & 0.015 \\
\hline Total $(W t \%)$ & & 100.00 & 100.00 & 100.00 & 100.00 & 100.00 & 100.00 & 100.00 & 100.00 & 100.00 & 100.00 & 100.00 \\
\hline
\end{tabular}

Note: Elemental concentrations have been converted to oxide forms on a $\mathrm{SO}_{3}$-free basis.

nd $=$ below detection limit 
Table B-7 (Continued)

Size-Segregated Elemental Concentrations of the Kentucky Fly Ash Sampled at Port 4 (0.7 residence second)

c) Trace Element Concentrations

\begin{tabular}{|c|c|c|c|c|c|c|c|c|c|c|c|c|}
\hline Impactor & Stage & 1 & 2 & 3 & 4 & 5 & 6 & 7 & 8 & 9 & 10 & 11 \\
\hline Cut-off & $\begin{array}{l}\text { Diameter } \\
\text { (microns) }\end{array}$ & 0.0324 & 0.0636 & 0.0926 & 0.168 & 0.337 & 0.535 & 0.973 & 1.96 & 3.77 & 7.33 & 15.7 \\
\hline Element & $\begin{array}{c}\text { Analytical } \\
\text { Method }\end{array}$ & & & & & & & & & & & \\
\hline As & GFAA & $1.7 \mathrm{E}+03$ & $3.9 \mathrm{E}+02$ & $3.5 \mathrm{E}+02$ & $3 . E+02$ & $1.8 \mathrm{E}+02$ & $1.46 E+02$ & $1.3 \mathrm{E}+02$ & $1.3 \mathrm{E}+02$ & $6 . E+01$ & $1.0 \mathrm{E}+01$ & $4 . E+01$ \\
\hline Se & GFAA & $9.9 \mathrm{E}+02$ & $3.5 \mathrm{E}+02$ & $1.6 \mathrm{E}+02$ & $1.7 E+02$ & $1.05 \mathrm{E}+02$ & $9.0 \mathrm{E}+01$ & $5 . E+01$ & $5 . E+01$ & $2.1 E+01$ & $2 . E+00$ & $1.1 \mathrm{E}+01$ \\
\hline $\mathrm{Sb}$ & GFAA & $7 . E+01$ & $1 . \mathrm{E}+02$ & nd & $1 . E+02$ & nd & $7 . E+00$ & $1 . E+01$ & $1.44 \mathrm{E}+01$ & $7 . E+00$ & $7 . E+00$ & $1 . E+01$ \\
\hline Co & GFAA & $2.4 \mathrm{E}+02$ & $2.8 \mathrm{E}+02$ & $1.1 E+02$ & $2 . E+02$ & $3 . E+02$ & $3 . E+02$ & $2.6 \mathrm{E}+02$ & $1.8 \mathrm{E}+02$ & 1.E+02 & $4.3 \mathrm{E}+01$ & $6 . E+01$ \\
\hline Total (wt\%) & & $3.0 \mathrm{E}-01$ & $1: 1 \mathrm{E}-01$ & $6.2 \mathrm{E}-02$ & $7.8 \mathrm{E}-02$ & $5.4 \mathrm{E}-02$ & $5.4 \mathrm{E}-02$ & $4.5 \mathrm{E}-02$ & $3.7 \mathrm{E}-02$ & $1.9 \mathrm{E}-02$ & $6.2 \mathrm{E}-03$ & $1.3 \mathrm{E}-02$ \\
\hline
\end{tabular}

d) Trace Element Uncertainties

\begin{tabular}{|c|c|c|c|c|c|c|c|c|c|c|c|c|}
\hline Impactor Stage & 1 & 2 & 3 & 4 & 5 & 6 & 7 & 8 & 9 & 10 & 11 \\
\hline Cut-off & $\begin{array}{c}\text { Diameter } \\
\text { (microns) }\end{array}$ & 0.0324 & 0.0636 & 0.0926 & 0.168 & 0.337 & 0.535 & 0.973 & 1.96 & 3.77 & 7.33 & 15.7 \\
\hline Element & $\begin{array}{c}\text { Analytical } \\
\text { Method }\end{array}$ & & & & & & & & & & & \\
\hline As & & $2 . E+02$ & $5 . E+01$ & $5 . E+01$ & $1 . E+02$ & $1 . E+01$ & $9 . E+00$ & $6 . E+01$ & $3 . E+01$ & $2 . E+01$ & $6 . E+00$ & $3 . E+01$ \\
\hline Se & & $9 . E+01$ & $5 . E+01$ & $2 . E+01$ & $2 . E+01$ & $8 . E+00$ & $6 . E+00$ & $2 . E+01$ & $1 . E+01$ & $9 . E+00$ & $4 . E+00$ & $8 . E+00$ \\
\hline Sb & & $1 . E+01$ & $2 . E+01$ & & $3 . E+02$ & & $6 . E+00$ & $1 . E+01$ & $9 . E+00$ & $7 . E+00$ & $6 . E+00$ & $1 . E+01$ \\
\hline Co & & $2 . E+01$ & $4 . E+01$ & $7 . E+01$ & $1 . E+02$ & $3 . E+02$ & $2 . E+02$ & $3 . E+02$ & $5 . E+01$ & $2 . E+01$ & $6 . E+00$ & $6 . E+01$ \\
\hline
\end{tabular}


Table B-8

Size-Segregated Elemental Concentrations of the Kentucky Fly Ash Sampled at Port 14 (2.9 residence second)

a) Major Species Results

\begin{tabular}{|c|c|c|c|c|c|c|c|c|c|c|c|c|}
\hline Impactor & Stage & 1 & 2 & 3 & 4 & 5 & 6 & 7 & 8 & 9 & 10 & 11 \\
\hline Cut-off & $\begin{array}{l}\text { Diameter } \\
\text { (microns) }\end{array}$ & 0.0324 & 0.0636 & 0.0926 & 0.168 & 0.337 & 0.535 & 0.973 & 1.96 & 3.77 & 7.33 & 15.7 \\
\hline Element & $\begin{array}{c}\text { Analytical } \\
\text { Method }\end{array}$ & & & & & & & & & & & \\
\hline $\begin{array}{c}\text { Total Mass Conc } \\
\left(\mathrm{g} / \mathrm{Nm}^{\wedge} 3\right)\end{array}$ & Gravametric & $7.03 E-03$ & $4.85 E-03$ & $5.12 \mathrm{E}-03$ & 7.42E-03 & $1.58 \mathrm{E}-02$ & $2.76 \mathrm{E}-02$ & $6.88 \mathrm{E}-01$ & $1.1 \mathrm{E}+00$ & $1.6 \mathrm{E}+00$ & $3.3 E+00$ & $1.0 E+00$ \\
\hline $\mathrm{SiO}_{2}(\mathrm{Wt} \%)$ & AAS & nd & nd & nd & $3 . E+01$ & $3.3 \mathrm{E}+01$ & $4.3 E+01$ & $4.0 E+01$ & $4.6 \mathrm{E}+01$ & $5.3 \mathrm{E}+01$ & $5.3 \mathrm{E}+01$ & $5 . E+01$ \\
\hline$+1-$ & & & & & 1.E+01 & $3 . E+00$ & $2 . E+00$ & $2 . E+01$ & $1 . E+01$ & $1 . E+01$ & $9 . E+00$ & $2 . E+01$ \\
\hline $\mathrm{Al}_{2} \mathrm{O}_{3}(\mathrm{Wt} \%)$ & AAS & nd & $1.1 \mathrm{E}+01$ & $1.4 E+01$ & $3.6 \mathrm{E}+01$ & $3.8 \mathrm{E}+01$ & $4.8 \mathrm{E}+01$ & 4.E+01 & $5 . E+01$ & $6 . E+01$ & $3 . \mathrm{E}+01$ & 7.E+01 \\
\hline$+1-$ & & & $2 . E+00$ & $2 . E+00$ & $3 . \mathrm{E}+01$ & $3 . E+00$ & $2 . E+00$ & $2 . E+01$ & 1.E+01 & $2 . \mathrm{E}+01$ & $3 . E+01$ & $6 . \mathrm{E}+01$ \\
\hline $\mathrm{Fe}_{2} \mathrm{O}_{3}(\mathrm{Wt} \%)$ & AAS & 9.E+00 & $6 . E+00$ & $1.3 \mathrm{E}+01$ & $2 . \mathrm{E}+01$ & $1.7 \mathrm{E}+01$ & $1.71 \mathrm{E}+01$ & $1.2 \mathrm{E}+01$ & $1.3 \mathrm{E}+01$ & $1.2 \mathrm{E}+01$ & $1.4 \mathrm{E}+01$ & $1.4 E+01$ \\
\hline+1 & & $1 . E+00$ & 1.E+00 & $2 . E+00$ & $3 . \mathrm{E}+01$ & $1 . E+00$ & 8.E-01 & $6 . \mathrm{E}+00$ & $4 . E+00$ & $3 . E+00$ & $2 . E+00$ & $6 . E+00$ \\
\hline $\mathrm{CaO}(\mathrm{Wt} \%)$ & AAS & $2.4 \mathrm{E}+00$ & nd & nd & nd & 9.E-01 & $2.4 E+00$ & 9.E-01 & $1.7 \mathrm{E}+00$ & $2.1 \mathrm{E}+00$ & $1.6 \mathrm{E}+00$ & $1.3 \mathrm{E}+00$ \\
\hline$+1-$ & & 4.E-01 & & & & 3.E-01 & 3.E-01 & $6 . E-01$ & 7.E-01 & 7.E-01 & 5.E-01 & 7.E-01 \\
\hline $\mathrm{MgO}(\mathrm{Wt} \%)$ & AAS & $8.9 \mathrm{E}+00$ & $1.2 \mathrm{E}+01$ & $1.4 E+01$ & 2.E+01 & $8.9 E+00$ & $7.1 E+00$ & $6 . \mathrm{E}+00$ & $5 . E+00$ & 4.E+00 & $3.5 \mathrm{E}+00$ & 7.E+00 \\
\hline$+1-$ & & 9.E-01 & $2 . E+00$ & 2.E+00 & $2 . \mathrm{E}+01$ & 4.E-01 & 2.E-01 & $3 . E+00$ & 1.E+00 & 1.E+00 & 6.E-01 & $3 . E+00$ \\
\hline $\mathrm{Na}_{2} \mathrm{O}(\mathrm{W} \%)$ & AES & $7.8 E+00$ & $3.3 \mathrm{E}+00$ & 7.E+00 & $8 . \mathrm{E}+00$ & $5.1 E+00$ & $3.9 E+00$ & $5 . E+00$ & $5 . E+00$ & 4.E+00 & $2.5 \mathrm{E}+00$ & 4.E+00 \\
\hline$+1-$ & & 8.E-01 & $6 . E-01$ & $8 . E+00$ & $6 . \mathrm{E}+00$ & 3.E-01 & 2.E-01 & $1 . E+00$ & 1.E+00 & $1 . E+00$ & 5.E-01 & $3 . E+00$ \\
\hline $\begin{array}{c}\text { Trace Elements } \\
(W \mathrm{t} \%)\end{array}$ & GFAA & $9.8 \mathrm{E}-02$ & $1.1 \mathrm{E}-01$ & $7.7 \mathrm{E}-02$ & $1.1 \mathrm{E}-01$ & $7.6 \mathrm{E}-02$ & $6.9 \mathrm{E}-02$ & $5.4 \mathrm{E}-02$ & $4.1 E-02$ & $3.3 \mathrm{E}-02$ & $1.5 \mathrm{E}-02$ & $2.6 \mathrm{E}-02$ \\
\hline Total $(W \mathrm{t} \%)$ & & 28 & 33 & 47 & 111 & 103 & 121 & 105 & 121 & 135 & 104 & 142 \\
\hline
\end{tabular}

Note: Elemental concentrations have been converted to oxide forms on a $\mathrm{SO}_{3}$-free basis.

nd $=$ below detection limit 
Table B-8 (Continued)

Size-Segregated Elemental Concentrations of the Kentucky Fly Ash Sampled at Port 14 (2.9 residence second)

b) Normalized Major Species Results

\begin{tabular}{|c|c|c|c|c|c|c|c|c|c|c|c|c|}
\hline Impactor & Stage & 1 & 2 & 3 & 4 & 5 & 6 & 7 & 8 & 9 & 10 & 11 \\
\hline Cut-off & $\begin{array}{l}\text { Diameter } \\
\text { (microns) }\end{array}$ & 0.0324 & 0.0636 & 0.0926 & 0.168 & 0.337 & 0.535 & 0.973 & 1.96 & 3.77 & 7.33 & 15.7 \\
\hline Element & $\begin{array}{l}\text { Analytical } \\
\text { Method }\end{array}$ & & & & & & & & & & & \\
\hline $\begin{array}{c}\text { Total Mass Conc } \\
\left(\mathrm{g} / \mathrm{Nm}^{\wedge} 3\right)\end{array}$ & Gravametric & $7.0 \mathrm{E}-03$ & $4.9 E-03$ & $5.1 E-03$ & $7.4 \mathrm{E}-03$ & $1.6 \mathrm{E}-02$ & $2.8 \mathrm{E}-02$ & $6.9 \mathrm{E}-01$ & $1.1 \mathrm{E}+00$ & $1.6 E+00$ & $3.2 \mathrm{E}+00$ & $1.0 \mathrm{E}+00$ \\
\hline $\mathrm{SiO}_{2}(\mathrm{Wt} \%)$ & AAS & nd & nd & nd & 28 & 32 & 36 & 38 & 38 & 39 & 51 & 33 \\
\hline $\mathrm{Al}_{2} \mathrm{O}_{3}(\mathrm{Wt} \%)$ & AAS & nd & 33 & 29 & 32 & 37 & 39 & 39 & 41 & 44 & 29 & 48 \\
\hline $\mathrm{Fe}_{2} \mathrm{O}_{3}(\mathrm{Wt} \%)$ & AAS & 31 & $: 18$ & 27 & 18 & 17 & 14 & 12 & 11 & 9.1 & 13 & 10 \\
\hline $\mathrm{CaO}(\mathrm{Wt} \%)$ & AAS & 9 & nd & nd & nd & 0.9 & 1.9 & 0.86 & 1.4 & 1.6 & 1.6 & 0.89 \\
\hline $\mathrm{MgO}(\mathrm{Wt} \%)$ & AAS & 32 & 38 & 30 & 15 & 8.6 & 5.9 & 6.0 & 4.3 & 3.0 & 3.4 & 5.0 \\
\hline $\mathrm{Na}_{2} \mathrm{O}(\mathrm{Wt} \%)$ & AES & 28 & 10 & 14 & 7.0 & 5.0 & 3.2 & 4.5 & 3.8 & 2.7 & 2.4 & 3.2 \\
\hline $\begin{array}{c}\text { Trace Elements } \\
(W t \%)\end{array}$ & GFAA & 0.35 & 0.33 & 0.16 & 0.10 & 0.074 & 0.057 & 0.052 & 0.034 & 0.025 & 0.015 & 0.018 \\
\hline Total $(W t \%)$ & & 100.00 & 100.00 & 100.00 & 100.00 & 100.00 & 100.00 & 100.00 & 100.00 & 100.00 & 100.00 & 100.00 \\
\hline
\end{tabular}

Note: Elemental concentrations have been converted to oxide forms on a $\mathrm{SO}_{3}$-free basis.

nd = below detection limit 
Table B-8 (Continued)

Size-Segregated Elemental Concentrations of the Kentucky Fly Ash Sampled at Port 14 (2.9 residence second)

c) Trace Element Concentrations

\begin{tabular}{|c|c|c|c|c|c|c|c|c|c|c|c|c|}
\hline Impactor & Stage & 1 & 2 & 3 & 4 & 5 & 6 & 7 & 8 & 9 & 10 & 11 \\
\hline Cut-off & $\begin{array}{l}\text { Diameter } \\
\text { (microns) }\end{array}$ & 0.0324 & 0.0636 & 0.0926 & 0.168 & 0.337 & 0.535 & 0.973 & 1.96 & 3.77 & 7.33 & 15.7 \\
\hline Element & $\begin{array}{c}\text { Analytical } \\
\text { Method }\end{array}$ & & & & & & & & & & & \\
\hline As & GFAA & $4.7 \mathrm{E}+02$ & $4.9 \mathrm{E}+02$ & $4.7 E+02$ & $5 . E+02$ & $3.3 E+02$ & $3.4 \mathrm{E}+02$ & $2.3 \mathrm{E}+02$ & $2 . E+02$ & $1.2 \mathrm{E}+02$ & $4 . E+01$ & 7.E+01 \\
\hline $\mathrm{Se}$ & GFAA & $4 . E+02$ & $4.7 \mathrm{E}+02$ & $2 . E+02$ & $1.7 \mathrm{E}+02$ & $1 . E+02$ & $8.2 E+01$ & 7.E+01 & 7.E+01 & $5 . E+01$ & $2 . E+01$ & 4.E+01 \\
\hline $\mathrm{Sb}$ & GFAA & nd & nd & nd & $6 . \mathrm{E}+01$ & $7 . E+01$ & $3 . E+01$ & $3 . E+01$ & 1.E+01 & $1.3 \mathrm{E}+01$ & $6 . E+00$ & 2.E+01 \\
\hline $\mathrm{Co}$ & GFAA & $8 . E+01$ & $1.4 \mathrm{E}+02$ & $1.4 \mathrm{E}+02$ & 4.E+02 & $2.6 \mathrm{E}+02$ & $2 . E+02$ & $2 . E+02$ & $1.5 \mathrm{E}+02$ & $1.5 \mathrm{E}+02$ & $8 . E+01$ & $1.3 E+02$ \\
\hline Total (wt\%) & & $9.8 \mathrm{E}-02$ & r.1E-01 & 7.7E-02 & 1.1E-01 & $7.6 \mathrm{E}-02$ & $6.9 \mathrm{E}-02$ & $5.4 \mathrm{E}-02$ & 4.1E-02 & $3.3 \mathrm{E}-02$ & $1.5 \mathrm{E}-02$ & $2.6 \mathrm{E}-02$ \\
\hline
\end{tabular}

nd $=$ below detection limit

d) Trace Element Uncertainties

\begin{tabular}{|c|l|c|c|c|c|c|c|c|c|c|c|c|}
\hline Impactor Stage & 1 & 2 & 3 & 4 & 5 & 6 & 7 & 8 & 9 & 10 & 11 \\
\hline Cut-off & $\begin{array}{c}\text { Diameter } \\
\text { (microns) }\end{array}$ & 0.0324 & 0.0636 & 0.0926 & 0.168 & 0.337 & 0.535 & 0.973 & 1.96 & 3.77 & 7.33 & 15.7 \\
\hline Element & $\begin{array}{c}\text { Analytical } \\
\text { Method }\end{array}$ & & & & & & & & & & \\
\hline As & & $5 . E+01$ & $8 . E+01$ & $8 . E+01$ & $4 . E+02$ & $2 . E+01$ & $2 . E+01$ & $8 . E+01$ & $1 . E+02$ & $4 . E+01$ & $1 . E+01$ & $3 . E+01$ \\
\hline Se & & $3 . E+02$ & $7 . E+01$ & $1 . E+02$ & $2 . E+01$ & $1 . E+01$ & $7 . E+00$ & $4 . E+01$ & $2 . E+01$ & $2 . E+01$ & $7 . E+00$ & $2 . E+01$ \\
\hline Sb & & & & & $1 . E+01$ & $1 . E+01$ & $6 . E+01$ & $2 . E+01$ & $1 . E+01$ & $9 . E+00$ & $7 . E+00$ & $1 . E+01$ \\
\hline Co & & $1 . E+01$ & $2 . E+01$ & $3 . E+01$ & $5 . E+02$ & $2 . E+01$ & $1 . E+02$ & $1 . E+02$ & $8 . E+01$ & $4 . E+01$ & $2 . E+01$ & $9 . E+01$ \\
\hline
\end{tabular}


Table B-9

Size-Segregated Elemental Concentrations of the Kentucky Fly Ash Sampled at the Baghouse Inlet Port

a) Major Species Results

\begin{tabular}{|c|c|c|c|c|c|c|c|c|c|c|c|c|}
\hline Impactor & tage & 1 & 2 & 3 & 4 & 5 & 6 & 7 & 8 & 9 & 10 & 11 \\
\hline Cut-off & $\begin{array}{l}\text { iameter } \\
\text { microns) }\end{array}$ & 0.0324 & 0.0636 & 0.0926 & 0.168 & 0.337 & 0.535 & 0.973 & 1.96 & 3.77 & 7.33 & 15.7 \\
\hline Element & $\begin{array}{c}\text { Analytical } \\
\text { Method }\end{array}$ & & & & & & & & & & & \\
\hline $\begin{array}{c}\text { Total Mass Conc } \\
\left(\mathrm{g} / \mathrm{Nm}^{\wedge} 3\right)\end{array}$ & $\begin{array}{l}\text { Grava- } \\
\text { metric }\end{array}$ & $7.42 \mathrm{E}-03$ & $6.21 E-03$ & $7.29 E-03$ & $6.95 \mathrm{E}-03$ & $1.15 E-02$ & $2.60 \mathrm{E}-02$ & 7.29E-02 & $1.61 \mathrm{E}-01$ & $3.28 \mathrm{E}-01$ & $8.10 \mathrm{E}-01$ & $8.03 \mathrm{E}-02$ \\
\hline $\mathrm{SiO}_{2}(\mathrm{Wt} \%)$ & AAS & $1.5 E+01$ & $1.6 E+01$ & $2.4 \mathrm{E}+01$ & $2.0 \mathrm{E}+01$ & $3.3 E+01$ & $4.0 \mathrm{E}+01$ & $4.0 \mathrm{E}+01$ & $4.3 \mathrm{E}+01$ & $4.5 E+01$ & $4.6 \mathrm{E}+01$ & $4.5 E+01$ \\
\hline+1 & & $3 . E+00$ & $3 . E+00$ & $3 . E+00$ & 4.E+00 & $4 . E+00$ & $2 . E+00$ & $1 . E+00$ & $4 . E+00$ & $4 . E+00$ & 7.E+00 & $8 . E+00$ \\
\hline $\mathrm{Al}_{2} \mathrm{O}_{3}(\mathrm{Wt} \%)$ & AAS & $1.7 E+01$ & $1.7 \mathrm{E}+01$ & $3.2 E+01$ & $4.4 \mathrm{E}+01$ & $3.5 E+01$ & $5.0 \mathrm{E}+01$ & $5.0 \mathrm{E}+01$ & $5.28 \mathrm{E}+01$ & $5.19 \mathrm{E}+01$ & $5.2 \mathrm{E}+01$ & $4.68 \mathrm{E}+01$ \\
\hline+1 & & $3 . E+00$ & 3.E+00 & $4 . E+00$ & $6 . \mathrm{E}+00$ & $2 . E+01$ & $2 . E+00$ & $2 . \mathrm{E}+01$ & 5.E-01 & 4.E-01 & $9 . E+00$ & 9.E-01 \\
\hline $\mathrm{Fe}_{2} \mathrm{O}_{3}(\mathrm{Wt} \%)$ & AAS & 7.E+00 & $9 . \mathrm{E}+00$ & $8 . E+00$ & $1.5 \mathrm{E}+01$ & $1.3 \mathrm{E}+01$ & $1.73 \mathrm{E}+01$ & $1.72 \mathrm{E}+01$ & $9 . E+00$ & $8.0 E+00$ & $7.6 \mathrm{E}+00$ & $7.1 \mathrm{E}+00$ \\
\hline$+1-$ & & 1.E+00 & $3 . \mathrm{E}+00$ & $3 . E+00$ & $2 . E+00$ & $5 . E+00$ & 8.E-01 & 6.E-01 & $3 . E+00$ & 9.E-01 & \begin{tabular}{|l|} 
4.E-01 \\
\end{tabular} & 7.E-01 \\
\hline $\mathrm{CaO}(\mathrm{Wt} \%)$ & AAS & nd & nd & nd & nd & $1.4 \mathrm{E}-02$ & $1.5 \mathrm{E}+00$ & $2.3 \mathrm{E}+00$ & $2.0 \mathrm{E}+00$ & $1.5 \mathrm{E}+00$ & $2.1 \mathrm{E}-01$ & $1.1 \mathrm{E}+00$ \\
\hline+1 & & & & & & 2.E-01 & 3.E-01 & 2.E-01 & 2.E-01 & 2.E-01 & 2.E-01 & 2.E-01 \\
\hline $\mathrm{MgO}(\mathrm{Wt} \%)$ & AAS & 1.E+01 & 2.E +01 & $2.5 E+01$ & $1.1 \mathrm{E}+01$ & $8.8 \mathrm{E}+00$ & $8.4 \mathrm{E}+00$ & $4.58 \mathrm{E}+00$ & $3 . E+00$ & $1.3 \mathrm{E}+00$ & $4.24 \mathrm{E}-01$ & $3.3 E+00$ \\
\hline$+1-$ & & 1.E+01 & $3 . E+01$ & $3 . E+00$ & $1 . E+00$ & 5.E-01 & 2.E-01 & 5.E-02 & 1.E+00 & 8.E-01 & 9.E-03 & 5.E-01 \\
\hline $\mathrm{Na}_{2} \mathrm{O}(\mathrm{Wt} \%)$ & AES & $3.2 \mathrm{E}+00$ & $2.1 \mathrm{E}+00$ & $2.4 \mathrm{E}+00$ & $9.8 \mathrm{E}+00$ & $4.3 E+00$ & $4.2 E+00$ & $3.1 \mathrm{E}+00$ & $2.38 \mathrm{E}+00$ & $1.88 \mathrm{E}+00$ & $.02 E+00$ & $2.4 \mathrm{E}+00$ \\
\hline+1 & & 5.E-01 & 6.E-01 & 2.E-01 & 1.E+00 & 4.E-01 & 9.E-01 & 1.E-01 & 9.E-02 & 8.E-02 & 8.E-02 & 7.E-01 \\
\hline $\begin{array}{c}\text { Trace Elements } \\
(W \mathrm{t} \%)\end{array}$ & GFAA & $9.5 \mathrm{E}-02$ & 1.7E-01 & $1.9 \mathrm{E}-01$ & $1.1 \mathrm{E}-01$ & $7.9 \mathrm{E}-02$ & $7.9 \mathrm{E}-02$ & $5.7 \mathrm{E}-02$ & $2.9 \mathrm{E}-02$ & $1.3 \mathrm{E}-02$ & $6.0 \mathrm{E}-03$ & $1.6 \mathrm{E}-02$ \\
\hline Total (Wt\%) & & 58 & 68 & 92 & 100 & 94 & 121 & 117 & 111 & 109 & 107 & 105 \\
\hline
\end{tabular}

Note: Elemental concentrations have been converted to oxide forms on a $\mathrm{SO}_{3}$-free basis. nd $=$ below detection limit 
Table B-9 (Continued)

Size-Segregated Elemental Concentrations of the Kentucky Fly Ash Sampled at the Baghouse Inlet Port

b) Normalized Major Species Results

\begin{tabular}{|c|c|c|c|c|c|c|c|c|c|c|c|c|}
\hline Impactor & Stage & 1 & 2 & 3 & 4 & 5 & 6 & 7 & 8 & 9 & 10 & 11 \\
\hline Cut-off & $\begin{array}{l}\text { Diameter } \\
\text { (microns) }\end{array}$ & 0.0324 & 0.0636 & 0.0926 & 0.168 & 0.337 & 0.535 & 0.973 & 1.96 & 3.77 & 7.33 & 15.7 \\
\hline Element & $\begin{array}{c}\text { Analytical } \\
\text { Method }\end{array}$ & & & & & & & & & & & \\
\hline $\begin{array}{c}\text { Total Mass Conc } \\
\left(\mathrm{g} / \mathrm{Nm}^{\wedge} 3\right)\end{array}$ & Gravametric & $7.4 \mathrm{E}-03$ & $6.2 \mathrm{E}-03$ & $7.3 \mathrm{E}-03$ & $7.0 \mathrm{E}-03$ & $1.2 \mathrm{E}-02$ & $2.6 \mathrm{E}-02$ & $7.3 E-02$ & $1.6 \mathrm{E}-01$ & $3.3 \mathrm{E}-01$ & $8.1 E-01$ & $8.0 \mathrm{E}-02$ \\
\hline $\mathrm{SiO}_{2}(\mathrm{Wt} \%)$ & AAS & 27 & 23 & 26 & 20 & 35 & 33 & 34 & 38 & 41 & 43 & 42 \\
\hline $\mathrm{Al}_{2} \mathrm{O}_{3}(\mathrm{~W}+\%)$ & AAS & 30 & 25 & 35 & 44 & 37 & 41 & 43 & 47 & 47 & 48 & 44 \\
\hline $\mathrm{Fe}_{2} \mathrm{O}_{3}(\mathrm{Wt} \%)$ & AAS & 12 & 13 & 9 & 15 & 14 & 14 & 15 & 7.9 & 7.3 & 7.1 & 6.8 \\
\hline $\mathrm{CaO}(\mathrm{Wt} \%)$ & AAS & nd & nd & nd & nd & nd & 1.2 & 1.9 & 1.8 & 1.4 & 0.2 & 1.0 \\
\hline $\mathrm{MgO}(\mathrm{Wt} \%)$ & AAS & 26 & 35 & 27 & 11 & 9.4 & 6.9 & 3.9 & 2.3 & 1.2 & 0.40 & 3.2 \\
\hline $\mathrm{Na}_{2} \mathrm{O}(\mathrm{Wt} \%)$ & AES & 5.6 & 3.1 & 2.6 & 9.8 & 4.5 & 3.5 & 2.7 & 2.1 & 1.7 & 0.9 & 2.3 \\
\hline $\begin{array}{c}\text { Trace Elements } \\
(W t \%)\end{array}$ & GFAA & 0.17 & 0.26 & 0.20 & 0.11 & 0.084 & 0.065 & 0.049 & 0.026 & 0.012 & 0.0056 & 0.015 \\
\hline Total $(\mathrm{Wt} \%)$ & & 100.00 & 100.00 & 100.00 & 100.00 & 99.99 & 100.00 & 100.00 & 100.00 & 100.00 & 100.00 & 100.00 \\
\hline
\end{tabular}

Note: Elemental concentrations have been converted to oxide forms on a $\mathrm{SO}_{3}$-free basis.

nd $=$ below detection limit 
Table B-9 (Continued)

Size-Segregated Elemental Concentrations of the Kentucky Fly Ash Sampled at the Baghouse Inlet Port

c) Trace Element Concentrations

\begin{tabular}{|c|c|c|c|c|c|c|c|c|c|c|c|c|}
\hline Impactor & Stage & 1 & 2 & 3 & 4 & 5 & 6 & 7 & 8 & 9 & 10 & 11 \\
\hline Cut-off & $\begin{array}{l}\text { Diameter } \\
\text { (microns) }\end{array}$ & 0.0324 & 0.0636 & 0.0926 & 0.168 & 0.337 & 0.535 & 0.973 & 1.96 & 3.77 & 7.33 & 15.7 \\
\hline Element & $\begin{array}{c}\text { Analytical } \\
\text { Method }\end{array}$ & & & & & & & & & & & \\
\hline As & GFAA & $8 . E+02$ & $1.6 \mathrm{E}+03$ & $1.7 \mathrm{E}+03$ & $8 . \mathrm{E}+02$ & $5 . E+02$ & $4.3 \mathrm{E}+02$ & $2.98 \mathrm{E}+02$ & $1.43 \mathrm{E}+0$ & $5.3 \mathrm{E}+01$ & $3 . E+01$ & $8 . E+01$ \\
\hline $\mathrm{Se}$ & GFAA & $1.8 \mathrm{E}+02$ & $1.5 \mathrm{E}+02$ & $1.2 \mathrm{E}+02$ & $1.6 \mathrm{E}+02$ & $4.9 \mathrm{E}+01$ & $6 . E+01$ & $5 . E+01$ & $2.8 \mathrm{E}+01$ & $1.5 \mathrm{E}+01$ & $5 . E+00$ & $1.2 E+01$ \\
\hline $\mathrm{Sb}$ & GFAA & nd & nd & nd & nd & $2.8 \mathrm{E}+01$ & $4.1 \mathrm{E}+01$ & $2.5 \mathrm{E}+01$ & 1.7E+01 & 7.E+00 & 5.E-01 & $1 . E+01$ \\
\hline $\mathrm{Co}_{0}$ & GFAA & nd & nd & nd & $1.9 \mathrm{E}+02$ & $2.3 \mathrm{E}+02$ & $2.7 \mathrm{E}+02$ & $2.00 E+02$ & $1.05 \mathrm{E}+0$ & $5 . \mathrm{E}+01$ & $2.8 \mathrm{E}+01$ & $6 . E+01$ \\
\hline Total $(w t \%)$ & & $9.5 E-02$ & 1.7E-01 & $1.9 \mathrm{E}-01$ & 1.1E-01 & $7.9 \mathrm{E}-02$ & $7.9 \mathrm{E}-02$ & $5.7 \mathrm{E}-02$ & $2.9 \mathrm{E}-02$ & $1.3 \mathrm{E}-02$ & $6.0 \mathrm{E}-03$ & $1.6 \mathrm{E}-02$ \\
\hline
\end{tabular}

nd $=$ below detection limit

d) Trace Element Uncertainties

\begin{tabular}{|c|c|c|c|c|c|c|c|c|c|c|c|c|}
\hline Impactor & Stage & 1 & 2 & 3 & 4 & 5 & 6 & 7 & 8 & 9 & 10 & 11 \\
\hline Cut-off & $\begin{array}{l}\text { Diameter } \\
\text { (microns) }\end{array}$ & 0.0324 & 0.0636 & 0.0926 & 0.168 & 0.337 & 0.535 & 0.973 & 1.96 & 3.77 & 7.33 & 15.7 \\
\hline Element & $\begin{array}{c}\text { Analytical } \\
\text { Method }\end{array}$ & & & & & & & & & & & \\
\hline As & & $6 . E+02$ & $3 . E+02$ & $2 . E+02$ & $1 . E+02$ & $3 . E+02$ & $2 . E+01$ & $9 . \mathrm{E}+00$ & $6 . \mathrm{E}+00$ & $5 . \mathrm{E}+00$ & $5 . E+00$ & $6 . \mathrm{E}+01$ \\
\hline $\mathrm{Se}$ & & $3 . E+01$ & $3 . E+01$ & $2 . E+01$ & $2 . E+01$ & $9 . \mathrm{E}+00$ & 4.E+01 & 2.E+01 & $5 . E+00$ & $4 . \mathrm{E}+00$ & $4 . E+00$ & $5 . E+00$ \\
\hline $\mathrm{Sb}$ & & & & & & $5 . E+00$ & $7 . E+00$ & $6 . E+00$ & $6 . E+00$ & $6 . \mathrm{E}+00$ & $4 . E+00$ & $6 . E+00$ \\
\hline Co & & & & & $3 . E+01$ & $2 . E+01$ & $1 . E+01$ & $6 . E+00$ & $4 . E+00$ & $7 . E+01$ & $4 . E+00$ & $9 . E+01$ \\
\hline
\end{tabular}


Table B-10

Size-Segregated Elemental Concentrations of the Ohio Fly Ash Sampled at Port 4 (0.7 residence second)

a) Major Species Results

\begin{tabular}{|c|c|c|c|c|c|c|c|c|c|c|c|c|}
\hline Impactor & Stage & I & 2 & 3 & 4 & 5 & 6 & 7 & 8 & 9 & 10 & II \\
\hline Cut-off & $\begin{array}{l}\text { Diameter } \\
\text { (microns) }\end{array}$ & 0.0324 & 0.0636 & 0.0926 & 0.168 & 0.337 & 0.535 & 0.973 & 1.96 & 3.77 & 7.33 & 15.7 \\
\hline Element & $\begin{array}{c}\text { Analytical } \\
\text { Method }\end{array}$ & & & & & & & & & & & \\
\hline $\begin{array}{c}\text { Total Mass Conc } \\
\left(\mathrm{g} / \mathrm{Nm}^{\wedge} 3\right)\end{array}$ & Gravametric & $1.96 \mathrm{E}-02$ & $2.40 \mathrm{E}-02$ & $8.27 \mathrm{E}-02$ & $4.64 \mathrm{E}-02$ & $4.00 \mathrm{E}-02$ & $9.15 \mathrm{E}-02$ & I.IIE +00 & $1.55 \mathrm{E}+00$ & $2.7 \mathrm{IE}+00$ & $4.84 \mathrm{E}+00$ & $1.07 \mathrm{E}+00$ \\
\hline $\mathrm{SiO}_{2}(\mathrm{Wt} \%)$ & AAS & $\mathrm{I} . \mathrm{IE}+0 \mathrm{I}$ & $8.2 \mathrm{E}+00$ & $5.6 \mathrm{E}+00$ & $\mathrm{I} .4 \mathrm{E}+0 \mathrm{I}$ & $1.2 \mathrm{E}+0 \mathrm{I}$ & $2.2 \mathrm{E}+0 \mathrm{I}$ & $2.9 \mathrm{E}+0 \mathrm{I}$ & $4.2 \mathrm{E}+0 \mathrm{I}$ & $4.5 \mathrm{E}+0 \mathrm{I}$ & $4.8 \mathrm{E}+0 \mathrm{I}$ & $4 . \mathrm{E}+0 \mathrm{I}$ \\
\hline$+/-$ & & I.E +00 & 9.E-0I & 9.E-0I & I.E +00 & $3 . E+00$ & $2 . E+00$ & $4 . E+00$ & $4 . E+00$ & $6 . E+00$ & $4 . E+00$ & I.E $+0 \mid$ \\
\hline $\mathrm{Al}_{2} \mathrm{O}_{3}(\mathrm{Wt} \%)$ & NAA/AAS & 7.E +00 & $1.3 \mathrm{E}+00$ & nd & nd & $2.8 \mathrm{E}+00$ & $9.0 \mathrm{E}+00$ & $2 . E+0 I$ & $4.0 \mathrm{E}+0 \mathrm{I}$ & $4.3 \mathrm{E}+0 \mathrm{I}$ & $3.7 \mathrm{E}+0 \mathrm{I}$ & $3.3 \mathrm{E}+0 \mathrm{I}$ \\
\hline$+/-$ & & $8 . E+00$ & 7.E-0I & & & 7.E-0I & 9.E-0I & $4 . \mathrm{E}+0 \mathrm{I}$ & $3 . E+00$ & $6 . \mathrm{E}+00$ & $3 . E+00$ & 7.E +00 \\
\hline $\mathrm{Fe}_{2} \mathrm{O}_{3}(\mathrm{Wt} \%)$ & NAA/AAS & I.E +02 & $2 . E+0 I$ & $2 . E+0 I$ & $4 . E+0 I$ & 7.E+0I & $3 . E+0 I$ & $8 . E+01$ & $1.24 \mathrm{E}+02$ & $5 . E+01$ & $1.04 \mathrm{E}+02$ & $7 . \mathrm{E}+0 \mathrm{I}$ \\
\hline$+/-$ & & $3 . E+02$ & $3 . \mathrm{E}+0 \mathrm{I}$ & $3 . E+0 I$ & $7 . E+0 I$ & $2 . E+02$ & $6 . \mathrm{E}+0 \mathrm{I}$ & $2 . E+02$ & $9 . \mathrm{E}+00$ & $\mathrm{I} . \mathrm{E}+02$ & $8 . E+00$ & $2 . E+0 I$ \\
\hline $\mathrm{Ca} 0(\mathrm{Wt} \%)$ & NAA/AAS & 4.E-OI & nd & nd & I.E-OI & 6.E-01 & 8.E-0I & $1.4 \mathrm{E}+00$ & I.E+00 & 9.E-OI & 8.E-OI & 8.E-0I \\
\hline$+/-$ & & 6.E-0I & & & 5.E-0I & 4.E-OI & 9.E-OI & 4.E-OI & I.E +00 & 3.E-OI & 3.E-0I & 4.E-OI \\
\hline $\mathrm{MgO}(\mathrm{Wt} \%)$ & NAA/AAS & $3.5 \mathrm{E}-0 \mathrm{I}$ & 2.E-0I & $1.9 \mathrm{E}-0 \mid$ & 9.E-02 & I.IE-0I & $2.5 \mathrm{E}-0 \mathrm{I}$ & $5.0 \mathrm{E}-\mathrm{OI}$ & $5.9 \mathrm{E}-0 \mathrm{I}$ & $5.0 \mathrm{E}-0 \mathrm{I}$ & $4.6 \mathrm{E}-0 \mathrm{I}$ & 5.E-0I \\
\hline$+/-$ & & 9.E-02 & I.E-OI & 8.E-02 & 8.E-02 & 9.E-02 & 9.E-02 & 7.E-02 & 5.E-02 & 7.E-02 & 4.E-02 & I.E-OI \\
\hline $\mathrm{Na}_{2} \mathrm{O}(\mathrm{Wt} \%)$ & NAA/AAS & $3 . \mathrm{E}+00$ & $2 . \mathrm{IE}+00$ & $2 . E+00$ & $2 . E+00$ & $3.4 \mathrm{E}+00$ & I.E +00 & $2 . \mathrm{E}+00$ & $2 . \mathrm{E}+00$ & $2 . E+00$ & I.E +00 & $3 . E+00$ \\
\hline$+/-$ & & $3 . E+00$ & I.E-0| & $3 . E+00$ & $4 . E+00$ & 5.E-0I & $2 . E+00$ & $6 . \mathrm{E}+00$ & $5 . E+00$ & $3 . E+00$ & $2 . E+00$ & $5 . E+00$ \\
\hline $\begin{array}{c}\text { Trace Elements } \\
(\mathrm{Wt} \%)\end{array}$ & NAA/GFAA & $\begin{array}{c}1.2 \mathrm{E}+0 \\
2 \\
\end{array}$ & I.IE +02 & I.IE +02 & I.IE +02 & I.IE +02 & I.IE +02 & $\mathrm{I} . \mathrm{IE}+02$ & I.IE +02 & I.IE +02 & I.IE +02 & I.IE +02 \\
\hline Total (Wt\%) & & 119 & 36 & 28 & 60 & 95 & 69 & 137 & 211 & 137 & 192 & $|5|$ \\
\hline
\end{tabular}

Note: Elemental concentrations have been converted to oxide forms on a $\mathrm{SO}_{3}$-free basis.

nd - below detection limit 
Table B-10 (continued)

Size-Segregated Elemental Concentrations of the Ohio Fly Ash Sampled at Port 4 (0.7 residence second)

b) Normalized Major Species Results

\begin{tabular}{|c|c|c|c|c|c|c|c|c|c|c|c|c|}
\hline Impactor & Stage & I & 2 & 3 & 4 & 5 & 6 & 7 & 8 & 9 & 10 & II \\
\hline Cut-off & $\begin{array}{l}\text { Diameter } \\
\text { (microns) }\end{array}$ & 0.0324 & 0.0636 & 0.0926 & 0.168 & 0.337 & 0.535 & 0.973 & 1.96 & 3.77 & 7.33 & 15.7 \\
\hline Element & $\begin{array}{c}\text { Analytical } \\
\text { Method }\end{array}$ & & & & & & & & & & & \\
\hline $\begin{array}{l}\text { Total Mass Conc } \\
(\mathrm{g} / \mathrm{Nm} \wedge 3)\end{array}$ & Gravametric & $2.0 \mathrm{E}-02$ & $2.4 \mathrm{E}-02$ & $8.3 \mathrm{E}-02$ & $4.6 \mathrm{E}-02$ & $4.0 \mathrm{E}-02$ & 9.IE-02 & $\mathrm{I} . \mathrm{IE}+00$ & $1.6 \mathrm{E}+00$ & $2.7 \mathrm{E}+00$ & $4.8 \mathrm{E}+00$ & $\mathrm{I} . \mathrm{IE}+00$ \\
\hline $\mathrm{SiO}_{2}(\mathrm{Wt} \%)$ & AAS & 10 & 23 & 20 & 24 & 13 & 32 & 21 & 20 & 33 & 25 & 29 \\
\hline $\mathrm{Al}_{2} \mathrm{O}_{3}(\mathrm{Wt} \%)$ & AAS & 5.5 & 3.6 & nd & nd & 3 & 13 & 17 & 19 & 31 & 20 & 22 \\
\hline $\mathrm{Fe}_{2} \mathrm{O}_{3}(\mathrm{Wt} \%)$ & AAS & 80 & 61 & 65 & 70 & 79 & 50 & 59 & 59 & 34 & 54 & 46 \\
\hline $\mathrm{Ca} 0(\mathrm{Wt} \%)$ & AAS & 0.35 & nd & nd & 0.23 & 0.62 & 1.1 & 1.0 & 0.46 & 0.69 & 0.41 & 0.51 \\
\hline $\mathrm{MgO}(\mathrm{Wt} \%)$ & AAS & 0.29 & 0.66 & 0.69 & 0.16 & 0.11 & 0.36 & 0.37 & 0.28 & 0.37 & 0.24 & 0.36 \\
\hline $\mathrm{Na}_{2} \mathrm{O}(\mathrm{Wt} \%)$ & AES & 2.2 & 5.9 & 7.6 & 3.5 & 3.6 & 2.0 & 1.8 & I.I & 1.2 & 0.51 & 1.7 \\
\hline $\begin{array}{l}\text { Trace Elements } \\
(\mathrm{Wt} \%)\end{array}$ & GFAA & 2.0 & 6.5 & 6.5 & 1.7 & 1.2 & 1.7 & 0.077 & 0.076 & 0.16 & 0.23 & 0.15 \\
\hline Total (Wt\%) & & 100.00 & 100.00 & 100.00 & 100.00 & 100.00 & 100.00 & 100.00 & 100.00 & 100.00 & 100.00 & 100.00 \\
\hline
\end{tabular}


Table B-10 (continued)

Size-Segregated Elemental Concentrations of the Ohio Fly Ash Sampled at Port 4 (0.7 residence second)

c) Trace Element Concentrations

\begin{tabular}{|c|c|c|c|c|c|c|c|c|c|c|c|c|}
\hline Impactor & Stage & I & 2 & 3 & 4 & 5 & 6 & 7 & 8 & 9 & 10 & II \\
\hline Element: As & NAA/GFAA & $2.7 \mathrm{E}+03$ & $3.15 \mathrm{E}+03$ & $2.25 \mathrm{E}+03$ & $1.6 \mathrm{E}+03$ & $2 . \mathrm{E}+03$ & $4.8 \mathrm{E}+02$ & $4.7 \mathrm{E}+02$ & $4.8 \mathrm{E}+02$ & $3.0 \mathrm{E}+02$ & $1.9 \mathrm{E}+02$ & $2.8 \mathrm{E}+02$ \\
\hline $\mathrm{Se}$ & NAA/GFAA & $2.5 E+02$ & $2.8 \mathrm{E}+02$ & $2.4 \mathrm{E}+02$ & $1.7 \mathrm{E}+02$ & $7 . E+01$ & $5 . E+0 I$ & $4 .|\mathrm{IE}+0|$ & $3.9 \mathrm{E}+01$ & $2.5 \mathrm{E}+01$ & $1.6 \mathrm{E}+0 \mathrm{I}$ & $2.2 \mathrm{E}+01$ \\
\hline $\mathrm{Sb}$ & NAA/GFAA & $2.4 \mathrm{E}+02$ & $2.00 \mathrm{E}+02$ & $1.42 \mathrm{E}+03$ & $7.8 \mathrm{E}+01$ & $2 . E+02$ & $4.7 \mathrm{E}+01$ & $4 . \mathrm{E}+0 \mathrm{I}$ & $3.8 \mathrm{E}+0 \mathrm{l}$ & $4 . \mathrm{E}+0 \mathrm{I}$ & $2.3 \mathrm{E}+01$ & I.E +02 \\
\hline$C_{0}$ & NAA/GFAA & $2.7 \mathrm{E}+01$ & $1.7 \mathrm{E}+0 \mathrm{I}$ & $1.2 \mathrm{E}+0 \mid$ & I.E +02 & $9 . \mathrm{E}+0 \mathrm{I}$ & $4.6 \mathrm{E}+0 \mathrm{I}$ & $4 .|E+0|$ & $4.2 \mathrm{E}+01$ & $3.6 \mathrm{E}+01$ & $|.3 \mathrm{E}+0|$ & $2 . \mathrm{E}+0 \mathrm{I}$ \\
\hline Cs & NAA & $3.0 \mathrm{E}+01$ & $2.7 \mathrm{E}+01$ & $1.8 \mathrm{E}+0 \mathrm{I}$ & $|| E+0 \mid$. & I.E+0I & $|.5 \mathrm{E}+0|$ & I.E +00 & $2 . \mathrm{E}+00$ & $2 . E+00$ & $5 . E+00$ & $2 . E+00$ \\
\hline $\mathrm{Cl}$ & NAA & $1.9 \mathrm{E}+03$ & $1 . I E+03$ & $9 . \mathrm{E}+02$ & $1.0 \mathrm{E}+03$ & $1.8 \mathrm{E}+03$ & $2.0 \mathrm{E}+03$ & $6 . \mathrm{E}+0 \mathrm{I}$ & $8 . \mathrm{E}+0 \mathrm{I}$ & I.E +02 & $5 . E+02$ & $4 . \mathrm{E}+02$ \\
\hline K & NAA & $1.4 \mathrm{E}+04$ & $1.5 \mathrm{E}+04$ & $1.0 \mathrm{E}+04$ & $5 . \mathrm{E}+03$ & $5 . E+03$ & $5 . \mathrm{E}+03$ & $2 . E+02$ & $6 . E+02$ & I.E +03 & $2 . E+03$ & $8 . E+02$ \\
\hline Sc & NAA & $3 . \mathrm{E}+00$ & $3 . E+00$ & $2 . E+00$ & $2 . E+00$ & $5 . E+00$ & $\mathrm{I} . \mathrm{E}+0 \mathrm{I}$ & 5.E-0I & I.E +00 & $2 . \mathrm{E}+00$ & $5 . E+00$ & I.E +00 \\
\hline $\mathrm{Ti}$ & NAA & $8 . E+02$ & $6 . \mathrm{E}+02$ & $5 . E+02$ & $3 . \mathrm{E}+02$ & I.IE +03 & $1.8 \mathrm{E}+03$ & $8 . E+01$ & $2 . E+02$ & $3 . \mathrm{E}+02$ & $8 . E+02$ & $3 . E+02$ \\
\hline$V$ & NAA & $2 . \mathrm{E}+02$ & $3 . \mathrm{E}+02$ & $2 . \mathrm{E}+02$ & I.E +02 & $8 . E+0 I$ & $9 . \mathrm{E}+0 \mathrm{I}$ & $5 . E+00$ & $7 . \mathrm{E}+00$ & $\mathrm{I} . \mathrm{E}+0 \mathrm{I}$ & $3 . E+0 I$ & $I . E+0 \mid$ \\
\hline $\mathrm{Cr}$ & NAA & $2.4 \mathrm{E}+03$ & 7.E +02 & $5 . E+02$ & $3 . \mathrm{E}+02$ & $3 . \mathrm{E}+02$ & $5 . E+02$ & $5 . \mathrm{E}+0 \mathrm{I}$ & $7 . \mathrm{E}+0 \mathrm{I}$ & $2 . \mathrm{E}+02$ & $3 . \mathrm{E}+02$ & $2 . E+02$ \\
\hline$M n$ & NAA & I.E +02 & $4 . \mathrm{E}+0 \mathrm{I}$ & $4 . E+01$ & $2 . E+0 I$ & $4 . \mathrm{E}+0 \mathrm{I}$ & $6 . \mathrm{E}+0 \mathrm{I}$ & 2.E +00 & $5 . E+00$ & $2 . E+0 I$ & $3 . \mathrm{E}+0 \mathrm{I}$ & I.E+0I \\
\hline Zn & NAA & $8 . E+02$ & $8 . E+02$ & $6 . \mathrm{E}+02$ & $5 . E+02$ & $4 . E+02$ & $3 . E+02$ & 8.E-OI & $6 . \mathrm{E}+00$ & I.E +0 I & $9 . \mathrm{E}+0 \mathrm{I}$ & I.E +00 \\
\hline $\mathrm{Ga}$ & NAA & $1.8 \mathrm{E}+02$ & $2.7 \mathrm{E}+02$ & $1.8 \mathrm{E}+02$ & I.E +02 & $8 . \mathrm{E}+0 \mathrm{I}$ & $8 . \mathrm{E}+0 \mathrm{I}$ & $3 . \mathrm{E}+00$ & $5 . E+00$ & $5 . \mathrm{E}+00$ & $9 . \mathrm{E}+00$ & $9 . \mathrm{E}+00$ \\
\hline $\mathrm{Br}$ & NAA & $1.3 \mathrm{E}+02$ & $1.3 \mathrm{E}+02$ & $1.3 \mathrm{E}+02$ & $1.2 \mathrm{E}+02$ & $1.3 \mathrm{E}+02$ & $1.7 \mathrm{E}+02$ & $5 . E+00$ & $8 . E+00$ & I.E+0I & $2 . \mathrm{E}+0 \mathrm{I}$ & $5 . E+01$ \\
\hline $\mathrm{Rb}$ & NAA & I.IE +02 & $1.17 \mathrm{E}+02$ & $1.33 \mathrm{E}+02$ & $n d^{2}$ & $2.9 \mathrm{E}+01$ & $3.4 \mathrm{E}+0 \mathrm{I}$ & nd & nd & nd & $|.8 \mathrm{E}+0|$ & nd \\
\hline $\mathrm{Sr}$ & NAA & $2 . \mathrm{E}+02$ & $6 . \mathrm{E}+0 \mathrm{l}$ & $5 . \mathrm{E}+0 \mathrm{I}$ & $2 . E+0 \mid$ & $7 . \mathrm{E}+0 \mid$ & $\mathrm{I} . \mathrm{E}+02$ & I.E $+0 \mid$ & $9 . \mathrm{E}+00$ & $3 . \mathrm{E}+0 \mathrm{I}$ & $6 . \mathrm{E}+0 \mathrm{I}$ & $2 . \mathrm{E}+0 \mathrm{I}$ \\
\hline Mo & NAA & $3.4 \mathrm{E}+02$ & $3.5 \mathrm{E}+02$ & $2.4 \mathrm{E}+02$ & $1.2 \mathrm{E}+02$ & $5 . E+0 I$ & $5 . \mathrm{E}+0 \mathrm{I}$ & $2 . E+00$ & $4 . E+00$ & $\mathrm{I} . \mathrm{E}+0 \mathrm{I}$ & $\mathrm{I} . \mathrm{E}+0 \mathrm{I}$ & $8 . E+00$ \\
\hline $\ln$ & NAA & I.IE +00 & $1.2 \mathrm{E}+00$ & 9.E-0l & 5.E-0I & 2.E-0I & 3.E-0I & $2 . E-02$ & I.E-02 & 2.E-02 & nd & 6.E-02 \\
\hline $\mathrm{Ba}$ & NAA & $1.4 \mathrm{E}+02$ & $6 . \mathrm{E}+0 \mathrm{I}$ & $6 . \mathrm{E}+01$ & $4 . \mathrm{E}+0 \mathrm{I}$ & $1.8 \mathrm{E}+02$ & $1.6 \mathrm{E}+02$ & I.E $+0 \mathrm{I}$ & $2 . \mathrm{E}+0 \mathrm{I}$ & $4 . \mathrm{E}+0 \mathrm{I}$ & $9 . \mathrm{E}+0 \mathrm{I}$ & $3 . \mathrm{E}+0 \mathrm{I}$ \\
\hline La & NAA & $4 . E+00$ & $2 . E+00$ & I.E +00 & $2 . E+00$ & $|| E+0 \mid$. & $2 . \mid \mathrm{E}+0 \mathrm{I}$ & I.E +00 & $2 . E+00$ & $3 . E+00$ & $|.3 \mathrm{E}+0|$ & $3 . E+00$ \\
\hline $\mathrm{Ce}_{\mathrm{e}}$ & NAA & I.E +0 I & $1.3 \mathrm{E}+0 \mid$ & $6 . \mathrm{E}+00$ & $6 . \mathrm{E}+00$ & $|.9 \mathrm{E}+0|$ & $4 . E+00$ & $2 . E+00$ & $4 . E+00$ & $8 . E+00$ & $3 . \mathrm{E}+0 \mathrm{I}$ & $4 . E+00$ \\
\hline $\mathrm{Nd}$ & NAA & nd & I.E $+0 \mid$ & $2 . \mathrm{E}+0 \mathrm{I}$ & $4 . \mathrm{E}+0 \mathrm{I}$ & $8 . \mathrm{E}+00$ & $3 . \mathrm{E}+0 \mathrm{l}$ & nd & $2 . \mathrm{E}+00$ & $6 . \mathrm{E}+00$ & $9 . \mathrm{E}+00$ & $3 . \mathrm{E}+0 \mathrm{I}$ \\
\hline $\mathrm{Sm}$ & NAA & $1.4 \mathrm{E}+00$ & I.IE +00 & 7.E-OI & 6.E-0I & $2 . \mathrm{IE}+00$ & $4.0 \mathrm{E}+00$ & 2.E-OI & 4.E-Ol & 2.E-OI & $2.6 \mathrm{E}+00$ & 5.E-0l \\
\hline Eu & NAA & $2.3 \mathrm{E}+00$ & nd & 2.E-OI & nd & 5.E-0I & $1.0 \mathrm{E}+00$ & 8.E-02 & I.E-OI & 2.E-OI & 7.E-0I & nd \\
\hline $\mathrm{Yb}$ & NAA & nd & nd & 9.E-0l & nd & I.E +00 & $3 . E+00$ & I.E-0| & 4.E-Ol & 5.E-0l & $2 . E+00$ & 4.E-0l \\
\hline Lu & NAA & nd & 5.E-02 & 7.E-02 & 6.E-02 & 2.E-OI & 4.E-OI & 2.E-02 & 5.E-02 & 6.E-02 & 3.E-0I & 3.E-02 \\
\hline $\mathrm{Au}$ & NAA & 5.E-02 & I.E-02 & I.E-02 & 9.E-03 & I.IE-0I & 6.E-02 & 5.E-04 & 5.E-04 & 4.E-04 & 4.E-03 & 3.E-03 \\
\hline $\mathrm{Hg}$ & NAA & $1.8 \mathrm{E}+00$ & $1.8 \mathrm{E}+00$ & $2.2 \mathrm{E}+00$ & $1.8 \mathrm{E}+00$ & $2.2 \mathrm{E}+00$ & $3.7 \mathrm{E}+00$ & 2.E-0I & 2.E-OI & 2.E-OI & 5.E-0l & 3.E-OI \\
\hline Th & NAA & $2 . \mathrm{E}+00$ & 6.E-0I & I.E +00 & $2 . E+00$ & $3 . \mathrm{E}+00$ & $5 . \mathrm{E}+00$ & 2.E-0I & 5.E-0l & 8.E-0l & $3 . \mathrm{E}+00$ & 7.E-0I \\
\hline U & NAA & $3.0 \mathrm{E}+01$ & $2.9 \mathrm{E}+0 \mathrm{I}$ & $1.97 \mathrm{E}+01$ & $9.4 \mathrm{E}+00$ & $5.5 \mathrm{E}+00$ & $7 . \mathrm{IE}+00$ & 3.E-0I & 4.E-Ol & 4.E-0l & $2.4 \mathrm{E}+00$ & 4.E-0l \\
\hline
\end{tabular}

${ }^{2}$ nd $=$ below detection limit 
Table B-10 (continued)

Size-Segregated Elemental Concentrations of the Ohio Fly Ash Sampled at Port 4 (0.7 residence second)

d) Trace Element Uncertainties

\begin{tabular}{|c|c|c|c|c|c|c|c|c|c|c|c|c|}
\hline Impactor & Stage & $\mathrm{I}$ & 2 & 3 & 4 & 5 & 6 & 7 & 8 & 9 & 10 & II \\
\hline Cut-off & Diameter $(\mu \mathrm{m})$ & 0.0324 & 0.0636 & 0.0926 & 0.168 & 0.337 & 0.535 & 0.973 & 1.96 & 3.77 & 7.33 & 15.7 \\
\hline \multicolumn{13}{|l|}{ Element } \\
\hline As & & I.E +02 & $7 . \mathrm{E}+0 \mid$ & $5 . E+0 I$ & 7.E +02 & $3 . E+03$ & $4 . E+0 I$ & $6 . \mathrm{E}+0 \mathrm{I}$ & $4 . E+0 I$ & $4 . E+0 I$ & $2 . E+0 I$ & $6 . E+01$ \\
\hline Se & & $3 . E+01$ & $2 . \mathrm{E}+0 \mathrm{I}$ & $2 . \mathrm{E}+0 \mathrm{I}$ & $2 . \mathrm{E}+0 \mathrm{I}$ & $2 . \mathrm{E}+0 \mathrm{I}$ & $2 . \mathrm{E}+0 \mathrm{I}$ & $9 . \mathrm{E}+00$ & $7 . \mathrm{E}+00$ & $8 . E+00$ & $6 . \mathrm{E}+00$ & $9 . \mathrm{E}+00$ \\
\hline $\mathrm{Sb}$ & & I.E+0I & $7 . \mathrm{E}+00$ & $3 . \mathrm{E}+0 \mathrm{I}$ & $6 . \mathrm{E}+00$ & $5 . \mathrm{E}+02$ & $6 . \mathrm{E}+00$ & $I . E+0 \mid$ & $9 . \mathrm{E}+00$ & I.E+0I & $8 . \mathrm{E}+00$ & $3 . E+02$ \\
\hline $\mathrm{Co}_{0}$ & & $8 . E+00$ & $7 . E+00$ & $7 . \mathrm{E}+00$ & $4 . E+02$ & $2 . E+02$ & $6 . \mathrm{E}+00$ & $8 . E+00$ & $7 . \mathrm{E}+00$ & $8 . E+00$ & $5 . E+00$ & $2 . E+01$ \\
\hline Cs & & $8 . \mathrm{E}+00$ & $7 . \mathrm{E}+00$ & $6 . \mathrm{E}+00$ & $6 . \mathrm{E}+00$ & $6 . \mathrm{E}+00$ & $6 . \mathrm{E}+00$ & $6 . \mathrm{E}+00$ & $6 . \mathrm{E}+00$ & $6 . \mathrm{E}+00$ & $7 . \mathrm{E}+00$ & $7 . \mathrm{E}+00$ \\
\hline $\mathrm{Cl}$ & & $5 . E+02$ & $4 . \mathrm{E}+02$ & $4 . E+02$ & $4 . E+02$ & $4 . \mathrm{E}+02$ & $4 . \mathrm{E}+02$ & $4 . E+02$ & $4 . E+02$ & $4 . E+02$ & $5 . E+02$ & $5 . E+02$ \\
\hline Sc & & $3 . \mathrm{E}+00$ & $3 . \mathrm{E}+00$ & $3 . \mathrm{E}+00$ & $3 . \mathrm{E}+00$ & $3 . E+00$ & $3 . \mathrm{E}+00$ & $3 . E+00$ & $3 . \mathrm{E}+00$ & $3 . \mathrm{E}+00$ & $3 . E+00$ & $3 . \mathrm{E}+00$ \\
\hline $\mathrm{Ti}$ & & $7 . \mathrm{E}+02$ & $6 . \mathrm{E}+02$ & $6 . \mathrm{E}+02$ & $6 . \mathrm{E}+02$ & $6 . \mathrm{E}+02$ & $7 . \mathrm{E}+02$ & $6 . \mathrm{E}+02$ & $6 . \mathrm{E}+02$ & $6 . E+02$ & $7 . \mathrm{E}+02$ & $7 . \mathrm{E}+02$ \\
\hline V & & $3 . \mathrm{E}+02$ & $3 . E+02$ & $3 . E+02$ & $3 . \mathrm{E}+02$ & $3 . E+02$ & $3 . E+02$ & $3 . E+02$ & $3 . E+02$ & $3 . E+02$ & $3 . E+02$ & $3 . E+02$ \\
\hline $\mathrm{Cr}$ & & $3 . \mathrm{E}+02$ & $2 . E+02$ & $2 . E+02$ & $2 . \mathrm{E}+02$ & $2 . E+02$ & $2 . E+02$ & $2 . E+02$ & $2 . \mathrm{E}+02$ & $2 . E+02$ & $2 . E+02$ & $2 . \mathrm{E}+02$ \\
\hline $\mathrm{Mn}$ & & $2 . \mathrm{E}+02$ & $2 . E+02$ & $2 . E+02$ & $2 . \mathrm{E}+02$ & $2 . E+02$ & $2 . \mathrm{E}+02$ & $2 . \mathrm{E}+02$ & $2 . \mathrm{E}+02$ & $2 . \mathrm{E}+02$ & $2 . \mathrm{E}+02$ & $2 . \mathrm{E}+02$ \\
\hline ln & & $3 . \mathrm{E}+02$ & $3 . E+02$ & $3 . E+02$ & $3 . \mathrm{E}+02$ & $3 . \mathrm{E}+02$ & $3 . \mathrm{E}+02$ & $3 . \mathrm{E}+02$ & $3 . \mathrm{E}+02$ & $3 . \mathrm{E}+02$ & $3 . E+02$ & $3 . E+02$ \\
\hline $\mathrm{Ga}$ & & $2 . E+0 \mid$ & $2 . E+0 \mid$ & $\mathrm{I} . \mathrm{E}+0 \mathrm{I}$ & $|. E+0|$ & $\mathrm{I} . \mathrm{E}+0 \mathrm{I}$ & $\mathrm{I} . \mathrm{E}+0 \mathrm{I}$ & I.E +0 I & $\mathrm{I} . \mathrm{E}+0 \mathrm{I}$ & $\mathrm{I} . \mathrm{E}+0 \mathrm{I}$ & I.E+0I & $2 . E+0 I$ \\
\hline $\mathrm{Br}$ & & $8 . \mathrm{E}+0 \mathrm{I}$ & $8 . \mathrm{E}+0 \mathrm{I}$ & $8 . \mathrm{E}+0 \mathrm{I}$ & $8 . E+0 I$ & $8 . E+0 I$ & $8 . \mathrm{E}+0 \mathrm{I}$ & $7 . \mathrm{E}+0 \mid$ & 7.E+0I & $7 . \mathrm{E}+0 \mathrm{I}$ & $8 . E+0 I$ & $9 . E+01$ \\
\hline $\mathrm{Rb}$ & & I.E $+0 \mid$ & $7 . \mathrm{E}+00$ & $6 . \mathrm{E}+00$ & $5 . E+00$ & $6 . \mathrm{E}+00$ & $6 . \mathrm{E}+00$ & $5 . E+00$ & $5 . E+00$ & $5 . E+00$ & 7.E +00 & $5 . \mathrm{E}+00$ \\
\hline Mo & & $4 . \mathrm{E}+0 \mathrm{I}$ & $3 . \mathrm{E}+01$ & $3 . \mathrm{E}+01$ & $2 . \mathrm{E}+0 \mathrm{l}$ & $2 . \mathrm{E}+0 \mathrm{l}$ & $2 . \mathrm{E}+0 \mathrm{l}$ & $2 . \mathrm{E}+0 \mathrm{l}$ & $2 . \mathrm{E}+0 \mathrm{l}$ & $2 . \mathrm{E}+0 \mathrm{l}$ & $3 . \mathrm{E}+0 \mathrm{I}$ & $3 . E+01$ \\
\hline $\mathrm{Cd}$ & & $6 . \mathrm{E}+0 \mathrm{I}$ & $6 . \mathrm{E}+0 \mathrm{I}$ & $6 . \mathrm{E}+0 \mathrm{I}$ & $6 . \mathrm{E}+0 \mathrm{I}$ & $6 . \mathrm{E}+0 \mathrm{I}$ & $6 . \mathrm{E}+0 \mathrm{I}$ & $6 . \mathrm{E}+0 \mathrm{I}$ & $6 . \mathrm{E}+0 \mathrm{I}$ & $6 . \mathrm{E}+0 \mathrm{I}$ & $6 . \mathrm{E}+0 \mathrm{I}$ & $6 . \mathrm{E}+0 \mathrm{I}$ \\
\hline In & & 4.E-OI & 4.E-OI & 4.E-OI & 4.E-OI & 4.E-OI & 4.E-OI & 4.E-0I & 4.E-0I & 4.E-0I & 4.E-OI & 4.E-OI \\
\hline $\mathrm{Ba}$ & & $4 . E+0 I$ & $4 . E+0 I$ & $4 . E+0 I$ & $4 . E+0 I$ & $4 . E+0 I$ & $4 . E+0 I$ & $4 . E+0 I$ & $4 . E+0 I$ & $4 . E+0 I$ & $5 . \mathrm{E}+0 \mathrm{I}$ & $4 . E+0 I$ \\
\hline $\mathrm{La}$ & & $2 . E+00$ & $2 . E+00$ & $2 . E+00$ & $2 . E+00$ & $2 . E+00$ & $2 . E+00$ & $2 . E+00$ & $2 . E+00$ & $2 . E+00$ & $3 . E+00$ & $2 . E+00$ \\
\hline $\mathrm{Ce}$ & & I.E +0 I & $9 . E+00$ & $9 . E+00$ & $9 . E+00$ & $9 . E+00$ & $9 . E+00$ & $9 . \mathrm{E}+00$ & $9 . E+00$ & $9 . E+00$ & I.E +0 I & I.E $+0 \mathrm{O}$ \\
\hline $\mathrm{Nd}$ & & $3 . E+0 \mid$ & $3 . \mathrm{E}+0 \mid$ & $3 . \mathrm{E}+0 \mid$ & $3 . \mathrm{E}+0 \mathrm{l}$ & $3 . E+01$ & $3 . E+0 \mid$ & $3 . \mathrm{E}+0 \mid$ & $3 . \mathrm{E}+01$ & $3 . E+0 \mid$ & $3 . \mathrm{E}+0 \mathrm{I}$ & $3 . E+01$ \\
\hline Sm & & 5.E-Ol & 5.E-Ol & 5.E-Ol & 5.E-Ol & 5.E-Ol & 5.E-Ol & 5.E-Ol & 5.E-Ol & 5.E-0l & 6.E-Ol & 6.E-0l \\
\hline Eu & & 4.E-OI & 3.E-0l & 3.E-0I & 3.E-0I & 3.E-0I & 3.E-0I & 3.E-0I & 3.E-0I & 3.E-0I & 4.E-OI & 3.E-0I \\
\hline $\mathrm{Yb}$ & & I.E +00 & I.E +00 & I.E +00 & I.E +00 & I.E +00 & $\mathrm{I} . \mathrm{E}+00$ & I.E +00 & I.E +00 & $\mathrm{I} . \mathrm{E}+00$ & I.E +00 & I.E +00 \\
\hline Lu & & 2.E-0I & 2.E-0l & 2.E-0I & 2.E-0I & 2.E-0I & 2.E-0I & 2.E-0I & 2.E-0I & 2.E-0I & 2.E-0I & 2.E-0I \\
\hline $\mathrm{Au}$ & & 5.E-02 & 5.E-02 & 5.E-02 & 5.E-02 & 5.E-02 & 5.E-02 & 5.E-02 & 5.E-02 & 5.E-02 & 5.E-02 & 5.E-02 \\
\hline $\mathrm{Hg}$ & & 8.E-Ol & 7.E-0| & 7.E-0| & 7.E-0I & 7.E-Ol & 7.E-Ol & 7.E-0I & 7.E-Ol & 7.E-0I & 7.E-0I & 7.E-0I \\
\hline Th & & $2 . \mathrm{E}+00$ & $2 . E+00$ & $2 . \mathrm{E}+00$ & $2 . E+00$ & $2 . \mathrm{E}+00$ & $2 . \mathrm{E}+00$ & $2 . \mathrm{E}+00$ & $2 . \mathrm{E}+00$ & $2 . \mathrm{E}+00$ & $2 . \mathrm{E}+00$ & $2 . \mathrm{E}+00$ \\
\hline $\mathrm{U}$ & & $2 . \mathrm{E}+00$ & I.E +00 & 9.E-OI & 8.E-0I & 8.E-0I & $8 . \mathrm{E}-01$ & 7.E-0I & 7.E-0I & 7.E-0I & 9.E-01 & 8.E-0I \\
\hline
\end{tabular}


Table B-11

Size-Segregated Elemental Concentrations of the Ohio Fly Ash Sampled at Port 14 (3.2 residence second)

a) Major Species Results

\begin{tabular}{|c|c|c|c|c|c|c|c|c|c|c|c|c|}
\hline Impactor & Stage & I & 2 & 3 & 4 & 5 & 6 & 7 & 8 & 9 & 10 & II \\
\hline Cut-off & $\begin{array}{l}\text { Diameter } \\
\text { (microns) }\end{array}$ & 0.0324 & 0.0636 & 0.0926 & 0.168 & 0.337 & 0.535 & 0.973 & 1.96 & 3.77 & 7.33 & 15.7 \\
\hline Element & $\begin{array}{c}\text { Analytical } \\
\text { Method }\end{array}$ & & & & & & & & & & & \\
\hline $\begin{array}{l}\text { Total Mass Conc } \\
(\mathrm{g} / \mathrm{Nm} \wedge 3)\end{array}$ & Gravametric & $1.00 \mathrm{E}-03$ & $2.00 \mathrm{E}-03$ & $3.00 \mathrm{E}-03$ & $4.00 \mathrm{E}-03$ & $5.00 \mathrm{E}-03$ & $6.00 \mathrm{E}-03$ & $7.00 \mathrm{E}-03$ & $8.00 \mathrm{E}-03$ & $9.00 \mathrm{E}-03$ & I.00E-02 & I.10E-02 \\
\hline $\mathrm{SiO}_{2}(\mathrm{Wt} \%)$ & AAS & $4.3 \mathrm{E}+00$ & $I . E+0 \mid$ & $4 . E+00$ & $8.4 \mathrm{E}+00$ & $2.3 \mathrm{E}+0 \mathrm{I}$ & $1.8 \mathrm{E}+02$ & $1.6 \mathrm{E}+02$ & $2.7 \mathrm{E}+0 \mathrm{I}$ & $4.5 \mathrm{E}+0 \mathrm{I}$ & $4.2 \mathrm{E}+0 \mathrm{I}$ & $3 . \mathrm{E}+0 \mathrm{I}$ \\
\hline$+/-$ & & I.E +00 & 9.E-OI & 9.E-0I & I.E +00 & $4 . E+00$ & $8 . E+00$ & $2 . E+0 I$ & $3 . E+00$ & 7.E +00 & $4 . E+00$ & $7 . \mathrm{E}+00$ \\
\hline $\mathrm{Al}_{2} \mathrm{O}_{3}(\mathrm{Wt} \%)$ & NAA/AAS & 7.E-OI & 8.E-0I & 9.E-OI & I.E +00 & $2 . E+0 I$ & $3 . \mathrm{E}+0 \mathrm{I}$ & $3 . E+02$ & $1.7 \mathrm{E}+0 \mathrm{|}$ & $2.0 \mathrm{E}+0 \mathrm{I}$ & $2.4 \mathrm{E}+0 \mathrm{I}$ & $2.5 \mathrm{E}+0 \mathrm{I}$ \\
\hline$+/-$ & & 7.E-0I & 7.E-0I & 7.E-0I & 7.E-0I & $3 . \mathrm{E}+00$ & $2 . E+00$ & $3 . E+01$ & $4 . \mathrm{E}+0 \mathrm{I}$ & $4 . \mathrm{E}+0 \mathrm{I}$ & $2 . E+00$ & $6 . \mathrm{E}+00$ \\
\hline $\mathrm{Fe}_{2} \mathrm{O}_{3}(\mathrm{Wt} \%)$ & NAA/AAS & $5 . E+0 I$ & $2 . E+0 I$ & $2 . E+0 I$ & 7.E+0I & $2 . E+02$ & $8 . E+0 I$ & $2 . E+02$ & $3.10 \mathrm{E}+01$ & 2.E+0I & $3.07 \mathrm{E}+02$ & $2 . \mathrm{E}+0 \mathrm{I}$ \\
\hline$+/-$ & & $2 . E+00$ & $4 . E+0 I$ & $4 . E+0 I$ & $2 . E+00$ & $2 . E+0 I$ & $4 . E+00$ & $2 . E+0 I$ & $3 . E+00$ & $4 . E+0 I$ & $8 . E+02$ & 4.E+0I \\
\hline $\mathrm{Ca} 0(\mathrm{Wt} \%)$ & NAA/AAS & $5 . E+00$ & 3.E-0I & 3.E-OI & I.E+00 & $3 . \mathrm{E}+00$ & $2 . E+00$ & 3.E-OI & 7.E-0I & 9.E-0I & $\mathrm{I} . \mathrm{E}+00$ & 9.E-OI \\
\hline$+/-$ & & 5.E-0I & 4.E-OI & 4.E-OI & 4.E-OI & 8.E-0I & 5.E-0I & 4.E-0I & 3.E-OI & 3.E-0I & $3 . \mathrm{E}-0 \mathrm{I}$ & 4.E-OI \\
\hline $\mathrm{MgO}(\mathrm{Wt} \%)$ & NAA/AAS & $3.7 \mathrm{E}-0 \mathrm{I}$ & 7.E-02 & I.IE-0I & 3.E-OI & $1.6 \mathrm{E}+00$ & $\mathrm{I} .0 \mathrm{E}+00$ & $3.7 \mathrm{E}+00$ & $2.5 \mathrm{E}-0 \mathrm{I}$ & $3.9 \mathrm{E}-0 \mathrm{I}$ & $4.8 \mathrm{E}-0 \mathrm{I}$ & 5.E-0I \\
\hline$+/-$ & & 8.E-OI & 8.E-02 & 8.E-02 & 5.E-OI & 2.E-0I & $2 . E+00$ & 4.E-OI & 6.E-OI & 6.E-02 & 4.E-02 & I.E-OI \\
\hline $\mathrm{Na}_{2} \mathrm{O}(\mathrm{Wt} \%)$ & NAA/AAS & $9 . E+00$ & $6.5 \mathrm{E}-0 \mathrm{I}$ & I.E +00 & $2 . E+00$ & $1.6 \mathrm{E}+0 \mathrm{I}$ & $5 . E+00$ & $2 . E+0 I$ & I.E +00 & I.E+00 & I.E +00 & $2 . E+00$ \\
\hline$+/-$ & & $2 . E+0 I$ & I.E +00 & 2.E +00 & I.E-0| & $6 . \mathrm{E}+00$ & $I . E+0 \mid$ & $3 . E+00$ & 2.E-OI & $3 . E+00$ & 2.E-OI & 6.E-0I \\
\hline $\begin{array}{c}\text { Trace Elements } \\
(\mathrm{Wt} \%)\end{array}$ & NAA/GFAA & $\mathrm{I} . \mathrm{IE}+02$ & I.IE +02 & I.IE +02 & $\mathrm{I} . \mathrm{IE}+02$ & $1.7 \mathrm{E}+02$ & $1.3 \mathrm{E}+02$ & $\mathrm{I} . \mathrm{IE}+02$ & I.IE + 02 & $\mathrm{I} . \mathrm{IE}+02$ & $\mathrm{I} . \mathrm{IE}+02$ & I.IE +02 \\
\hline Total (Wt\%) & & 66 & 33 & 28 & 84 & 224 & 310 & 618 & 77 & 89 & 376 & 80 \\
\hline
\end{tabular}

Note: Elemental concentrations have been converted to oxide forms on a $\mathrm{SO}_{3}$-free basis. 
Table B-11 (continued)

Size-Segregated Elemental Concentrations of the Ohio Fly Ash Sampled at Port 14 (3.2 residence second)

b) Normalized Major Species Results

\begin{tabular}{|c|c|c|c|c|c|c|c|c|c|c|c|c|}
\hline Impactor & Stage & I & 2 & 3 & 4 & 5 & 6 & 7 & 8 & 9 & 10 & II \\
\hline Cut-off & $\begin{array}{l}\text { Diameter } \\
\text { (microns) }\end{array}$ & 0.0324 & 0.0636 & 0.0926 & 0.168 & 0.337 & 0.535 & 0.973 & 1.96 & 3.77 & 7.33 & 15.7 \\
\hline Element & $\begin{array}{c}\text { Analytical } \\
\text { Method }\end{array}$ & & & & & & & & & & & \\
\hline $\begin{array}{l}\text { Total Mass Conc } \\
(\mathrm{g} / \mathrm{Nm} \wedge 3)\end{array}$ & Gravametric & I.OE-03 & $2.0 \mathrm{E}-03$ & $3.0 \mathrm{E}-03$ & $4.0 \mathrm{E}-03$ & $5.0 \mathrm{E}-03$ & $6.0 \mathrm{E}-03$ & 7.0E-03 & $8.0 \mathrm{E}-03$ & $9.0 \mathrm{E}-03$ & I.0E-02 & I.IE-02 \\
\hline $\mathrm{SiO}_{2}(\mathrm{Wt} \%)$ & AAS & 6.5 & 36 & 13 & 10 & 10 & 59 & 25 & 35 & 51 & II & 39 \\
\hline $\mathrm{Al}_{2} \mathrm{O}_{3}(\mathrm{Wt} \%)$ & AAS & 1.1 & 2.5 & 3.2 & 1.6 & 8.4 & 9.3 & 41 & 22 & 22 & 6.4 & 31 \\
\hline $\mathrm{Fe}_{2} \mathrm{O}_{3}(\mathrm{Wt} \%)$ & AAS & 69 & 57 & 76 & 83 & 71 & 27 & 29 & 40 & 24 & 82 & 24 \\
\hline $\mathrm{CaO}(\mathrm{Wt} \%)$ & AAS & 7.7 & 0.82 & 1.2 & 1.7 & 1.3 & 0.75 & 0.047 & 0.86 & 0.97 & 0.27 & 1.1 \\
\hline $\mathrm{Mg0}(\mathrm{Wt} \%)$ & AAS & 0.56 & 0.21 & 0.42 & 0.36 & 0.73 & 0.34 & 0.60 & 0.32 & 0.43 & 0.13 & 0.61 \\
\hline $\mathrm{Na}_{2} \mathrm{O}(\mathrm{Wt} \%)$ & AES & 13.5 & 2.0 & 3.8 & 2.2 & 7.1 & 1.6 & 3.8 & 1.4 & 1.6 & 0.36 & 3.1 \\
\hline $\begin{array}{l}\text { Trace Elements } \\
(\mathrm{Wt} \%)\end{array}$ & GFAA & 1.2 & 1.4 & 2.1 & 0.85 & 1.3 & 1.3 & 0.066 & 0.091 & 0.22 & 0.036 & 0.25 \\
\hline Total (Wt\%) & & 100.00 & 100.00 & 100.00 & 100.00 & 100.00 & 100.00 & 100.00 & 100.00 & 100.00 & 100.00 & 100.00 \\
\hline
\end{tabular}


Table B-11 (continued)

Size-Segregated Elemental Concentrations of the Ohio Fly Ash Sampled at Port 14 (3.2 residence second)

c) Trace Element Concentrations

\begin{tabular}{|c|c|c|c|c|c|c|c|c|c|c|c|c|}
\hline Impactor & Stage & $\mathrm{I}$ & 2 & 3 & 4 & 5 & 6 & 7 & 8 & 9 & 10 & II \\
\hline Element: As & NAA/GFAA & $5 . E+02$ & $7 . \mathrm{E}+02$ & $6 . \mathrm{E}+02$ & $9 . E+02$ & $2 . \mathrm{E}+03$ & $8 . E+02$ & $3 . E+03$ & $9 . \mathrm{E}+01$ & $2 . \mathrm{E}+02$ & $2 . \mathrm{E}+02$ & $4 . E+02$ \\
\hline $\mathrm{Se}$ & NAA/GFAA & $3.0 \mathrm{E}+02$ & $1.8 \mathrm{E}+02$ & $3.4 \mathrm{E}+02$ & $3.0 \mathrm{E}+02$ & $2.4 \mathrm{E}+02$ & $1.3 \mathrm{E}+02$ & $7 . \mathrm{E}+0 \mathrm{I}$ & $7 . \mathrm{E}+00$ & $2.2 \mathrm{E}+01$ & $5 . E+00$ & $1.0 \mathrm{E}+0 \mathrm{I}$ \\
\hline $\mathrm{Sb}$ & NAA/GFAA & $1.24 \mathrm{E}+02$ & $1.90 \mathrm{E}+02$ & 6. $1 \mathrm{E}+02$ & $7.0 \mathrm{E}+0 \mathrm{I}$ & $1.4 \mathrm{E}+02$ & $\mathrm{I} . \mathrm{E}+02$ & 6.E-0I & 5.E-0l & $\mathrm{I} . \mathrm{E}+00$ & 6.E-0I & I.E +00 \\
\hline $\mathrm{Co}_{0}$ & NAA/GFAA & $4 . E+0 I$ & $9 . \mathrm{E}+00$ & $|.4 \mathrm{E}+0|$ & $2 . E+0 \mid$ & $3 . E+02$ & $9 . \mathrm{E}+0 \mathrm{I}$ & $3.2 \mathrm{E}+02$ & $4 . \mathrm{E}+00$ & $6 . \mathrm{E}+0 \mathrm{I}$ & $\mathrm{I} . \mathrm{E}+02$ & $4 . E+0 \mid$ \\
\hline Cs & NAA & $6 . \mathrm{E}+00$ & $6 . \mathrm{E}+00$ & $8 . E+00$ & $9 . \mathrm{E}+00$ & $1.5 \mathrm{E}+02$ & $2.3 \mathrm{E}+0 \mathrm{I}$ & 7.E-01 & 9.E-Ol & I.E +00 & I.E +00 & $2 . E+00$ \\
\hline $\mathrm{Cl}$ & NAA & $9 . E+02$ & $2 . \mathrm{E}+02$ & $3 . \mathrm{E}+02$ & $8 . \mathrm{E}+02$ & $3.6 \mathrm{E}+03$ & $1.7 \mathrm{E}+03$ & $2 . E+02$ & I.E +02 & $2 . \mathrm{E}+02$ & I.E +02 & $2 . E+02$ \\
\hline K & NAA & $2 . \mathrm{E}+03$ & I.E +03 & I.E +03 & I.E +03 & $n d^{3}$ & $1.2 \mathrm{E}+04$ & $2 . \mathrm{E}+02$ & $2 . \mathrm{E}+02$ & $5 . E+02$ & $4 . \mathrm{E}+02$ & $4 . E+02$ \\
\hline Sc & NAA & $2 . E+00$ & I.E +00 & $2 . E+00$ & $3 . E+00$ & $5.7 \mathrm{E}+0 \mathrm{I}$ & 9. $|E+0|$ & 5.E-0I & 5.E-0l & I.E +00 & I.E +00 & 5.E-0l \\
\hline $\mathrm{Ti}$ & NAA & $8 . E+02$ & $9 . \mathrm{E}+02$ & $1.3 \mathrm{E}+03$ & I.IE +03 & $1.10 \mathrm{E}+04$ & $1.69 \mathrm{E}+04$ & I.E +02 & $1 . E+02$ & $3 . \mathrm{E}+02$ & $2 . \mathrm{E}+02$ & I.E +02 \\
\hline $\mathrm{V}$ & NAA & $8.6 \mathrm{E}+0 \mathrm{I}$ & $1.35 \mathrm{E}+02$ & $1.53 \mathrm{E}+02$ & $1.48 \mathrm{E}+02$ & $4.21 \mathrm{E}+02$ & $4.60 \mathrm{E}+02$ & $6 . \mathrm{E}+00$ & $5 . E+00$ & $\mathrm{I} . \mathrm{IE}+0 \mathrm{I}$ & $9 . \mathrm{E}+00$ & $4 . E+00$ \\
\hline $\mathrm{Cr}$ & NAA & $1.9 \mathrm{E}+03$ & $4 . \mathrm{E}+02$ & $5 . E+02$ & $1.3 \mathrm{E}+03$ & $5.6 \mathrm{E}+03$ & $2.7 \mathrm{E}+03$ & $2 . E+02$ & I.E+02 & $2 . \mathrm{E}+02$ & $2 . E+02$ & $6 . E+02$ \\
\hline $\mathrm{Mn}$ & NAA & $1 . E+02$ & $4 . \mathrm{E}+0 \mathrm{I}$ & $5 . E+01$ & $5 . E+0 \mid$ & $2 . E+02$ & $2 . E+02$ & $6 . \mathrm{E}+00$ & $4 . E+00$ & $\mathrm{I} . \mathrm{E}+0 \mathrm{I}$ & $9 . E+00$ & $8 . E+00$ \\
\hline $\mathrm{Zn}$ & NAA & $2 . E+02$ & $6 . \mathrm{E}+0 \mathrm{I}$ & $8 . \mathrm{E}+0 \mathrm{I}$ & I.E +02 & $6 . \mathrm{E}+02$ & $6 . \mathrm{E}+02$ & $3 . E+0 \mid$ & $2 . \mathrm{E}+0 \mathrm{I}$ & $3 . \mathrm{E}+02$ & $\mathrm{I} . \mathrm{E}+0 \mathrm{I}$ & $2 . \mathrm{E}+02$ \\
\hline $\mathrm{Ga}$ & NAA & $6 . \mathrm{E}+0 \mathrm{I}$ & $1.6 \mathrm{E}+02$ & $1.8 \mathrm{E}+02$ & $1.3 \mathrm{E}+02$ & $1.8 \mathrm{E}+02$ & $1.7 \mathrm{E}+02$ & nd & nd & $3 . \mathrm{E}+00$ & nd & nd \\
\hline $\mathrm{Br}$ & NAA & $1.0 \mathrm{E}+02$ & $6 . \mathrm{E}+0 \mathrm{I}$ & $1.0 \mathrm{E}+02$ & $2.4 \mathrm{E}+02$ & $1.7 \mathrm{E}+03$ & $6 . \mathrm{E}+02$ & $8 . \mathrm{E}+00$ & $6 . \mathrm{E}+00$ & I.E $+0 \mid$ & $8 . E+00$ & $9 . E+00$ \\
\hline $\mathrm{Rb}$ & NAA & nd & nd & $1.5 \mathrm{E}+0 \mid$ & $2.5 \mathrm{E}+0 \mathrm{I}$ & nd & $8 .|E+0|$ & nd & nd & nd & $4 . E+00$ & nd \\
\hline $\mathrm{Sr}$ & NAA & nd & $3 . \mathrm{E}+0 \mathrm{I}$ & $3 . \mathrm{E}+0 \mathrm{I}$ & $5 . E+0 \mid$ & $4 . E+02$ & $6 . \mathrm{E}+02$ & $\mathrm{I} . \mathrm{E}+0 \mathrm{O}$ & $5 . \mathrm{E}+00$ & $3 . \mathrm{E}+0 \mathrm{I}$ & $2 . \mathrm{E}+0 \mathrm{I}$ & $|. E+0|$ \\
\hline Mo & NAA & $3.1 \mathrm{E}+02$ & $2.5 \mathrm{E}+02$ & $2.6 \mathrm{E}+02$ & $2.3 \mathrm{E}+02$ & $3.2 \mathrm{E}+02$ & $2.0 \mathrm{E}+02$ & $2 . E+00$ & $2 . E+00$ & $6 . \mathrm{E}+00$ & $5 . \mathrm{E}+00$ & $4 . E+00$ \\
\hline$C d$ & NAA & $4 . E+0 I$ & $3 . \mathrm{E}+0 \mathrm{I}$ & $3 . E+01$ & $5 . E+0 \mid$ & $6 . \mathrm{E}+02$ & $\mathrm{I} .0 \mathrm{E}+03$ & $2 . E+0 \mid$ & $3 . \mathrm{E}+0 \mathrm{I}$ & $2 . \mathrm{E}+0 \mathrm{I}$ & $7 . \mathrm{E}+\mathrm{OI}$ & $2 . E+01$ \\
\hline $\ln$ & NAA & 4.E-0I & 2.E-0l & 3.E-0l & 3.E-0I & I.E +00 & 8.E-0I & 2.E-02 & 2.E-02 & 2.E-02 & nd & nd \\
\hline $\mathrm{Ba}$ & NAA & $8 . \mathrm{E}+0 \mathrm{I}$ & $9 . E+01$ & $1.5 \mathrm{E}+02$ & $1.6 \mathrm{E}+02$ & $7 . \mathrm{E}+02$ & $9.4 \mathrm{E}+02$ & I.E $+0 \mathrm{I}$ & $5 . E+00$ & $3 . \mathrm{E}+0 \mathrm{I}$ & $|. E+0|$ & nd \\
\hline $\mathrm{La}$ & NAA & $2 . \mathrm{E}+00$ & I.E +00 & I.E +00 & $3 . \mathrm{E}+00$ & $8 . E+0 I$ & I.4IE +02 & 9.E-0I & I.E +00 & $3 . \mathrm{E}+00$ & $3 . \mathrm{E}+00$ & I.E +00 \\
\hline $\mathrm{Ce}$ & NAA & nd & $5 . \mathrm{E}+00$ & $8 . E+00$ & $|. E+0|$ & $1.5 \mathrm{E}+02$ & $2.8 \mathrm{E}+02$ & $\mathrm{I} . \mathrm{E}+00$ & $2 . \mathrm{E}+00$ & $6 . \mathrm{E}+00$ & $6 . \mathrm{E}+00$ & I.E +00 \\
\hline $\mathrm{Nd}$ & NAA & $4 . \mathrm{E}+0 \mathrm{I}$ & I.E+0| & $2 . \mathrm{E}+0 \mathrm{I}$ & $2 . E+0 I$ & $2.0 \mathrm{E}+02$ & I.IE +02 & $3 . \mathrm{E}+00$ & $4 . \mathrm{E}+00$ & $3 . \mathrm{E}+00$ & $4 . \mathrm{E}+00$ & $9 . E+00$ \\
\hline Sm & NAA & 3.E-0I & 4.E-0I & 5.E-0I & 9.E-0I & $5 . \mathrm{E}+00$ & $3 . \mathrm{IE}+0 \mathrm{I}$ & 2.E-0I & 2.E-0I & 6.E-0l & 6.E-0l & 2.E-0I \\
\hline $\mathrm{Eu}$ & NAA & nd & 3.E-01 & 5.E-OI & 9.E-OI & $5 . E+00$ & $6.8 \mathrm{E}+00$ & I.E-OI & 5.E-02 & nd & 2.E-OI & 2.E-OI \\
\hline $\mathrm{Yb}$ & NAA & nd & nd & nd & nd & I.IE $+0 \mid$ & $2.0 \mathrm{E}+0 \mathrm{I}$ & 2.E-Ol & 2.E-OI & 5.E-0l & 4.E-0l & 3.E-0I \\
\hline Lu & NAA & 0 & I.E-0l & I.E-0| & I.E-0| & $2.4 \mathrm{E}+00$ & $4.3 \mathrm{E}+00$ & 2.E-02 & 2.E-02 & 8.E-02 & 6.E-02 & nd \\
\hline $\mathrm{Au}$ & NAA & 3.E-02 & I.E-02 & 2.E-02 & 2.E-02 & 5.E-02 & 2.E-02 & 2.E-03 & 2.E-03 & 3.E-03 & 2.E-02 & 2.E-03 \\
\hline $\mathrm{Hg}$ & NAA & 8.E-Ol & nd & 5.E-0l & I.E +00 & $8 . \mathrm{E}+00$ & $3.0 \mathrm{E}+00$ & 3.E-0I & 3.E-0I & 5.E-0l & 3.E-Ol & 5.E-0l \\
\hline Th & NAA & nd & 6.E-OI & I.E +00 & I.E +00 & $2.7 \mathrm{E}+01$ & $4.0 \mathrm{E}+0 \mathrm{O}$ & 2.E-OI & 2.E-OI & 7.E-OI & 5.E-0l & 4.E-0I \\
\hline U & NAA & $2.7 \mathrm{E}+00$ & $5.6 \mathrm{E}+00$ & $6.6 \mathrm{E}+00$ & $3.8 \mathrm{E}+00$ & $3.2 \mathrm{E}+0 \mathrm{I}$ & $7.5 \mathrm{E}+0 \mathrm{I}$ & I.E-OI & 5.E-02 & 6.E-01 & nd & I.E-0l \\
\hline
\end{tabular}

${ }^{3}$ nd $=$ below detection limit 
Table B-11 (continued)

Size-Segregated Elemental Concentrations of the Ohio Fly Ash Sampled at Port 14 (3.2 residence second)

d) Trace Element Uncertainties

\begin{tabular}{|c|c|c|c|c|c|c|c|c|c|c|c|c|}
\hline Impactor & Stage & I & 2 & 3 & 4 & 5 & 6 & 7 & 8 & 9 & 10 & II \\
\hline Cut-off & Diameter $(\mu \mathrm{m})$ & 0.0324 & 0.0636 & 0.0926 & 0.168 & 0.337 & 0.535 & 0.973 & 1.96 & 3.77 & 7.33 & 15.7 \\
\hline \multicolumn{13}{|l|}{ Element } \\
\hline As & & $3 . \mathrm{E}+02$ & $4 . \mathrm{E}+02$ & I.E +03 & I.E +03 & $3 . \mathrm{E}+03$ & $6 . \mathrm{E}+02$ & $8 . \mathrm{E}+03$ & $2 . \mathrm{E}+02$ & $4 . E+02$ & $4 . E+02$ & $9 . E+01$ \\
\hline $\mathrm{Se}$ & & $3 . \mathrm{E}+0 \mathrm{I}$ & $2 . E+01$ & $2 . E+01$ & $3 . \mathrm{E}+0 \mathrm{I}$ & $5 . \mathrm{E}+0 \mathrm{I}$ & $2 . \mathrm{E}+0 \mathrm{I}$ & $2 . \mathrm{E}+02$ & $5 . E+00$ & $7 . \mathrm{E}+00$ & $5 . E+00$ & $7 . \mathrm{E}+00$ \\
\hline $\mathrm{Sb}$ & & $8 . E+00$ & $6 . \mathrm{E}+00$ & $\mathrm{I} . \mathrm{E}+0 \mathrm{O}$ & $6 . E+00$ & $2 . \mathrm{E}+0 \mathrm{I}$ & $2 . E+02$ & $3 . E+00$ & $3 . E+00$ & $3 . E+00$ & $3 . E+00$ & $3 . E+00$ \\
\hline$C_{0}$ & & $8 . E+0 I$ & $7 . \mathrm{E}+00$ & $7 . \mathrm{E}+00$ & $8 . E+00$ & $6 . \mathrm{E}+02$ & I.E+0I & $4 . E+0 I$ & $7 . \mathrm{E}+00$ & I.E+0I & $3 . E+02$ & $|. E+0|$ \\
\hline Cs & & $6 . \mathrm{E}+00$ & $6 . \mathrm{E}+00$ & $6 . \mathrm{E}+00$ & $6 . \mathrm{E}+00$ & $3 . \mathrm{E}+01$ & $7 . \mathrm{E}+00$ & $6 . \mathrm{E}+00$ & $6 . \mathrm{E}+00$ & $6 . \mathrm{E}+00$ & $6 . \mathrm{E}+00$ & $7 . \mathrm{E}+00$ \\
\hline $\mathrm{Cl}$ & & $4 . E+02$ & $4 . E+02$ & $4 . E+02$ & $4 . E+02$ & $9 . E+02$ & $5 . E+02$ & $4 . E+02$ & $4 . E+02$ & $4 . E+02$ & $4 . E+02$ & $5 . E+02$ \\
\hline Sc & & $3 . E+00$ & $3 . E+00$ & $3 . E+00$ & $3 . E+00$ & I.E+0I & $6 . \mathrm{E}+00$ & $3 . E+00$ & $3 . E+00$ & $3 . E+00$ & $3 . E+00$ & $3 . E+00$ \\
\hline $\mathrm{Ti}$ & & $7 . \mathrm{E}+02$ & $6 . \mathrm{E}+02$ & $7 . \mathrm{E}+02$ & $7 . \mathrm{E}+02$ & $2 . \mathrm{E}+03$ & I.E +03 & $6 . \mathrm{E}+02$ & $6 . \mathrm{E}+02$ & $7 . \mathrm{E}+02$ & $7 . \mathrm{E}+02$ & $7 . \mathrm{E}+02$ \\
\hline V & & $5 . E+00$ & $5 . E+00$ & $6 . \mathrm{E}+00$ & $6 . E+00$ & $5 . E+00$ & $9 . E+00$ & $5 . E+00$ & $5 . E+00$ & $5 . E+00$ & $6 . \mathrm{E}+00$ & $5 . \mathrm{E}+00$ \\
\hline $\mathrm{Cr}$ & & $2 . \mathrm{E}+02$ & $2 . E+02$ & $2 . \mathrm{E}+02$ & $2 . \mathrm{E}+02$ & $9 . \mathrm{E}+02$ & $3 . \mathrm{E}+02$ & $2 . E+02$ & $2 . E+02$ & $2 . \mathrm{E}+02$ & $2 . E+02$ & $3 . E+02$ \\
\hline $\mathrm{Mn}$ & & $2 . E+02$ & $2 . E+02$ & $2 . E+02$ & $2 . E+02$ & $2 . E+02$ & $2 . E+02$ & $2 . \mathrm{E}+02$ & $2 . E+02$ & $2 . E+02$ & $2 . \mathrm{E}+02$ & $2 . E+02$ \\
\hline $\ln$ & & $3 . E+02$ & $3 . E+02$ & $3 . E+02$ & $3 . E+02$ & $4 . E+02$ & $3 . \mathrm{E}+02$ & $3 . E+02$ & $3 . E+02$ & $3 . \mathrm{E}+02$ & $3 . E+02$ & $3 . \mathrm{E}+02$ \\
\hline $\mathrm{Ga}$ & & $2 . \mathrm{E}+0 \mathrm{I}$ & $|. E+0|$ & $2 . \mathrm{E}+0 \mid$ & $2 . \mathrm{E}+0 \mathrm{I}$ & $4 . E+0 I$ & $2 . E+01$ & $|. E+0|$ & $|. E+0|$ & I.E+0I & $|. E+0|$ & $|. E+0|$ \\
\hline $\mathrm{Br}$ & & $8 . E+0 I$ & $8 . E+01$ & $8 . E+01$ & $8 . E+0 l$ & $3 . E+02$ & I.E +02 & $8 . \mathrm{E}+0 \mathrm{I}$ & $7 . \mathrm{E}+0 \mathrm{I}$ & $8 . \mathrm{E}+0 \mathrm{I}$ & $8 . \mathrm{E}+0 \mathrm{I}$ & $8 . E+01$ \\
\hline $\mathrm{Rb}$ & & $5 . \mathrm{E}+00$ & $5 . \mathrm{E}+00$ & $6 . \mathrm{E}+00$ & $6 . \mathrm{E}+00$ & $5 . \mathrm{E}+00$ & $9 . \mathrm{E}+00$ & $5 . \mathrm{E}+00$ & $5 . \mathrm{E}+00$ & $5 . \mathrm{E}+00$ & $6 . \mathrm{E}+00$ & $5 . \mathrm{E}+00$ \\
\hline Mo & & $3 . \mathrm{E}+01$ & $3 . \mathrm{E}+01$ & $3 . E+01$ & $3 . \mathrm{E}+01$ & $7 . \mathrm{E}+0 \mid$ & $3 . \mathrm{E}+01$ & $2 . \mathrm{E}+01$ & $2 . \mathrm{E}+0 \mathrm{I}$ & $2 . \mathrm{E}+0 \mathrm{I}$ & $2 . \mathrm{E}+0 \mathrm{I}$ & $2 . \mathrm{E}+0 \mathrm{I}$ \\
\hline $\mathrm{Cd}$ & & $6 . \mathrm{E}+0 \mathrm{I}$ & $6 . \mathrm{E}+0 \mathrm{I}$ & $6 . \mathrm{E}+0 \mathrm{I}$ & $6 . \mathrm{E}+0 \mathrm{l}$ & I.E +02 & $\mathrm{I} . \mathrm{E}+02$ & $6 . \mathrm{E}+0 \mathrm{I}$ & $6 . \mathrm{E}+0 \mathrm{l}$ & $6 . \mathrm{E}+0 \mathrm{I}$ & $6 . \mathrm{E}+0 \mathrm{I}$ & $6 . \mathrm{E}+0 \mathrm{l}$ \\
\hline In & & 4.E-0I & 4.E-0I & 4.E-OI & 4.E-0I & 5.E-Ol & 4.E-OI & 4.E-0I & 4.E-OI & 4.E-OI & 4.E-OI & 4.E-0I \\
\hline $\mathrm{Ba}$ & & $4 . \mathrm{E}+0 \mathrm{I}$ & $4 . \mathrm{E}+0 \mathrm{I}$ & $4 . \mathrm{E}+0 \mathrm{I}$ & $4 . E+0 I$ & I.E +02 & $8 . \mathrm{E}+0 \mathrm{I}$ & $4 . E+0 I$ & $4 . E+0 I$ & $4 . E+0 I$ & $4 . E+0 I$ & $4 . E+0 I$ \\
\hline $\mathrm{La}$ & & $2 . \mathrm{E}+00$ & $2 . \mathrm{E}+00$ & $2 . E+00$ & $2 . E+00$ & I.E+0I & $7 . \mathrm{E}+00$ & $2 . E+00$ & $2 . E+00$ & $2 . E+00$ & $2 . \mathrm{E}+00$ & $2 . \mathrm{E}+00$ \\
\hline $\mathrm{Ce}$ & & $9 . E+00$ & $9 . E+00$ & $9 . \mathrm{E}+00$ & $\mathrm{I} . \mathrm{E}+0 \mathrm{I}$ & $3 . E+01$ & $2 . E+01$ & $9 . E+00$ & $9 . E+00$ & I.E+0I & $I . E+0 \mid$ & $9 . E+00$ \\
\hline $\mathrm{Nd}$ & & $3 . E+0 \mid$ & $3 . E+0 \mid$ & $3 . E+0 \mid$ & $3 . E+0 \mid$ & $5 . E+0 I$ & $3 . E+0 \mid$ & $3 . E+0 \mid$ & $3 . E+0 \mid$ & $3 . E+0 \mid$ & $3 . E+0 I$ & $3 . E+01$ \\
\hline Sm & & 5.E-Ol & 5.E-Ol & 5.E-Ol & 5.E-Ol & I.E +00 & $2 . E+00$ & 5.E-Ol & 5.E-Ol & 5.E-OI & 5.E-Ol & 5.E-OI \\
\hline Eu & & 3.E-Ol & 3.E-Ol & 3.E-Ol & 3.E-OI & I.E +00 & 6.E-Ol & 3.E-OI & 3.E-Ol & 3.E-0I & 3.E-OI & 4.E-OI \\
\hline $\mathrm{Yb}$ & & I.E +00 & I.E +00 & I.E +00 & I.E +00 & $3 . E+00$ & $2 . E+00$ & I.E +00 & I.E +00 & I.E +00 & I.E +00 & I.E +00 \\
\hline Lu & & 2.E-0I & 2.E-0l & 2.E-0l & 2.E-OI & 5.E-Ol & 3.E-0I & 2.E-Ol & 2.E-Ol & 2.E-0I & 2.E-Ol & 2.E-OI \\
\hline $\mathrm{Au}$ & & 5.E-02 & 5.E-02 & 5.E-02 & 5.E-02 & 6.E-02 & 5.E-02 & 5.E-02 & 5.E-02 & 5.E-02 & 5.E-02 & 5.E-02 \\
\hline $\mathrm{Hg}$ & & 7.E-0l & 7.E-01 & 7.E-0l & 7.E-0I & $2 . \mathrm{E}+00$ & 8.E-0I & 7.E-0I & 7.E-0I & 7.E-0I & 7.E-0I & 8.E-0I \\
\hline Th & & $2 . \mathrm{E}+00$ & $2 . \mathrm{E}+00$ & $2 . \mathrm{E}+00$ & $2 . E+00$ & $6 . \mathrm{E}+00$ & $4 . \mathrm{E}+00$ & $2 . E+00$ & $2 . E+00$ & $2 . \mathrm{E}+00$ & $2 . \mathrm{E}+00$ & $2 . E+00$ \\
\hline $\mathrm{U}$ & & 8.E-0I & 8.E-0I & 8.E-0I & 8.E-0I & $5 . E+00$ & $4 . E+00$ & 7.E-0I & 7.E-0I & 8.E-01 & 7.E-0I & 8.E-0I \\
\hline
\end{tabular}


Table B-12

Size-Segregated Elemental Concentrations of the Ohio Fly Ash Sampled at the Baghouse Inlet Port

a) Trace Element Concentrations

\begin{tabular}{|c|c|c|c|c|c|c|c|c|c|c|c|c|}
\hline Impactor & Stage & I & 2 & 3 & 4 & 5 & 6 & 7 & 8 & 9 & 10 & II \\
\hline Cut-off & $\begin{array}{l}\text { Diameter } \\
\text { (microns) }\end{array}$ & 0.0324 & 0.0636 & 0.0926 & 0.168 & 0.337 & 0.535 & 0.973 & 1.96 & 3.77 & 7.33 & 15.7 \\
\hline Element & $\begin{array}{c}\text { Analytical } \\
\text { Method }\end{array}$ & & & & & & & & & & & \\
\hline As & GFAA & nd & $2.2 \mathrm{E}+02$ & $4.9 \mathrm{E}+02$ & $5 . \mathrm{IE}+02$ & $3.7 \mathrm{E}+02$ & $4 . \mathrm{IE}+02$ & $3.4 \mathrm{E}+02$ & $2.6 \mathrm{E}+02$ & $1.6 \mathrm{E}+02$ & $7.4 \mathrm{E}+0 \mathrm{I}$ & $6.2 \mathrm{E}+0 \mathrm{I}$ \\
\hline $\mathrm{Se}$ & GFAA & nd & $1.5 \mathrm{E}+02$ & $1.4 \mathrm{E}+02$ & $2.2 \mathrm{E}+02$ & I.IE +02 & $5.4 \mathrm{E}+0 \mathrm{I}$ & $2.3 \mathrm{E}+0 \mathrm{I}$ & $1.9 \mathrm{E}+0 \mid$ & $2.3 \mathrm{E}+0 \mathrm{I}$ & $9.6 \mathrm{E}+00$ & $9.0 \mathrm{E}+00$ \\
\hline $\mathrm{Sb}$ & GFAA & nd & $1.5 \mathrm{E}+0 \mathrm{I}$ & $3.4 \mathrm{E}+01$ & $8.5 \mathrm{E}+01$ & $5 . I E+0 I$ & $4.3 \mathrm{E}+0 \mathrm{I}$ & $3.3 \mathrm{E}+01$ & $2.4 \mathrm{E}+0 \mathrm{I}$ & $2.7 \mathrm{E}+0 \mathrm{I}$ & $|.3 \mathrm{E}+0|$ & $3.0 \mathrm{E}+0 \mathrm{I}$ \\
\hline
\end{tabular}

nd $=$ below detection limit

b) Trace Element Uncertainties

\begin{tabular}{|c|c|c|c|c|c|c|c|c|c|c|c|c|}
\hline Impactor & Stage & I & 2 & 3 & 4 & 5 & 6 & 7 & 8 & 9 & 10 & II \\
\hline Cut-off & $\begin{array}{l}\text { Diameter } \\
\text { (microns) }\end{array}$ & 0.0324 & 0.0636 & 0.0926 & 0.168 & 0.337 & 0.535 & 0.973 & 1.96 & 3.77 & 7.33 & 15.7 \\
\hline Element & $\begin{array}{c}\text { Analytical } \\
\text { Method }\end{array}$ & & & & & & & & & & & \\
\hline As & & $5.3 \mathrm{E}+00$ & $7.6 \mathrm{E}+00$ & $2.0 \mathrm{E}+0 \mathrm{I}$ & $3.4 \mathrm{E}+0 \mathrm{I}$ & $3.7 \mathrm{E}+0 \mathrm{I}$ & $2.8 \mathrm{E}+0 \mathrm{I}$ & $1.3 \mathrm{E}+0 \mid$ & $9.7 \mathrm{E}+00$ & $9.7 \mathrm{E}+00$ & $6.0 \mathrm{E}+00$ & $6.1 E+00$ \\
\hline $\mathrm{Se}$ & & $4.4 \mathrm{E}+00$ & $6.0 \mathrm{E}+00$ & $8.7 \mathrm{E}+00$ & $|.7 \mathrm{E}+0|$ & $1.4 \mathrm{E}+0 \mid$ & $7.4 \mathrm{E}+00$ & $4.9 \mathrm{E}+00$ & $4.7 \mathrm{E}+00$ & $5.0 \mathrm{E}+00$ & $4.5 \mathrm{E}+00$ & $4.5 \mathrm{E}+00$ \\
\hline $\mathrm{Sb}$ & & $5.9 \mathrm{E}+00$ & $6.0 \mathrm{E}+00$ & $6.9 \mathrm{E}+00$ & I.IE+0I & $1.0 \mathrm{E}+0 \mathrm{I}$ & $8.3 \mathrm{E}+00$ & $6.6 \mathrm{E}+00$ & $6.3 \mathrm{E}+00$ & $6.6 \mathrm{E}+00$ & $6.0 \mathrm{E}+00$ & $6.3 \mathrm{E}+00$ \\
\hline Co & & $3.7 \mathrm{E}+00$ & $3.8 \mathrm{E}+00$ & $4.0 \mathrm{E}+00$ & $5.0 \mathrm{E}+00$ & $7.0 \mathrm{E}+00$ & $6.7 \mathrm{E}+00$ & $4.3 \mathrm{E}+00$ & $4 . I E+00$ & $4.2 \mathrm{E}+00$ & $3.8 \mathrm{E}+00$ & $3.9 \mathrm{E}+00$ \\
\hline
\end{tabular}


Table B-13

Size-Segregated Elemental Concentrations of the Wyodak Fly Ash Sampled at Port 4 (1.4 residence second)

a) Major Species Results

\begin{tabular}{|c|c|c|c|c|c|c|c|c|c|c|c|c|}
\hline Impactor & Stage & I & 2 & 3 & 4 & 5 & 6 & 7 & 8 & 9 & 10 & II \\
\hline Cut-off & $\begin{array}{l}\text { Diameter } \\
\text { (microns) }\end{array}$ & 0.0324 & 0.0636 & 0.0926 & 0.168 & 0.337 & 0.535 & 0.973 & 1.96 & 3.77 & 7.33 & 15.7 \\
\hline Element & $\begin{array}{l}\text { Analytical } \\
\text { Method }\end{array}$ & & & & & & & & & & & \\
\hline $\begin{array}{c}\text { Total Mass Conc } \\
\left(\mathrm{g} / \mathrm{Nm}^{\wedge} 3\right)\end{array}$ & Gravametric & I.07E-02 & $1.29 \mathrm{E}-02$ & I.91E-02 & $2.56 \mathrm{E}-02$ & I.75E-02 & $2.79 \mathrm{E}-02$ & $5.3 \mathrm{IE}-02$ & $9.69 \mathrm{E}-02$ & $9.8 \mathrm{IE}-02$ & I.72E-0I & $4.60 \mathrm{E}-02$ \\
\hline $\mathrm{SiO}_{2}(\mathrm{Wt} \%)$ & AAS & nd & nd & nd & $2.6 \mathrm{E}+00$ & $6 . \mathrm{E}+00$ & $2.3 \mathrm{E}+0 \mathrm{I}$ & $7.6 \mathrm{E}+0 \mathrm{I}$ & $1.4 \mathrm{IE}+02$ & $1.3 \mathrm{IE}+02$ & $3.28 \mathrm{E}+02$ & $1.06 \mathrm{E}+02$ \\
\hline$+/-$ & & & & & 9.E-0I & I.E +00 & $2 . E+00$ & $2 . E+00$ & $2 . \mathrm{E}+00$ & $2 . E+00$ & $3 . E+00$ & $4 . E+00$ \\
\hline $\mathrm{Al}_{2} \mathrm{O}_{3}(\mathrm{Wt} \%)$ & NAA/AAS & $1.3 \mathrm{E}+00$ & 3.E-0I & I.IE +00 & $3 . \mathrm{E}+00$ & $4 . E+00$ & $2.7 \mathrm{E}+0 \mathrm{I}$ & $1.22 \mathrm{E}+02$ & $1.79 \mathrm{E}+02$ & $1.4 \mathrm{E}+02$ & $2 . E+02$ & $9.4 \mathrm{E}+01$ \\
\hline$+/-$ & & 4.E-OI & 4.E-OI & 4.E-OI & I.E +00 & $6 . \mathrm{E}+00$ & I.E +00 & $2 . E+00$ & $2 . \mathrm{E}+00$ & $5 . E+0 I$ & $3 . E+02$ & $3 . E+00$ \\
\hline $\mathrm{Fe}_{2} \mathrm{O}_{3}(\mathrm{Wt} \%)$ & NAA/AAS & $1.5 \mathrm{E}+00$ & nd & 8.E-0I & $2.3 \mathrm{E}+00$ & $2.5 \mathrm{E}+00$ & $9.0 \mathrm{E}+00$ & $2.87 \mathrm{E}+0 \mathrm{I}$ & $4 . \mathrm{E}+0 \mathrm{I}$ & $4.29 \mathrm{E}+01$ & $9.758 \mathrm{E}+01$ & $2.06 \mathrm{E}+01$ \\
\hline$+/-$ & & 6.E-0I & & 7.E-0I & 7.E-0I & 5.E-0I & 7.E-0I & 8.E-0I & $4 . \mathrm{E}+0 \mathrm{I}$ & 8.E-0I & 8.E-0I & 9.E-OI \\
\hline $\mathrm{Ca} 0(\mathrm{Wt} \%)$ & NAA/AAS & $2.8 \mathrm{E}+00$ & 5.E-OI & $1.0 \mathrm{E}+00$ & $\mathrm{I} . \mathrm{IE}+00$ & $2.4 \mathrm{E}+00$ & I.E+0I & $3.40 \mathrm{E}+0 \mathrm{I}$ & $1.44 \mathrm{E}+02$ & $4 . \mathrm{E}+0 \mathrm{I}$ & $5.02 \mathrm{E}+02$ & $7.0 \mathrm{E}+0 \mathrm{I}$ \\
\hline$+/-$ & & 5.E-0I & 2.E-OI & 3.E-0I & 4.E-0I & 5.E-Ol & 6.E-0I & 8.E-01 & $2 . E+00$ & $8 . E+0 I$ & $2 . \mathrm{E}+00$ & I.E+00 \\
\hline $\mathrm{MgO}(\mathrm{Wt} \%)$ & NAA/AAS & $2.3 \mathrm{E}-0 \mathrm{I}$ & 4.E-02 & 2.E-OI & I.E-OI & $2.7 \mathrm{E}-0 \mathrm{I}$ & $2.07 \mathrm{E}+00$ & $6.9 \mathrm{E}+00$ & 7.E +00 & $9.4 \mathrm{E}+00$ & I.E+OI & $5.9 \mathrm{E}+00$ \\
\hline$+/-$ & & 3.E-02 & I.E-02 & 3.E-0I & I.E-0| & 2.E-02 & 8.E-02 & I.E-0| & $6 . \mathrm{E}+00$ & I.E-OI & $2 . \mathrm{E}+0 \mathrm{I}$ & 2.E-OI \\
\hline $\mathrm{Na}_{2} \mathrm{O}(\mathrm{Wt} \%)$ & NAA/AAS & I.IE +00 & 3.E-OI & 7.E-OI & 4.E-OI & 7.E-0I & $2.9 \mathrm{E}+00$ & $6.8 \mathrm{E}+00$ & $6.9 \mathrm{E}+00$ & $2 . \mathrm{E}+0 \mathrm{I}$ & I.0IE +01 & $3.8 \mathrm{E}+00$ \\
\hline$+/-$ & & 2.E-OI & I.E-OI & I.E-0| & I.E-OI & I.E-0| & 2.E-0I & 2.E-OI & 2.E-0I & $4 . \mathrm{E}+0 \mathrm{I}$ & I.E-OI & 2.E-OI \\
\hline $\begin{array}{c}\text { Trace Elements } \\
(\mathrm{Wt} \%)\end{array}$ & NAA/GFAA & $7.2 \mathrm{E}-03$ & $1.6 \mathrm{E}-03$ & $3.5 \mathrm{E}-0 \mathrm{I}$ & $3.0 \mathrm{E}-01$ & $4.0 \mathrm{E}-0 \mathrm{I}$ & $4.9 \mathrm{E}-02$ & $6.0 \mathrm{E}-02$ & $2.9 \mathrm{E}+00$ & $1.2 \mathrm{E}+00$ & $\mathrm{I} .0 \mathrm{E}+00$ & $5.4 \mathrm{E}-02$ \\
\hline Total (Wt\%) & & 6.9 & I.I & 4.2 & 10 & 16 & 76 & 274 & 517 & 387 & 1179 & 300 \\
\hline
\end{tabular}

Note: Elemental concentrations have been converted to oxide forms on a $\mathrm{SO}_{3}$-free basis. nd - below detection limit 
Table B-13 (continued)

Size-Segregated Elemental Concentrations of the Wyodak Fly Ash Sampled at Port 4 (1.4 residence second)

b) Normalized Major Species Results

\begin{tabular}{|c|c|c|c|c|c|c|c|c|c|c|c|c|}
\hline Impactor & Stage & I & 2 & 3 & 4 & 5 & 6 & 7 & 8 & 9 & 10 & II \\
\hline Cut-off & $\begin{array}{l}\text { Diameter } \\
\text { (microns) }\end{array}$ & 0.0324 & 0.0636 & 0.0926 & 0.168 & 0.337 & 0.535 & 0.973 & 1.96 & 3.77 & 7.33 & 15.7 \\
\hline Element & $\begin{array}{c}\text { Analytical } \\
\text { Method }\end{array}$ & & & & & & & & & & & \\
\hline $\begin{array}{c}\text { Total Mass Conc } \\
\left(\mathrm{g} / \mathrm{Nm}^{\wedge} 3\right)\end{array}$ & Gravametric & I.IE-02 & I.3E-02 & $1.9 \mathrm{E}-02$ & $2.6 \mathrm{E}-02$ & $1.8 \mathrm{E}-02$ & $2.8 \mathrm{E}-02$ & $5.3 \mathrm{E}-02$ & $9.7 \mathrm{E}-02$ & $9.8 \mathrm{E}-02$ & I.7E-0I & $4.6 \mathrm{E}-02$ \\
\hline $\mathrm{SiO}_{2}(\mathrm{Wt} \%)$ & AAS & nd & nd & nd & 25 & 37 & 30 & 28 & 27 & 34 & 28 & 35 \\
\hline $\mathrm{Al}_{2} \mathrm{O}_{3}(\mathrm{Wt} \%)$ & AAS & 19 & 27 & 26 & 32 & 23 & 36 & 44 & 35 & 37 & 19 & 31 \\
\hline $\mathrm{Fe}_{2} \mathrm{O}_{3}(\mathrm{Wt} \%)$ & AAS & 22 & 0 & 20 & 23 & 16 & 12 & 10 & 7 & II & 8 & 7 \\
\hline $\mathrm{CaO}(\mathrm{Wt} \%)$ & AAS & 40 & 43 & 25 & 11 & 15 & 16 & 12 & 28 & II & 43 & 23 \\
\hline $\mathrm{MgO}(\mathrm{Wt} \%)$ & AAS & 3.3 & 4.0 & 4.2 & 1.4 & 1.7 & 2.7 & 2.5 & 1.4 & 2.4 & 0.97 & 2.0 \\
\hline $\mathrm{Na}_{2} \mathrm{O}(\mathrm{Wt} \%)$ & AES & 16 & 26 & 16 & 4.3 & 4.1 & 3.8 & 2.5 & 1.3 & 4.1 & 0.86 & 1.3 \\
\hline $\begin{array}{l}\text { Trace Elements } \\
(\mathrm{Wt} \%)\end{array}$ & GFAA & 0.10 & 0.14 & 8.4 & 3.0 & 2.5 & 0.06 & 0.022 & 0.55 & 0.30 & 0.085 & 0.018 \\
\hline Total (Wt\%) & & 100.00 & 100.00 & 100.00 & 100.00 & 100.00 & 100.00 & 100.00 & 100.00 & 100.00 & 100.00 & 100.00 \\
\hline
\end{tabular}


Table B-13 (continued)

Size-Segregated Elemental Concentrations of the Wyodak Fly Ash Sampled at Port 4 (1.4 residence second)

c) Trace Element Concentrations

\begin{tabular}{|c|c|c|c|c|c|c|c|c|c|c|c|c|}
\hline Impactor & Stage & I & 2 & 3 & 4 & 5 & 6 & 7 & 8 & 9 & 10 & II \\
\hline Element : As & NAA/GFAA & $5 . E+01$ & $9 . E+00$ & $8 . E+00$ & $6 . \mathrm{E}+00$ & $\mathrm{I} . \mathrm{E}+0 \mathrm{I}$ & $6.2 \mathrm{E}+01$ & $1.59 \mathrm{E}+02$ & $2.07 \mathrm{E}+02$ & $2.39 \mathrm{E}+02$ & $2.83 \mathrm{E}+02$ & $2.2 \mathrm{E}+02$ \\
\hline Se & NAA/GFAA & $1.5 \mathrm{E}+0 \mathrm{I}$ & $2 . E+00$ & $7 . \mathrm{E}+00$ & $4 . E+00$ & $5 . E+00$ & $3.7 \mathrm{E}+01$ & $1.02 \mathrm{E}+02$ & $1.25 \mathrm{E}+02$ & $1.07 \mathrm{E}+02$ & $1.34 \mathrm{E}+02$ & $6 .|\mathrm{E}+0|$ \\
\hline Sb & NAA/GFAA & $|| I E+0 \mid$. & $6 . E+00$ & $5 . E+00$ & $5 . E+00$ & I.E+0I & $3.3 \mathrm{E}+02$ & $5.8 \mathrm{E}+0 \mathrm{I}$ & $4.2 \mathrm{E}+0 \mathrm{I}$ & $5.6 \mathrm{E}+0 \mathrm{I}$ & $7 . I E+0 I$ & $8.4 \mathrm{E}+0 \mathrm{I}$ \\
\hline $\mathrm{Co}_{0}$ & NAA/GFAA & nd & nd & $|. E+0|$ & $8 . E+00$ & $2 . \mathrm{E}+0 \mathrm{I}$ & $6.3 \mathrm{E}+01$ & $2.82 \mathrm{E}+02$ & $4 . E+02$ & $4.7 \mathrm{IE}+02$ & $7 . \mathrm{E}+02$ & $1.78 \mathrm{E}+02$ \\
\hline Cs & NAA & & & $2.3 \mathrm{E}+01$ & $1.9 \mathrm{E}+0 \mid$ & $2.7 \mathrm{E}+01$ & & & $5.7 \mathrm{E}+01$ & $1.5 \mathrm{E}+01$ & $9 . \mathrm{E}+00$ & \\
\hline Sc & NAA & & & nd & nd & nd & & & nd & nd & nd & \\
\hline $\mathrm{Cr}$ & NAA & & & $1.4 \mathrm{E}+03$ & $8 . E+02$ & $\mathrm{I} . \mathrm{IE}+03$ & & & $7 . \mathrm{E}+02$ & $7 . \mathrm{E}+02$ & $2 . \mathrm{E}+02$ & \\
\hline $\ln$ & NAA & & & $3 . \mathrm{E}+02$ & $2 . \mathrm{E}+02$ & $3 . \mathrm{E}+02$ & & & $4 . E+02$ & $2 . \mathrm{E}+02$ & I.E +02 & \\
\hline $\mathrm{Br}$ & NAA & & & $3.9 \mathrm{E}+02$ & $2.4 \mathrm{E}+02$ & $2.8 \mathrm{E}+02$ & & & $1.3 \mathrm{E}+03$ & $1.4 \mathrm{E}+02$ & $7 . E+0 I$ & \\
\hline Mo & NAA & & & nd & nd & $3 . \mathrm{E}+00$ & & & $5 . E+00$ & $2 . E+00$ & $4 . E+00$ & \\
\hline$C d$ & NAA & & & $2.7 \mathrm{E}+02$ & $2.7 \mathrm{E}+02$ & $3.7 \mathrm{E}+02$ & & & $4.4 \mathrm{E}+03$ & $1.91 \mathrm{E}+03$ & $1.06 \mathrm{E}+03$ & \\
\hline $\mathrm{Ba}$ & NAA & & & $7 . \mathrm{E}+00$ & $6 . \mathrm{E}+00$ & I.E+0I & & & $9 . \mathrm{E}+0 \mid$ & $3 . \mathrm{E}+0 \mathrm{I}$ & 2.E+OI & \\
\hline La & NAA & & & $1.8 \mathrm{E}+0 \mid$ & $|.4 \mathrm{E}+0|$ & $|.5 \mathrm{E}+0|$ & & & $8 . I E+0 I$ & $3.6 \mathrm{E}+01$ & $2.7 \mathrm{E}+01$ & \\
\hline $\mathrm{Ce}$ & NAA & & & $2 . \mathrm{E}+0 \mathrm{I}$ & $\mathrm{I} . \mathrm{E}+0 \mathrm{I}$ & $2 . \mathrm{E}+0 \mathrm{I}$ & & & I.E +02 & $6 . \mathrm{E}+0 \mathrm{I}$ & $5 . E+01$ & \\
\hline $\mathrm{Nd}$ & NAA & & & nd & nd & nd & & & nd & $3 . \mathrm{E}+0 \mathrm{I}$ & $2 . \mathrm{E}+0 \mathrm{I}$ & \\
\hline $\mathrm{Sm}$ & NAA & & & 3.E-0I & 6.E-0I & $1.5 \mathrm{E}+00$ & & & $|.34 \mathrm{E}+0|$ & $6.6 \mathrm{E}+00$ & $4.8 \mathrm{E}+00$ & \\
\hline $\mathrm{Eu}$ & NAA & & & $4.5 \mathrm{E}+00$ & $3.5 \mathrm{E}+00$ & $2.3 \mathrm{E}+00$ & & & nd & $1.7 \mathrm{E}+00$ & I.IE +00 & \\
\hline Lu & NAA & & & nd & nd & $6 . \mathrm{E}-02$ & & & $8 . E-01$ & 4.E-0I & 3.E-0l & \\
\hline $\mathrm{Hf}$ & NAA & & & nd & nd & nd & & & nd & $3.6 \mathrm{E}+00$ & $3.3 \mathrm{E}+00$ & \\
\hline $\mathrm{Ta}$ & NAA & & & nd & nd & nd & & & nd & nd & nd & \\
\hline $\mathrm{Au}$ & NAA & & & $2.3 \mathrm{E}-01$ & $|.4 \mathrm{E}-0|$ & 8.E-02 & & & nd & 7.E-02 & 2.E-02 & \\
\hline $\mathrm{Hg}$ & NAA & & & $1.9 \mathrm{E}+00$ & $\mathrm{I} . \mathrm{IE}+00$ & 8.E-0I & & & 9.E-0I & nd & nd & \\
\hline Th & NAA & & & nd & $2 . E+00$ & $3 . E+00$ & & & $2.9 \mathrm{E}+0 \mathrm{I}$ & $|.4 \mathrm{E}+0|$ & $1.0 \mathrm{E}+0 \mathrm{I}$ & \\
\hline U & NAA & & & nd & nd & nd & & & nd & nd & nd & \\
\hline $\mathrm{Cl}$ & NAA & & & nd & $8 . E+02$ & $1.2 \mathrm{E}+03$ & & & $2.1 \mathrm{IE}+03$ & $4 . E+02$ & $2 . E+02$ & \\
\hline K & NAA & & & nd & nd & nd & & & nd & nd & nd & \\
\hline $\mathrm{Ti}$ & NAA & & & $7 . E+02$ & nd & nd & & & $4.4 \mathrm{E}+03$ & $1.9 \mathrm{E}+03$ & $3.0 \mathrm{E}+03$ & \\
\hline V & NAA & & & $5 . E+0 I$ & $3 . E+0 I$ & $8 . E+00$ & & & $4 . \mathrm{E}+02$ & $2 . E+02$ & $2 . E+02$ & \\
\hline$M n$ & NAA & & & $4 . E+0 I$ & $3 . E+0 I$ & $4 . E+0 I$ & & & $2 . E+02$ & $7 . \mathrm{E}+0 \mathrm{I}$ & $4 . E+0 I$ & \\
\hline Sr & NAA & & & nd & nd & nd & & & $4.6 \mathrm{E}+03$ & $2.2 \mathrm{E}+03$ & $1.4 \mathrm{E}+03$ & \\
\hline $\mathrm{Ba}$ & NAA & & & $2.6 \mathrm{E}+02$ & $5 . \mathrm{IE}+02$ & $5.9 \mathrm{E}+02$ & & & $8.8 \mathrm{E}+03$ & $2.8 \mathrm{IE}+03$ & $2.50 \mathrm{E}+03$ & \\
\hline
\end{tabular}

nd $=$ below detection limit 
TABLE B-13 (continued)

Size-Segregated Elemental Concentrations of the Wyodak Fly Ash Sampled at Port 4 (1.4 residence second)

d) Trace Element Uncertainties

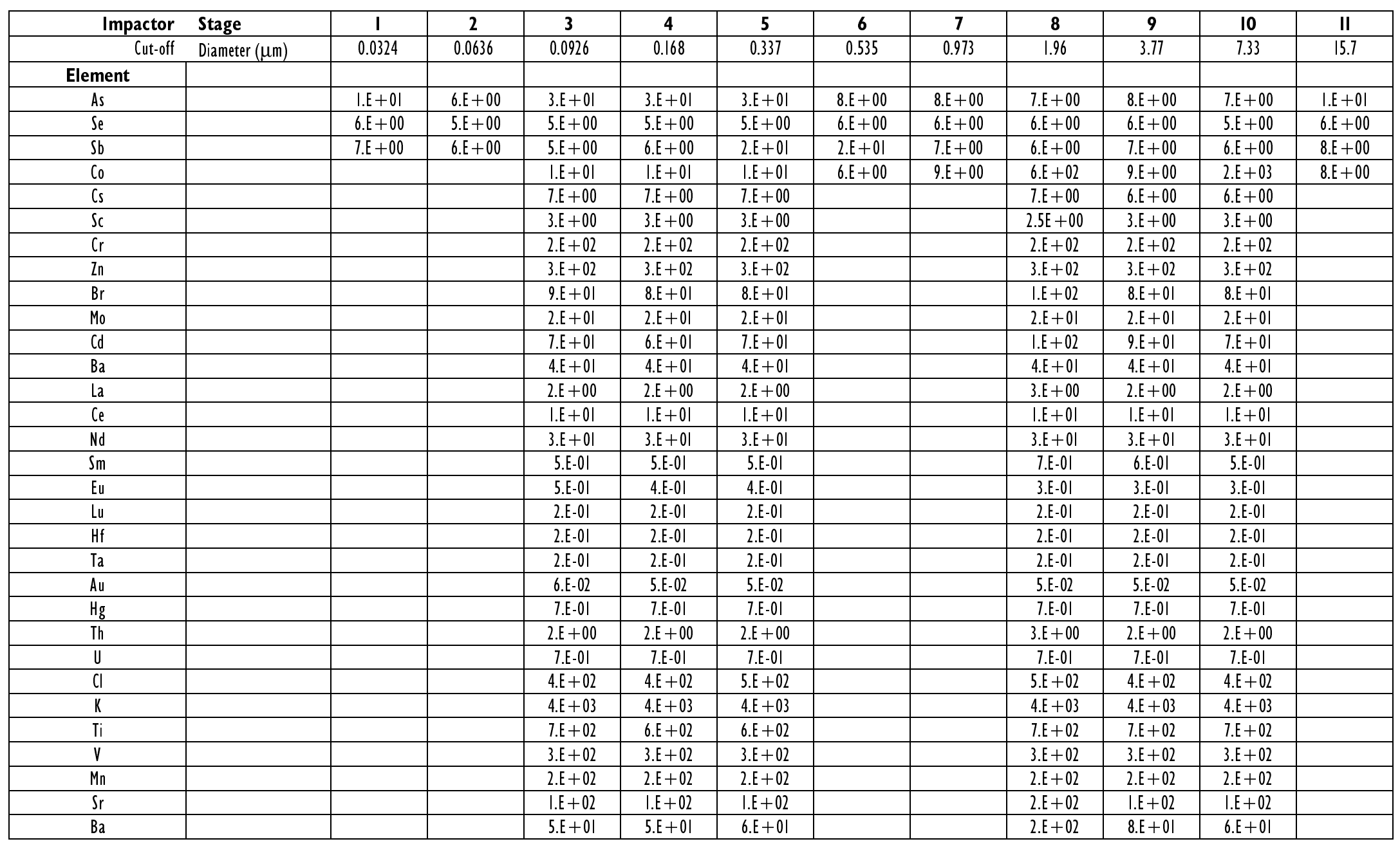


Table B-14

Size-Segregated Elemental Concentrations of the Wyodak Fly Ash Sampled at Port 14 (6.6 residence second)

a) Major Species Results

\begin{tabular}{|c|c|c|c|c|c|c|c|c|c|c|c|c|}
\hline Impactor & Stage & I & 2 & 3 & 4 & 5 & 6 & 7 & 8 & 9 & 10 & II \\
\hline Cut-offD & $\begin{array}{l}\text { Diameter } \\
\text { (microns) }\end{array}$ & 0.0324 & 0.0636 & 0.0926 & 0.168 & 0.337 & 0.535 & 0.973 & 1.96 & 3.77 & 7.33 & 15.7 \\
\hline Element & $\begin{array}{l}\text { Analytical } \\
\text { Method }\end{array}$ & & & & & & & & & & & \\
\hline $\begin{array}{c}\text { Total Mass Conc } \\
(\mathrm{g} / \mathrm{Nm} \wedge 3)\end{array}$ & Gravametric & $1.54 \mathrm{E}-03$ & $2.53 \mathrm{E}-03$ & $5.60 \mathrm{E}-03$ & $5.93 \mathrm{E}-03$ & $3.92 \mathrm{E}-03$ & $1.22 \mathrm{E}-02$ & $2.34 \mathrm{E}-02$ & $4.57 \mathrm{E}-02$ & $3.62 \mathrm{E}-02$ & $4.60 \mathrm{E}-02$ & $1.68 \mathrm{E}-02$ \\
\hline $\mathrm{SiO}_{2}(\mathrm{Wt} \%)$ & AAS & nd & nd & nd & nd & $6 . \mathrm{E}+0 \mathrm{I}$ & $3 . I E+0 I$ & $2.5 \mathrm{E}+0 \mathrm{I}$ & $2.3 \mathrm{E}+0 \mathrm{I}$ & $2.6 \mathrm{E}+01$ & $2.9 \mathrm{E}+0 \mathrm{I}$ & $2.8 \mathrm{E}+0 \mathrm{I}$ \\
\hline$+/-$ & & & & & & I.E+0I & 2.E +00 & I.E +00 & I.E +00 & I.E +00 & I.E +00 & $2 . E+00$ \\
\hline $\mathrm{Al}_{2} \mathrm{O}_{3}(\mathrm{Wt} \%)$ & NAA/AAS & nd & nd & $8 . E+01$ & $2.4 \mathrm{E}+02$ & $1 . E+02$ & $2.9 \mathrm{E}+0 \mathrm{I}$ & $6.1 \mathrm{IE}+0 \mathrm{I}$ & $4.70 \mathrm{E}+0 \mathrm{I}$ & $3.67 \mathrm{E}+0 \mathrm{I}$ & I.7IE $+0 \mathrm{I}$ & $2.3 \mathrm{E}+0 \mathrm{I}$ \\
\hline$+/-$ & & & & $2 . E+0 I$ & $4 . \mathrm{E}+0 \mathrm{I}$ & $3 . E+02$ & $2 . E+00$ & $2 . E+00$ & 8.E-0I & 8.E-0I & 5.E-OI & I.E +00 \\
\hline $\mathrm{Fe}_{2} \mathrm{O}_{3}(\mathrm{Wt} \%)$ & NAA/AAS & $8 . \mathrm{E}+0 \mathrm{I}$ & $5.7 \mathrm{E}+0 \mathrm{I}$ & $7 . \mathrm{E}+00$ & $2 . E+0 I$ & $1.3 \mathrm{E}+0 \mid$ & $1.4 \mathrm{E}+0 \mid$ & $1.57 \mathrm{E}+0 \mid$ & I. $|2 \mathrm{E}+0|$ & $1.24 \mathrm{E}+0 \mathrm{I}$ & $9.56 \mathrm{E}+00$ & $7.0 \mathrm{E}+00$ \\
\hline$+/-$ & & $5 . E+01$ & $9 . E+00$ & I.E +00 & $5 . E+01$ & $5 . E+00$ & I.E +00 & 7.E-0I & 5.E-OI & 5.E-OI & 5.E-OI & 6.E-0I \\
\hline $\mathrm{Ca} 0(\mathrm{Wt} \%)$ & NAA/AAS & $7 . \mathrm{E}+0 \mathrm{I}$ & $2.5 \mathrm{E}+0 \mathrm{I}$ & $3 . \mathrm{E}+0 \mathrm{I}$ & $3 . \mathrm{E}+0 \mathrm{I}$ & $3.7 \mathrm{E}+0 \mathrm{I}$ & $2 . I E+0 \mid$ & $2.73 \mathrm{E}+0 \mathrm{I}$ & $6 . \mathrm{E}+01$ & $6 . \mathrm{E}+0 \mathrm{I}$ & $3 . \mathrm{E}+0 \mathrm{I}$ & $1.28 \mathrm{E}+01$ \\
\hline$+/-$ & & $4 . \mathrm{E}+0 \mathrm{I}$ & $4 . E+00$ & $4 . \mathrm{E}+0 \mathrm{I}$ & $4 . E+0 I$ & 7.E+00 & I.E +00 & 8.E-0I & $\mathrm{I} . \mathrm{E}+02$ & $\mathrm{I} . \mathrm{E}+02$ & $4 . E+0 I$ & 7.E-OI \\
\hline $\mathrm{MgO}(\mathrm{Wt} \%)$ & NAA/AAS & 7.E +00 & $3.4 \mathrm{E}+00$ & $4 . E+00$ & $4.6 \mathrm{E}+00$ & $5 . E+00$ & $3.3 \mathrm{E}+00$ & $3.77 \mathrm{E}+00$ & $2.44 \mathrm{E}+00$ & $2.82 \mathrm{E}+00$ & $2.04 \mathrm{E}+00$ & $1.68 \mathrm{E}+00$ \\
\hline$+/-$ & & $4 . E+00$ & 5.E-0I & $8 . E+00$ & $\mathrm{I} . \mathrm{E}+0 \mathrm{I}$ & $5 . E+00$ & 2.E-0I & 9.E-02 & 3.E-02 & 4.E-02 & 3.E-02 & 8.E-02 \\
\hline $\mathrm{Na}_{2} \mathrm{O}(\mathrm{Wt} \%)$ & NAA/AAS & $3 . \mathrm{E}+0 \mathrm{I}$ & $9 . E+00$ & $1.5 \mathrm{E}+0 \mathrm{I}$ & $2 . E+0 I$ & $6 . \mathrm{E}+00$ & $2.1 \mathrm{E}+00$ & $3.5 \mathrm{E}+00$ & $3.9 \mathrm{E}+00$ & $3.4 \mathrm{E}+00$ & $1.20 \mathrm{E}+00$ & $2.4 \mathrm{E}+00$ \\
\hline$+/-$ & & $2 . \mathrm{E}+0 \mathrm{I}$ & I.E+00 & $2 . E+00$ & $5 . \mathrm{E}+0 \mathrm{I}$ & I.E +00 & 2.E-0I & 2.E-OI & I.E-0| & I.E-0| & 9.E-02 & 2.E-OI \\
\hline $\begin{array}{c}\text { Trace Elements } \\
(\mathrm{Wt} \%)\end{array}$ & NAA/GFAA & $6.8 \mathrm{E}-02$ & $4.0 \mathrm{E}-02$ & $1.0 \mathrm{E}+0 \mathrm{I}$ & $1.6 \mathrm{E}+0 \mathrm{I}$ & $7.0 \mathrm{E}+00$ & $3.3 \mathrm{E}-02$ & $2.7 \mathrm{E}-02$ & $2.2 \mathrm{E}+0 \mathrm{I}$ & $2.8 \mathrm{E}+0 \mathrm{I}$ & $6.8 \mathrm{E}+00$ & $6.8 \mathrm{E}-03$ \\
\hline Total (Wt\%) & & 195 & 95 & 142 & 327 & 273 & 101 & 136 & 174 & 169 & 95 & 75 \\
\hline
\end{tabular}

Note: Elemental concentrations have been converted to oxide forms on a $\mathrm{SO}_{3}$-free basis. nd - below detection limit 
Table B-14 (continued)

Size-Segregated Elemental Concentrations of the Wyodak Fly Ash Sampled at Port 14 (6.6 residence second)

b) Normalized Major Species Results

\begin{tabular}{|c|c|c|c|c|c|c|c|c|c|c|c|c|}
\hline Impactor & Stage & I & 2 & 3 & 4 & 5 & 6 & 7 & 8 & 9 & 10 & II \\
\hline Cut-off & $\begin{array}{l}\text { Diameter } \\
\text { (microns) }\end{array}$ & 0.0324 & 0.0636 & 0.0926 & 0.168 & 0.337 & 0.535 & 0.973 & 1.96 & 3.77 & 7.33 & 15.7 \\
\hline Element & $\begin{array}{c}\text { Analytical } \\
\text { Method }\end{array}$ & & & & & & & & & & & \\
\hline $\begin{array}{c}\text { Total Mass Conc } \\
(\mathrm{g} / \mathrm{Nm} \wedge 3)\end{array}$ & Gravametric & I.5E-03 & $2.5 \mathrm{E}-03$ & $5.6 \mathrm{E}-03$ & $5.9 \mathrm{E}-03$ & $3.9 \mathrm{E}-03$ & $1.2 \mathrm{E}-02$ & $2.3 \mathrm{E}-02$ & $4.6 \mathrm{E}-02$ & $3.6 \mathrm{E}-02$ & $4.6 \mathrm{E}-02$ & $1.7 \mathrm{E}-02$ \\
\hline $\mathrm{SiO}_{2}(\mathrm{Wt} \%)$ & AAS & nd & nd & nd & nd & 22 & 31 & 18 & 13 & 15 & 30 & 38 \\
\hline $\mathrm{Al}_{2} \mathrm{O}_{3}(\mathrm{Wt} \%)$ & AAS & nd & nd & 56 & 74 & 53 & 29 & 45 & 27 & 22 & 18 & 30 \\
\hline $\mathrm{Fe}_{2} \mathrm{O}_{3}(\mathrm{Wt} \%)$ & AAS & 43 & 60 & 5 & 7 & 5 & 14 & 12 & 6 & 7 & 10 & 9 \\
\hline $\mathrm{CaO}(\mathrm{Wt} \%)$ & AAS & 37 & 27 & 19 & 7.8 & 13 & 21 & 20 & 37 & 35 & 31 & 17 \\
\hline $\mathrm{MgO}(\mathrm{Wt} \%)$ & AAS & 3.4 & 3.6 & 2.8 & 1.4 & 1.8 & 3.2 & 2.8 & 1.4 & 1.7 & 2.1 & 2.2 \\
\hline $\mathrm{Na}_{2} \mathrm{O}(\mathrm{Wt} \%)$ & AES & 16 & 9.6 & 10 & 5.4 & 2.3 & 2.0 & 2.6 & 2.2 & 2.0 & 1.3 & 3.2 \\
\hline $\begin{array}{c}\text { Trace Elements } \\
(\mathrm{Wt} \%)\end{array}$ & GFAA & 0.035 & 0.042 & 7.4 & 4.8 & 2.6 & 0.033 & 0.020 & 13 & 17 & 7.1 & 0.009 \\
\hline Total (Wt\%) & & 100.00 & 100.00 & 100.00 & 100.00 & 100.00 & 100.00 & 100.00 & 100.00 & 100.00 & 100.00 & 100.00 \\
\hline
\end{tabular}


Table B-14 (continued)

Size-Segregated Elemental Concentrations of the Wyodak Fly Ash Sampled at Port 14 (6.6 residence second)

c) Trace Element Concentrations

\begin{tabular}{|c|c|c|c|c|c|c|c|c|c|c|c|c|}
\hline Impactor & Stage & I & 2 & 3 & 4 & 5 & 6 & 7 & 8 & 9 & 10 & II \\
\hline Element: As & NAA/GFAA & $6.2 \mathrm{E}+02$ & $3.3 \mathrm{E}+02$ & $1.3 \mathrm{E}+02$ & $1.8 \mathrm{E}+02$ & $1.7 \mathrm{E}+02$ & $1.7 \mathrm{E}+02$ & $1.08 \mathrm{E}+02$ & $8.7 \mathrm{E}+0 \mathrm{I}$ & $6.6 \mathrm{E}+01$ & $4 . \mathrm{E}+0 \mathrm{I}$ & $5.2 \mathrm{E}+0 \mathrm{I}$ \\
\hline $\mathrm{Se}$ & NAA/GFAA & nd & nd & $8 . E+01$ & $\mathrm{I} . \mathrm{E}+02$ & $6 . \mathrm{E}+0 \mathrm{I}$ & $5 . E+01$ & $5 . \mathrm{E}+0 \mathrm{I}$ & $3 . \mathrm{E}+0 \mathrm{I}$ & $2 . \mathrm{E}+0 \mathrm{I}$ & $9 . \mathrm{E}+00$ & nd \\
\hline $\mathrm{Sb}$ & NAA/GFAA & $5.9 \mathrm{E}+0 \mathrm{I}$ & $6.4 \mathrm{E}+0 \mathrm{I}$ & $2.0 \mathrm{E}+0 \mathrm{I}$ & $4.3 \mathrm{E}+0 \mathrm{l}$ & $5.0 \mathrm{E}+0 \mathrm{I}$ & $1.9 \mathrm{E}+0 \mid$ & $1.7 \mathrm{E}+0 \mid$ & $5.0 \mathrm{E}+01$ & $2.7 \mathrm{E}+01$ & $|.0 \mathrm{E}+0|$ & $|.6 \mathrm{E}+0|$ \\
\hline $\mathrm{Co}_{0}$ & NAA/GFAA & nd & nd & nd & nd & nd & $9 . \mathrm{E}+0 \mid$ & I.E +02 & I.E +02 & I.E +02 & $5 . E+0 \mid$ & nd \\
\hline Cs & NAA & & & $3.2 \mathrm{E}+02$ & $5 . E+02$ & $1.7 \mathrm{E}+02$ & & & $6.1 \mathrm{E}+02$ & $6.0 \mathrm{E}+02$ & $4.5 \mathrm{E}+02$ & \\
\hline Sc & NAA & & & $0 . \mathrm{E}+00$ & $0 . E+00$ & $0 . E+00$ & & & $0 . E+00$ & $0 . E+00$ & $0 . E+00$ & \\
\hline $\mathrm{Cr}$ & NAA & & & $1.2 \mathrm{E}+04$ & $2.5 \mathrm{E}+04$ & $7 . \mathrm{E}+03$ & & & $1.76 \mathrm{E}+04$ & $2.73 \mathrm{E}+04$ & $3 . \mathrm{IE}+03$ & \\
\hline $\ln$ & NAA & & & $\mathrm{I} .0 \mathrm{E}+03$ & $4 . \mathrm{E}+03$ & $2.8 \mathrm{E}+03$ & & & $9.4 \mathrm{E}+03$ & nd & nd & \\
\hline $\mathrm{Br}$ & NAA & & & $4 . E+03$ & $3.5 \mathrm{E}+04$ & $2.9 \mathrm{E}+03$ & & & $4.7 \mathrm{E}+03$ & $4.6 \mathrm{E}+04$ & $6.5 \mathrm{E}+03$ & \\
\hline Mo & NAA & & & nd & nd & nd & & & $2.1 \mathrm{IE}+02$ & $1.7 \mathrm{E}+02$ & $5 . E+01$ & \\
\hline$C d$ & NAA & & & $2.0 \mathrm{E}+03$ & $3.0 \mathrm{E}+04$ & $3.0 \mathrm{E}+03$ & & & $4.78 \mathrm{E}+04$ & $5.0 \mathrm{E}+04$ & $7.2 \mathrm{E}+03$ & \\
\hline $\mathrm{Ba}$ & NAA & & & $6 . \mathrm{E}+02$ & $2.3 \mathrm{E}+02$ & $1.8 \mathrm{E}+02$ & & & $1.32 \mathrm{E}+03$ & $1.48 \mathrm{E}+03$ & $1.3 \mathrm{E}+02$ & \\
\hline $\mathrm{La}$ & NAA & & & $4 . E+0 I$ & $1.0 \mathrm{E}+02$ & $1.3 \mathrm{E}+02$ & & & $1.29 \mathrm{E}+03$ & $\mathrm{I} .60 \mathrm{E}+03$ & I. $70 \mathrm{E}+02$ & \\
\hline $\mathrm{Ce}$ & NAA & & & $8 . \mathrm{E}+01$ & $1.8 \mathrm{E}+02$ & $1.7 \mathrm{E}+02$ & & & $2.72 \mathrm{E}+03$ & $2.89 \mathrm{E}+03$ & $3.9 \mathrm{E}+02$ & \\
\hline $\mathrm{Nd}$ & NAA & & & nd & $8 . E+02$ & $3.3 \mathrm{E}+02$ & & & $8.3 \mathrm{E}+02$ & nd & $1.25 \mathrm{E}+03$ & \\
\hline $\mathrm{Sm}$ & NAA & & & $5 . E+00$ & $|.3 \mathrm{E}+0|$ & $2.0 \mathrm{E}+01$ & & & $2.25 \mathrm{E}+02$ & $2.96 \mathrm{E}+02$ & $3.2 \mathrm{E}+0 \mathrm{l}$ & \\
\hline $\mathrm{Eu}$ & NAA & & & $2.7 \mathrm{E}+01$ & $7 . \mathrm{E}+00$ & $8 . E+00$ & & & $2.70 E+01$ & nd & $6.5 \mathrm{E}+00$ & \\
\hline Lu & NAA & & & nd & nd & 8.E-OI & & & $1.28 \mathrm{E}+0 \mathrm{I}$ & $2.20 \mathrm{E}+0 \mathrm{I}$ & $2.8 \mathrm{E}+00$ & \\
\hline $\mathrm{Hf}$ & NAA & & & nd & nd & nd & & & nd & nd & nd & \\
\hline $\mathrm{Ta}$ & NAA & & & nd & nd & nd & & & nd & nd & nd & \\
\hline $\mathrm{Au}$ & NAA & & & $2.3 \mathrm{E}+00$ & nd & 7.E-0I & & & $2.7 \mathrm{E}+00$ & $1.09 \mathrm{E}+00$ & $2.0 \mathrm{E}-01$ & \\
\hline $\mathrm{Hg}$ & NAA & & & $9 . \mathrm{E}+00$ & nd & $|| E+0 \mid$. & & & nd & nd & nd & \\
\hline Th & NAA & & & nd & $1.0 \mathrm{E}+0 \mid$ & $3.7 \mathrm{E}+01$ & & & $4.7 \mathrm{E}+02$ & $6.0 \mathrm{E}+02$ & $7.7 \mathrm{E}+0 \mathrm{I}$ & \\
\hline$U$ & NAA & & & nd & nd & nd & & & $1.16 \mathrm{E}+02$ & nd & $1.01 E+0 \mid$ & \\
\hline $\mathrm{Cl}$ & NAA & & & I.IE +04 & $3.9 \mathrm{E}+04$ & I.IE +04 & & & $8.8 \mathrm{E}+03$ & $1.45 \mathrm{E}+04$ & $8.8 \mathrm{E}+03$ & \\
\hline$K$ & NAA & & & nd & nd & nd & & & nd & nd & nd & \\
\hline $\mathrm{Ti}$ & NAA & & & nd & nd & $9.6 \mathrm{E}+03$ & & & $4.7 \mathrm{E}+04$ & $5.3 \mathrm{E}+04$ & $1.32 \mathrm{E}+04$ & \\
\hline$V$ & NAA & & & $4 . \mathrm{E}+03$ & $8 . \mathrm{E}+02$ & $9 . \mathrm{E}+02$ & & & $2.9 \mathrm{E}+03$ & $3.4 \mathrm{E}+03$ & $1.2 \mathrm{E}+03$ & \\
\hline$M n$ & NAA & & & $4 . E+02$ & $1.8 \mathrm{E}+03$ & $5 . E+02$ & & & $2.2 \mathrm{E}+03$ & $1.6 \mathrm{E}+03$ & $7 . \mathrm{E}+02$ & \\
\hline $\mathrm{Sr}$ & NAA & & & nd & nd & nd & & & $2.77 \mathrm{E}+04$ & $3.7 \mathrm{E}+04$ & $7.9 \mathrm{E}+03$ & \\
\hline $\mathrm{Ba}$ & NAA & & & $7 . \mathrm{E}+04$ & $2.0 \mathrm{E}+04$ & $3 . \mathrm{IE}+04$ & & & $4.26 \mathrm{E}+04$ & $4.3 \mathrm{E}+04$ & $1.63 \mathrm{E}+04$ & \\
\hline
\end{tabular}

nd = below detection limit 
Table B-14 (continued)

Size-Segregated Elemental Concentrations of the Wyodak Fly Ash Sampled at Port 14 (6.6residence second)

d) Trace Element Uncertainties

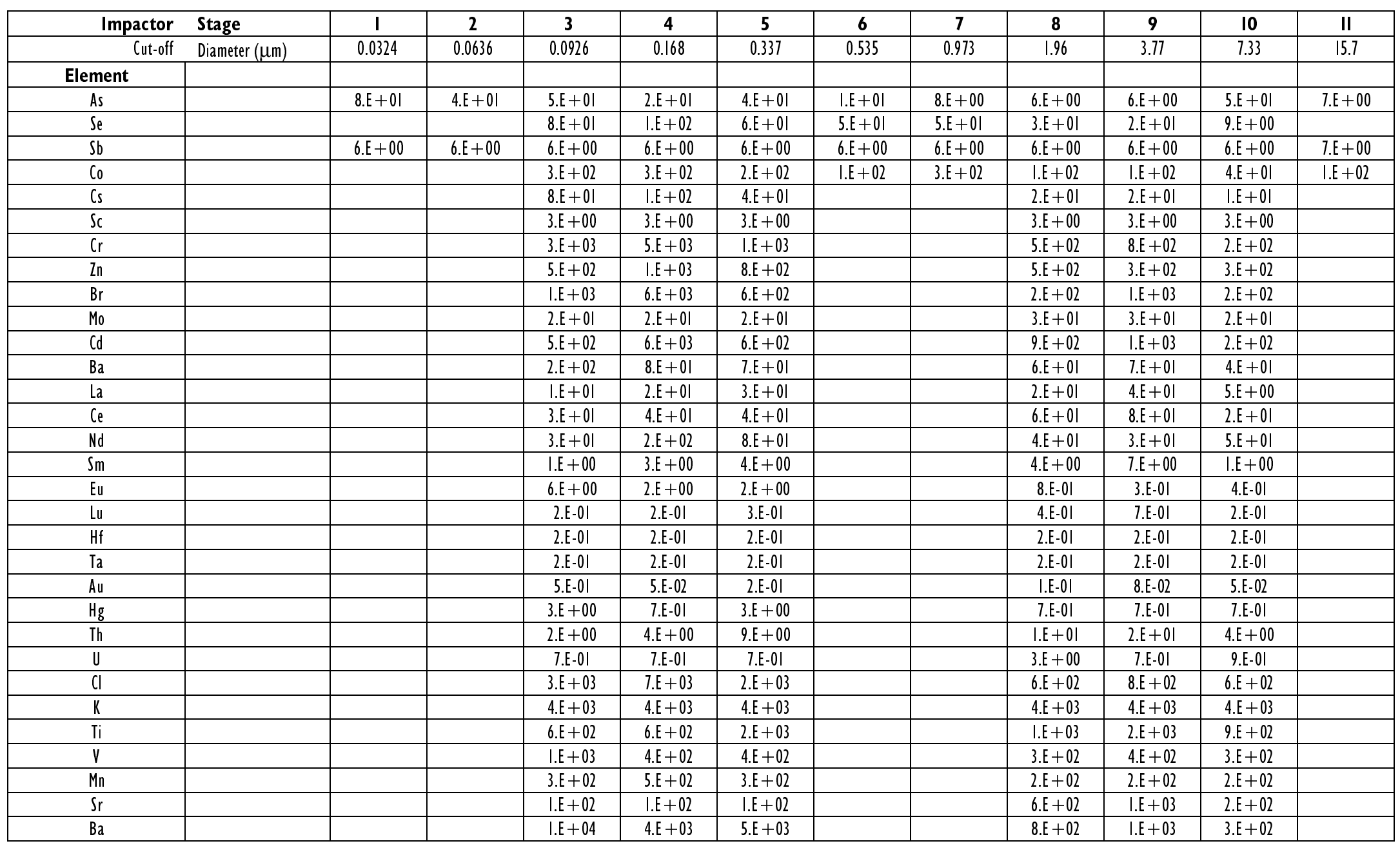


Table B-15

Size-Segregated Elemental Concentrations of the Wyodak Fly Ash Sampled at the Baghouse Inlet Port

a) Major Species Results

\begin{tabular}{|c|c|c|c|c|c|c|c|c|c|c|c|c|}
\hline Impactor & Stage & I & 2 & 3 & 4 & 5 & 6 & 7 & 8 & 9 & 10 & II \\
\hline Cut-off & $\begin{array}{l}\text { Diameter } \\
\text { (microns) }\end{array}$ & 0.0324 & 0.0636 & 0.0926 & 0.168 & 0.337 & 0.535 & 0.973 & 1.96 & 3.77 & 7.33 & 15.7 \\
\hline Element & $\begin{array}{c}\text { Analytical } \\
\text { Method }\end{array}$ & & & & & & & & & & & \\
\hline $\begin{array}{l}\text { Total Mass Conc } \\
(\mathrm{g} / \mathrm{Nm} \wedge 3)\end{array}$ & Gravametric & $3.5 \mathrm{IE}+03$ & $5.27 \mathrm{E}-03$ & $9.66 \mathrm{E}-03$ & $9.48 \mathrm{E}-03$ & $9.47 \mathrm{E}-03$ & $2.23 \mathrm{E}-02$ & $6.09 \mathrm{E}-02$ & $1.32 \mathrm{E}-0 \mid$ & 2.2IE-0I & $4.47 \mathrm{E}-01$ & $4.86 \mathrm{E}-02$ \\
\hline $\mathrm{SiO}_{2}(\mathrm{Wt} \%)$ & AAS & nd & nd & nd & $1.2 \mathrm{E}+0 \mathrm{I}$ & $1.6 \mathrm{E}+01$ & $1.5 \mathrm{E}+0 \mathrm{I}$ & $2 . E+0 I$ & $3.2 \mathrm{E}+0 \mathrm{I}$ & $3.2 \mathrm{E}+0 \mathrm{I}$ & $2 . \mathrm{E}+0 \mathrm{I}$ & $4.2 \mathrm{E}+0 \mathrm{I}$ \\
\hline$+/-$ & & & & & I.E+00 & $2 . E+00$ & I.E+00 & I.E+00 & I.E+00 & I.E +00 & $3 . \mathrm{E}+0 \mathrm{I}$ & $2 . \mathrm{E}+00$ \\
\hline $\mathrm{Al}_{2} \mathrm{O}_{3}(\mathrm{Wt} \%)$ & AAS & $6 . E+00$ & $8 . E+00$ & $1.8 \mathrm{E}+00$ & 7.E-OI & $6 . \mathrm{E}-02$ & $5.3 \mathrm{E}+00$ & $3 . I E+00$ & $1.5 \mathrm{E}+00$ & 7.E-0I & 6.E-0I & $2.6 \mathrm{E}+00$ \\
\hline$+/-$ & & $2 . E+00$ & I.E+00 & 5.E-0I & 4.E-OI & 4.E-OI & 4.E-0I & 4.E-0I & 4.E-0I & 4.E-0I & 4.E-0I & 4.E-OI \\
\hline $\mathrm{Fe}_{2} \mathrm{O}_{3}(\mathrm{Wt} \%)$ & AAS & I.E $+0 \mid$ & $7 . E+00$ & $4.0 \mathrm{E}+00$ & $2.4 \mathrm{E}+0 \mathrm{I}$ & I.IE +0I & $1.36 \mathrm{E}+01$ & $1.46 \mathrm{E}+0 \mathrm{I}$ & $2 . E+0 I$ & $6.5 \mathrm{E}+00$ & $8.1 E+00$ & $1.04 \mathrm{E}+0 \mathrm{I}$ \\
\hline$+/-$ & & $2 . E+0 I$ & I.E +00 & 6.E-OI & $4 . E+00$ & I.E +00 & 8.E-0I & 6.E-0I & $|. E+0|$ & 5.E-OI & 4.E-0I & 4.E-OI \\
\hline $\mathrm{Ca} 0(\mathrm{Wt} \%)$ & AAS & $I . E+0 \mid$ & $9 . \mathrm{E}+00$ & $1.8 \mathrm{E}+0 \mathrm{I}$ & $7.3 \mathrm{E}+00$ & $8.0 \mathrm{E}+00$ & $2.4 \mathrm{E}+0 \mathrm{I}$ & $2 . \mathrm{E}+0 \mathrm{I}$ & $2 . \mathrm{E}+0 \mathrm{I}$ & $I . E+0 \mid$ & $4 . \mathrm{E}+00$ & $3 . E+0 I$ \\
\hline$+/-$ & & I.E+0I & $8 . E+00$ & $\mathrm{I} . \mathrm{E}+00$ & 5.E-OI & 6.E-0I & I.E +00 & $3 . E+0 I$ & $5 . E+01$ & $2 . E+0 I$ & $5 . E+00$ & $4 . \mathrm{E}+0 \mathrm{I}$ \\
\hline $\operatorname{MgO}(\mathrm{Wt} \%)$ & AAS & $\mathrm{I} . \mathrm{IE}+00$ & $9.4 \mathrm{E}-0 \mathrm{I}$ & $1.57 \mathrm{E}+00$ & $1.42 \mathrm{E}+00$ & $1.9 \mathrm{E}+00$ & $4 . E+00$ & $4 . E+00$ & $5 . E+00$ & I.E +00 & I.E +00 & $3 . E+00$ \\
\hline$+/-$ & & 2.E-0I & I.E-0| & I.E-0| & 6.E-02 & I.E-0| & $2 . E+00$ & $5 . E+00$ & $9 . E+00$ & I.E +00 & $2 . E+00$ & I.E +00 \\
\hline $\mathrm{Na}_{2} \mathrm{O}(\mathrm{Wt} \%)$ & AES & $1.4 \mathrm{E}+0 \mathrm{I}$ & $4 . E+00$ & $4 . E+00$ & $6.5 \mathrm{E}+00$ & $1.8 \mathrm{E}+00$ & $2 . E+00$ & $3.0 \mathrm{E}+00$ & $4 . E+00$ & $2 . E+00$ & $1.03 \mathrm{E}+00$ & $1.55 \mathrm{E}+00$ \\
\hline$+/-$ & & $4 . E+00$ & $3 . E+00$ & $4 . E+00$ & I.E+0I & 2.E-0I & I.E +00 & I.E-0I & $4 . E+00$ & I.E +00 & 8.E-02 & 9.E-02 \\
\hline $\begin{array}{l}\text { Trace Elements } \\
(\mathrm{Wt} \%)\end{array}$ & GFAA & $3.2 \mathrm{E}-02$ & $2.3 \mathrm{E}-02$ & $2.4 \mathrm{E}-02$ & $2.8 \mathrm{E}-02$ & $2.7 \mathrm{E}-02$ & $3.4 \mathrm{E}-02$ & $2.9 \mathrm{E}-02$ & $3.5 \mathrm{E}-02$ & $1.9 \mathrm{E}-02$ & $8.5 \mathrm{E}-03$ & $1.4 \mathrm{E}-02$ \\
\hline Total (Wt\%) & & 47 & 29 & 30 & 51 & 38 & 64 & 66 & 79 & 53 & 37 & 87 \\
\hline
\end{tabular}

Note: Elemental concentrations have been converted to oxide forms on a $\mathrm{SO}_{3}$-free basis.

nd $=$ below detection limit 
Table B-15 (continued)

Size-Segregated Elemental Concentrations of the Wyodak Fly Ash Sampled at the Baghouse Inlet Port

b) Normalized Major Species Results

\begin{tabular}{|c|c|c|c|c|c|c|c|c|c|c|c|c|}
\hline Impactor & Stage & I & 2 & 3 & 4 & 5 & 6 & 7 & 8 & 9 & 10 & II \\
\hline Cut-off & $\begin{array}{l}\text { Diameter } \\
\text { (microns) }\end{array}$ & 0.0324 & 0.0636 & 0.0926 & 0.168 & 0.337 & 0.535 & 0.973 & 1.96 & 3.77 & 7.33 & 15.7 \\
\hline Element & $\begin{array}{c}\text { Analytical } \\
\text { Method }\end{array}$ & & & & & & & & & & & \\
\hline $\begin{array}{l}\text { Total Mass Conc } \\
(\mathrm{g} / \mathrm{Nm} \wedge 3)\end{array}$ & Gravametric & $\begin{array}{c}3.5 \mathrm{E}+0 \\
3 \\
\end{array}$ & $5.3 \mathrm{E}-03$ & $9.7 \mathrm{E}-03$ & $9.5 \mathrm{E}-03$ & $9.5 \mathrm{E}-03$ & $2.2 \mathrm{E}-02$ & 6.IE-02 & I.3E-0I & $2.2 \mathrm{E}-0 \mathrm{I}$ & $4.5 \mathrm{E}-0 \mathrm{I}$ & $4.9 \mathrm{E}-02$ \\
\hline $\mathrm{SiO}_{2}(\mathrm{Wt} \%)$ & AAS & nd & nd & nd & 23 & 41 & 24 & 34 & 40 & 61 & 61 & 48 \\
\hline $\mathrm{Al}_{2} \mathrm{O}_{3}(\mathrm{Wt} \%)$ & AAS & 13 & 29 & 6.1 & 1.4 & 0.15 & 8.2 & 4.7 & 1.9 & 1.4 & 1.6 & 3.1 \\
\hline $\mathrm{Fe}_{2} \mathrm{O}_{3}(\mathrm{Wt} \%)$ & AAS & 28 & 23 & 14 & 46 & 28 & 21 & 22 & 22 & 12 & 22 & 12 \\
\hline $\mathrm{CaO}(\mathrm{Wt} \%)$ & AAS & 27 & 31 & 62 & 14 & 21 & 37 & 29 & 25 & 19 & 10 & 32 \\
\hline $\mathrm{MgO}(\mathrm{Wt} \%)$ & AAS & 2.3 & 3.2 & 5.3 & 2.8 & 5.0 & 5.9 & 5.3 & 5.9 & 2.6 & 3.0 & 3.0 \\
\hline $\mathrm{Na}_{2} \mathrm{O}(\mathrm{Wt} \%)$ & AES & 30 & 13 & 13 & 13 & 4.8 & 3.8 & 4.5 & 5.3 & 3.1 & 2.77 & 1.8 \\
\hline $\begin{array}{l}\text { Trace Elements } \\
(\mathrm{Wt} \%)\end{array}$ & GFAA & 0.068 & 0.078 & 0.082 & 0.055 & 0.071 & 0.053 & 0.043 & 0.044 & 0.036 & 0.023 & 0.016 \\
\hline Total (Wt\%) & & 100.00 & 100.00 & 100.00 & 100.00 & 100.00 & 100.00 & 100.00 & 100.00 & 100.00 & 100.00 & 100.00 \\
\hline
\end{tabular}


Table B-15 (continued)

Size-Segregated Elemental Concentrations of the Wyodak Fly Ash Sampled at the Baghouse Inlet Port

c) Trace Element Concentrations

\begin{tabular}{|c|c|c|c|c|c|c|c|c|c|c|c|c|}
\hline Impactor & Stage & I & 2 & 3 & 4 & 5 & 6 & 7 & 8 & 9 & 10 & II \\
\hline Cut-off & $\begin{array}{l}\text { Diameter } \\
\text { (microns) }\end{array}$ & 0.0324 & 0.0636 & 0.0926 & 0.168 & 0.337 & 0.535 & 0.973 & 1.96 & 3.77 & 7.33 & 15.7 \\
\hline Element & $\begin{array}{l}\text { Analytical } \\
\text { Method }\end{array}$ & & & & & & & & & & & \\
\hline As & GFAA & 2.E +02 & $9.9 \mathrm{E}+0 \mathrm{I}$ & $9 . \mathrm{E}+0 \mathrm{I}$ & $6 . I E+0 I$ & $9.5 \mathrm{E}+01$ & $6.7 \mathrm{E}+0 \mathrm{I}$ & 7.E+0I & 7.E $+0 \mathrm{I}$ & $3.4 \mathrm{E}+0 \mathrm{I}$ & $\mathrm{I} .0 \mathrm{E}+0 \mathrm{I}$ & $3 . \mathrm{E}+0 \mathrm{I}$ \\
\hline Se & GFAA & nd & nd & $7.8 \mathrm{E}+0 \mathrm{I}$ & $4.8 \mathrm{E}+0 \mathrm{I}$ & $8 . I E+0 \mid$ & $4.6 \mathrm{E}+0 \mathrm{I}$ & $5 . E+0 I$ & $5.6 \mathrm{E}+0 \mathrm{I}$ & $2.20 \mathrm{E}+0 \mathrm{I}$ & $8 . E+00$ & $2.7 \mathrm{E}+01$ \\
\hline $\mathrm{Sb}$ & GFAA & $1.3 \mathrm{E}+02$ & $8 . E+0 I$ & $4.3 \mathrm{E}+0 \mathrm{I}$ & $1.3 \mathrm{E}+02$ & $2.4 \mathrm{E}+0 \mathrm{I}$ & I.E +02 & $2.4 \mathrm{E}+0 \mathrm{I}$ & $2 . E+0 I$ & $3 . \mathrm{E}+00$ & 8.E-OI & $9 . E+00$ \\
\hline$C_{0}$ & GFAA & nd & 4.E+OI & $3.8 \mathrm{E}+0 \mathrm{I}$ & $4 . I E+0 I$ & 7.E+0I & $9.80 \mathrm{E}+0 \mathrm{I}$ & $1.42 \mathrm{E}+02$ & $2 . E+02$ & $1.32 \mathrm{E}+02$ & $7 . E+0 I$ & $7.4 \mathrm{E}+0 \mathrm{I}$ \\
\hline
\end{tabular}

nd = below detection limit

d) Trace Element Uncertainties

\begin{tabular}{|c|c|c|c|c|c|c|c|c|c|c|c|c|}
\hline Impactor & Stage & I & 2 & 3 & 4 & 5 & 6 & 7 & 8 & 9 & 10 & II \\
\hline Cut-off & $\begin{array}{l}\text { Diameter } \\
\text { (microns) }\end{array}$ & 0.0324 & 0.0636 & 0.0926 & 0.168 & 0.337 & 0.535 & 0.973 & 1.96 & 3.77 & 7.33 & 15.7 \\
\hline Element & $\begin{array}{c}\text { Analytical } \\
\text { Method }\end{array}$ & & & & & & & & & & & \\
\hline As & & $2 . \mathrm{E}+02$ & $2 . \mathrm{E}+0 \mathrm{I}$ & $I . E+0 \mid$ & $8 . \mathrm{E}+00$ & $6 . \mathrm{E}+0 \mathrm{I}$ & $6 . \mathrm{E}+00$ & $6 . \mathrm{E}+01$ & $6 . \mathrm{E}+01$ & $5 . E+00$ & $5 . \mathrm{E}+00$ & I.E+0I \\
\hline Se & & & & $9 . \mathrm{E}+00$ & $6 . E+00$ & $8 . E+00$ & $6 . \mathrm{E}+00$ & $6 . \mathrm{E}+0 \mathrm{I}$ & $5 . E+00$ & 7.E-0I & $4 . \mathrm{E}+00$ & $5 . E+00$ \\
\hline $\mathrm{Sb}$ & & $4 . \mathrm{E}+0 \mathrm{I}$ & $2 . \mathrm{E}+0 \mathrm{I}$ & $8 . E+00$ & $4 . \mathrm{E}+0 \mathrm{I}$ & $7 . \mathrm{E}+00$ & $3 . \mathrm{E}+02$ & $6 . \mathrm{E}+00$ & $4 . \mathrm{E}+0 \mathrm{I}$ & $6 . \mathrm{E}+00$ & $6 . \mathrm{E}+00$ & $6 . \mathrm{E}+00$ \\
\hline$C_{0}$ & & & $9 . \mathrm{E}+00$ & $6 . \mathrm{E}+00$ & $5 . E+00$ & $6 . \mathrm{E}+0 \mathrm{I}$ & $7 . E+00$ & 7.E +00 & I.E +02 & $6 . \mathrm{E}+00$ & $3 . \mathrm{E}+0 \mathrm{I}$ & $5 . E+00$ \\
\hline
\end{tabular}


Table B-16

Size-Segregated Elemental Concentrations of the North Dakota Fly Ash Sampled at Port 4 (1.9 residence second)

a) Major Species Results

\begin{tabular}{|c|c|c|c|c|c|c|c|c|c|c|c|c|}
\hline Impactor & Stage & $\mathbf{I}$ & 2 & 3 & 4 & 5 & 6 & 7 & 8 & 9 & 10 & II \\
\hline Cut-off & $\begin{array}{l}\text { fDiameter } \\
\text { (microns) }\end{array}$ & 0.0324 & 0.0636 & 0.0926 & 0.168 & 0.337 & 0.535 & 0.973 & 1.96 & 3.77 & 7.33 & 15.7 \\
\hline Element & $\begin{array}{l}\text { Analytical } \\
\text { Method }\end{array}$ & & & & & & & & & & & \\
\hline $\begin{array}{c}\text { Total Mass Conc } \\
(\mathrm{g} / \mathrm{Nm} \wedge 3)\end{array}$ & Gravametric & $1.53 \mathrm{E}-0 \mid$ & $1.36 \mathrm{E}-01$ & |.4IE-0| & $|.87 \mathrm{E}-0|$ & $2.55 \mathrm{E}-01$ & $3.25 \mathrm{E}-01$ & 4.IIE-0I & $1.14 \mathrm{E}+00$ & $2.22 \mathrm{E}+00$ & $5.10 \mathrm{E}+00$ & $5.60 \mathrm{E}-01$ \\
\hline $\mathrm{SiO}_{2}(\mathrm{Wt} \%)$ & AAS & $1.5 \mathrm{E}+0 \mathrm{I}$ & $2 . I E+0 I$ & $1.7 \mathrm{E}+0 \mathrm{I}$ & $2.2 \mathrm{E}+0 \mathrm{I}$ & $2.3 \mathrm{E}+0 \mathrm{I}$ & $3 . I E+0 I$ & $3.2 \mathrm{E}+0 \mathrm{I}$ & $3.2 \mathrm{E}+0 \mathrm{I}$ & $4.0 \mathrm{E}+0 \mathrm{I}$ & $2.37 \mathrm{E}+0 \mathrm{I}$ & $4.0 \mathrm{E}+0 \mathrm{I}$ \\
\hline$+/-$ & & $2 . E+00$ & $3 . E+00$ & $2 . E+00$ & $2 . E+00$ & $2 . E+00$ & $2 . E+00$ & $2 . E+00$ & I.E +00 & I.E +00 & 9.E-0I & $2 . E+00$ \\
\hline $\mathrm{Al}_{2} \mathrm{O}_{3}(\mathrm{Wt} \%)$ & NAA/AAS & nd & nd & $8.0 \mathrm{E}+0 \mathrm{I}$ & $3 . \mathrm{E}+0 \mathrm{I}$ & $2.7 \mathrm{E}+0 \mathrm{I}$ & $2.6 \mathrm{E}+01$ & $2.8 \mathrm{E}+0 \mathrm{I}$ & $3.4 \mathrm{IE}+0 \mathrm{I}$ & $2.40 \mathrm{E}+0 \mathrm{I}$ & $1.24 \mathrm{E}+0 \mathrm{I}$ & $2.7 \mathrm{E}+0 \mathrm{I}$ \\
\hline$+/-$ & & & & $9 . \mathrm{E}+00$ & $5 . E+0 I$ & $2 . E+00$ & I.E +00 & I.E +00 & 8.E-0I & 5.E-OI & 4.E-OI & I.E +00 \\
\hline $\mathrm{Fe}_{2} \mathrm{O}_{3}(\mathrm{Wt} \%)$ & NAA/AAS & $4.7 \mathrm{E}+00$ & $6.2 \mathrm{E}+00$ & $6.3 \mathrm{E}+00$ & I.IE+0I & $5.9 \mathrm{E}+0 \mathrm{I}$ & $1.90 \mathrm{E}+0 \mathrm{I}$ & $2 . I E+0 I$ & $2.09 \mathrm{E}+01$ & $1.89 \mathrm{E}+0 \mathrm{I}$ & $1.6 \mathrm{E}+0 \mathrm{I}$ & $1.54 \mathrm{E}+0 \mathrm{I}$ \\
\hline$+/-$ & & 7.E-0I & 9.E-0I & 9.E-0I & I.E +00 & $4 . E+00$ & 9.E-0I & I.E +00 & 6.E-0I & 6.E-0I & $7 . \mathrm{E}+00$ & 7.E-0I \\
\hline $\mathrm{Ca} 0(\mathrm{Wt} \%)$ & NAA/AAS & $6 . \mathrm{IE}+00$ & $4.4 \mathrm{E}+00$ & $9 . \mathrm{E}+00$ & $7.6 \mathrm{E}+00$ & $I . E+0 \mid$ & $1.21 \mathrm{E}+0 \mathrm{I}$ & $1.29 \mathrm{E}+0 \mathrm{I}$ & $1.3 \mathrm{E}+0 \mid$ & $1.45 \mathrm{E}+0 \mathrm{I}$ & $9 . \mathrm{E}+00$ & $1.39 \mathrm{E}+01$ \\
\hline$+/-$ & & 7.E-0I & 6.E-0I & I.E+0I & 6.E-0I & 6.E-0I & 6.E-0I & 6.E-0I & $3 . E+00$ & 4.E-OI & $\mathrm{I} . \mathrm{E}+0 \mathrm{I}$ & 5.E-0I \\
\hline $\mathrm{MgO}(\mathrm{Wt} \%)$ & NAA/AAS & $2.2 \mathrm{E}+00$ & $1.9 \mathrm{E}+00$ & $2 . E+00$ & $3 . E+00$ & $3.9 \mathrm{E}+00$ & $4.7 \mathrm{E}+00$ & $5 . \mathrm{IE}+00$ & $3.3 \mathrm{E}+00$ & $3.8 \mathrm{E}+00$ & $2.27 \mathrm{E}+00$ & $4.4 \mathrm{E}+00$ \\
\hline$+/-$ & & 2.E-OI & 2.E-0I & $2 . E+00$ & $2 . \mathrm{E}+00$ & 2.E-0I & I.E-OI & 2.E-OI & I.E-OI & 8.E-0I & I.E-02 & I.E-0| \\
\hline $\mathrm{Na}_{2} \mathrm{O}(\mathrm{Wt} \%)$ & NAA/AAS & $1.4 \mathrm{E}+0 \mid$ & $2.0 \mathrm{E}+0 \mathrm{I}$ & $8 . E+00$ & $1.55 \mathrm{E}+0 \mathrm{I}$ & $2 . E+01$ & $2.10 E+01$ & $2.20 \mathrm{E}+0 \mathrm{I}$ & $2.13 \mathrm{E}+01$ & $1.2 \mathrm{E}+0 \mathrm{I}$ & $6.33 \mathrm{E}+00$ & $2 . \mathrm{E}+0 \mathrm{I}$ \\
\hline$+/-$ & & I.E +00 & $2 . E+00$ & I.E+0I & 8.E-0I & $|. E+0|$ & 7.E-0I & 7.E-0I & 3.E-0I & $8 . E+00$ & 9.E-02 & 6.E-0I \\
\hline $\begin{array}{c}\text { Trace Elements } \\
(\mathrm{Wt} \%)\end{array}$ & NAA/GFAA & I.5E-0I & $1.6 \mathrm{E}-0 \mathrm{I}$ & $3.4 \mathrm{E}+00$ & $3.0 \mathrm{E}+00$ & $3.3 \mathrm{E}+00$ & $3.4 \mathrm{E}-02$ & $2.8 \mathrm{E}-02$ & $5.4 \mathrm{E}+00$ & $2.8 \mathrm{E}+00$ & $2.2 \mathrm{E}+00$ & $2.7 \mathrm{E}-02$ \\
\hline Total (Wt\%) & & 42 & 53 & 127 & 87 & 150 & 114 & 121 & 130 & 116 & 73 & 122 \\
\hline
\end{tabular}

Note: Elemental concentrations have been converted to oxide forms on a $\mathrm{SO}_{3}$-free basis. nd - below detection limit 
Table B-16 (continued)

Size-Segregated Elemental Concentrations of the North Dakota Fly Ash Sampled at Port 4 (1.9 residence second)

b) Normalized Major Species Results

\begin{tabular}{|c|c|c|c|c|c|c|c|c|c|c|c|c|}
\hline Impactor & Stage & I & 2 & 3 & 4 & 5 & 6 & 7 & 8 & 9 & 10 & II \\
\hline Cut-off & $\begin{array}{l}\text { Diameter } \\
\text { (microns) }\end{array}$ & 0.0324 & 0.0636 & 0.0926 & 0.168 & 0.337 & 0.535 & 0.973 & 1.96 & 3.77 & 7.33 & 15.7 \\
\hline Element & $\begin{array}{c}\text { Analytical } \\
\text { Method }\end{array}$ & & & & & & & & & & & \\
\hline $\begin{array}{c}\text { Total Mass Conc } \\
\left(\mathrm{g} / \mathrm{Nm}^{\wedge} 3\right)\end{array}$ & Gravametric & I.5E-0I & I.4E-0I & I.4E-0I & $1.9 \mathrm{E}-0 \mathrm{I}$ & $2.6 \mathrm{E}-01$ & $3.3 \mathrm{E}-01$ & 4.IE-0I & $\begin{array}{c}\text { I.IE }+0 \\
0\end{array}$ & $\begin{array}{c}2.2 \mathrm{E}+0 \\
0\end{array}$ & $\begin{array}{c}5 . \mathrm{IE}+0 \\
0\end{array}$ & $5.6 \mathrm{E}-01$ \\
\hline $\mathrm{SiO}_{2}(\mathrm{Wt} \%)$ & AAS & 35 & 39 & 13 & 25 & 15 & 27 & 27 & 25 & 35 & 33 & 33 \\
\hline $\mathrm{Al}_{2} \mathrm{O}_{3}(\mathrm{Wt} \%)$ & AAS & nd & nd & 63 & 30 & 18 & 23 & 23 & 26 & 21 & 17 & 22 \\
\hline $\mathrm{Fe}_{2} \mathrm{O}_{3}(\mathrm{Wt} \%)$ & AAS & II & 12 & 5.0 & 12 & 40 & 17 & 17 & 16 & 16 & 22 & 13 \\
\hline $\mathrm{CaO}(\mathrm{Wt} \%)$ & AAS & 15 & 8.3 & 7.3 & 8.7 & 7.0 & II & 11 & 10 & 13 & 13 & II \\
\hline $\mathrm{MgO}(\mathrm{Wt} \%)$ & AAS & 5.1 & 3.5 & 1.7 & 3.0 & 2.6 & 4.1 & 4.2 & 2.5 & 3.3 & 3.1 & 3.6 \\
\hline $\mathrm{Na}_{2} \mathrm{O}(\mathrm{Wt} \%)$ & AES & 34 & 38 & 7 & 18 & 16 & 19 & 18 & 16 & 10 & 8.7 & 18 \\
\hline $\begin{array}{l}\text { Trace Elements } \\
(\mathrm{Wt} \%)\end{array}$ & GFAA & 0.35 & 0.29 & 2.7 & 3.5 & 2.2 & 0.030 & 0.023 & 4.2 & 2.4 & 3.1 & 0.022 \\
\hline Total (Wt\%) & & 100.00 & 100.00 & 100.00 & 100.00 & 100.00 & 100.00 & 100.00 & 100.00 & 100.00 & 100.00 & 100.00 \\
\hline
\end{tabular}

Note: Elemental concentrations have been converted to oxide forms on $\mathrm{SO}_{3}$-free basis. nd - below detection limit 
Table B-16 (continued)

Size-Segregated Elemental Concentrations of the North Dakota Fly Ash Sampled at Port 4 (1.9 residence second)

c) Trace Element Concentrations

\begin{tabular}{|c|c|c|c|c|c|c|c|c|c|c|c|c|}
\hline Impactor & Stage & I & 2 & 3 & 4 & 5 & 6 & 7 & 8 & 9 & 10 & II \\
\hline Element : As & NAA/GFAA & $5.9 \mathrm{E}+02$ & $3.6 \mathrm{E}+02$ & $2 . \mathrm{IE}+02$ & $1.4 \mathrm{E}+02$ & $1.5 \mathrm{E}+02$ & $1.6 \mathrm{E}+02$ & $1.42 \mathrm{E}+02$ & $1.47 \mathrm{E}+02$ & I.IE +02 & $4 . \mathrm{E}+0 \mathrm{I}$ & $1.01 \mathrm{E}+02$ \\
\hline $\mathrm{Se}$ & NAA/GFAA & $8 . \mathrm{E}+01$ & $5 . \mathrm{E}+0 \mathrm{I}$ & $3 . \mathrm{E}+0 \mathrm{I}$ & nd & nd & $2 . \mathrm{E}+0 \mathrm{I}$ & $3 . \mathrm{E}+01$ & $|\mathrm{I} . \mathrm{E}+0|$ & $9 . \mathrm{E}+00$ & $3 . E+00$ & nd \\
\hline $\mathrm{Sb}$ & NAA/GFAA & $8.0 \mathrm{E}+02$ & I.IE +03 & I.E+02 & $2 . \mathrm{E}+03$ & $4 . E+02$ & $5.6 \mathrm{E}+01$ & $\mathrm{I} .3 \mathrm{E}+0 \mathrm{I}$ & $|. E+0|$ & $4.6 \mathrm{E}+0 \mathrm{I}$ & $2 . E+00$ & $4.0 \mathrm{E}+0 \mathrm{I}$ \\
\hline$C_{0}$ & NAA/GFAA & nd & nd & $1.9 \mathrm{E}+02$ & $5.3 \mathrm{E}+01$ & $7.9 \mathrm{E}+0 \mathrm{I}$ & $9.77 \mathrm{E}+0 \mathrm{I}$ & $1.01 \mathrm{E}+02$ & $1.32 \mathrm{E}+02$ & I.E +02 & $5.2 \mathrm{E}+0 \mathrm{I}$ & $1.26 \mathrm{E}+02$ \\
\hline Cs & NAA & & & $8.5 \mathrm{E}+01$ & $1.5 \mathrm{E}+02$ & $1.9 \mathrm{E}+02$ & & & $4.9 \mathrm{E}+02$ & $6.2 \mathrm{E}+01$ & $2 . I E+0 I$ & \\
\hline Sc & NAA & & & nd & nd & nd & & & nd & nd & nd & \\
\hline $\mathrm{Cr}$ & NAA & & & $4 . \mathrm{IE}+03$ & $5.7 \mathrm{E}+03$ & $\mathrm{nd}$ & & & $2.0 \mathrm{E}+03$ & $6 . \mathrm{E}+02$ & $5 . \mathrm{E}+02$ & \\
\hline $\ln$ & NAA & & & $1.2 \mathrm{E}+03$ & $8 . \mathrm{E}+02$ & nd & & & $2.4 \mathrm{E}+03$ & nd & $3 . E+02$ & \\
\hline $\mathrm{Br}$ & NAA & & & $9 . \mathrm{E}+03$ & $7.5 \mathrm{E}+03$ & $1.5 \mathrm{E}+04$ & & & $2.2 \mathrm{E}+03$ & $6.8 \mathrm{E}+02$ & $4.5 \mathrm{E}+02$ & \\
\hline Mo & NAA & & & $2 . \mathrm{E}+0 \mathrm{I}$ & $2 . E+0 \mid$ & nd & & & $4 . \mathrm{E}+0 \mathrm{I}$ & $2 . \mathrm{E}+0 \mathrm{I}$ & I.E $+0 \mid$ & \\
\hline$C d$ & NAA & & & $3.9 \mathrm{E}+03$ & $5 . \mathrm{IE}+03$ & $1.6 \mathrm{E}+04$ & & & $2.3 \mathrm{IE}+04$ & $3.22 \mathrm{E}+03$ & $3.4 \mathrm{IE}+03$ & \\
\hline $\mathrm{Ba}$ & NAA & & & $2 . E+0 I$ & $2 . E+0 I$ & $4.7 \mathrm{E}+02$ & & & $1.6 \mathrm{E}+02$ & $4 . \mathrm{E}+0 \mathrm{I}$ & $3 . \mathrm{E}+0 \mathrm{I}$ & \\
\hline $\mathrm{La}$ & NAA & & & $|| I E+0 \mid$. & $\mathrm{I} .3 \mathrm{E}+0 \mathrm{I}$ & $5 . \mathrm{IE}+02$ & & & $8.2 \mathrm{E}+0 \mathrm{I}$ & $2.7 \mathrm{E}+0 \mathrm{I}$ & $2 . \mathrm{E}+0 \mathrm{I}$ & \\
\hline $\mathrm{Ce}$ & NAA & & & nd & $\mathrm{I} . \mathrm{E}+0 \mathrm{I}$ & $9 . \mathrm{IE}+02$ & & & $\mathrm{I} .4 \mathrm{E}+02$ & $4.7 \mathrm{E}+01$ & $4.0 \mathrm{E}+0 \mathrm{I}$ & \\
\hline $\mathrm{Nd}$ & NAA & & & nd & nd & nd & & & $1.3 \mathrm{E}+02$ & $\mathrm{I} . \mathrm{IE}+02$ & nd & \\
\hline $\mathrm{Sm}$ & NAA & & & 9.E-0I & $1.2 \mathrm{E}+00$ & 9.E-02 & & & $|.24 \mathrm{E}+0|$ & $4.4 \mathrm{E}+00$ & $4.0 \mathrm{E}+00$ & \\
\hline $\mathrm{Eu}$ & NAA & & & nd & $6.5 \mathrm{E}+00$ & nd & & & nd & nd & 8.E-0I & \\
\hline Lu & NAA & & & nd & $2 . \mathrm{E}-0 \mid$ & nd & & & $1.4 \mathrm{E}+00$ & 5.E-0I & 5.E-0I & \\
\hline $\mathrm{Hf}$ & NAA & & & nd & nd & nd & & & nd & nd & $3.9 \mathrm{E}+00$ & \\
\hline $\mathrm{Ta}$ & NAA & & & $d$ & nd & nd & & & nd & nd & nd & \\
\hline $\mathrm{Au}$ & NAA & & & 7.E-02 & 8.E-02 & $3.5 \mathrm{E}-01$ & & & nd & $3.66 \mathrm{E}+00$ & I.E-02 & \\
\hline $\mathrm{Hg}$ & NAA & & & $7 . E+00$ & $2.6 \mathrm{E}+00$ & nd & & & nd & nd & nd & \\
\hline Th & NAA & & & nd & $4 . E+00$ & nd & & & $3.3 \mathrm{E}+01$ & $|.0 \mathrm{E}+0|$ & $9 . E+00$ & \\
\hline U & NAA & & & nd & nd & nd & & & $3.0 \mathrm{E}+00$ & $\mathrm{I} . \mathrm{E}+0 \mathrm{I}$ & nd & \\
\hline $\mathrm{Cl}$ & NAA & & & I.IE+04 & $9 . \mathrm{E}+03$ & I.E +02 & & & $1.5 \mathrm{E}+03$ & $1.6 \mathrm{E}+03$ & $1.2 \mathrm{E}+03$ & \\
\hline K & NAA & & & nd & nd & nd & & & $\mathrm{I} . \mathrm{IE}+04$ & $9.9 \mathrm{E}+03$ & $8 . \mathrm{E}+03$ & \\
\hline $\mathrm{Ti}$ & NAA & & & nd & nd & nd & & & $2.1 \mathrm{IE}+03$ & $3.0 \mathrm{E}+03$ & $2.5 \mathrm{E}+03$ & \\
\hline V & NAA & & & $2 . E+02$ & $7 . \mathrm{E}+0 \mathrm{I}$ & $5 . E+0 I$ & & & $2 . E+02$ & $2 . E+02$ & $\mathrm{II.E}+02$ & \\
\hline$M n$ & NAA & & & $4 . E+02$ & $2 . E+02$ & nd & & & $4 . E+02$ & $4 . E+02$ & $4 . E+02$ & \\
\hline $\mathrm{Sr}$ & NAA & & & nd & nd & nd & & & $2.5 \mathrm{E}+03$ & $3.0 \mathrm{E}+03$ & $2.4 \mathrm{E}+03$ & \\
\hline $\mathrm{Ba}$ & NAA & & & $3.7 \mathrm{E}+03$ & nd & $6 . E+00$ & & & $5.22 \mathrm{E}+03$ & $4.98 \mathrm{E}+03$ & $3.06 \mathrm{E}+03$ & \\
\hline
\end{tabular}

nd = below detection limit 
Table B-16 (continued)

Size-Segregated Elemental Concentrations of the North Dakota Fly Ash Sampled at Port 4 (1.9 residence second)

d) Trace Element Uncertainties

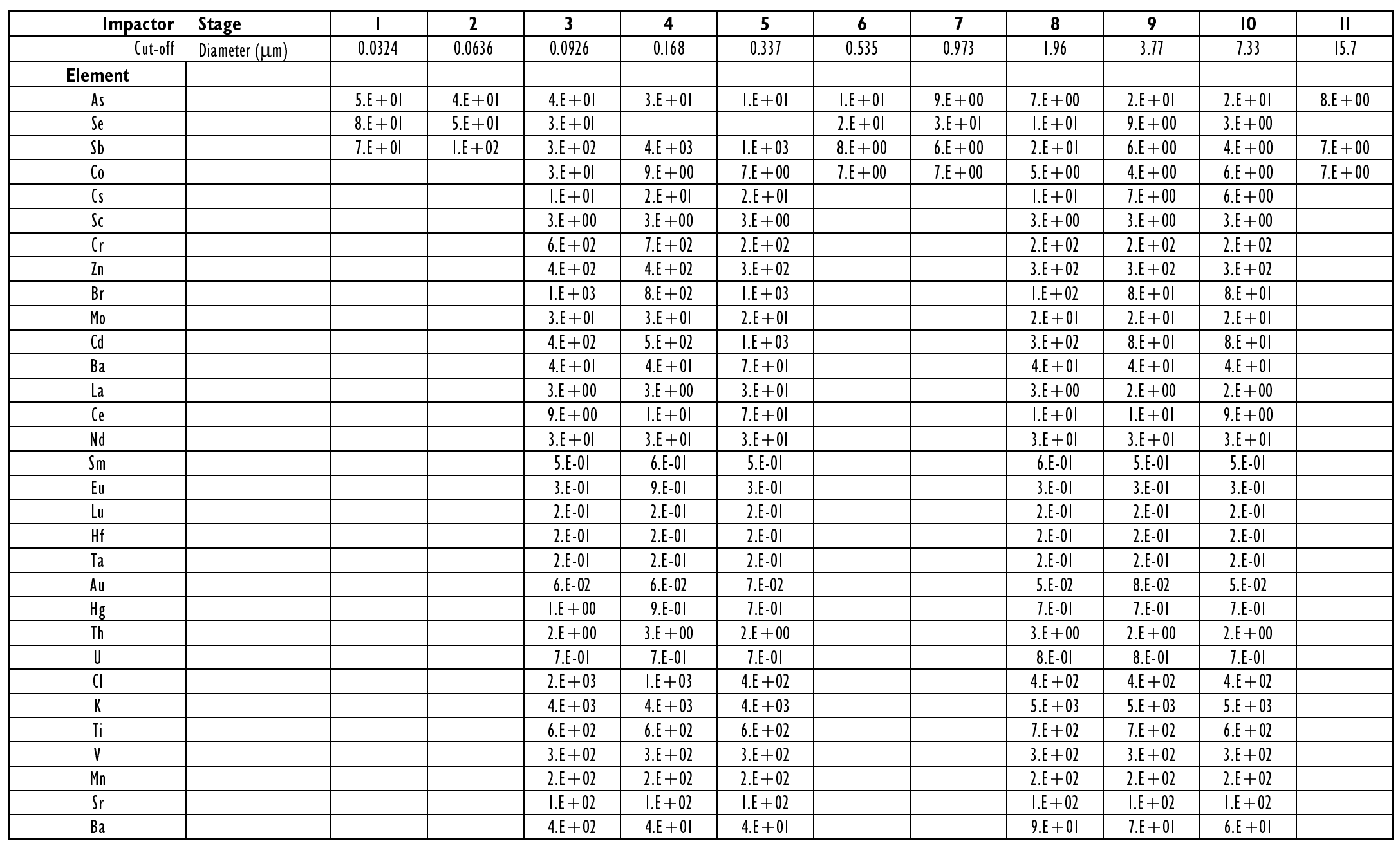


Table B-17

Size-Segregated Elemental Concentrations of the North Dakota Fly Ash Sampled at Port 14 (9.4 residence second)

a) Major Species Results

\begin{tabular}{|c|c|c|c|c|c|c|c|c|c|c|c|c|}
\hline Impactor & Stage & I & 2 & 3 & 4 & 5 & 6 & 7 & 8 & 9 & 10 & II \\
\hline \multicolumn{2}{|c|}{$\begin{array}{r}\text { Cut-offDiameter } \\
\text { (microns) }\end{array}$} & 0.0324 & 0.0636 & 0.0926 & 0.168 & 0.337 & 0.535 & 0.973 & 1.96 & 3.77 & 7.33 & 15.7 \\
\hline Element & $\begin{array}{l}\text { Analytical } \\
\text { Method }\end{array}$ & & & & & & & & & & & \\
\hline $\begin{array}{c}\text { Total Mass Conc } \\
(\mathrm{g} / \mathrm{Nm} \wedge 3)\end{array}$ & Gravametric & $6.18 \mathrm{E}-02$ & $9.80 \mathrm{E}-02$ & I.37E-0I & I.44E-0| & $1.85 \mathrm{E}-01$ & $2.86 \mathrm{E}-01$ & $3.64 \mathrm{E}-01$ & $1.17 \mathrm{E}+00$ & $2.39 \mathrm{E}+00$ & $4.85 E+00$ & $7.60 \mathrm{E}-01$ \\
\hline $\mathrm{SiO}_{2}(\mathrm{Wt} \%)$ & AAS & $3 . I E+0 \mid$ & $1.7 \mathrm{E}+0 \mathrm{I}$ & $1.9 \mathrm{E}+0 \mathrm{I}$ & $4.4 \mathrm{E}+0 \mathrm{I}$ & $3.6 \mathrm{E}+0 \mathrm{I}$ & $3.4 \mathrm{E}+0 \mathrm{I}$ & $2 . I E+0 \mid$ & $3.7 \mathrm{E}+0 \mathrm{I}$ & $4 . I E+0 I$ & $3.94 \mathrm{E}+0 \mathrm{I}$ & $3.8 \mathrm{E}+0 \mathrm{I}$ \\
\hline$+/-$ & & $6 . E+00$ & $3 . E+00$ & $2 . E+00$ & $4 . E+00$ & $3 . E+00$ & $2 . E+00$ & $2 . E+00$ & I.E +00 & $\mathrm{I} . \mathrm{E}+00$ & 9.E-0I & I.E +00 \\
\hline $\mathrm{Al}_{2} \mathrm{O}_{3}(\mathrm{Wt} \%)$ & NAA/AAS & $2.3 \mathrm{E}+0 \mathrm{I}$ & $9.6 \mathrm{E}+00$ & $4.2 \mathrm{E}+0 \mathrm{I}$ & $3 . \mathrm{E}+0 \mathrm{I}$ & $3.0 \mathrm{E}+0 \mathrm{I}$ & $2.9 \mathrm{E}+0 \mathrm{I}$ & $2.7 \mathrm{E}+01$ & $3.33 \mathrm{E}+0 \mathrm{I}$ & $2.70 \mathrm{E}+0 \mathrm{I}$ & $1.45 \mathrm{E}+0 \mathrm{I}$ & $2.73 \mathrm{E}+01$ \\
\hline$+/-$ & & $3 . E+00$ & I.E +00 & $3 . E+00$ & $3 . \mathrm{E}+0 \mathrm{I}$ & $2 . E+00$ & I.E+00 & $\mathrm{I} . \mathrm{E}+00$ & 8.E-0I & 5.E-OI & 4.E-0I & 8.E-0I \\
\hline $\mathrm{Fe}_{2} \mathrm{O}_{3}(\mathrm{Wt} \%)$ & NAA/AAS & $1.4 \mathrm{E}+0 \mathrm{I}$ & $8 . E+01$ & 7.E +00 & $9.70 \mathrm{E}+0 \mathrm{I}$ & $6 . \mathrm{E}+0 \mathrm{I}$ & $1.9 \mathrm{E}+01$ & $1.74 \mathrm{E}+0 \mathrm{I}$ & $2.23 \mathrm{E}+0 \mathrm{I}$ & $1.58 \mathrm{E}+0 \mid$ & $1.58 \mathrm{E}+0 \mathrm{I}$ & $1.49 \mathrm{E}+01$ \\
\hline$+/-$ & & $3 . E+00$ & $2 . E+0 I$ & I.E +00 & 7.E +00 & I.E +02 & I.E +00 & 9.E-OI & 8.E-0I & 4.E-OI & 4.E-OI & 6.E-0I \\
\hline $\mathrm{Ca} 0(\mathrm{Wt} \%)$ & NAA/AAS & $4.2 \mathrm{E}+00$ & $4.0 \mathrm{E}+00$ & $5.0 \mathrm{E}+00$ & $9.7 \mathrm{E}+00$ & $1.03 \mathrm{E}+01$ & $9.59 \mathrm{E}+00$ & $7.4 \mathrm{E}+00$ & $1.38 \mathrm{E}+01$ & $|\mathrm{I.E}+0|$ & $8.3 \mathrm{E}+00$ & $1.12 \mathrm{E}+01$ \\
\hline$+/-$ & & 8.E-0I & 8.E-0I & 7.E-0I & I.E +00 & 9.E-OI & 5.E-OI & 4.E-OI & 5.E-OI & $\mathrm{I} . \mathrm{E}+0 \mathrm{I}$ & $\mathrm{I} . \mathrm{E}+0 \mathrm{I}$ & 4.E-OI \\
\hline $\mathrm{MgO}(\mathrm{Wt} \%)$ & NAA/AAS & $2 . I E+00$ & $2.7 \mathrm{E}+00$ & $2.0 \mathrm{E}+00$ & $3.6 \mathrm{E}+00$ & $4 . E+00$ & $4.8 \mathrm{E}+00$ & $4.7 \mathrm{E}+00$ & $3.7 \mathrm{E}+00$ & $3.77 \mathrm{E}+00$ & $2.29 \mathrm{E}+00$ & $4.65 \mathrm{E}+00$ \\
\hline$+/-$ & & 4.E-OI & 5.E-0I & 2.E-OI & 3.E-0I & $3 . E+00$ & 2.E-OI & 2.E-0I & I.E-OI & 9.E-02 & I.E-02 & 8.E-02 \\
\hline $\mathrm{Na}_{2} \mathrm{O}(\mathrm{Wt} \%)$ & NAA/AAS & $2.2 \mathrm{E}+0 \mathrm{I}$ & $3.9 \mathrm{E}+0 \mathrm{I}$ & $3.2 \mathrm{E}+0 \mathrm{I}$ & $3 . \mid \mathrm{IE}+0 \mathrm{I}$ & $4.4 \mathrm{E}+0 \mathrm{I}$ & $2.48 \mathrm{E}+0 \mathrm{I}$ & $1.93 \mathrm{E}+0 \mathrm{I}$ & $1.76 \mathrm{E}+0 \mathrm{I}$ & $1.2 \mathrm{E}+0 \mathrm{I}$ & $9.7 \mathrm{E}+00$ & $1.76 \mathrm{E}+0 \mathrm{I}$ \\
\hline$+/-$ & & $5 . E+00$ & $8 . E+00$ & $3 . E+00$ & $2 . E+00$ & 2.E +00 & 9.E-OI & 7.E-0I & 2.E +01 & $6 . E+00$ & $9 . E+00$ & 3.E-OI \\
\hline $\begin{array}{c}\text { Trace Elements } \\
(\mathrm{Wt} \%)\end{array}$ & NAA/GFAA & $2.5 \mathrm{E}-0 \mathrm{I}$ & $6.6 \mathrm{E}-02$ & $3 . I E+00$ & $\mathrm{I} . \mathrm{IE}+00$ & $4 . I E+00$ & $3.6 \mathrm{E}-02$ & $6.2 \mathrm{E}-02$ & $3 . I E+00$ & $3.3 \mathrm{E}+00$ & $3.2 \mathrm{E}+00$ & $2.6 \mathrm{E}-02$ \\
\hline Total (Wt\%) & & 97 & 156 & 110 & 213 & 189 & 121 & 97 & 130 & 115 & 93 & 114 \\
\hline
\end{tabular}

Note: Elemental concentrations have been converted to oxide forms on a $\mathrm{SO}_{3}$-free basis. nd - below detection limit 
Table B-17 (continued)

Size-Segregated Elemental Concentrations of the North Dakota Fly Ash Sampled at Port 14 (9.3 residence second)

b) Normalized Major Species Results

\begin{tabular}{|c|c|c|c|c|c|c|c|c|c|c|c|c|}
\hline Impactor & Stage & I & 2 & 3 & 4 & 5 & 6 & 7 & 8 & 9 & 10 & II \\
\hline Cut-off & $\begin{array}{l}\text { Diameter } \\
\text { (microns) }\end{array}$ & 0.0324 & 0.0636 & 0.0926 & 0.168 & 0.337 & 0.535 & 0.973 & 1.96 & 3.77 & 7.33 & 15.7 \\
\hline Element & $\begin{array}{c}\text { Analytical } \\
\text { Method }\end{array}$ & & & & & & & & & & & \\
\hline $\begin{array}{c}\text { Total Mass Conc } \\
\left(\mathrm{g} / \mathrm{Nm}^{\wedge} 3\right)\end{array}$ & Gravametric & $6.2 \mathrm{E}-02$ & $9.8 \mathrm{E}-02$ & I.4E-0I & I.4E-0I & $1.9 \mathrm{E}-01$ & $2.9 \mathrm{E}-0 \mathrm{I}$ & $3.6 \mathrm{E}-01$ & $\begin{array}{c}1.2 \mathrm{E}+0 \\
0\end{array}$ & $\begin{array}{c}2.4 \mathrm{E}+0 \\
0\end{array}$ & $\begin{array}{c}4.8 \mathrm{E}+0 \\
0\end{array}$ & $7.6 \mathrm{E}-01$ \\
\hline $\mathrm{SiO}_{2}(\mathrm{Wt} \%)$ & AAS & 32 & II & 18 & 21 & 19 & 28 & 22 & 28 & 36 & 42 & 33 \\
\hline $\mathrm{Al}_{2} \mathrm{O}_{3}(\mathrm{Wt} \%)$ & AAS & 24 & 6 & 38 & 12 & 16 & 24 & 27 & 26 & 23 & 16 & 24 \\
\hline $\mathrm{Fe}_{2} \mathrm{O}_{3}(\mathrm{Wt} \%)$ & AAS & 15 & 53 & 6 & 46 & 32 & 16 & 18 & 17 & 14 & 17 & 13 \\
\hline $\mathrm{CaO}(\mathrm{Wt} \%)$ & AAS & 4.3 & 2.6 & 4.6 & 4.6 & 5.4 & 7.9 & 7.6 & II & 10 & 8.9 & 10 \\
\hline $\mathrm{MgO}(\mathrm{Wt} \%)$ & AAS & 2.1 & 1.8 & 1.8 & 1.7 & 2.1 & 4.0 & 4.9 & 2.9 & 3.3 & 2.5 & 4.1 \\
\hline $\mathrm{Na}_{2} \mathrm{O}(\mathrm{Wt} \%)$ & AES & 23 & 25 & 29 & 15 & 23 & 20 & 20 & 13 & II & 10 & 15 \\
\hline $\begin{array}{l}\text { Trace Elements } \\
(\mathrm{Wt} \%)\end{array}$ & GFAA & 0.25 & 0.042 & 2.8 & 0.5 & 2.2 & 0.030 & 0.064 & 2.4 & 2.8 & 3.4 & 0.023 \\
\hline Total $(\mathrm{Wt} \%)$ & & 100.00 & 100.00 & 100.00 & 100.00 & 100.00 & 100.00 & 100.00 & 100.00 & 100.00 & 100.00 & 100.00 \\
\hline
\end{tabular}

Note: Elemental concentrations have been converted to oxide forms on a $\mathrm{SO}_{3}$-free basis.

nd - below detection limit 
Table B-17 (continued)

Size-Segregated Elemental Concentrations of the North Dakota Fly Ash Sampled at Port 14 (9.3 residence second)

c) Trace Element Concentrations

\begin{tabular}{|c|c|c|c|c|c|c|c|c|c|c|c|c|}
\hline Impactor & Stage & I & 2 & 3 & 4 & 5 & 6 & 7 & 8 & 9 & 10 & II \\
\hline Element: As & NAA/GFAA & $4.2 \mathrm{E}+02$ & $3.6 \mathrm{E}+02$ & $2.7 \mathrm{E}+02$ & $2.4 \mathrm{E}+02$ & $4 . E+02$ & $2.3 \mathrm{E}+02$ & $2.0 \mathrm{E}+02$ & $1.94 \mathrm{E}+02$ & $1.5 \mathrm{E}+02$ & $6.5 \mathrm{E}+01$ & $1.05 E+02$ \\
\hline $\mathrm{Se}$ & NAA/GFAA & nd & $2 . \mathrm{E}+02$ & $6 . \mathrm{E}+01$ & nd & nd & $2 . \mathrm{E}+0 \mathrm{I}$ & $3 . \mathrm{E}+0 \mathrm{I}$ & $9 . \mathrm{E}+00$ & $4 . \mathrm{E}+00$ & $2 . \mathrm{E}+00$ & nd \\
\hline $\mathrm{Sb}$ & NAA/GFAA & $2 . I E+03$ & $1.5 \mathrm{E}+02$ & $2.6 \mathrm{E}+0 \mathrm{I}$ & $2.6 \mathrm{E}+01$ & $4.0 \mathrm{E}+0 \mathrm{I}$ & $1.4 \mathrm{E}+0 \mathrm{I}$ & $3.1 \mathrm{I}+02$ & $8 . E+00$ & $9 . \mathrm{E}+00$ & $|.4 \mathrm{E}+0|$ & $6.4 \mathrm{E}+0 \mathrm{I}$ \\
\hline $\mathrm{Co}_{0}$ & NAA/GFAA & nd & nd & $5 . E+01$ & $7 . \mathrm{E}+0 \mid$ & $2 . E+02$ & $9 . \mathrm{E}+0 \mid$ & $9 . \mathrm{E}+0 \mathrm{I}$ & I.E +02 & $9 . \mathrm{E}+0 \mathrm{I}$ & $7 . \mathrm{E}+0 \mathrm{I}$ & $9 . \mathrm{E}+0 \mathrm{I}$ \\
\hline Cs & NAA & & & $9 . \mathrm{E}+01$ & $2.1 \mathrm{E}+02$ & $4.3 \mathrm{E}+02$ & & & $8 . I E+0 I$ & $4.8 \mathrm{E}+0 \mathrm{I}$ & $5.2 \mathrm{E}+0 \mathrm{I}$ & \\
\hline Sc & NAA & & & nd & nd & nd & & & nd & $5.9 \mathrm{E}+01$ & nd & \\
\hline $\mathrm{Cr}$ & NAA & & & $2.8 \mathrm{E}+03$ & nd & nd & & & $3 . \mathrm{E}+02$ & $3 . E+02$ & $9 . \mathrm{E}+02$ & \\
\hline $\ln$ & NAA & & & $4 . \mathrm{E}+02$ & nd & nd & & & $6 . \mathrm{E}+02$ & $4 . \mathrm{E}+02$ & nd & \\
\hline $\mathrm{Br}$ & NAA & & & $5.8 \mathrm{E}+03$ & $3 . E+00$ & $4.8 \mathrm{E}+03$ & & & $4.5 E+02$ & $2.4 \mathrm{E}+02$ & $8.7 \mathrm{E}+02$ & \\
\hline Mo & NAA & & & nd & I.E-0| & $1.2 \mathrm{E}+02$ & & & $|. E+0|$ & $|. E+0|$ & $4 . \mathrm{E}+0 \mathrm{I}$ & \\
\hline$C d$ & NAA & & & $2.4 \mathrm{E}+03$ & $3 . \mathrm{E}+0 \mathrm{I}$ & $2.2 \mathrm{E}+04$ & & & $7.8 \mathrm{E}+03$ & $3.17 \mathrm{E}+03$ & $4.5 \mathrm{IE}+03$ & \\
\hline $\mathrm{Ba}$ & NAA & & & $4 . E+0 I$ & $3.2 \mathrm{E}+02$ & $2.6 \mathrm{E}+02$ & & & nd & $5 . E+0 I$ & I.IE +02 & \\
\hline $\mathrm{La}$ & NAA & & & $2 . I E+0 I$ & $2.4 \mathrm{E}+02$ & $1.8 \mathrm{E}+02$ & & & $2.9 \mathrm{E}+0 \mathrm{I}$ & $3.2 \mathrm{E}+0 \mathrm{I}$ & $8.3 \mathrm{E}+0 \mathrm{I}$ & \\
\hline $\mathrm{Ce}$ & NAA & & & nd & $4.0 \mathrm{E}+02$ & $3.2 \mathrm{E}+02$ & & & $4 . E+0 I$ & $6.3 \mathrm{E}+01$ & $1.69 \mathrm{E}+02$ & \\
\hline $\mathrm{Nd}$ & NAA & & & $5.8 \mathrm{E}+02$ & nd & $7.6 \mathrm{E}+02$ & & & nd & nd & $\mathrm{I} .4 \mathrm{E}+02$ & \\
\hline $\mathrm{Sm}$ & NAA & & & $1.2 \mathrm{E}+00$ & 4.E-02 & $3 .|\mathrm{E}+0|$ & & & $4.5 \mathrm{E}+00$ & $5.0 \mathrm{E}+00$ & $1.46 \mathrm{E}+01$ & \\
\hline $\mathrm{Eu}$ & NAA & & & $5 . \mathrm{IE}+00$ & nd & nd & & & nd & nd & $3.0 \mathrm{E}+00$ & \\
\hline Lu & NAA & & & nd & nd & 4.E-03 & & & 4.E-0I & 5.E-0I & $1.6 \mathrm{E}+00$ & \\
\hline $\mathrm{Hf}$ & NAA & & & nd & nd & nd & & & nd & nd & nd & \\
\hline $\mathrm{Ta}$ & NAA & & & nd & nd & nd & & & nd & nd & nd & \\
\hline $\mathrm{Au}$ & NAA & & & 7.E-02 & $1.2 \mathrm{E}-0 \mathrm{O}$ & 3.E-02 & & & nd & nd & $1.6 \mathrm{E}-0 \mid$ & \\
\hline $\mathrm{Hg}$ & NAA & & & $1.3 \mathrm{E}+00$ & $6 . \mathrm{E}-02$ & nd & & & nd & nd & nd & \\
\hline Th & NAA & & & $4 . E+00$ & $9.3 \mathrm{E}+01$ & $7 .|\mathrm{E}+0|$ & & & $1.0 \mathrm{E}+0 \mathrm{I}$ & $|.4 \mathrm{E}+0|$ & $3.5 \mathrm{E}+0 \mathrm{I}$ & \\
\hline U & NAA & & & nd & nd & $9.6 \mathrm{IE}+0 \mathrm{I}$ & & & nd & $2.5 \mathrm{E}+00$ & $5.34 \mathrm{E}+0 \mathrm{I}$ & \\
\hline $\mathrm{Cl}$ & NAA & & & $7.6 \mathrm{E}+03$ & $2.5 \mathrm{E}+03$ & $5.2 \mathrm{E}+03$ & & & $8 . E+02$ & $6 . \mathrm{E}+02$ & $4 . E+02$ & \\
\hline K & NAA & & & nd & nd & nd & & & $9 . \mathrm{E}+03$ & $1.7 \mathrm{E}+04$ & $1.4 \mathrm{E}+04$ & \\
\hline $\mathrm{Ti}$ & NAA & & & nd & nd & nd & & & $1.8 \mathrm{E}+03$ & $2.8 \mathrm{E}+03$ & $2.4 \mathrm{E}+03$ & \\
\hline$V$ & NAA & & & $\mathrm{I} . \mathrm{E}+02$ & $3 . E+02$ & I.E+02 & & & $2 . E+02$ & $2 . E+02$ & $2 . E+02$ & \\
\hline$M n$ & NAA & & & $2 . E+02$ & $5 . E+0 I$ & $3 . \mathrm{E}+02$ & & & $4 . E+02$ & $4 . E+02$ & $4 . E+02$ & \\
\hline $\mathrm{Sr}$ & NAA & & & nd & nd & $3 . \mathrm{E}+02$ & & & $4.0 \mathrm{E}+03$ & $2.5 \mathrm{E}+03$ & $2.5 \mathrm{E}+03$ & \\
\hline $\mathrm{Ba}$ & NAA & & & $1.07 \mathrm{E}+04$ & $6.4 \mathrm{E}+03$ & $4.8 \mathrm{E}+03$ & & & $4.69 \mathrm{E}+03$ & $4.19 \mathrm{E}+03$ & $4.93 \mathrm{E}+03$ & \\
\hline
\end{tabular}

nd $=$ below detection limit 
Table B-17 (continued)

Size-Segregated Elemental Concentrations of the North Dakota Fly Ash Sampled at Port 14 (9.3 residence second)

d) Trace Element Uncertainties

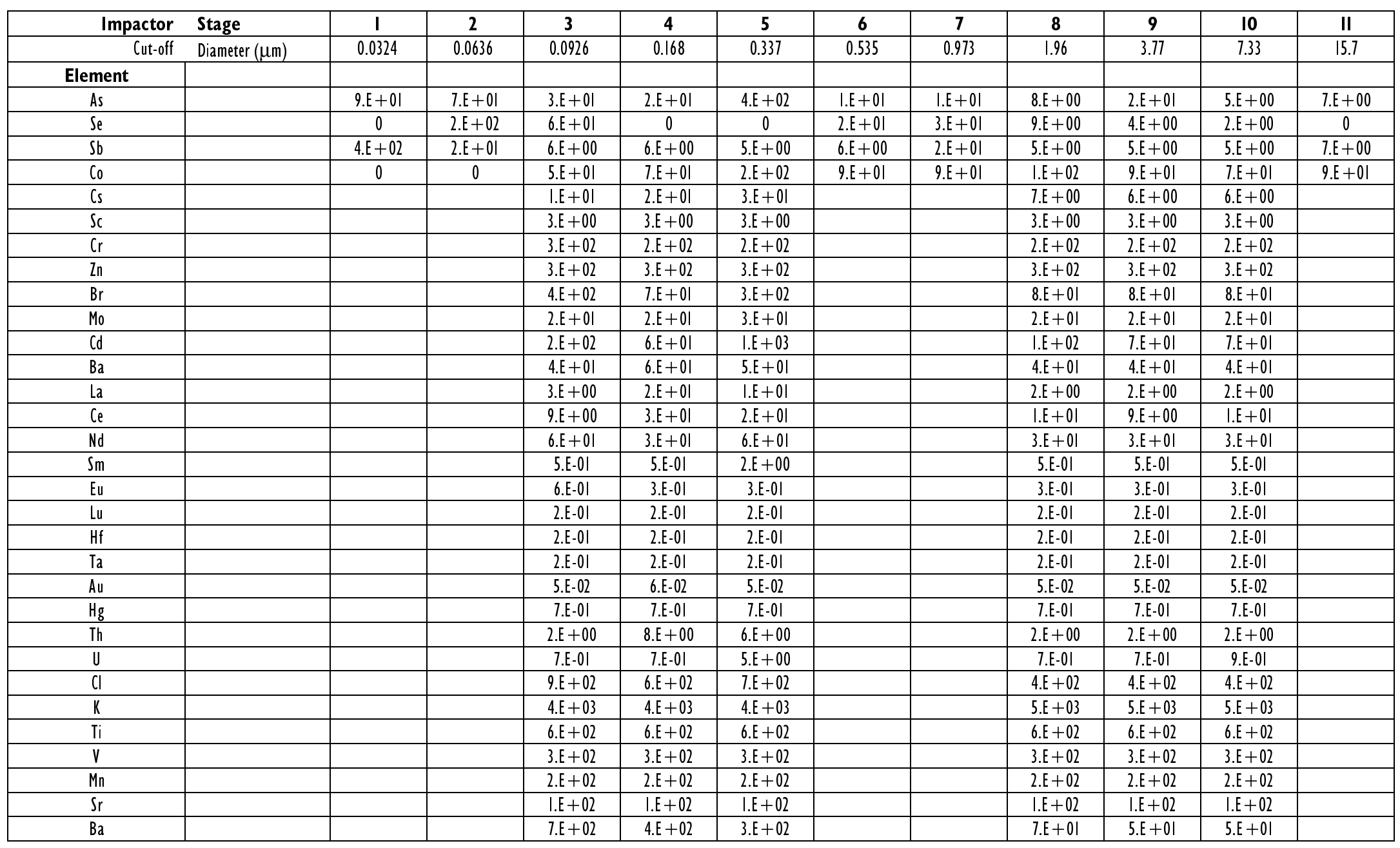


Table B-18

Size-Segregated Elemental Concentrations of the North Dakota Fly Ash Sampled at the Baghouse Inlet Port

a) Major Species Results

\begin{tabular}{|c|c|c|c|c|c|c|c|c|c|c|c|c|}
\hline Impactor & Stage & I & 2 & 3 & 4 & 5 & 6 & 7 & 8 & 9 & 10 & II \\
\hline Cut-off & $\begin{array}{l}\text { Diameter } \\
\text { (microns) }\end{array}$ & 0.0324 & 0.0636 & 0.0926 & 0.168 & 0.337 & 0.535 & 0.973 & 1.96 & 3.77 & 7.33 & 15.7 \\
\hline Element & $\begin{array}{l}\text { Analytical } \\
\text { Method }\end{array}$ & & & & & & & & & & & \\
\hline $\begin{array}{c}\text { Total Mass Conc } \\
(\mathrm{g} / \mathrm{Nm} \wedge 3) \\
\end{array}$ & Gravametric & $4.17 \mathrm{E}-02$ & $5.2 \mathrm{IE}-02$ & $7.25 \mathrm{E}-02$ & $9.19 \mathrm{E}-02$ & $1.23 \mathrm{E}-01$ & $1.90 \mathrm{E}-0 \mathrm{I}$ & $2.68 \mathrm{E}-01$ & $7.57 \mathrm{E}-01$ & $1.59 \mathrm{E}+00$ & $5.83 \mathrm{E}+00$ & $5.39 \mathrm{E}-01$ \\
\hline $\mathrm{SiO}_{2}(\mathrm{Wt} \%)$ & AAS & $3.6 \mathrm{E}+0 \mathrm{I}$ & $4.4 \mathrm{E}+0 \mathrm{I}$ & $4 . I E+0 I$ & $3.2 \mathrm{E}+0 \mathrm{I}$ & $4 . I E+0 I$ & $3 . \mathrm{E}+0 \mathrm{I}$ & $3 . \mathrm{E}+0 \mathrm{I}$ & $4 . \mathrm{E}+0 \mathrm{I}$ & $5 . E+01$ & $4 . \mathrm{E}+0 \mathrm{I}$ & $2.8 \mathrm{E}+0 \mathrm{I}$ \\
\hline$+/-$ & & $5 . E+00$ & $6 . \mathrm{E}+00$ & $4 . E+00$ & $3 . E+00$ & $3 . E+00$ & $2 . E+0 I$ & $5 . E+0 I$ & $5 . E+0 I$ & $9 . \mathrm{E}+0 \mathrm{I}$ & $6 . \mathrm{E}+0 \mathrm{I}$ & I.E +00 \\
\hline $\mathrm{Al}_{2} \mathrm{O}_{3}(\mathrm{Wt} \%)$ & AAS & $3.8 \mathrm{E}+00$ & $8 . E+00$ & $|. E+0|$ & $1.4 \mathrm{E}+0 \mathrm{I}$ & $2.3 \mathrm{E}+0 \mathrm{I}$ & $2.5 \mathrm{E}+01$ & $2.8 \mathrm{E}+0 \mathrm{I}$ & $2.83 \mathrm{E}+0 \mathrm{I}$ & $1.3 \mathrm{E}+0 \mid$ & $9.65 \mathrm{E}+00$ & $2.59 \mathrm{E}+0 \mathrm{I}$ \\
\hline$+/-$ & & 8.E-0I & I.E +00 & $I . E+0 \mid$ & I.E +00 & I.E +00 & I.E +00 & I.E +00 & 6.E-0I & $6 . E+00$ & 4.E-OI & 7.E-0I \\
\hline $\mathrm{Fe}_{2} \mathrm{O}_{3}(\mathrm{Wt} \%)$ & AAS & $6 . \mathrm{E}+00$ & $5.9 \mathrm{E}+00$ & I.E+0| & $1.5 \mathrm{E}+0 \mathrm{I}$ & $1.9 \mathrm{E}+0 \mathrm{I}$ & $2 . \mathrm{E}+0 \mathrm{I}$ & $3.0 \mathrm{E}+0 \mathrm{I}$ & $2.3 \mathrm{E}+0 \mathrm{I}$ & $1.7 \mathrm{E}+0 \mid$ & 2.E+OI & $1.69 \mathrm{E}+01$ \\
\hline$+/-$ & & I.E +00 & 9.E-OI & $|. E+0|$ & $6 . E+00$ & I.E +00 & $\mathrm{I} . \mathrm{E}+0 \mathrm{I}$ & I.E +00 & $9 . E+00$ & $3 . E+00$ & I.E $+0 \mid$ & 5.E-0I \\
\hline $\mathrm{Ca} 0$ (Wto) & AAS & $5 . E+00$ & $4 . E+00$ & $7.6 \mathrm{E}+00$ & $9.3 \mathrm{E}+00$ & $\mathrm{I} . \mathrm{IIE}+0 \mathrm{I}$ & $1.24 \mathrm{E}+0 \mathrm{I}$ & $1.5 \mathrm{E}+0 \mathrm{I}$ & $I .|E+0|$ & $6.4 \mathrm{E}+00$ & $7.8 \mathrm{E}+00$ & $1.5 \mathrm{IE}+0 \mathrm{I}$ \\
\hline$+/-$ & & $6 . \mathrm{E}+00$ & $4 . E+00$ & 9.E-OI & 7.E-0I & 6.E-0I & 6.E-0I & $7 . E+00$ & $4 . E+00$ & 2.E-OI & 2.E-0I & 3.E-0I \\
\hline $\mathrm{MgO}(\mathrm{Wt} \%)$ & AAS & $\mathrm{I} . \mathrm{E}+00$ & $9.8 \mathrm{E}-0 \mathrm{I}$ & $2.3 \mathrm{E}+00$ & $2.9 \mathrm{E}+00$ & $4.4 \mathrm{E}+00$ & $4.8 \mathrm{E}+00$ & $6 . \mathrm{E}+00$ & $2.91 \mathrm{E}+00$ & $3 . E+00$ & I.E+00 & $3.65 \mathrm{E}+00$ \\
\hline$+/-$ & & I.E +00 & I.E-0| & 9.E-OI & 2.E-0I & 2.E-0I & I.E-0| & $4 . E+00$ & 3.E-02 & I.E +00 & $\mathrm{I} . \mathrm{E}+00$ & 4.E-02 \\
\hline $\mathrm{Na}_{2} \mathrm{O}(\mathrm{Wt} \%)$ & AES & $1.3 \mathrm{E}+0 \mathrm{I}$ & $1.5 \mathrm{E}+0 \mathrm{I}$ & $3.0 \mathrm{E}+0 \mathrm{I}$ & $3.6 \mathrm{E}+0 \mathrm{I}$ & $2.5 \mathrm{E}+0 \mathrm{I}$ & $2.35 \mathrm{E}+01$ & $2 . E+0 I$ & $1.6 \mathrm{E}+0 \mathrm{I}$ & I.IE $+0 \mid$ & $4.55 \mathrm{E}+00$ & $1.45 \mathrm{E}+0 \mathrm{I}$ \\
\hline$+/-$ & & $2 . E+00$ & I.E +00 & $2 . E+00$ & 2.E +00 & $9 . E+00$ & 7.E-0I & I.E+0I & $8 . E+00$ & $6 . E+00$ & 8.E-02 & 3.E-0I \\
\hline $\begin{array}{c}\text { Trace Elements } \\
(\mathrm{Wt} \%)\end{array}$ & GFAA & $2.8 \mathrm{E}-0 \mathrm{I}$ & 2.IE-0I & $1.5 \mathrm{E}-0 \mathrm{I}$ & $3.0 \mathrm{E}-02$ & $3.3 \mathrm{E}-02$ & $2.7 \mathrm{E}-02$ & $3.4 \mathrm{E}-02$ & $2.8 \mathrm{E}-02$ & $2.2 \mathrm{E}-02$ & I.IE-02 & $2.5 \mathrm{E}-02$ \\
\hline Total (Wt\%) & & 65 & 77 & 106 & 109 & 124 & 119 & 134 & 119 & 102 & 83 & 104 \\
\hline
\end{tabular}

Note: Elemental concentrations have been converted to oxide forms on a $\mathrm{SO}_{3}$-free basis.

nd $=$ below detection limit 
Table B-18 (continued)

Size-Segregated Elemental Concentrations of the North Dakota Fly Ash Sampled at the Baghouse Inlet Port

b) Normalized Major Species Results

\begin{tabular}{|c|c|c|c|c|c|c|c|c|c|c|c|c|}
\hline Impactor & Stage & I & 2 & 3 & 4 & 5 & 6 & 7 & 8 & 9 & 10 & II \\
\hline Cut-off & $\begin{array}{l}\text { Diameter } \\
\text { (microns) }\end{array}$ & 0.0324 & 0.0636 & 0.0926 & 0.168 & 0.337 & 0.535 & 0.973 & 1.96 & 3.77 & 7.33 & 15.7 \\
\hline Element & $\begin{array}{c}\text { Analytical } \\
\text { Method }\end{array}$ & & & & & & & & & & & \\
\hline $\begin{array}{c}\text { Total Mass Conc } \\
(\mathrm{g} / \mathrm{Nm} \wedge 3)\end{array}$ & Gravametric & $4.2 \mathrm{E}-02$ & $5.2 \mathrm{E}-02$ & $7.3 \mathrm{E}-02$ & $9.2 \mathrm{E}-02$ & $1.2 \mathrm{E}-0 \mathrm{I}$ & I.9E-0I & $2.7 \mathrm{E}-0 \mathrm{I}$ & $7.6 \mathrm{E}-0 \mathrm{I}$ & $1.6 \mathrm{E}+00$ & $5.8 \mathrm{E}+00$ & $5.4 \mathrm{E}-01$ \\
\hline $\mathrm{SiO}_{2}(\mathrm{Wt} \%)$ & AAS & 56 & 57 & 38 & 29 & 33 & 27 & 25 & 31 & 52 & 54 & 27 \\
\hline $\mathrm{Al}_{2} \mathrm{O}_{3}(\mathrm{Wt} \%)$ & AAS & 5.9 & 10 & 13 & 13 & 19 & 21 & 21 & 24 & 12 & 12 & 25 \\
\hline $\mathrm{Fe}_{2} \mathrm{O}_{3}(\mathrm{Wt} \%)$ & AAS & 9 & 8 & II & 14 & 16 & 18 & 23 & 20 & 17 & 18 & 16 \\
\hline $\mathrm{CaO}(\mathrm{Wt} \%)$ & AAS & 7.3 & 4.6 & 7.2 & 8.5 & 8.9 & 10 & II & 9.0 & 6.3 & 9.5 & 15 \\
\hline $\mathrm{MgO}(\mathrm{Wt} \%)$ & AAS & 2.3 & 1.3 & 2.2 & 2.7 & 3.5 & 4.0 & 4.6 & 2.5 & 2.6 & 1.4 & 3.5 \\
\hline $\mathrm{Na}_{2} \mathrm{O}(\mathrm{Wt} \%)$ & AES & 19 & 19 & 28 & 33 & 20 & 20 & 16 & 14 & 10 & 5.49 & 14 \\
\hline $\begin{array}{c}\text { Trace Elements } \\
(\mathrm{Wt} \%)\end{array}$ & GFAA & 0.43 & 0.27 & 0.14 & 0.027 & 0.026 & 0.023 & 0.025 & 0.023 & 0.022 & 0.013 & 0.024 \\
\hline Total (Wt\%) & & 100.00 & 100.00 & 100.00 & 100.00 & 100.00 & 100.00 & 100.00 & 100.00 & 100.00 & 100.00 & 100.00 \\
\hline
\end{tabular}


Table B-18 (continued)

Size-Segregated Elemental Concentrations of the North Dakota Fly Ash Sampled at the Baghouse Inlet Port

c) Trace Element Concentrations

\begin{tabular}{|c|c|c|c|c|c|c|c|c|c|c|c|c|}
\hline Impactor & Stage & I & 2 & 3 & 4 & 5 & 6 & 7 & 8 & 9 & 10 & II \\
\hline Cut-off & $\begin{array}{l}\text { Diameter } \\
\text { (microns) }\end{array}$ & 0.0324 & 0.0636 & 0.0926 & 0.168 & 0.337 & 0.535 & 0.973 & 1.96 & 3.77 & 7.33 & 15.7 \\
\hline Element & $\begin{array}{c}\text { Analytical } \\
\text { Method }\end{array}$ & & & & & & & & & & & \\
\hline As & GFAA & $1.5 \mathrm{E}+02$ & $1.5 \mathrm{E}+02$ & $3 . E+02$ & $1.9 \mathrm{E}+02$ & $1.8 \mathrm{E}+02$ & $1.8 \mathrm{E}+02$ & $1.9 \mathrm{E}+02$ & $1.54 \mathrm{E}+02$ & $1.48 \mathrm{E}+02$ & $3.9 \mathrm{E}+0 \mathrm{I}$ & $1.0 \mathrm{E}+02$ \\
\hline Se & GFAA & nd & nd & nd & $2.8 \mathrm{E}+0 \mathrm{I}$ & $2 .|E+0|$ & $2.2 \mathrm{E}+0 \mathrm{I}$ & $2.3 \mathrm{E}+01$ & $7 . E+00$ & $3 . E+00$ & I.E +00 & nd \\
\hline $\mathrm{Sb}$ & GFAA & $2.6 \mathrm{E}+03$ & $1.9 \mathrm{E}+03$ & $1.2 \mathrm{E}+03$ & $3 . I E+0 \mid$ & $6.4 \mathrm{E}+01$ & $8 . E+00$ & $2.9 \mathrm{E}+01$ & $9 . \mathrm{E}+00$ & $8 . \mathrm{E}+00$ & $1.9 \mathrm{E}+0 \mathrm{I}$ & $8.2 \mathrm{E}+0 \mathrm{I}$ \\
\hline$C_{0}$ & GFAA & nd & nd & $5.9 \mathrm{E}+01$ & $5 . \mathrm{E}+0 \mathrm{I}$ & $5.9 \mathrm{E}+01$ & $6.0 \mathrm{E}+0 \mathrm{I}$ & $9 . \mathrm{E}+0 \mathrm{I}$ & I.E +02 & $6 . \mathrm{E}+0 \mathrm{I}$ & $5 .|\mathrm{E}+0|$ & $7 . \mathrm{E}+0 \mathrm{I}$ \\
\hline
\end{tabular}

nd $=$ below detection limit

d) Trace Element Uncertainties

\begin{tabular}{|c|c|c|c|c|c|c|c|c|c|c|c|c|}
\hline Impactor & Stage & I & 2 & 3 & 4 & 5 & 6 & 7 & 8 & 9 & 10 & II \\
\hline Cut-off & $\begin{array}{l}\text { Diameter } \\
\text { (microns) }\end{array}$ & 0.0324 & 0.0636 & 0.0926 & 0.168 & 0.337 & 0.535 & 0.973 & 1.96 & 3.77 & 7.33 & 15.7 \\
\hline Element & $\begin{array}{c}\text { Analytical } \\
\text { Method }\end{array}$ & & & & & & & & & & & \\
\hline As & & $2 . \mathrm{E}+0 \mathrm{I}$ & $9 . \mathrm{E}+0 \mathrm{I}$ & $2 . E+02$ & $2 . \mathrm{E}+0 \mathrm{I}$ & I.E+0I & I.E $+0 \mid$ & $9 . \mathrm{E}+0 \mathrm{I}$ & 7.E +00 & $6 . \mathrm{E}+00$ & $5 . E+00$ & I.E+OI \\
\hline $\mathrm{Se}$ & & $0 . \mathrm{E}+00$ & $0 . \mathrm{E}+00$ & $0 . \mathrm{E}+00$ & $6 . \mathrm{E}+00$ & $5 . E+00$ & $5 . E+00$ & $5 . E+00$ & $4 . E+00$ & $4 . E+00$ & $4 . E+00$ & \\
\hline $\mathrm{Sb}$ & & $3 . E+02$ & $3 . \mathrm{E}+02$ & I.E +02 & $8 . E+00$ & $9 . \mathrm{E}+00$ & $6 . \mathrm{E}+00$ & $7 . \mathrm{E}+00$ & $6 . \mathrm{E}+00$ & $6 . \mathrm{E}+00$ & $6 . \mathrm{E}+00$ & $7 . \mathrm{E}+00$ \\
\hline$C_{0}$ & & & & $9 . E+00$ & $3 . \mathrm{E}+0 \mathrm{I}$ & 7.E +00 & $6 . E+00$ & I.E +02 & I.E +02 & $2 . \mathrm{E}+0 \mathrm{I}$ & $4 . E+00$ & $5 . E+01$ \\
\hline
\end{tabular}




\section{APPENDIX C}

Composite Results from Special Large-Scale Combustion Studies at the University of Arizona

C-1/C-2 
Table C-1

Analytical Results For Wyodak Doping Experiments: Oxygen Enrichment without Doping

a) Sampled At Port 4

\begin{tabular}{|c|c|c|c|c|c|c|c|c|c|c|c|c|}
\hline Impactor & Stage & I & 2 & 3 & 4 & 5 & 6 & 7 & 8 & 9 & 10 & II \\
\hline Cut-off & $\begin{array}{l}\text { Diameter } \\
\text { (microns) }\end{array}$ & 0.0324 & 0.0636 & 0.0926 & 0.168 & 0.337 & 0.535 & 0.973 & 1.96 & 3.77 & 7.33 & 15.7 \\
\hline Element & $\begin{array}{c}\text { Analytical } \\
\text { Method }\end{array}$ & & & & & & & & & & & \\
\hline $\begin{array}{c}\text { Total Mass } \\
\text { Conc }\left(\mathrm{g} / \mathrm{Nm}^{3}\right) \\
\end{array}$ & Gravametric & $1.64 \mathrm{E}-02$ & $4.73 \mathrm{E}-02$ & $5.05 \mathrm{E}-02$ & $5.64 \mathrm{E}-02$ & $5.27 \mathrm{E}-02$ & $9.35 \mathrm{E}-02$ & $2.92 \mathrm{E}-0 \mathrm{I}$ & $8.26 \mathrm{E}-01$ & $1.47 \mathrm{E}+00$ & $1.28 \mathrm{E}+00$ & I.57E-01 \\
\hline \multicolumn{13}{|l|}{ Concentrations } \\
\hline $\mathrm{Ca} 0(\mathrm{Wt} \%)$ & AAS & nd & $4.8 \mathrm{E}+00$ & $5 . \mathrm{IE}+00$ & $3.6 \mathrm{E}+00$ & $4.4 \mathrm{E}+00$ & $1.35 \mathrm{E}+0 \mathrm{I}$ & 6.E-OI & 7.E-0I & $1.7 \mathrm{E}+00$ & $6.4 \mathrm{E}+00$ & $2.6 \mathrm{E}+00$ \\
\hline $\mathrm{Fe}_{2} \mathrm{O}_{3}(\mathrm{Wt} \%)$ & AAS & $\mathrm{I} .0 \mathrm{E}+00$ & 5.E-0I & 8.IIE-0I & $2.0 \mathrm{E}+00$ & $1.09 \mathrm{E}+01$ & $1.23 \mathrm{E}+0 \mathrm{I}$ & $7.7 \mathrm{E}+00$ & $1.02 \mathrm{E}+01$ & $7.5 \mathrm{E}+00$ & $6.0 \mathrm{E}+00$ & $5.7 \mathrm{E}+00$ \\
\hline $\mathrm{Al}_{2} \mathrm{O}_{3}(\mathrm{Wt} \%)$ & AAS & nd & nd & $1.17 \mathrm{E}+01$ & $1.99 \mathrm{E}+01$ & $4.2 \mathrm{E}+0 \mathrm{I}$ & $5.52 \mathrm{E}+0 \mathrm{I}$ & $3.04 \mathrm{E}+0 \mathrm{I}$ & $1.55 \mathrm{E}+0 \mathrm{I}$ & $1.50 \mathrm{E}+0 \mathrm{I}$ & $2.04 \mathrm{E}+0 \mathrm{I}$ & $5.42 \mathrm{E}+0 \mathrm{I}$ \\
\hline As (ppmw) & GFAA & $3.0 \mathrm{E}+03$ & $2.27 \mathrm{E}+03$ & $6 . \mathrm{IE}+02$ & $1.52 \mathrm{E}+03$ & $6.2 \mathrm{E}+03$ & $4.2 \mathrm{IE}+02$ & $1.43 \mathrm{E}+02$ & $1.13 \mathrm{E}+02$ & $1.27 \mathrm{E}+02$ & $8.8 \mathrm{E}+01$ & $2.93 \mathrm{E}+02$ \\
\hline Se (ppmw) & GFAA & $2.6 \mathrm{E}+03$ & $1.02 \mathrm{E}+03$ & $6.3 \mathrm{E}+02$ & $5.7 \mathrm{E}+02$ & $5.8 \mathrm{E}+02$ & $4.70 E+02$ & $8.6 \mathrm{E}+0 \mathrm{I}$ & $6.2 \mathrm{E}+01$ & $2.5 \mathrm{E}+0 \mathrm{I}$ & $1.8 \mathrm{E}+0 \mathrm{I}$ & $5 . I E+0 I$ \\
\hline Sb (ppmw) & GFAA & $1.45 \mathrm{E}+03$ & $8.9 \mathrm{E}+02$ & $4.7 \mathrm{E}+0 \mathrm{I}$ & $2.06 \mathrm{E}+02$ & $2.02 \mathrm{E}+02$ & $2.58 \mathrm{E}+02$ & $9.0 \mathrm{E}+0 \mathrm{I}$ & $2.43 \mathrm{E}+02$ & $1.07 \mathrm{E}+02$ & $1.32 \mathrm{E}+02$ & $2.03 \mathrm{E}+02$ \\
\hline Co (ppmw) & GFAA & $9.2 \mathrm{E}+01$ & $3.2 \mathrm{E}+0 \mathrm{I}$ & $3.9 \mathrm{E}+0 \mathrm{I}$ & $4.5 \mathrm{E}+0 \mathrm{I}$ & $9.64 \mathrm{E}+01$ & $1.56 \mathrm{E}+02$ & $1.64 \mathrm{E}+02$ & $7.2 \mathrm{E}+0 \mathrm{I}$ & $5 . I E+0 \mid$ & $2.8 \mathrm{E}+01$ & $9.75 \mathrm{E}+0 \mathrm{I}$ \\
\hline \multicolumn{13}{|l|}{ Uncertainties } \\
\hline $\mathrm{Ca} 0(\mathrm{Wt} \%)$ & & & 3.E-OI & 3.E-OI & 3.E-OI & 3.E-OI & 3.E-OI & 2.E-OI & 2.E-OI & 2.E-OI & 2.E-OI & 2.E-OI \\
\hline $\mathrm{Fe}_{2} \mathrm{O}_{3}(\mathrm{Wt} \%)$ & & 4.E-OI & 4.E-OI & 4.E-OI & 4.E-0I & 5.E-OI & 5.E-OI & 4.E-OI & 4.E-OI & 4.E-OI & 4.E-OI & 4.E-OI \\
\hline $\mathrm{Al}_{2} \mathrm{O}_{3}(\mathrm{Wt} \%)$ & & & & 5.E-OI & 6.E-0I & I.E +00 & 8.E-0I & 4.E-OI & 4.E-OI & 4.E-OI & 4.E-0I & 6.E-0I \\
\hline As (ppmw) & & I.E +02 & $4 . \mathrm{E}+0 \mathrm{I}$ & I.E $+0 \mid$ & $3 . \mathrm{E}+0 \mathrm{I}$ & I.E +02 & $9 . \mathrm{E}+00$ & $6 . \mathrm{E}+00$ & $5 . E+00$ & $5 . E+00$ & $5 . E+00$ & 7.E +00 \\
\hline Se (ppmw) & & I.E +02 & $2 . \mathrm{E}+0 \mathrm{I}$ & I.E+0I & I.E+0I & I.E+0I & $8 . E+00$ & $5 . E+00$ & $4 . E+00$ & $4 . E+00$ & $4 . E+00$ & $5 . E+00$ \\
\hline Sb (ppmw) & & $7 . \mathrm{E}+0 \mathrm{I}$ & $2 . \mathrm{E}+0 \mathrm{I}$ & 7.E +00 & $9 . \mathrm{E}+00$ & $9 . \mathrm{E}+00$ & $8 . E+00$ & $6 . \mathrm{E}+00$ & $6 . \mathrm{E}+00$ & $6 . \mathrm{E}+00$ & $6 . \mathrm{E}+00$ & $7 . \mathrm{E}+00$ \\
\hline Co (ppmw) & & $8 . E+00$ & $4 . E+00$ & $4 . E+00$ & $4 . \mathrm{E}+00$ & $5 . E+00$ & $5 . E+00$ & $4 . E+00$ & $4 . E+00$ & $4 . E+00$ & $4 . E+00$ & $4 . E+00$ \\
\hline
\end{tabular}

Note: Elemental Concentrations have been converted to Oxide forms on a $\mathrm{SO}_{3}$-free basis nd $=$ below detection limit 
Table C-1 (continued)

Analytical Results For Wyodak Doping Experiments: Oxygen Enrichment without Doping

b) Sampled At Port 14

\begin{tabular}{|c|c|c|c|c|c|c|c|c|c|c|c|c|}
\hline Impactor & Stage & I & 2 & 3 & 4 & 5 & 6 & 7 & 8 & 9 & 10 & II \\
\hline \multicolumn{2}{|c|}{$\begin{array}{r}\text { Cut-offDiameter } \\
\text { (microns) }\end{array}$} & 0.0324 & 0.0636 & 0.0926 & 0.168 & 0.337 & 0.535 & 0.973 & 1.96 & 3.77 & 7.33 & 15.7 \\
\hline Element & $\begin{array}{c}\text { Analytical } \\
\text { Method }\end{array}$ & & & & & & & & & & & \\
\hline $\begin{array}{l}\text { Total Mass Conc } \\
\left(\mathrm{g} / \mathrm{Nm}^{3}\right)\end{array}$ & Grava-metric & $4.42 \mathrm{E}+00$ & $5.98 \mathrm{E}+00$ & $5.20 \mathrm{E}+00$ & $2.39 \mathrm{E}+00$ & $1.45 E+0 \mid$ & $3.66 \mathrm{E}+00$ & $6.89 \mathrm{E}+00$ & $1.28 \mathrm{E}+00$ & $6.79 \mathrm{E}-0 \mathrm{I}$ & $9.73 \mathrm{E}-0 \mathrm{I}$ & $2.00 \mathrm{E}+0 \mathrm{I}$ \\
\hline \multicolumn{13}{|l|}{ Concentrations } \\
\hline $\mathrm{CaO}(\mathrm{Wt} \%)$ & AAS & $4.4 \mathrm{E}+00$ & $6.0 \mathrm{E}+00$ & $5.2 \mathrm{E}+00$ & $2.4 \mathrm{E}+00$ & $1.45 \mathrm{E}+0 \mathrm{I}$ & $3.7 \mathrm{E}+00$ & $6.9 \mathrm{E}+00$ & $1.3 \mathrm{E}+00$ & 7.E-0I & $9.7 \mathrm{E}-0 \mathrm{I}$ & $2.00 \mathrm{E}+0 \mathrm{I}$ \\
\hline $\mathrm{Fe}_{2} \mathrm{O}_{3}(\mathrm{Wt} \%)$ & AAS & $9 . \mathrm{E}+0 \mathrm{I}$ & $1.5 \mathrm{E}+0 \mathrm{I}$ & $3.6 \mathrm{E}+00$ & $1.2 \mathrm{E}+00$ & $8.9 \mathrm{E}+00$ & $1.22 \mathrm{E}+0 \mathrm{I}$ & $1.25 \mathrm{E}+0 \mathrm{I}$ & $1.00 \mathrm{E}+01$ & $7.2 \mathrm{E}+00$ & $2.55 \mathrm{E}+01$ & nd \\
\hline $\mathrm{Al}_{2} \mathrm{O}_{3}(\mathrm{Wt} \%)$ & AAS & nd & nd & nd & $\mathrm{I} .00 \mathrm{E}+0 \mathrm{I}$ & $3.8 \mathrm{E}+0 \mathrm{I}$ & $5.23 \mathrm{E}+0 \mathrm{I}$ & $4.19 \mathrm{E}+01$ & $2.18 \mathrm{E}+01$ & I.IIE +0I & $1.03 \mathrm{E}+01$ & $5.19 \mathrm{E}+0 \mathrm{I}$ \\
\hline As (ppmw) & GFAA & $4.7 \mathrm{E}+03$ & $4.6 \mathrm{E}+04$ & $6.8 \mathrm{E}+02$ & $5.4 \mathrm{E}+02$ & $6.6 \mathrm{E}+02$ & $6.0 \mathrm{E}+02$ & $1.39 E+02$ & $8.2 \mathrm{E}+0 \mathrm{I}$ & $9.2 \mathrm{E}+0 \mathrm{I}$ & $6.1 \mathrm{E}+0 \mathrm{I}$ & $1.73 \mathrm{E}+02$ \\
\hline Se (ppmw) & GFAA & $2.9 \mathrm{E}+03$ & $2.7 \mathrm{E}+03$ & $4 . I E+02$ & $2.46 \mathrm{E}+02$ & $4.4 \mathrm{E}+02$ & $2 . E+02$ & $6.5 \mathrm{E}+0 \mathrm{I}$ & $2.6 \mathrm{E}+01$ & $1.9 \mathrm{E}+0 \mathrm{I}$ & $2.2 \mathrm{E}+0 \mathrm{I}$ & $2.9 \mathrm{E}+0 \mathrm{I}$ \\
\hline Sb (ppmw) & GFAA & $5.9 \mathrm{E}+02$ & $9 . \mathrm{E}+02$ & $9.98 \mathrm{E}+02$ & $2.3 \mathrm{E}+0 \mathrm{I}$ & $1.58 \mathrm{E}+02$ & $7.7 \mathrm{E}+0 \mathrm{I}$ & $4.7 \mathrm{E}+0 \mathrm{I}$ & $6.0 \mathrm{E}+0 \mathrm{I}$ & $5.5 \mathrm{E}+01$ & $5.0 \mathrm{E}+0 \mathrm{I}$ & $7.2 \mathrm{E}+0 \mathrm{I}$ \\
\hline Co (ppmw) & GFAA & $1.5 \mathrm{E}+02$ & nd & $3.9 \mathrm{E}+0 \mathrm{I}$ & $2.0 \mathrm{E}+0 \mathrm{I}$ & $9.3 \mathrm{E}+0 \mathrm{I}$ & $1.64 \mathrm{E}+02$ & $1.32 \mathrm{E}+02$ & $7.0 \mathrm{E}+0 \mathrm{I}$ & $5.0 \mathrm{E}+0 \mathrm{I}$ & $3 . \mathrm{IE}+0 \mathrm{I}$ & $1.2 \mathrm{IE}+02$ \\
\hline \multicolumn{13}{|l|}{ Uncertainties } \\
\hline $\mathrm{CaO}(\mathrm{Wt} \%)$ & & 7.E-0I & 9.E-0I & 3.E-OI & 2.E-OI & 5.E-Ol & 2.E-OI & 2.E-OI & 2.E-OI & 2.E-OI & 2.E-OI & 3.E-OI \\
\hline $\mathrm{Fe}_{2} \mathrm{O}_{3}(\mathrm{Wt} \%)$ & & I.E+0I & $2 . E+00$ & 4.E-OI & 4.E-OI & 5.E-OI & 5.E-OI & 4.E-OI & 4.E-OI & 4.E-OI & 4.E-OI & 4.E-OI \\
\hline $\mathrm{Al}_{2} \mathrm{O}_{3}(\mathrm{Wt} \%)$ & & & & & 5.E-OI & I.E +00 & 9.E-OI & 5.E-OI & 4.E-0I & 4.E-0I & 4.E-OI & 5.E-OI \\
\hline As (ppmw) & & $5 . E+02$ & $5 . E+03$ & $2 . \mathrm{E}+0 \mathrm{I}$ & I.E $+0 \mid$ & $2 . \mathrm{E}+0 \mathrm{I}$ & I.E $+0 \mid$ & $6 . \mathrm{E}+00$ & $5 . E+00$ & $5 . E+00$ & $5 . E+00$ & $6 . \mathrm{E}+00$ \\
\hline Se (ppmw) & & $3 . \mathrm{E}+02$ & $3 . E+02$ & I.E $+0 \mid$ & $8 . E+00$ & I.E $+0 \mathrm{I}$ & $6 . \mathrm{E}+00$ & $5 . E+00$ & $4 . E+00$ & $4 . E+00$ & $4 . E+00$ & $4 . E+00$ \\
\hline Sb (ppmw) & & 7.E+0I & I.E +02 & $3 . \mathrm{E}+0 \mathrm{I}$ & $6 . \mathrm{E}+00$ & $9 . E+00$ & 7.E +00 & $6 . \mathrm{E}+00$ & $6 . \mathrm{E}+00$ & $6 . \mathrm{E}+00$ & $6 . \mathrm{E}+00$ & $6 . \mathrm{E}+00$ \\
\hline Co (ppmw) & & $2 . \mathrm{E}+0 \mathrm{I}$ & $4 . E+00$ & $5 . E+00$ & $4 . \mathrm{E}+00$ & $5 . E+00$ & $5 . E+00$ & $4 . E+00$ & $4 . \mathrm{E}+00$ & $4 . E+00$ & $4 . \mathrm{E}+00$ & $4 . \mathrm{E}+00$ \\
\hline
\end{tabular}

Note: Elemental Concentrations have been converted to Oxide forms on a $\mathrm{SO}_{3}$-free basis nd $=$ below detection limit tbd $=$ to be determined 
Table C-2

Analytical Results For Wyodak Doping Experiments: Arsenic Doping with No Oxygen Enrichment

a) Sampled At Port 4

\begin{tabular}{|c|c|c|c|c|c|c|c|c|c|c|c|c|}
\hline \multirow{2}{*}{\multicolumn{2}{|c|}{$\begin{array}{r}\text { Impactor Stage } \\
\text { Cut-offDiameter } \\
\text { (microns) }\end{array}$}} & I & 2 & 3 & 4 & 5 & 6 & 7 & 8 & 9 & 10 & II \\
\hline & & 0.0324 & 0.0636 & 0.0926 & 0.168 & 0.337 & 0.535 & 0.973 & 1.96 & 3.77 & 7.33 & 15.7 \\
\hline Element & $\begin{array}{l}\text { Analytical } \\
\text { Method }\end{array}$ & & & & & & & & & & & \\
\hline $\begin{array}{c}\text { Total Mass Conc } \\
\left(\mathrm{g} / \mathrm{Nm}^{3}\right)\end{array}$ & Gravametric & $5.00 \mathrm{E}-04$ & $2.13 \mathrm{E}-03$ & $1.25 \mathrm{E}-03$ & $2.75 \mathrm{E}-03$ & $7.87 \mathrm{E}-03$ & I.3IE-02 & $5.55 \mathrm{E}-02$ & I.54E-0| & I.3IE-0I & I.39E-0I & $5.16 \mathrm{E}-02$ \\
\hline \multicolumn{13}{|l|}{ Concentrations } \\
\hline $\mathrm{Ca} 0$ (Wt\%) & AAS & nd & $1.3 \mathrm{E}+0 \mid$ & nd & $1.7 \mathrm{E}+00$ & $9.8 \mathrm{E}+00$ & $2.2 \mathrm{E}+0 \mathrm{I}$ & $7.8 \mathrm{E}+00$ & $4.9 \mathrm{E}+00$ & $1.25 \mathrm{E}+0 \mathrm{I}$ & $5.4 \mathrm{E}+00$ & $1.95 \mathrm{E}+0 \mathrm{I}$ \\
\hline $\mathrm{Fe}_{2} \mathrm{O}_{3}(\mathrm{Wt} \%)$ & AAS & nd & 5.E-0I & $1.4 \mathrm{E}+0 \mathrm{I}$ & $7.7 \mathrm{E}+00$ & $1.20 \mathrm{E}+0 \mathrm{I}$ & I.74E +01 & I.3IE $+0 \mathrm{I}$ & $1.26 \mathrm{E}+01$ & I.4IE +01 & $1.46 \mathrm{E}+0 \mathrm{I}$ & I. $34 \mathrm{E}+0 \mathrm{I}$ \\
\hline $\mathrm{Al}_{2} \mathrm{O}_{3}(\mathrm{Wt} \%)$ & AAS & nd & nd & nd & nd & $2.6 \mathrm{E}+01$ & $4.3 \mathrm{E}+0 \mathrm{I}$ & $2.27 \mathrm{E}+01$ & $3 . I E+00$ & $4.63 \mathrm{E}+0 \mathrm{I}$ & $1.93 \mathrm{E}+01$ & $4.34 \mathrm{E}+0 \mathrm{I}$ \\
\hline As (ppmw) & GFAA & 7.E +04 & $9 . \mathrm{E}+03$ & 7.E +03 & $2.9 \mathrm{E}+03$ & $4.3 \mathrm{E}+03$ & $9.3 \mathrm{E}+03$ & $6.92 \mathrm{E}+03$ & $4.38 \mathrm{E}+03$ & $3.05 E+03$ & $1.205 \mathrm{E}+03$ & $1.67 \mathrm{E}+03$ \\
\hline Co (ppmw) & GFAA & nd & nd & nd & nd & $1.06 \mathrm{E}+02$ & $1.64 \mathrm{E}+02$ & $1.20 \mathrm{E}+02$ & 9.IE+0I & $7.0 \mathrm{E}+01$ & $4.6 \mathrm{E}+0 \mathrm{I}$ & $4 . I E+0 I$ \\
\hline \multicolumn{13}{|l|}{ Uncertainties } \\
\hline $\mathrm{Ca} 0(\mathrm{Wt} \%)$ & & & $3 . \mathrm{E}+00$ & & 7.E-OI & I.E +00 & I.E +00 & 5.E-0I & 4.E-OI & 5.E-0I & 4.E-OI & 6.E-0I \\
\hline $\mathrm{Fe}_{2} \mathrm{O}_{3}(\mathrm{Wt} \%)$ & & & 2.E-OI & I.E +00 & 5.E-Ol & 4.E-OI & 4.E-OI & 2.E-0I & 2.E-OI & 2.E-OI & 2.E-OI & 2.E-0I \\
\hline $\mathrm{Al}_{2} \mathrm{O}_{3}(\mathrm{Wt} \%)$ & & & & & & I.E +00 & I.E +00 & 5.E-0I & 4.E-0I & 5.E-0I & 4.E-0I & 6.E-0I \\
\hline As (ppmw) & & $2 . E+04$ & I.E +03 & $\mathrm{I} . \mathrm{E}+03$ & $3 . \mathrm{E}+02$ & $2 . E+02$ & $2 . E+02$ & $4 . \mathrm{E}+0 \mathrm{I}$ & I.E+0I & I.E $+0 \mid$ & $8 . E+00$ & I.E $+0 \mid$ \\
\hline Co (ppmw) & & & & & & 7.E +00 & 7.E +00 & $4 . E+00$ & $4 . E+00$ & $4 . E+00$ & $4 . E+00$ & $4 . E+00$ \\
\hline
\end{tabular}

Note: Elemental Concentrations have been converted to Oxide forms on a $\mathrm{SO}_{3}$-free basis nd $=$ below detection limit 
Table C-2 (continued)

Analytical Results For Wyodak Doping Experiments: Arsenic Doping with No Oxygen Enrichment

b) Sampled At Port 14

\begin{tabular}{|c|c|c|c|c|c|c|c|c|c|c|c|c|}
\hline \multicolumn{2}{|c|}{ Impactor Stage } & I & 2 & 3 & 4 & 5 & 6 & 7 & 8 & 9 & 10 & II \\
\hline \multicolumn{2}{|c|}{$\begin{array}{r}\text { Cut-offDiameter } \\
\text { (microns) }\end{array}$} & 0.0324 & 0.0636 & 0.0926 & 0.168 & 0.337 & 0.535 & 0.973 & 1.96 & 3.77 & 7.33 & 15.7 \\
\hline Element & $\begin{array}{l}\text { Analytical } \\
\text { Method }\end{array}$ & & & & & & & & & & & \\
\hline $\begin{array}{c}\text { Total Mass } \\
\text { Conc }\left(\mathrm{g} / \mathrm{Nm}^{3}\right)\end{array}$ & Gravametric & $3.01 \mathrm{IE}-04$ & $8.03 \mathrm{E}-04$ & $6.02 \mathrm{E}-04$ & $4.12 \mathrm{E}-03$ & $6.63 \mathrm{E}-03$ & $3.7 \mathrm{EE}-03$ & $4.50 \mathrm{E}-02$ & I.35E-0| & $1.68 \mathrm{E}-0 \mid$ & I.54E-0| & $3.97 \mathrm{E}-02$ \\
\hline \multicolumn{13}{|l|}{$\begin{array}{c}\text { Concentration } \\
\mathrm{s}\end{array}$} \\
\hline $\mathrm{CaO}(\mathrm{Wt} \%)$ & AAS & $2 . E+00$ & $2 . E+0 I$ & $\mathrm{I} . \mathrm{IE}+02$ & $2 .|E+0|$ & $3.3 \mathrm{E}+0 \mathrm{I}$ & $4.3 \mathrm{E}+0 \mathrm{I}$ & $9.50 \mathrm{E}+00$ & $5.0 \mathrm{E}+00$ & $5.2 \mathrm{E}+00$ & $8.6 \mathrm{E}+00$ & $2.05 \mathrm{E}+01$ \\
\hline $\mathrm{Fe}_{2} \mathrm{O}_{3}(\mathrm{Wt} \%)$ & AAS & $3.3 \mathrm{E}+0 \mathrm{I}$ & $|.7 \mathrm{E}+0|$ & $4.9 \mathrm{E}+0 \mathrm{I}$ & $\mathrm{I} .40 \mathrm{E}+0 \mathrm{I}$ & $2.49 \mathrm{E}+0 \mathrm{I}$ & $3.3 \mathrm{E}+0 \mathrm{I}$ & $1.43 \mathrm{E}+0 \mid$ & $9.58 \mathrm{E}+00$ & $9.55 \mathrm{E}+00$ & $1.14 \mathrm{E}+0 \mathrm{I}$ & $1.19 \mathrm{E}+01$ \\
\hline $\mathrm{Al}_{2} \mathrm{O}_{3}(\mathrm{Wt} \%)$ & AAS & nd & ND & $7 . E+00$ & $1.4 \mathrm{E}+0 \mathrm{I}$ & $6.5 \mathrm{E}+0 \mathrm{I}$ & $8 . I E+0 I$ & $2.22 \mathrm{E}+01$ & $2.37 \mathrm{E}+0 \mathrm{I}$ & $1.65 \mathrm{E}+0 \mathrm{I}$ & $1.88 \mathrm{E}+0 \mathrm{I}$ & $3.33 \mathrm{E}+01$ \\
\hline As (ppmw) & GFAA & ND & ND & $1.8 \mathrm{E}+04$ & $3.62 \mathrm{E}+04$ & $1.732 \mathrm{E}+05$ & $2.14 \mathrm{E}+05$ & $5.876 \mathrm{E}+04$ & $6.260 \mathrm{E}+04$ & $4.376 \mathrm{E}+04$ & $4.9793 \mathrm{E}+04$ & $8.82 \mathrm{E}+04$ \\
\hline Co (ppmw) & GFAA & ND & ND & ND & ND & $1.06 \mathrm{E}+02$ & $1.5 \mathrm{E}+02$ & $4.0 \mathrm{E}+0 \mathrm{I}$ & $2.9 \mathrm{E}+01$ & $2.5 \mathrm{E}+01$ & $1.9 \mathrm{E}+0 \mathrm{I}$ & $2.7 \mathrm{E}+0 \mathrm{I}$ \\
\hline \multicolumn{13}{|l|}{ Uncertainties } \\
\hline $\mathrm{Ca} 0(\mathrm{Wt} \%)$ & & $2 . E+00$ & I.E $+0 \mid$ & $6 . \mathrm{E}+0 \mathrm{I}$ & $3 . E+00$ & $3 . E+00$ & $5 . E+00$ & 5.E-OI & 4.E-OI & 4.E-OI & 4.E-OI & 7.E-OI \\
\hline $\mathrm{Fe}_{2} \mathrm{O}_{3}(\mathrm{Wt} \%)$ & & $7 . E+00$ & $2 . E+00$ & 7.E +00 & 5.E-OI & 6.E-0I & I.E +00 & 2.E-OI & 2.E-0I & 2.E-OI & 2.E-OI & 2.E-OI \\
\hline $\mathrm{Al}_{2} \mathrm{O}_{3}(\mathrm{Wt} \%)$ & & & & $2 . E+00$ & I.E +00 & $3 . \mathrm{E}+00$ & $5 . E+00$ & 5.E-0I & 4.E-OI & 4.E-OI & 4.E-OI & 6.E-0I \\
\hline As (ppmw) & & & & $8 . \mathrm{E}+03$ & $3 . E+02$ & $5 . E+02$ & I.E +03 & $4 . \mathrm{E}+0 \mathrm{I}$ & $2 . E+0 I$ & I.E+0I & $8 . E+00$ & $2 . E+02$ \\
\hline Co (ppmw) & & & & & & 7.E +00 & I.E+0I & $4 . E+00$ & $4 . E+00$ & $4 . E+00$ & $4 . E+00$ & $4 . E+00$ \\
\hline
\end{tabular}

Note: Elemental Concentrations have been converted to Oxide forms on a $\mathrm{SO}_{3}$-free basis nd $=$ below detection limit 
Table C-3

Analytical Results For Wyodak Doping Experiments: Arsenic Doping with Oxygen Enrichment

a) Sampled At Port 4

\begin{tabular}{|c|c|c|c|c|c|c|c|c|c|c|c|c|}
\hline \multirow{2}{*}{\multicolumn{2}{|c|}{$\begin{array}{r}\text { Impactor Stage } \\
\begin{array}{r}\text { Cut-offDiameter } \\
\text { (microns) }\end{array}\end{array}$}} & I & 2 & 3 & 4 & 5 & 6 & 7 & 8 & 9 & 10 & II \\
\hline & & 0.0324 & 0.0636 & 0.0926 & 0.168 & 0.337 & 0.535 & 0.973 & 1.96 & 3.77 & 7.33 & 15.7 \\
\hline Element & $\begin{array}{l}\text { Analytical } \\
\text { Method }\end{array}$ & & & & & & & & & & & \\
\hline $\begin{array}{c}\text { Total Mass Conc } \\
\left(\mathrm{g} / \mathrm{Nm}^{3}\right)\end{array}$ & Grava-metric & 7.7IE-03 & $2.3 \mathrm{IE}-02$ & $5.57 \mathrm{E}-02$ & $4.17 \mathrm{E}-02$ & $3.60 \mathrm{E}-02$ & $6.63 \mathrm{E}-02$ & $2.23 \mathrm{E}-01$ & 7.0IE-0I & $7.98 \mathrm{E}-0 \mathrm{I}$ & $8.93 \mathrm{E}-01$ & $9.00 \mathrm{E}-02$ \\
\hline \multicolumn{13}{|l|}{ Concentrations } \\
\hline $\mathrm{Ca} 0(\mathrm{Wt} \%)$ & AAS & nd & $8.9 \mathrm{E}+00$ & $7.8 \mathrm{E}+00$ & $1.52 \mathrm{E}+01$ & $7.5 \mathrm{E}+00$ & I.35E+0I & $6.5 \mathrm{E}+00$ & $1.8 \mathrm{E}+00$ & $1.0 \mathrm{E}+00$ & $1.2 \mathrm{E}+00$ & $1.83 \mathrm{E}+0 \mathrm{I}$ \\
\hline $\mathrm{Fe}_{2} \mathrm{O}_{3}(\mathrm{Wt} \%)$ & AAS & nd & $3.5 \mathrm{E}+00$ & $4.2 \mathrm{E}+00$ & $9.1 \mathrm{E}+00$ & $6.9 \mathrm{E}+00$ & $1.42 \mathrm{E}+01$ & $1.37 \mathrm{E}+01$ & $8.0 \mathrm{E}+00$ & $6.4 \mathrm{E}+00$ & $4.5 \mathrm{E}+00$ & $9.99 \mathrm{E}+00$ \\
\hline $\mathrm{Al}_{2} \mathrm{O}_{3}(\mathrm{Wt} \%)$ & AAS & nd & nd & $9.93 \mathrm{E}+00$ & $1.98 \mathrm{E}+01$ & $3.9 \mathrm{E}+0 \mathrm{I}$ & $4.96 \mathrm{E}+0 \mathrm{I}$ & $3.92 \mathrm{E}+01$ & $1.23 \mathrm{E}+01$ & $1.56 \mathrm{E}+01$ & $1.42 \mathrm{E}+0 \mathrm{I}$ & $4.42 \mathrm{E}+0 \mathrm{I}$ \\
\hline As (ppmw) & GFAA & $6.9 \mathrm{E}+03$ & $3.8 \mathrm{E}+03$ & $4.02 \mathrm{E}+03$ & $3.14 \mathrm{E}+03$ & $2.47 \mathrm{E}+03$ & $2.30 \mathrm{E}+03$ & $2.4 \mathrm{IE}+03$ & $1.678 \mathrm{E}+03$ & $1.536 \mathrm{E}+03$ & $8.02 \mathrm{E}+02$ & $1.54 \mathrm{E}+03$ \\
\hline \multicolumn{13}{|l|}{ Uncertainties } \\
\hline $\mathrm{CaO}(\mathrm{Wt} \%)$ & & & 4.E-0I & 3.E-0I & 4.E-OI & $3 . \mathrm{E}-0 \mathrm{I}$ & 3.E-0I & 2.E-OI & 2.E-0I & 2.E-0I & 2.E-0I & 3.E-0I \\
\hline $\mathrm{Fe}_{2} \mathrm{O}_{3}(\mathrm{Wt} \%)$ & & & 5.E-OI & 4.E-OI & 5.E-0I & 5.E-OI & 5.E-0I & 4.E-OI & 4.E-0I & 4.E-OI & 4.E-0I & 4.E-OI \\
\hline $\mathrm{Al}_{2} \mathrm{O}_{3}(\mathrm{Wt} \%)$ & & & & 5.E-OI & 7.E-OI & I.E +00 & 8.E-OI & 5.E-OI & 4.E-OI & 4.E-OI & 4.E-OI & 7.E-OI \\
\hline As (ppmw) & & $5 . E+02$ & I.E +02 & $5 . E+01$ & $5 . \mathrm{E}+0 \mathrm{I}$ & $5 . \mathrm{E}+0 \mathrm{I}$ & $3 . \mathrm{E}+0 \mathrm{I}$ & I.E+0I & $7 . \mathrm{E}+00$ & $6 . \mathrm{E}+00$ & $6 . \mathrm{E}+00$ & $2 . \mathrm{E}+0 \mathrm{I}$ \\
\hline
\end{tabular}

Note: Elemental Concentrations have been converted to Oxide forms on a $\mathrm{SO}_{3}$-free basis nd $=$ below detection limit 
Table C-3 (continued)

Analytical Results for Wyodak Doping Experiments: Arsenic Doping with Oxygen Enrichment

b) Sampled At Port 14

\begin{tabular}{|c|c|c|c|c|c|c|c|c|c|c|c|c|}
\hline \multirow{2}{*}{\multicolumn{2}{|c|}{$\begin{array}{r}\text { Impactor Stage } \\
\text { Cut-offDiameter } \\
\text { (microns) }\end{array}$}} & 1 & 2 & 3 & 4 & 5 & 6 & 7 & 8 & 9 & 10 & II \\
\hline & & 0.0324 & 0.0636 & 0.0926 & 0.168 & 0.337 & 0.535 & 0.973 & 1.96 & 3.77 & 7.33 & 15.7 \\
\hline Element & $\begin{array}{c}\text { Analytical } \\
\text { Method }\end{array}$ & & & & & & & & & & & \\
\hline $\begin{array}{c}\text { Total Mass Conc } \\
\left(\mathrm{g} / \mathrm{Nm}^{3}\right)\end{array}$ & Grava-metric & $1.69 \mathrm{E}-03$ & $5.65 \mathrm{E}-03$ & $2.34 \mathrm{E}-02$ & $6.72 \mathrm{E}-02$ & $4.55 \mathrm{E}-02$ & $8.8 \mathrm{IE}-02$ & $2.28 \mathrm{E}-01$ & $5.67 \mathrm{E}-01$ & $1.02 \mathrm{E}+00$ & $1.86 \mathrm{E}+00$ & $1.75 \mathrm{E}-01$ \\
\hline \multicolumn{13}{|l|}{ Concentrations } \\
\hline $\mathrm{Ca} 0$ (Wt\%) & AAS & $2.1 E+00$ & $2.9 \mathrm{E}+00$ & $1.00 \mathrm{E}+01$ & $5.0 \mathrm{E}+00$ & $4.8 \mathrm{E}+00$ & $9.47 \mathrm{E}-01$ & $1.72 \mathrm{E}+0 \mathrm{I}$ & $7.45 \mathrm{E}-01$ & $3.3 \mathrm{E}+00$ & $6.66 \mathrm{E}-01$ & $3.32 \mathrm{E}+01$ \\
\hline $\mathrm{Fe}_{2} \mathrm{O}_{3}(\mathrm{Wt} \%)$ & AAS & nd & $2.2 \mathrm{E}+00$ & $2.5 \mathrm{E}+00$ & $2.2 \mathrm{E}+00$ & $3.0 \mathrm{E}+00$ & $5.7 \mathrm{E}+00$ & $1.25 \mathrm{E}+0 \mathrm{I}$ & $4.9 \mathrm{E}+00$ & $8.4 \mathrm{E}+00$ & $4.0 \mathrm{E}+00$ & $1.40 \mathrm{E}+0 \mid$ \\
\hline $\mathrm{Al}_{2} \mathrm{O}_{3}(\mathrm{Wt} \%)$ & AAS & nd & nd & nd & $1.57 \mathrm{E}+0 \mathrm{I}$ & $2.32 \mathrm{E}+01$ & $1.97 \mathrm{E}+0 \mathrm{I}$ & $4.12 \mathrm{E}+0 \mathrm{I}$ & $\mathrm{I} .02 \mathrm{E}+0 \mathrm{I}$ & $\mathrm{I} .33 \mathrm{E}+0 \mathrm{I}$ & $5.2 \mathrm{E}+00$ & $6.44 \mathrm{E}+01$ \\
\hline As (ppmw) & GFAA & $1.9 \mathrm{E}+04$ & $6.0 \mathrm{E}+03$ & $3.6 \mathrm{E}+03$ & $2.13 \mathrm{E}+03$ & $1.94 \mathrm{E}+03$ & $2.46 \mathrm{E}+03$ & $3.24 \mathrm{E}+03$ & $1.921 \mathrm{IE}+03$ & $2.599 \mathrm{E}+03$ & $1.119 \mathrm{E}+03$ & $2.91 \mathrm{E}+03$ \\
\hline \multicolumn{13}{|l|}{ Uncertainties } \\
\hline $\mathrm{CaO}(\mathrm{Wt} \%)$ & & 8.E-0I & 5.E-OI & 5.E-0I & 2.E-OI & 3.E-0I & 2.E-0I & 3.E-OI & 2.E-OI & 2.E-OI & 2.E-OI & 3.E-0I \\
\hline $\mathrm{Fe}_{2} \mathrm{O}_{3}(\mathrm{Wt} \%)$ & & & 6.E-0I & 4.E-OI & 4.E-OI & 4.E-OI & 4.E-OI & 4.E-0I & 4.E-OI & 4.E-0I & 4.E-0I & 4.E-OI \\
\hline $\mathrm{Al}_{2} \mathrm{O}_{3}(\mathrm{Wt} \%)$ & & & & & 5.E-Ol & 7.E-OI & 5.E-OI & 5.E-OI & 4.E-OI & 4.E-0I & 4.E-OI & 6.E-OI \\
\hline As (ppmw) & & $5 . E+03$ & $6 . \mathrm{E}+02$ & I.E +02 & $3 . \mathrm{E}+0 \mathrm{I}$ & $3 . \mathrm{E}+0 \mathrm{I}$ & $2 . E+0 I$ & I.E+0I & $7 . \mathrm{E}+00$ & $7 . \mathrm{E}+00$ & $6 . \mathrm{E}+00$ & $2 . \mathrm{E}+0 \mathrm{I}$ \\
\hline
\end{tabular}

Note: Elemental Concentrations have been converted to Oxide forms on a $\mathrm{SO}_{3}$-free basis nd $=$ below detection limit 
Table C-4

Analytical Results for Wyodak Doping Experiments: Selenium Doping with No Oxygen Enrichment

a) Sampled At Port 4

\begin{tabular}{|c|c|c|c|c|c|c|c|c|c|c|c|c|}
\hline \multirow{2}{*}{\multicolumn{2}{|c|}{$\begin{array}{r}\text { Impactor Stage } \\
\begin{array}{r}\text { Cut-offDiameter } \\
\text { (microns) }\end{array}\end{array}$}} & I & 2 & 3 & 4 & 5 & 6 & 7 & 8 & 9 & 10 & II \\
\hline & & 0.0324 & 0.0636 & 0.0926 & 0.168 & 0.337 & 0.535 & 0.973 & 1.96 & 3.77 & 7.33 & 15.7 \\
\hline Element & $\begin{array}{c}\text { Analytical } \\
\text { Method }\end{array}$ & & & & & & & & & & & \\
\hline $\begin{array}{c}\text { Total Mass Conc } \\
\left(\mathrm{g} / \mathrm{Nm}^{3}\right)\end{array}$ & Grava-metric & $2.42 \mathrm{E}-03$ & $8.48 \mathrm{E}-04$ & $5.21 \mathrm{IE}-03$ & $6.54 \mathrm{E}-03$ & $1.26 \mathrm{E}-02$ & $2.39 \mathrm{E}-02$ & $5.77 \mathrm{E}-02$ & $1.54 \mathrm{E}-0 \mid$ & $1.55 \mathrm{E}-0 \mid$ & $1.04 \mathrm{E}-01$ & $2.13 \mathrm{E}-02$ \\
\hline \multicolumn{13}{|l|}{ Concentrations } \\
\hline $\mathrm{CaO}(\mathrm{Wt} \%)$ & AAS & nd & $1.6 \mathrm{E}+01$ & $1.5 \mathrm{E}+00$ & $1.13 \mathrm{E}+0 \mid$ & $1.86 \mathrm{E}+01$ & $7.8 \mathrm{E}+00$ & $3.8 \mathrm{E}+00$ & $1.8 \mathrm{E}+00$ & $2.8 \mathrm{E}+00$ & $8.0 \mathrm{E}+00$ & $1.88 \mathrm{E}+01$ \\
\hline $\mathrm{Fe}_{2} \mathrm{O}_{3}(\mathrm{Wt} \%)$ & AAS & $2.4 \mathrm{E}+00$ & $1.2 \mathrm{E}+0 \mathrm{I}$ & $1.5 \mathrm{E}+00$ & $8.1 \mathrm{E}+00$ & $1.29 \mathrm{E}+01$ & $1.10 \mathrm{E}+0 \mid$ & $1.08 \mathrm{E}+01$ & $8.4 \mathrm{E}+00$ & $6.9 \mathrm{E}+00$ & $1.13 \mathrm{E}+0 \mathrm{I}$ & $1.10 \mathrm{E}+01$ \\
\hline $\mathrm{Al}_{2} \mathrm{O}_{3}(\mathrm{Wt} \%)$ & AAS & nd & nd & nd & nd & $4.6 \mathrm{E}+0 \mathrm{I}$ & $4.57 \mathrm{E}+0 \mathrm{I}$ & $3.86 \mathrm{E}+0 \mathrm{I}$ & $1.85 \mathrm{E}+01$ & $1.23 \mathrm{E}+01$ & $2.87 \mathrm{E}+0 \mathrm{I}$ & $3.55 \mathrm{E}+01$ \\
\hline Se (ppmw) & GFAA & $5.2 \mathrm{E}+02$ & $2.4 \mathrm{E}+03$ & $8.8 \mathrm{E}+01$ & $4 . I E+02$ & $3.4 \mathrm{E}+02$ & $2 . \mathrm{E}+02$ & $8.6 \mathrm{E}+0 \mathrm{I}$ & $5.0 \mathrm{E}+0 \mathrm{I}$ & $5 .|\mathrm{E}+0|$ & $4.5 \mathrm{E}+0 \mathrm{I}$ & $3.2 \mathrm{E}+0 \mathrm{I}$ \\
\hline \multicolumn{13}{|l|}{ Uncertainties } \\
\hline $\mathrm{CaO}(\mathrm{Wt} \%)$ & & & I.E +00 & 2.E-OI & 6.E-OI & 7.E-OI & 3.E-OI & 2.E-OI & 2.E-OI & 2.E-OI & 2.E-OI & 3.E-0I \\
\hline $\mathrm{Fe}_{2} \mathrm{O}_{3}(\mathrm{Wt} \%)$ & & 4.E-OI & I.E +00 & 4.E-OI & 7.E-OI & 7.E-OI & 5.E-OI & 4.E-OI & 4.E-OI & 4.E-OI & 4.E-OI & 4.E-OI \\
\hline $\mathrm{Al}_{2} \mathrm{O}_{3}(\mathrm{Wt} \%)$ & & & & & & $2 . E+00$ & 8.E-0I & 5.E-OI & 4.E-0I & 4.E-0I & 4.E-OI & 6.E-01 \\
\hline
\end{tabular}

Note: Elemental Concentrations have been converted to Oxide forms on $\mathrm{SO}_{3}$-free basis nd $=$ below detection limit 
Table C-4 (continued)

Analytical Results for Wyodak Doping Experiments: Selenium Doping with No Oxygen Enrichment

b) Sampled At Port 14

\begin{tabular}{|c|c|c|c|c|c|c|c|c|c|c|c|c|}
\hline \multicolumn{2}{|c|}{ Impactor Stage } & 1 & 2 & 3 & 4 & 5 & 6 & 7 & 8 & 9 & 10 & II \\
\hline \multicolumn{2}{|c|}{$\begin{array}{r}\text { Cut-offDiameter } \\
\text { (microns) }\end{array}$} & 0.0324 & 0.0636 & 0.0926 & 0.168 & 0.337 & 0.535 & 0.973 & 1.96 & 3.77 & 7.33 & 15.7 \\
\hline Element & $\begin{array}{c}\text { Analytical } \\
\text { Method }\end{array}$ & & & & & & & & & & & \\
\hline \multicolumn{2}{|c|}{\begin{tabular}{|c|}
$\begin{array}{c}\text { Total Mass Conc Grava-metric } \\
\left(\mathrm{g} / \mathrm{Nm}^{3}\right)\end{array}$ \\
\end{tabular}} & $1.00 \mathrm{E}-04$ & $3.50 \mathrm{E}-05$ & $2.15 E-04$ & $2.70 \mathrm{E}-04$ & $5.20 \mathrm{E}-04$ & $9.85 \mathrm{E}-04$ & $2.38 \mathrm{E}-03$ & $6.33 \mathrm{E}-03$ & $6.39 \mathrm{E}-03$ & 4.28E-03 & $8.80 \mathrm{E}-04$ \\
\hline \multicolumn{13}{|c|}{\begin{tabular}{|l|l|} 
Concentrations \\
\end{tabular}} \\
\hline $\mathrm{CaO}(\mathrm{Wt} \%)$ & AAS & nd & $5 . E+01$ & I.E+0I & 2.E+OI & $2 . \mathrm{E}+0 \mathrm{I}$ & $2 . E+0 I$ & I.E+0| & $8 . E+00$ & 7.E + 00 & $9 . \mathrm{E}+00$ & $2 . E+0 I$ \\
\hline $\mathrm{Fe}_{2} \mathrm{O}_{3}(\mathrm{Wt} \%)$ & AAS & $5 . \mathrm{E}+01$ & $3 . E+0 I$ & $2 . E+0 I$ & $2 . \mathrm{E}+0 \mathrm{I}$ & $2 . \mathrm{E}+0 \mathrm{I}$ & $I . E+0 \mid$ & I.E+0| & $I . E+0 \mid$ & $8 . E+00$ & I.E+0| & I.E $+0 \mid$ \\
\hline $\mathrm{Al}_{2} \mathrm{O}_{3}(\mathrm{Wt} \%)$ & AAS & nd & nd & nd & $6 . \mathrm{E}+01$ & $6 . \mathrm{E}+01$ & $5 . \mathrm{E}+0 \mathrm{I}$ & $5 . E+01$ & $4 . E+01$ & $3 . E+01$ & $3 . \mathrm{E}+0 \mathrm{I}$ & $5 . E+01$ \\
\hline Se (ppmw) & GFAA & $6 . \mathrm{E}+02$ & $2 . E+03$ & $5 . \mathrm{E}+02$ & $5 . \mathrm{E}+02$ & $2 . \mathrm{E}+02$ & $\mathrm{I} . \mathrm{E}+02$ & 7.E +01 & $8 . E+01$ & $5 . \mathrm{E}+0 \mathrm{I}$ & $4 . \mathrm{E}+0 \mathrm{I}$ & $5 . E+01$ \\
\hline \multicolumn{13}{|l|}{ Uncertainties } \\
\hline $\mathrm{CaO}(\mathrm{Wt} \%)$ & & & $|. E+0|$ & 9.E-Ol & 9.E-OI & 6.E-OI & 4.E-OI & 3.E-OI & 2.E-OI & 2.E-OI & 2.E-OI & 5.E-OI \\
\hline $\mathrm{Fe}_{2} \mathrm{O}_{3}(\mathrm{Wt} \%)$ & & $5 . \mathrm{E}+00$ & $9 . E+00$ & I.E +00 & I.E +00 & 7.E-0I & 5.E-OI & 4.E-0I & 4.E-Ol & 4.E-Ol & 4.E-0I & 5.E-Ol \\
\hline $\mathrm{Al}_{2} \mathrm{O}_{3}(\mathrm{Wt} \%)$ & & & & & $3 . \mathrm{E}+00$ & $2 . \mathrm{E}+00$ & 9.E-0I & 6.E-Ol & 4.E-0I & 4.E-0I & 4.E-OI & I.E +00 \\
\hline
\end{tabular}

Note: Elemental Concentrations have been converted to Oxide forms on a $\mathrm{SO}_{3}$-free basis nd $=$ below detection limit 
Table C-5

Analytical Results For Wyodak Doping Experiments: Selenium Doping with Oxygen Enrichment

a) Sampled At Port 4

\begin{tabular}{|c|c|c|c|c|c|c|c|c|c|c|c|c|}
\hline \multicolumn{2}{|c|}{ Impactor Stage } & I & 2 & 3 & 4 & 5 & 6 & 7 & 8 & 9 & 10 & II \\
\hline \multicolumn{2}{|c|}{$\begin{array}{r}\text { Cut-offDiameter } \\
\text { (microns) }\end{array}$} & 0.0324 & 0.0636 & 0.0926 & 0.168 & 0.337 & 0.535 & 0.973 & 1.96 & 3.77 & 7.33 & 15.7 \\
\hline Element & $\begin{array}{c}\text { Analytical } \\
\text { Method }\end{array}$ & & & & & & & & & & & \\
\hline $\begin{array}{c}\text { Total Mass Conc } \\
\left(\mathrm{g} / \mathrm{Nm}^{3}\right)\end{array}$ & Grava-metric & $1.17 \mathrm{E}-02$ & $3.13 \mathrm{E}-02$ & $9.46 \mathrm{E}-02$ & I.18E-0I & $8.00 \mathrm{E}-02$ & $1.12 \mathrm{E}-0 \mid$ & $3.30 \mathrm{E}-0 \mathrm{I}$ & $9.10 \mathrm{E}-01$ & $1.5 \mathrm{IE}+00$ & $2.80 \mathrm{E}+00$ & 2.4IE-0I \\
\hline \multicolumn{13}{|l|}{ Concentrations } \\
\hline $\mathrm{Ca} 0(\mathrm{Wt} \%)$ & AAS & nd & 6.E-OI & $7.7 \mathrm{E}+00$ & $5.3 \mathrm{E}+00$ & $5.5 \mathrm{E}+00$ & $1.23 \mathrm{E}+0 \mathrm{I}$ & $1.5 \mathrm{E}+00$ & $9.1 \mathrm{E}+00$ & $1.6 \mathrm{E}+00$ & $1.4 \mathrm{E}+00$ & $3.1 \mathrm{E}+00$ \\
\hline $\mathrm{Fe}_{2} \mathrm{O}_{3}(\mathrm{Wt} \%)$ & AAS & 2.E-OI & $\mathrm{I} . \mathrm{IE}+00$ & $1.4 \mathrm{E}+00$ & $1.4 \mathrm{E}+00$ & $4.5 \mathrm{E}+00$ & $1.06 \mathrm{E}+0 \mid$ & $9.2 \mathrm{E}+00$ & $1.44 \mathrm{E}+01$ & $8.9 \mathrm{E}+00$ & $7.7 \mathrm{E}+00$ & $1.26 \mathrm{E}+01$ \\
\hline $\mathrm{Al}_{2} \mathrm{O}_{3}(\mathrm{Wt} \%)$ & AAS & nd & nd & nd & $9.8 \mathrm{E}+00$ & $2.30 \mathrm{E}+01$ & $4.00 \mathrm{E}+0 \mathrm{I}$ & $3.09 E+01$ & $3.14 \mathrm{E}+01$ & $9.2 \mathrm{E}+00$ & $5.6 \mathrm{E}+00$ & $5.77 \mathrm{E}+0 \mathrm{l}$ \\
\hline Se (ppmw) & GFAA & $3.7 \mathrm{E}+02$ & $1.28 \mathrm{E}+02$ & $2.37 \mathrm{E}+02$ & $1.24 \mathrm{E}+02$ & $7.5 \mathrm{E}+01$ & $7.8 \mathrm{E}+0 \mathrm{I}$ & $4 . I E+0 \mid$ & $3.7 \mathrm{E}+01$ & $1.5 \mathrm{E}+0 \mathrm{I}$ & $2.7 \mathrm{E}+01$ & $1.9 \mathrm{E}+01$ \\
\hline \multicolumn{13}{|l|}{ Uncertainties } \\
\hline $\mathrm{CaO}(\mathrm{Wt} \%)$ & & & 2.E-OI & 3.E-OI & 2.E-OI & 3.E-OI & 3.E-OI & 2.E-0I & 2.E-OI & 2.E-OI & 2.E-OI & 2.E-OI \\
\hline $\mathrm{Fe}_{2} \mathrm{O}_{3}(\mathrm{Wt} \%)$ & & 4.E-OI & 4.E-OI & 4.E-OI & 4.E-OI & 4.E-0I & 5.E-OI & 4.E-OI & 4.E-OI & 4.E-OI & 4.E-OI & 4.E-OI \\
\hline $\mathrm{Al}_{2} \mathrm{O}_{3}(\mathrm{Wt} \%)$ & & & & & 4.E-0I & 6.E-0I & 7.E-OI & 5.E-OI & 4.E-0I & 4.E-0I & 4.E-0I & 6.E-OI \\
\hline Se (ppmw) & & $3 . \mathrm{E}+0 \mathrm{I}$ & $8 . E+00$ & 7.E +00 & $5 . E+00$ & $5 . \mathrm{E}+00$ & $5 . E+00$ & $4 . E+00$ & $4 . \mathrm{E}+00$ & $4 . \mathrm{E}+00$ & $4 . E+00$ & $4 . \mathrm{E}+00$ \\
\hline
\end{tabular}

Note: Elemental Concentrations have been converted to Oxide forms on $\mathrm{SO}_{3}$-free basis nd $=$ below detection limit 
Table C-5 (continued)

Analytical Results for Wyodak Doping Experiments: Selenium Doping with Oxygen Enrichment

b) Sampled At Port 14

\begin{tabular}{|c|c|c|c|c|c|c|c|c|c|c|c|c|}
\hline \multicolumn{2}{|c|}{ Impactor Stage } & I & 2 & 3 & 4 & 5 & 6 & 7 & 8 & 9 & 10 & II \\
\hline \multicolumn{2}{|c|}{$\begin{array}{r}\text { Cut-offDiameter } \\
\text { (microns) }\end{array}$} & 0.0324 & 0.0636 & 0.0926 & 0.168 & 0.337 & 0.535 & 0.973 & 1.96 & 3.77 & 7.33 & 15.7 \\
\hline Element & $\begin{array}{c}\text { Analytical } \\
\text { Method }\end{array}$ & & & & & & & & & & & \\
\hline \multicolumn{2}{|c|}{\begin{tabular}{|c|}
$\begin{array}{c}\text { Total Mass Conc Grava-metric } \\
\left(\mathrm{g} / \mathrm{Nm}^{3}\right)\end{array}$ \\
\end{tabular}} & $3.64 \mathrm{E}-03$ & $8.18 \mathrm{E}-03$ & $9.39 \mathrm{E}-03$ & $7.58 \mathrm{E}-02$ & $6.55 E-02$ & $8.58 \mathrm{E}-02$ & $2.29 \mathrm{E}-01$ & $6.80 \mathrm{E}-01$ & $7.85 \mathrm{E}-0 \mathrm{I}$ & $2.15 \mathrm{E}+00$ & $2.22 \mathrm{E}-0 \mathrm{I}$ \\
\hline \multicolumn{13}{|c|}{\begin{tabular}{|l|l|} 
Concentrations \\
\end{tabular}} \\
\hline $\mathrm{CaO}(\mathrm{Wt} \%)$ & AAS & nd & $1.5 \mathrm{E}+0 \mathrm{|}$ & $1.3 \mathrm{E}+0 \mid$ & $1.23 \mathrm{E}+0 \mathrm{I}$ & $7.7 \mathrm{E}+00$ & $6.4 \mathrm{E}+00$ & $5.4 \mathrm{E}+00$ & $2.4 \mathrm{E}+00$ & $3.1 \mathrm{E}+00$ & $1.4 \mathrm{E}+00$ & $3.3 \mathrm{E}+00$ \\
\hline $\mathrm{Fe}_{2} \mathrm{O}_{3}(\mathrm{Wt} \%)$ & AAS & $9.6 \mathrm{E}+00$ & $2.4 \mathrm{E}+01$ & $\mathrm{I} .0 \mathrm{E}+0 \mathrm{I}$ & $5.9 \mathrm{E}+00$ & $8.8 \mathrm{E}+00$ & $|.21 \mathrm{E}+0|$ & $1.37 \mathrm{E}+0 \mathrm{I}$ & $1.14 \mathrm{E}+0 \mid$ & $9.55 \mathrm{E}+00$ & $9.4 \mathrm{E}+00$ & $1.35 \mathrm{E}+0 \mid$ \\
\hline $\mathrm{Al}_{2} \mathrm{O}_{3}(\mathrm{Wt} \%)$ & AAS & nd & nd & nd & $1.45 \mathrm{E}+01$ & $3.4 \mathrm{IE}+0 \mathrm{I}$ & $4.25 \mathrm{E}+01$ & $3.88 \mathrm{E}+0 \mathrm{I}$ & I.4IE $+0 \mid$ & $1.32 \mathrm{E}+0 \mathrm{I}$ & $6.2 \mathrm{E}+00$ & $4.54 \mathrm{E}+0 \mathrm{I}$ \\
\hline Se (ppmw) & GFAA & $4.8 \mathrm{E}+02$ & $3.4 \mathrm{E}+02$ & $3.9 \mathrm{E}+02$ & $6.3 \mathrm{E}+02$ & $1.65 \mathrm{E}+02$ & $1.55 \mathrm{E}+02$ & $1.4 \mathrm{IE}+02$ & $8.0 \mathrm{E}+0 \mathrm{I}$ & $3.6 \mathrm{E}+01$ & $1.4 \mathrm{E}+0 \mathrm{I}$ & $3.2 \mathrm{E}+01$ \\
\hline \multicolumn{13}{|l|}{ Uncertainties } \\
\hline $\mathrm{CaO}(\mathrm{Wt} \%)$ & & & I.E +00 & I.E +00 & 3.E-OI & 3.E-OI & 3.E-0I & 2.E-OI & 2.E-0I & 2.E-0I & 2.E-OI & 2.E-OI \\
\hline $\mathrm{Fe}_{2} \mathrm{O}_{3}(\mathrm{Wt} \%)$ & & 2.E +00 & $2 . \mathrm{E}+00$ & I.E +00 & 4.E-OI & 5.E-OI & 5.E-Ol & 4.E-OI & 4.E-OI & 4.E-OI & 4.E-OI & 4.E-OI \\
\hline $\mathrm{Al}_{2} \mathrm{O}_{3}(\mathrm{Wt} \%)$ & & & & & 5.E-OI & 7.E-0I & 7.E-0I & 5.E-OI & 4.E-OI & 4.E-OI & 4.E-0I & 5.E-0I \\
\hline Se (ppmw) & & $8 . \mathrm{E}+0 \mathrm{I}$ & $3 . \mathrm{E}+0 \mathrm{I}$ & $3 . \mathrm{E}+0 \mathrm{I}$ & I.E+0I & $6 . \mathrm{E}+00$ & $6 . \mathrm{E}+00$ & $5 . \mathrm{E}+00$ & $4 . \mathrm{E}+00$ & $4 . E+00$ & $4 . E+00$ & $4 . \mathrm{E}+00$ \\
\hline
\end{tabular}

Note: Elemental Concentrations have been converted to Oxide forms on a $\mathrm{SO}_{3}$-free basis nd $=$ below detection limit 
Table C-6

Analytical Results For Wyodak Doping Experiments: Antimony Doping with No Oxygen Enrichment

a) Sampled At Port 4

\begin{tabular}{|c|c|c|c|c|c|c|c|c|c|c|c|c|}
\hline \multicolumn{2}{|c|}{ Impactor Stage } & I & 2 & 3 & 4 & 5 & 6 & 7 & 8 & 9 & 10 & II \\
\hline \multicolumn{2}{|c|}{$\begin{array}{r}\text { Cut-offDiameter } \\
\text { (microns) }\end{array}$} & 0.0324 & 0.0636 & 0.0926 & 0.168 & 0.337 & 0.535 & 0.973 & 1.96 & 3.77 & 7.33 & 15.7 \\
\hline Element & $\begin{array}{c}\text { Analytical } \\
\text { Method }\end{array}$ & & & & & & & & & & & \\
\hline $\begin{array}{l}\text { Total Mass Conc } \\
\left(\mathrm{g} / \mathrm{Nm}^{3}\right)\end{array}$ & Grava-metric & $3.46 \mathrm{E}-02$ & $3.14 \mathrm{E}-02$ & $4.86 \mathrm{E}-02$ & $5.09 \mathrm{E}-02$ & $4.44 \mathrm{E}-01$ & $2.79 \mathrm{E}-01$ & $4.50 \mathrm{E}-01$ & $1.14 \mathrm{E}+00$ & $1.51 \mathrm{E}+00$ & $\begin{array}{c}2.58 \mathrm{E}+0 \\
0\end{array}$ & $4.95 \mathrm{E}-01$ \\
\hline \multicolumn{13}{|l|}{ Concentrations } \\
\hline $\mathrm{Ca} 0(\mathrm{Wt} \%)$ & AAS & nd & $3.6 \mathrm{E}+00$ & 9.E-OI & I.IE +00 & 7.E-0I & $2.0 \mathrm{E}+00$ & $5.0 \mathrm{E}+00$ & $3.1 \mathrm{E}+00$ & $4.9 \mathrm{E}+00$ & $3.0 \mathrm{E}+00$ & $2.01 \mathrm{E}+01$ \\
\hline $\mathrm{Fe}_{2} \mathrm{O}_{3}(\mathrm{Wt} \%)$ & AAS & 3.E-0I & $1.78 \mathrm{E}+0 \mathrm{I}$ & $9.2 \mathrm{E}+00$ & 2.E-0I & nd & $1.3 \mathrm{E}+00$ & $8.4 \mathrm{E}+00$ & $8.0 \mathrm{E}+00$ & $9.85 \mathrm{E}+00$ & $1.38 \mathrm{E}+0 \mathrm{I}$ & $2 . \mathrm{E}+0 \mathrm{I}$ \\
\hline $\mathrm{Al}_{2} \mathrm{O}_{3}(\mathrm{Wt} \%)$ & AAS & $4.0 \mathrm{E}+00$ & $6.6 \mathrm{E}+00$ & $5.7 \mathrm{E}+00$ & $4.3 \mathrm{E}+00$ & $2.2 \mathrm{E}+00$ & $1.04 \mathrm{E}+0 \mathrm{l}$ & $2.43 \mathrm{E}+01$ & $1.46 \mathrm{E}+01$ & $1.39 \mathrm{E}+0 \mid$ & $1.26 \mathrm{E}+01$ & $4.01 \mathrm{E}+01$ \\
\hline Se (ppmw) & GFAA & $5.8 \mathrm{E}+0 \mathrm{I}$ & $2.4 \mathrm{E}+02$ & $8.8 \mathrm{E}+01$ & $4.8 \mathrm{E}+0 \mathrm{I}$ & $1.4 \mathrm{E}+0 \mathrm{I}$ & $1.04 \mathrm{E}+02$ & $2.10 \mathrm{E}+02$ & $1.63 \mathrm{E}+02$ & $9.2 \mathrm{E}+0 \mathrm{I}$ & $3.3 \mathrm{E}+01$ & $6.3 \mathrm{E}+01$ \\
\hline Co (ppmw) & & nd & $1.16 \mathrm{E}+02$ & $6.8 \mathrm{E}+01$ & $3.0 \mathrm{E}+0 \mathrm{I}$ & $5 . E+00$ & $3.2 \mathrm{E}+0 \mathrm{I}$ & $8.7 \mathrm{E}+0 \mathrm{I}$ & $9 .|\mathrm{E}+0|$ & $9.73 \mathrm{E}+0 \mathrm{I}$ & $6.2 \mathrm{E}+01$ & $1.00 \mathrm{E}+02$ \\
\hline \multicolumn{13}{|l|}{ Uncertainties } \\
\hline $\mathrm{CaO}(\mathrm{Wt} \%)$ & & & 3.E-0I & 2.E-0I & 2.E-0I & 2.E-OI & 2.E-OI & 2.E-OI & 2.E-OI & 2.E-OI & 2.E-OI & 2.E-0I \\
\hline $\mathrm{Fe}_{2} \mathrm{O}_{3}(\mathrm{Wt} \%)$ & & 4.E-0I & 9.E-0I & 6.E-01 & 4.E-0I & & 4.E-0I & 4.E-0I & 4.E-0I & 4.E-0I & 4.E-0I & 4.E-OI \\
\hline $\mathrm{Al}_{2} \mathrm{O}_{3}(\mathrm{Wt} \%)$ & & 5.E-OI & 6.E-01 & 5.E-OI & 4.E-OI & 4.E-OI & 4.E-Ol & 4.E-OI & 4.E-OI & 4.E-OI & 4.E-OI & 4.E-OI \\
\hline Se (ppmw) & & $8 . \mathrm{E}+00$ & I.E $+0 \mid$ & $8 . E+00$ & 7.E +00 & $6 . \mathrm{E}+00$ & $6 . E+00$ & $6 . \mathrm{E}+00$ & $6 . \mathrm{E}+00$ & $6 . E+00$ & $6 . \mathrm{E}+00$ & $6 . \mathrm{E}+00$ \\
\hline Co (ppmw) & & & $7 . E+00$ & $5 . E+00$ & $4 . E+00$ & $4 . E+00$ & $4 . E+00$ & $4 . E+00$ & $4 . E+00$ & $4 . \mathrm{E}+00$ & $4 . \mathrm{E}+00$ & $4 . E+00$ \\
\hline
\end{tabular}

Note: Elemental Concentrations have been converted to Oxide forms on a $\mathrm{SO}_{3}$-free basis nd = below detection limit 
TABLE C-6 (continued)

Analytical Results For Wyodak Doping Experiments: Antimony Doping with No Oxygen Enrichment

b) Sampled At Port 14

\begin{tabular}{|c|c|c|c|c|c|c|c|c|c|c|c|c|}
\hline \multicolumn{2}{|c|}{ Impactor Stage } & I & 2 & 3 & 4 & 5 & 6 & 7 & 8 & 9 & 10 & II \\
\hline \multicolumn{2}{|c|}{$\begin{array}{r}\text { Cut-offDiameter } \\
\text { (microns) }\end{array}$} & 0.0324 & 0.0636 & 0.0926 & 0.168 & 0.337 & 0.535 & 0.973 & 1.96 & 3.77 & 7.33 & 15.7 \\
\hline Element & $\begin{array}{c}\text { Analytical } \\
\text { Method }\end{array}$ & & & & & & & & & & & \\
\hline \multicolumn{2}{|c|}{\begin{tabular}{|c|}
$\begin{array}{c}\text { Total Mass Conc Gravametric } \\
\left(\mathrm{g} / \mathrm{Nm}^{3}\right)\end{array}$ \\
\end{tabular}} & $5.26 \mathrm{E}-03$ & $2.1 \mathrm{IE}-03$ & $6.84 \mathrm{E}-03$ & $1.52 \mathrm{E}-02$ & $2.90 \mathrm{E}-02$ & $1.47 \mathrm{E}-02$ & I.IOE-0I & $2.83 \mathrm{E}-01$ & $4.90 \mathrm{E}-0 \mathrm{I}$ & $7.20 \mathrm{E}-0 \mathrm{I}$ & |.38E-0| \\
\hline \multicolumn{13}{|c|}{ Concentrations } \\
\hline $\mathrm{CaO}(\mathrm{Wt} \%)$ & AAS & nd & nd & $6.3 \mathrm{E}+00$ & $3.8 \mathrm{E}+00$ & $2.6 \mathrm{E}+00$ & $1.47 \mathrm{E}+0 \mathrm{I}$ & $1.42 \mathrm{E}+0 \mathrm{l}$ & $5.8 \mathrm{E}+00$ & $4.5 \mathrm{E}+00$ & $3.9 \mathrm{E}+00$ & $2.51 \mathrm{E}+01$ \\
\hline $\mathrm{Fe}_{2} \mathrm{O}_{3}(\mathrm{Wt} \%)$ & AAS & nd & nd & $2.7 \mathrm{E}+00$ & $2.6 \mathrm{E}+00$ & $1.9 \mathrm{E}+00$ & $1.69 \mathrm{E}+0 \mathrm{I}$ & $1.90 \mathrm{E}+0 \mathrm{I}$ & $1.53 \mathrm{E}+0 \mathrm{I}$ & $1.89 \mathrm{E}+0 \mathrm{I}$ & $1.83 \mathrm{E}+0 \mathrm{I}$ & $1.75 \mathrm{E}+0 \mathrm{I}$ \\
\hline $\mathrm{Al}_{2} \mathrm{O}_{3}(\mathrm{Wt} \%)$ & AAS & nd & nd & nd & nd & $1.75 \mathrm{E}+01$ & $1.03 \mathrm{E}+02$ & $5.01 E+0 \mid$ & $3.57 \mathrm{E}+0 \mathrm{I}$ & $2.77 \mathrm{E}+0 \mathrm{I}$ & $1.94 \mathrm{E}+0 \mathrm{I}$ & $7.16 \mathrm{E}+01$ \\
\hline Se (ppmw) & GFAA & $1.9 \mathrm{E}+02$ & $9 . E+02$ & $2.4 \mathrm{E}+03$ & $1.57 \mathrm{E}+03$ & $4.4 \mathrm{E}+02$ & $3.6 \mathrm{E}+03$ & $1.48 \mathrm{E}+03$ & $7.6 \mathrm{IE}+02$ & $5.10 \mathrm{E}+02$ & $2.60 \mathrm{E}+02$ & $2.26 \mathrm{E}+02$ \\
\hline Co (ppmw) & & nd & nd & $8.7 \mathrm{E}+01$ & $5.2 \mathrm{E}+0 \mathrm{I}$ & $3.3 \mathrm{E}+01$ & $2.9 \mathrm{E}+02$ & $1.89 \mathrm{E}+02$ & $1.64 \mathrm{E}+02$ & $1.62 \mathrm{E}+02$ & $1.01 \mathrm{E}+02$ & $1.14 \mathrm{E}+02$ \\
\hline \multicolumn{13}{|l|}{ Uncertainties } \\
\hline $\mathrm{CaO}(\mathrm{Wt} \%)$ & & 2.E-OI & 2.E-OI & 5.E-OI & 3.E-OI & 2.E-OI & 6.E-OI & 3.E-OI & 2.E-OI & 2.E-OI & 2.E-OI & 3.E-OI \\
\hline $\mathrm{Fe}_{2} \mathrm{O}_{3}(\mathrm{Wt} \%)$ & & 3.E-0I & 2.E-0I & 5.E-Ol & 4.E-0I & 4.E-OI & 8.E-OI & 4.E-OI & 4.E-OI & 4.E-Ol & 4.E-Ol & 4.E-Ol \\
\hline $\mathrm{Al}_{2} \mathrm{O}_{3}(\mathrm{Wt} \%)$ & & & & & & 6.E-Ol & $3 . \mathrm{E}+00$ & 5.E-Ol & 4.E-OI & 4.E-OI & 4.E-OI & 6.E-OI \\
\hline Se (ppmw) & & $2 . \mathrm{E}+0 \mathrm{I}$ & I.E +02 & I.E +02 & $5 . E+01$ & I.E $+0 \mid$ & $\mathrm{I} . \mathrm{E}+02$ & $|. E+0|$ & 7.E +00 & $6 . \mathrm{E}+00$ & $6 . E+00$ & $7 . \mathrm{E}+00$ \\
\hline Co (ppmw) & & $4 . \mathrm{E}+00$ & $4 . E+00$ & $8 . \mathrm{E}+00$ & $5 . \mathrm{E}+00$ & $4 . \mathrm{E}+00$ & $|. E+0|$ & $4 . \mathrm{E}+00$ & $4 . E+00$ & $4 . \mathrm{E}+00$ & $4 . \mathrm{E}+00$ & $4 . \mathrm{E}+00$ \\
\hline
\end{tabular}

Note: Elemental Concentrations have been converted to Oxide forms on a $\mathrm{SO}_{3}$-free basis

nd $=$ below detection limit 
Table C-7

Analytical Results For Wyodak Doping Experiments: Antimony Doping with Oxygen Enrichment

a) Sampled At Port 4

\begin{tabular}{|c|c|c|c|c|c|c|c|c|c|c|c|c|}
\hline \multicolumn{2}{|c|}{ Impactor Stage } & I & 2 & 3 & 4 & 5 & 6 & 7 & 8 & 9 & 10 & II \\
\hline \multicolumn{2}{|c|}{$\begin{array}{r}\text { Cut-offDiameter } \\
\text { (microns) }\end{array}$} & 0.0324 & 0.0636 & 0.0926 & 0.168 & 0.337 & 0.535 & 0.973 & 1.96 & 3.77 & 7.33 & 15.7 \\
\hline Element & $\begin{array}{c}\text { Analytical } \\
\text { Method }\end{array}$ & & & & & & & & & & & \\
\hline $\begin{array}{l}\text { Total Mass Conc } \\
\left(\mathrm{g} / \mathrm{Nm}^{3}\right)\end{array}$ & Grava-metric & $2.58 \mathrm{E}-03$ & $1.16 \mathrm{E}-02$ & $5.01 \mathrm{E}-02$ & $4.64 \mathrm{E}-02$ & $1.98 \mathrm{E}-02$ & $3.27 \mathrm{E}-02$ & I.0|E-0| & $3.12 \mathrm{E}-01$ & $3.66 \mathrm{E}-0 \mathrm{I}$ & 9.4IE-0I & $8.29 \mathrm{E}-0 \mathrm{I}$ \\
\hline \multicolumn{13}{|l|}{ Concentrations } \\
\hline $\mathrm{Ca} 0(\mathrm{Wt} \%)$ & AAS & nd & $6.0 \mathrm{E}+00$ & $1.07 \mathrm{E}+01$ & $6.5 \mathrm{E}+00$ & $5.8 \mathrm{E}+00$ & $7.2 \mathrm{E}+00$ & $1.87 \mathrm{E}+01$ & $4.5 \mathrm{E}+00$ & $6.4 \mathrm{E}+00$ & $2.4 \mathrm{E}+00$ & $6.1 \mathrm{E}+00$ \\
\hline $\mathrm{Fe}_{2} \mathrm{O}_{3}(\mathrm{Wt} \%)$ & AAS & nd & 8.E-0I & $3 . \mathrm{IE}+00$ & $1.8 \mathrm{E}+00$ & nd & $3.1 \mathrm{E}+00$ & $|.4 \mathrm{IE}+0|$ & $1.05 \mathrm{E}+0 \mid$ & $9.3 \mathrm{E}+00$ & $7.7 \mathrm{E}+00$ & $1.05 \mathrm{E}+0 \mid$ \\
\hline $\mathrm{Al}_{2} \mathrm{O}_{3}(\mathrm{Wt} \%)$ & AAS & nd & nd & nd & nd & $2.28 \mathrm{E}+0 \mathrm{I}$ & $1.76 \mathrm{E}+0 \mathrm{I}$ & $4.74 \mathrm{E}+0 \mathrm{I}$ & $2.69 \mathrm{E}+0 \mathrm{I}$ & $2.89 \mathrm{E}+0 \mathrm{I}$ & 8.E-OI & $1.5 \mathrm{E}+00$ \\
\hline Se (ppmw) & GFAA & $2.5 \mathrm{E}+02$ & $3.2 \mathrm{E}+02$ & $3.54 \mathrm{E}+02$ & $1.94 \mathrm{E}+02$ & $2.2 \mathrm{E}+02$ & $2.8 \mathrm{E}+02$ & $3.47 \mathrm{E}+02$ & $2.57 \mathrm{E}+02$ & $1.58 \mathrm{E}+02$ & $8.8 \mathrm{E}+01$ & $1.08 \mathrm{E}+02$ \\
\hline Co (ppmw) & & nd & $5.7 \mathrm{E}+0 \mathrm{l}$ & $5.2 \mathrm{E}+0 \mathrm{l}$ & $2.9 \mathrm{E}+0 \mathrm{I}$ & $5.4 \mathrm{E}+0 \mathrm{I}$ & $7.4 \mathrm{E}+0 \mathrm{I}$ & $1.26 \mathrm{E}+02$ & $1.3 \mathrm{IE}+02$ & $1.07 \mathrm{E}+02$ & $5 .|\mathrm{E}+0|$ & $5.9 \mathrm{E}+0 \mathrm{I}$ \\
\hline \multicolumn{13}{|l|}{ Uncertainties } \\
\hline $\mathrm{CaO}(\mathrm{Wt} \%)$ & & & 4.E-OI & 3.E-0I & 3.E-OI & 3.E-0I & 3.E-0I & 3.E-OI & 2.E-0I & 2.E-OI & 2.E-OI & 2.E-OI \\
\hline $\mathrm{Fe}_{2} \mathrm{O}_{3}(\mathrm{Wt} \%)$ & & & 4.E-OI & 4.E-OI & 4.E-OI & & 4.E-OI & 4.E-OI & 4.E-OI & 4.E-OI & 4.E-OI & 4.E-OI \\
\hline $\mathrm{Al}_{2} \mathrm{O}_{3}(\mathrm{Wt} \%)$ & & & & & & 9.E-Ol & 6.E-OI & 6.E-OI & 4.E-OI & 4.E-OI & 4.E-OI & 4.E-0I \\
\hline Se (ppmw) & & $5 . \mathrm{E}+01$ & $2 . \mathrm{E}+0 \mathrm{I}$ & $9 . \mathrm{E}+00$ & $8 . E+00$ & I.E $+0 \mid$ & I.E $+0 \mid$ & $8 . \mathrm{E}+00$ & $6 . E+00$ & $6 . \mathrm{E}+00$ & $6 . \mathrm{E}+00$ & $6 . \mathrm{E}+00$ \\
\hline Co (ppmw) & & & $6 . \mathrm{E}+00$ & $4 . \mathrm{E}+00$ & $4 . E+00$ & $5 . \mathrm{E}+00$ & $5 . \mathrm{E}+00$ & $4 . \mathrm{E}+00$ & $4 . \mathrm{E}+00$ & $4 . \mathrm{E}+00$ & $4 . \mathrm{E}+00$ & $4 . \mathrm{E}+00$ \\
\hline
\end{tabular}

Note: Elemental Concentrations have been converted to Oxide forms on a $\mathrm{SO}_{3}$-free basis

nd $=$ below detection limit 
Table C-7 (continued)

Analytical Results For Wyodak Doping Experiments: Antimony Doping with Oxygen Enrichment

b) Sampled At Port 14

\begin{tabular}{|c|c|c|c|c|c|c|c|c|c|c|c|c|}
\hline \multirow{2}{*}{\multicolumn{2}{|c|}{$\begin{array}{r}\text { Impactor Stage } \\
\text { Cut-offDiameter } \\
\text { (microns) }\end{array}$}} & I & 2 & 3 & 4 & 5 & 6 & 7 & 8 & 9 & 10 & II \\
\hline & & 0.0324 & 0.0636 & 0.0926 & 0.168 & 0.337 & 0.535 & 0.973 & 1.96 & 3.77 & 7.33 & 15.7 \\
\hline Element & $\begin{array}{c}\text { Analytical } \\
\text { Method }\end{array}$ & & & & & & & & & & & \\
\hline \multicolumn{2}{|c|}{\begin{tabular}{|c|} 
Total Mass Conc Grava-metric \\
$\left(\mathrm{g} / \mathrm{Nm}^{3}\right)$
\end{tabular}} & $0.00 \mathrm{E}+00$ & $2.34 \mathrm{E}-03$ & $1.99 \mathrm{E}-02$ & $3.52 \mathrm{E}-02$ & $2.32 \mathrm{E}-02$ & $3.36 \mathrm{E}-02$ & $9.14 \mathrm{E}-02$ & $2.75 \mathrm{E}-01$ & $5.22 \mathrm{E}-01$ & $1.17 \mathrm{E}+00$ & $|.87 \mathrm{E}-0|$ \\
\hline \multicolumn{13}{|c|}{\begin{tabular}{|l|l|} 
Concentrations \\
\end{tabular}} \\
\hline $\mathrm{CaO}(\mathrm{Wt} \%)$ & AAS & & nd & $5.3 \mathrm{E}+00$ & $6.3 \mathrm{E}+00$ & $4.9 \mathrm{E}+00$ & $5.1 \mathrm{E}+00$ & $7.4 \mathrm{E}+00$ & $6.7 \mathrm{E}+00$ & $1.4 \mathrm{E}+00$ & $2.8 \mathrm{E}+00$ & $1.97 \mathrm{E}+01$ \\
\hline $\mathrm{Fe}_{2} \mathrm{O}_{3}(\mathrm{Wt} \%)$ & AAS & & nd & 6.E-OI & $1.9 \mathrm{E}+00$ & $1.6 \mathrm{E}+00$ & $3.3 \mathrm{E}+00$ & $1.32 \mathrm{E}+0 \mathrm{I}$ & $1.12 \mathrm{E}+0 \mid$ & $7.9 \mathrm{E}+00$ & $1.29 \mathrm{E}+01$ & $1.15 \mathrm{E}+01$ \\
\hline $\mathrm{Al}_{2} \mathrm{O}_{3}(\mathrm{Wt} \%)$ & AAS & & nd & nd & nd & nd & $2.31 \mathrm{E}+0 \mathrm{I}$ & $3.60 \mathrm{E}+01$ & $2.73 \mathrm{E}+01$ & $1.04 \mathrm{E}+01$ & $8.9 \mathrm{E}+00$ & $3.05 \mathrm{E}+01$ \\
\hline Se (ppmw) & GFAA & & $6.5 \mathrm{E}+02$ & $4.7 \mathrm{E}+02$ & $8.1 E+02$ & $6.3 \mathrm{E}+02$ & $5.5 \mathrm{E}+02$ & $8.62 \mathrm{E}+02$ & $4.95 \mathrm{E}+02$ & $2.63 \mathrm{E}+02$ & $2.55 \mathrm{E}+02$ & $1.49 \mathrm{E}+02$ \\
\hline Co (ppmw) & & & nd & $3.2 \mathrm{E}+0 \mathrm{I}$ & $3.4 \mathrm{E}+01$ & $3.8 \mathrm{E}+0 \mathrm{I}$ & $5 . \mid \mathrm{E}+0 \mathrm{I}$ & $1.16 \mathrm{E}+02$ & $1.16 \mathrm{E}+02$ & $7.2 \mathrm{E}+0 \mathrm{I}$ & $6.9 \mathrm{E}+01$ & $8.5 \mathrm{E}+01$ \\
\hline \multicolumn{13}{|l|}{ Uncertainties } \\
\hline $\mathrm{CaO}(\mathrm{Wt} \%)$ & & & & 3.E-0I & 3.E-0I & 3.E-0I & 3.E-0I & 2.E-OI & 2.E-OI & 2.E-OI & 2.E-OI & 2.E-OI \\
\hline $\mathrm{Fe}_{2} \mathrm{O}_{3}(\mathrm{Wt} \%)$ & & & & 4.E-0I & 4.E-OI & 4.E-OI & 4.E-0I & 4.E-OI & 4.E-OI & 4.E-OI & 4.E-OI & 4.E-OI \\
\hline $\mathrm{Al}_{2} \mathrm{O}_{3}(\mathrm{Wt} \%)$ & & & & & & & 6.E-0I & 5.E-OI & 4.E-OI & 4.E-OI & 4.E-OI & 4.E-OI \\
\hline Se (ppmw) & & & $9 . \mathrm{E}+0 \mathrm{I}$ & I.E $+0 \mid$ & I.E $+0 \mid$ & I.E $+0 \mid$ & I.E $+0 \mid$ & $9 . \mathrm{E}+00$ & $6 . \mathrm{E}+00$ & $6 . \mathrm{E}+00$ & $6 . \mathrm{E}+00$ & $6 . \mathrm{E}+00$ \\
\hline$C_{0}(\mathrm{ppmw})$ & & & & $4 . \mathrm{E}+00$ & $4 . \mathrm{E}+00$ & $4 . \mathrm{E}+00$ & $4 . \mathrm{E}+00$ & $4 . \mathrm{E}+00$ & 4.E+00 & $4 . \mathrm{E}+00$ & $4 . \mathrm{E}+00$ & $4 . \mathrm{E}+00$ \\
\hline
\end{tabular}

Note: Elemental Concentrations have been converted to Oxide forms on a $\mathrm{SO}_{3}$-free basis nd $=$ below detection limit 
Table C-8

Analytical Results For Wyodak Doping Experiments:

Iron Doping with No Oxygen Enrichment

a) Sampled At Port 4

\begin{tabular}{|c|c|c|c|c|c|c|}
\hline Impactor & Stage & 6 & 7 & 8 & 9 & 10 \\
\hline Cut-off & $\begin{array}{l}\text { Diameter } \\
\text { (microns) }\end{array}$ & 0.535 & 0.973 & 1.96 & 3.77 & 7.33 \\
\hline Element & $\begin{array}{l}\text { Analytical } \\
\text { Method }\end{array}$ & & & & & \\
\hline $\begin{array}{l}\text { Total Mass Conc } \\
\left(\mathrm{g} / \mathrm{Nm}^{3}\right)\end{array}$ & Gravametric & $5.34 \mathrm{E}-02$ & I.69E-0I & $3.99 \mathrm{E}-0 \mathrm{I}$ & $6.68 \mathrm{E}-0 \mathrm{I}$ & $1.46 \mathrm{E}+00$ \\
\hline \multicolumn{7}{|l|}{ Concentrations } \\
\hline $\mathrm{Ca} 0(\mathrm{Wt} \%)$ & AAS & $9.7 \mathrm{E}+00$ & I.I7E+0I & $9.78 \mathrm{E}+00$ & $5.2 \mathrm{E}+00$ & $2.2 \mathrm{E}+00$ \\
\hline $\mathrm{Fe}_{2} \mathrm{O}_{3}(\mathrm{Wt} \%)$ & AAS & $4.2 \mathrm{E}+0 \mathrm{I}$ & $3.74 \mathrm{E}+0 \mathrm{I}$ & $2.15 \mathrm{E}+01$ & $2.92 \mathrm{E}+0 \mathrm{I}$ & $3.33 \mathrm{E}+01$ \\
\hline $\mathrm{Al}_{2} \mathrm{O}_{3}(\mathrm{Wt} \%)$ & AAS & $4 . I E+0 I$ & $4.30 \mathrm{E}+01$ & $4.00 \mathrm{E}+01$ & $2.12 \mathrm{E}+0 \mathrm{I}$ & $9.3 \mathrm{E}+00$ \\
\hline As (ppmw) & GFAA & $5.62 \mathrm{E}+02$ & $1.87 \mathrm{E}+02$ & $6.8 \mathrm{E}+0 \mathrm{I}$ & $5.2 \mathrm{E}+0 \mathrm{I}$ & $2.3 \mathrm{E}+0 \mathrm{I}$ \\
\hline Se (ppmw) & GFAA & $7.4 \mathrm{E}+0 \mathrm{I}$ & $5.5 \mathrm{E}+0 \mathrm{I}$ & $3.8 \mathrm{E}+0 \mathrm{I}$ & $1.5 \mathrm{E}+0 \mathrm{I}$ & $7 . \mathrm{E}+00$ \\
\hline Sb (ppmw) & GFAA & $2.15 \mathrm{E}+02$ & $2.33 \mathrm{E}+02$ & $1.46 \mathrm{E}+02$ & $9.3 \mathrm{E}+01$ & $5.7 \mathrm{E}+0 \mathrm{I}$ \\
\hline Co (ppmw) & GFAA & $1.75 \mathrm{E}+02$ & $1.65 \mathrm{E}+02$ & $5.2 \mathrm{E}+0 \mathrm{I}$ & $3.5 \mathrm{E}+01$ & $1.9 \mathrm{E}+0 \mid$ \\
\hline \multicolumn{7}{|l|}{ Uncertainties } \\
\hline $\mathrm{CaO}(\mathrm{Wt} \%)$ & & 3.E-OI & 3.E-OI & 2.E-OI & 2.E-OI & 2.E-OI \\
\hline $\mathrm{Fe}_{2} \mathrm{O}_{3}(\mathrm{Wt} \%)$ & & I.E +00 & 5.E-0l & 4.E-OI & 4.E-OI & 4.E-0I \\
\hline $\mathrm{Al}_{2} \mathrm{O}_{3}(\mathrm{Wt} \%)$ & & I.E +00 & 6.E-OI & 4.E-0I & 4.E-OI & 4.E-OI \\
\hline As (ppmw) & & I.E $+0 \mid$ & $6 . \mathrm{E}+00$ & $5 . E+00$ & $5 . E+00$ & $5 . E+00$ \\
\hline Se (ppmw) & & $5 . E+00$ & $5 . E+00$ & $4 . E+00$ & $4 . \mathrm{E}+00$ & $4 . E+00$ \\
\hline Sb (ppmw) & & $9 . \mathrm{E}+00$ & $7 . \mathrm{E}+00$ & $6 . \mathrm{E}+00$ & $6 . \mathrm{E}+00$ & $6 . \mathrm{E}+00$ \\
\hline Co (ppmw) & & $6 . \mathrm{E}+00$ & $5 . \mathrm{E}+00$ & $4 . \mathrm{E}+00$ & $4 . E+00$ & $4 . E+00$ \\
\hline
\end{tabular}

Note: Elemental Concentrations have been converted to Oxide forms on a $\mathrm{SO}_{3}$-free basis 
Table C-8 (continued)

Analytical Results For Wyodak Doping Experiments:

Iron Doping with No Oxygen Enrichment

b) Sampled At Port 14

\begin{tabular}{|c|c|c|c|c|c|c|}
\hline Impactor & Stage & 6 & 7 & 8 & 9 & 10 \\
\hline Cut-off & $\begin{array}{l}\text { Diameter } \\
\text { (microns) }\end{array}$ & 0.535 & 0.973 & 1.96 & 3.77 & 7.33 \\
\hline Element & $\begin{array}{c}\text { Analytical } \\
\text { Method }\end{array}$ & & & & & \\
\hline $\begin{array}{c}\text { Total Mass Conc } \\
\left(\mathrm{g} / \mathrm{Nm}^{3}\right)\end{array}$ & Gravametric & $3.75 E-02$ & $1.04 \mathrm{E}-01$ & $1.93 \mathrm{E}-01$ & $2.75 E-01$ & $6.65 \mathrm{E}-01$ \\
\hline \multicolumn{7}{|l|}{ Concentrations } \\
\hline $\mathrm{CaO}(\mathrm{Wt} \%)$ & AAS & $|.4| \mathrm{E}+0 \mid$ & $1.46 \mathrm{E}+01$ & $9.3 \mathrm{E}+00$ & $1.64 \mathrm{E}+01$ & $6.5 E+00$ \\
\hline $\mathrm{Fe}_{2} \mathrm{O}_{3}(\mathrm{Wt} \%)$ & AAS & $4.2 \mathrm{E}+0 \mathrm{I}$ & $3.81 \mathrm{E}+0 \mathrm{I}$ & $3.19 \mathrm{E}+01$ & $2.96 \mathrm{E}+0 \mathrm{I}$ & $3.7|\mathrm{E}+0|$ \\
\hline $\mathrm{Al}_{2} \mathrm{O}_{3}(\mathrm{Wt} \%)$ & AAS & $3.8 \mathrm{E}+0 \mathrm{l}$ & $4.54 \mathrm{E}+0 \mathrm{I}$ & $4.33 \mathrm{E}+0 \mathrm{I}$ & $3.66 \mathrm{E}+01$ & $2.33 \mathrm{E}+01$ \\
\hline As (ppmw) & GFAA & $6.9 E+02$ & $2.36 \mathrm{E}+02$ & $1.31 \mathrm{IE}+02$ & $1.01 E+02$ & $4.4 \mathrm{E}+0 \mathrm{I}$ \\
\hline Se (ppmw) & GFAA & $6.6 \mathrm{E}+01$ & $4.3 \mathrm{E}+01$ & $4.0 \mathrm{E}+01$ & $2.5 \mathrm{E}+0 \mathrm{I}$ & $1.4 \mathrm{E}+0 \mathrm{I}$ \\
\hline Sb (ppmw) & GFAA & $2.3 \mathrm{E}+02$ & $2.36 \mathrm{E}+02$ & $1.61 \mathrm{E}+02$ & $1.06 \mathrm{E}+02$ & $8.0 E+01$ \\
\hline Co (ppmw) & GFAA & $1.52 \mathrm{E}+02$ & $1.33 \mathrm{E}+02$ & $1.16 \mathrm{E}+02$ & $8 . I E+0 \mid$ & $2.9 \mathrm{E}+0 \mathrm{I}$ \\
\hline \multicolumn{7}{|l|}{ Uncertainties } \\
\hline $\mathrm{Ca0}(\mathrm{Wt} \%)$ & & 5.E-OI & 3.E-0I & 2.E-01 & 3.E-01 & 2.E-01 \\
\hline $\mathrm{Fe}_{2} \mathrm{O}_{3}(\mathrm{Wt} \%)$ & & I.E +00 & 7.E-0I & 5.E-0I & 5.E-OI & 4.E-0I \\
\hline $\mathrm{Al}_{2} \mathrm{O}_{3}(\mathrm{Wt} \%)$ & & I.E+00 & 8.E-01 & 6.E-01 & 5.E-01 & 4.E-01 \\
\hline As (ppmw) & & $2 . E+01$ & $7 . E+00$ & $6 . E+00$ & $6 . E+00$ & $5 . E+00$ \\
\hline Se (ppmw) & & $6 . \mathrm{E}+00$ & $5 . E+00$ & $5 . E+00$ & $4 . E+00$ & $4 . E+00$ \\
\hline Sb (ppmw) & & $|. E+0|$ & $8 . E+00$ & $7 . E+00$ & $6 . E+00$ & $6 . E+00$ \\
\hline Co (ppmw) & & $7 . E+00$ & $5 . E+00$ & $4 . E+00$ & $4 . E+00$ & $4 . E+00$ \\
\hline
\end{tabular}

Note: Elemental Concentrations have been converted to Oxide forms on a $\mathrm{SO}_{3}$-free basis 
Table C-9

Analytical Results For Wyodak Doping Experiments:

Iron Doping with Oxygen Enrichment

a) Sampled At Port 4

\begin{tabular}{|c|c|c|c|c|c|c|}
\hline Impactor & Stage & 6 & 7 & 8 & 9 & 10 \\
\hline Cut-off & $\begin{array}{l}\text { Diameter } \\
\text { (microns) }\end{array}$ & 0.535 & 0.973 & 1.96 & 3.77 & 7.33 \\
\hline Element & $\begin{array}{c}\text { Analytical } \\
\text { Method }\end{array}$ & & & & & \\
\hline $\begin{array}{l}\text { Total Mass Conc } \\
\left(\mathrm{g} / \mathrm{Nm}^{3}\right)\end{array}$ & Gravametric & $1.78 \mathrm{E}-02$ & $3.20 \mathrm{E}-02$ & $6.62 \mathrm{E}-02$ & $8.76 \mathrm{E}-02$ & $2.44 \mathrm{E}-01$ \\
\hline \multicolumn{7}{|l|}{ Concentrations } \\
\hline $\mathrm{CaO}(\mathrm{Wt} \%)$ & AAS & $2.9 \mathrm{E}+0 \mathrm{I}$ & $1.60 \mathrm{E}+0 \mathrm{I}$ & $1.75 \mathrm{E}+01$ & $2.36 \mathrm{E}+01$ & $1.25 \mathrm{E}+01$ \\
\hline $\mathrm{Fe}_{2} \mathrm{O}_{3}(\mathrm{Wt} \%)$ & AAS & $2.9 \mathrm{E}+0 \mathrm{I}$ & $2.29 \mathrm{E}+0 \mathrm{I}$ & $2.77 \mathrm{E}+01$ & $3.5 \mathrm{IE}+0 \mathrm{I}$ & $3.36 \mathrm{E}+01$ \\
\hline $\mathrm{Al}_{2} \mathrm{O}_{3}(\mathrm{Wt} \%)$ & AAS & $6 . I E+0 I$ & $5.2 \mathrm{E}+0 \mathrm{I}$ & $4.58 \mathrm{E}+0 \mathrm{I}$ & $4.09 \mathrm{E}+01$ & $3.37 \mathrm{E}+01$ \\
\hline As (ppmw) & GFAA & $2.2 \mathrm{E}+03$ & $1.15 E+03$ & $5.4 \mathrm{E}+02$ & $3.38 \mathrm{E}+02$ & $1.26 \mathrm{E}+02$ \\
\hline Se (ppmw) & GFAA & $3.3 \mathrm{E}+02$ & $1.68 \mathrm{E}+02$ & $9.2 \mathrm{E}+0 \mathrm{I}$ & $7.0 \mathrm{E}+0 \mathrm{I}$ & $1.9 \mathrm{E}+0 \mathrm{I}$ \\
\hline Sb (ppmw) & GFAA & $1.2 \mathrm{E}+02$ & $7.8 \mathrm{E}+0 \mathrm{I}$ & $7.0 E+01$ & $6.9 \mathrm{E}+0 \mathrm{I}$ & $6 . I E+01$ \\
\hline Co (ppmw) & GFAA & $2.0 E+02$ & $1.38 \mathrm{E}+02$ & $2.12 \mathrm{E}+02$ & $1.32 \mathrm{E}+02$ & $7 . \mid \mathrm{IE}+0 \mathrm{I}$ \\
\hline \multicolumn{7}{|l|}{ Uncertainties } \\
\hline $\mathrm{CaO}(\mathrm{Wt} \%)$ & & I.E+00 & 6.E-01 & 4.E-01 & 4.E-0I & $2 . \mathrm{E}-01$ \\
\hline $\mathrm{Fe}_{2} \mathrm{O}_{3}(\mathrm{Wt} \%)$ & & $2 . E+00$ & 9.E-0I & 7.E-0I & $7 . \mathrm{E}-0 \mathrm{OI}$ & 5.E-0I \\
\hline $\mathrm{Al}_{2} \mathrm{O}_{3}(\mathrm{Wt} \%)$ & & $3 . E+00$ & $2 . E+00$ & 9.E-0I & 7.E-0I & 5.E-0I \\
\hline As (ppmw) & & I.E +02 & $3 . E+01$ & I.E $+0 \mid$ & $8 . E+00$ & $6 . E+00$ \\
\hline Se (ppmw) & & $2 . E+01$ & $9 . E+00$ & $6 . \mathrm{E}+00$ & $5 . E+00$ & $4 . E+00$ \\
\hline Sb (ppmw) & & I.E $+0 \mid$ & $8 . E+00$ & $7 . \mathrm{E}+00$ & $7 . \mathrm{E}+00$ & $6 . E+00$ \\
\hline Co (ppmw) & & $|. E+0|$ & 7.E +00 & $6 . \mathrm{E}+00$ & $5 . E+00$ & $4 . E+00$ \\
\hline
\end{tabular}

Note: Elemental Concentrations have been converted to Oxide forms on a $\mathrm{SO}_{3}$-free basis 
Table C-9 (continued)

Analytical Results For Wyodak Doping Experiments:

Iron Doping with Oxygen Enrichment

b) Sampled At Port 14

\begin{tabular}{|c|c|c|c|c|c|c|}
\hline Impactor & Stage & 6 & 7 & 8 & 9 & 10 \\
\hline Cut-off & $\begin{array}{l}\text { Diameter } \\
\text { (microns) }\end{array}$ & 0.535 & 0.973 & 1.96 & 3.77 & 7.33 \\
\hline Element & $\begin{array}{c}\text { Analytical } \\
\text { Method }\end{array}$ & & & & & \\
\hline $\begin{array}{c}\text { Total Mass Conc } \\
\left(\mathrm{g} / \mathrm{Nm}^{3}\right)\end{array}$ & Gravametric & $2.18 \mathrm{E}-02$ & $6.49 \mathrm{E}-02$ & $1.15 \mathrm{E}-01$ & $1.72 \mathrm{E}-01$ & $3.77 \mathrm{E}-01$ \\
\hline \multicolumn{7}{|l|}{ Concentrations } \\
\hline $\mathrm{CaO}(\mathrm{Wt} \%)$ & AAS & $1.28 \mathrm{E}+01$ & $1.32 \mathrm{E}+01$ & $1.24 \mathrm{E}+01$ & $1.95 E+01$ & $1.04 E+01$ \\
\hline $\mathrm{Fe}_{2} \mathrm{O}_{3}(\mathrm{Wt} \%)$ & AAS & $3.6 \mathrm{E}+0 \mathrm{I}$ & $2.06 \mathrm{E}+01$ & $2.58 \mathrm{E}+0 \mathrm{I}$ & $2.92 \mathrm{E}+01$ & $3.67 \mathrm{E}+01$ \\
\hline $\mathrm{Al}_{2} \mathrm{O}_{3}(\mathrm{Wt} \%)$ & AAS & $8.2 \mathrm{E}+0 \mathrm{l}$ & $5.6 \mathrm{E}+0 \mathrm{I}$ & $5.4 \mid \mathrm{I}+0 \mathrm{I}$ & $4.40 \mathrm{E}+0 \mathrm{I}$ & $3.03 \mathrm{E}+01$ \\
\hline As (ppmw) & GFAA & $2.0 E+03$ & $5.3 \mathrm{IE}+02$ & $3.67 \mathrm{E}+02$ & $2.08 \mathrm{E}+02$ & I.IIE +02 \\
\hline Se (ppmw) & GFAA & $4 . I E+02$ & $1.89 \mathrm{E}+02$ & $1.44 \mathrm{E}+02$ & $5.0 \mathrm{E}+01$ & $1.7 \mathrm{E}+0 \mathrm{I}$ \\
\hline Sb (ppmw) & GFAA & $1.0 E+02$ & $6.8 \mathrm{E}+0 \mathrm{I}$ & $7 . \mid \mathrm{IE}+0 \mathrm{I}$ & $6.6 \mathrm{E}+01$ & $5.8 \mathrm{E}+0 \mathrm{I}$ \\
\hline Co (ppmw) & GFAA & $3.0 E+02$ & $1.97 \mathrm{E}+02$ & $1.67 \mathrm{E}+02$ & $1.33 \mathrm{E}+02$ & $7.0 \mathrm{E}+0 \mathrm{I}$ \\
\hline \multicolumn{7}{|l|}{ Uncertainties } \\
\hline $\mathrm{Ca0}(\mathrm{Wt} \%)$ & & 8.E-OI & 4.E-01 & 3.E-01 & 3.E-01 & 2.E-01 \\
\hline $\mathrm{Fe}_{2} \mathrm{O}_{3}(\mathrm{Wt} \%)$ & & $2 . E+00$ & 7.E-01 & 6.E-01 & 6.E-0l & 5.E-0l \\
\hline $\mathrm{Al}_{2} \mathrm{O}_{3}(\mathrm{Wt} \%)$ & & $4 . E+00$ & I.E+00 & 9.E-0I & 7.E-01 & 5.E-01 \\
\hline As (ppmw) & & I.E+02 & $|. E+0|$ & $9 . E+00$ & $7 . E+00$ & $6 . E+00$ \\
\hline Se (ppmw) & & $2 . E+01$ & $8 . \mathrm{E}+00$ & $6 . E+00$ & $5 . E+00$ & $4 . E+00$ \\
\hline Sb (ppmw) & & $|. E+0|$ & $7 . E+00$ & $7 . E+00$ & $6 . E+00$ & $6 . E+00$ \\
\hline Co (ppmw) & & $2 . E+01$ & $7 . \mathrm{E}+00$ & $5 . E+00$ & $5 . E+00$ & $4 . E+00$ \\
\hline
\end{tabular}

Note: Elemental Concentrations have been converted to Oxide forms on a $\mathrm{SO}_{3}$-free basis 
Table C-10

Analytical Results for Ohio Special Experiments:

$\mathrm{CO}_{2}$ Addition with no Calcium Addition

a) Sampled At Port 4

\begin{tabular}{|c|c|c|c|c|c|c|}
\hline Impactor & Stage & 6 & 7 & 8 & 9 & 10 \\
\hline Cut-off & $\begin{array}{l}\text { Diameter } \\
\text { (microns) }\end{array}$ & 0.535 & 0.973 & 1.96 & 3.77 & 7.33 \\
\hline Element & $\begin{array}{c}\text { Analytical } \\
\text { Method }\end{array}$ & & & & & \\
\hline $\begin{array}{c}\text { Total Mass Conc } \\
\left(\mathrm{g} / \mathrm{Nm}^{3}\right)\end{array}$ & Gravametric & $4.57 \mathrm{E}-02$ & $8.66 \mathrm{E}-02$ & $3.00 \mathrm{E}-01$ & $7.19 \mathrm{E}-01$ & $9.60 \mathrm{E}-01$ \\
\hline \multicolumn{7}{|l|}{ Concentrations } \\
\hline $\mathrm{CaO}(\mathrm{Wt} \%)$ & AAS & $2.9 \mathrm{E}+00$ & $3.3 \mathrm{E}+00$ & $3.5 \mathrm{E}+00$ & $2.9 \mathrm{E}+00$ & $2.9 \mathrm{E}+00$ \\
\hline $\mathrm{Fe}_{2} \mathrm{O}_{3}(\mathrm{Wt} \%)$ & AAS & $2.3 \mathrm{E}+0 \mathrm{I}$ & $2.34 \mathrm{E}+01$ & $1.53 \mathrm{E}+01$ & $1.79 E+01$ & $1.60 \mathrm{E}+01$ \\
\hline $\mathrm{Al}_{2} \mathrm{O}_{3}(\mathrm{Wt} \%)$ & AAS & $2 . E+00$ & $2 . E+00$ & 6.E-01 & 5.E-0I & 4.E-0I \\
\hline As (ppmw) & GFAA & $3 . \mathrm{IE}+03$ & $1.34 \mathrm{E}+03$ & $4.99 \mathrm{E}+02$ & $2.20 E+02$ & $1.51 \mathrm{IE}+02$ \\
\hline Se (ppmw) & GFAA & $1.8 \mathrm{E}+02$ & $8.7 \mathrm{E}+0 \mathrm{I}$ & $1.04 E+02$ & $5.2 \mathrm{E}+01$ & $9.7 \mathrm{E}+00$ \\
\hline $\mathrm{Sb}$ (ppmw) & GFAA & $3.5 \mathrm{E}+0 \mathrm{I}$ & $5.0 \mathrm{E}+0 \mathrm{I}$ & $3.2 \mathrm{E}+0 \mathrm{I}$ & $2 . I E+0 \mid$ & I.IE $+0 \mid$ \\
\hline Co (ppmw) & GFAA & $1.6 \mathrm{E}+01$ & $1.8 \mathrm{E}+01$ & $1.5 \mathrm{E}+0 \mid$ & $2.3 \mathrm{E}+01$ & $2.3 \mathrm{E}+01$ \\
\hline \multicolumn{7}{|l|}{ Uncertainties } \\
\hline $\mathrm{Ca0}(\mathrm{Wt} \%)$ & & 3.E-OI & 3.E-0I & 2.E-01 & 2.E-0I & 2.E-01 \\
\hline $\mathrm{Fe}_{2} \mathrm{O}_{3}(\mathrm{Wt} \%)$ & & I.E +00 & 8.E-OI & 5.E-0I & 4.E-OI & 4.E-OI \\
\hline $\mathrm{Al}_{2} \mathrm{O}_{3}(\mathrm{Wt} \%)$ & & $2 . E+00$ & $2 . E+00$ & 6.E-0I & 5.E-0I & 4.E-OI \\
\hline As (ppmw) & & I.E+02 & $3 . E+01$ & $8 . E+00$ & $6 . E+00$ & $6 . E+00$ \\
\hline Se (ppmw) & & $|. E+0|$ & $6 . E+00$ & $5 . E+00$ & $5 . E+00$ & $4 . E+00$ \\
\hline Sb (ppmw) & & $7 . E+00$ & $7 . E+00$ & $6 . E+00$ & $6 . E+00$ & $6 . E+00$ \\
\hline Co (ppmw) & & $9 . E+00$ & $6 . \mathrm{E}+00$ & $4 . E+00$ & $4 . E+00$ & $4 . E+00$ \\
\hline
\end{tabular}

Note: Elemental Concentrations have been converted to Oxide forms on a $\mathrm{SO}_{3}$-free basis 
Table C-10 (continued)

Analytical Results for Ohio Special Experiments:

$\mathrm{CO}_{2}$ Addition with no Calcium Addition

b) Sampled At Port 14

\begin{tabular}{|c|c|c|c|c|c|c|}
\hline Impactor & Stage & 6 & 7 & 8 & 9 & 10 \\
\hline Cut-off & $\begin{array}{l}\text { Diameter } \\
\text { (microns) }\end{array}$ & 0.535 & 0.973 & 1.96 & 3.77 & 7.33 \\
\hline Element & $\begin{array}{c}\text { Analytical } \\
\text { Method }\end{array}$ & & & & & \\
\hline $\begin{array}{c}\text { Total Mass Conc } \\
\left(\mathrm{g} / \mathrm{Nm}^{3}\right)\end{array}$ & Gravametric & $3.98 \mathrm{E}-02$ & $1.01 E-0 \mid$ & $3.33 \mathrm{E}-01$ & $6.23 \mathrm{E}-01$ & $1.90 \mathrm{E}+00$ \\
\hline \multicolumn{7}{|l|}{ Concentrations } \\
\hline $\mathrm{CaO}(\mathrm{Wt} \%)$ & AAS & $1.30 \mathrm{E}+01$ & $1.06 \mathrm{E}+01$ & $1.12 \mathrm{E}+01$ & $8 . I E+00$ & $8.0 E+00$ \\
\hline $\mathrm{Fe}_{2} \mathrm{O}_{3}(\mathrm{Wt} \%)$ & AAS & $3.0 \mathrm{E}+0 \mathrm{I}$ & $1.99 \mathrm{E}+01$ & $1.41 \mathrm{E}+0 \mid$ & $1.43 \mathrm{E}+0 \mathrm{I}$ & $1.79 \mathrm{E}+01$ \\
\hline $\mathrm{Al}_{2} \mathrm{O}_{3}(\mathrm{Wt} \%)$ & AAS & $1.7 \mathrm{E}+01$ & $3.9 \mathrm{E}+0 \mathrm{I}$ & $3.83 \mathrm{E}+0 \mathrm{I}$ & $2.55 \mathrm{E}+0 \mathrm{I}$ & $1.65 \mathrm{E}+01$ \\
\hline As (ppmw) & GFAA & $2.8 \mathrm{E}+03$ & $1.22 \mathrm{E}+03$ & $5.92 \mathrm{E}+02$ & $3.22 \mathrm{E}+02$ & $1.27 \mathrm{E}+02$ \\
\hline Se (ppmw) & GFAA & $1.3 \mathrm{E}+02$ & $6.3 \mathrm{E}+01$ & $1.06 \mathrm{E}+02$ & $1.7 \mathrm{E}+0 \mathrm{I}$ & $1.0 E+01$ \\
\hline Sb (ppmw) & GFAA & $9 . \mathrm{E}+0 \mathrm{I}$ & $5.8 \mathrm{E}+0 \mathrm{I}$ & $3.4 \mathrm{E}+0 \mathrm{I}$ & $2 . I E+0 \mid$ & I.IE $+0 \mid$ \\
\hline Co (ppmw) & GFAA & $2.1 E+02$ & $1.09 \mathrm{E}+02$ & $5.0 E+01$ & $2.9 \mathrm{E}+01$ & $2.2 \mathrm{E}+01$ \\
\hline \multicolumn{7}{|l|}{ Uncertainties } \\
\hline $\mathrm{Ca0}(\mathrm{Wt} \%)$ & & 8.E-0I & 4.E-0I & 3.E-01 & 2.E-0I & 2.E-01 \\
\hline $\mathrm{Fe}_{2} \mathrm{O}_{3}(\mathrm{Wt} \%)$ & & $2 . E+00$ & 7.E-0I & 4.E-OI & 4.E-0I & 4.E-OI \\
\hline $\mathrm{Al}_{2} \mathrm{O}_{3}(\mathrm{Wt} \%)$ & & I.E +00 & I.E +00 & 6.E-0I & 4.E-0I & 4.E-OI \\
\hline As (ppmw) & & I.E +02 & $3 . E+0 I$ & $9 . E+00$ & $6 . E+00$ & $5 . E+00$ \\
\hline Se (ppmw) & & $|. E+0|$ & $6 . E+00$ & $5 . E+00$ & $4 . E+00$ & $4 . E+00$ \\
\hline Sb (ppmw) & & $|. E+0|$ & 7.E +00 & $6 . E+00$ & $6 . E+00$ & $6 . E+00$ \\
\hline Co (ppmw) & & $|. E+0|$ & $6 . \mathrm{E}+00$ & $4 . E+00$ & $4 . E+00$ & $4 . E+00$ \\
\hline
\end{tabular}

Note: Elemental Concentrations have been converted to Oxide forms on a $\mathrm{SO}_{3}$-free basis 
Table C-11

Analytical Results for Ohio Special Experiments:

Calcium Addition with no $\mathrm{CO}_{2}$ Addition

a) Sampled At Port 4

\begin{tabular}{|c|c|c|c|c|c|c|}
\hline Impactor & Stage & 6 & 7 & 8 & 9 & 10 \\
\hline Cut-off & $\begin{array}{l}\text { Diameter } \\
\text { (microns) }\end{array}$ & 0.535 & 0.973 & 1.96 & 3.77 & 7.33 \\
\hline Element & $\begin{array}{l}\text { Analytical } \\
\text { Method }\end{array}$ & & & & & \\
\hline $\begin{array}{l}\text { Total Mass Conc } \\
\left(\mathrm{g} / \mathrm{Nm}^{3}\right)\end{array}$ & Gravametric & $8.59 \mathrm{E}-02$ & I.40E-0I & $4.62 \mathrm{E}-0 \mathrm{I}$ & $7.60 \mathrm{E}-0 \mathrm{I}$ & $2.66 \mathrm{E}+00$ \\
\hline \multicolumn{7}{|l|}{ Concentrations } \\
\hline $\mathrm{Ca} 0(\mathrm{Wt} \%)$ & AAS & $2.3 \mathrm{E}+0 \mathrm{I}$ & $2.20 \mathrm{E}+0 \mathrm{I}$ & $1.18 \mathrm{E}+01$ & $9.70 \mathrm{E}+00$ & $1.14 \mathrm{E}+0 \mathrm{I}$ \\
\hline $\mathrm{Fe}_{2} \mathrm{O}_{3}(\mathrm{Wt} \%)$ & AAS & $9.7 \mathrm{IE}+00$ & $9.2 \mathrm{E}+00$ & $6.4 \mathrm{E}+00$ & $9 . \mathrm{IE}+00$ & $1.28 \mathrm{E}+0 \mathrm{I}$ \\
\hline $\mathrm{Al}_{2} \mathrm{O}_{3}(\mathrm{Wt} \%)$ & AAS & $7.0 \mathrm{E}+0 \mathrm{I}$ & $9.68 \mathrm{E}+01$ & I.IIE +0I & $8.58 \mathrm{E}+01$ & $1.08 \mathrm{E}+01$ \\
\hline As (ppmw) & GFAA & $1.97 \mathrm{E}+03$ & I.30E +03 & $5.03 \mathrm{E}+02$ & $3.28 \mathrm{E}+02$ & $8.6 \mathrm{E}+01$ \\
\hline Se (ppmw) & GFAA & $9.72 \mathrm{E}+0 \mathrm{I}$ & $6.3 \mathrm{E}+0 \mathrm{I}$ & $3.4 \mathrm{E}+0 \mathrm{I}$ & $1.9 \mathrm{E}+0 \mathrm{I}$ & $8 . E+00$ \\
\hline Sb (ppmw) & GFAA & $3 . \mathrm{IE}+02$ & $3.4 \mathrm{E}+0 \mathrm{I}$ & $3.5 \mathrm{E}+0 \mathrm{I}$ & $2 . I E+0 \mid$ & $6 . \mathrm{E}+00$ \\
\hline Co (ppmw) & GFAA & $2.3 \mathrm{E}+0 \mathrm{I}$ & $2.5 \mathrm{E}+0 \mathrm{I}$ & $2.3 \mathrm{E}+0 \mathrm{I}$ & $2.6 \mathrm{E}+01$ & $1.3 \mathrm{E}+0 \mid$ \\
\hline \multicolumn{7}{|l|}{ Uncertainties } \\
\hline $\mathrm{CaO}(\mathrm{Wt} \%)$ & & I.E +00 & 7.E-0I & 3.E-OI & 2.E-OI & 2.E-OI \\
\hline $\mathrm{Fe}_{2} \mathrm{O}_{3}(\mathrm{Wt} \%)$ & & 7.E-0I & 6.E-0I & 4.E-OI & 4.E-OI & 4.E-0I \\
\hline $\mathrm{Al}_{2} \mathrm{O}_{3}(\mathrm{Wt} \%)$ & & $3 . E+00$ & $2 . E+00$ & 4.E-OI & 7.E-0I & 4.E-OI \\
\hline As (ppmw) & & $7 . \mathrm{E}+0 \mathrm{I}$ & $3 . E+01$ & $9 . \mathrm{E}+00$ & $7 . \mathrm{E}+00$ & $5 . E+00$ \\
\hline Se (ppmw) & & $8 . E+00$ & $6 . \mathrm{E}+00$ & $5 . E+00$ & $4 . E+00$ & $4 . E+00$ \\
\hline Sb (ppmw) & & $2 . E+0 I$ & $7 . \mathrm{E}+00$ & $6 . \mathrm{E}+00$ & $6 . \mathrm{E}+00$ & $6 . \mathrm{E}+00$ \\
\hline Co (ppmw) & & $5 . \mathrm{E}+00$ & $4 . E+00$ & $4 . E+00$ & $4 . \mathrm{E}+00$ & $4 . E+00$ \\
\hline
\end{tabular}

Note: Elemental Concentrations have been converted to Oxide forms on a $\mathrm{SO}_{3}$-free basis 
Table C-11 (continued)

Analytical Results for Ohio Special Experiments:

Calcium Addition with no $\mathrm{CO}_{2}$ Addition

b) Sampled At Port 14

\begin{tabular}{|c|c|c|c|c|c|c|}
\hline Impactor & Stage & 6 & 7 & 8 & 9 & 10 \\
\hline Cut-off & $\begin{array}{l}\text { Diameter } \\
\text { (microns) }\end{array}$ & 0.535 & 0.973 & 1.96 & 3.77 & 7.33 \\
\hline Element & $\begin{array}{c}\text { Analytical } \\
\text { Method }\end{array}$ & & & & & \\
\hline $\begin{array}{c}\text { Total Mass Conc } \\
\left(\mathrm{g} / \mathrm{Nm}^{3}\right)\end{array}$ & Gravametric & $1.00 \mathrm{E}-01$ & I.I3E-0I & $4.34 \mathrm{E}-0 \mathrm{I}$ & $8.74 \mathrm{E}-01$ & $1.74 \mathrm{E}+00$ \\
\hline \multicolumn{7}{|l|}{ Concentrations } \\
\hline $\mathrm{CaO}(\mathrm{Wt} \%)$ & AAS & $2.28 \mathrm{E}+01$ & $2.40 \mathrm{E}+01$ & $1.96 \mathrm{E}+01$ & $1.02 \mathrm{E}+01$ & $1.40 \mathrm{E}+01$ \\
\hline $\mathrm{Fe}_{2} \mathrm{O}_{3}(\mathrm{Wt} \%)$ & AAS & $9.58 \mathrm{E}+00$ & $5.7 \mathrm{E}+0 \mathrm{I}$ & $1.34 \mathrm{E}+01$ & $1.05 E+01$ & $1.18 \mathrm{E}+01$ \\
\hline $\mathrm{Al}_{2} \mathrm{O}_{3}(\mathrm{Wt} \%)$ & AAS & & & & & \\
\hline As (ppmw) & GFAA & $1.62 \mathrm{E}+03$ & $1.39 E+03$ & $6.19 \mathrm{E}+02$ & $4.35 E+02$ & $2.33 \mathrm{E}+02$ \\
\hline Se (ppmw) & GFAA & $1.22 \mathrm{E}+02$ & $1.22 \mathrm{E}+02$ & $5.3 \mathrm{E}+0 \mathrm{I}$ & $\mathrm{I} .3 \mathrm{E}+0 \mathrm{I}$ & $7 . E+00$ \\
\hline $\mathrm{Sb}$ (ppmw) & GFAA & $4 . I E+0 \mid$ & $4.8 \mathrm{E}+0 \mathrm{I}$ & $3.0 \mathrm{E}+0 \mathrm{I}$ & $2 . I E+0 \mid$ & I.IE $+0 \mid$ \\
\hline Co (ppmw) & GFAA & $5.6 \mathrm{E}+0 \mathrm{I}$ & $1.44 \mathrm{E}+02$ & $3.6 \mathrm{E}+0 \mathrm{I}$ & $2.8 \mathrm{E}+0 \mathrm{I}$ & $2 . I E+0 \mid$ \\
\hline \multicolumn{7}{|l|}{ Uncertainties } \\
\hline $\mathrm{Ca0}(\mathrm{Wt} \%)$ & & 8.E-0I & 8.E-OI & 3.E-01 & 2.E-01 & 2.E-01 \\
\hline $\mathrm{Fe}_{2} \mathrm{O}_{3}(\mathrm{Wt} \%)$ & & 6.E-0I & $2 . E+00$ & 4.E-OI & 4.E-OI & 4.E-OI \\
\hline \multicolumn{7}{|l|}{$\mathrm{Al}_{2} \mathrm{O}_{3}(\mathrm{Wt} \%)$} \\
\hline As (ppmw) & & $5 . E+01$ & $4 . E+01$ & $9 . E+00$ & 7.E +00 & $6 . E+00$ \\
\hline Se (ppmw) & & $8 . E+00$ & $7 . E+00$ & $5 . E+00$ & $4 . E+00$ & $4 . E+00$ \\
\hline Sb (ppmw) & & $7 . E+00$ & $7 . E+00$ & $6 . E+00$ & $6 . E+00$ & $6 . E+00$ \\
\hline Co (ppmw) & & $5 . E+00$ & $7 . \mathrm{E}+00$ & $4 . E+00$ & $4 . E+00$ & $4 . E+00$ \\
\hline
\end{tabular}

Note: Elemental Concentrations have been converted to Oxide forms on a $\mathrm{SO}_{3}$-free basis 
Table C-12

Analytical Results for Ohio Special Experiments:

Calcium Addition with $\mathrm{CO}_{2}$ Addition

a) Sampled At Port 4

\begin{tabular}{|c|c|c|c|c|c|c|}
\hline Impactor & Stage & 6 & 7 & 8 & 9 & 10 \\
\hline Cut-off & $\begin{array}{l}\text { Diameter } \\
\text { (microns) }\end{array}$ & 0.535 & 0.973 & 1.96 & 3.77 & 7.33 \\
\hline Element & $\begin{array}{c}\text { Analytical } \\
\text { Method }\end{array}$ & & & & & \\
\hline $\begin{array}{c}\text { Total Mass Conc } \\
\left(\mathrm{g} / \mathrm{Nm}^{3}\right)\end{array}$ & Gravametric & 0.06 & 0.19 & 0.65 & 1.31 & 4.54 \\
\hline \multicolumn{7}{|l|}{ Concentrations } \\
\hline $\mathrm{CaO}(\mathrm{Wt} \%)$ & AAS & $2.18 \mathrm{E}+01$ & $2.14 \mathrm{E}+01$ & $1.25 E+01$ & $8.4 \mathrm{E}+00$ & $2.5 \mathrm{E}+00$ \\
\hline $\mathrm{Fe}_{2} \mathrm{O}_{3}(\mathrm{Wt} \%)$ & AAS & $2.48 \mathrm{E}+0 \mathrm{I}$ & $1.14 \mathrm{E}+0 \mid$ & $6.5 \mathrm{E}+00$ & $6.9 E+00$ & $7.6 \mathrm{E}+00$ \\
\hline $\mathrm{Al}_{2} \mathrm{O}_{3}(\mathrm{Wt} \%)$ & AAS & $3.8 \mathrm{E}+01$ & $2.43 \mathrm{E}+0 \mathrm{I}$ & $1.70 E+01$ & $1.54 \mathrm{E}+0 \mid$ & $5.2 \mathrm{E}+00$ \\
\hline As (ppmw) & GFAA & $1.87 \mathrm{E}+03$ & $8.3 \mathrm{E}+02$ & $6.89 \mathrm{E}+02$ & $4.90 E+02$ & $6.4 \mathrm{E}+0 \mathrm{I}$ \\
\hline Se (ppmw) & GFAA & $2.0 \mathrm{E}+02$ & $8.0 E+01$ & $6.4 \mathrm{E}+0 \mathrm{I}$ & $1.3 \mathrm{E}+01$ & $3 . E+00$ \\
\hline $\mathrm{Sb}$ (ppmw) & GFAA & $4.4 \mathrm{E}+0 \mathrm{I}$ & $3.7 \mathrm{E}+0 \mathrm{I}$ & $6.2 \mathrm{E}+0 \mathrm{I}$ & $2.0 \mathrm{E}+0 \mathrm{I}$ & $7 . E+00$ \\
\hline Co (ppmw) & GFAA & $1.39 \mathrm{E}+02$ & $5.0 \mathrm{E}+01$ & $3 .|E+0|$ & $2.4 \mathrm{E}+0 \mathrm{I}$ & $1.6 \mathrm{E}+01$ \\
\hline \multicolumn{7}{|l|}{ Uncertainties } \\
\hline $\mathrm{Ca0}(\mathrm{Wt} \%)$ & & 9.E-OI & 4.E-01 & 2.E-01 & 2.E-0I & 2.E-01 \\
\hline $\mathrm{Fe}_{2} \mathrm{O}_{3}(\mathrm{Wt} \%)$ & & I.E +00 & 5.E-OI & 4.E-OI & 4.E-OI & 4.E-OI \\
\hline $\mathrm{Al}_{2} \mathrm{O}_{3}(\mathrm{Wt} \%)$ & & $2 . E+00$ & 6.E-0I & 4.E-OI & 4.E-0I & 4.E-OI \\
\hline As (ppmw) & & $7 . E+01$ & $|. E+0|$ & $7 . E+00$ & $6 . E+00$ & $5 . E+00$ \\
\hline Se (ppmw) & & $|. E+0|$ & $5 . E+00$ & $5 . E+00$ & $4 . E+00$ & $4 . E+00$ \\
\hline Sb (ppmw) & & $7 . E+00$ & $6 . E+00$ & $6 . E+00$ & $6 . E+00$ & $6 . E+00$ \\
\hline Co (ppmw) & & $8 . E+00$ & $4 . E+00$ & $4 . E+00$ & $4 . E+00$ & $4 . E+00$ \\
\hline
\end{tabular}

Note: Elemental Concentrations have been converted to Oxide forms on a $\mathrm{SO}_{3}$-free basis 
Table C-12 (continued)

Analytical Results for Ohio Special Experiments:

Calcium Addition with $\mathrm{CO}_{2}$ Addition

b) Sampled At Port 14

\begin{tabular}{|c|c|c|c|c|c|c|}
\hline Impactor & Stage & 6 & 7 & 8 & 9 & 10 \\
\hline Cut-off & $\begin{array}{l}\text { Diameter } \\
\text { (microns) }\end{array}$ & 0.535 & 0.973 & 1.96 & 3.77 & 7.33 \\
\hline Element & $\begin{array}{c}\text { Analytical } \\
\text { Method }\end{array}$ & & & & & \\
\hline $\begin{array}{c}\text { Total Mass Conc } \\
\left(\mathrm{g} / \mathrm{Nm}^{3}\right)\end{array}$ & Gravametric & $8.24 \mathrm{E}-02$ & $1.93 \mathrm{E}-01$ & $5.00 \mathrm{E}-01$ & $9.10 \mathrm{E}-01$ & $3.10 \mathrm{E}+00$ \\
\hline \multicolumn{7}{|l|}{ Concentrations } \\
\hline $\mathrm{CaO}(\mathrm{Wt} \%)$ & AAS & $|. E+0|$ & $1 . E+0 \mid$ & $|. E+0|$ & $2 . E+0 I$ & $6.9 \mathrm{E}+00$ \\
\hline $\mathrm{Fe}_{2} \mathrm{O}_{3}(\mathrm{Wt} \%)$ & AAS & $2 . E+0 I$ & $|. E+0|$ & $9.4 \mathrm{E}+00$ & $9.3 \mathrm{E}+00$ & $9.3 \mathrm{E}+00$ \\
\hline $\mathrm{Al}_{2} \mathrm{O}_{3}(\mathrm{Wt} \%)$ & AAS & $1.73 \mathrm{E}+01$ & $8.3 \mathrm{E}+0 \mathrm{I}$ & $1.69 \mathrm{E}+0 \mathrm{I}$ & $1.89 \mathrm{E}+0 \mid$ & $6.8 \mathrm{E}+00$ \\
\hline As (ppmw) & GFAA & $1.37 \mathrm{E}+03$ & 7.IE +02 & $5.50 E+02$ & $3.61 E+02$ & $1.22 \mathrm{E}+02$ \\
\hline Se (ppmw) & GFAA & $5.4 \mathrm{E}+01$ & $5.3 \mathrm{E}+01$ & $4.4 \mathrm{E}+0 \mathrm{I}$ & $2.2 \mathrm{E}+0 \mathrm{I}$ & $4 . E+00$ \\
\hline Sb (ppmw) & GFAA & $2.4 \mathrm{E}+0 \mathrm{I}$ & $4.0 \mathrm{E}+0 \mathrm{I}$ & $4.4 \mathrm{E}+0 \mathrm{I}$ & $2.6 \mathrm{E}+01$ & $1.0 \mathrm{E}+01$ \\
\hline Co (ppmw) & GFAA & $1.21 \mathrm{E}+02$ & $5.5 \mathrm{E}+0 \mathrm{I}$ & $3.2 \mathrm{E}+01$ & $2.4 \mathrm{E}+01$ & $1.8 \mathrm{E}+01$ \\
\hline \multicolumn{7}{|l|}{ Uncertainties } \\
\hline $\mathrm{Ca0}(\mathrm{Wt} \%)$ & & 5.E-0I & 3.E-0I & 3.E-01 & 2.E-0I & 2.E-01 \\
\hline $\mathrm{Fe}_{2} \mathrm{O}_{3}(\mathrm{Wt} \%)$ & & $8 . E-01$ & 5.E-OI & 4.E-OI & 4.E-0I & 4.E-0I \\
\hline $\mathrm{Al}_{2} \mathrm{O}_{3}(\mathrm{Wt} \%)$ & & 8.E-OI & I.E +00 & 4.E-0I & 4.E-0I & 4.E-0I \\
\hline As (ppmw) & & $4 . E+01$ & $|. E+0|$ & $7 . E+00$ & $6 . E+00$ & $5 . E+00$ \\
\hline Se (ppmw) & & $6 . E+00$ & $5 . E+00$ & $5 . E+00$ & $4 . E+00$ & $4 . E+00$ \\
\hline Sb (ppmw) & & $6 . E+00$ & $6 . E+00$ & $6 . E+00$ & $6 . E+00$ & $6 . E+00$ \\
\hline Co (ppmw) & & $7 . \mathrm{E}+00$ & $4 . E+00$ & $4 . E+00$ & $4 . E+00$ & $4 . E+00$ \\
\hline
\end{tabular}

Note: Elemental Concentrations have been converted to Oxide forms on a $\mathrm{SO}_{3}$-free basis 
Table C-13

Analytical Results for Kentucky $\mathrm{SO}_{2}$ Addition Experiments

a) Sampled At Port 4

\begin{tabular}{|c|c|c|c|c|c|c|}
\hline Impactor & Stage & 6 & 7 & 8 & 9 & 10 \\
\hline Cut-off & $\begin{array}{l}\text { Diameter } \\
\text { (microns) }\end{array}$ & 0.535 & 0.973 & 1.96 & 3.77 & 7.33 \\
\hline Element & $\begin{array}{c}\text { Analytical } \\
\text { Method }\end{array}$ & & & & & \\
\hline $\begin{array}{l}\text { Total Mass Conc } \\
\left(\mathrm{g} / \mathrm{Nm}^{3}\right)\end{array}$ & Gravametric & $6.8 \mathrm{IE}-02$ & I.IIE-0I & $2.17 \mathrm{E}-01$ & $4.02 \mathrm{E}-0 \mathrm{I}$ & $8.10 \mathrm{E}-01$ \\
\hline \multicolumn{7}{|l|}{ Concentrations } \\
\hline $\mathrm{CaO}(\mathrm{Wt} \%)$ & AAS & $9 . \mathrm{E}-0 \mathrm{I}$ & $1.7 \mathrm{E}+00$ & $2.0 \mathrm{E}+00$ & $2.0 \mathrm{E}+00$ & $1.3 \mathrm{E}+00$ \\
\hline $\mathrm{Fe}_{2} \mathrm{O}_{3}(\mathrm{Wt} \%)$ & AAS & $6.8 \mathrm{E}+00$ & $1.14 \mathrm{E}+0 \mathrm{I}$ & $9.86 \mathrm{E}+00$ & $8.2 \mathrm{E}+00$ & $8.0 \mathrm{E}+00$ \\
\hline $\mathrm{Al}_{2} \mathrm{O}_{3}(\mathrm{Wt} \%)$ & AAS & $6.0 \mathrm{E}+01$ & $7 . I E+0 I$ & $6.8 \mathrm{E}+01$ & $5.53 \mathrm{E}+0 \mathrm{I}$ & $4.89 \mathrm{E}+0 \mathrm{I}$ \\
\hline As (ppmw) & GFAA & $1.06 \mathrm{E}+03$ & $7 . \mathrm{IE}+02$ & $4.4 \mathrm{E}+02$ & $2.12 E+02$ & $9.3 \mathrm{E}+01$ \\
\hline Se (ppmw) & GFAA & $2.4 \mathrm{E}+02$ & $1.22 \mathrm{E}+02$ & $9.3 \mathrm{E}+0 \mathrm{I}$ & $5.0 \mathrm{E}+0 \mathrm{I}$ & $2.2 \mathrm{E}+01$ \\
\hline Sb (ppmw) & GFAA & $1.7 \mathrm{E}+01$ & $3.9 \mathrm{E}+0 \mathrm{I}$ & $2.3 \mathrm{E}+0 \mathrm{I}$ & $1.6 \mathrm{E}+0 \mid$ & $1.7 \mathrm{E}+0 \mid$ \\
\hline Co (ppmw) & GFAA & $1.25 E+02$ & $1.36 \mathrm{E}+02$ & $1.22 \mathrm{E}+02$ & $7.2 \mathrm{E}+0 \mathrm{I}$ & $3.7 \mathrm{E}+01$ \\
\hline \multicolumn{7}{|l|}{ Uncertainties } \\
\hline $\mathrm{CaO}(\mathrm{Wt} \%)$ & & 2.E-0I & $2 . \mathrm{E}-0 \mathrm{I}$ & 2.E-0I & $2 . \mathrm{E}-0 \mathrm{I}$ & $2 . \mathrm{E}-01$ \\
\hline $\mathrm{Fe}_{2} \mathrm{O}_{3}(\mathrm{Wt} \%)$ & & 6.E-0I & 6.E-0I & 5.E-0I & 4.E-0I & 4.E-0I \\
\hline $\mathrm{Al}_{2} \mathrm{O}_{3}(\mathrm{Wt} \%)$ & & $2 . E+00$ & $2 . E+00$ & I.E +00 & 7.E-0I & 5.E-0I \\
\hline As (ppmw) & & 4.E+0I & $2 . E+0 I$ & $|. E+0|$ & $6 . E+00$ & $6 . E+00$ \\
\hline Se (ppmw) & & $|. E+0|$ & $7 . E+00$ & $5 . E+00$ & $5 . E+00$ & $4 . E+00$ \\
\hline $\mathrm{Sb}$ (ppmw) & & $6 . E+00$ & $7 . E+00$ & $6 . E+00$ & $6 . E+00$ & $6 . E+00$ \\
\hline Co (ppmw) & & $8 . E+00$ & $7 . E+00$ & $5 . E+00$ & $4 . E+00$ & $4 . E+00$ \\
\hline
\end{tabular}

Note: Elemental Concentrations have been converted to Oxide forms on a $\mathrm{SO}_{3}$-free basis 
Table C-13 (continued)

Analytical Results for Kentucky $\mathrm{SO}_{2}$ Addition Experiments

b) Sampled At Port 14

\begin{tabular}{|c|c|c|c|c|c|c|}
\hline Impactor & Stage & 6 & 7 & 8 & 9 & 10 \\
\hline Cut-off & $\begin{array}{l}\text { Diameter } \\
\text { (microns) }\end{array}$ & 0.535 & 0.973 & 1.96 & 3.77 & 7.33 \\
\hline Element & $\begin{array}{c}\text { Analytical } \\
\text { Method }\end{array}$ & & & & & \\
\hline $\begin{array}{l}\text { Total Mass Conc } \\
\left(\mathrm{g} / \mathrm{Nm}^{3}\right)\end{array}$ & Gravametric & $4.26 \mathrm{E}-02$ & $7.23 \mathrm{E}-02$ & $1.38 \mathrm{E}-0 \mid$ & $2.37 \mathrm{E}-01$ & $5.70 \mathrm{E}-01$ \\
\hline \multicolumn{7}{|l|}{ Concentrations } \\
\hline $\mathrm{CaO}(\mathrm{Wt} \%)$ & AAS & $1.2 \mathrm{E}+00$ & $1.5 \mathrm{E}+00$ & $1.9 \mathrm{E}+00$ & $2.3 \mathrm{E}+00$ & $1.4 \mathrm{E}+00$ \\
\hline $\mathrm{Fe}_{2} \mathrm{O}_{3}(\mathrm{Wt} \%)$ & AAS & $7.7 \mathrm{E}+00$ & $1.21 \mathrm{E}+0 \mid$ & $9.5 \mathrm{E}+00$ & $1.05 E+01$ & $1.07 \mathrm{E}+01$ \\
\hline $\mathrm{Al}_{2} \mathrm{O}_{3}(\mathrm{Wt} \%)$ & AAS & $3.7 \mathrm{E}+01$ & $6.1 \mathrm{IE}+0 \mathrm{I}$ & $6.0 \mathrm{E}+0 \mathrm{I}$ & $5.70 \mathrm{E}+0 \mathrm{I}$ & $5.09 \mathrm{E}+01$ \\
\hline As (ppmw) & GFAA & $1.60 E+03$ & $1.03 \mathrm{E}+03$ & $6.5 \mathrm{E}+02$ & $3.4 \mathrm{IE}+02$ & $1.36 \mathrm{E}+02$ \\
\hline Se (ppmw) & GFAA & $3.4 \mathrm{E}+02$ & $1.59 \mathrm{E}+02$ & $1.24 \mathrm{E}+02$ & $1.07 \mathrm{E}+02$ & $4.4 \mathrm{E}+0 \mathrm{I}$ \\
\hline Sb (ppmw) & GFAA & $4.8 \mathrm{E}+0 \mathrm{I}$ & $4.4 \mathrm{E}+0 \mathrm{I}$ & $4.7 \mathrm{E}+0 \mathrm{I}$ & $5.7 \mathrm{E}+01$ & $1.0 \mathrm{E}+01$ \\
\hline Co (ppmw) & GFAA & $1.5 \mathrm{E}+02$ & $1.59 \mathrm{E}+02$ & $1.16 \mathrm{E}+02$ & $8.9 \mathrm{E}+0 \mathrm{I}$ & $4.8 \mathrm{E}+0 \mathrm{I}$ \\
\hline \multicolumn{7}{|l|}{ Uncertainties } \\
\hline $\mathrm{CaO}(\mathrm{Wt} \%)$ & & 3.E-0I & 2.E-0I & 2.E-0I & 2.E-0I & 2.E-0I \\
\hline $\mathrm{Fe}_{2} \mathrm{O}_{3}(\mathrm{Wt} \%)$ & & 7.E-01 & 7.E-0I & 5.E-01 & 5.E-0I & 4.E-0I \\
\hline $\mathrm{Al}_{2} \mathrm{O}_{3}(\mathrm{Wt} \%)$ & & $2 . E+00$ & $2 . E+00$ & I.E +00 & 9.E-OI & 6.E-01 \\
\hline As (ppmw) & & $8 . E+01$ & $4 . E+01$ & $2 . E+01$ & $8 . \mathrm{E}+00$ & $6 . E+00$ \\
\hline Se (ppmw) & & $2 . E+01$ & $9 . E+00$ & $6 . E+00$ & $5 . E+00$ & $5 . E+00$ \\
\hline Sb (ppmw) & & $8 . E+00$ & $7 . \mathrm{E}+00$ & $7 . E+00$ & $6 . E+00$ & $6 . E+00$ \\
\hline Co (ppmw) & & $|. E+0|$ & $8 . E+00$ & $6 . \mathrm{E}+00$ & $5 . E+00$ & $4 . E+00$ \\
\hline
\end{tabular}

Note: Elemental Concentrations have been converted to Oxide forms on a $\mathrm{SO}_{3}$-free basis 
Table C-14

Analytical Results for Pittsburgh Calcium Addition Experiments

a) Sampled At Port 4

\begin{tabular}{|c|c|c|c|c|c|c|}
\hline Impactor & Stage & 6 & 7 & 8 & 9 & 10 \\
\hline Cut-off & $\begin{array}{l}\text { Diameter } \\
\text { (microns) }\end{array}$ & 0.535 & 0.973 & 1.96 & 3.77 & 7.33 \\
\hline Element & $\begin{array}{c}\text { Analytical } \\
\text { Method }\end{array}$ & & & & & \\
\hline $\begin{array}{c}\text { Total Mass Conc } \\
\left(\mathrm{g} / \mathrm{Nm}^{3}\right)\end{array}$ & Gravametric & $5.05 E-02$ & I.I4E-0I & $3.19 \mathrm{E}-01$ & $3.86 \mathrm{E}-01$ & $9.30 \mathrm{E}-01$ \\
\hline \multicolumn{7}{|l|}{ Concentrations } \\
\hline $\mathrm{Ca} 0(\mathrm{Wt} \%)$ & AAS & $8.8 \mathrm{E}+00$ & $1.27 \mathrm{E}+0 \mathrm{I}$ & $1.42 \mathrm{E}+0 \mathrm{I}$ & $1.26 \mathrm{E}+0 \mathrm{I}$ & $6.2 \mathrm{E}+00$ \\
\hline $\mathrm{Fe}_{2} \mathrm{O}_{3}(\mathrm{Wt} \%)$ & AAS & $5.9 \mathrm{E}+00$ & $8.3 \mathrm{E}+00$ & $8.1 E+00$ & $9.9 \mathrm{IE}+00$ & $1.03 \mathrm{E}+01$ \\
\hline $\mathrm{Al}_{2} \mathrm{O}_{3}(\mathrm{Wt} \%)$ & AAS & $1.25 \mathrm{E}+0 \mathrm{I}$ & $3.88 \mathrm{E}+0 \mathrm{I}$ & $5.04 \mathrm{E}+01$ & $4.45 \mathrm{E}+0 \mathrm{I}$ & $2.28 \mathrm{E}+01$ \\
\hline As (ppmw) & GFAA & $1.14 \mathrm{E}+03$ & $4.8 \mathrm{E}+02$ & $2.3 \mathrm{IE}+02$ & $1.92 \mathrm{E}+02$ & $6.1 \mathrm{E}+0 \mathrm{I}$ \\
\hline Se (ppmw) & GFAA & $1.57 \mathrm{E}+02$ & $2.60 \mathrm{E}+02$ & $1.32 \mathrm{E}+02$ & $5.3 \mathrm{E}+0 \mathrm{I}$ & $1.5 \mathrm{E}+0 \mathrm{I}$ \\
\hline $\mathrm{Sb}$ (ppmw) & GFAA & $2.9 \mathrm{E}+0 \mathrm{I}$ & $5.7 \mathrm{E}+0 \mathrm{I}$ & $2.2 \mathrm{E}+0 \mathrm{I}$ & $2.0 \mathrm{E}+0 \mathrm{I}$ & $9 . E+00$ \\
\hline Co (ppmw) & GFAA & $6.8 \mathrm{E}+0 \mathrm{I}$ & $5.9 \mathrm{E}+0 \mathrm{I}$ & $4.9 \mathrm{E}+0 \mathrm{I}$ & $4.0 \mathrm{E}+0 \mathrm{I}$ & $1.9 \mathrm{E}+0 \mathrm{I}$ \\
\hline \multicolumn{7}{|l|}{ Uncertainties } \\
\hline $\mathrm{Ca} 0(\mathrm{Wt} \%)$ & & 5.E-OI & 4.E-OI & 3.E-OI & 3.E-OI & 2.E-OI \\
\hline $\mathrm{Fe}_{2} \mathrm{O}_{3}(\mathrm{Wt} \%)$ & & 5.E-0I & 5.E-OI & 4.E-OI & 4.E-OI & 4.E-OI \\
\hline $\mathrm{Al}_{2} \mathrm{O}_{3}(\mathrm{Wt} \%)$ & & 8.E-OI & 9.E-OI & 6.E-0I & $6 . \mathrm{E}-01$ & 4.E-0I \\
\hline As (ppmw) & & $4 . E+0 I$ & I.E $+0 \mid$ & $6 . \mathrm{E}+00$ & $6 . \mathrm{E}+00$ & $5 . E+00$ \\
\hline Se (ppmw) & & $9 . \mathrm{E}+00$ & $8 . E+00$ & $5 . E+00$ & $5 . E+00$ & $4 . E+00$ \\
\hline Sb (ppmw) & & $7 . \mathrm{E}+00$ & $7 . \mathrm{E}+00$ & $6 . \mathrm{E}+00$ & $6 . \mathrm{E}+00$ & $6 . \mathrm{E}+00$ \\
\hline Co (ppmw) & & $6 . \mathrm{E}+00$ & $5 . E+00$ & $4 . E+00$ & $4 . E+00$ & 4.E +00 \\
\hline
\end{tabular}

Note: Elemental Concentrations have been converted to Oxide forms on a $\mathrm{SO}_{3}$-free basis 
Table C-14 (continued)

Analytical Results for Pittsburgh Calcium Addition Experiments

b) Sampled At Port 14

\begin{tabular}{|c|c|c|c|c|c|c|}
\hline Impactor & Stage & 6 & 7 & 8 & 9 & 10 \\
\hline Cut-off & $\begin{array}{l}\text { Diameter } \\
\text { (microns) }\end{array}$ & 0.535 & 0.973 & 1.96 & 3.77 & 7.33 \\
\hline Element & $\begin{array}{c}\text { Analytical } \\
\text { Method }\end{array}$ & & & & & \\
\hline $\begin{array}{l}\text { Total Mass Conc } \\
\left(\mathrm{g} / \mathrm{Nm}^{3}\right)\end{array}$ & Gravametric & $6.34 \mathrm{E}-02$ & $1.82 \mathrm{E}-01$ & $5.67 \mathrm{E}-01$ & $8.86 \mathrm{E}-01$ & $1.45 E+00$ \\
\hline \multicolumn{7}{|l|}{ Concentrations } \\
\hline $\mathrm{CaO}(\mathrm{Wt} \%)$ & AAS & $1.20 \mathrm{E}+0 \mathrm{I}$ & $1.14 \mathrm{E}+01$ & $5.4 \mathrm{E}+00$ & $1.14 E+01$ & $9 . I E+00$ \\
\hline $\mathrm{Fe}_{2} \mathrm{O}_{3}(\mathrm{Wt} \%)$ & AAS & $2.44 \mathrm{E}+0 \mathrm{I}$ & $1.30 \mathrm{E}+0 \mid$ & $7.4 \mathrm{E}+00$ & $8.8 \mathrm{E}+00$ & $9.4 \mathrm{E}+00$ \\
\hline $\mathrm{Al}_{2} \mathrm{O}_{3}(\mathrm{Wt} \%)$ & AAS & $4.0 \mathrm{E}+0 \mathrm{I}$ & $5.38 \mathrm{E}+01$ & $3.61 \mathrm{E}+0 \mathrm{I}$ & $2.12 \mathrm{E}+01$ & $2.24 \mathrm{E}+01$ \\
\hline As (ppmw) & GFAA & $8.0 \mathrm{E}+02$ & $3.06 \mathrm{E}+02$ & $2.33 \mathrm{E}+02$ & $1.85 \mathrm{E}+02$ & $4.6 \mathrm{E}+01$ \\
\hline Se (ppmw) & GFAA & $7.5 \mathrm{E}+0 \mathrm{I}$ & $3.3 \mathrm{E}+01$ & $2.0 \mathrm{E}+0 \mathrm{I}$ & $9 . \mathrm{E}+00$ & $6 . \mathrm{E}+00$ \\
\hline Sb (ppmw) & GFAA & $5.0 \mathrm{E}+0 \mathrm{I}$ & $8.0 \mathrm{E}+0 \mathrm{I}$ & $1.7 \mathrm{E}+01$ & $1.7 \mathrm{E}+01$ & $7 . E+00$ \\
\hline Co (ppmw) & GFAA & $7.6 \mathrm{E}+01$ & $5.5 \mathrm{E}+0 \mathrm{I}$ & $4.9 \mathrm{E}+0 \mathrm{I}$ & $3.6 \mathrm{E}+0 \mathrm{I}$ & $2.5 \mathrm{E}+0 \mathrm{I}$ \\
\hline \multicolumn{7}{|l|}{ Uncertainties } \\
\hline $\mathrm{CaO}(\mathrm{Wt} \%)$ & & 5.E-0I & 3.E-0I & 2.E-0I & 2.E-0I & 2.E-0I \\
\hline $\mathrm{Fe}_{2} \mathrm{O}_{3}(\mathrm{Wt} \%)$ & & 7.E-01 & 4.E-0I & 4.E-0I & 4.E-0I & 4.E-0I \\
\hline $\mathrm{Al}_{2} \mathrm{O}_{3}(\mathrm{Wt} \%)$ & & I.E +00 & 8.E-0I & 5.E-01 & 4.E-0I & 4.E-0I \\
\hline As (ppmw) & & $2 . E+01$ & $8 . \mathrm{E}+00$ & $6 . E+00$ & $6 . \mathrm{E}+00$ & $5 . E+00$ \\
\hline Se (ppmw) & & $6 . E+00$ & $5 . E+00$ & 4.E+00 & $4 . E+00$ & 4.E+00 \\
\hline Sb (ppmw) & & $7 . E+00$ & $7 . \mathrm{E}+00$ & $6 . E+00$ & $6 . E+00$ & $6 . E+00$ \\
\hline Co (ppmw) & & $5 . E+00$ & $4 . E+00$ & $4 . E+00$ & $4 . E+00$ & $4 . E+00$ \\
\hline
\end{tabular}

Note: Elemental Concentrations have been converted to Oxide forms on a $\mathrm{SO}_{3}$-free basis 
Table C-15

Analytical Results for Pittsburgh Iron Doping Experiments

a) Sampled At Port 4

\begin{tabular}{|c|c|c|c|c|c|c|}
\hline Impactor & Stage & 6 & 7 & 8 & 9 & 10 \\
\hline Cut-off & $\begin{array}{l}\text { Diameter } \\
\text { (microns) }\end{array}$ & 0.535 & 0.973 & 1.96 & 3.77 & 7.33 \\
\hline Element & $\begin{array}{c}\text { Analytical } \\
\text { Method }\end{array}$ & & & & & \\
\hline $\begin{array}{l}\text { Total Mass Conc } \\
\left(\mathrm{g} / \mathrm{Nm}^{3}\right)\end{array}$ & Gravametric & $5.65 \mathrm{E}-02$ & $1.63 \mathrm{E}-0 \mathrm{I}$ & $4.16 \mathrm{E}-0 \mathrm{I}$ & $8.84 \mathrm{E}-0 \mathrm{I}$ & $2.26 \mathrm{E}+00$ \\
\hline \multicolumn{7}{|l|}{ Concentrations } \\
\hline $\mathrm{CaO}(\mathrm{Wt} \%)$ & AAS & $5.4 \mathrm{E}+00$ & $4.2 \mathrm{E}+00$ & $6.3 \mathrm{E}+00$ & $7.7 \mathrm{E}+00$ & $3.0 \mathrm{E}+00$ \\
\hline $\mathrm{Fe}_{2} \mathrm{O}_{3}(\mathrm{Wt} \%)$ & AAS & $1.97 \mathrm{E}+01$ & $1.68 \mathrm{E}+0 \mathrm{I}$ & $1.47 \mathrm{E}+0 \mid$ & $1.80 \mathrm{E}+0 \mathrm{I}$ & $2.77 \mathrm{E}+01$ \\
\hline $\mathrm{Al}_{2} \mathrm{O}_{3}(\mathrm{Wt} \%)$ & AAS & $3.8 \mathrm{E}+0 \mathrm{I}$ & $5.13 \mathrm{E}+01$ & $5.40 \mathrm{E}+0 \mathrm{I}$ & $3.63 \mathrm{E}+0 \mathrm{I}$ & $3.32 \mathrm{E}+01$ \\
\hline As (ppmw) & GFAA & $9.3 \mathrm{E}+02$ & $3.50 \mathrm{E}+02$ & $1.99 \mathrm{E}+02$ & $1.19 E+02$ & $4.7 \mathrm{E}+01$ \\
\hline Se (ppmw) & GFAA & $1.48 \mathrm{E}+03$ & $3.3 \mathrm{IE}+02$ & $6.9 \mathrm{E}+0 \mathrm{I}$ & $3.5 \mathrm{E}+0 \mathrm{I}$ & $8 . E+00$ \\
\hline Sb (ppmw) & GFAA & $4.6 \mathrm{E}+02$ & $5.9 \mathrm{E}+0 \mathrm{I}$ & $1.5 \mathrm{E}+0 \mid$ & $1.6 \mathrm{E}+0 \mid$ & $1.2 \mathrm{E}+0 \mid$ \\
\hline Co (ppmw) & GFAA & $8.7 E+01$ & $5.9 \mathrm{E}+0 \mathrm{I}$ & $5.4 \mathrm{E}+01$ & $5.3 \mathrm{E}+0 \mathrm{I}$ & $2.8 \mathrm{E}+0 \mathrm{I}$ \\
\hline \multicolumn{7}{|l|}{ Uncertainties } \\
\hline $\mathrm{CaO}(\mathrm{Wt} \%)$ & & 4.E-0I & $2 . \mathrm{E}-0 \mathrm{I}$ & $2 . E-01$ & $2 . \mathrm{E}-0 \mathrm{I}$ & $2 . \mathrm{E}-01$ \\
\hline $\mathrm{Fe}_{2} \mathrm{O}_{3}(\mathrm{Wt} \%)$ & & 9.E-0I & 5.E-OI & 4.E-0I & 4.E-0I & 4.E-0I \\
\hline $\mathrm{Al}_{2} \mathrm{O}_{3}(\mathrm{Wt} \%)$ & & I.E +00 & 9.E-0I & 6.E-0I & 4.E-0I & 4.E-0I \\
\hline As (ppmw) & & $3 . E+01$ & $9 . E+00$ & $6 . E+00$ & $5 . E+00$ & $5 . E+00$ \\
\hline Se (ppmw) & & $5 . E+01$ & $8 . E+00$ & $5 . E+00$ & $4 . E+00$ & $4 . E+00$ \\
\hline $\mathrm{Sb}$ (ppmw) & & $2 . E+01$ & $6 . E+00$ & $6 . E+00$ & $6 . E+00$ & $6 . E+00$ \\
\hline Co (ppmw) & & $6 . E+00$ & $4 . E+00$ & $4 . E+00$ & $4 . E+00$ & $4 . E+00$ \\
\hline
\end{tabular}

Note: Elemental Concentrations have been converted to Oxide forms on a $\mathrm{SO}_{3}$-free basis 
Table C-15 (continued)

Analytical Results for Pittsburgh Iron Doping Experiments

b) Sampled At Port 14

\begin{tabular}{|c|c|c|c|c|c|c|}
\hline Impactor & Stage & 6 & 7 & 8 & 9 & 10 \\
\hline Cut-off & $\begin{array}{l}\text { Diameter } \\
\text { (microns) }\end{array}$ & 0.535 & 0.973 & 1.96 & 3.77 & 7.33 \\
\hline Element & $\begin{array}{c}\text { Analytical } \\
\text { Method }\end{array}$ & & & & & \\
\hline $\begin{array}{l}\text { Total Mass Conc } \\
\left(\mathrm{g} / \mathrm{Nm}^{3}\right)\end{array}$ & Gravametric & 5.44E-02 & $9.01 \mathrm{E}-02$ & $2.47 \mathrm{E}-01$ & $5.57 \mathrm{E}-01$ & $9.52 \mathrm{E}-01$ \\
\hline \multicolumn{7}{|l|}{ Concentrations } \\
\hline $\mathrm{CaO}(\mathrm{Wt} \%)$ & AAS & $4.5 \mathrm{E}+00$ & $5.4 \mathrm{E}+00$ & $5.0 \mathrm{E}+00$ & $5.6 \mathrm{E}+00$ & $5.3 \mathrm{E}+00$ \\
\hline $\mathrm{Fe}_{2} \mathrm{O}_{3}(\mathrm{Wt} \%)$ & AAS & $9 . E+00$ & $5.0 \mathrm{E}+0 \mathrm{I}$ & $4.56 \mathrm{E}+01$ & $1.59 \mathrm{E}+01$ & $2.46 \mathrm{E}+01$ \\
\hline $\mathrm{Al}_{2} \mathrm{O}_{3}(\mathrm{Wt} \%)$ & AAS & $3.4 \mathrm{E}+0 \mathrm{I}$ & $4.0 \mathrm{E}+0 \mathrm{I}$ & $5.39 \mathrm{E}+0 \mathrm{I}$ & $3.72 \mathrm{E}+0 \mathrm{I}$ & $3.88 \mathrm{E}+01$ \\
\hline As (ppmw) & GFAA & $1.14 \mathrm{E}+03$ & $7.9 \mathrm{E}+02$ & $2.73 \mathrm{E}+02$ & $1.27 \mathrm{E}+02$ & $9.1 E+01$ \\
\hline Se (ppmw) & GFAA & 9.IE +02 & $3.8 \mathrm{E}+02$ & $1.78 \mathrm{E}+02$ & $3.0 \mathrm{E}+0 \mathrm{I}$ & $1.8 \mathrm{E}+0 \mathrm{I}$ \\
\hline Sb (ppmw) & GFAA & $8.3 \mathrm{E}+02$ & $1.4 \mathrm{E}+0 \mathrm{I}$ & $3.4 \mathrm{E}+0 \mathrm{I}$ & $9.8 \mathrm{E}+00$ & $7 . E+00$ \\
\hline Co (ppmw) & GFAA & $2.9 \mathrm{E}+02$ & $3.6 \mathrm{E}+02$ & $5.3 \mathrm{E}+01$ & $3.2 \mathrm{E}+0 \mathrm{I}$ & $2.8 \mathrm{E}+0 \mathrm{I}$ \\
\hline \multicolumn{7}{|l|}{ Uncertainties } \\
\hline $\mathrm{CaO}(\mathrm{Wt} \%)$ & & 4.E-0I & 3.E-0I & 2.E-0I & 2.E-0I & 2.E-0I \\
\hline $\mathrm{Fe}_{2} \mathrm{O}_{3}(\mathrm{Wt} \%)$ & & $2 . E+00$ & $1 . E+00$ & 5.E-01 & 4.E-0I & 4.E-0I \\
\hline $\mathrm{Al}_{2} \mathrm{O}_{3}(\mathrm{Wt} \%)$ & & $2 . E+00$ & I.E +00 & 8.E-0I & 5.E-OI & 4.E-0I \\
\hline As (ppmw) & & $4 . E+01$ & $2 . E+01$ & $7 . E+00$ & $6 . \mathrm{E}+00$ & $5 . E+00$ \\
\hline Se (ppmw) & & $4 . E+01$ & $|. E+0|$ & $6 . E+00$ & $4 . E+00$ & 4.E+00 \\
\hline Sb (ppmw) & & $3 . E+01$ & $6 . E+00$ & $6 . E+00$ & $6 . E+00$ & $6 . E+00$ \\
\hline Co (ppmw) & & $|. E+0|$ & $1 . E+0 \mid$ & $4 . E+00$ & $4 . E+00$ & $4 . E+00$ \\
\hline
\end{tabular}

Note: Elemental Concentrations have been converted to Oxide forms on a $\mathrm{SO}_{3}$-free basis 